\title{
Teil IV: Das frühkaiserzeitliche Pompeji - der dritte Stil
}

Pompeji war in augusteischer Zeit bereits dicht bebaut, architektonische Veränderungen bedeuteten ein Bauen im Bestand ${ }^{1}$. Kaum ein innerstädtisches Haus wurde noch neu errichtet, sodass sich der Zusammenhang von Neubau und Neuausstattung nur an ausgewählten Befunden beurteilen lässt. Die Casa di Giasone wird im Folgenden als Beispiel für ein in augusteischer Zeit grundlegend neu gestaltetes Haus vorgestellt, für das die Wechselwirkung von architektonischer Innovation und neuen Decor-Formen analysiert werden kann. Besonders aufschlussreich sind in dieser Hinsicht die Räume auf der Westseite des Peristyls. Diese sind mit komplexen Bild-Ensembles ausgestattet worden, für die sich die Frage nach ästhetischen und semantischen Korrespondenzen anschneiden lässt. Mit der Casa di Marcus Lucretius Fronto kommt ein exzellent erhaltenes, in situ analysierbares Ausstattungsensemble des späten dritten Stils in den Blick. Die Neuausstattung galt jedoch Räumen am Atrium, die in ihrer architektonischen Disposition auf das 2.Jh.v. Chr. zurückgehen. Die beiden ausgewählten Komplexe bilden zugleich unterschiedliche Phasen innerhalb des dritten Stils $a^{2}$. Die im Anschluss diskutierten Vergleichsbeispiele erlauben neben einer Diskussion der an Boden und Wand relevanten Decor-Strategien auch eine Berücksichtigung von dreidimensionalen Ausstattungselementen, die in augusteischer Zeit für die Wahrnehmung der Häuser besonders relevant werden.

\section{Zwei Fallbeispiele: die Casa di Giasone (IX 5,18) und die Casa di Marcus Lucretius Fronto (V 4,a)}

\subsection{Die Casa di Giasone (IX 5,18) - ein augusteisches Bau- und Ausstattungsensemble (Plan 3; Abb. 261)}

Die in ihrem Grundriss annähernd quadratische Casa di Giasone gehört zu den mittelgroßen Häusern in Pompeji ${ }^{3}$. Über Zugang (IX 5,18) im Süden gelangt man in die Fauces (a), über Eingang IX 5,21 im Westen in Korridor (q) ${ }^{4}$. Beide führen direkt in den Hof (Abb. 262), der spätestens in augusteischer Zeit eine vierseitige Portikus erhielt.

1 So bereits Dickmann 1999, 299.

2 Bei Bastet - de Vos 1979, 24. 49. 64 gehört die Casa di Giasone der Phase Ic, die Casa di Marcus Lucretius Fronto der Phase IIb an.

3 Zur Rekonstruktion Mau 1880; Befund ausführlich diskutiert bei Zevi 1964, jedoch mit einer nicht immer nachvollziehbaren Feindifferenzierung verschiedener Bauphasen auf der Basis von verschiedenen Typen von Opus incertum. 4 In augusteischer Zeit lag der Zugang noch in der Korridorachse, bevor nach 62 n. Chr. der Treppenzugang IX 5,21 Raum (v) entsprechend - angelegt und Raum (t) verkürzt wurde, um den neuen Eingang etwas nach Norden zu versetzen; s. Zevi 1964, 7.11.14 und PPM IX (1999) 670-719 s. v. IX 5,18, Casa di Giasone (V. Sampaolo) 670f. In der Publikation von Zevi 1964, 6 Abb. 1 ist die Nummerierung der Zugänge IX 5,20 und IX 5,21 vertauscht. 


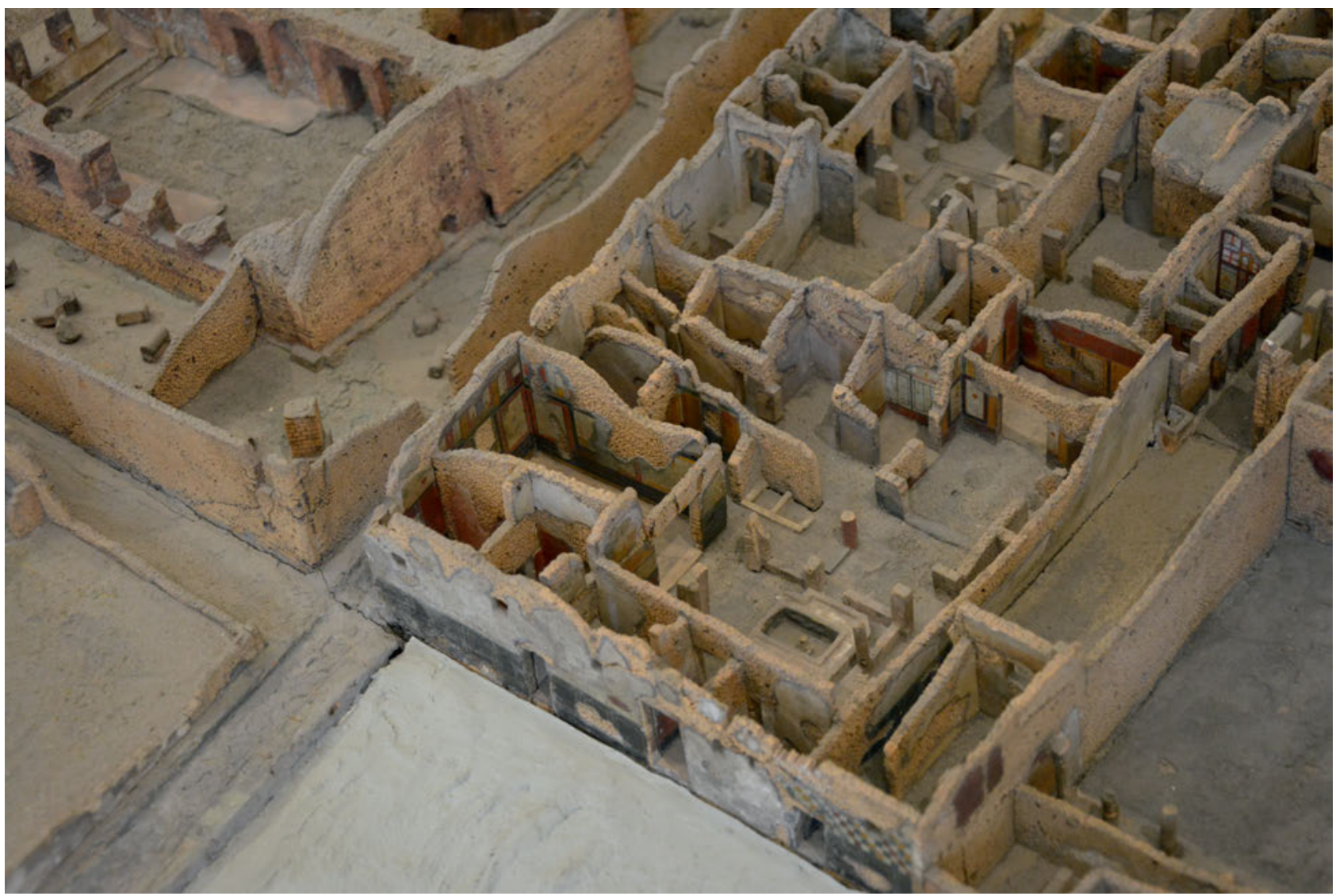

Abb. 261: Korkmodell Fiorellis, Detail der Casa di Giasone (Neapel, NM).
Die Rekonstruktion der Räume auf der Nordseite bereitet für diese Phase Schwierigkeiten. Vielleicht hat man in der Achse des Eingangs einen tablinumsartigen Verteilerraum (l) anzunehmen ${ }^{5}$. Die Dreiraumgruppe auf der Westseite geht in ihrer architektonischen Konzeption und decorativen

5 Die Rekonstruktion hängt hier maßgeblich von dem architektonischen Zusammenhang zwischen dem hier vorauszusetzenden Portikus-Nordflügel und dessen Rückwand ab. Als Dachauflager wird von Zevi ausschließlich die Ante angenommen, die an die den Treppenaufgang (k) begrenzende Mauer anschließt. Mau 1880, 22: „L'anta che dal principio della sudetta scala si stende verso 0 , non ha, per quando si vede, alcun significato pratico, ed è probabilmente un avanzo dun'epoca, quando in questo punto eravi una stanza con larga apertura sul portico; era questa allora l'anta destra dell'ingresso, e si vedono ancora nel pavimento le tracce sicure dell'anta corrispondente a sinistra nonché la soglia di una porta per la quale quella stanza era accessibile anche da O.“ Aufgegriffen bei Zevi 1964, 10. 14. Tatsächlich macht dies aber nur Sinn, wenn man eine zweite, damit korrespondierende Ante oder Säule als Auflager postuliert. Mau hat eine solche Ante beschrieben und noch heute ist ein möglicherweise zugehöriger Steinblock im Boden sichtbar (so hier im Plan), während das Korkmodell an dieser Stelle eine Säule zeigt. Eine weitere Stütze müsste man dann in der Achse nach Westen versetzt auf der Ecke eines marmorverkleideten Sockels (heute verloren) annehmen. Eine solche Rekonstruktion vorausgesetzt, ergäbe sich in der Achse der Fauces eine Staffelung von drei Räumen - einem weitgehend offenen (?) Vorraum, Raum (l) und Raum (o). Die Räume auf der Nordseite des Peristyls wie auch Treppe (k) und das zugehörige Obergeschoss könnten somit in augusteische Zeit gehören. Setzt man voraus, dass vor Raum (l) ein Vorraum mit Anten lag, der das Peristyldach trug, so hätte das Peristyl auf der Nordseite einen weiteren Tür-Zugang von Korridor (q) her besessen - eine Lösung, die architektonisch plausibel wäre. Im erhaltenen Zustand verfügt der etwa quadratische Raum (l) über eine breite Raumöffnung und besetzt die traditionelle Position eines Tablinums. Er besitzt eine späte Ausstattung im vierten Stil, selbiges gilt für die Einbauten unter der Treppe (k) Alkoven (n) und Schrank (m) - sowie den im Norden anschließenden Raum (o). Raum (l) fungierte dadurch gewissermaßen als Verteilerraum in die angrenzenden Räume. Prinzipiell denkbar wäre, für die augusteische Zeit von einer wenigstens ähnlichen Raumordnung auszugehen. Die späteren, nacherdbebenzeitlichen Veränderungen beschränken sich auf wenige bauliche Eingriffe. Allerdings erhielten einige Räume eine neue Ausstattung im vierten Stil. 


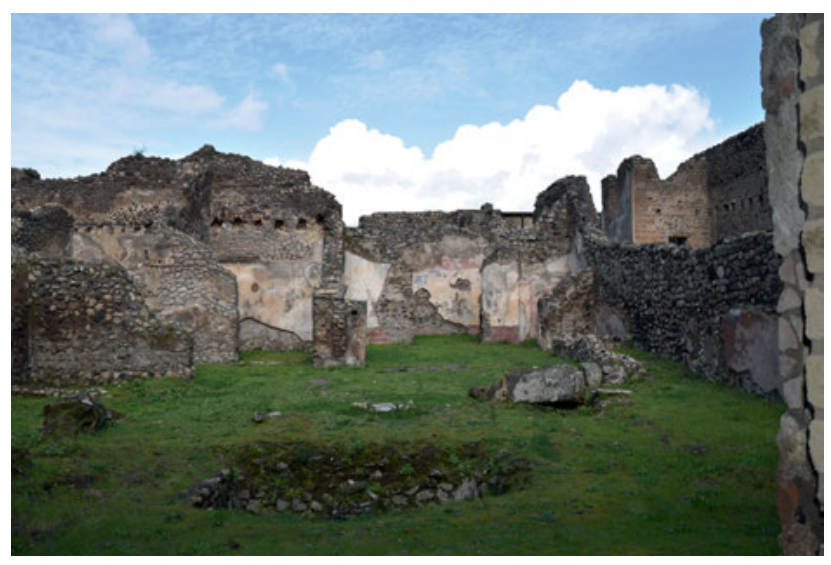

Abb. 262: Casa di Giasone, Blick von den Fauces in der Achse des Hauses auf die Nordseite des Atriums.

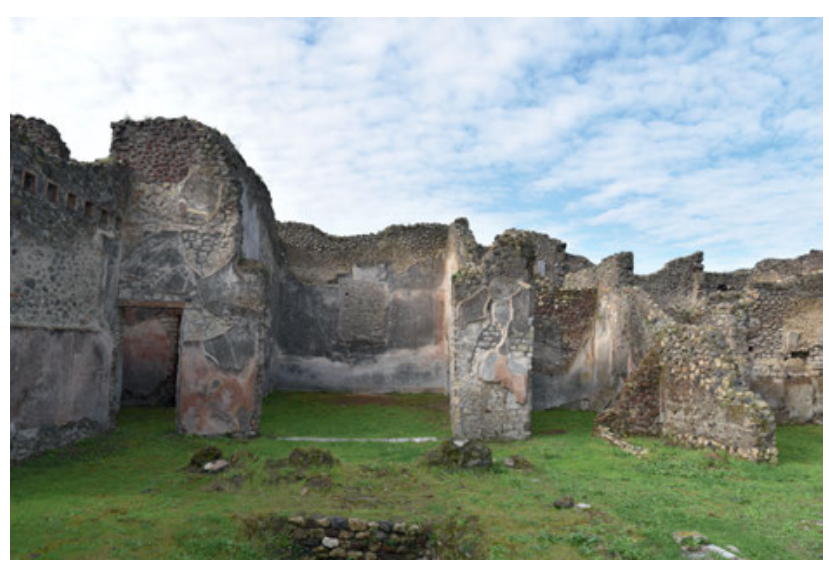

Abb. 263: Casa di Giasone, Blick auf die Dreiraumgruppe im Westen.

Ausstattung auf die augusteische Neugestaltung zurück (Abb. 263). Das geradezu monumentale Triclinium (f) nimmt mit seiner extrem breiten Raumöffnung das Zentrum der Westseite ein. Es wird zu beiden Seiten von niedrigeren Türdurchgängen flankiert und dadurch zusätzlich akzentuiert. Dieses symmetrisch gestaltete Raum-Ensemble besaß zum Hof hin Marmorschwellen, die das Erscheinungsbild vereinheitlichten ${ }^{6}$. Hinter den seitlichen Türdurchgängen verbergen sich dann aber unterschiedliche räumliche Lösungen: Vorraum (d), der auf Cubiculum (e) hinführt und zugleich mit Triclinium (f) verbunden ist ${ }^{7}$, sowie Cubiculum/Oecus (g) ${ }^{8}$.

In dieser Raumdisposition zeigt sich, dass in der Casa di Giasone Gestaltungsideen von Peristyl und Atrium miteinander verschränkt wurden. Wie sonst für ein Atrium üblich sind die Hofseiten auf ein weitgehend symmetrisches Erscheinungsbild hin angelegt - auf der Westseite ein zentraler Hauptraum (f) mit flankierenden Seiteneingängen, auf der Nordseite vermutlich ein zentraler ,Tablinums'-Raum, auf der Südseite die von Cubicula flankierten Fauces (a) ${ }^{9}$. Gleichzeitig sind mit der Säulenstellung, dem Garten und dem Prunk-Triclinium Elemente eingeführt, die ein Peristyl charakterisieren.

6 Marmorschwellen in (f) und (d) erhalten, s. Zevi 1964, 12.

7 Im Zuge der Eingriffe in Cubiculum (c) (nach 62 n. Chr.) wurde auch die Südostecke von (d) modifiziert. Zevi 1964, 12.

8 Peters 1963, 96-99; Dickmann 1999, 327.

9 Die beiden Seitenräume wurden nachträglich verändert. Ausstattungsreste ersten Stils in Raum (h) zeugen von einem hohen Alter, der Raum wurde jedoch nachträglich in eine Küche mit angeschlossener Latrine verwandelt; s. PPM IX (1999) 670-719 s. v. IX 5,18, Casa di Giasone (V. Sampaolo) 707f. Abb. 48; hier m. E. zu Recht als erster Stil angesprochen; laut Mau 1880, 24 zweiter Stil; aufgrund der fragmentarischen Erhaltung angezweifelt bei Zevi 1964, 9. Cubiculum (c) erhielt nach 62 n. Chr. einen straßenseitigen Zugang. 
Abb. 264: Aquarell der Casa di Giasone, Peristylbereich mit Tisch, Luigi Bazzani.

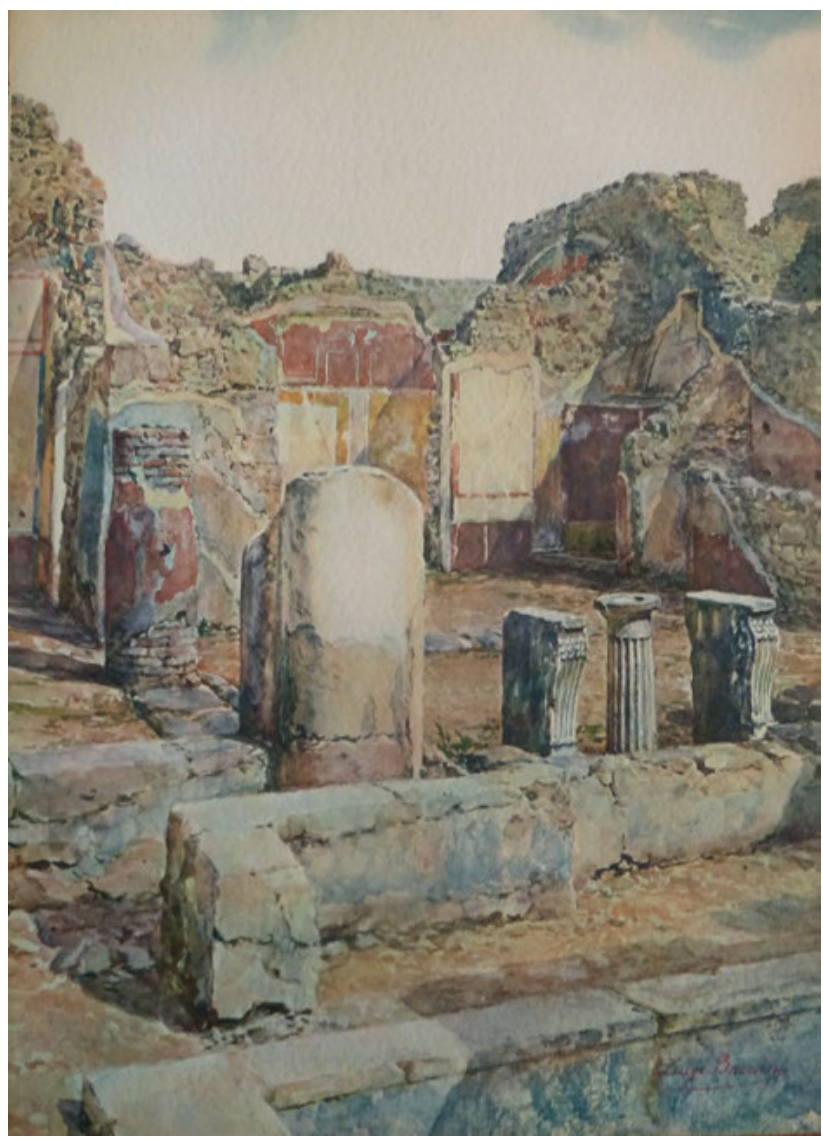

Die vierseitige Portikus gab ein ausgesprochen heterogenes Bild ab. Verschiedene Stützelemente Säulen, Pfeiler sowie Pfeiler mit Halbsäulen ${ }^{10}$ - trugen das Dach von unterschiedlich breiten Portikusflügeln. Auch die Breite der Interkolumnien variierte und reagierte darin auf die Blickachsen, die sich von verschiedenen Aufenthaltsorten ergaben. Auf Nord- und Südseite fiel das östliche Interkolumnium besonders breit aus und rahmte so den Blick von den Fauces (a) zu den Haupträumen im Norden $(1,0)$. Auf der Westseite war die Mittelstütze herausgenommen, sodass der Blick vom großen Triclinium (f) in den Garten nicht verstellt wurde, während auf der Ostseite, an die keine Räume anschließen, eine mittige Säule zur Säulenrahmung des Gartens beitrug ${ }^{11}$. Dieser war zusätzlich von einer niedrigen, U-förmigen Gartenmauer eingefasst ${ }^{12}$, in seinem Zentrum befand sich ein kleines, jedoch relativ tiefes, mit Opus signinum verputztes, rechteckiges Brunnenbecken. Aus einer gemauerten Säule im Zentrum des Beckens sprudelte das Wasser (Abb. 261. 262) ${ }^{13}$.

Zur Ausstattung des Gartens gehörte aufwendiges Mobiliar, das in den Interkolumnien aufgestellt war. Auf der Nordseite handelt es sich um ein Puteal, einen Tisch mit Löwenfüßen sowie

10 Die Stützen sind heute weitgehend verloren und lassen sich nur anhand älterer Beschreibungen, Fotos und Pläne rekonstruieren. Zevi 1964, 11 deutet den Sockel (w) im Korridor (q) als Herd - dies wäre für einen Herd aber eine doch ungewöhnliche Platzierung. Mau 1880, 24 hat hier eine Zisternenmündung und ein Tuffbecken nachgewiesen, die vielleicht auf eine ursprünglich andere Hausdisposition mit Atrium und Impluvium in diesem Bereich hindeuten und so auch den Sockel (w) erklären würden.

11 Zevi 1964, 8.

12 Sogliano $1878,263 \mathrm{f}$.

13 Mau 1880, 21 mit Hinweis auf eine Wasserleitung, die das Wasserspiel versorgte. 
ein Monopodium mit kanneliertem Fuß (Abb. 264) ${ }^{14}$. Dieses Arrangement mit Wasserspiel, eingefasstem Garten und Tischen könnte auf die Neugestaltung in augusteischer Zeit zurückgehen. Das Haus besaß damit einen kleinen, variationsreich gestalteten Gartenbereich.

Das architektonische Konzept bediente somit zwei Perspektiven: den Blick auf ein symmetrisch gestaltetes Ensemble von Prunkräumen, der sich allerdings erst ergab, wenn man den Hof bereits betreten hatte; sowie den Blick von den Prunkräumen aus auf ein ansprechendes Gartenareal. Beides wird sich als charakteristisch für die augusteische Zeit erweisen ${ }^{15}$.

Diese neuartige Architektur wurde mit den neuen Decor-Formen der Zeit ausgestattet. Fauces (a), der Hof sowie die Räume der Westseite erhielten neue Böden und eine ,moderne' Wandmalerei im dritten Stil ${ }^{16}$. Ein Cocciopesto mit polychromen Marmorplättchen ${ }^{17}$ war an der Peristylrückwand mit einer schwarzen Sockelzone und einer Mittelzone aus annähernd quadratischen monochromen Feldern in Gelb, Schwarz und Rot kombiniert (Abb. 261). Besonders aufschlussreich ist das Verhältnis von Architektur und Decor jedoch für die neuen Raumformen auf der Westseite des Hofes, die daher im Folgenden im Fokus stehen.

\section{Decor und Architektur: Triclinium (f)}

An Triclinium (f) (Abb. 261. 263. 265) lässt sich prägnant analysieren, wie der dritte Stil auf neuartige Raumlösungen reagiert ${ }^{18}$. Aufgrund seiner enormen Größe $(7,85 \times 5,35 \mathrm{~m})$ besaß es ein immenses Raumvolumen mit ganz neuen atmosphärischen Eigenschaften. Man betrat den Raum über eine breite Marmorschwelle, in die zweiflügelige, hohe Türen eingesetzt gewesen sein müssen. Bei geöffneten Türen war er folglich verhältnismäßig hell. Das immense Raumvolumen wird durch den Decor strukturiert: Opus signinum ${ }^{19}$ und Wandmalerei augusteischer Zeit nehmen eine Untergliederung in Vorraum und Klinenbereich vor.

14 Sogliano 1878, 264; Zevi 1964, 19 postuliert für den Tisch mit zwei Auflagern eine sullanische Datierung - in diesem Fall müsste das Objekt allerdings älter sein als die Neugestaltung der Domus. Dies ist freilich möglich, aber nicht unbedingt zwingend. Der Garten wurde nachträglich - nach 62 n. Chr. - abgeschrankt, die Schranken aber für die Durchblicke von den Fauces (a) im Süden und vom großen Triclinium (f) im Westen geöffnet. Mit anderen Worten wurde der Gartenbereich aus verschiedenen Perspektiven als Blickpunkt inszeniert. Auf der Ostseite haben sich an der Gartenmauer Reste einer Bemalung mit Pflanzen erhalten. Zevi 1964, 8 Anm. 17.

15 s. u. S. 402-407.

16 In den Fauces haben sich an der Westwand Reste der roten Sockelzone erhalten, während die Ostwand nach 62 n.Chr. mit Rohputz ausgebessert wurde; Zevi 1964, 8.

17 Pernice 1938, $117 \mathrm{f}$.

18 Zur Beschreibung des Decors, s. Zevi 1964, 22-24.

19 Pernice 1938, $117 f$. 
Abb. 265: Korkmodell Fiorellis, Detail der Casa di Giasone mit Triclinium (f) (Neapel, NM).

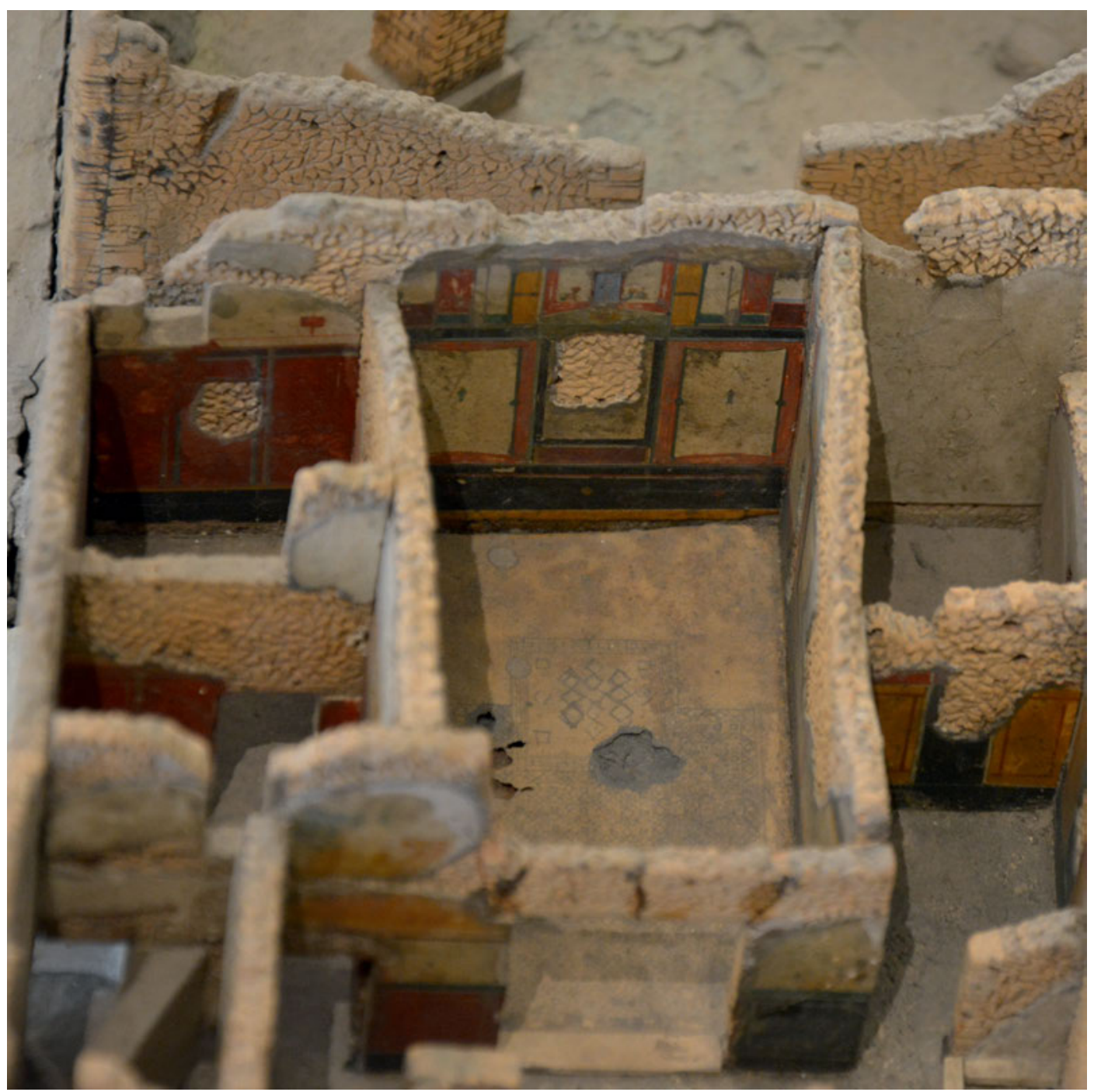

Den quer gelagerten Vorraum schmückt ein Stern- und Quadrat-Decor, im etwa quadratischen Klinenbereich sind in den Netz-Decor verschiedene quadratische und hexagonale Steinplatten (Cipollino; Portasanta) eingesetzt (Abb. 266). An den Längswänden im Norden und Süden markiert ein gemalter Pilaster den Übergang zwischen den Raumteilen (Abb. 267). Vorraum und Klinenbereich werden durch eine einheitliche schwarze Sockel- und Predellazone zusammengeschlossen. Eine gewisse Differenzierung wird jedoch über die Füllmotive eingeführt. Nur im Klinenbereich sind die Rauten des Sockels polychrom (gelb, lila, grün), in der Predellazone treten Masken, Vasen und andere Objekte hinzu ${ }^{20}$. Die Mittelzone fällt in beiden Raumteilen ausgesprochen hoch aus und ist darin an die Dimensionen des Raumes angepasst. Im Klinenbereich ist sie auf allen drei Wandseiten in drei Felder gegliedert, im Vorraum in zwei. Indem im Klinenbereich das mittlere Feld 


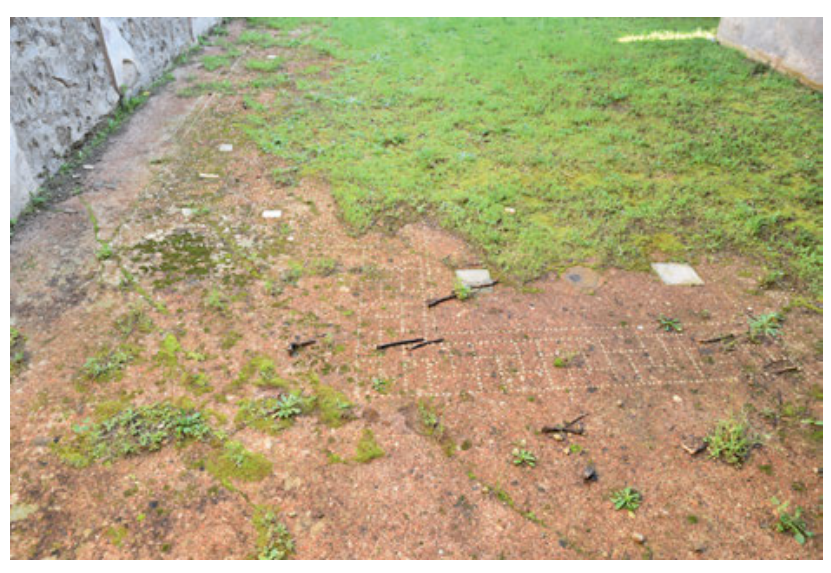

Abb. 266: Casa di Giasone, Triclinium (f), Paviment.

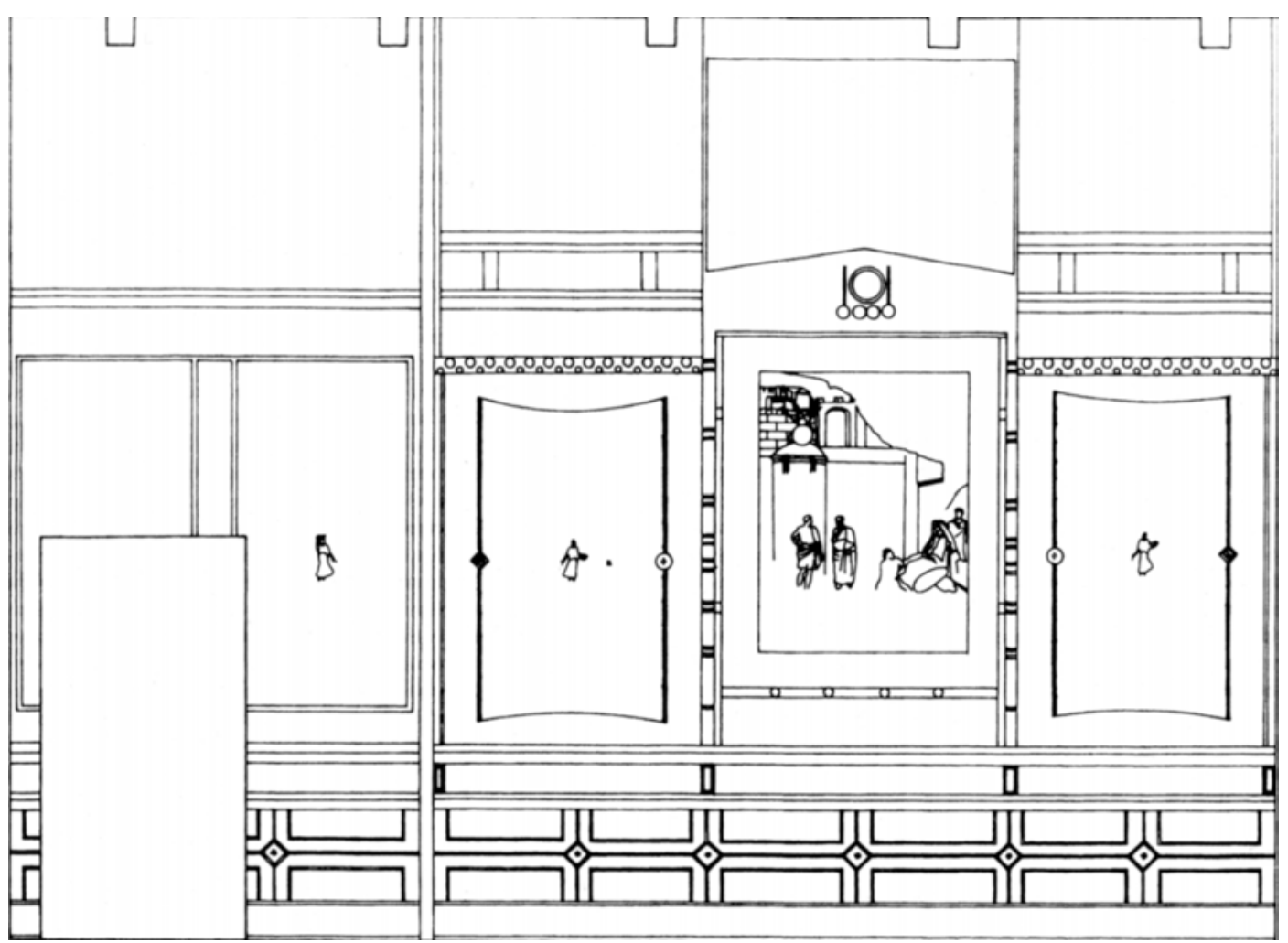

Abb. 267: Casa di Giasone, Triclinium (f), Rekonstruktion der Südwand.

durch eine Ädikula akzentuiert wird, die ein mythologisches Bild einfasst, wirkt dieser Raumteil wie ein ,Raum im Raum'. Auf der dem Eingang gegenüberliegenden Westwand handelt es sich um Iason auf Iolkos (Abb. 268), die Themen der schlechter erhaltenen Bilder der Nord- und Südwand lassen sich nicht sicher bestimmen. Die rahmenden Seitenfelder sind wie die beiden Felder des Vorraums weißgrundig und tragen Vignetten von Einzelfiguren ${ }^{21}$. Während die Felder im Klinenbereich jedoch von roten, geschwungenen Streifen eingefasst sind, sind die Felder des Vorraums durch gelbe Streifen gegliedert. Im Klinenbereich tritt über den Seitenfeldern eine weitere Bildzone am Übergang zwischen Mittel- und Oberzone hinzu. Sie zeigt ein Opfer sowie Amor mit einem Wagen $^{22}$. Die Unterschiede zwischen Klinenbereich und Vorraum setzen sich auch in der Oberzone

21 Sogliano 1878, 265.

22 Heute verloren, s. Mau 1880, 83. 
Abb. 268: Casa di Giasone, Triclinium (f), Mittelbild der Westwand mit der Darstellung von lason auf lolkos (Neapel, NM 111436).

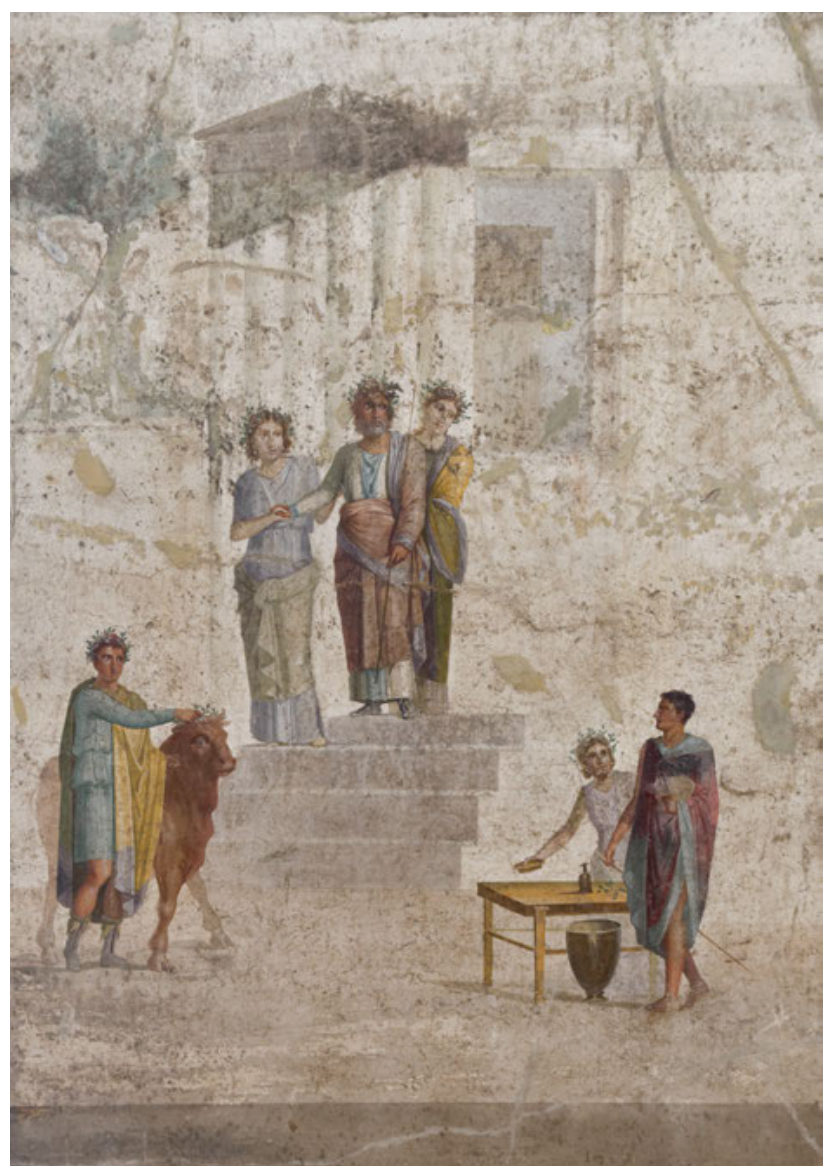

fort. Im Klinenbereich war sie analog zur Mittelzone dreigeteilt. Auf der Rückwand im Westen war oberhalb des Ädikulagiebels eine Satyr- oder Mercur-Statue dargestellt, der den kleinen Bacchus auf der Schulter trägt ${ }^{23}$. Sie wurde in den seitlichen Feldern von jeweils zwei Büsten flankiert: links, laut Antonio Sogliano, eine Bacchantin und ein Satyr, rechts zwei weibliche Büsten ${ }^{24}$. Auf der schlechter dokumentierten Nord- und Südwand enthielten die seitlichen quadratischen Felder Darstellungen von Büsten, die in den Raum blicken ${ }^{25}$.

Für das Verhältnis von Raumzuschnitt und Decor ist zunächst bedeutsam, dass Boden- und Wand-Decor eine Gliederung in Vorraum und Klinenbereich vornehmen. Dickmann weist darauf hin, dass diese Untergliederung ein republikanisches Prinzip darstelle. In der Kaiserzeit sei das Triclinium der Casa di Giasone der einzige neu angelegte Prunkraum, der diesem Schema verpflichtet geblieben sei $^{26}$. Allerdings bringen alle großen Prunkräume, sofern sie sich erhalten haben, schon aufgrund ihrer Maße die konventionelle Dreigliederung an ihre Grenze (s. u.). Man kann daher die Lösung für Triclinium (f) auch als eine besonders innovative begreifen, die eine neuartige Raumgröße und -proportion mit den neuen Möglichkeiten des dritten Stils zusammenbrachte. Der Decor wurde jedoch nicht nur an die Raumtiefe, sondern auch an die enorme Raumhöhe angepasst: Die Felder der Mittelzone setzten hoch an und fielen zudem ausgesprochen

23 Sogliano 1878, 265.

24 Sogliano 1878, 265; Mau 1880, 84; zur ikonographischen Diskussion der Statuendarstellung Zevi 1964, 24.

25 Mau 1880, 83.

26 Dickmann 1999, 338. Zevi 1964, 22 begründet diese Decor-Disposition damit, dass in der Südwand eine Tür eingelassen ist, auf die der Decor Rücksicht genommen habe. Tatsächlich ist auch die Verbindung von Räumen zu Suiten in der Kaiserzeit aus der Mode gekommen. 
groß aus. Die Mythenbilder wurden dadurch deutlich über den Köpfen der Betrachter präsentiert, waren dementsprechend aber auch von allen Stellen im Raum sichtbar.

Die Gesamtwirkung des Raumes war primär durch die großen Farbflächen bestimmt. Der rote Cocciopesto kontrastierte mit der schwarzen Sockel- und Predellazone, die sich wiederum auffällig von der weißgrundigen Mittel- und Oberzone absetzte. Einen besonderen Akzent setzten in der Mittelzone die farbigen, mythologischen Bildfelder im Klinenbereich. Sie traten dem Betrachter auf Augenhöhe gegenüber und rahmten die Handlungen, die im Klinenbereich stattfanden. In Triclinium (f) waren es folglich insbesondere die von Ädikulen gerahmten Mythenbilder, die den Klinenbereich als separaten Raumteil erfahrbar machten. Ein feingliedriges Ornamentnetz leistete eine Integration verschiedenster, auch kleinteiliger Bildelemente in den Wandaufbau: Einzelobjekte in der Predellazone, Vignetten mit Einzelfiguren auf den Seitenfeldern der Mittelzone, eine figürliche Frieszone zwischen Mittel- und Oberzone, Büsten und figürlicher Architekturschmuck in der Oberzone. Bei Triclinium (f) handelt es sich folglich um ein komplexes Bild-Ensemble, das jedoch aufgrund des schlechten Erhaltungszustandes keiner detaillierten Analyse unterzogen werden soll.

\section{Die Cubicula (e) und (g) und die Frage der Ausstattungsensembles}

In den Cubicula (e) und (g) ist der Wandaufbau nicht erhalten, die mythologischen Mittelbilder wurden jedoch schon frühzeitig aus den Wänden geschnitten. An diesen beiden Räumen lässt sich dadurch das ästhetische und semantische Wechselspiel analysieren, das sich zwischen den ,zentralen` Bildern ergibt. In beiden Cubicula schließen sich die Mythenbilder zunächst auf einer formalen Ebene zusammen. Dies betrifft das einheitliche Format, die ähnliche Figurengröße sowie den vergleichbaren Bildhintergrund. Diese formale Angleichung bringt eine spezifische Ausdeutung des mythischen Geschehens mit sich und befördert eine inhaltliche Parallelisierung der Bilder.

Auf den drei Mythenbildern des Cubiculums (e) werden mit Medea, Phaedra sowie Paris und Helena $^{27}$ drei Frauen in einer Entscheidungssituation erfasst, wobei sich der dramatisch zugespitzte Entscheidungsmoment in allen drei Fällen aus einer ,gestörten' Paarbeziehung ergibt. Diese Störung wird nicht allein durch die Charakterisierung der Protagonisten, sondern auch durch die Hintergrundarchitektur zum Ausdruck gebracht. Die Architektur trägt folglich zur inhaltlichen Akzentuierung der Szenen bei ${ }^{28}$.

Auf der Nordwand (Abb. 269) tritt aus einer hohen, halb geöffneten Tür in der Bildmitte ein kleiner Eros, seitlich schließen Scherwände an. Diese hinterfangen die beiden Hauptfiguren, Paris und Helena, die sich einander leicht zuwenden. Der auf der linken Seite sitzende Paris nimmt deutlich mehr Bildraum ein als die rechts des Eros stehende Helena ${ }^{29}$. Das Liebespaar ist nicht nur in großem Abstand gezeigt, beide sind zudem vollständig bekleidet und blicken aus dem Bild heraus. Die Erotik ist dadurch stark zurückgenommen. Auf dem ,Beisammensein“ liegt die Schwere des künftigen Schicksals - das Sterben zahlloser Krieger vor Troja.

Auch auf dem Bild der westlichen Rückwand (Abb. 270) leistet die Hintergrundarchitektur eine Dreiteilung: Ein verschlossener Türdurchgang im Zentrum und flankierende Scherwände ${ }^{30}$ bilden die Kulisse für die Handlung. Medea sitzt rechts der Tür, den Kopf nachdenklich in die Hand

27 Brilliant 1984, 69f.; Bergmann 1996, 200-209; 2002, bes. 28-32; Lorenz 2008, 425-427.

28 So auch Zevi 1964, 52f., jedoch mit zum Teil abweichenden Detailbeobachtungen zum genannten Raum; Schefold 1972, 142-144 spricht sich trotz der beobachteten formalen Ähnlichkeiten zwischen den Bildern dafür aus, dass die Bilder auf griechische Vorbilder zurückgingen; vgl. Leach 1988, 396; eine räumliche Visualisierung der Bildfelder bei Venditto 2007, 518.

29 Neapel, NM 114320; PPM IX (1999) 670-719 s. v. IX 5,18, Casa di Giasone (V. Sampaolo) 681f. Abb. 17.

30 Neapel, NM 114321; PPM IX (1999) 670-719 s. v. IX 5,18, Casa di Giasone (V. Sampaolo) 687-689 Abb. 23; Schefold 1972, 142 und ihm folgend Venditto 2007, 33 wollen darin - wie auch in den anderen beiden Bildern des Raumes - eine theatrale Architektur erkennen, die die dargestellten mythischen Szenen mit einer würdigen Atmosphäre versehen hätten. 
Abb. 269: Casa di Giasone, Cubiculum (e), Bildfeld der Nordwand mit der Darstellung von $\mathrm{Pa}$ ris und Helena (Neapel, NM 114320).
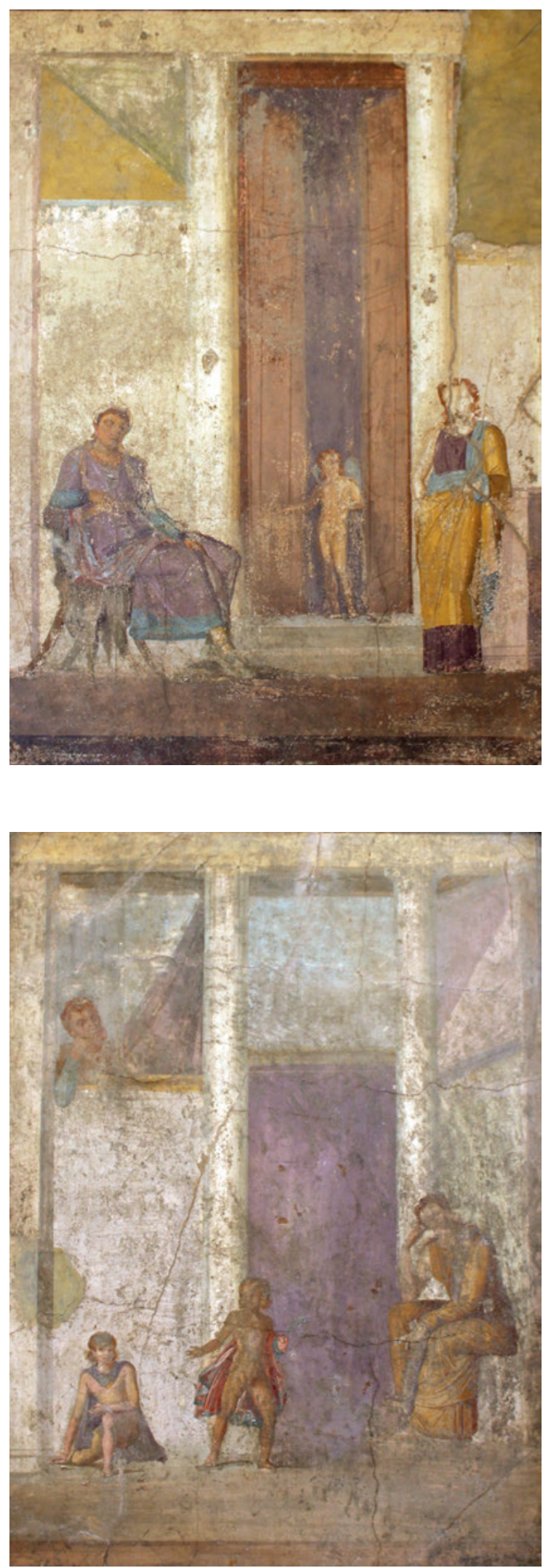

Abb. 270: Casa di Giasone, Cubiculum (e), Bildfeld der Westwand mit der Darstellung der Medea (Neapel, NM 114321). 


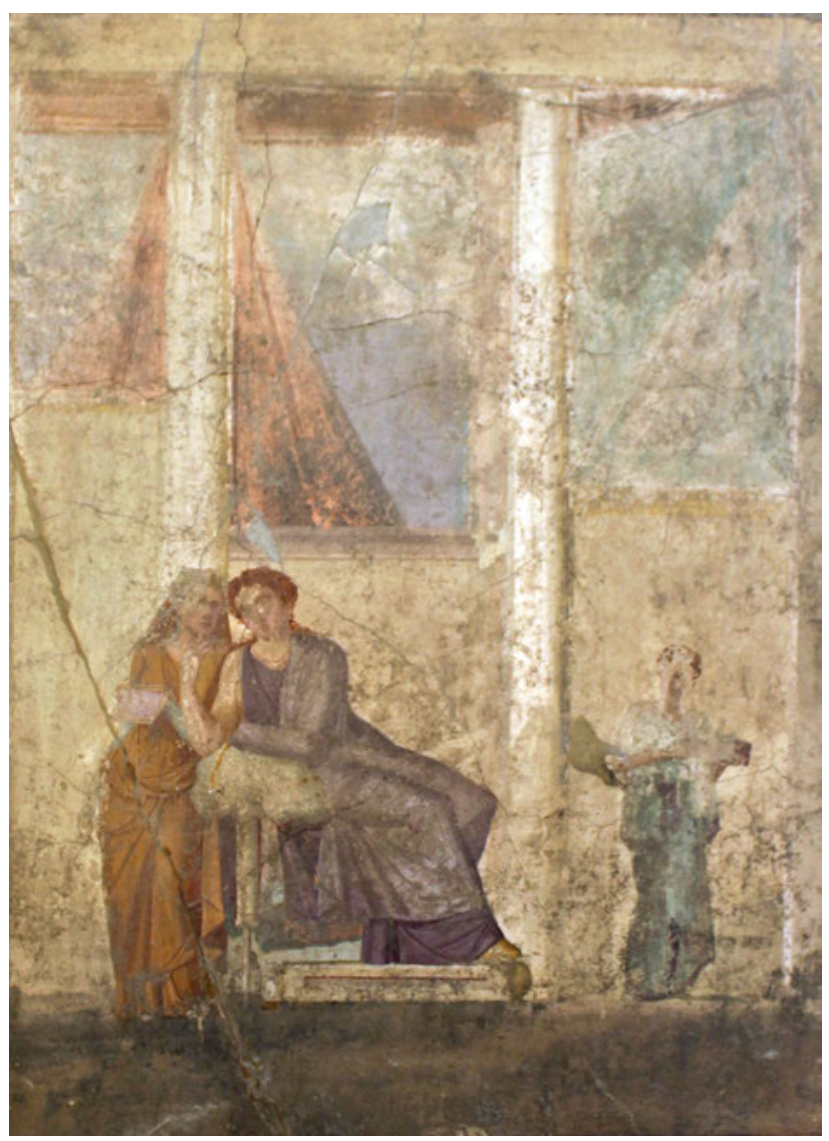

Abb. 271: Casa di Giasone, Cubiculum (e), Bildfeld der Südwand mit der Darstellung von Phaedra (Neapel, NM 114322).

gestützt; ihre beiden Kinder, die sie umbringen wird, links davon. Indem die Tür nicht im Bildzentrum, sondern zu Medea hin versetzt ist, wird der Bildfokus auf die nachdenkliche Mutter gerichtet. Zugleich lädt die Architektur auch die Haltung der Knaben mit Bedeutung auf. Während der eine von ihnen die durch die Tür gegebene, Schwelle übertritt, sich zur Mutter hin bewegt und dabei zu seinem Bruder zurückblickt, ist der andere zum Bildbetrachter gewandt.

Auf der Südwand (Abb. 271) wird ebenfalls eine Dreiteilung des Bildhintergrundes durch Säulen vorgenommen, deren Interkolumnien hier jedoch von unterschiedlich hohen Scherwänden geschlossen werden. Vor dem zentralen ,Feld“ sitzt Phaedra, die sich nach hinten zu einer Amme wendet. Diese steht vor einer der Säulen und wird dadurch besonders betont. Die Dienerfigur vor der rechten Scherwand ist als Zuschauerin konzipiert ${ }^{31}$. Hier wird der tragische Moment erfasst, als Phaedra vor ihrem Selbstmord den Brief, in dem sie ihre Liebe zu ihrem Stiefsohn Hippolytos bekennt, der Amme überreicht. Hippolytos, der ihre Liebe zurückweist, ist nicht im Bild.

In allen drei Bildern geht es folglich um tragische Liebschaften, die zentrale Werte des Familienlebens durch Ehebruch, Kindsmord und Inzest infrage stellen und dadurch in die Katastrophe führen ${ }^{32}$. Die Bilder finden unterschiedliche Mittel, um den spannungsvollen Moment - den ,fruchtbaren Augenblick ${ }^{6}$ - darzustellen, welcher der Liebestragödie vorausgeht ${ }^{33}$. Der formale Rahmen, d.h. die Hintergrundarchitekturen, befördert ein solches aus dem Bildvergleich heraus entwickeltes Verständnis.

31 Neapel, NM 114322; PPM IX (1999) 670-719 s. v. IX 5,18, Casa di Giasone (V. Sampaolo) 684f. Abb. 21.

32 Zevi 1964, 54; ausführlich Bergmann 1996, bes. 208; Lorenz 2008, 232-234. 425f.; Mattuch 2008, 79.

33 Dazu auch Leach 1988, 396f.; Bergmann 1996, 202-209; Lorenz 2008, 425 f. 
In ganz ähnlicher Weise sind die Mythenbilder in Cubiculum (g) zunächst einmal formal aufeinander bezogen (Abb. 272-274). Hier ist es ein Landschaftshintergrund, der die Szenen hinterfängt, gliedert und mit Bedeutung auflädt. Mit Europa auf dem Stier, Pan und Nymphe sowie Hercules und Nessos kommen ganz unterschiedliche ,Paare' zur Darstellung ${ }^{34}$. Die Landschaftselemente zeigen an, dass es um das Zusammentreffen von Menschen mit naturhaften Wesen geht ${ }^{35}$. Dabei lenken sie die Aufmerksamkeit auf den männlichen Part der Paarkonstellation. So wird der Stierkopf in der Bildmitte durch eine Säule im Hintergrund akzentuiert, eine diagonale Felsformation setzt Pan, ebenfalls im Bildzentrum, in Szene, während auf Hercules gleich mehrere Achsen zulaufen - ein Fels, ein Flussverlauf und ein Baum, der ihn von den anderen Akteuren trennt. Die Landschaftselemente legen somit eine vergleichende Lektüre der männlichen Protagonisten nahe. Die Bilder setzen jeweils einen Mann in Szene, dem es gelingt, eine Frau für sich (zurück-) zugewinnen. Der Göttervater Zeus verwandelt sich in einen Stier, um die Angebetete unter der Bewunderung ihrer Gespielinnen davonzutragen, der Muskelprotz Hercules beseitigt seinen Nebenbuhler, indem er ihn mit geradezu lässiger Geste erschlägt, während der elegant auf einem Felsen sitzende Pan die Aufmerksamkeit der Frauen durch sein Flötenspiel gewinnt ${ }^{36}$. Die verschiedenen männlichen Akteure setzen jeweils unterschiedliche Qualitäten ein, um ,ihre' Frau zu beeindrucken, während die Frauen die Rolle der passiven Bewunderin einnehmen.

\section{Zwischenergebnis: Imagescapes in der Casa di Giasone}

An den beiden Cubicula zeigt sich, dass sich zwischen den Bildern eines Raumes vielfältige Beziehungsgeflechte entfalten, die auf einer formalen wie inhaltlichen Ebene liegen können. Manche Bezüge sind durch die Maler gezielt angelegt worden, reichen die Parallelen doch bis in die Bildkompositionen hinein ${ }^{37}$. Diese Beobachtung hat weitreichende Konsequenzen für die Frage nach der Bildproduktion überhaupt. Es ist vor diesem Hintergrund ausgeschlossen, dass die Maler ,fertige“ Bildschemata wählten, die sie auf die Wand brachten. Vielmehr wurden diese in Bezug auf ihr kontextuelles Setting angepasst bzw. modelliert ${ }^{38}$. Fausto Zevi hat dies ausgehend von den Bild-Ensembles der Casa di Giasone wie folgt formuliert: „È logico aspettarsi, infatti, che, nel trasferire le composizioni dall'originale alla decorazione parietale, si tentasse in qualche modo di armonizzarle al complesso in cui venivano inserite, ad esempio variando i colori nel quadro, rimpicciolendo o ingrandendo le figure a seconda delle superfici a disposizione, e in ogni caso adattando la composizione stessa al punto di vista dello spettatore." 39 Eleanor Leach hat diese Annahme in eine komparativ-kontextuelle Analyse von Mythenbildern überführt und kommt mit Blick auf ein anderes Beispiel, die Darstellung des Polyphem, zu folgendem Schluss: „Polyphemus joined with Andromeda takes a different form and communicates a different significance from Polyphemus joined with Acteon [...]. Subtle changes effected by the selection and disposition of figures, the organization of setting, and the prejudice of an action alert the spectator to new points

34 Die Ostwand trug eine Malerei vierten Stils und wird hier nicht berücksichtigt.

35 In diesem Sinn Lorenz 2008, 424.

36 Diese komparative Deutung hat im Rahmen einer Exkursion Irene Ebke entwickelt, der ich für den Hinweis danke. 37 Schmaltz 1989a, 269 streift diese Frage nur en passant, als er am Beispiel von Perseus und Andromeda die Frage nach der Verwendung von (griechischen) Bildvorlagen diskutiert: „[...] man [muss] sich angesichts der skizzierten Eigenständigkeit der campanischen Bildtradition fragen, ob und bis zu welchem Grade es wahrscheinlich ist, daß Tafelbilder einer weit zurückliegenden Epoche in einen andersartigen und eigenwertigen Zusammenhang wie Wanddekorationen integriert wurden, sei es als getreue, auch maßstäblich getreue Kopien oder als variierende Umbildungen. Zumal letztere Möglichkeit verdient Aufmerksamkeit, da die Gegebenheiten des jeweiligen Raumes und der gelegentlich rekonstruierbare thematische Zusammenhang eines galerieartigen Bild-Ensembles sehr leicht zu formalen oder auch inhaltlichen Veränderungen einer Vorlage führen mussten.“

38 So bereits Trendelenburg 1876, bes. 3; jüngst etwa Lorenz 2018, $146 \mathrm{f}$.

39 Zevi 1964, 52. 


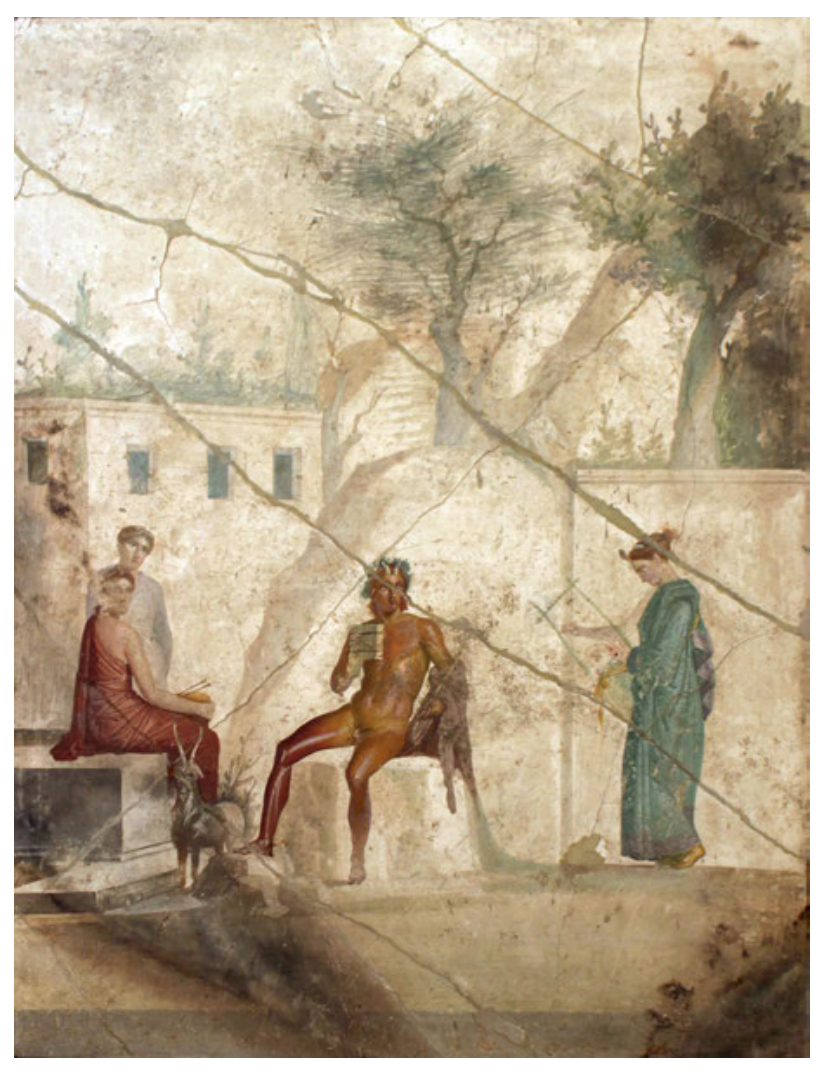

Abb. 272: Casa di Giasone, Cubiculum (g), Bildfeld der Südwand mit der Darstellung von Pan und Nymphen (Neapel, NM 111473).

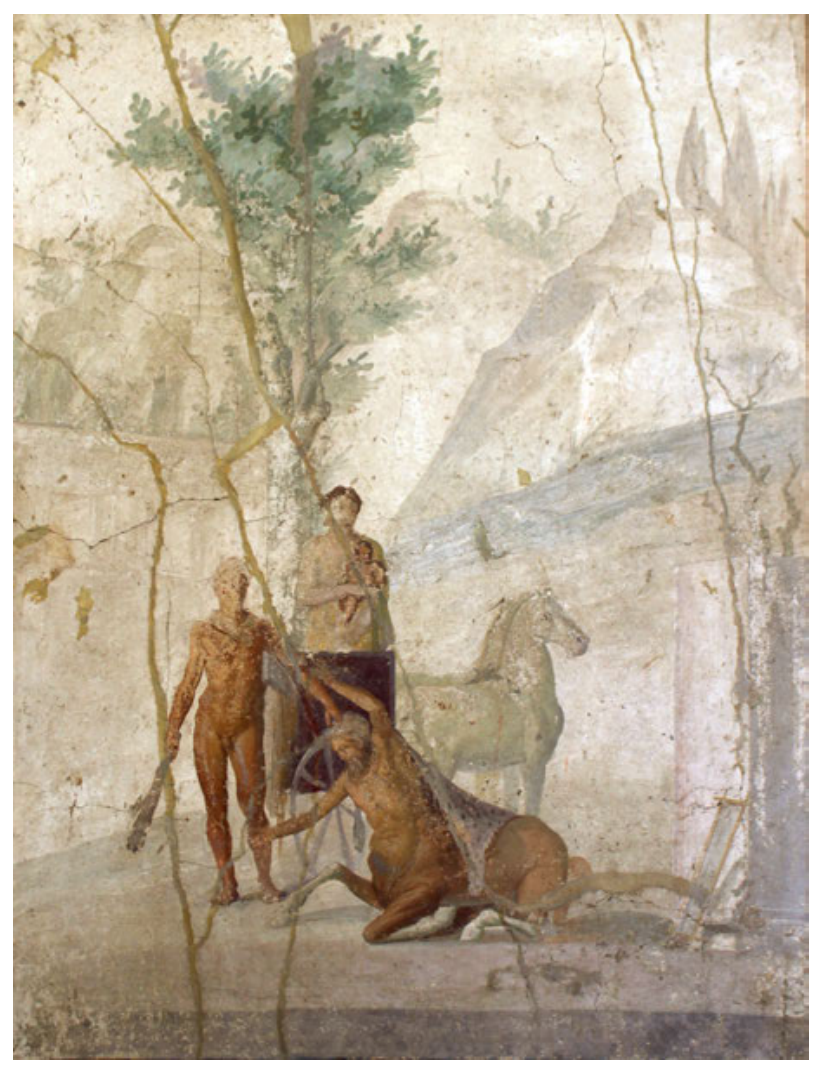

Abb. 273: Casa di Giasone, Cubiculum (g), Bildfeld der Nordwand mit der Darstellung von Hercules und Nessos (Neapel, NM 111474). 
Abb. 274: Casa di Giasone, Cubiculum (g), Bildfeld der Westwand mit der Darstellung von Europa auf dem Stier (Neapel, NM 111475).

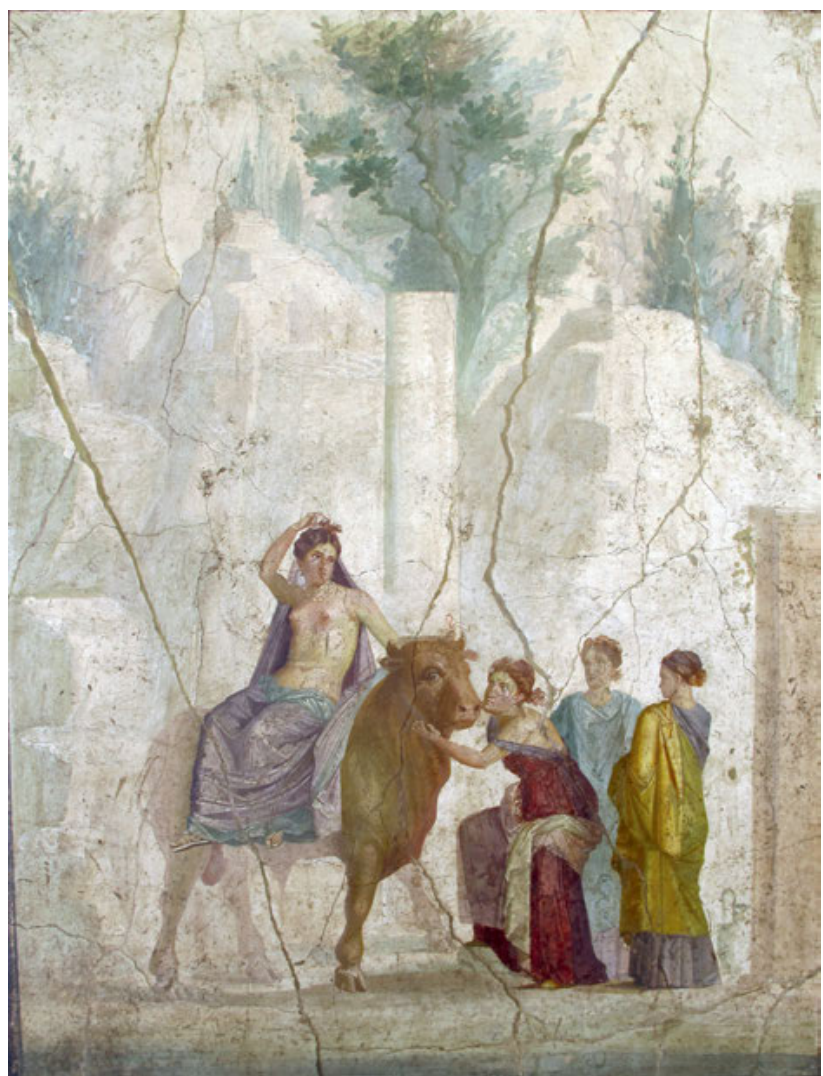

for comparison among familiar myths. Such perceptions [...] constitute the kind of sophisticated aesthetic re-creation to appeal to a society initiated into the cultural cachet of myth. ${ }^{\text {“40 }}$ Mit Bildern scheint man folglich ähnlich verfahren zu sein wie mit dem Wandschema als Ganzem, das zwar durch ein hohes Maß an Konventionalität geprägt ist, jedoch ebenfalls auf die spezifische architektonische Situation hin zugeschnitten wurde. Das Prinzip des decorum hatte eine Anpassung von visuellen Konzepten an den jeweiligen Kontext zur Folge. In diesem versatzstückhaften Umgang mit Bildvorlagen ist eine ganz eigene Form visuellen Argumentierens gefunden.

\section{Decor im Kontext: semantische Ordnungen in der Casa di Giasone}

Die Bild-Ensembles der prominenten Raumgruppe lassen sich auch untereinander vergleichen. Lorenz geht davon aus, dass die Bilder des Tricliniums (f) männliche Tugenden ins Zentrum rückten; im Iason-Bild komme mit der Palastarchitektur im Hintergrund ein besonders repräsentatives Setting zum Tragen. Sie deutet das Triclinium daher als Ort der Statusrepräsentation. In den Cubicula stünden andere Themen im Vordergrund: Liebe im häuslichen Rahmen in Cubiculum (e) und phantastisch-naturhafte Wesen in Cubiculum (g) ${ }^{41}$.

Tatsächlich ist die Bilderwelt von Triclinium (f) nur bruchstückhaft bekannt, doch ist Lorenz darin zuzustimmen, dass das zentrale Mittelbild auf der Rückwand des Raumes eine royal-würdige, zudem auch sakral aufgeladene Szene zeigt. Die beiden Cubicula können über Lorenz hinausgehend als Pendants beschrieben werden, in denen verschiedene Aspekte des Liebeslebens akzentuiert werden. In Cubiculum (e) sind Frauen, die im Inneren von Häusern gezeigt werden, im

40 Leach 1988, 403.

41 Lorenz 2008, 427. 
Moment einer dramatischen Entscheidungssituationen erfasst, während in Cubiculum (g) Männer im ,wilden' Außenraum um Frauen werben. Für die zentrale Raumgruppe ist somit eine atmosphärische Differenzierung zwischen dem zentralen Triclinium und seinen seitlich anschließenden Nebencubicula greifbar, wobei die Bild-Ensembles der flankierenden Cubicula als Pendants entworfen sind und weibliche und männliche Perspektiven auf Paarkonstellationen vorführen.

\subsection{Die Casa di Marcus Lucretius Fronto (V 4,a) - ein Decor-Ensemble claudischer Zeit (Plan 4)}

Die Casa di Marcus Lucretius Fronto gehört mit einer Fläche von $450 \mathrm{~m}^{2}$ ebenfalls zu den mittelgroßen Häusern in Pompeji ${ }^{42}$. Sie verfügte zwar über Atrium und Garten, fiel aber deutlich kleiner als etwa die Casa del Fauno und andere samnitische Prunkkomplexe aus ${ }^{43}$. Der Atriumsbereich geht in seiner Grundstruktur auf das 2.Jh.v.Chr. zurück, im 1.Jh.v.Chr. kam es zu einer größeren Umgestaltung, bevor in augusteischer Zeit noch einmal in die Struktur des Hauses eingegriffen wurde. In diesem Zuge erhielten das Atrium und die angrenzenden Räume neue Pavimente ${ }^{44}$. Vor allem sind umfangreiche bauliche Veränderungen im Gartentrakt (l) zu verzeichnen, der nun mit einer ersten Portikus und repräsentativen Räumen auf seiner Südseite ausgestattet wurde ${ }^{45}$. Am Ende des dritten Stils wurde der Atriumsbereich vollständig neu ausgemalt. Erhalten ist der Decor im Atrium selbst, in Tablinum (h) sowie in den Cubicula (c) und (g), während Triclinium (f) und Cubiculum (i) im vierten Stil erneuert wurden ${ }^{46}$. Nach dem Erdbeben 62 n. Chr. wurde insbesondere der Gartenbereich völlig umgestaltet ${ }^{47}$ und neu ausgestattet. Im Folgenden interessiert der Zustand des Hauses nach Abschluss der dem dritten Stil zuzuweisenden Eingriffe, d.h. um 50 n. Chr. Der Fokus liegt daher auf dem Atrium und den angrenzenden Räumen, die exemplarisch für ein DecorEnsemble aus der Zeit des dritten Stils stehen können.

\section{Fauces und Atrium}

Von der Straße aus tritt man über eine breite Travertinschwelle, deren zweiflügelige Tür sich nach innen öffnete, in die Fauces (a). Durch einen in die Gangmitte einsetzbaren Balken konnte diese Außentür zusätzlich gesichert werden (Abb. 275). Das Bodenniveau steigt leicht an, den Übergang zum Atrium markiert eine mit Marmorplatten verkleidete Stufe. Diese weist Einlassspuren für eine

42 Peters 1991, 135.

43 Grundlegend zum Haus die Grabungsberichte von Mau 1901; Sogliano 1901 sowie die monografische Bearbeitung von Peters 1993 (mit Beitrag Heres 1993), die den folgenden Überlegungen zugrunde liegt.

44 Pernice 1938, 97.

45 Wynia 1982, 330 verweist auf den Nachweis einer Portikus unter der erhaltenen mit leicht abweichender Orientierung.

46 Intensiv diskutiert ist die Datierung. Heres 1993, 136-138: „Fine sec. I A. C. /Primo Periodo Imperiale“. Die Wandmalereien werden bereits von Mau 1901, 339, Schefold 1962, 71 und erneut etwa von Bastet 1975 mit dem späten dritten Stil in Verbindung gebracht. Letztere schlägt eine Datierung in tiberisch-caliguläische Zeit vor; anders Ehrhardt 1987, 100 f.; eine sehr ausführliche Diskussion bei Peters - Moormann 1993, 261-267; Peters - Moormann 1993a.

47 In diesem Zusammenhang entstand die heute erhaltene Portikus. Die Raumgruppe (p-q-r) wurde umgestaltet und erhielt jetzt eine Latrine. Vor allem aber wurden die Räume auf der Süd- und Ostseite (s-x) neu errichtet, die Zugänge auf der Ostseite wurden vermauert. Alle Räume im Gartenareal erhielten eine neue Wandbemalung im vierten Stil. Eine ausführliche Phasendiskussion bei Heres 1993, 83. 138; kritisch Oswald 2016, 46-48. 


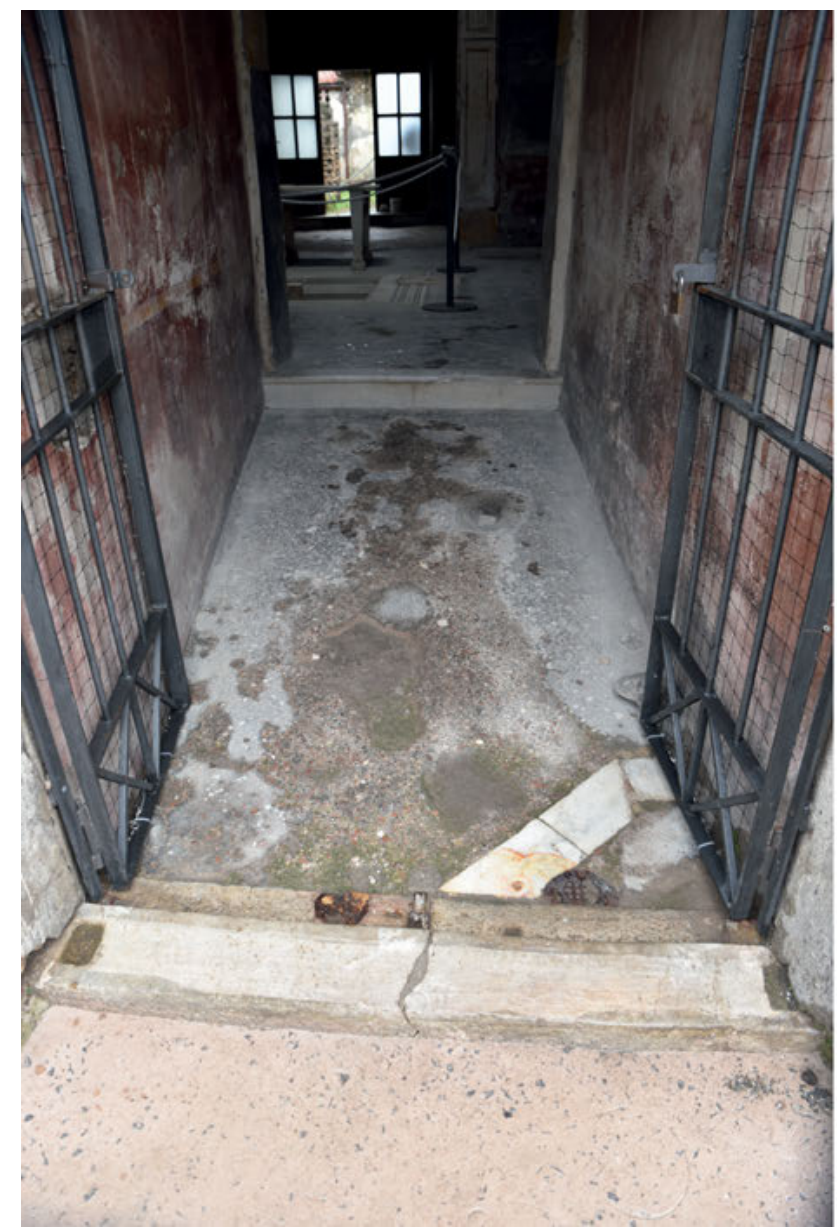

Abb. 275: Casa di Marcus Lucretius Fronto, Fauces (a), Paviment.

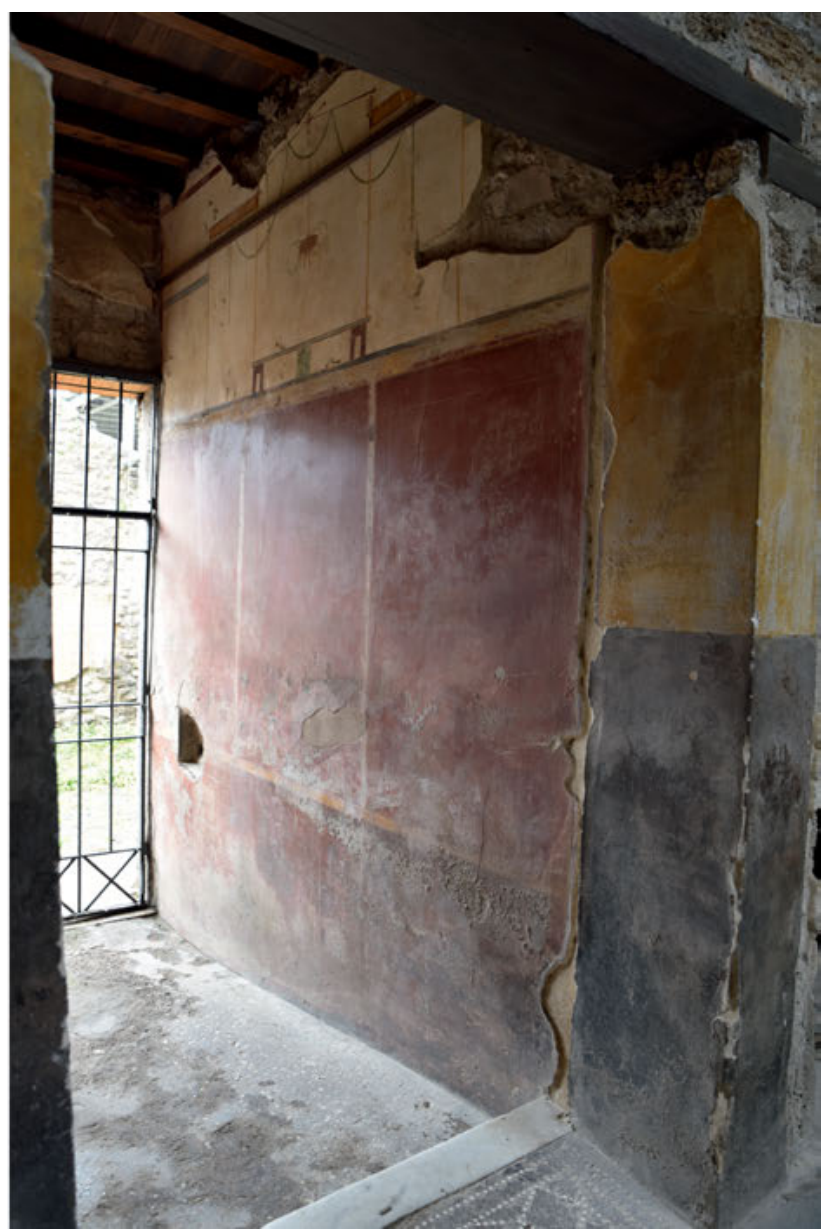

Abb. 276: Casa di Marcus Lucretius Fronto, Blick vom Atrium zurück auf die Nordwand der Fauces.

zweiflügelige Tür auf, die sich nach außen, in die Fauces, öffnete ${ }^{48}$. Der Zugang zum Haus war somit durch zwei Türen reguliert, die Außentür besonders gut gesichert. Die Fauces-Wände verlaufen nicht orthogonal zur Hausaußenwand und Atriumsrückwand, sondern leicht versetzt von Südwesten nach Nordosten. Die südliche Fauceswand fluchtet dadurch ungefähr auf die südliche Mauer des Tablinums. Die leicht schräg verlaufenden Faucesmauern tragen folglich dazu bei, den Betrachterblick auf das aus der Achse verrückte Tablinum (h) zu lenken ${ }^{49}$.

Die Fauces sind durch eine relativ geringe Decor-Dichte gekennzeichnet. Sie besitzen einen schwarzen Lavapesta-Boden mit roten, schwarzen und weißen Steinsplittern, die Wandbemalung folgt einer horizontalen und vertikalen Dreiteilung (Abb. 276). Eine schwarze Plinthe gleicht das ansteigende Bodenniveau aus. Die exakt horizontale schwarze Sockelzone wird durch weiße Rahmenlinien in Segmente gegliedert. In der durch gelbe Bänder eingefassten Orthostatenzone trennen gelb-weiße Streifen drei rote, decorlose Felder. Die weißgrundige Oberzone wird durch ein filigranes Architekturgestänge gegliedert. Ihr Zentrum besetzt eine aus dünnen, gelben Pilasterchen gebildete Ädikula, die von niedrigeren Baukörpern flankiert wird. In die stilisierte Architektur hängen grüne Girlanden herab, wobei an der zentralen Girlande ein brauner, flacher Korb aufgehängt ist. 


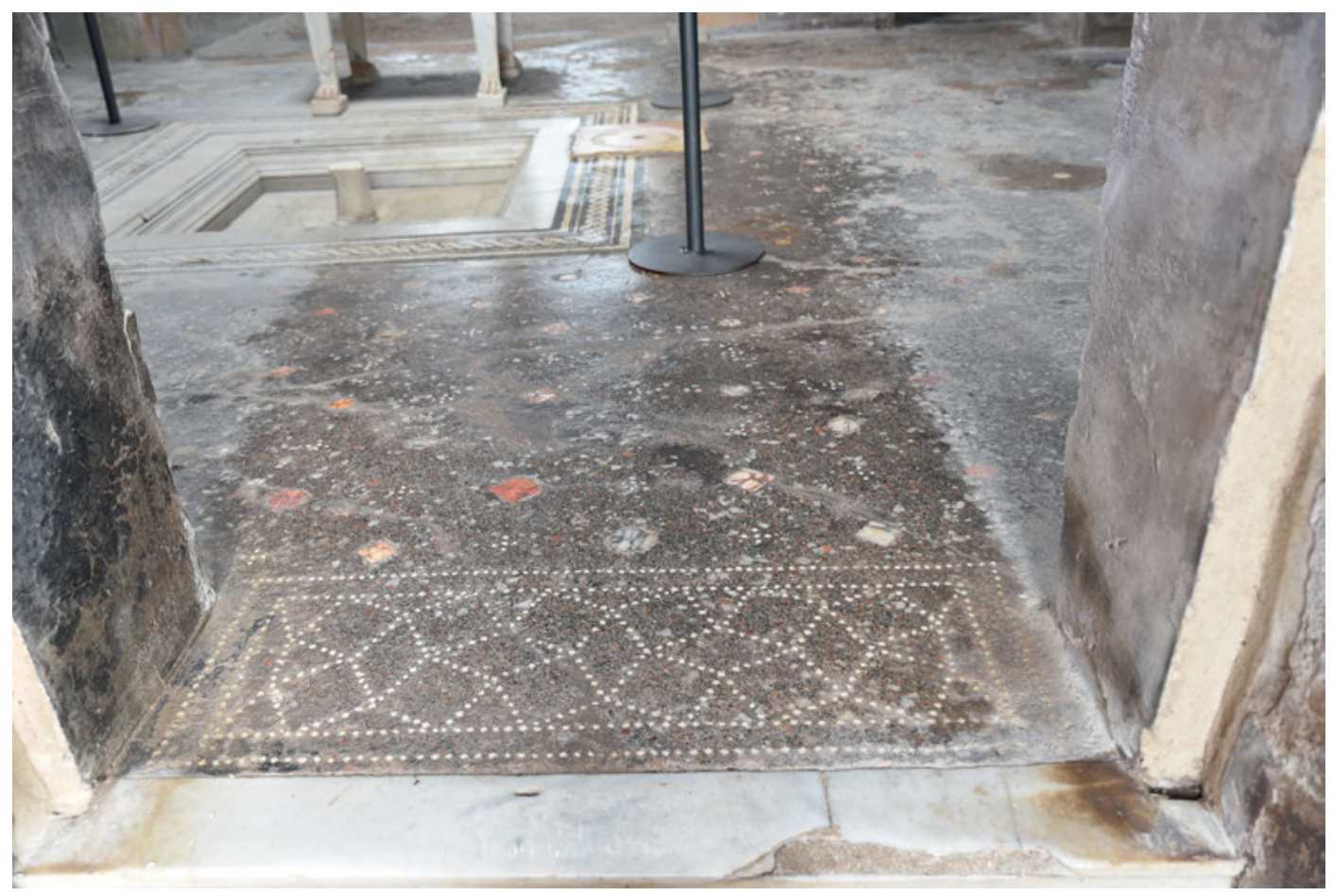

Die Wahrnehmung der Fauces wird folglich durch den ansteigenden, schwarzen Boden und die farblich klar gegliederte Wand bestimmt: schwarze Sockel-, rote Mittel- und weiße Oberzone. Dünne Decor-Bänder, in der Oberzone die filigrane Architektur, leisten eine Dreiteilung der Wand. In der Sockel- und Mittelzone wird auf eine axialsymmetrische Betonung der Wandmitte verzichtet, stattdessen erzeugen die roten Felder einen parataktischen Rhythmus. Durch den Verzicht auf figürliche Darstellungen ist die Zone schnell zu überblicken, der in das Haus Eintretende wird zum prunkvollen Atrium regelrecht ,hingeleitet ${ }^{50}$. Allein in der Oberzone wird das Wandzentrum durch die Ädikula herausgehoben. Sichtbar ist diese aber nur für denjenigen, der vom Atrium aus in die Fauces zurückblickt.

Der Übergang zum tuskanischen Atrium (b) ist durch zwei stuckierte, nicht-kannelierte Pilaster markiert, die im unteren Teil schwarz, im oberen gelb gefasst sind und damit die Farbigkeit der Hauptzone des Atriums vorwegnehmen ${ }^{51}$. Die Zweizonigkeit der Pilaster entspricht weder der Wandgliederung der Fauces noch der des Atriums, sie eignet sich dadurch jedoch in besonderer Weise, um zwischen den verschieden strukturierten Decor-Zonen zu vermitteln. Am Boden besetzt die Schwelle ein kompliziertes Tessera-Ornament aus aneinander angesetzten Quadraten, Dreiecken und Rauten (Abb. 277).

Der Atriumshof selbst besitzt ein Lavapesta-Paviment, in das größere hexagonale, quadratische, dreieckige und rautenförmige Buntmarmorplättchen eingesetzt sind. Dazwischen sind im Estrich Kreuzblumenornamente in Tesserae verlegt. Das Atrium verfügt damit über einen aufwendigen Boden-Decor, der Marmor-Luxus und Tessera-Ornamentierung miteinander verbindet. Von diesem
Abb. 277: Casa di Marcus Lucretius Fronto, Schwellbereich zwischen Fauces und Atrium. 
Abb. 278: Casa di Marcus Lucretius Fronto, Blick aus Cubiculum (c), über Schwelle hinweg, in das Atrium mit Impluvium und Tisch.

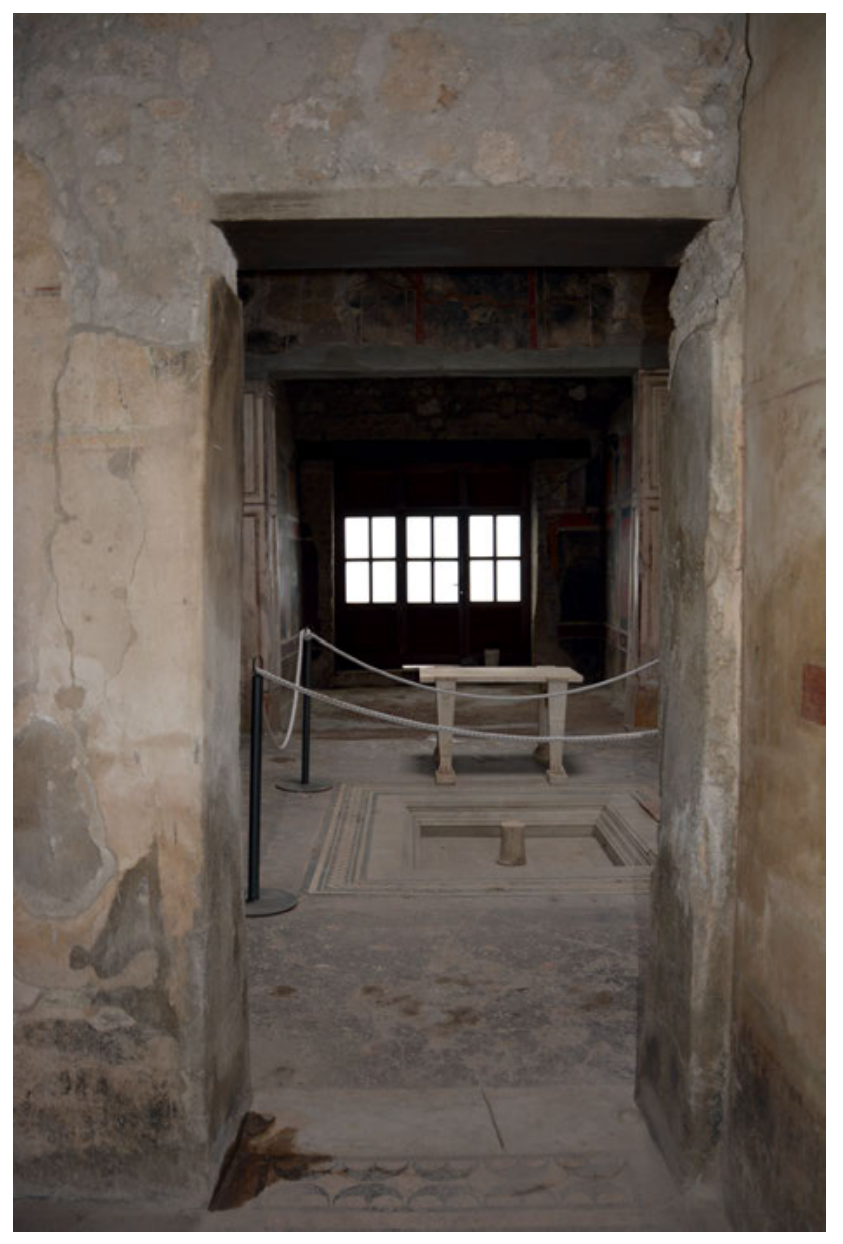

dunklen Boden hebt sich das prunkvolle, graue Marmorimpluvium eindrucksvoll ab (Abb. 278) ${ }^{52}$. Ein von schwarzen und weißen Streifen gerahmtes, weißes Flechtband auf schwarzem Grund fasst das Impluvium ein und fokussiert die Aufmerksamkeit auf das Zentrum des Atriums. Nachträglich war in die Mosaikrahmung auf der Südseite des Impluviums eine Zisternenöffnung eingelassen worden $^{53}$. In der Achse hinter dem Impluvium war ein zweibeiniger Tisch aus lunensischem Marmor mit vier Löwenfüßen aufgestellt, den man vielleicht in die augusteische Neuausstattungsphase weisen darf $f^{5}$. Die Blickachse des Hauses war folglich durch ein prunkvolles Möbelstück betont.
52 Laut Pernice 1938, 97 nachträglich, und damit „spät“ eingesetzt, wozu der Lavapesta-Boden aufgebrochen worden sei.

53 Hinweise auf eine Wasserleitung, die das Haus versorgt hätte, fehlen; so auch Mau 1901, 356f., der zugleich auf den Fund eines Eimers hinweist, den er hypothetisch mit der Zisterne verbindet; s. Sogliano 1901, 147.

54 Moormann 1993b, 391f. unter Verweis auf Moss 1988, 831 mit iulisch-claudischer oder frühflavischer Datierung, ohne kontextuelle Argumente. 


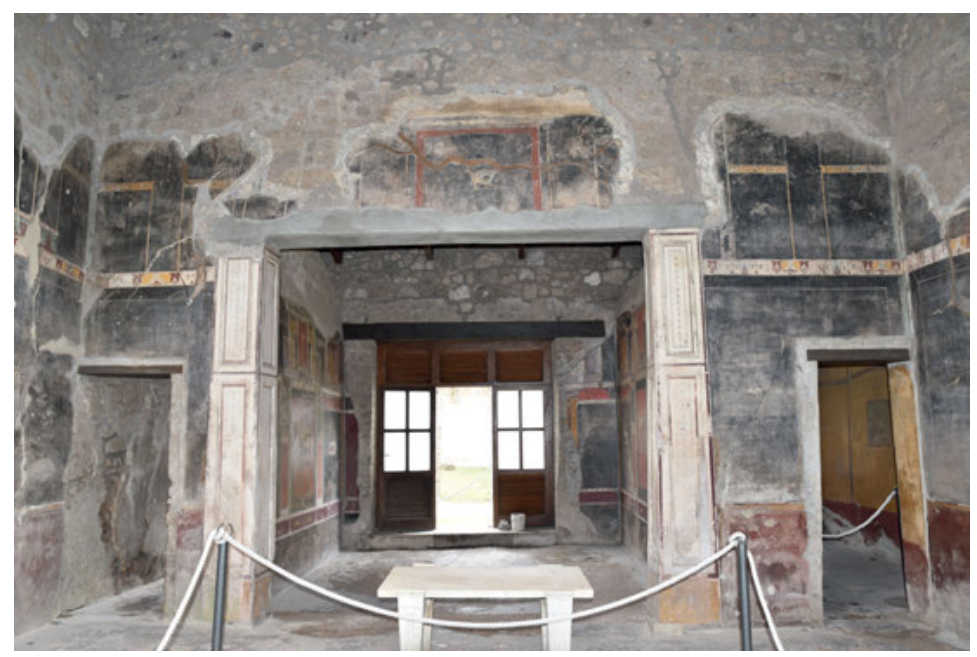

Abb. 279: Casa di Marcus Lucretius Fronto, Ostseite des Atriums mit Tablinum.

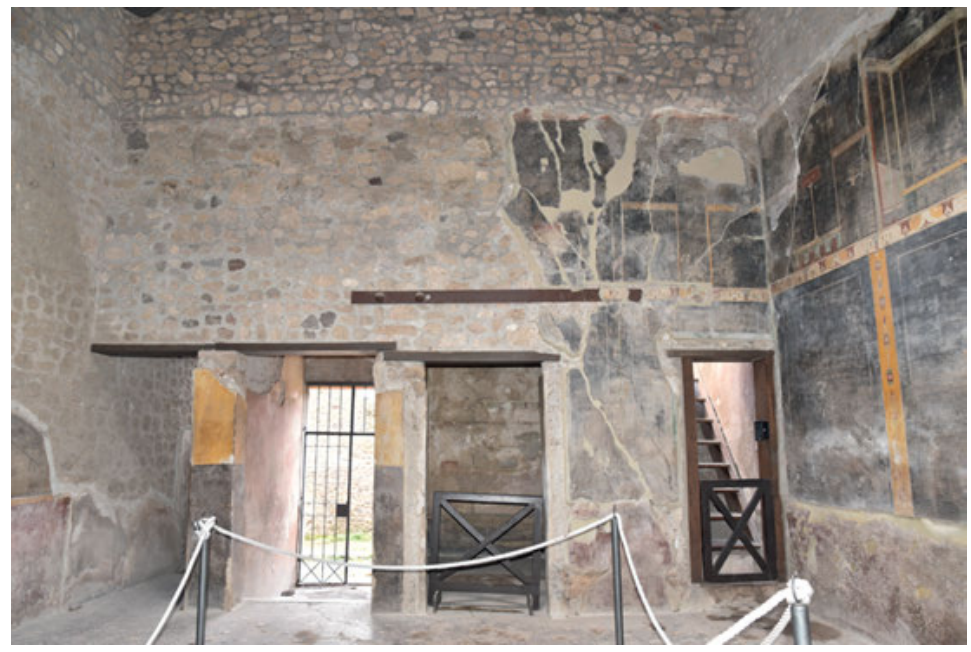

Abb. 280: Casa di Marcus Lucretius Fronto, Westseite des Atriums mit Fauces.

Die Wandseiten des Atriums werden durch verschiedene Raumöffnungen definiert, die in eine ungefähr symmetrische Struktur einbinden ${ }^{55}$. Tablinum (h) dominiert als höchster und am weitesten geöffneter Raum die Ostseite des Atriums. Seine breite Raumöffnung wird flankiert von zwei schmalen Türdurchgängen zu Korridor (k) im Norden und Cubiculum (i) im Süden (Abb. 279). Mit diesen korrespondieren auf der gegenüberliegenden Eingangsseite die schmalen Durchgänge zu Treppe (e) und Schrank (d), die seitlich die beiden Durchgänge zu Cubiculum (c) und Fauces (a) rahmen (Abb. 280). Nord- und Südseite entziehen sich einer Symmetrisierung, da auf der Nord-

55 Die im Folgenden beschriebene Raumdisposition ist das Ergebnis mehrfacher Umgestaltungen. Die straßenseitigen Räume (c) und (f) mögen sich ursprünglich als Tabernae auf die Straße hin geöffnet haben, bevor sie zum Atrium orientiert wurden. Raum (c) umfasste dann zunächst noch den späteren Raum (e), während Raum (f) durch das Herausnehmen einer Trennwand nachträglich vergrößert wurde. Auf der Südseite des Atriumhofs lag neben dem ursprünglich kleineren Raum (f) auch Cubiculum (g). Die Ostseite dürfte bereits ursprünglich ein zentrales Tablinum (h), ein südlich daran anschließendes Cubiculums (i) sowie Korridor (k) im Norden besessen haben; dazu Heres 1993, 133-135 mit Phasenplan Abb. 112. Möglicherweise befanden sich auf der Nordseite zunächst verschiedene Räume, die spätestens im 1.Jh.v.Chr. dem Nachbarhaus zugeschlagen wurden. Heres 1993, 134f. verweist dazu auf einen später vermauerten Türdurchgang gegenüber von (g); bezweifelt bei Oswald 2016, 45f. Auch Raum (n), der aus der Achse der Atriumsnordwand verspringt, spräche für eine ursprüngliche Ausdehnung des Hauses nach Norden. Allerdings könnte dieser unorganisch aus der Flucht springende Raum auch erst nachträglich dem Komplex zugeschlagen worden sein (Heres 1993, 135f.; anders Oswald 2016, 45f.). 
Abb. 281: Casa di Marcus Lucretius Fronto, Nordseite des Atriums, ohne Räume.

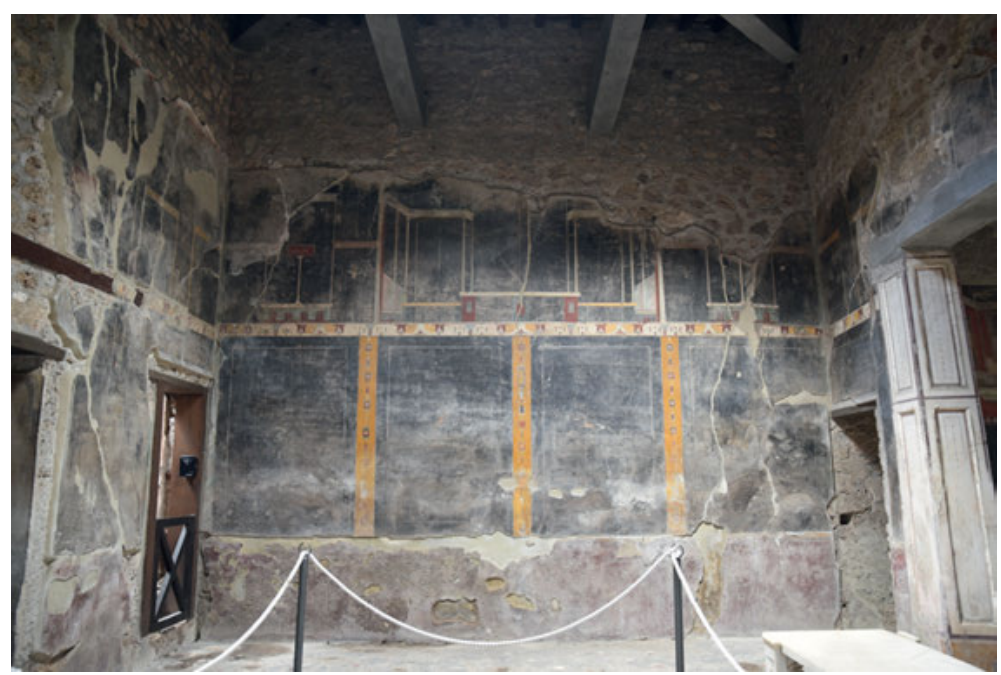

Abb. 282: Casa di Marcus Lucretius Fronto, Südseite des Atriums, mit Cubiculum (g) und Triclinium (f).

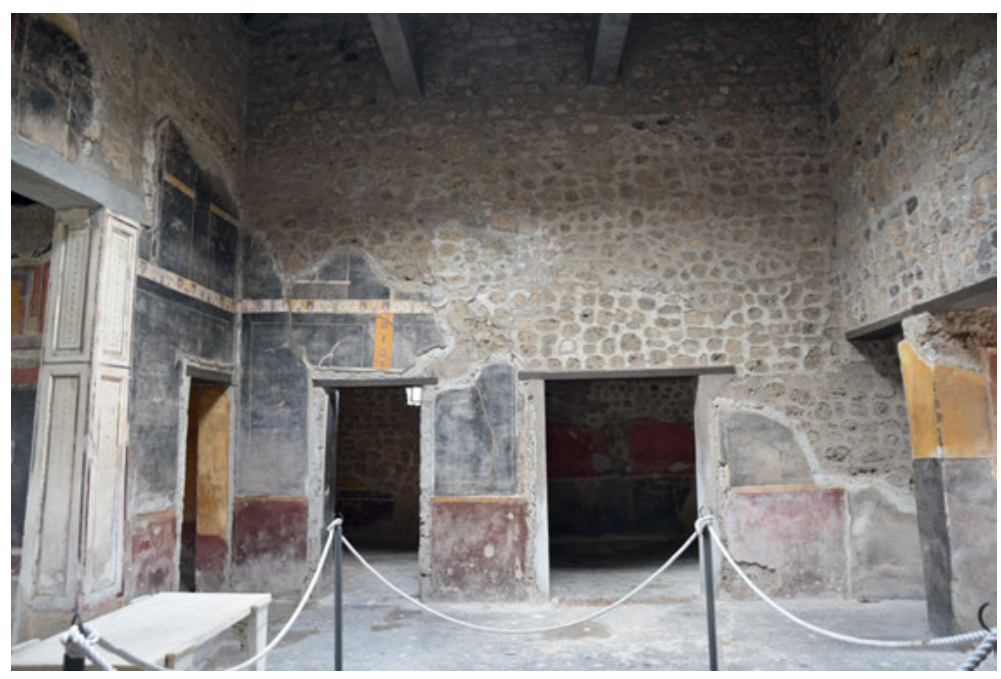

seite keine Räume liegen (Abb. 281-282). Triclinium (f) und Cubiculum (g) auf der Südseite unterscheiden sich hinsichtlich ihrer Türbreite und -höhe. Auf die Anlage einer Ala wurde verzichtet. Die fehlende Einheitlichkeit der Raumöffnungen schlägt sich auch in verschiedenartigen Schwelltypen nieder. So verfügen allein Cubiculum (c) und Korridor (k) über eine durchgehende Marmorschwelle, während Triclinium (f) und die Cubicula (g) und (i) unregelmäßig versetzte, an die Türwange angeschobene, marmorne Schwellsteine besitzen. Bei aller Heterogenität zeichnen sich die Schwellsituationen durch die Verwendung eines aufwendigen, ,modernen“ Materials (Marmor) aus ${ }^{56}$. Allein bei Schrank (k) waren die (verlorenen) Holzbalken direkt in den LavapestaBoden eingetieft.

Die Asymmetrie der Raumöffnungen wurde durch die Wandbemalung in ein einheitlich wirkendes Raum-Bild überführt. Über der nicht erhaltenen Sockelzone ${ }^{57}$ fällt die Mittelzone, den Dimensionen des Atriums entsprechend, sehr hoch aus. Sie ist an der nicht durch Türöffnungen unterbrochenen Nordwand von drei gelben Lisenen in vier schwarze, parataktisch geordnete

56 Lauritsen 2015, 308 f.

57 Laut Mau 1901, 335f. im vierten Stil in Rot restauriert. 


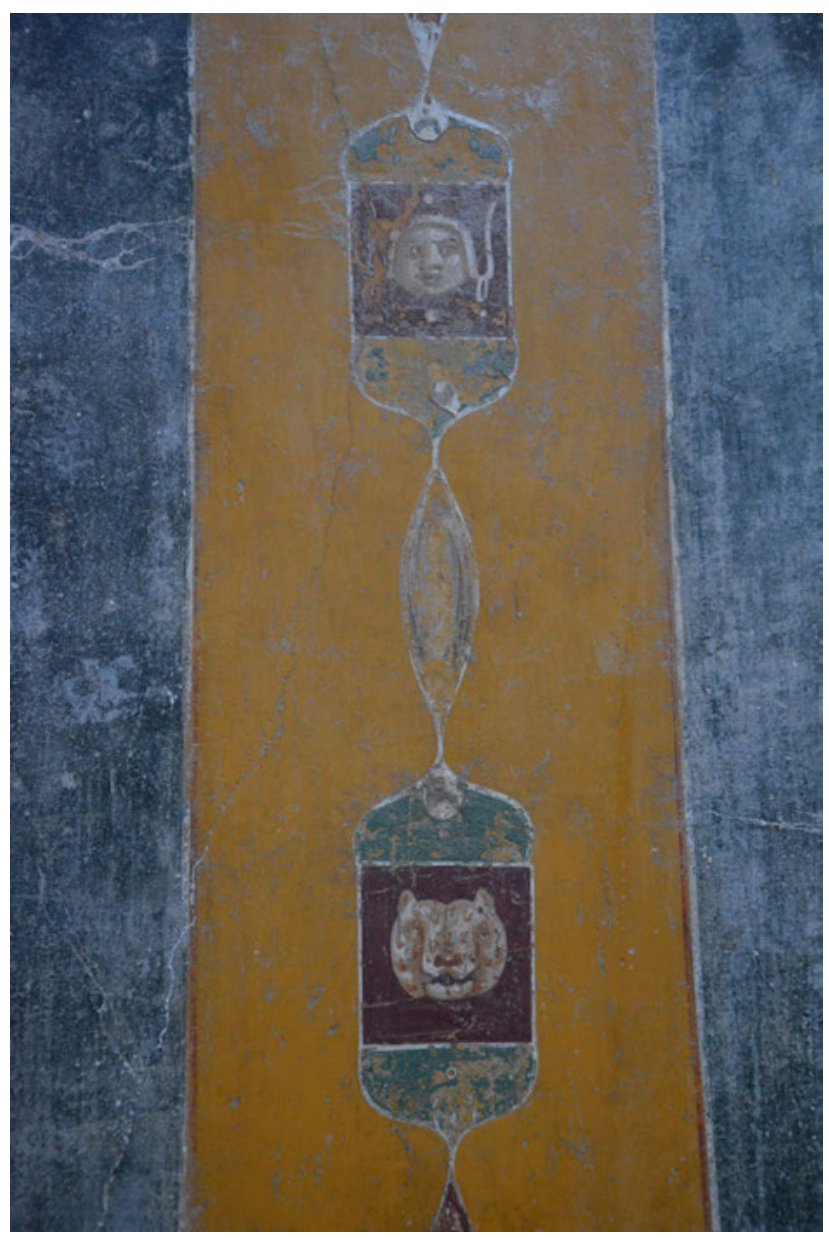

\begin{abstract}
Abb. 283: Casa di Marcus Lucretius Fronto, Nordseite des Atriums, Ornamentband auf gelber Lisene.
\end{abstract}

Orthostatenfelder gegliedert ${ }^{58}$. Die farblich besonders herausgehobenen Lisenen werden zum Träger von Ornamentbändern (Abb. 283), die abwechselnd aus weiß gefassten spitzblattförmigen und ovalen Schmuckformen bestehen. In die ovalen Felder sind rot grundierte Quadrate eingefügt, die als Hintergrund für die Darstellung von Medusen- und Tierköpfen dienen ${ }^{59}$. Die durch eine weiße Rahmenlinie noch einmal untergliederten Orthostaten fungieren als ,Träger von Tiervignetten. Auf der Nordwand sind es von West nach Ost ein Greif bzw. eine Sphinx ${ }^{60}$, ein Hirsch mit Hund (Abb. 284), ein von einem Hund verfolgter Hirsch und ein Schwan. Auf der durch Türen zergliederten Südwand wollte man ebenfalls eine Lisenengliederung evozieren. Dies zeigt sich in der Südostecke, wo über dem Türdurchgang zu (g) ein gelbes Lisenenband auf Höhe des östlichen Lisenenbandes der Nordseite eingefügt ist (Abb. 282). In den Wandfeldern, die durch die Türdurchgänge entstehen, sind der Nordseite entsprechend Tierdarstellungen angebracht. Von Ost nach West sind dies ein Vogel sowie ein von einem Hund verfolgter Hirsch. Auf der Ostseite wird das Tablinum durch zwei weiße, in sich ornamentierte Eckpilaster eingefasst (Abb. 279). Das unregelmäßige schwarze Feld, das zwischen Südpilaster und Türdurchgang zu Cubiculum (i) verbleibt, ist mit einem Spiegel versehen, der dem Verlauf der Türöffnung angepasst ist. Die Tierdarstellung -

58 Mau 1901, 336: „Die großen schwarzen Felder der Hauptfläche, 1,90×1,28 bis 1,33, umsäumt von einem violetten Streif zwischen zwei weissen Linien, sind getrennt durch gelbe Vertikalstreifen die je einen Ornamentstreifen enthalten, [...], in Violett, Grün, Rot, getrennt durch weisse Linien; dazwischen Masken, Tierköpfe, Leiern, Delphine u. A.“ 59 Sogliano 1901, 148 spricht von ägyptisierenden Motiven.

60 Bei Sogliano 1901, 148: Sphinx. 
Abb. 284: Casa di Marcus Lucretius Fronto, Nordseite des Atriums, Tierbild auf zweitem Orthostaten von links.
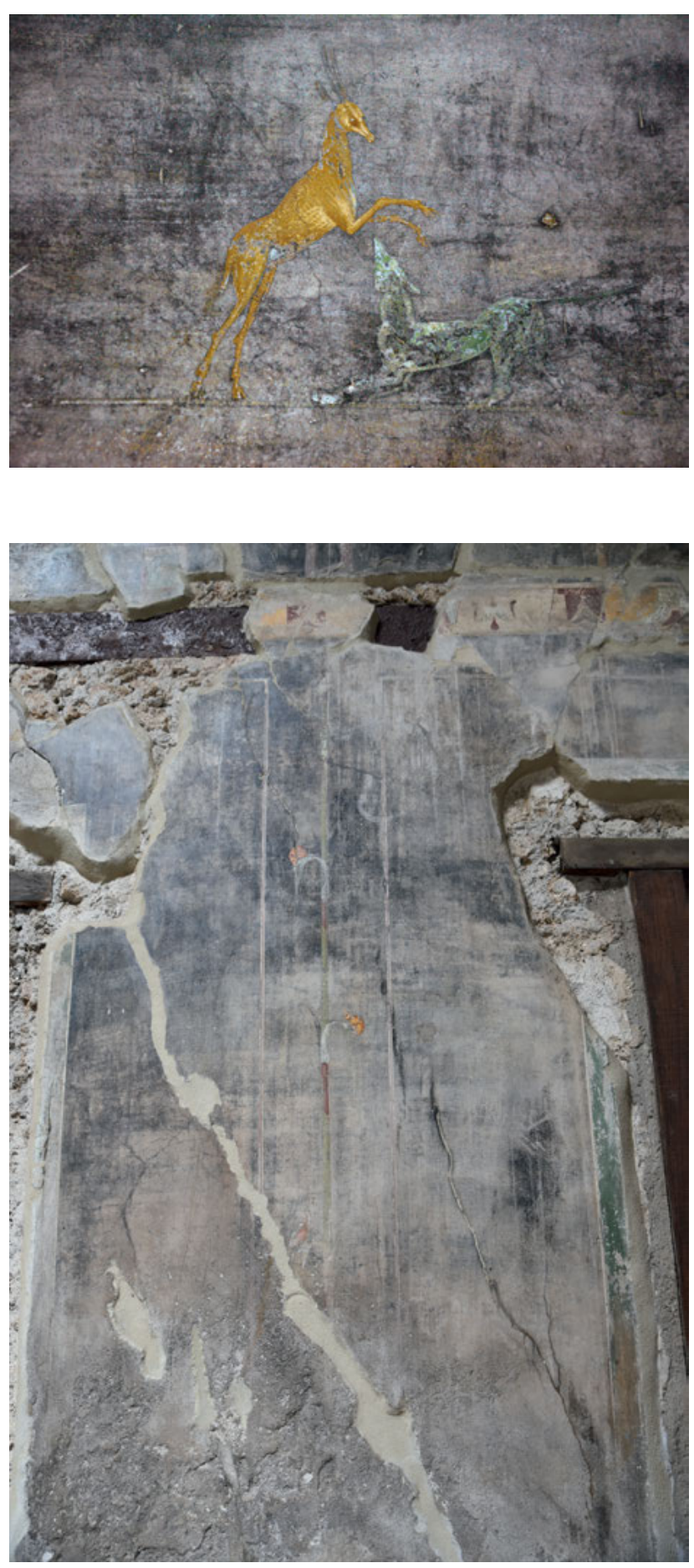

Abb. 285: Casa di Marcus Lucretius Fronto, Westseite des Atriums, Wandabschnitt zwischen den Räumen (e) und (c) mit Rankenpfeiler.

ein Hund, der ein Kaninchen verfolgt - fällt hier etwas kleiner aus. Auf der Westseite bleibt zwischen Cubiculum (c) und Treppe (e) ein breiteres Wandsegment, das mit dem Nordpilaster der Ostwand korrespondiert (Abb. 280). Hier hat man auf eine gelbe Lisene verzichtet und stattdessen ein vertikales Rankengebilde eingefügt, auf dessen Blättern kleine Tiere sitzen (Abb. 285). In der Mittelzone der Atriumsrückwände ergibt sich damit ein interessanter Effekt. Im Zentrum der Orthostatenfelder ist Bildlichkeit ganz zurückgenommen, die kleinen Tiervignetten heben sich kaum vom schwarzen Grund ab. Durch die parataktische Felderordnung sind auch die Vignetten auf eine parataktische Präsentation festgelegt. Sehr viel stärker fallen indes die rahmenden, gelbgrundigen 


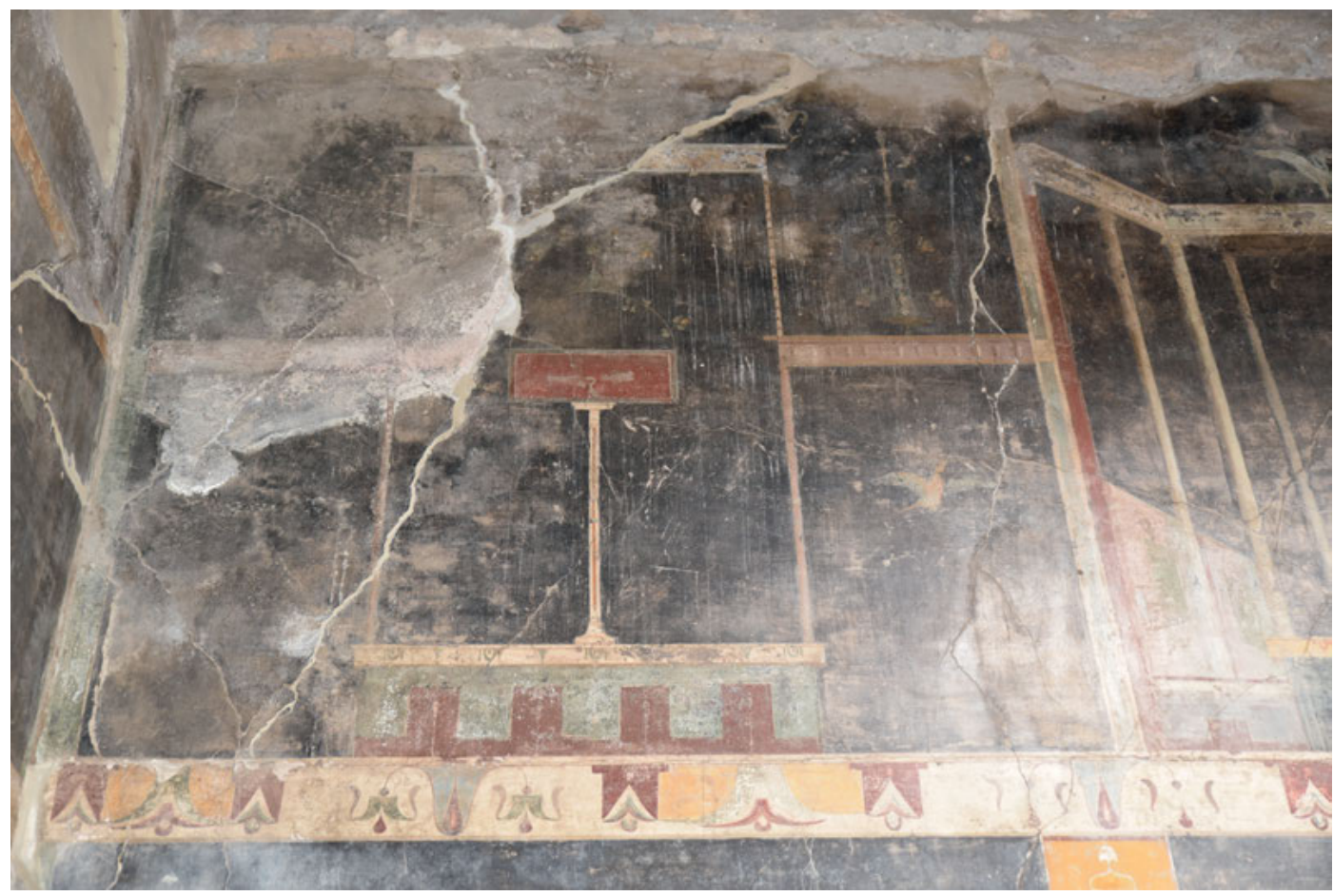

Lisenen mit ihren gerahmten ,Bild‘-Ornamenten ins Auge. ,Bilder` und ,Ornamente' sind dadurch in komplexer Weise ineinander verschränkt.

Alle vier Atriumsseiten werden durch einen umlaufenden, weißgrundigen Fries mit stilisierten Blüten und geometrischen Motiven in Rot und Gelb zusammengeschlossen ${ }^{61}$, der sich optisch deutlich von der schwarzgrundigen Wand abhebt. Er leistet eine strenge Trennung zwischen Mittelund Oberzone. Wieder liegt auf einer Übergangszone besonderes gestalterisches Gewicht.

Die Oberzone füllen axialsymmetrisch organisierte, luftige Architekturen auf schwarzem Grund. Dünne Säulchen mit Miniaturkapitellen tragen ein Gebälk. Im Zentrum der Nordseite fasst eine symmetrisch organisierte, filigrane Portikusarchitektur einen Baitylos ein. Seitlich schließen sich Ädikulen an, die Stylopinakes mit der Darstellung von Enten rahmen (Abb. 286). Auf der Ostseite nimmt die Zone oberhalb der Tablinumsöffnung eine zentrale Architektur ein, in der auf schwarzem Grund eine Tiergruppe präsentiert wird (Abb. 287). Tiere und Gefäße sind auch in die seitlichen Architekturfelder eingefügt.

Das Atrium muss mit seinem schwarzen Boden, seinem prunkvollen Marmorimpluvium, dem Tisch und den schwarzen Wänden eine ehrwürdige Atmosphäre besessen haben. Anstelle gerahmter Bilder werden an der Wand auf schwarzem Grund verschiedene ,Bildmotive vorgeführt, die in die ,wilde‘ Natur und die Welt der Mischwesen verweisen. Durch die Einbindung in ein architektonisches Ordnungssystem wird diese Natur jedoch gezähmt und ornamentalisiert.

\section{Das Tablinum als exzeptioneller Schauraum}

Tablinum (h) öffnet sich nicht nur auf ganzer Front zum Atrium hin, sondern besitzt auf seiner Rückseite auch eine etwas niedrigere und schmalere Öffnung zum rückwärtigen Hof (Abb. 279). Dadurch ergibt sich ein besonderer visueller Effekt: Die beiden etwa quadratischen Raumöffnungen - die größere Atriumsöffnung und die kleinere Peristylöffnung - schaffen eine doppelte
Abb. 286: Casa di Marcus Lucretius Fronto, Nordwand des Atriums, Detail der Oberzone im Nordwesten, mit Pinax. 
Abb. 287: Casa di Marcus Lucretius Fronto, Ostseite des Atriums, Oberzone oberhalb der Tablinumsöffnung: Architektur mit Tiergruppe.

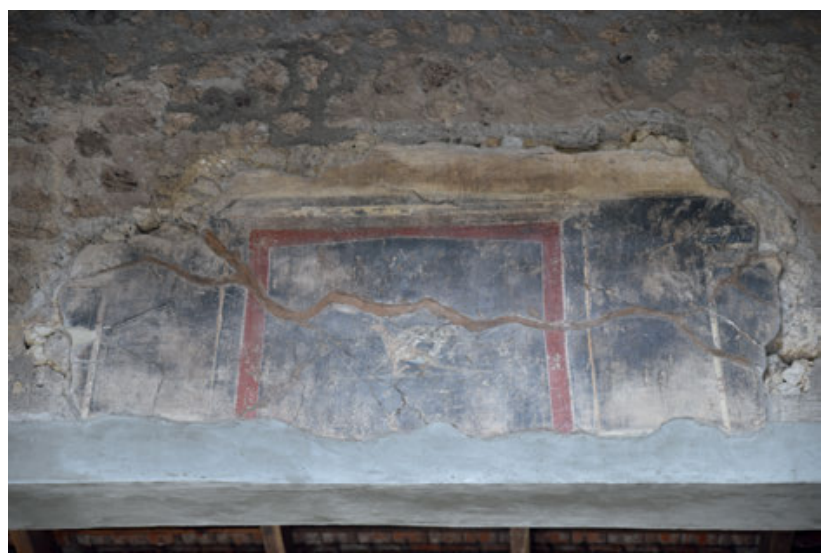

Rahmung für den Durchblick zum Garten. Zudem ermöglichten sie es, das Tablinum sowohl als Repräsentationsraum am Atrium als auch als Gelageraum am Peristyl zu nutzen. Atriumsseitig ließ sich die Raumöffnung durch Vorhänge verschließen ${ }^{62}$, peristylseitig durch eine dreiflügelige Tür. Als Durchgangsraum im engeren Sinn hat das Tablinum nicht gedient, dafür stand Korridor (k) zur Verfügung.

Die Übergänge vom Atrium zum Tablinum sowie vom Tablinum zum Peristyl wurden durch Decor akzentuiert. Zwei mächtige, weiße Eckpfeiler, die in Stuck einen Holztürrahmen nachahmen, flankieren die Öffnung zum Atrium. Sie sind in zwei rechteckige Zonen mit stuckiertem Profil und zurücktretendem rechteckigem Spiegel gegliedert, eine höhere untere und eine kürzere obere. Diese Gliederung entspricht weder dem Wandaufbau des Atriums noch dem des Tablinums, leistet dadurch aber wie die Fauces-Pfeiler einen Übergang zwischen den beiden Decor-Räumen. Das Profil ist durch einen grünen und einen roten Streifen eingefasst, in jeden Spiegel ist in Hellblau ein Rechteck eingeschrieben, das in sich weiter ornamentiert ist ${ }^{63}$. Am Boden ist der Übergang vom Atrium zum Tablinum weniger klar markiert. Der Lavapesta-Boden des Atriums setzt sich im Tablinum fort. War er im Atrium jedoch aufwendig ornamentiert, so wird er im Bereich des Tablinums allein durch unregelmäßige Steinsplitter belebt. Der Durchgang zum Peristyl ist nicht eigens durch Pilaster markiert worden ${ }^{64}$. Am Boden hebt eine mit Marmorplatten verkleidete Stufe die Schwellsituation hervor. Die atriumsseitige Pilasterrahmung zeigt an, dass der Blick auf das Tablinum inszeniert wurde. Am Garten hingegen war der Ausblick von den Prunkräumen auf den Garten wichtig - das Tablinum lag nicht in dieser Sichtachse und erhielt wohl deshalb auch keine aufwendige Einfassung.

Der Decor übernimmt die Funktion, das Tablinum als Aufenthaltsraum zu entwerfen. Ist das Paviment gegenüber dem Atrium in seinem Aufwand zurückgenommen, fällt die Wandgestaltung umso aufwendiger aus: durch die Farbenpracht, durch die kleinteiligere, an die Raummaße angepasste Wandgliederung, die strenge Axialität und Symmetrie der Wandmalerei sowie durch

62 Mau 1901, 336-338 macht auf ein Loch „in der Mitte der Vorderseite dieser Stuckantepagmenta“ aufmerksam, das er mit der Aufhängung eines Vorhangs in Verbindung bringt.

63 Mau 1901, 336.

64 Peristylseitig haben sich Reste von Rohputz, vermutlich zu einer Ausmalung vierten Stils gehörig, erhalten, die keinen Pilasteransatz erkennen lassen. 


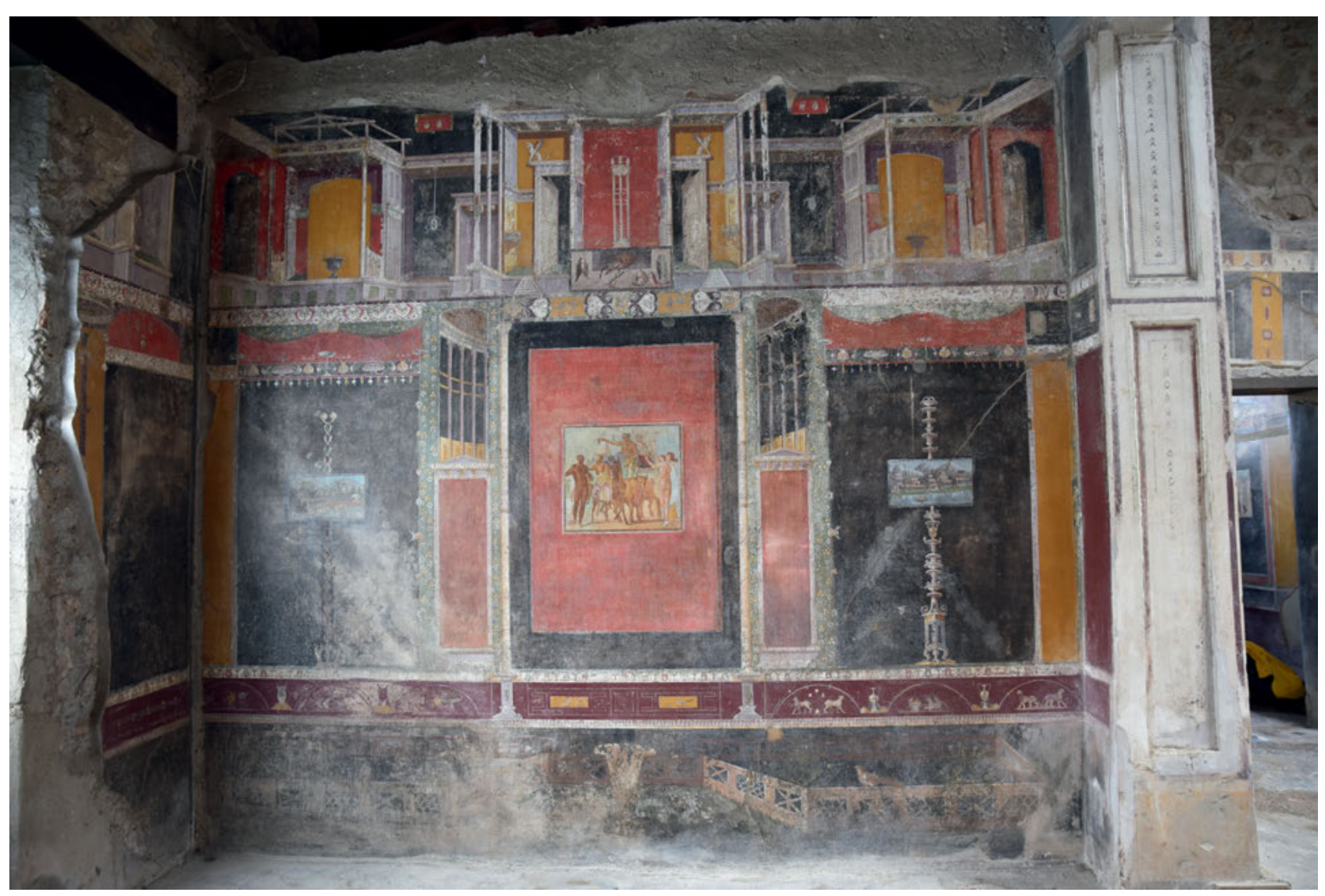

die Verwendung von zahlreichen Bildelementen ${ }^{65}$. Nord- und Südwand (Abb. 288) sind spiegelsymmetrisch aufeinander bezogen, unterscheiden sich jedoch in Details. Dadurch entsteht eine Vielzahl an Interpiktorialitäts-Effekten, d.h. ein Spiel mit verschiedenen Graden an Ähnlichkeit.

Auf der schwarzen Sockelzone umhegt auf beiden Wandseiten ein halbhoher, aus rechteckigen Segmenten bestehender, braunroter Holzzaun einen Garten. Indem die einzelnen Zaunsegmente jeweils unterschiedliche Gitter-Ausfachungen aufweisen, wird die Garteneinfassung mit besonderer Aufmerksamkeit belegt. Die Variation wird noch einmal dadurch gesteigert, dass die Gittermuster im Vergleich von Nord- und Südseite verschieden ausfallen. Der Zaun umfasst eine rechteckige Gartenfläche, springt jedoch im Wandzentrum zurück. Auf der Nordwand nimmt sich der Gitterrücksprung halbkreisförmig, auf der Südseite stärker eckig aus. Vor und damit auch außerhalb des Gartens wird auf der Nordwand ein Springbrunnen (Abb. 289), auf der Südwand ein Kantharos (Abb. 290) präsentiert. Der gesamte Garten wird so als aufwendige Rahmung eines Brunnens verständlich. Auf der Gartengrenze, dem Zaun, haben sich verschiedene Vogelarten niedergelassen, welche die strenge Axialsymmetrie auflockern. Im Inneren des umzäunten Areals entwickelt sich ein dichter Pflanzenbewuchs. Das Bild nimmt eine axonometrische Perspektive von oben ein - und tatsächlich blickt ein aufrecht stehender Betrachter auf den Garten ,hinunter'. Auf schwarzem Grund und ohne Bezug zu den anderen Elementen der Wand dargestellt, entzieht er sich einem statisch-architektonischen Wandverständnis, stellt dieses sogar infrage. Vielmehr prä-
Abb. 288: Casa di Marcus Lucretius Fronto, südliche Tablinumswand. 


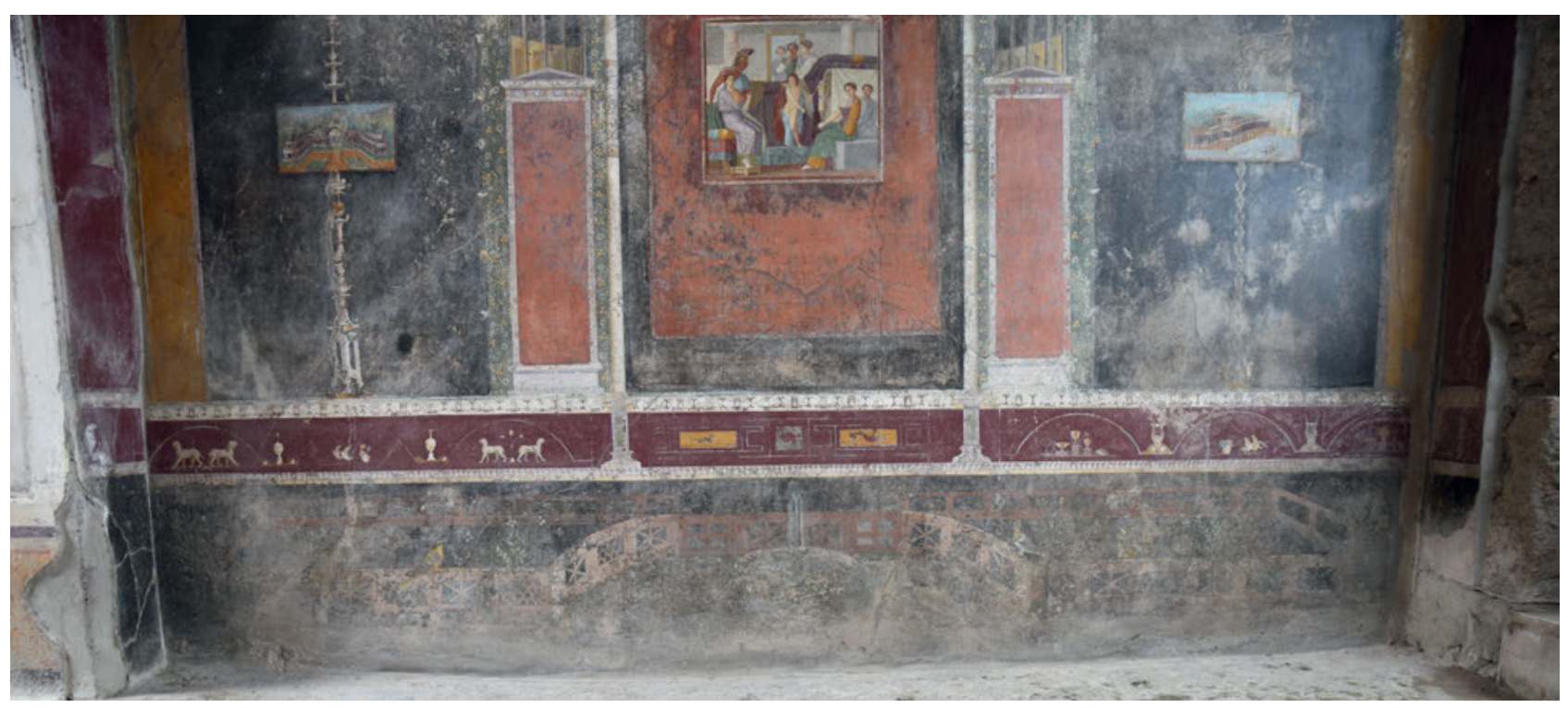

Abb. 289: Casa di Marcus Lucretius Fronto, Tablinum, Sockel- und

Predellazone der Nordwand.

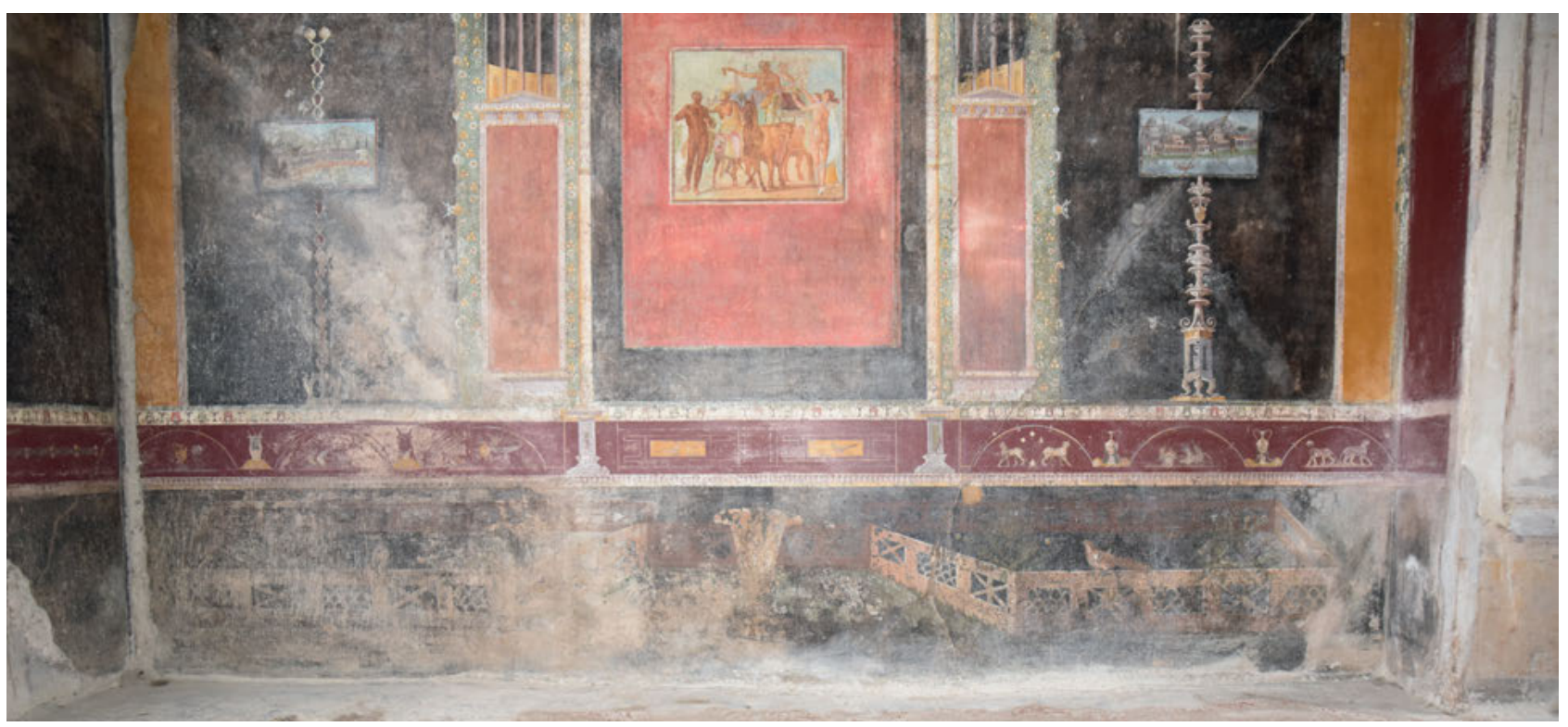

Abb. 290: Casa di

Marcus Lucretius

Fronto, Tablinum,

Sockel- und

Predellazone der

Südwand. 


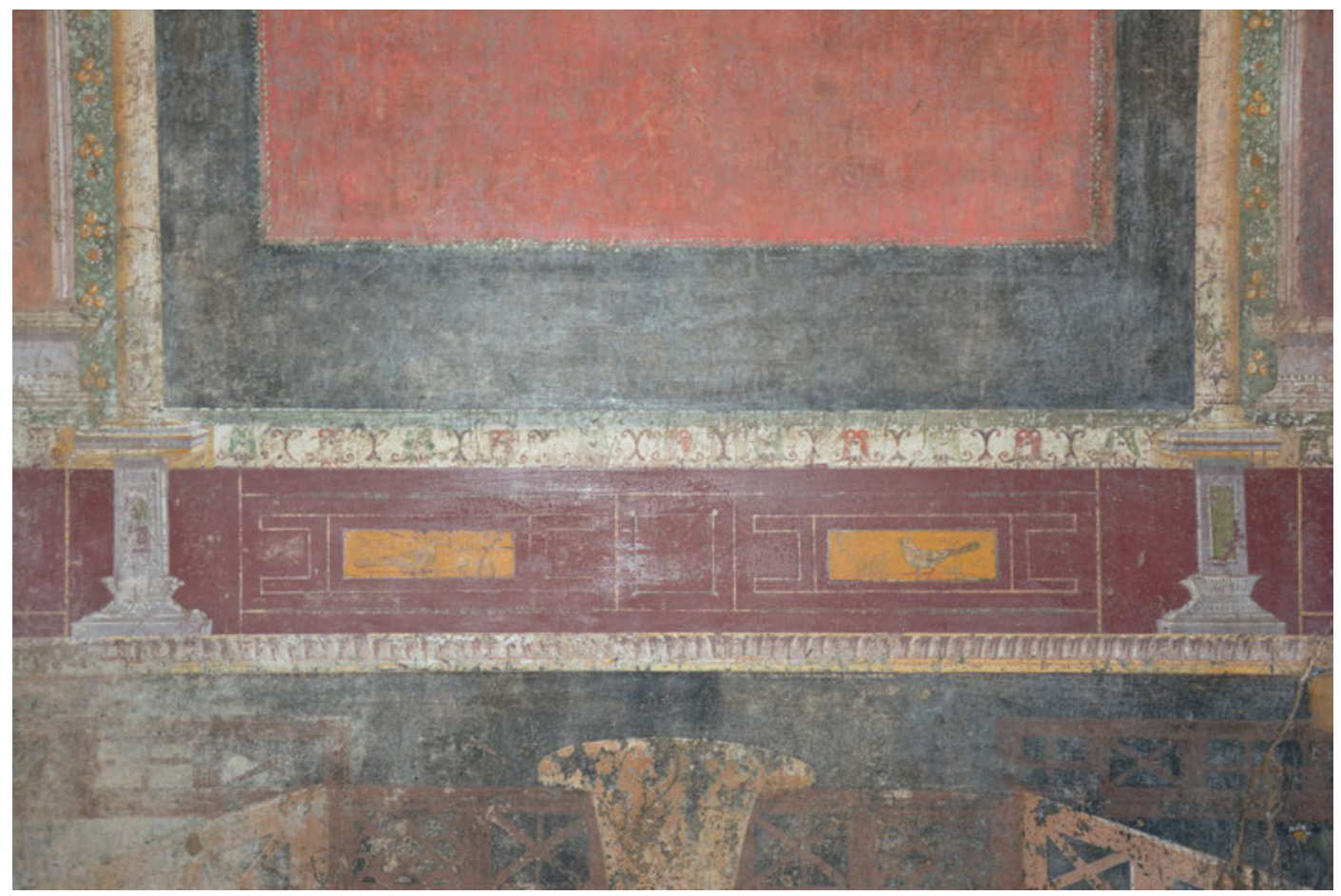

sentiert das Gartenbild eine Welt ,für sich', deren Abgeschlossenheit durch das prominente Gartengitter angezeigt wird ${ }^{66}$.

Die auffällige, purpurne Predellazone markiert den Übergang zu einem anderen Wandverständnis: der Wand als Architekturkulisse. Zwei Sockel, die sich in der Mittelzone als Ädikulasäulen fortsetzen, gliedern die Predellazone in zwei breitere seitliche und ein schmaleres mittiges Feld. Das zentrale Predellapaneel ist streng axialsymmetrisch aufgebaut, in ein Mäanderornament sind drei kleine Bildfelder eingesetzt (Abb. 291). Im zentralen, grün grundierten Feld war ein Menschenkopf zu sehen, der seitlich von gelbgrundigen Vogelbildern eingefasst ist, wobei die Vögel auf das Zentrum hin orientiert sind. Es handelt sich somit um eine formal wie inhaltlich symmetrisierte ,Bild'-Zone. In den breiteren, seitlichen Predellapaneelen fassen jeweils drei bogenförmige Ranken figürliche Darstellungen ein (Abb. 289-290). Im atriumsseitigen Paneel rahmt der mittige Rankenbogen einen von Schwänen gezogenen Karren, während die seitlichen Bögen Panther einfassen, die einander den Rücken zukehren. Peristylseitig handelt es sich um einen Schwanen-Karren, der von Amphoren und Kitharae gerahmt ist. Die Karren sind jeweils nach außen, d.h. zu den Öffnungen des Tablinums hin, orientiert. Dadurch wird das kleine grüngrundige Kopfporträt als Mittelpunkt einer axialsymmetrischen Komposition verständlich, deren Symmetrieseiten nur leicht variiert werden. Die Spiegelsymmetrie zur gegenüberliegenden Wandseite fällt indes streng aus, auf Variationen hat man verzichtet. Aufgrund der symmetrischen Organisation der Bildfelder, der Kleinteiligkeit der Darstellungen und der geringen semantischen Komplexität wirkt die Predellazone wie ein Ornamentstreifen.

In der Mittelzone sind Architekturraum und Bildlichkeit in komplexer Weise miteinander verschränkt. Filigrane weiße Säulchen, die auf den Postamenten der Predellazone aufsitzen, leisten eine Gliederung in gänzlich flach vorgestellte Felder (Abb. 289-290). Sie rahmen eine schwarze Paneelfläche, auf der ein großer roter, rechteckiger Passepartout-Rahmen ein deutlich kleineres,
Abb. 291: Casa di Marcus Lucretius Fronto, Tablinum, zentraler Abschnitt der Predellazone der Südwand.

66 Ausführlich zu dieser Darstellungsform Bergmann 2014, bes. 249f.; zum Beispiel der Casa di Marcus Lucretius Fronto bes. S. 258. 


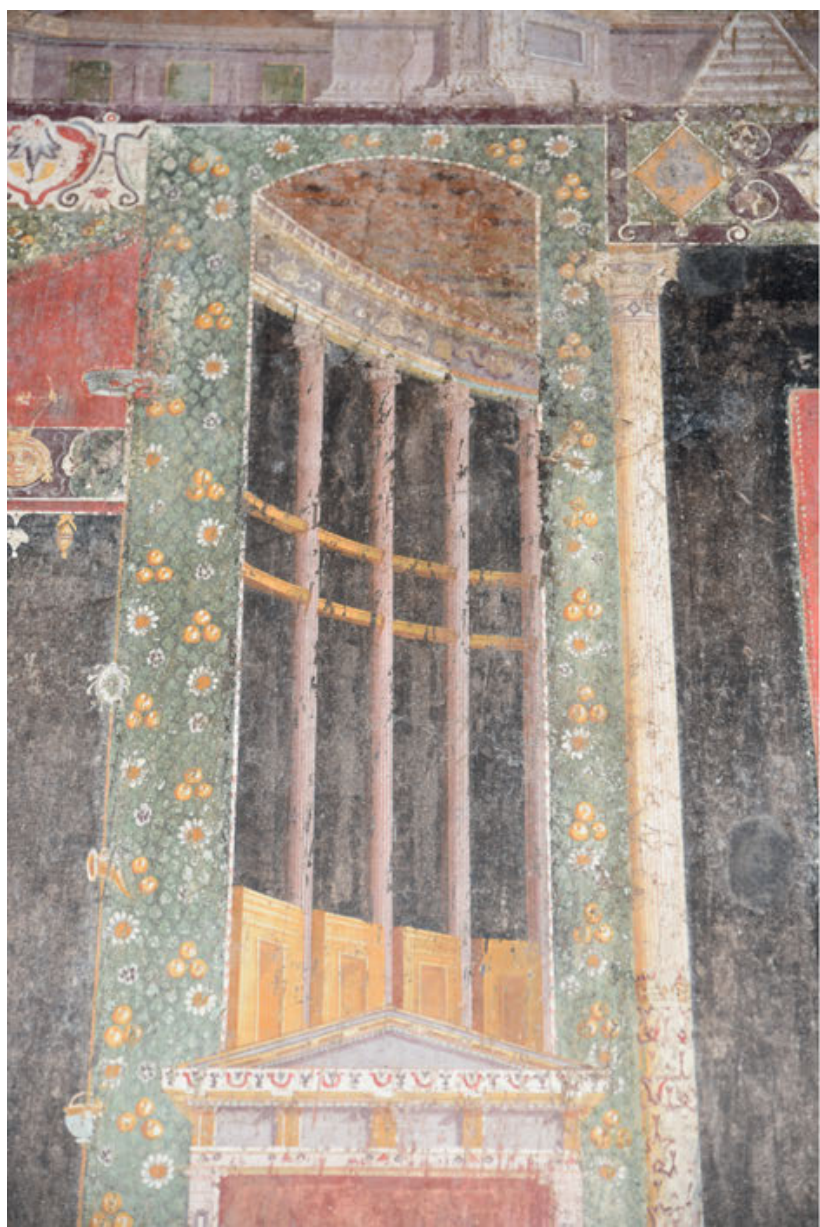

Abb. 292: Casa di Marcus Lucretius Fronto, Tablinum, Mittelzone der Südwand.

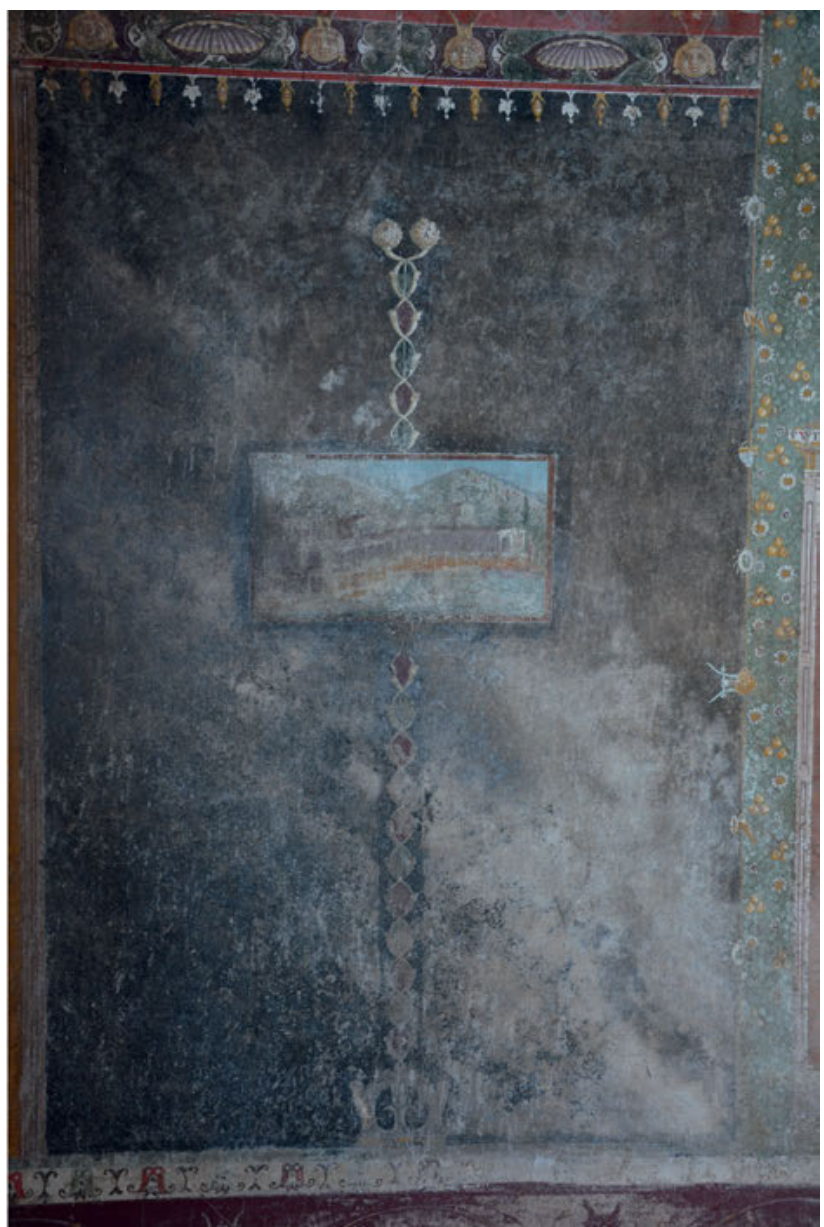

Abb. 293: Casa di Marcus Lucretius Fronto, Tablinum, Mittelzone der Südwand, Feld mit Kandelaber.

annähernd quadratisches Mythenbild umgibt. Den oberen Abschluss des Feldes bildet eine Frieszone mit herzförmigen Motiven. Zusätzlich wird das Mittelfeld von einer illusionistischen Architektur eingefasst. Diese ,Rahmenarchitektur` wird nun aber ihrerseits von Girlanden eingefasst, die aus Blättern und Früchten bestehen. Innerhalb des Girlandenrahmens ist die Architektur zweigeteilt. Den unteren Teil nimmt eine geschlossene Giebelarchitektur ein, darüber öffnet sich die Wand und man blickt auf eine filigrane, perspektivisch dargestellte, gebogene Säulenarchitektur (Abb. 292). Sie erzeugt den Eindruck, hinter dem zentralen Bildfeld umzulaufen und es dadurch symmetrisch einzufassen. Die ,Rahmung“ wird so zum besonderen Blickfang.

,Vor' den beiden seitlich anschließenden, schwarzgrundigen Feldern steht auf der Nord- wie auf der Südwand jeweils mittig ein weiß-gelber, mehrstöckiger Kandelaber. Der atriumsseitige ist aus Schalenmotiven gebildet und weist ein Springbrunnenmotiv auf, der peristylseitige ist aus sich kreuzenden Füllhörnern zusammengesetzt und läuft in Pinienzapfen aus (Abb. 293) ${ }^{67}$. Durch ihren verspielten Decor erzeugen die Kandelaber eine Atmosphäre von luxuria, die dadurch noch einmal gesteigert wird, dass sie als Träger von Pinakes dienen. Diese kleinformatigen gerahmten Bildtafeln zeigen jeweils leicht variierte, topisch angelegte Architekturlandschaften ${ }^{68}$, die anders als die

67 Curtius 1929, 64.

68 Peters 1963, 114f.; zur Topik der Landschaftsbilder und ihrer additiven Komposition etwa Bergmann 1991. 


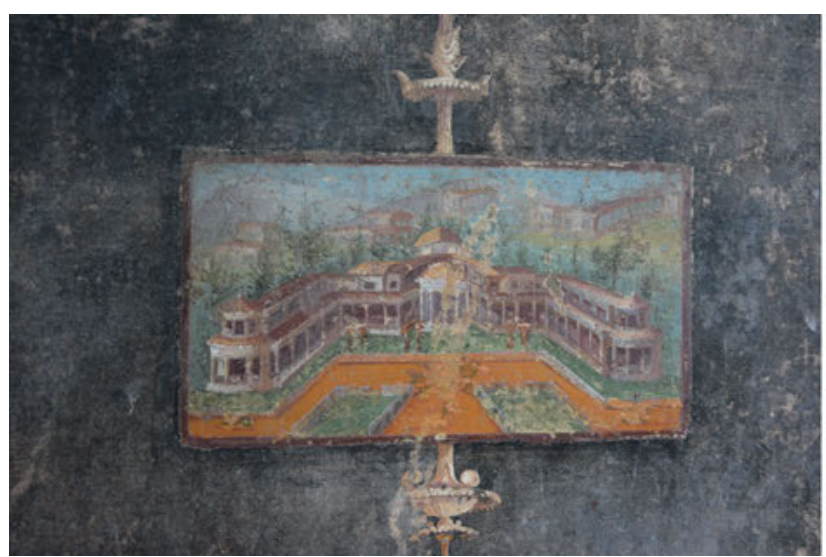

Abb. 294: Casa di Marcus Lucretius Fronto, Tablinum, Mittelzone der Nordwand, westliches, atriumsseitiges Landschaftsbild.

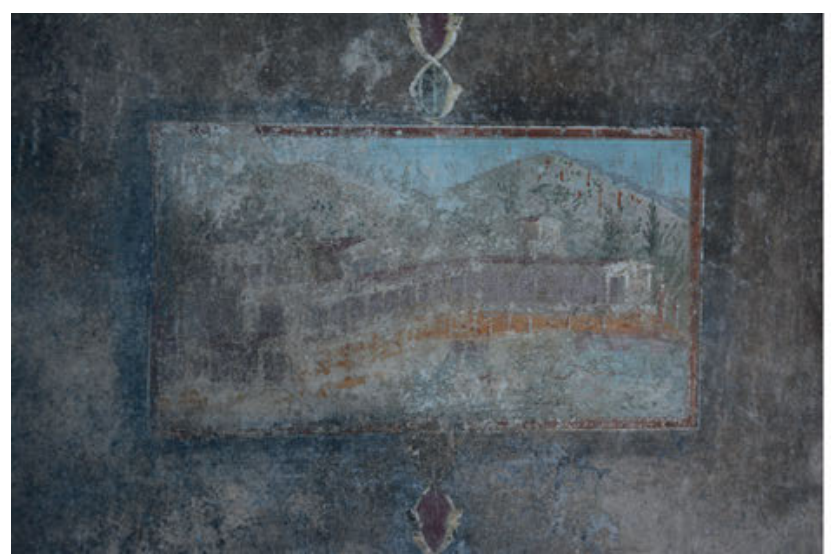

Abb. 296: Casa di Marcus Lucretius Fronto, Tablinum, Mittelzone der Südwand, östliches, peristylseitiges Landschaftsbild.

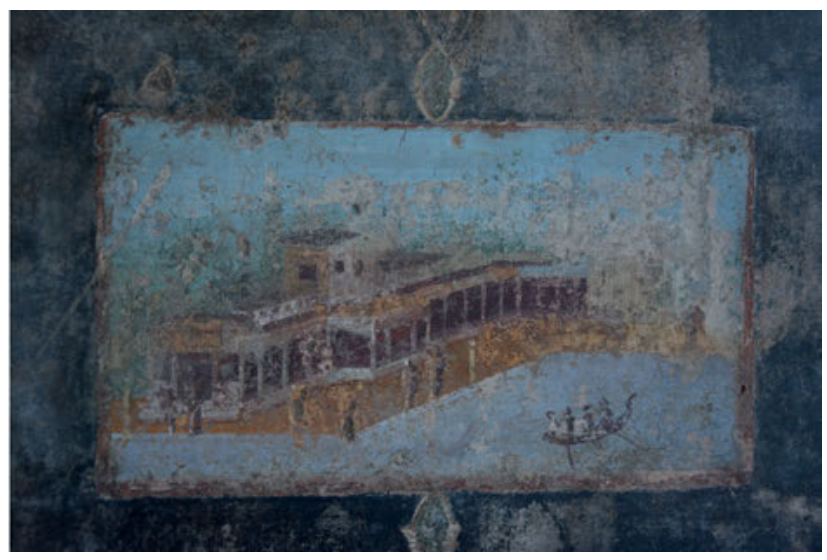

Abb. 295: Casa di Marcus Lucretius Fronto, Tablinum, Mittelzone der Nordwand, östliches, peristylseitiges Landschaftsbild.

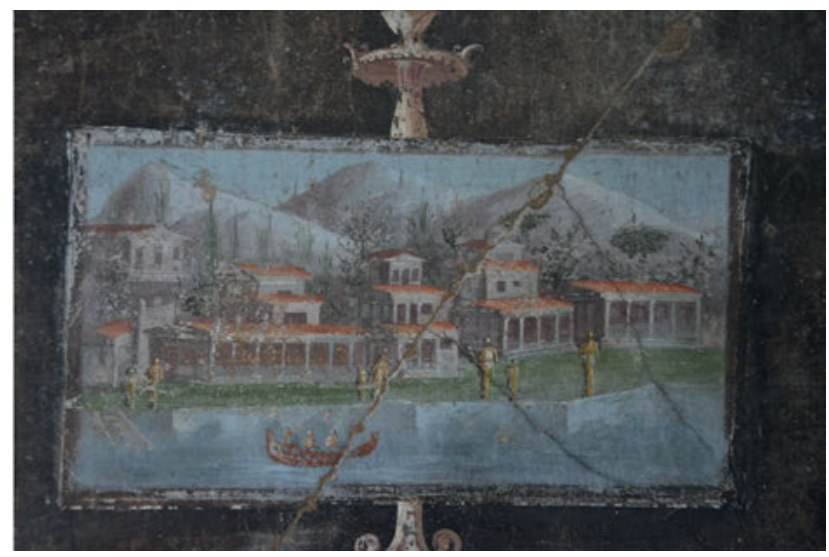

Abb. 297: Casa di Marcus Lucretius Fronto, Tablinum, Mittelzone der Südwand, westliches, atriumsseitiges Landschaftsbild.

Gartenbilder der Sockelzone ganz ohne Abschrankungen auskommen ${ }^{69}$. In drei Fällen handelt es sich um einen in Vogelperspektive erfassten Baukörper. Im westlichen Bild der Nordwand (Abb. 294) ist dies ein axialsymmetrisch angelegter, П-förmiger Flügelbau, dessen Seitenflügel mit einer tholosartigen Architektur abschließen. Im östlichen Bild der Nordwand (Abb. 295) und im östlichen Bild der Südwand (Abb. 296) handelt es sich um eine L-förmige Portikus mit dahinter anschließenden Baukörpern. Das westliche Bild der Südwand (Abb. 297) indes zeigt verschiedene Baueinheiten am Gestade vom Wasser aus. Während die geschlossenen Baukomplexe an Villenarchitekturen erinnern, wird im letztgenannten Bild eine lockere Uferbebauung vorgeführt. Die Bilder unterscheiden sich jedoch nicht nur in Bezug auf die Architekturen, sondern auch hinsichtlich ihres Landschaftssettings. Die Uferarchitektur und die beiden L-förmigen Baukomplexe liegen am Wasser, während sich vor dem П-förmigen Komplex eine Gartenanlage ausbreitet. In allen Fällen werden die Anlagen von Hügelketten hinterfangen, die sich jedoch unterschiedlich hoch ausnehmen. Alle Szenerien sind zudem durch kleine Figuren bevölkert. Die vier Pinakes spielen folglich mit Ähnlichkeiten und Unterschieden, die sich jedoch erst durch eine vergleichende Betrachtung erschließen. Zu den Seiten hin wird die Mittelzone durch ein gelbes hochrechteckiges Paneel beschlossen. Nach oben sind die schwarzen Paneele durch eine Schmuckborte begrenzt, in

69 Mit Hinweis auf entsprechende Unterschiede Bergmann 2014, $257 \mathrm{f}$. 
Abb. 298: Casa di Marcus Lucretius Fronto, Tablinum, zentraler Bereich der Oberzone der Südwand.

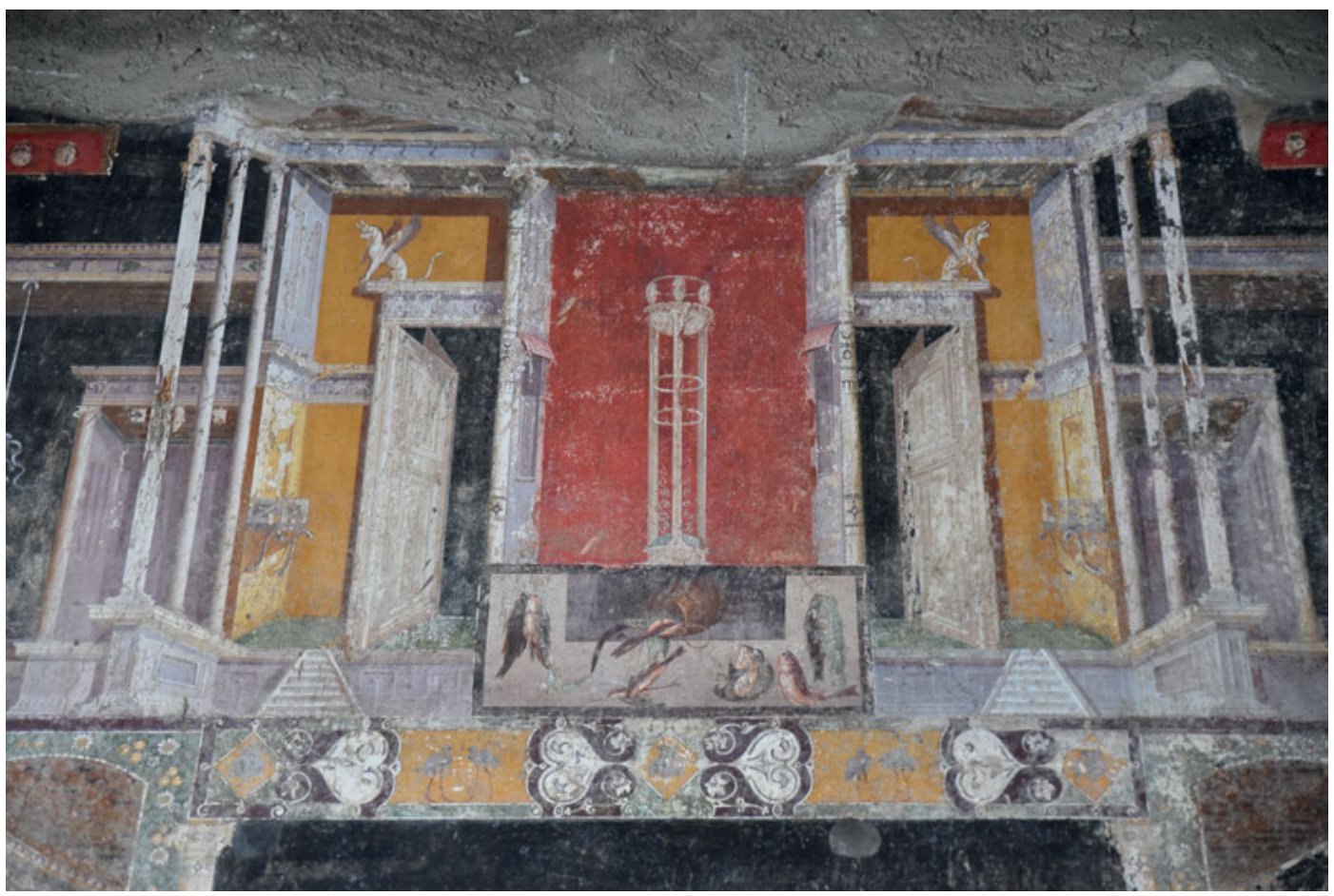

die Medusenköpfe mit Leiern auf dem Kopf, Muscheln und Krönchen eingesetzt sind. Es folgt eine rote Zone, in die an einem mittigen ,Schlussstein' befestigt dichte Blütengirlanden vorhangartig herabhängen. Auf Höhe des Architravs schließen die seitlichen Zonen mit einer weißgrundigen, erneut reich ornamentierten Friesborte ab.

In der Oberzone ist die symmetrisch aufgebaute, dreiteilige, filigrane, „wahrscheinlich-unwahrscheinliche“70 Architektur wie die Mittelzone durch rote, gelbe und schwarze Flächen strukturiert. Auf einem verkröpften Podium entwickelt sich ein axialsymmetrisch angelegter Baukörper. Das Zentrum nimmt auf beiden Wandseiten eine Ädikula ein, die einen vor rotem Hintergrund präsentierten Dreifuß einfasst (Abb. 298). In ihrer Sockelzone ist ein Pinax mit einem ,Stilleben' platziert. Wieder laden die Bildtafeln dazu ein, Nord- und Südwand miteinander zu vergleichen. Auf der Südwand macht das gerahmte Bildfeld die Verschränkung von Architektur, Objekt und Bild explizit. Es zeigt ein angeschnittenes Fenster, auf dessen Sims ein umgestürzter Korb liegt, aus dem Fische in den Bereich vor dem Fenster fallen. Zu beiden Seiten des Fensters sind Fischpaare an einer räumlich nicht weiter definierten ,Wand' aufgehängt. Das Bildfeld verbindet Architekturimitation (angeschnittenes Fenster) und Objektpräsentation (Fische), Räumlichkeit und Flächigkeit, und tritt so in ein reizvolles Wechselspiel mit den anderen illusionistischen Elementen (Architekturimitation, Bildfelder, Motive) der Wand. Auf der Gegenseite scheint sich die Ädikularahmung im Bildfeld als horizontaler Streif fortzusetzen, ,real' gedachte Architektur dringt in ein Bild ein. In Bezug auf diese ,Architektur' werden zu Gruppen zusammengebundene Fische platziert. Damit ist ein nochmals anderer Modus der Bild-Architektur-Interferenz gefunden. Auf beiden Wandseiten wird die zentrale Ädikula hinterfangen und gerahmt von einer Architektur mit gelber Rückwand, in der sich jeweils zu ihren Seiten zwei Türen in ein schwarzes Inneres öffnen. Der zentrale Ädikulabau wird wiederum seitlich - mit den schwarzen Feldern der Mittelzone korrespondierend - von Pavillonarchitekturen eingefasst, in die Gefäße eingestellt sind. Auf diesen Architekturen tragen Ständer rote Pinakes mit Masken.

70 So die Charakterisierung des Realitätscharakters bei Curtius 1929, 68. 


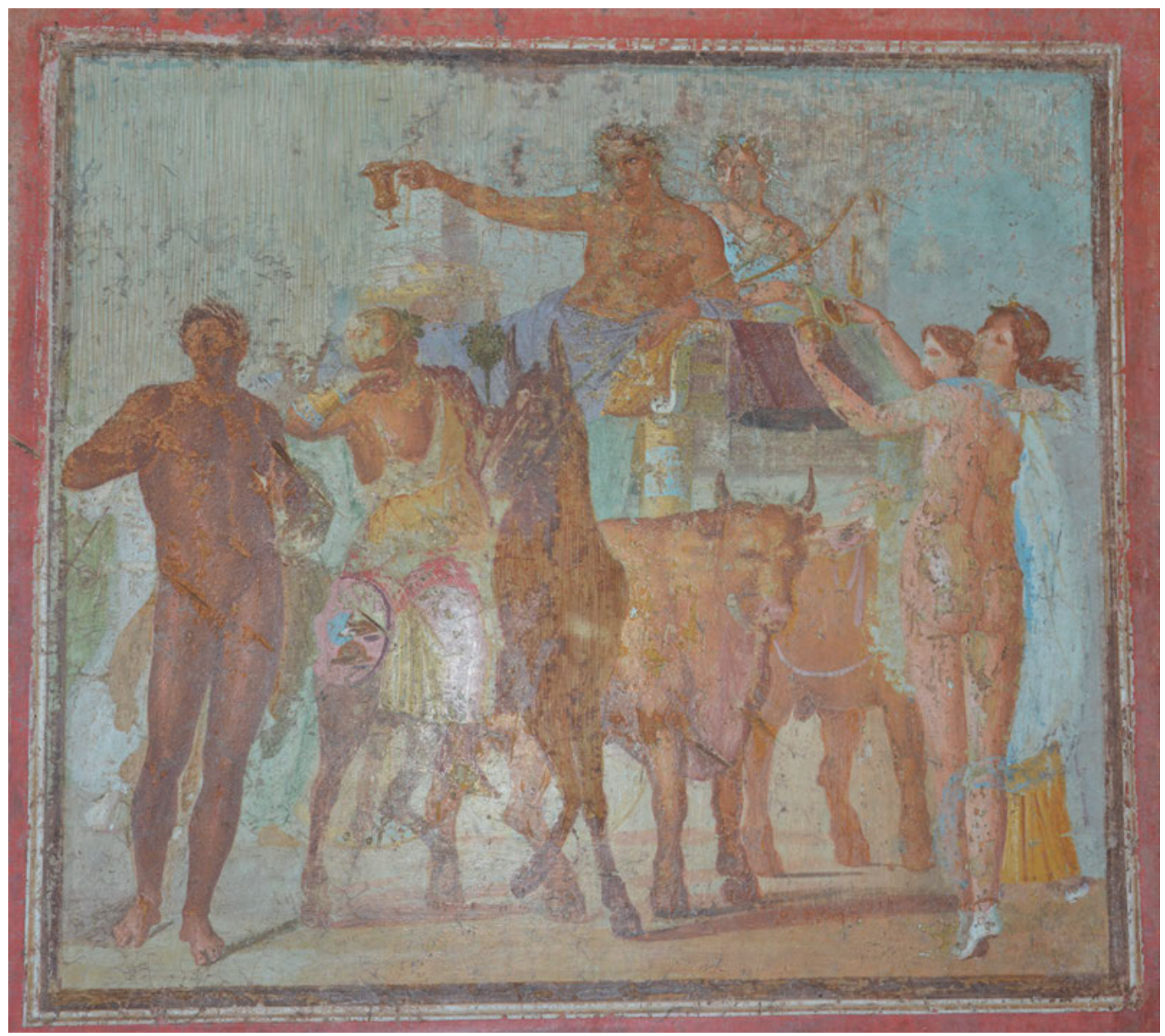

Abb. 299: Casa di Marcus Lucretius Fronto, Tablinum, mythologisches Mittelbild der Südwand mit der Darstellung von Bacchus und Ariadne im Wagen.

Durch Rahmen, Symmetriebeziehungen und Farbwechsel besonders hervorgehoben sind die mythologischen Mittelbilder. Auf der Südseite lagern Bacchus und hinter ihm Ariadne auf einem Wagen, der von zwei Ochsen gezogen wird (Abb. 299) ${ }^{71}$. Bacchus hebt mit der ausgestreckten Rechten im Stil eines Zechers einen Kantharos, in der Linken hält er einen Thyrsosstab. Dem Wagen gehen ein auf einem Esel reitender Silen sowie ein nackter jugendlicher Satyr mit Doppelflöte voraus. Den Zug beschließen zwei Bacchantinnen - eine nackt tanzend, die andere, weitgehend verdeckt, in einem langen Chiton. Im Bild der Nordseite tritt der behelmte Mars, mit blauem Gewand, das die Schulter freilässt, von hinten an die gänzlich bekleidete Venus heran (Abb. 300) ${ }^{72}$. Mit der Linken greift er ihr an die Brust, während sie ihn am Arm fasst. Im Zentrum des Bildfeldes steht Amor auf einem rechteckigen Möbel oder einer Stufe, wendet sich den beiden zu und spannt einen Bogen. Am rechten Bildrand sitzen auf einem Würfelhocker zwei gewandete Mädchen, die aus dem Bild herausblicken. Drei weitere Figuren, die ihren Blick auf Mars und Venus richten, erscheinen hinter einem Bett, das den Raum in Vorder- und Hintergrund gliedert. Es handelt sich um eine Figur mit dunklerem Teint und Flügeln am Kopf ${ }^{73}$, die von zwei weiblichen Personen gerahmt wird. Die Szene wird hinterfangen von einer Säulenarchitektur, die anzeigt, dass es sich um einen Innenraum handelt.

71 Peters 1963, $107 \mathrm{f}$; Lorenz 2008, $117 \mathrm{f}$.

72 Lorenz 2008, $151 \mathrm{f}$.

73 Mau 1901, 339-343; bei Sogliano 1901, 157 die mittlere Figur aufgrund ihrer dunklen Hautfarbe als Mann; bei Strocka 1997, 131 wenig überzeugend als Somnus; bei Pappalardo 2005, 276 als ,junger Mann mit zwei Flügeln auf der Stirn“; Lorenz 2008, 152; vgl. die Diskussion bei Clarke 1991, $156 \mathrm{f}$. 
Abb. 300: Casa di Marcus Lucretius Fronto, Tablinum, mythologisches Mittelbild der Nordwand mit der Darstellung von Mars und Venus.

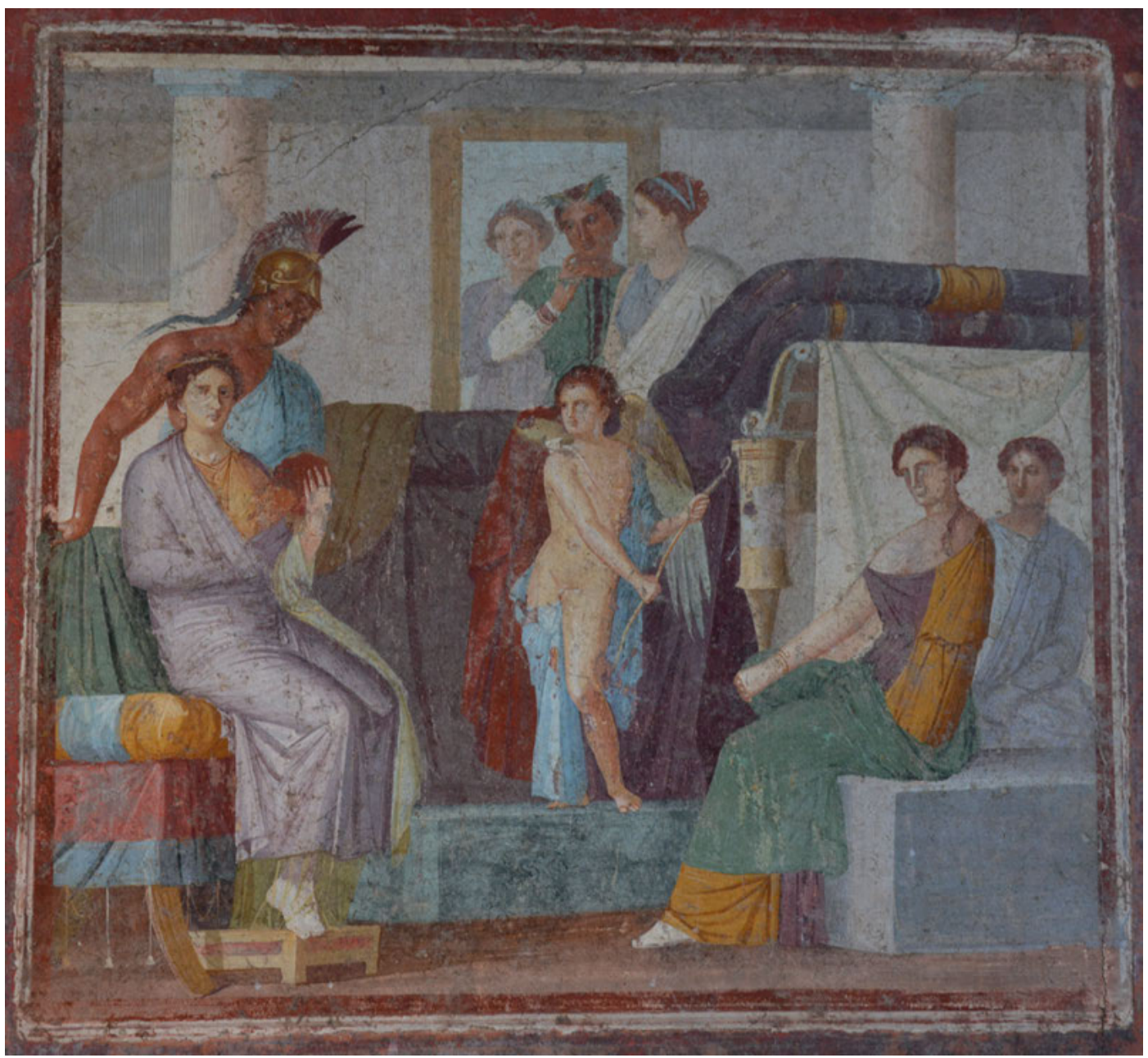

Mit den beiden Mythenbildern kommen ganz unterschiedliche Bildkompositionen und Bildthemen zur Darstellung, und doch ergibt sich auch hier ein Spiel mit Ähnlichkeiten und Unterschieden. Mit Bacchus und Ariadne sowie Mars und Venus präsentieren die Mittelbilder prominente mythologische Liebespaare. Während sich der triumphale Auftritt von Bacchus und Ariadne aber im Außenraum vollzieht und mit Publikum rechnet, ergibt sich zwischen Mars und Venus ein geradezu intimes Tête-à-Tête in einem häuslichen Ambiente. Bacchus und Ariadne werden von ihrem Gefolge begleitet, die den Zug durch ihre Handlungen (Tanz, Musik) atmosphärisch orchestrieren, während Mars und Venus den Blicken von heimlichen, d.h. vom Liebespaar unbemerkten Zuschauern ausgesetzt sind.

An diesem dicht bebilderten Tablinum werden visuelle Strukturen beschreibbar, wie sie für den dritten Stil charakteristisch sind. Die Prinzipien der Axialität und Symmetrie, welche die Wandgliederung des dritten Stils bestimmen, führen eine Wichtung der Felder ein. Die zentrale Position besetzt das mythologische Mittelbild, das seitlich sowie unten und oben von untergeordneten Bildern und Ornamenten umgeben wird. Bei den Mythenbildern handelt es sich somit um das privilegierteste Darstellungselement. Nachgeordnet sind die von Kandelabern getragenen Pinakes mit Architekturlandschaften in den Seitenfeldern der Mittelzone. Dasselbe gilt für die ,Stillleben'-Darstellungen im Zentrum der Oberzone. Landschaftsdarstellungen und ,Stillleben` fallen thematisch weniger dicht als die zentralen Mythenbilder aus. Noch einmal semantisch schwächer sind die Ornament-Bilder der Sockel- und Predellazone mit Gartendarstellungen, Tierund Gefäßmotiven. In der Oberzone entfaltet sich, wie im dritten Stil üblich, eine filigrane Architektur. Dieses Ordnungssystem ist dazu geeignet, nicht nur verschiedene Bildinhalte, sondern auch 
verschiedene Medien zu organisieren. Die gerahmten Mythenbilder sind von Passepartout-Rahmen eingefasst und als Tafelbilder inszeniert. Mächtige Prunkkandelaber erscheinen vor den Seitenfeldern und tragen Pinakes, die ebenso objekthaft vorgestellt werden, während der materielle ,Status' der Stillleben ambivalent bleibt. Im Sockelbereich wird ohne Bezug zum ,aufgehenden“ Wandaufbau ein Garten entfaltet, ebenso abrupt öffnet sich in der Oberzone ein Ausblick in eine komplex gestaffelte Architektur. Eine Vielzahl von Ornament- und Schmuckzonen verkomplizieren dieses System weiter.

Indem Nord- und Südwand spiegelbildlich aufeinander bezogen sind, drängt sich dem Betrachter eine komparative Wahrnehmung der jeweils gleichartig gestalteten Bildzonen auf: insbesondere der Mythenbilder, Landschaftsbilder und ,Stillleben', aber auch der kleinteiligen Ornamente. Die ikonographisch dichten, formal und inhaltlich unterschiedlich angelegten Mythenbilder im Wandzentrum laden in besonderer Weise zu einem vergleichenden Sehen, d.h. zum Ausloten von Ähnlichkeiten und Unterschieden, ein. Deutlich gleichartiger fallen die vier Landschaftsbilder aus. Doch auch hier ergeben sich Unterschiede hinsichtlich der Lage der Architekturen (Wasser/Land), der Gestalt der Baukörper und ihrer Anordnung (in der Höhe gestaffelt/auf einer Höhe). Ähnliches gilt für die ,Stillleben', die sich durch ein ähnliches Thema und auch eine ähnliche Farbigkeit auszeichnen, jedoch mit unterschiedlichen Kompositionen arbeiten. Im Fall der Gartendarstellungen in den Sockelzonen sind die Variationen auf kleine Details beschränkt. Noch weiter ist schließlich die Symmetrisierung in der Predella- und Oberzone geführt. Die visuelle ,Wertigkeit' der Darstellungselemente bemisst sich folglich an ihrer ikonographischen Dichte, ihrer schieren Größe, an ihrer Präsentationsform, ihrem Präsentationsort und dem Grad an Symmetrisierung, dem sie unterworfen sind. Diese verschiedenen Aspekte werden jeweils in Abhängigkeit voneinander entfaltet. Schon in formaler Hinsicht lässt sich somit eine Vielzahl von interpiktorialen Bezügen aufzeigen, die auf Gleichheit, Variatio und Differenz angelegt sind.

Mit Blick auf diesen ,Bilder'-Reichtum lässt sich aber auch danach fragen, ob sich die DecorElemente zu einem kohärenten sinnstiftenden Konzept zusammenführen lassen. John Clarke hat von einer „balance between Apollo and Bacchus“ gesprochen ${ }^{74}$. Tatsächlich finden sich im Tablinum Themen und Motive, die mit Apollo und Bacchus in Verbindung zu bringen sind: Kithara und Dreifuß als Verweis auf Apollo, die Panther als Attribut des Bacchus. Bei anderen Bildmotiven wie dem Schwanenwagen ist ein solcher Bezug möglich, aber nicht zwingend. Überhaupt darf man verwundert sein, weshalb Clarke nicht auf eine Gegenüberstellung von Bacchus und Venus verweist - sind es doch diese beiden Protagonisten, die in den zentralen Mythenbildern des Raumes gefeiert werden. In diesem letzteren Sinne dient Shelley Hales das Tablinum der Casa di Marcus Lucretius Fronto als Beispiel für ihre generellere These, dass Venus und Bacchus in römischen Häusern als ,role models‘ aufgegriffen würden ${ }^{75}$. So ließen sich in der Sockelzone Kantharos und Springbrunnen auf diese beiden Protagonisten beziehen ${ }^{76}$. Mit den Eroten in der Predellazone und den Muscheln des Schmuck-Frieses wären weitere Venus-Motive gewonnen, mit den Masken in den Oberzonen käme ein zusätzliches dionysisches Motiv hinzu ${ }^{77}$. Auch dann würde man aber der Komplexität des Decors nicht gerecht. Die Landschaftsbilder lassen sich ebenso wenig wie das ,Stillleben' plausibel auf ein verbal verfasstes Schlagwort reduzieren. Für den figürlichen Schmuck des Tablinums zeigt sich vielmehr, dass er sich nicht zu einer homogenen Lektüre verdichten lässt. Zwischen den verschiedenen Bildern und Bildmotiven ergeben sich vielfältige Bezüge.

Resümieren wir an dieser Stelle noch einmal die Decor-Formen der auf das Atrium geöffneten Räume. Diese fallen zuvorderst deshalb unterschiedlich komplex aus, weil sie unterschiedliche

74 Clarke 1991, 157.

75 Hales 2008, bes. $237 \mathrm{f}$.

76 Mit diesem Hinweis Schefold 1962, 71.

77 Zur Theatralität der Maske, die auf einen entsprechenden sozialen Habitus neronischer Zeit rekurriere, s. Hales 2008, 241f. In der Casa di Marcus Lucretius Fronto bleibt dieses Motiv jedoch verhältnismäßig marginal. 
Betrachterhaltungen voraussetzen. Die roten Orthostaten der Fauces rhythmisieren die Bewegung, der Verzicht auf figürliche Elemente führt den Blick nach vorn in das komplexer gestaltete Atrium. Dort ist die Farbigkeit ganz zurückgenommen, durch die gelben Lisenen erhält der Hof eine übersichtliche, schnell zu erfassende visuelle Struktur. Erst auf den zweiten Blick werden die kleinen Vignetten sichtbar, die durch ihre kleine Größe jedoch den Charakter von beiläufig wahrnehmbaren ,Ornamenten' annehmen und mit der reichen Ornamentik der Lisenen konkurrieren. Die semantische und ästhetische Dichte des Tablinums ${ }^{78}$ erschließt sich nur demjenigen, der hier verweilt und sich auf eine intensive, auch vergleichende Betrachtung einlässt. Die Einzelelemente treten in eine regelrechte optische Konkurrenz zueinander, sie fordern, ja überfordern, den Betrachter gezielt. Damit weisen sie das Tablinum aber zugleich als ,Hauptraum` am Atrium aus.

\section{Räume des Übergangs und der Lagerung: Korridore, Treppen, Schränke}

Am Atrium befinden sich auf der West- und Ostseite einige Korridore - die Fauces (a), der zum rückwärtigen Garten führende Korridor (k) und Treppenraum (e $)^{79}$. Die große Zahl an Türen suggeriert eine Vielzahl von sich symmetrisch gegenüberliegenden Wohnräumen. Mit Ausnahme der Fauces (a) haben sich in diesen konnektiven Räumen keine nennenswerten Reste von WandDecor erhalten. Zum Boden sind nur Aussagen für Korridor (k) möglich, der eine bläulich-graue Lavapesta möglicherweise später Zeitstellung besitzt.

Erhalten hat sich die Ausstattung im Schrankraum (d) (Abb. 301), der von einer einfachen Holztür verschlossen wurde. Der Rahmen war direkt in das Lavapesta-Paviment eingesetzt, sodass sich der Boden des Atriums im Raum fortsetzte. Der die Fauces rahmende südliche Pilaster ist schrankseitig schwarz gefasst. Für das Schrankinnere darf man annehmen, dass die auf der Nordwand erhaltene Malerei auf der Südseite wiederholt wurde. Auf eine schwarze Plinthe folgen ein schwarzer Sockel und ein von weißen Linien eingefasstes, grünes Band. In der Mittelzone sind große rote Felder von weißen Lisenen mit geometrischen Motiven getrennt. Im Raum dominiert die Farbe Rot, auf Farbenvielfalt und Bildlichkeit wurde verzichtet. Damit darf der Schrankraum als Beispiel für eine einfache Raumgestaltung im dritten Stil gelten, die man freilich deshalb gewählt hat, weil die hier aufbewahrten Objekte den Blick auf die Wände verstellt haben. An dem Schrank zeigt sich somit in besonders offensichtlicher Weise, dass Gestaltungsformen auf bestimmte Wahrnehmungsoptionen hin kalkuliert wurden.

\section{Aufenthaltsräume am Atrium}

Die am Atrium gelegenen Räume (i), (g) und (c) lassen sich aufgrund ihrer relativ geringen Größe als Cubicula ansprechen. Die Wandbemalung des dritten Stils hat sich in den Cubicula (c) und (g) erhalten, in Cubiculum (i) sind die Reste durch die Neugestaltung im vierten Stil so sporadisch, dass sie vernachlässigt werden können. Cubiculum (i) ist allerdings baulich interessant, weil es ein großes Fenster auf Oberkörperhöhe besitzt, das einen Ausblick in den Garten gewährt. Sollte diese Form der Durchfensterung auf augusteische Zeit zurückgehen, so würden wir ein am Atrium gelegenes ,Gartencubiculum' greifen. Triclinium (f) mag aufgrund seiner doppelten Größe und der Wandeinlassung für Betten als größerer Gelageraum gedient haben ${ }^{80}$, seine Wandbemalung gehört allerdings ebenfalls in den vierten Stil. In allen Räumen haben sich die Pavimente augusteischer

78 So bereits Schefold 1962, 71; Ling 1991, $60 \mathrm{f}$.

79 Sowohl in Korridor (k) als auch im Treppenraum (e) sind nachträgliche Restaurierungen zu greifen, die vermutlich nach $62 \mathrm{n}$. Chr. notwendig geworden waren.

$80 \mathrm{Zu}$ Installationen, s. Moormann 1993a, 405. 


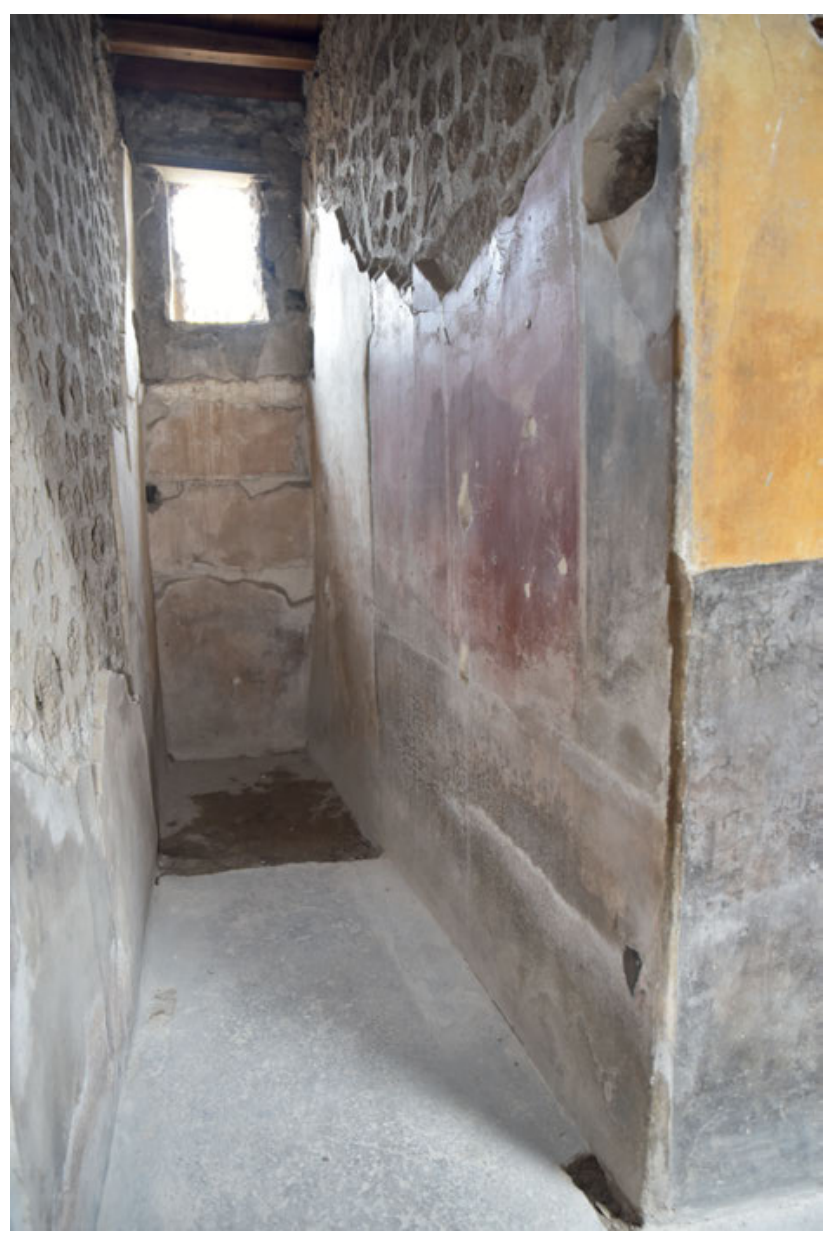

Abb. 301: Casa di Marcus Lucretius Fronto, Schrankraum (d).

Zeit erhalten ${ }^{81}$. Im Fokus stehen im Folgenden mit den Cubicula (c) und (g) jedoch nur die beiden Räume, für die sich Aussagen sowohl zur Boden- als auch zur Wandgestaltung des dritten Stils treffen lassen.

Cubiculum (c) liegt ungefähr gegenüber von Tablinum (h), sodass man von hier aus axial auf den Prunkraum des Hauses blickte (Abb. 278). Der Raum wird über eine Marmorschwelle betreten, auf der Nordwand befindet sich ein sehr niedriger Durchlass zu einem Raum unter Treppe (e) ${ }^{82}$. An der Südwand zeigt ein kleiner Wandversprung die Aufstellung eines Bettes vor der Ostwand an. Die Raumnutzung wird durch das Paviment visualisiert. Hinter der Schwelle befindet sich ein rechteckiges Mosaikfeld mit gegeneinandergesetzten Peltae, die von einem schwarzen Rahmen eingefasst sind. Den Hauptraum nimmt ein geometrisches Mosaik aus weißen Rauten und Quadraten ein, zwischen die schwarze, spitz zulaufende Dreiecke gesetzt sind (Abb. 302). Bei der Betrachtung können die Formen zu zahllosen Mustern zusammengesetzt werden - große weiße Sterne in schwarzen Hexagonen, schwarze Windmühlen in einem weißen Blütenkranz oder schwarze Sterne, die ein weißes Zentrum rahmen und von einem weißen Hexagon umgeben sind. Der rückwärtige Klinenstreifen, der nicht exakt mit der Wandnische zusammenfällt, besitzt ein einfaches Lavapesta-Paviment. Während der Boden somit eine funktionale Gliederung des Raumes anzeigt, nimmt das Ost-West orientierte, abgehängte Gewölbe diese Differenzierung nicht auf.

81 Pernice 1932, 97.

82 Mau 1901, 346 
Abb. 302: Casa di Marcus Lucretius Fronto, Cubiculum (c), Paviment.
Abb. 303: Casa di Marcus Lucretius Fronto, Cubiculum (c), Nordwand.
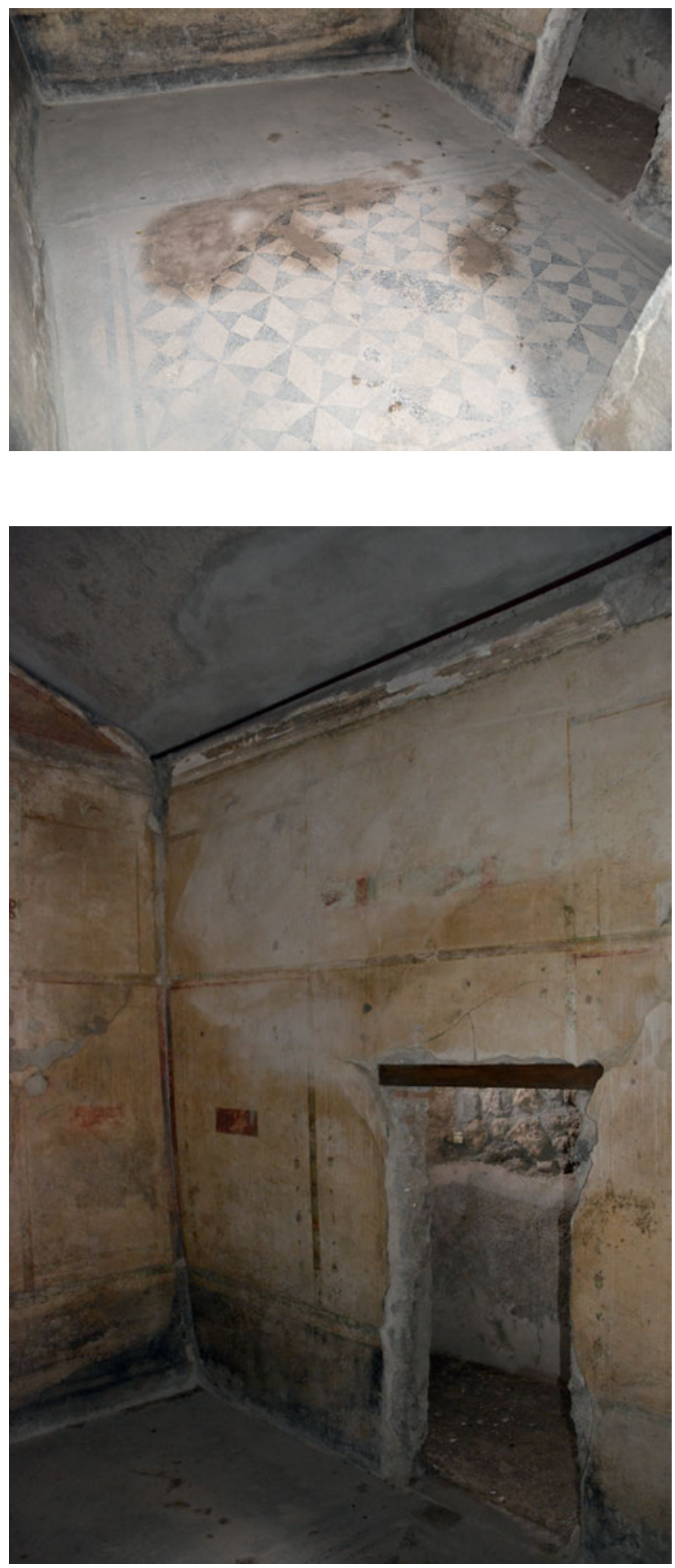

Auch die Wandmalerei reagiert nicht auf die am Boden eingeführte und durch den Wandversprung angezeigte Binnengliederung, sondern befördert einen einheitlichen Raumeindruck. Der geringen Raumhöhe entsprechend fällt die Wandgliederung kleinteilig aus. Die Plinthe und der sehr niedrige Sockel, beide schwarz, schaffen einen visuellen Abstand zum Muster des Paviments. Der Sockel ist durch weiße Linien dreigeteilt, wodurch die Dreiteilung von Mittel- und Oberzone vorweggenommen wird. Ein weißes und grünes Band schließen den Sockel ab. Auf allen vier Raumseiten werden eine weiße Mittel- und Oberzone durch ein Gesims getrennt (Abb. 303-305). Beide Zonen werden 


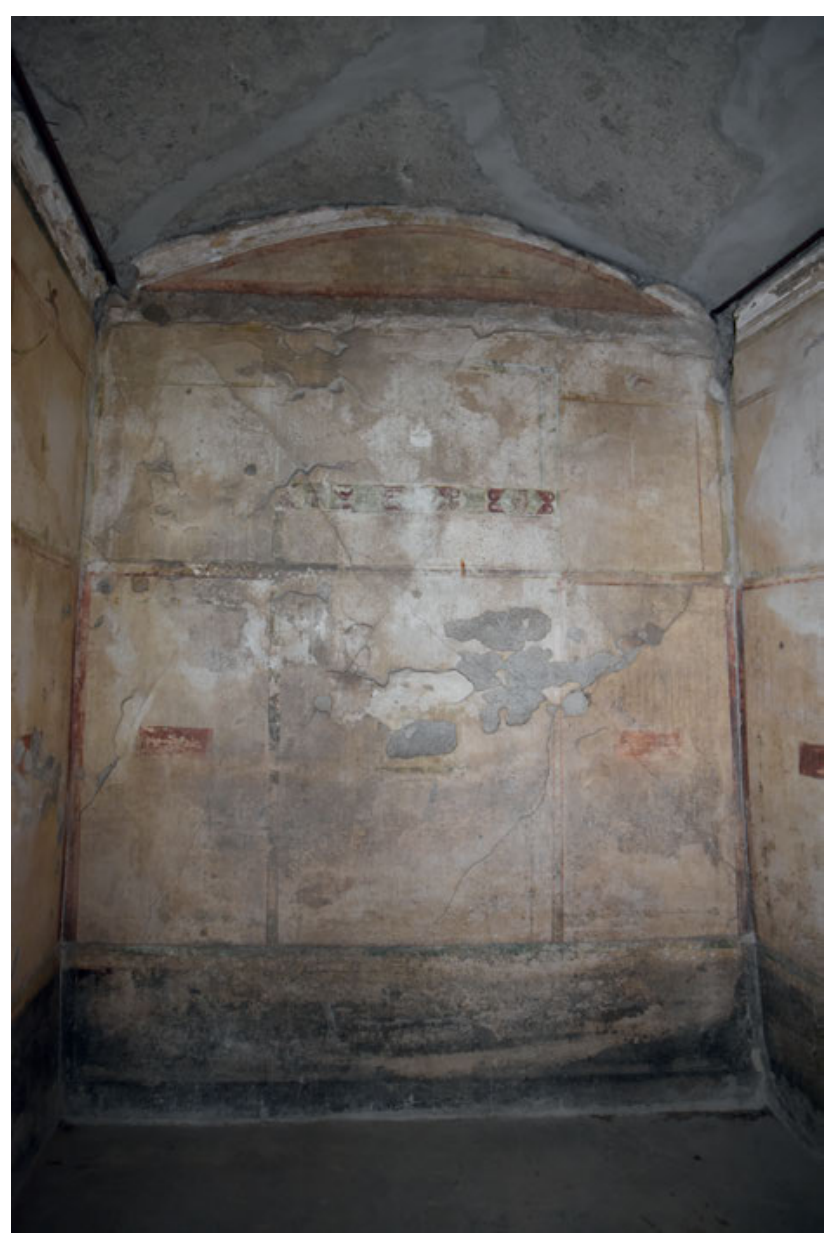

Abb. 304: Casa di

Marcus Lucretius

Fronto, Cubiculum

(c), Westwand.

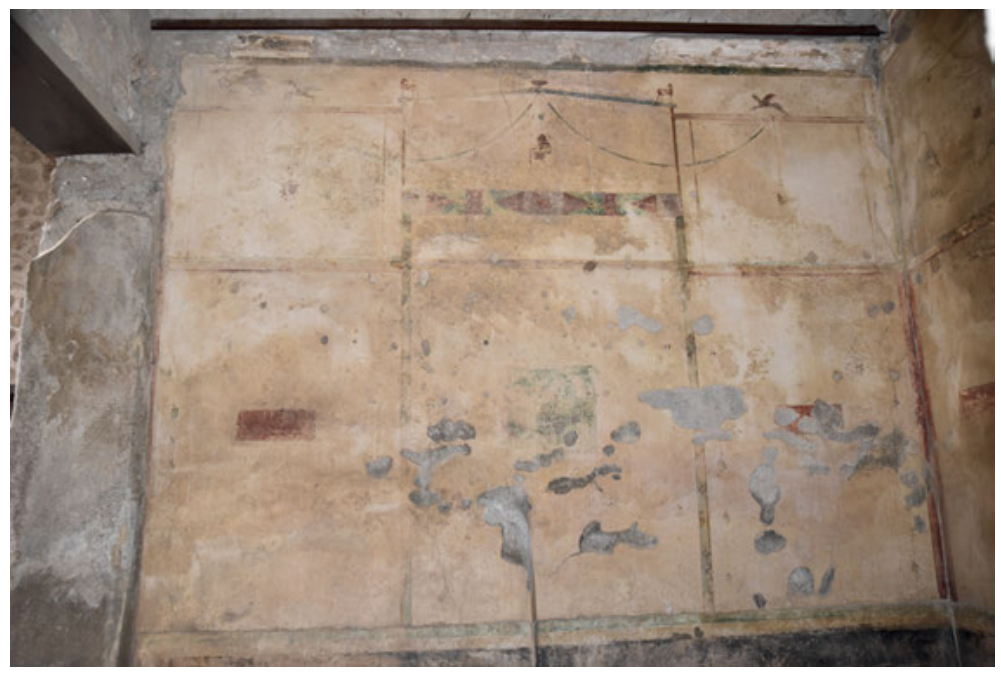

Abb. 305: Casa di Marcus Lucretius Fronto, Cubiculum (c), Südwand. 
Abb. 306: Casa di Marcus Lucretius Fronto, Cubiculum (g), Nordwand mit Eingang.

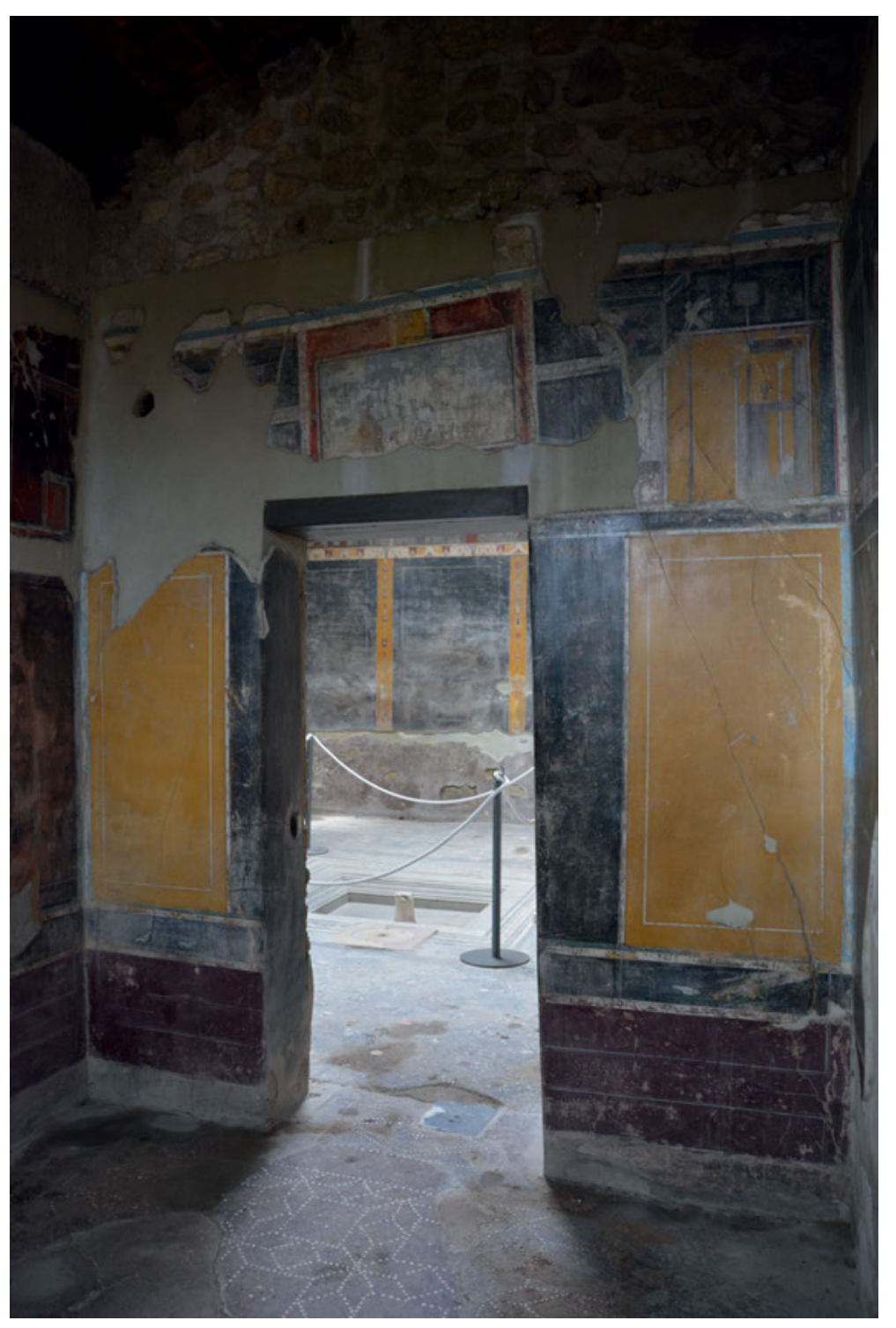

auf der West-, Nord- und Südseite durch eine mittig platzierte Ädikulaarchitektur in drei Segmente gegliedert. Auf der Süd- und Westseite rahmen die schmalen, geometrisch ornamentierten, gräulich-blauen Ädikulasäulchen ein kleines quadratisches Bildfeld, auf der Nordseite befindet sich an dieser Stelle der Türdurchgang zu (e). In den seitlichen Feldern ist auf derselben Höhe jeweils ein querrechteckiges, rotgrundiges - und dadurch besonders auffälliges - Bildfeld platziert. Da die Ädikulaarchitektur aufgrund ihrer Filigranität ganz zurücktritt, ist die Mittelzone durch einen regelhaften Rhythmus von Bildfeldern strukturiert. Soweit heute noch nachvollziehbar handelt es sich um wenig komplexe Sujets. Auf der West- und Südwand hatte Mau im zentralen Paneel „eine kleine Landschaft $(0,32 \times 0,32)$ mit vielen tempelartigen Gebäuden, nachlässig gemalt“, erkennen können ${ }^{83}$. Die seitlichen, rotgrundigen Bildfelder könnten auf der Südwand Hunde bei der Jagd auf Hasen und Hirsche, auf der Nordwand unter anderem einen jagenden Hund gezeigt haben. Die Kleinteiligkeit der Bildfelder, ihr semantisch schwacher Decor und ihre Rhythmisierung tragen zur Ornamentalisierung der Bildlichkeit bei.

83 Mau 1901, 346; bei Sogliano 1901, 149: „un piccolo passaggio mal conservato“. 


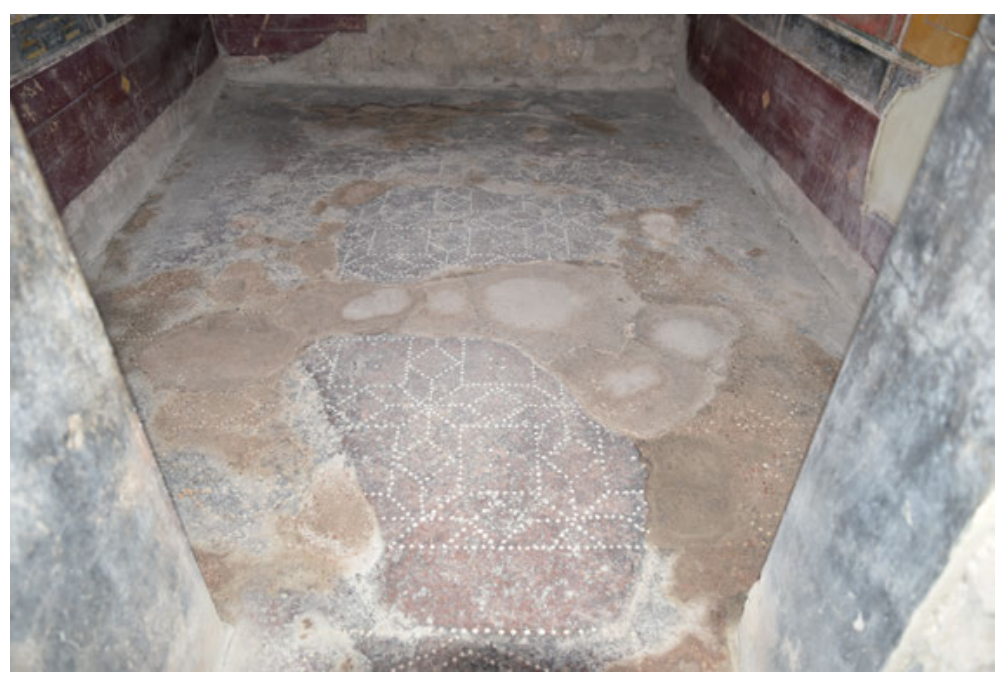

Abb. 307: Casa di Marcus Lucretius Fronto, Cubiculum (g), Paviment.

Mit der hohen Bilddichte der Mittelzone kontrastiert in der Oberzone eine luftig-leere Architektur. Die filigranen Säulen tragen in der Wandmitte einen massiven, polychrom ornamentierten Architrav, auf den eine Ädikula aufgesetzt ist - mit spitzem Giebel auf der Westwand, mit sehr flachem Giebel auf Nord- und Südwand. Seitlich schließen Flachdacharchitekturen an. Girlanden und Objekte hängen in die Architekturen hinein. Figürliche Akroterfiguren schmücken das Dach - Tiere an den Seiten, ein Gefäß als Mittelakroter.

Durch den schwarz-weißen Boden, den schwarzen Wandsockel und die weiße Mittelzone ist der Raumeindruck durch harte Schwarz-Weiß-Kontraste bestimmt, der Gesamteindruck ist jedoch hell. Die Bildfelder verleihen dem Raum farbliche Akzente - grüne Bildquadrate werden von querrechteckigen roten Bildtafeln flankiert. Ein besonders auffälliger Farbkontrast ergibt sich beim Blick aus dem Raum heraus (Abb. 278). Mit dem hellen Cubiculum kontrastierte das dunkle Atrium, durch das hindurch der Blick auf das prunkvolle, polychrome Tablinum (h) gelenkt wird. Nicht nur die Farbigkeit, sondern auch die Bilddichte unterliegt einer Steigerung. Die semantisch schwachen Landschafts- und Tierbilder des Cubiculums bereiten auf den Decor des Atriums mit seinen Tiervignetten vor, während im Tablinum nicht nur zahlreiche, sondern auch ikonographisch komplexe Bilder zur Darstellung kommen.

Cubiculum (g) auf der Südseite des Hofes war durch einen Querbalken von innen verschließbar. Zwei kleine Fenster in der Ost- und Südwand sorgen für Licht. Die schmalen Schwellsteine sind längs des Türpfostens versetzt und haben eine zweiflügelige Tür aufgenommen. Den Schwellbereich besetzt ein Opus signinum (Cocciopesto) mit Tessera-Decor - ein großes Rechteck mit zwei ineinander gestaffelten Rauten (Abb. 306). Im Rauminneren weist der quer gelagerte Vorraum ein Tesserae-Muster auf, das sich je nach Betrachtungsweise unterschiedlich zusammensetzt - etwa zu Sternen, die von Quadraten gerahmt werden, oder zu Quadraten, um die herum sich ein kompliziertes Muster aus kleinen Quadraten und Rauten legt, sodass sich ein andersartiger ,Stern“ ergibt (Abb. 307). Der Klinenstreifen vor der Südwand ist undecoriert.

Die Trennung in Vorraum und Klinenbereich wird durch die Wandmalerei nicht aufgegriffen. Ost- und Westwand (Abb. 308-309) sind axialsymmetrisch organisiert und spiegelbildlich aufeinander bezogen, auf der Eingangsseite setzt sich das System logisch fort; auf der dem Eingang gegenüberliegenden Südwand haben sich nur sporadische Malereireste erhalten. Die schwarze Plinthe und der bordeauxrote Sockel, der durch weiße Linien einen Felder-Decor erhält, schlossen alle vier Wandseiten zusammen. Die schwarze Predellazone ist durch weiße Streifen mit stilisierten vegetabilen und geometrischen Motiven vom Sockel und von der Mittelzone abgesetzt. Auf Ostund Westseite entstehen durch vertikale, weiße Trennstreifen fünf schwarzgrundige Felder - ein zentrales breiteres und zu den Seiten zwei schmalere. Im zentralen Predellafeld ist ein golden 
Abb. 308: Casa di Marcus Lucretius Fronto, Cubiculum (g), Ostwand.
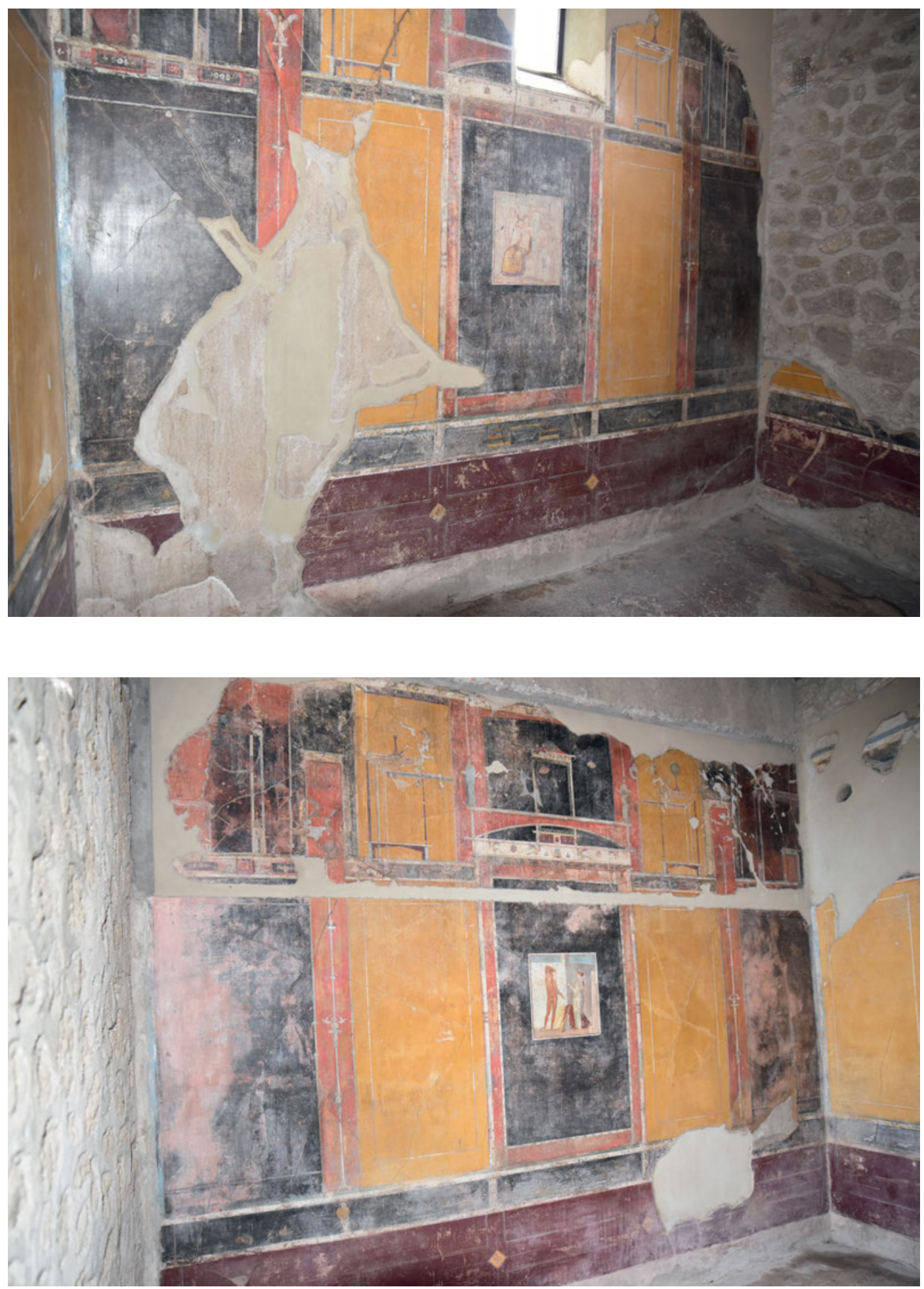

eingefasster Garten dargestellt, seitlich anschließend jeweils zwei sich gegenüber hockende Vögel, auf den äußeren Feldern ,Stillleben“ mit Masken. Die Variationen nehmen sich, vergleicht man die Wandseiten, minimal aus.

In der Mittelzone setzt sich die fünfteilige Gliederung der Predella fort. Im Wandzentrum fasst eine filigrane Ädikulaarchitektur mit weißen, in sich ornamentierten Säulen und Architrav mit Sphingen-Decor ein Mythenbild ein. Die Ädikulainnenfläche ist auf einen roten Rahmenstreifen 
reduziert, ,davor' setzt ein großer, schwarzer Passepartout-Hintergrund das Mythenbild effektvoll in Szene. Seitlich der Ädikula folgen ein gelbes und ein schwarzes Paneel, jeweils mit weißem Spiegel, sonst aber ohne Decor. Die beiden Felder werden von einem massiven, rotgrundigen Pilaster getrennt, der in die Oberzone hineinragt und aus äußerst filigranen Thyrsoi gebildet ist. Vor diesem Pilaster wird ein hoher, silberner Kandelaber präsentiert, dessen Schaft mit Blättern und eingesetzten Masken geschmückt ist und auf dessen oberem Teller eine Sphinx mit großen Schwingen hockt.

Die Struktur der Mittelzone setzt sich in der Oberzone fort, indem die zentrale Mittelädikula in die Oberzone hineinragt. Hier stehen Karyatiden auf dem Architrav, die ihrerseits noch schlankere Säulchen tragen, die dann wiederum den Ädikulagiebel stützen. Die zentrale Ädikula wird seitlich von Architekurflügeln flankiert, die mit den Feldern der Mittelzone korrespondieren. Die Verbindung zwischen Mittel- und Oberzone wird insbesondere durch ein vergleichbares Farbmuster erreicht. Der Schwarz-Rot-Kontrast des Wandzentrums setzt sich in der Oberzone ebenso fort wie das Gelb und Schwarz der Seitenpaneele. Eine besonders reiche Ornamentierung erhält die schmale, schwarzgrundige Frieszone am Übergang zwischen Mittel- und Oberzone im Bereich der Seitenfelder. Über den gelben Feldern enthält sie vegetabile und geometrische Motive zusammen mit Panthern, über den schwarzen Feldern eine geometrisch-ornamentale Struktur.

Die Eingangswand (Abb. 306) weicht in der Mittel- und Oberzone von den Seitenwänden leicht ab. Hier besteht die Mittelzone seitlich aus zwei hochrechteckigen gelben Feldern, an die Stelle des breiteren schwarzen Mittelfeldes tritt der Türdurchlass. In der Oberzone ist das Zentrum, d.h. der Bereich oberhalb des Türdurchgangs, durch ein gerahmtes Bildfeld herausgehoben. Es wird seitlich von geöffneten Scheintüren gerahmt.

Der Raumeindruck wird somit durch die alternierend schwarzen und gelben Felder und roten Rahmungen dominiert. Sie lenken die Aufmerksamkeit auf die beiden Mittelbilder im Osten und Westen (ursprünglich wohl auch im Süden), die sich dadurch für eine vergleichende Lektüre anbieten. Das Bild über der Tür wird erst auf den zweiten Blick wahrgenommen und ist durch seine Anbringungshöhe nicht unmittelbar in das Bildspiel eingebunden.

Auf der Westwand präsentiert Theseus (Abb. 310) seinen nackten Körper in elegant-lässiger Haltung, mit über den Kopf gelegtem Arm, einen blaugrünen ,Streifen` haltend ${ }^{84}$. Die züchtig gekleidete, ihm zugewandte Ariadne überreicht ihm mit der Linken die Spule, mit der Rechten das Fadenende des Garns, das ihn aus dem Labyrinth führen wird. Zwischen den beiden Protagonisten werden gefaltete Tücher und das Attribut des Theseus, die Knotenkeule, gezeigt. Das unspezifische Gebäude im Hintergrund wird durch den Handlungskontext als Palast des Minos verständlich. Für eine konkretere Deutung ist die Interpretation des ,Streifens' entscheidend, den Theseus hält. Sogliano hat ihn als grünen Faden interpretiert ${ }^{85}$, allerdings hat Ariadne Knäuel und Faden noch in der Hand. Willem J. Th. Peters und Eric M. Moormann haben darin die Siegerbinde sehen wollen, die sich Theseus nach vollbrachter Tat umlegen würde. Das Bild würde zwei verschiedene Momente zusammenführen - das Überreichen des Wollknäuels vor dem Betreten des Labyrinths und den Moment nach der Tat ${ }^{86}$. Roger Ling deutet das Riemchen unter Verweis auf andere Darstellungen des Themas am plausibelsten als Schwertgürtel, den Theseus zu lösen im Begriff sei ${ }^{87}$. Auch das Anlegen des Schwertgürtels käme infrage ${ }^{88}$. Entscheidend ist $\mathrm{m}$. E. aber etwas anderes - nämlich, dass Theseus seinen Körper vor den Augen des Betrachters ausbreitet. Tatsächlich hat schon Schefold darauf hingewiesen, dass der Mythos in den Hintergrund tritt, um Theseus und Ariadne

84 Mau 1901, 344-346; Lorenz 2008, 85f. $198 \mathrm{f}$.

85 Sogliano 1901, 151: „[...] tiene pendente in questa mano il filo verde [...]“.

86 Peters - Moormann 1993, 208.

87 Ling 2009.

88 Als Option diskutiert bei Ling 2009, 116, jedoch nur mit Verweis auf die entspannte Haltung des Theseus verworfen. Wenn man diese wie hier anders motiviert versteht - nämlich durch den Blick Ariadnes - entfällt das Argument. 
Abb. 310: Casa di Marcus Lucretius Fronto, Cubiculum (g), Mythenbild der Westwand (Theseus und Ariadne).

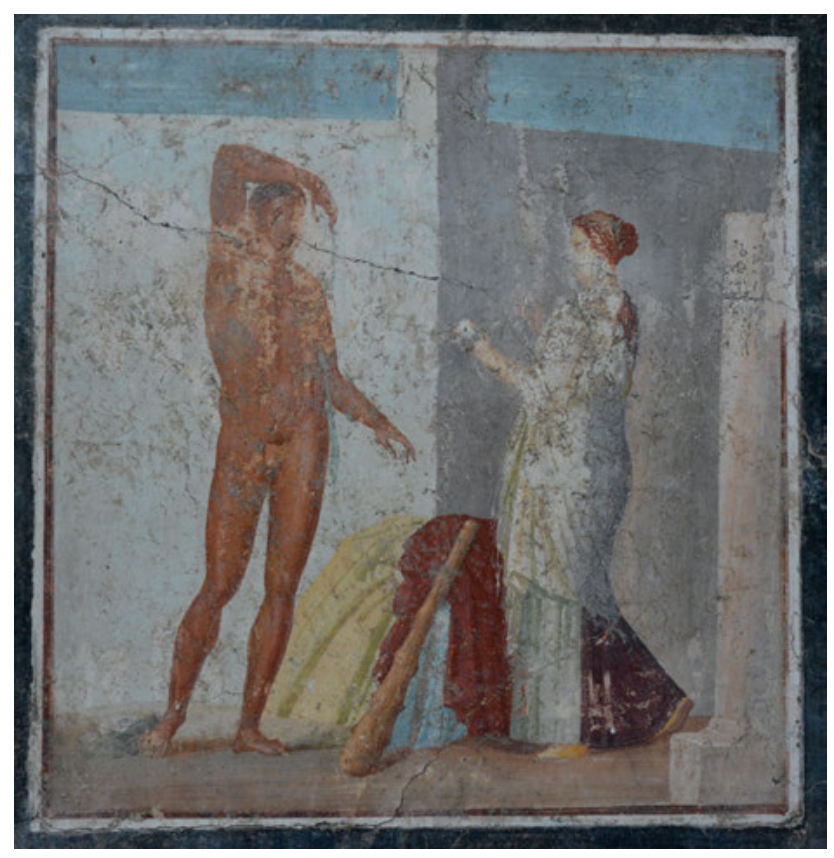

Abb. 311: Casa di Marcus Lucretius Fronto, Cubiculum (g), Mythenbild der Ostwand (Venus bei der Toilette).

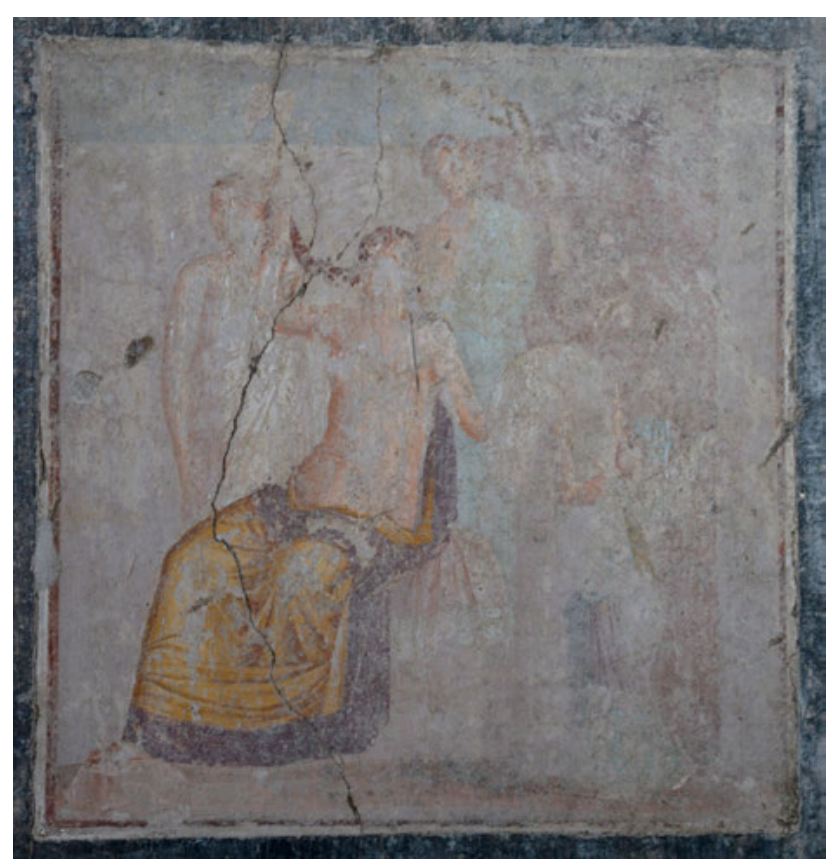

als Liebespaar vorzustellen ${ }^{89}$. Letztere schenkt dem nackten Theseus ihre volle Aufmerksamkeit. Obwohl ein narrativer Rahmen verfügbar ist, bedient sich die Darstellung dessen nur bedingt.

Das gegenüberliegende Bildfeld (Abb. 311) nimmt Narrativität ganz zurück und konzentriert sich auf die Präsentation der schönen Venus mit ihren Gefährtinnen. Die Göttin sitzt im Zentrum des Bildes, leicht nach rechts gewandt, auf einem blockartigen, lehnenlosen Sessel und präsentiert sich dem Betrachter in Dreiviertelansicht ${ }^{90}$. Ihr Unterkörper ist in einen Mantel gehüllt, während

89 Schefold 1952, 115.

90 Zur Beschreibung Mau 1901, 344f.; Lorenz 2008, 198 f. 


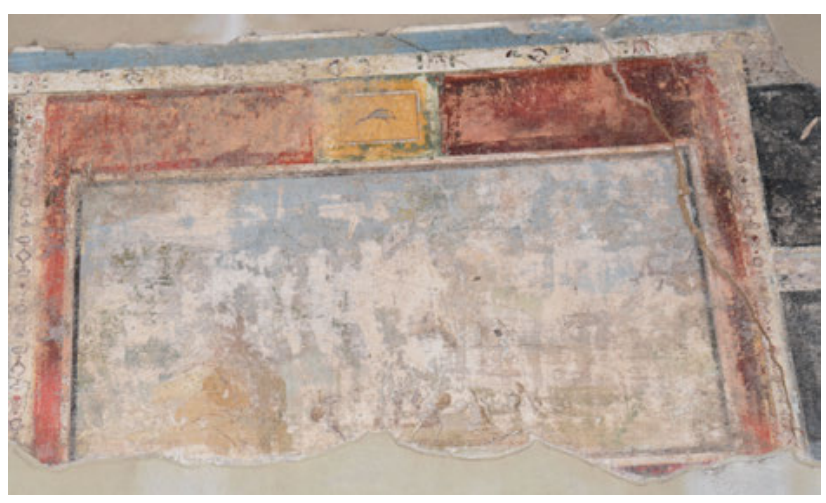

Abb. 312: Casa di Marcus Lucretius Fronto, Cubiculum (g), Kampfbild über der Tür im Norden.

der nackte Oberkörper von ihren Armen gerahmt wird. Sie wendet den Kopf nach links, um sich in einem großen, runden Spiegel zu betrachten, der von einer Psyche gehalten wird. Der Gestus der Rechten ist unklar - eventuell greift sie in einen Haarschopf, laut Sogliano hat sie einen Gewandzipfel gehalten ${ }^{91}$. Mit der Linken berührt sie den Spiegel. Zwei Dienstmädchen, die hinter der Göttin stehen, assistieren ihr bei der Toilette. Das Mädchen links hinter ihr greift in ihr Haar, um sie zu frisieren. Die Szenerie wird hinterfangen von einer nur summarisch mit großen, indefiniten Flächen gezeichneten Innenraumarchitektur.

Die beiden Bilder zeichnen sich durch eine Atmosphäre der Intimität aus. Die Akteure präsentieren ihre nackten Körper entweder einander (Theseus gegenüber Ariadne) oder sich selbst (Venus im Spiegel). Der Körper wird entweder im Auge des anderen oder aber in der Selbstwahrnehmung zum Bild $^{92}$. Zugleich erlauben es die Akteure dem Bildbetrachter, an diesem Blick auf den nackten Körper zu partizipieren. Für die beiden Mythenbilder lassen sich im dritten und vierten Stil Parallelen finden. Ihr spezifisches Sinnpotenzial entfaltet sich jedoch durch ihre Gegenüberstellung. In Kombination mit der schönen Venus wird auch für den nackten Theseus eine erotische Lektüre nahegelegt.

Der Kontrast zum monochromen, violett-gelblichen Bild ${ }^{93}$ der Nordseite (Abb. 312), das ursprünglich an ein Relief erinnert haben mag, könnte kaum größer ausfallen. An die Stelle großformatiger Hauptfiguren tritt eine größere Zahl an Bildakteuren. Im Bildvordergrund treffen zwei Kampfgruppen aufeinander - drei Krieger links, zwei rechts. Ein sechster Krieger steht etwas abseits am linken Bildrand, neben ihm ein Fels. Alle sind mit Schild und Lanze gerüstet. Darüber ist ein weiterer Kampf zwischen zwei Kriegerpaaren dargestellt. Rechts im Bild zeigen ein größeres und ein kleineres Boot an, dass es sich um eine Schlacht am Gestade handelt. Den Bildhintergrund nimmt eine Landschaftsdarstellung ein. Die intime, erotische Atmosphäre weicht hier einer gespannten Kampfsituation.

An Cubiculum (g) bestätigt sich somit, dass Bildfelder, die durch einen architektonischen Rahmen in Beziehung zueinander gestellt werden, eine vergleichende Lektüre stimulieren. Indem die seitlichen Felder - von den Kandelabern abgesehen - leer bleiben, wird die Aufmerksamkeit stärker als im Tablinum (h) auf die zentralen Mittelbilder gelenkt. Dennoch fügt sich das Kampfbild über der Tür zumindest auf den zweiten Blick in dieses Ensemble und eröffnet einen auffälligen Kontrast zu den erotischen Körpern.

Die beiden Cubicula (c) und (g) könnten nicht unterschiedlicher gestaltet sein. Während im einen Farbigkeit bis auf die bunten Bildfelder ganz zurückgenommen ist, der Raum durch seinen

91 Sogliano 1901, 150; heute unklar.

92 Zur mimetischen Qualität des Spiegels und seinem Potenzial, eine soziale Konstruktion von Identität zu leisten, vgl. Hales 2008, 243-250. Im vorliegenden Fall werden jedoch der direkte Blick und der gespiegelte Blick einander als verschiedene Perzeptionsoptionen gegenübergestellt.

93 Mau 1901, 346; Sogliano 1901, 150. 
weißen Grundton jedoch sehr hell wirkt, wurde das andere mit seinen Schwarz-Rot-Gelb-Kontrasten an die Ästhetik des Tablinums angeglichen. Im einen wirken Bilder durch ihre Repetition regelrecht ornamenthaft, im anderen fordern sie durch ihre ikonographische Dichte Aufmerksamkeit ein. Mit den beiden Cubicula verfügt das Haus folglich über zwei ganz unterschiedlich gestaltete und erfahrbare Aufenthaltsräume. Im Folgenden soll die Wahl der Ausstattungsformen in Abhängigkeit von der Raumfunktion, von spezifischen Betrachterhaltungen sowie von möglichen sozialen Wertigkeiten einzelner Raumkonstellationen betrachtet werden.

\section{Decor im Kontext: ästhetische Ordnungen}

Architektur, Wandmalerei und Pavimente stellen durch ihr Zusammenwirken einen Raumrhythmus her. Am Boden wird dieser zuvorderst durch die Materialität der (gleichzeitigen, augusteischen) Böden erreicht. Fauces, Atrium und Tablinum besitzen ein Lavapesta-Paviment, das den Hof und die angrenzenden Räume als Raum-Ensemble ausweist und mit einem dunklen Grundeindruck versieht. Unterschiedlich fallen jedoch die Muster aus. In den Fauces sind es rote, schwarze und weiße Steinsplitter, im Atrium hexagonale, quadratische, dreieckige und rautenförmige Buntmarmorplättchen, zwischen die Kreuzblumenornamente gesetzt sind, im Tablinum unregelmäßige Steinsplitter. Das Paviment des Atriums, das zwei Decor-Modi - Tesserae und Marmorplättchen kombiniert, erweist sich als besonders raffiniert und aufwendig. Die Wertigkeit des Atriums wird aber insbesondere durch das prunkvolle Marmorimpluvium im Raumzentrum gesteigert.

Für die verschließbaren Aufenthaltsräume (i), (g), (f) und (c) wurden unterschiedliche Pavimentlösungen gewählt. In Triclinium (f), Cubiculum (i) und Cubiculum (g) erzeugt ein Cocciopesto einen roten ,Grundton', Varianz entsteht durch unterschiedliche ,Ornamente'. In Triclinium (f) und Cubiculum (g) führen Tessera-Muster eine Differenzierung in Vorraum und Klinenbereich ein, während in den Estrich von Cubiculum (i), dem Atrium vergleichbar, weiße und graue Marmorstücke in Rauten-, Quadrat- und Sechseck-Form eingesetzt sind. Ganz anders nimmt sich der Raumeindruck von Cubiculum (c) mit seinem weißen Tessellat aus, das durch Schwell- und Raumornamente eine Binnenstruktur erhält.

Mit der Materialität der Böden korrespondiert die jeweils unterschiedliche Farbigkeit der Wände. In den Fauces geht mit der dunklen Lavapesta eine rote Mittelzone zusammen. Im Atrium ist die Farbigkeit invertiert, mit einem weinroten Sockel korrespondiert eine schwarze Sockelzone, wodurch der Raum gänzlich dunkel wirkt. Allein gelbe Lisenen strukturieren die Wand. Im Tablinum hingegen kontrastiert das einfache Lavapesta-Paviment mit einem reichen Farbspiel an der Wand, das die nach und nach in das Haus ,eingeführten' Farben - Schwarz, Rot und Gelb zusammenbringt. Es hebt sich dadurch in seiner Polychromie deutlich vom Atrium ab. Auf Weiß wird im Hofbereich fast gänzlich verzichtet, sodass das marmorne Impluvium mit seiner Mosaikrahmung einen Blickfang dargestellt haben dürfte. Dasselbe gilt für die weiße Pilaster-Einfassung des Tablinums.

In den Aufenthaltsräumen ergeben sich durch die Kombination von Wand- und Boden-Farben unterschiedliche Effekte. Cubiculum (c) mit seinem weißen Boden erhielt auch eine monochrom weiße Ausmalung, wodurch einerseits die farbigen Bildfelder ausgesprochen gut zur Geltung kommen, sich der Raum andererseits aber auch deutlich vom schwarzen Atrium abhebt. In Cubiculum (g) verbindet sich mit dem rötlichen Boden ein Farbschema, das jenem des Tablinums verwandt ist. Bereits durch Materialität und Farbigkeit entstanden somit ganz gegensätzliche Raumatmosphären.

Ein weiteres Gliederungsmoment stellt der Umgang mit Bildern dar, die im Haus ausschließlich auf die Wand beschränkt sind. Entlang der Hausachse ergibt sich eine sukzessive Steigerung der Bilddichte. Die Fauces verzichten in der Mittelzone gänzlich auf Darstellungen. Das monochrom schwarze Tablinum weist mit seinen Tiervignetten und den ornamentierten Lisenen einen semantisch schwachen Decor auf. Damit kontrastiert die hohe Bilderdichte im Tablinum. Auf 
Kontrast angelegt sind in dieser Hinsicht auch die beiden Cubicula (c) und (g). Während im Cubiculum (c) vor einer weißen, hellen Wand kleinformatige Bilder präsentiert werden, imitiert Cubiculum (g) mit den mittig platzierten Mythenbildern und einem weiteren ,dichten` Bild in der Oberzone das Tablinum.

In den Fauces trägt das Fehlen von Bildern dazu bei, den Betrachter nach vorn, auf das Atrium und Tablinum hin zu leiten. Im Atrium reagieren die semantisch schwachen Motive auf einen Akteur, der sich im Raum fortbewegt und den Wänden eine nur beiläufige Aufmerksamkeit schenkt. Im Tablinum als dem größten Aufenthaltsraum wird hingegen eine besondere Dichte an Bildern entfaltet, die eine hohe Aufmerksamkeit für Decor voraussetzt. Die große Vielfalt an Ausstattungselementen bietet ganz unterschiedliche inhaltliche Anknüpfungspunkte. Demgegenüber ist die Bilddichte in den Cubicula (c) und (g) reduziert, doch auch hier wird der Betrachter auf Augenhöhe von verschiedenen Bildern unterhalten. Sie unterscheiden sich von Cubiculum zu Cubiculum jedoch in ihrer Präsentationsform wie auch in ihren Inhalten.

Nimmt man die verschiedenen Gestaltungsaspekte - Materialität, Farbigkeit, Bilddichte und Komplexität der Einzelbilder - zusammen, so erweist sich der Atriumsbereich als ein DecorEnsemble, das seine Wirkung erst im Zusammenspiel der Elemente erreicht. Die Fauces werden zum Durchgangsraum, das Atrium jedoch durch sein Marmorimpluvium und das Paviment mit Marmorplättchen als besonders wertiger Bereich inszeniert. In einem Aufenthaltsraum wie dem Tablinum findet ,Wertigkeit' ihren Ausdruck in der Verdichtung figürlich-darstellender DecorElemente. Vor allem aber entsteht ein zusätzlicher Wert des Ausstattungs-Ensembles durch die Rhythmisierung und Kontrastierung verschiedener Raumerfahrungen.

\section{Decor im Kontext: semantische Ordnungen}

Die Forschung zum dritten Stil hat herausgestellt, dass die Raumausstattung durch ihre formalen Qualitäten, ihre Dichte, aber darüber hinaus auch durch ihre Inhalte auf die räumlichen Zusammenhänge Bezug nehmen würde. ,Intime‘ Cubicula hätten wenigstens graduell andere Themen als die ,öffentlicheren` Tablina erhalten. Eine solche Annahme setzt nicht nur die eingangs kritisierte Opposition von ,öffentlichen` und ,privaten' Räumen voraus, sondern postuliert zugleich, dass auch Ikonographien entlang dieser Achse interpretiert werden könnten.

Schränken wir den Blick zunächst auf Mythenbilder ein, so zeigt sich, dass sowohl im Tablinum als auch in Cubiculum (g) im weiteren Sinn erotische Szenen präsentiert werden. Eine Beschränkung der Liebesthematik auf ,intimere ' Cubicula findet offensichtlich nicht statt ${ }^{94}$. Doch hat Lorenz zu Recht darauf hingewiesen, dass sich die Stimmlage der Mythenbilder unterschei$\operatorname{det}^{95}$. Im Tablinum handelt es sich um zwei göttliche Liebespaare. Bacchus und Ariadne erscheinen in einer Pompa, vom Gefolge des Bacchus umgeben, Mars und Venus in einem intimeren Innenraumkontext. Beide Paare zeigen sich dem Betrachter aber züchtig verhüllt. Lorenz deutet die Darstellungen daher als Ausdruck der familiären Statusrepräsentation - allerdings wird mit Mars und Venus dafür auch ein problematisches und daher vielleicht auch besonders reizvolles Paar gewählt, das als Paar im Moment des Ehebruchs zusammenfindet ${ }^{96}$. Anders nehmen sich das Beisammensein von Theseus und Ariadne sowie die Präsentation von Venus im Frauengemach aus. Venus inszeniert ihren nackten Körper regelrecht vor den Augen der Betrachter. Ähnliches gilt für

94 Für eine am Raumtypus orientierte Auswahl der Bildthemen (Dionysisches für Triclinia) etwa Ling 1995; kritisch bereits Tybout 2001, 52, der konstatiert, dass Venus-Darstellungen nicht automatisch für Cubicula ,passend' waren. Ausführlich Romizzi 2006, bes. 79, die für den dritten Stil konstatiert, dass Themen kein Anzeiger von Raumfunktionen sind, jedoch auf Aktivitäten in einem Raum anspielen können.

95 Lorenz 2008, 428f.

96 Swetnam-Burland 2018 mit ausführlicher Diskussion auch der literarischen Quellen. Sie weist darauf hin, dass der narrative Hintergrund auch dann, wenn er im Bild explizit nicht aktiviert wird, implizit präsent bleibt. 
den nackten Theseus, der sich Ariadne präsentiert. Dadurch entsteht eine deutlich erotisierte Atmosphäre. Es sind folglich nicht unterschiedliche Bildthemen, sondern unterschiedliche Darstellungsstrategien, die eingesetzt werden, um Mythenbilder mit einer spezifischen Atmosphäre zu belegen.

Noch komplexer wird die Frage nach der inhaltlichen Struktur des Hauses, wenn man die anderen Bildthemen hinzunimmt. Im Tablinum sind dies neben Landschafts- und Gartenbildern, sowie ,Stillleben` eine Vielzahl figürlicher Motive, in Cubiculum (g) ist das Kampfbild in Rechnung zu stellen. Der komplexe Decor des Tablinums lässt sich schwerlich auf Schlagworte wie gravitas und austeritas reduzieren, um ihn dann als Ausdruck der Statusrepräsentation des Dominus zu begreifen ${ }^{97}$. Schließt man in Cubiculum (g) das Kampfbild in die Betrachtung mit ein, so lässt sich sein Decor nicht mehr schlüssig als intim-erotisch-privat beschreiben. Auch Cubiculum (c) entzieht sich einer Kategorisierung, die sich an Vorstellungen von öffentlich und privat orientiert. Mit seinen Tier- und Landschaftsbildern greift es Sujets auf, wie sie in ganz ähnlicher Weise im Atrium und auch im Tablinum anzutreffen sind. Gänzlich unübersichtlich wird die Lage, wenn die vielen gegenständlichen ,Ornament'-Motive mitberücksichtigt werden. ,Öffentlichkeit‘ bemisst sich vielmehr daran, dass auch in der Casa di Marcus Lucretius Fronto der besonders herausgehobene Raum mit einer Vielzahl von unterschiedlichen, auch konkurrierenden Betrachtungsangeboten versehen ist. Sein Decor vermag so in Bezug auf ganz unterschiedliche Handlungen wirksam zu werden.

\section{Raum - Decor - Handlung. Häuser im frühkaiserzeitlichen Pompeji}

\subsection{Architektonische Gestaltungsoptionen: Innovationen der frühen Kaiserzeit}

Im Folgenden sollen zunächst die architektonischen Innovationen der frühen Kaiserzeit thematisiert werden, die den Wirkungsrahmen für die Decor-Elemente vorgeben.

\section{Das äußere Erscheinungsbild der Häuser: Fassaden}

Aufgrund der häufigen Neuverputzung der Fassaden haben sich Fassadenmalereien dritten Stils kaum erhalten. Allerdings sind unfigürliche Fassadengestaltungen nicht verlässlich datierbar, sodass die ein- und zweifarbigen Putze schon im dritten Stil in Mode gekommen sein könnten. Mehrheitlich gehören die roten Sockel mit gelber Oberzone, die schwarzen Sockel mit gelber Oberzone sowie die monochromen (gelben und schwarzen) Wände aber wohl die Zeit des vierten Stils ${ }^{98}$. Zwei figürliche Fassadenbilder lassen sich mit etwas größerer Wahrscheinlichkeit dem dritten Stil zuweisen ${ }^{99}$. Im äußeren, straßenseitigen und frei zugänglichen Teil der Fauces der Casa del Bell'Impluvio (I 9,1) findet sich an der östlichen Fauces-Wand die Darstellung von Hercules und Mercur, an der westlichen Iuno mit Pfau und Minerva ${ }^{100}$. Mehrere Putzschichten mit Wandmalerei sind für den Fassadenabschnitt zwischen dem Eingang zur Domus (I 12,11) und der angrenzenden

97 So etwa Romizzi 2006, 117-124 mit Blick auf das Vestibül.

98 Für eine allgemeine Charakterisierung der Optionen, s. Hartnett 2017, 155, mit Beispielen.

99 Die nachfolgenden Befunde sind Fröhlich 1991 entnommen, diskutiert werden nur die von ihm dem dritten Stil bzw. augusteischer Zeit/der frühen Kaiserzeit zugewiesenen Bilder.

100 PPM I (1990) 919-941 s. v. I 9,1, Casa del Bell’Impluvio (V. Sampaolo) 922f. Abb. 2. 3; Fröhlich 1991, 308 Kat. F6

mit Taf. 52, 1-2. 


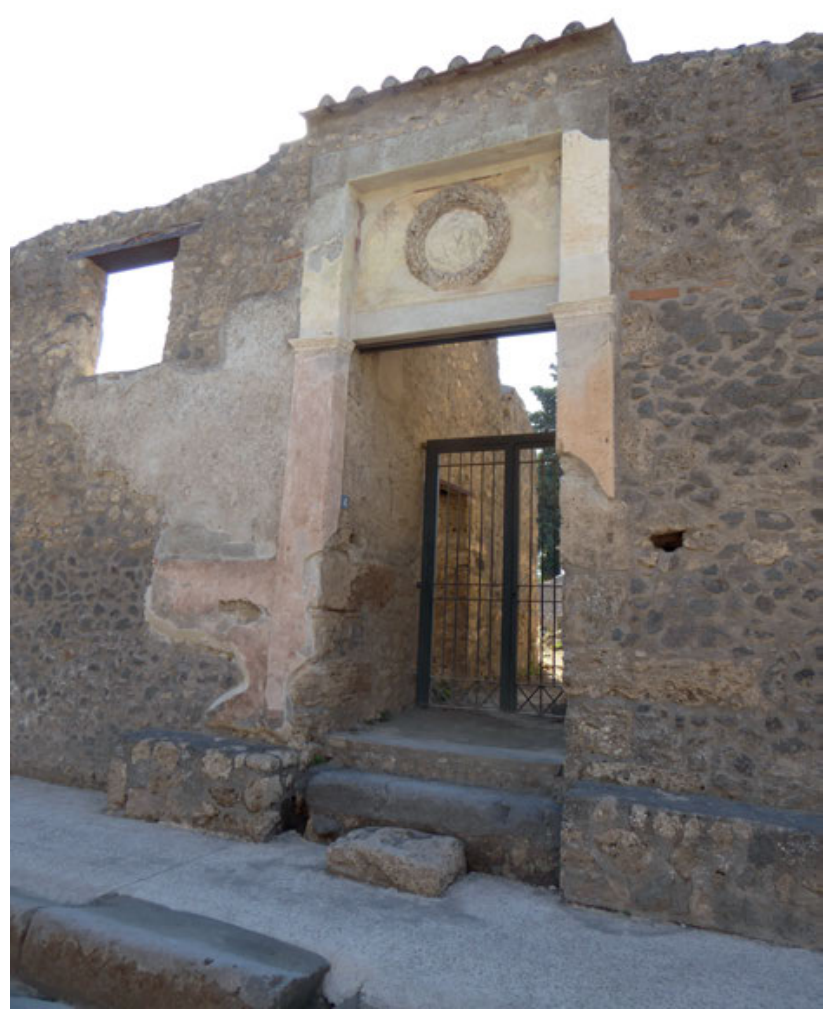

Abb. 313: Casa dell'Augustale (II 2,4), Eingang.

Taberna (I 12,10) dokumentiert. Einer augusteischen Phase mag das Bild einer Göttin, wohl Minerva, angehören ${ }^{101}$. Die Bilder fügen sich damit gut in das Spektrum der Themen, wie sie dann im vierten Stil an den Fassaden beliebt sind. Am Eingang werden einfache Götterikonographien präsentiert, die - für einen Passanten leicht verständlich - auf Glück, Wohlleben und göttlichen Schutz verweisen ${ }^{102}$.

In Einzelfällen wurden architektonisch aufwendige Fassadenlösungen realisiert. Die Casa delle Vestali (VI 1,7) öffnete sich seit augusteischer Zeit über eine Pfeiler-Portikus auf die Straße ${ }^{103}$. Eine Aufwertung erfuhr auch das Portal der Casa dell'Augustale (II 2,4) an der Via dell'Abbondanza (Abb. 313). Es war von zwei verstuckten Pfeilern mit Marmorimitation eingefasst, über dem Türsturz wurde ein Eichenkranz in Stuck angebracht - ein Decor-Motiv, das auf die Corona civica des Augustus als Ehrenzeichen anspielen und auf einen lokalen Magistraten bezogen worden sein mag $^{104}$. In diesem Zusammenhang könnten auch die Bänke zu Seiten des Eingangs angelegt worden sein ${ }^{105}$. Vielleicht darf man aus diesen Einzelzeugnissen vorsichtig schließen, dass es in der frühen Kaiserzeit zu einer gewissen Aufwertung der Hausfront kam.

101 PPM II (1990) 794-830 s. v. I 12,11, Casa dei Pittori (S. C. Nappo - M. de Vos) 795 Abb. 1; Fröhlich 1991, 311 Kat. Nr. F12.

102 Zur ökonomischen Konnotation der an Fassaden, insbesondere Taberna-Eingängen, häufig auftretenden MercurDarstellungen, s. MacRae 2019, $205 \mathrm{f}$.

103 PPM IV (1993) 5-49 s. v. VI 1,7, Casa delle Vestali (I. Bragantini) 6f. Abb. 1. 2; vgl. Jones - Robinson 2005, 699; Helg 2018, 64. 79f. 223f. Taf. Va.

104 PPM III (1991) 109-111 s. v. II 2,4 (M. de Vos) 110f. Abb. 1f.; vgl. Helg 2018, 64 f.

105 Helg 2018, 68f. 


\section{Das Atrium als Architektur- und Decor-Raum}

Neu angelegte Atrien sind in augusteischer Zeit die Ausnahme, weshalb sich die ästhetischen Vorstellungen vor allem in Umbaumaßnahmen greifen lassen. Axialität und Symmetrie bleiben bedeutsame Strukturprinzipien. So tragen am Atrium der Casa di Marcus Lucretius Fronto neu geschaffene Zugänge zu einem noch einheitlicheren Erscheinungsbild bei und auch im neu geschaffenen Atrium-Peristyl der Casa di Giasone kommen verschiedene Symmetrieformen zum Tragen. Das Atrium erhält Qualitäten eines Peristyls und umgekehrt. Tatsächlich stattete man Atrien in augusteischer Zeit verschiedentlich mit Säulen aus, die dem Hof ein peristylhaftes Erscheinungsbild verliehen. Dies gilt für das korinthische Atrium-Peristyl (16) der Casa del Centauro (VI 9,3.5; Plan 17) ${ }^{106}$, für das tetrastyle Atrium (2) der Domus VI 7,3 ${ }^{107}$, vielleicht auch für das Atrium der Casa dei Ceii (I 6,15) ${ }^{108}$. Vor diesem Hintergrund wird man sicher nicht von einem Bedeutungsverlust des Atriums in augusteischer Zeit sprechen können ${ }^{109}$. Zudem wird sich zeigen, dass das Atrium durch die Aufstellung von Bild-Objekten zu einem regelrechten Schauraum avancierte.

\section{Tablinum zwischen Atrium und Peristyl}

Das Tablinum bildete zunehmend nicht mehr den Endpunkt einer Bewegungsachse, sondern wurde häufiger als zuvor als Zwischenraum zwischen Atrium und Peristyl konzipiert ${ }^{110}$. Durch seine beidseitige Öffnung konnte es als Repräsentationsraum am Atrium wie als Gelageraum am Peristyl dienen ${ }^{111}$. Insbesondere die Ausrichtung auf den Garten dürfte dem Geschmack der Zeit entsprochen haben, wie sich beispielhaft an der Casa di L. Caecilius Iucundus (V 1,23.26; Plan 14) greifen lässt. Im Zuge der Neugestaltung des Peristyls um die Mitte des 1.Jhs.v.Chr. ${ }^{12}$ wurden die am Atrium gelegenen Räume, so auch Tablinum (10; i), auf den Garten ausgerichtet. Gleichzeitig wurde der nördlich angrenzende Raum in einen Aufenthaltsraum (12; m) und die Fauces (11; k) unterteilt, die als eigentlicher Durchgang vom Atrium zum Peristyl fungierten. Dabei war die atriumsseitige Tablinumsöffnung üblicherweise nicht durch Türen, sondern allenfalls durch mobile Paravents verschließbar, während die peristylseitige Öffnung üblicherweise mit Türen versehen war - neben der Casa di Marcus Lucretius Fronto gilt dies etwa für die Casa del Frutteto (I 9,5; Plan 7$)^{113}$.

Das Tablinum blieb folglich primär auf das Atrium orientiert - auch hier waren jedoch Ausnahmen möglich. In der Casa del Citarista (I 4,5.6.25.28; Plan 5) wurde das Niveau des Tablinums um etwa einen Meter erhöht, um den Raum an das Gehniveau des Peristyls anzupassen (Abb. 314).

106 PPM IV (1993) 819-859 s. v. VI 9,3.5, Casa del Centauro (I. Bragantini); Dickmann 1999, 141f. weist die Anlage des Atrium-Peristyls noch in die Zeit des ersten Stils; zur späten Datierung Pesando 2011, 429-433.

107 Maratini 2017a, 196f.

108 s. o. S. 147.

109 Dieses Dekadenzmodell findet sich in der Forschung geradezu durchgängig; s. De Albentiis 1990; Dwyer 1991; Wallace-Hadrill 1994, 51f.; Brothers 1996, 48; Ellis 2000, 33-35; Gros 2001, 40f.; Wallace-Hadrill 2007, 286-288; kritisch zum traditionellen Narrativ von Ausbildung, Etablierung und Verfall des Atriumhauses, s. Anderson Robinson 2018, $53 \mathrm{f}$.

110 s. o. S. $135 \mathrm{f}$.

111 Eine Entwertung des Tablinums ging mit der Öffnung der rückwärtigen Wand jedoch nicht einher; so allerdings Jung 1984, 83: „Die volle Durchbrechung der Rückwand hat nicht nur eine einmalige Achsensituation, sondern auch zu einer Entwertung des Tablinums geführt - schliesslich konnte man darauf, wie wir sahen, ebensogut verzichten.“ 112 Dexter 1979, 109-114 mit Datierung in den späten zweiten Stil, allerdings besitzt das Tablinum (10; i) eine Ausmalung im frühen dritten Stil. Raumbenennung im Folgenden nach Dexter und PPM; die 3D-Rekonstruktion des Swedish Pompeii Project ist abrufbar unter <http://vr.humlab.lu.se/projects/pompei_online_backup/Pompei_insulav1.html> (25.09.2018).

113 PPM II (1990) 1-137 s. v. I 9,5, Casa dei Cubicoli floreali o del Frutteto (M. de Vos) 4f. Abb. 4; 37 Abb. 49. 

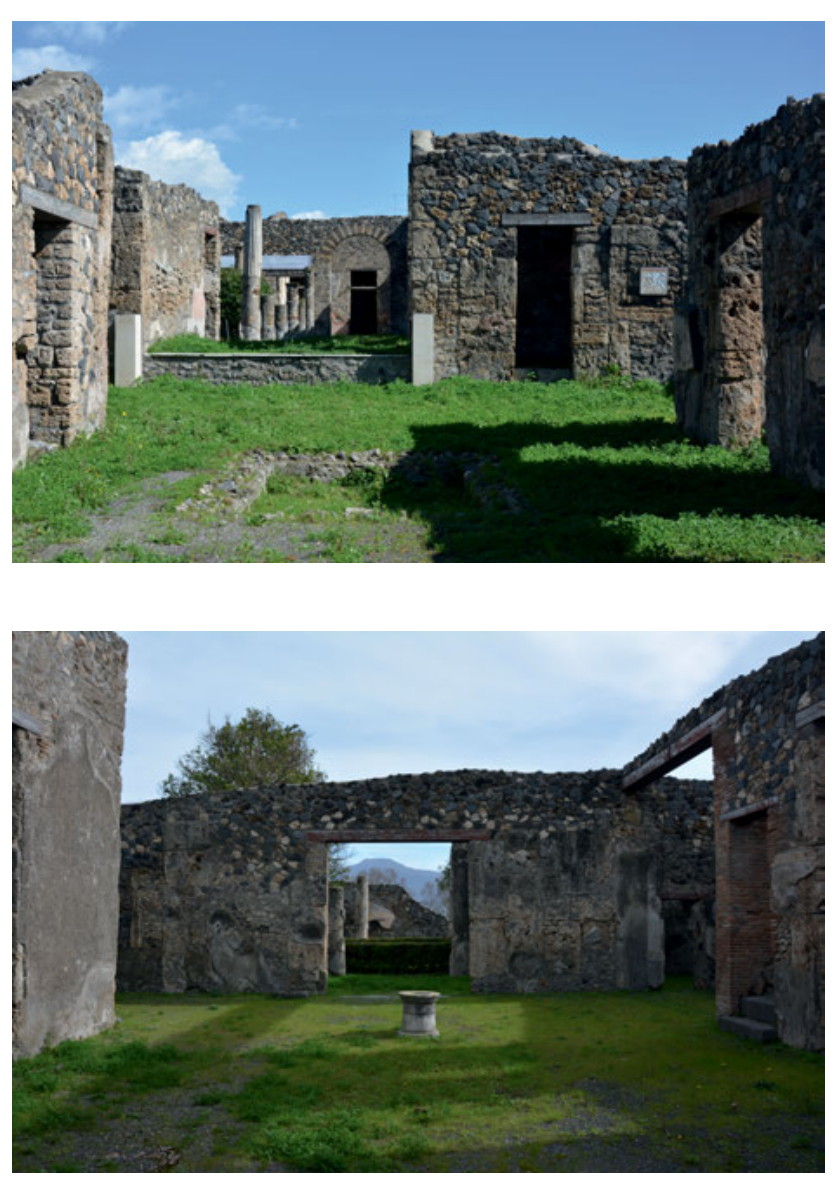

Abb. 314: Casa del Citarista (I 4, 5.6.25.28), Blick auf das Tablinum (14).

Abb. 315: Casa del Citarista ( 4,5.25), Blick durch das Atrium (47) in Peristyl (56).

Dadurch war es nicht mehr vom Atrium, sondern nur noch vom Peristyl aus zugänglich ${ }^{114}$. Zum Atrium hin fungierte es nun als Bühne, zum Peristyl als (Gelage-)Raum.

Deutlich häufiger als zuvor hat man auf ein Tablinum als Aufenthaltsraum zwischen Atrium und Peristyl ganz verzichtet ${ }^{115}$ und dadurch Gartenfläche gewonnen. Im nördlichen Atriumhaus der Casa del Citarista (I 4,5.25; Plan 5) ${ }^{116}$ gelangte man vom tuskanischen Atrium (47) über eine breite Öffnung in der dem Eingang gegenüber liegenden Rückwand direkt in das im späten dritten Stil neu ausgestattete Peristyl (56) (Abb. 315) ${ }^{117}$. Mit dem Wegfall des Tablinums lag kein prominenter Aufenthaltsraum mehr in der Blickachse des Hauses. Dies muss für den ästhetischen Effekt jedoch nicht nachteilig gewesen sein. Vom Eingang aus blickte man auf eine Schauwand, die den Durchblick in den Garten effektvoll rahmte. In der bescheidenen Casa di P. F. L. (IX 6,3) weist die Rückwand von Atrium (2), die den Übergang zum sehr kleinen Garten (f) herstellt, drei Öffnungen

114 Überlegungen zu Bauphasen des Komplexes werden demnächst monografisch vorgelegt: Busen - Haug, in Vorbereitung.

115 Tamm 1973, 58 geht von einer kaiserzeitlichen Datierung der von ihr zusammengestellten 48 Häuser ohne Tablinum aus. Hier ist bereits darauf hingewiesen worden, dass diese Bauidee noch in die Zeit des ersten Stils zurückreichen dürfte; sie gewinnt jedoch an Beliebtheit.

116 PPM I (1990) 117-177 s. v. I 4,5.25, Casa del Citarista (M. de Vos).

117 Ähnliche Lösungen, die auf ein Tablinum zwischen Atrium und Peristyl verzichten, finden sich in der relativ bescheidenen Domus I 2,6, s. PPM I (1990) 8-15 s. v. I 2,6 (I. Bragantini); in der Casa di Ercole (VI 7,4-6), s. Zaccaria Ruggiu - Maratini 2017, Taf. 44; Maratini 2017, 81f. (Beschreibung hier indefinit); in der Casa dei Quadretti teatrali (I 6,11), s. PPM I (1990) 361-396 s. v. I 6,11, Casa dei Quadretti teatrali (M. de Vos) 366 Abb. 5; vgl. Oswald 2016, 34-36; sowie in der Casa di D. Octavius Quartio (II 2,2), s. PPM III (1991) 42-108 s. v. II 2,2, Casa di D. Octavius Quartio (M. de Vos) 82f. Abb. 63. 
Abb. 316: Casa di P.L.F. (IX 6,3), Blick auf die Atriumsrückwand, die den Übergang zu Garten (f) herstellt.

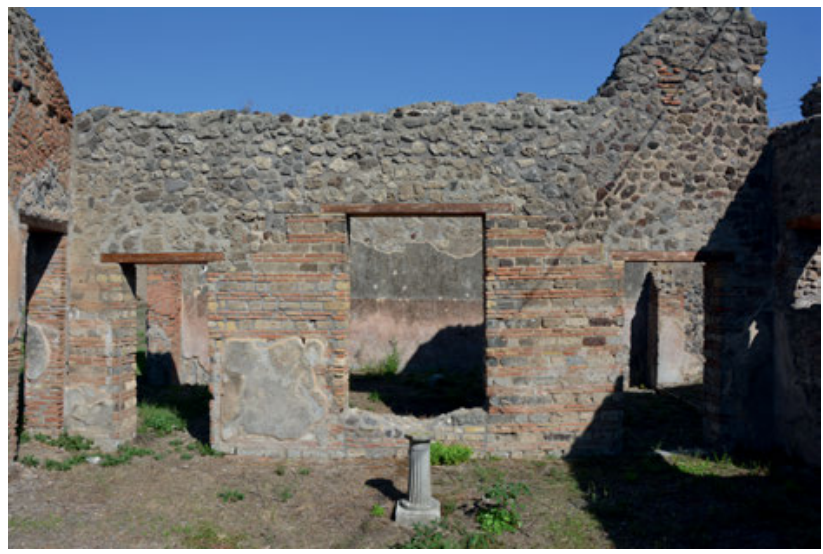

auf (Abb. 316) ${ }^{118}$. Die etwas aus der Eingangsachse versetzte, nachträglich zu einem Fenster umgestaltete Öffnung wird seitlich von zwei niedrigeren Durchgängen flankiert. Damit folgt die Trennwand einem die Mitte betonenden, axialen Gliederungsprinzip, das der Wandgliederung des dritten Stils verwandt ist. Indem sich in den Durchgängen ein Blick in den Garten auftut, werden die Türdurchgänge zu einer ,Bild'-Rahmung. Architektur und Durchblick werden bildhaft inszeniert, die Rückwand des Atriums wird zu einer regelrechten Scaenae frons.

\section{Das Peristyl als Wohnbereich}

Das Peristyl hatte sich bereits im Verlauf des 1.Jhs.v.Chr. als eigentlicher Bereich des Wohnens etabliert. Immer häufiger verzichtete man auf eine vierte Portikus, um einerseits Platz für Räume, andererseits eine attraktive Schauseite zu gewinnen ${ }^{119}$.

So entstanden am Peristyl im fortgeschrittenen 1.Jh.v.Chr. monumentale Prunkräume von bis dahin ungekannter Größe ${ }^{120}$, wie die Oeci (19) und (35) der Casa del Citarista (I 4,5.6.25.28; Plan 5), Triclinium (10) der Casa del Chirurgo (VI 1,10) ${ }^{121}$, die Cenatio (18) der Casa del Menandro $(\mathrm{I} 10,4)^{122}$, schließlich aber auch das Prunk-Triclinium (f) in der sonst eher bescheidenen Casa di Giasone. Diese breiten und zugleich hohen Räume besitzen ein enormes Raumvolumen, müssen über neuartige akustische Eigenschaften verfügt haben und fielen durch ihre weiten Raumöffnungen zudem besonders hell aus. Die Atmosphäre dieser Säle muss sich somit von den intimeren älteren Triclinia erheblich unterschieden haben. Sie setzten sich aber auch funktional von allem Dagewesenen ab, vermochten sie doch eine deutlich größere Zahl an Gästen aufzunehmen ${ }^{123}$. Die häuslichen Rituale dürften stärker als zuvor auf diese Prunkräume ausgerichtet gewesen sein. Indem sie nicht am Atrium, sondern am Peristyl platziert wurden, muss der Charakter des Gartens zwischen der Inszenierung von Privatheit und Abgeschiedenheit und einer regelrecht öffentlichen Nutzung geschillert haben. Allerdings liegen die Prunkräume nicht mehr unmittelbar in der Blickachse, die sich vom Eingang aus ergab ${ }^{124}$. Sie konnten von dem Betrachter erahnt werden, wenn er

118 PPM IX (1999) 736-746 s. v. IX 6,3, Casa di P. F. L. (V. Sampaolo) 738-740 Abb. 6.

119 Man darf m.E. das Vollperistyl nicht per se als prestigereichste Form der Ausstattung begreifen; so allerdings (ohne Berücksichtigung von Chronologie und ästhetischen Aspekten) Simelius 2018, 89.

120 Zum Phänomen, s. Dickmann 1999, 313-322.

121 Zur augusteischen Umgestaltung, s. Anderson - Robinson 2018b, 87-98; bes. 89 Abb. 4. 24.

122 Dickmann 1999, 317-319.

123 Dickmann 1999, 320 f.

124 Von Jung 1984 als Ausdruck des Bedeutungsverlustes des Atriums gelesen. Man wird allerdings hierin sehr viel mehr einen differenzierten Umgang mit Zeigen und Verbergen sehen; ähnlich bereits Hales 2004, 119-122. 


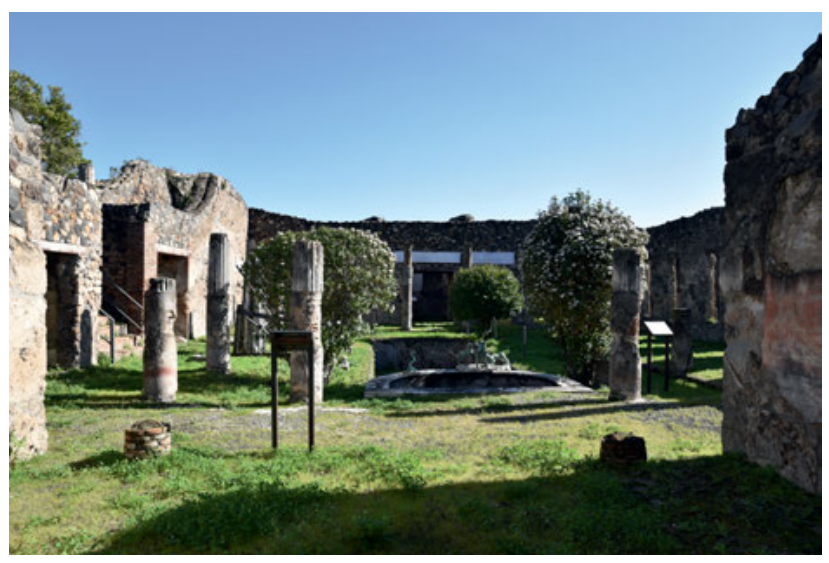

Abb. 317: Casa del Citarista ( $4,5.25)$, Blick von Exedra (18) nach Osten in Richtung Brunnen und Kanopus.

in den Peristylhof eintrat und präsentierten sich in voller Pracht erst, wenn man direkt vor ihnen stand. Gleichzeitig ergab sich von den Prunkräumen, die häufig im Zentrum einer Hofseite platziert waren, ein attraktiver Blick auf den Garten. In der Casa del Citarista (I 4,5.6.25.28; Plan 5) gilt dies für die Exedra (18), aus der man in die Achse von Brunnen und Kanopus blickt (Abb. 317) ${ }^{125}$. Der Brunnen mit seinen attraktiven, figürlichen Wasserspeiern (s. u.) ist ganz auf einen Betrachter in der Exedra hin kalkuliert.

Mit der Schaffung großer Prunkräume ging am Peristyl die Anlage kleiner, intimerer Aufenthaltsräume mit Gartenblick einher. Diese neuen Cubicula besaßen häufig ein Proportionsverhältnis von 3:2 und wiesen eine zentral platzierte, rückwärtige Kline auf ${ }^{126}$. In der Casa del Citarista (I 4,5.6.25.28; Plan 5) wurde die intime Raumwirkung gesteigert, indem Cubiculum (20) mit Vorraum (20a) versehen wurde. Zugleich trat die Raumstaffelung in den Dienst einer Inszenierung des Blicks in den Garten, der mehrfach gerahmt wurde - durch die Türöffnung des Raumes selbst, durch die Öffnung des Vorraums (20a) sowie durch die Rahmung der Portikussäulen (Abb. 318). Noch expliziter fällt die Garten-Inszenierung bei den Diaetae aus, die sich über große Fenster auf den Garten öffneten.

Große Prunkräume und kleinere Cubicula sind im Verlauf des 1.Jhs.v.Chr. nicht selten zu Raumgruppen zusammengeführt worden, die stärker als zuvor symmetrisiert wurden, sodass sich sog. Dreiraumgruppen ergaben ${ }^{127}$. So ist Triclinium (f) der Casa di Giasone zu beiden Seiten von niedrigeren Durchgängen flankiert. Eine besonders raffinierte Lösung wählte man in der Casa degli Amorini dorati (VI 16,7.38; Plan 18) ${ }^{128}$. Beim Betreten des rhodischen Peristyls fällt der Blick auf den erhöhten Peristylflügel im Westen (Abb. 319). Zu Beginn der Kaiserzeit war die hofseitige ,Fassade' durch fünf Interkolumnien strukturiert, wobei das zentrale Interkolumnium durch einen kleineren Giebel akzentuiert worden sein $\operatorname{mag}^{129}$. Dieses war auf den zentralen Prunkraum (O) bezogen, dem die Räume (R) und (Q) symmetrisch zugeordnet waren. Dadurch ergab sich vom Hauptraum aus ein attraktiver Blick, von den Säulen des mittigen Interkolumniums gerahmt, in die zentrale Achse des ,abgesenkten', auf allen Seiten von Portiken eingefassten Gartens. Die Räume

125 Von Dickmann 1999, 129 mit bautypologischen Argumenten der ersten, tuffzeitlichen Bauphase des Hauses zugewiesen.

126 Dickmann 1999, 332 postuliert eine stärkere Einheitlichkeit der architektonischen Lösungen ab der frühen Kaiserzeit, die auf eine Opposition großer Cenationes und kleiner, standardisierter Cubicula ziele. Tatsächlich fallen jedoch sowohl große Prunkräume als auch kleine Aufenthaltsräume sehr unterschiedlich aus, spätestens durch ihren Decor wird jedoch eine große Vielfalt erzeugt.

127 Dickmann 1999, 322-331, mit weiteren Beispielen.

128 PPM V (1994) 714-846 s. v. VI 16,7.38, Casa degli Amorini dorati (F. Seiler); zur Datierung in caliguläischclaudische Zeit ausführlich Seiler 1992, 78-81.

129 PPM V (1994) 714-846 s. v. VI 16,7.38, Casa degli Amorini dorati (F. Seiler) 817 Abb. 48; Dickmann 1999, $323 f$. 
Abb. 318: Casa del Citarista (I 4,5.25), Blick von Cubiculum (20) durch Vorraum (20a) in den Peristylgarten (17).

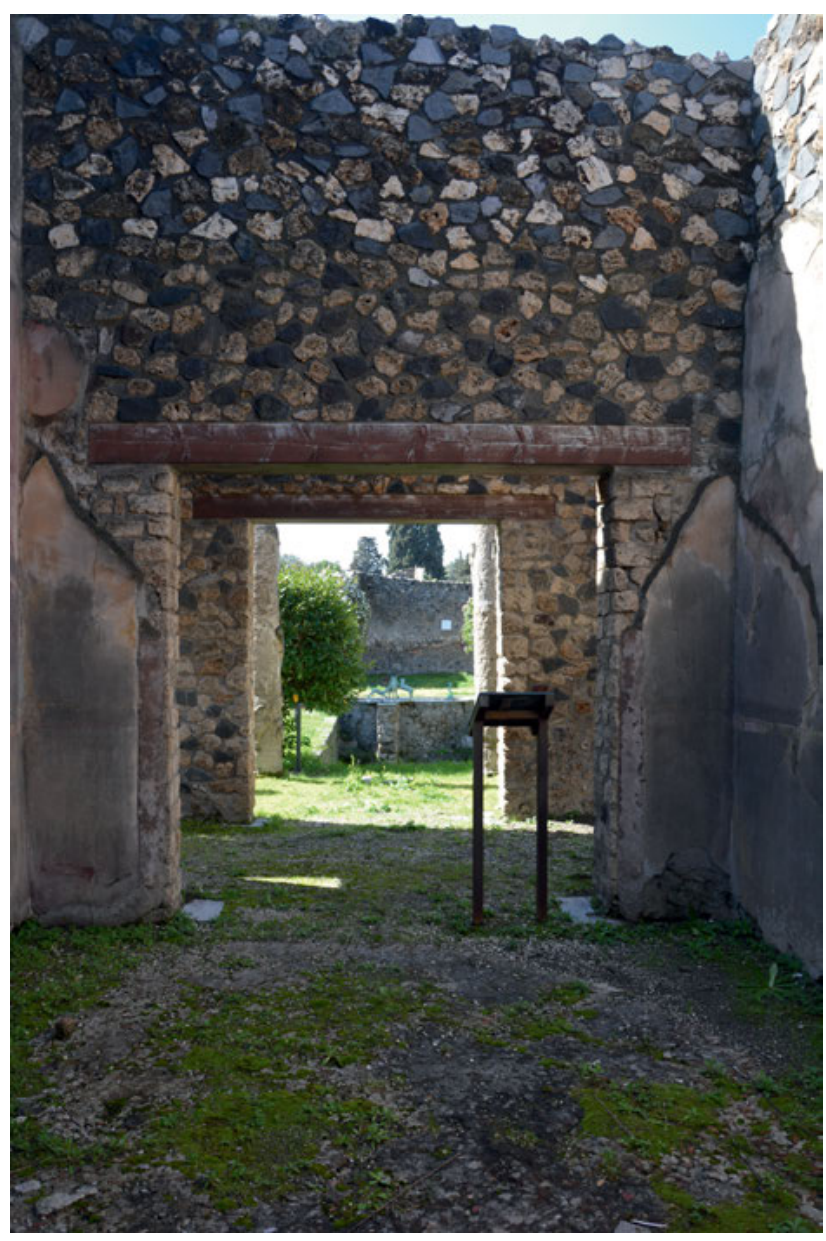

Abb. 319: Casa degli Amorini dorati (VI 16,7.38), Blick auf den erhöhten Westflügel des Peristyls.

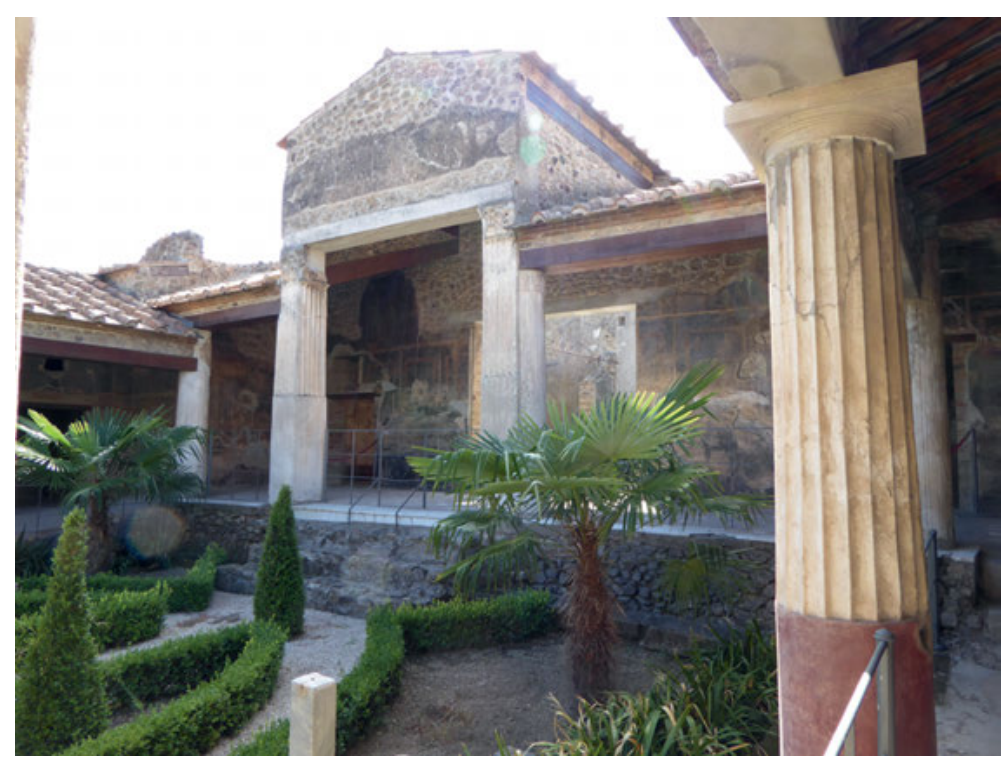




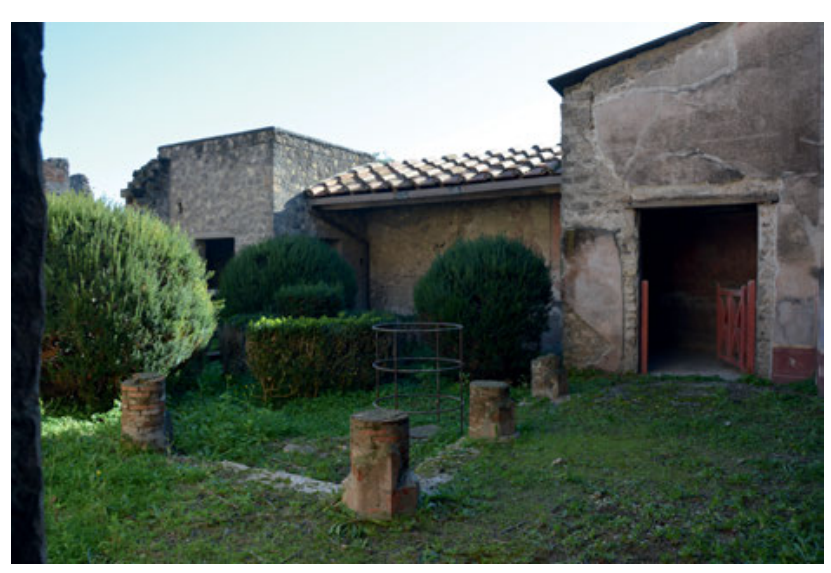

Abb. 320: Casa di Sallustio (VI 2,4), Blick in den Garten mit symmetrisch angelegten Diaetae.

auf den anderen Portikusseiten folgten keiner symmetrischen Anlage. Mit der Symmetrisierung einer Hauptansichtsseite wird am Peristyl ein Schauprinzip eingeführt, das ursprünglich nur am Atrium zum Tragen kam. Vor allem ergab sich dadurch eine Neudefinition des traditionellen Nukleus von Triclinium und Cubiculum. Die das Triclinium rahmenden Cubicula waren als separate Festräume nutzbar ${ }^{130}$.

Raumgruppen am Peristyl konnten so weit anwachsen, dass sie zu einem separaten Wohnbereich wurden. So dient Oecus (21) der Casa del Citarista (I 4,5.6.25.28; Plan 5) als Aufenthaltsund zugleich als Verteilerraum, an den sich mehrere Cubicula, ein Triclinium und ein Korridor anschließen. Die gefangenen Räume sind visuell wie auch funktional auf diesen ,Vorraum ' bezogen. Durch diese architektonische Einbindung sind sie aber zugleich mit höherer Intimität belegt, da sie von den Hofbereichen aus nicht einsehbar sind.

Mit der Casa di Sallustio (VI 2,4) soll im Folgenden ein Haus zur Sprache kommen, in dem verschiedene Neuerungen augusteischer Zeit zusammenkommen. Auf der Südseite des Hauses erhielt Gartenbereich (32) ${ }^{131}$ eine U-förmige Portikus. Mit Triclinium (35) lag hier ein großer Festsaal, von dem aus man in den Nordflügel der Portikus blickte. Besonders spektakulär sind die beiden an den Portikus-Enden symmetrisch angelegten und im vierten Stil neu ausgestatteten Diaetae (33; 34) mit ihren großen Gartenfenstern (Abb. 320) ${ }^{132}$. Sehr wahrscheinlich waren darin Klinen aufgestellt, die sie als Liege- und Aufenthaltsräume bei Tag nutzbar machten ${ }^{133}$. Diese Raumdisposition bediente zwei verschiedene Blickoptionen, die wir schon in der Casa di Giasone als Gestaltungsprinzip kennengelernt hatten: den Blick auf eine symmetrisch arrangierte Raumgruppe einerseits, der Ausblick von diesen Räumen andererseits. Der Blick auf die Räume war auf einen transitorischen Moment festgelegt. Er ergab sich für denjenigen, der über Durchgang (29) in den Garten eintrat. Von den Diaetae aus blickte man bei geöffneter Tür in den jeweiligen (westlichen bzw. östlichen) Portikusflügel. Besonders attraktiv war der Blick vom dunklen Innenraum durch das Fenster über die Bepflanzung des Gartens hinweg auf und durch das Fenster des gegenüberliegenden Raums. Von Diaeta zu Diaeta ergab sich eine rhythmisierte Blickachse.

Während dieser südliche Gartenbereich als Schaugarten inszeniert wurde, war das rückwärtige Gartenareal (24) zum Betreten gedacht (Abb. 346-347) ${ }^{134}$. Er gehörte bereits zur samnitischen

130 Dickmann 1999, 322f.

131 Zur Bauphase, s. Laidlaw - Stella 2014, 144-154.

132 PPM IV (1993) 87-147 s. v. VI 2,4, Casa di Sallustio (V. Sampaolo) 134-143 Abb. 81-95.

133 Als Tendenz beschrieben bei Elia 1932, 261: „Nell'ultima fase edilizia pompeiana il cubicolo non ha più alcun carattere architettonico proprio nè una ubicazione determinata; si trova allogato nell'atrio o nel peristilio, dovunque la necessità lo richieda, senza particolari predilezioni. I cubicoli appariscono nella loro fase più tarda come un ambiente piuttosto basso o a soffitta piana, o a volta con arco ribassato."

134 Die Form des Zugangs über den Graben hinweg auf das höhere Gartenniveau ist heute im Befund unklar. 
Abb. 321: Casa detta di Trebius Valens (III 2,1), Gartentriclinium in Peristyl (x).

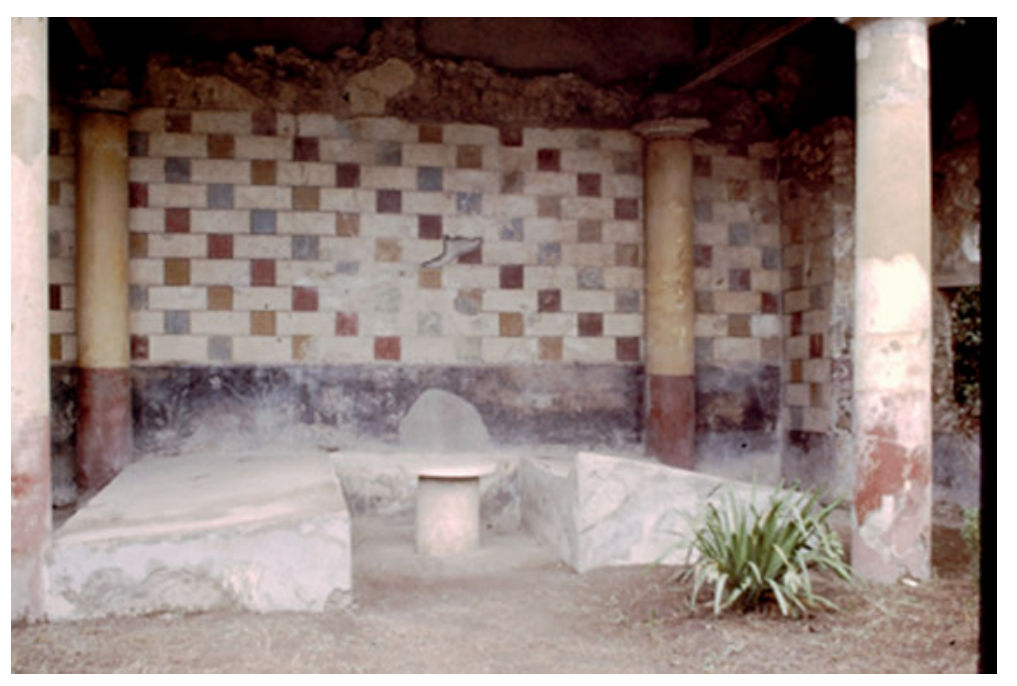

Anlage des Hauses, erhielt in augusteischer Zeit jedoch eine neue Gestaltung. Auf seiner nördlichen Schmalseite entstand ein Gartentriclinium (25) mit gemauerten Klinen. Von hier aus fiel der Blick axial auf einen Garten, der linker Hand von einer Gartenmauer, rechter Hand von einer Portikus eingefasst wurde ${ }^{135}$. In tiberischer Zeit oder noch später wurde im Zentrum der Klinen ein kleiner Brunnen angelegt ${ }^{136}$. In dieser Reihe von Maßnahmen kommt das zunehmende Interesse an der Ausgestaltung von Gartenbereichen zum Ausdruck.

Tatsächlich gehört ein solches Gartentriclinium seit dem 1.Jh.n.Chr. zum besonderen Highlight eines Gartens ${ }^{137}$. Im Unterschied zu den geschlossenen Aufenthaltsräumen mit ihrer dichten Bebilderung bieten sie einen naturhaften Rahmen für das Convivium. Entsprechende Anlagen finden sich in Wirtsräumen ${ }^{138}$, aber auch in Häusern ${ }^{139}$ wie der Casa detta di Trebius Valens $(\text { III } 2,1)^{140}$. Vor die Rückwand von Peristyl (x), die mit einem polychromem Opus quadratum bemalt wurde, setzte man ein gemauertes, $\Pi$ - förmiges Gartentriclinium, das an den Ecken von vier rot und gelb verputzten Ziegelsäulen eingefasst wurde (Abb. 321). Der Decor der Kline nahm auf das Gartenambiente, aber auch auf den Gelagekontext Bezug. Im Zentrum der Klineninnenseite, am lectus medius, waren Greifen zu Seiten eines Kraters zu sehen, am lectus imus und lectus summus Enten und Pflanzen. Die Frontseiten zeigten jeweils einen Pfau. Zu der Anlage gehörte ein Tisch, dessen Verputz Marmor numidicum imitierte und über eine Tischfontäne verfügte. Von den Klinen aus blickte man auf einen kleinen, halbkreisförmigen, zum Triclinium hin ausgerichteten Brunnen mit

135 PPM IV (1993) 87-147 s. v. VI 2,4, Casa di Sallustio (V. Sampaolo) 122 Abb. 59; Döhl - Zanker 1979, 204 setzen das Auftreten von Gartentriclinia in claudische Zeit, tatsächlich fällt die Mehrzahl der Belege in die letzte Phase Pompejis. 136 Zu den Phasen, Laidlaw - Stella 2014, 156f.

137 Zur Chronologie Massoth 2005, bes. 67 Anm. 474; vgl. Morvillez 2018, 58 f.

138 Gartentriclinium in einem Thermopolium und Wohnhaus umfassenden Komplex (I 8,8), mit Bemalung später dritter Stil, s. Massoth 2005, 191f. Kat. Nr. 12; PPM I (1990) 802-825 s. v. I 8,8, Termopolio (V. Sampaolo) 814f. Abb. 23; weiterhin I 11,16, wo das Peristyl mit Gartentriclinium mit einem Thermopolium verbunden ist, s. PPM II (1990) 654665 s. v. I 11,16 (L. Fergola - F. P. Badoni) 661-665 Abb. 10-18.

139 Etwa im Peristyl von I 5,2, vermutlich vor Umwandlung des Komplexes in eine Gerberei, s. Massoth 2005, 187 Kat. Nr. 7; PPM (1990) 185-192 s. v. I 5,2 (I. Bragantini); weiterhin am unteren Garteneuripus von II 2,2, vermutlich durch das Erdbeben 62 n. Chr. zerstört, s. Massoth 2005, 202f. Kat. Nr. 26; PPM III (1991) 42-108 s. v. II 2,2, Casa di D. Octavius Quartio (M. de Vos) 98f. Abb. 99. Im weitläufigen, bepflanzten Garten von Domus I 21,1.2, die für die Weinproduktion genutzt wurde, hat man noch vor dem Erdbeben ein Triclinium errichtet, das von einer Pergola, einem Olivenbaum und von Weinreben beschattet wurde; s. Massoth 2005, 198f. Kat. Nr. 21; PPM II (1990) 1083-1085 s. v. I 21,1.2 (M. R. Borriello). Auch das Gartentriclinium (o) in Domus V 2,15 mag noch vorerdbebenzeitlich, um 50 n. Chr., datieren, s. PPM III (1991) 854-869 s. v. V 2,15 (V. Sampaolo) 855. 860 Abb. 13.

140 Zum Folgenden PPM III (1991) 341-391 s. v. III 2,1, Casa detta di Trebius Valens (I. Bragantini); Massoth 2005, 211f. Kat. Nr. 38; eine Rekonstruktion bei Spinazzola 1953, 295 Abb. 332; vgl. Bergmann 2002, $34 \mathrm{f}$. 
einer mittigen Säule ${ }^{141}$. Er scheint leicht aus der Achse versetzt gewesen zu sein, um vom prominentesten Platz des Tricliniums optimal wahrgenommen werden zu können. Das Gartentriclinium der Casa detta di Trebius Valens bot damit ein neuartiges Erlebnissetting. Das Convivium konnte nun im Freien, mit Blick auf einen künstlich gestalteten Garten, mit eigenem Wasserspiel und seitlich einfassender Säulenkolonnade erlebt werden. Sabine Massoth sieht ganz richtig, dass Gartentriclinia seit augusteischer Zeit ein Repräsentationselement im häuslichen Raum darstel$\operatorname{len}^{142}$.

\section{Peristyle und die neue Aufmerksamkeit für die Gärten}

Die Peristyle erhielten ihre visuelle Qualität durch ihren zentralen Garten. Dessen Portikusrahmung blieb ein optisch besonders prägendes Element. Die Portiken legten die Betrachter auf eine liminale Position im Verhältnis zum Garten fest ${ }^{143}$, von hier aus blickte man durch die semipermeable ,Schranke‘ der Säulenstellungen in den Garten. Tücher und Vorhänge, aber auch Bildobjekte wie Oscilla (s. u.), die in den Interkolumnien aufgehängt werden konnten, trugen zusätzlich zur Abschrankung des Gartens bei.

Eine besonders wichtige ästhetische Funktion kam der Gestaltung der Säulen zu. Schon mit dem dritten Stil dürfte sich eine Vorliebe für eine visuelle Untergliederung des Säulenschaftes ergeben haben. Das untere Säulendrittel wurde dunkelrot verputzt, die Oberzone weiß. Auf Kanneluren verzichtete man entweder ganz oder sie blieben auf den oberen Säulenabschnitt beschränkt. Gut erhalten hat sich ein solches Design im nacherdbebenzeitlich umgestalteten Peristyl der Casa degli Amorini dorati (VI 16,7.38; Plan 18; Abb. 319). Die Rumpfperistyle der Casa di Sallustio (VI 2,4; Abb. 346-347) und der Casa annessa alla Casa dell'Efebo (I 7,19; Abb. 345) sprechen aber dafür, dass diese Mode bereits im dritten Stil aufkam. In die Peristyle wurde durch diese Farb- und Formdifferenzierung eine horizontale Strukturierung eingeführt, zugleich ergab sich durch die rot-weiße Farbigkeit und die geometrische Säulenform ein auffälliger Kontrast zum Grün des zentralen Gartenbereichs.

Die Gärten sind seit augusteischer Zeit immer stärker in die Hauskonzeption integriert. Der Heterotopos wird zum Topos - mithin zu einem Ort, der für das Selbstverständnis der Bewohner zentral wurde ${ }^{144}$. Das Arrangement der Räume am Peristyl, die Gestaltung von Ausblicken auf den Garten, seine ,Bespielung، mit Skulptur (s. u.) und die Anlage von Gartentriclinia machen deutlich, dass der Garten in augusteischer Zeit als Blick- und Bezugspunkt gestaltet wurde. Aus Schriftquellen ist uns bekannt, dass nun enorme Summen für eine aufwendige Bepflanzung aufgewandt wurden $^{145}$. Bis dato unbekannte Gewächse wurden aus allen Teilen des Mittelmeerraums nach Italien ,importiert ${ }^{\times 146}$, sodass im häuslichen Garten ganz andere Orte evoziert werden konnten ${ }^{147}$.

In Pompeji wurde die ,Qualität‘ der Gärten in augusteischer Zeit durch das nunmehr verfügbare Fließwasser befördert. Zwar nahm Christoph Ohlig auf der Basis seiner Untersuchung des Castellum aquae an, Pompeji habe mit der Avella-Leitung schon seit sullanischer Zeit eine Aquäduktleitung besessen und nur die Serino-Leitung sei in augusteischer Zeit neu hinzugekommen ${ }^{148}$.

141 Laut Morvillez 2018, 50 erst in den letzten Jahren der Stadt als Brunnen gestaltet.

142 Massoth 2005, 68; zu Gartentriclinia ohne weitere chronologische Differenzierung Simelius 2018, 61.

143 Vitr. 5,9,5; diese ,Rahmung‘ des Gartens durch Portiken wird als Konzept auch bildlich umgesetzt, vgl. O’Sullivan 2007.

144 Bei Foucault 2005 ist dem Heterotopos allerdings immer schon ein für die Gemeinschaft konstitutiv-sinnstiftendes Element eingeschrieben. Gärten als Heterotopien: von Stackelberg 2009, 62; dort allerdings auch mit Hinweis auf literarische Quellen, die die soziale Relevanz der Horti hinterlegen (S. 12f.); ebenso Marzano 2014.

145 Val. Max. 9,1,4; Plin. nat. 17,3-4.

146 Marzano 2014 auch mit Verweis auf die militärischen Expeditionen, die als ,Beute‘ die ,Natur` des besiegten Landstriches nach Rom bringen; vgl. Zarmakoupi 2014, 114.

147 Zur ars topiaria, s. Landgren 2004, 178-192; Gleason 2013, 17.

148 Ohlig 2001, 270-277. 
Jean-Pierre Adam und Pierre Varène kommen hingegen zu dem Schluss, dass zumindest das Castellum aquae erst in augusteischer Zeit errichtet worden sei ${ }^{149}$. Tatsächlich wurden die wasserintensiven öffentlichen Thermenanlagen Pompejis erst jetzt mit Fließwasser versorgt ${ }^{150}$, auch in den Häusern fällt der regelrechte ,Brunnen-Boom` in diese Zeit ${ }^{151}$. Daher darf man annehmen, dass Fließwasser erst mit dem Übergang zur frühen Kaiserzeit in größerem Umfang verfügbar war, auch wenn wohl nur ein Viertel bis ein Drittel der Häuser an das Wasserverteilungssystem angeschlossen wurde ${ }^{152}$. Die ostentative Verschwendung von Fließwasser für die ästhetisch anspruchsvolle Inszenierung von Brunnen und Nymphäen darf man somit als Luxuselement auffassen.

In Pompeji hatte die Verfügbarkeit von Fließwasser neuartige Bepflanzungskonzepte nach sich gezogen. An die Stelle von Gärten, die wie jener der Casa di C. Iulius Polybius (IX 13,1-3) locker von Bäumen bestanden waren und der Versorgung des Hauses mit Früchten dienten, traten nun vermehrt Gärten, die mit bewässerungsintensiven Blumen und Gewächsen bepflanzt waren. Dadurch dürfte sich das Erscheinungsbild der Gärten erheblich verändert haben ${ }^{153}$. Wie die Bepflanzung im Detail ausgesehen hat, lässt sich für die frühe Kaiserzeit kaum nachvollziehen. Pflanzkübel und Setzgruben sind, wenn sie überhaupt dokumentiert wurden, häufig nicht datiert oder den letzten Jahrzehnten Pompejis zuzurechnen ${ }^{154}$. Einzelfälle sind aber aufschlussreich. In der Casa del Chirurgo (VI 1,10) fällt die Neuorganisation des Gartenbereichs mit Pflanzkübeln, die in Reihen versetzt waren, in augusteische Zeit ${ }^{155}$. In der Casa degli Epigrammi Greci (V 1,18.11.12) entstand im Zuge einer Um- und Neugestaltung in den letzten drei Jahrzehnten vor Christi Geburt ein dreiseitiges Peristyl mit einem Brunnen. Die Bepflanzung des Gartens datiert in die Jahre nach 15 n.Chr., nach Verfüllung der Materialentnahmegruben ${ }^{156}$. In einer ersten Phase (15-40 n.Chr.) besaß das Peristyl einen zentralen, über eine Wasserleitung versorgten Brunnen mit Wasserspiel. Pflanzkübel wurden auf der Innenseite der Säulen sowie vor der Rückwand des Peristyls platziert. Die Bepflanzung folgte damit gängigen Decor-Prinzipien. Sie akzentuierte die Architektur und trug zur Gestaltung der Peristylrückwand als Schauseite bei. Die neue Gartenkultur muss sich nachhaltig auf die Atmosphäre dieser Höfe ausgewirkt haben.

\section{Kultnischen mit Larenikonographie}

Mit dem dritten Stil erhält die Diskussion der Kultorte im Haus eine neue Richtung, weil nun mit den Larendarstellungen erstmals eine spezifische Kultikonographie greifbar ist, die einzelne Nischen als Kultnischen ausweist. Im Folgenden werden drei signifikante, frühe Belege für eine ,Larenikonographie‘, wie sie dann im vierten Stil weit verbreitet war, im Hinblick auf ihre Aussagekraft für die kultische Nutzung des Hauses diskutiert ${ }^{157}$.

149 Adam - Varène 2008, 48f.; ob es eine ältere, republikanische Aquäduktleitung gegeben hat, lassen sie offen. 150 Trümper 2018, 99 Anm. 66.

151 So bereits ursprünglich Jashemski 1979, 32f.; Dwyer 1982, 113; Richardson 1988, 55; in der Casa di N. Popidius Priscus (VII 2,20.40) lässt sich die Verlegung von Bleileitungen, die einen Brunnen am Atrium bedienten, in augusteische oder tiberische Zeit weisen, s. Pedroni 2008, 240; De Carolis 2017, 256; in der Casa delle Vestali (VI 1,7) folgt die Installation auf die Einrichtung der Wasserleitung in augusteischer Zeit, in den 20er Jahren vor der Zeitenwende, s. Jones - Robinson 2005, 697-699; für Regio VI, Insula 7 Maratini 2017b, 332.

152 Jones - Robinson 2005, 697-699; dort auch zur statistischen Häufigkeit eines Wasseranschlusses.

153 Jashemski 1996.

154 So auch die bei Robinson 2019 diskutierten Fälle.

155 Anderson - Robinson 2018b, 95.

156 Staub-Gierow 2008, 97-99; Robinson 2019, 230-236 (dort auch zu den späteren, hier nicht diskutierten Phasen). 157 Eine systematische Zusammenstellung aller Lararienbilder bei Fröhlich 1991, auf die die hier vorgenommenen Einordnungen rekurrieren; bei Boyce 1937 unvollständig. 


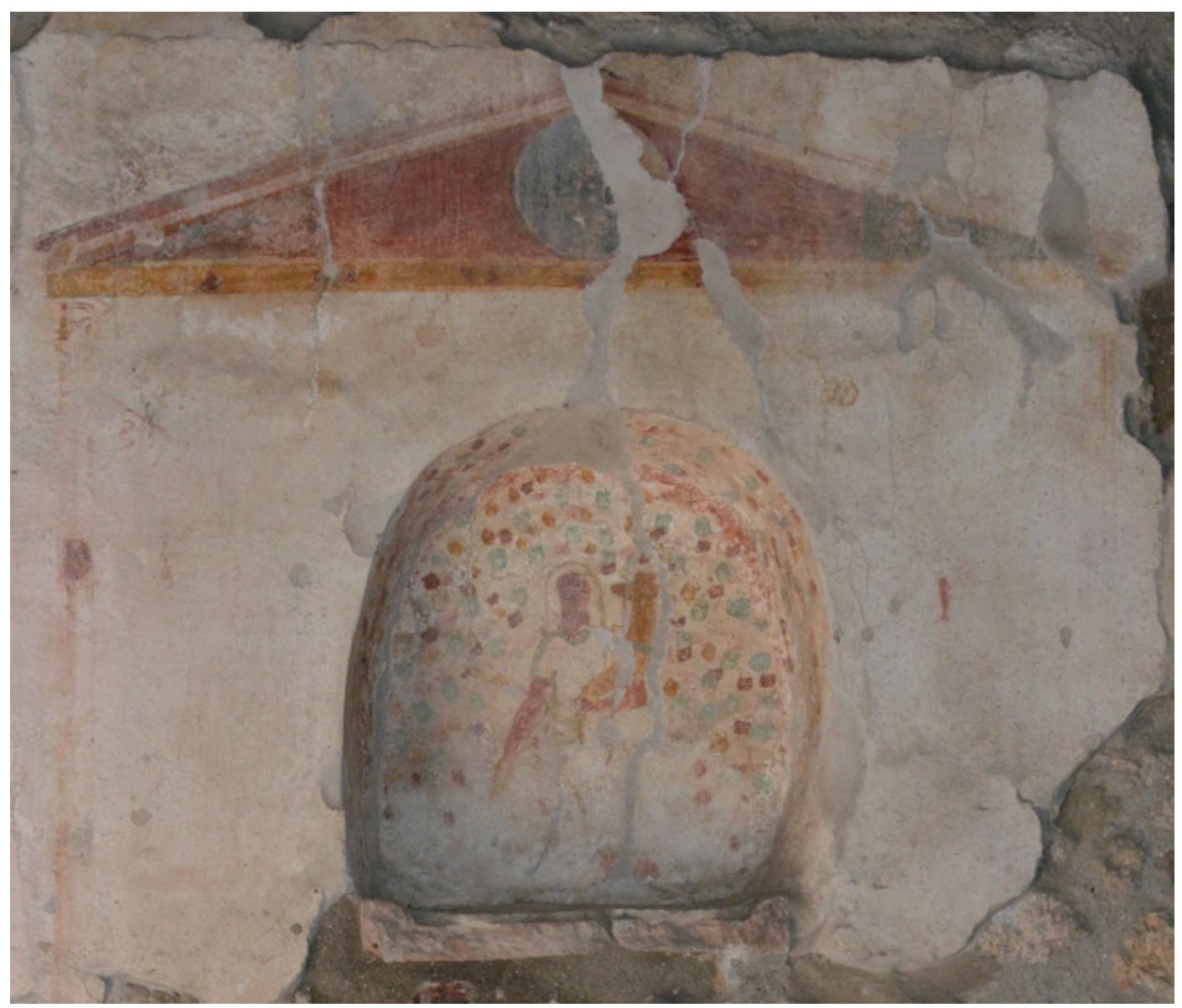

Abb. 322: Casa di Obellius Firmus (IX 14,4), Küche (18) mit Kultnische.

In Küche (18) der Casa di Obellius Firmus (IX 14,4) wird eine Rundbogen-Nische von einer gemalten, rotgrundigen Ädikula mit Giebel eingefasst (Abb. 322) ${ }^{158}$. Die Ausmalung der Nische weist zwei Phasen auf, wobei Fröhlich die ältere in frühaugusteische Zeit weist. In dieser ersten Phase nimmt ein Genius mit Cornucopia die Nischenrückwand ein, seitlich wurde die Nische von später noch einmal neu gemalten Laren flankiert. Unterhalb windet sich eine Schlange einem Altar entgegen, rechter Hand ist ein Bankett mit sechs Teilnehmern dargestellt, links ein Schwein. Dasselbe Haus besitzt in Atrium (B) ein weiteres, jedoch sicher späteres, architektonisch gefasstes ,Tempel'-Lararium mit vier Säulen auf einem Nischen-Unterbau ${ }^{159}$.

An der Nordwand von Küche (17) der Casa di Sutoria Primigenia (I 13,2) verbindet sich eine Nische mit einer in augusteische Zeit datierten Larariumsikonographie ${ }^{160}$. Um die Nische sind grob gemalte Würste, Fleisch-Spieße und große Schinken gruppiert (Abb. 323), darunter schlängelt sich eine Schlange durch hoch aufsprießendes Gras zu einem kleinen Altar. Auf der über Eck anschließenden Ostwand versammeln sich, deutlich kleinteiliger gezeichnet, zwischen zwei großen, stehenden Laren ein Flötenspieler sowie die Opfergemeinschaft am Altar. Darunter folgt ein Fries mit

158 PPM X (2003) 361-500 s. v. IX 14,4, Casa di Obellius Firmus (V. Sampaolo) 453-459 Abb. 167. 168; Fröhlich 1991, 69f. Kat. L111.

159 PPM X (2003) 361-500 s. v. IX 14,4, Casa di Obellius Firmus (V. Sampaolo) 370 Abb. 12. 13.

160 PPM II (1990) 860-880 s. v. I 13,2, Casa di Sutoria Primigenia (O. B. Mondini - V. Sampaolo) 876-880 Abb. 23-27; mit augusteischer Datierung Fröhlich 1991, 261 Kat. L29; Giacobello 2008, 156; vgl. Flower 2017, 58f.; mit einer Datierung nach 62 n. Chr. Gallo 1994, 47-50.79. 
Abb. 323: Casa di Sutoria Primigenia (I 13,2), Küche (17), Kultnische mit Kultikonographie.

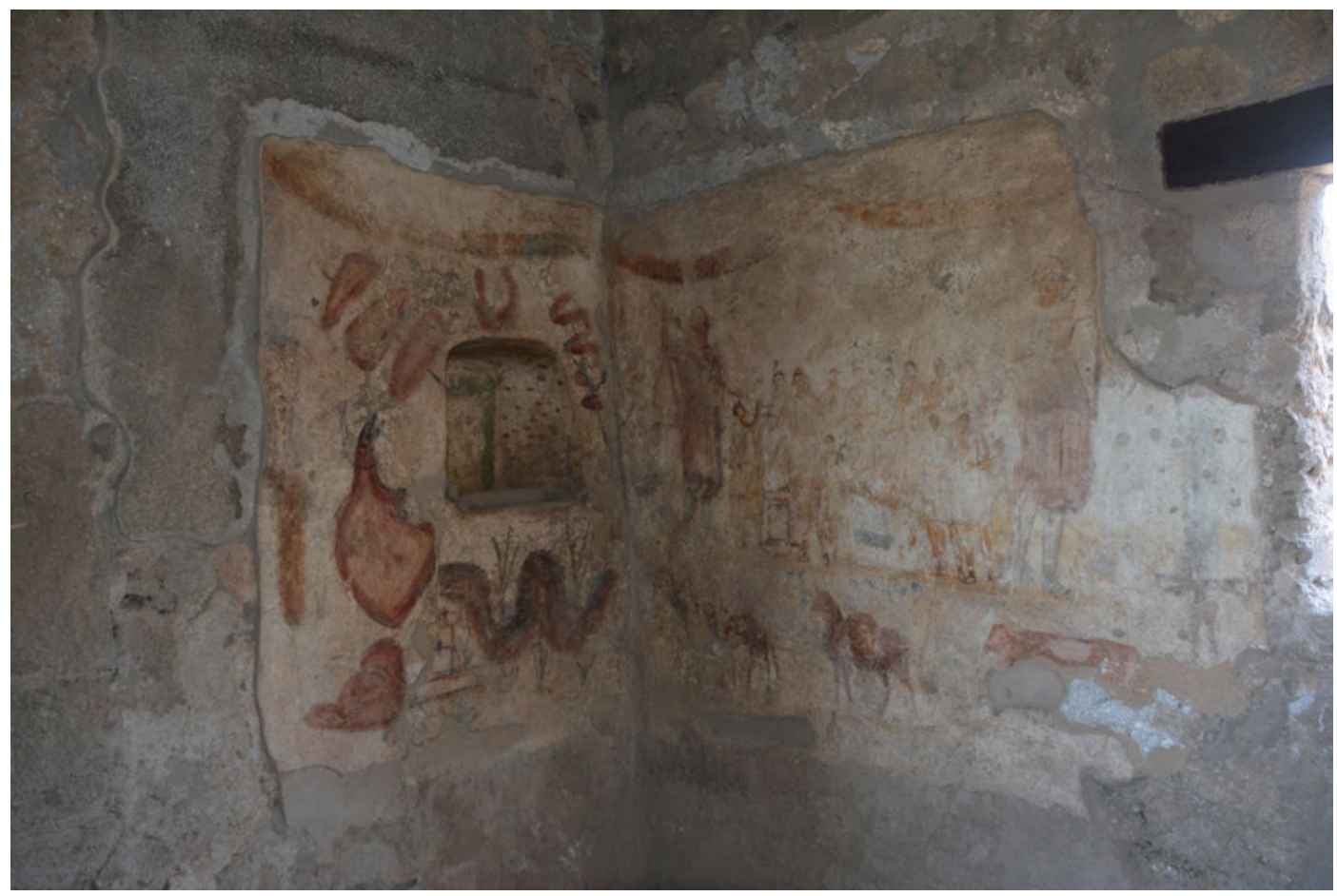

Tieren. Harriet Flower identifiziert in der Opfergemeinschaft Hausherr und Hausherrin nebst zwölf Sklaven in Tunica und fasst das Bild als wörtlichen Beleg dafür auf, dass der Dominus zu entsprechenden Opferanlässen den Küchenbereich aufsuchte. In der kleinen Küche haben zwar sicher keine 15 Personen vor einem Rundaltar Platz, man darf das Bild aber als Ausdruck eines solchen rituellen Konzepts werten.

Dem mittleren bis späten dritten Stil weist Fröhlich die Darstellung eines Genius mit Füllhorn sowie eines Camillus aus dem Küchentrakt im Untergeschoss der Casa del Bracciale d'oro (VI 17 [Ins. Occ.],42) $\mathrm{zu}^{161}$.

Mit augusteischer Zeit werden somit erstmals Nischen greifbar, deren Ikonographie auf den Larenkult Bezug nimmt ${ }^{162}$. Neben den Laren selbst können Opfernde und Opfergaben dargestellt sein. Alle drei frühen Belege für eine solche Kultikonographie finden sich in Küchen.

\section{(Kult-)Nischen mit andersartiger Ikonographie}

Nischen können in der frühen Kaiserzeit auch mit nicht-rituellen Ikonographien belegt werden. In diesen Fällen lassen sie sich nicht ohne weiteres als Kultnischen ansprechen.

In der Domus I 12,16 ist die Nische an der Südwand von Atrium (2) mit einem Bacchus unter einer Pergola ausgemalt, im unteren Bildfeld erscheint eine Schlange (Abb. 324) ${ }^{163}$. Allerdings setzt sie etwa $2 \mathrm{~m}$ über Gehniveau an. Am ehesten wird man von einem optisch inszenierten Götterbereich sprechen.

161 Fröhlich 1991, 282 Kat. L78.

162 Am Übergang vom dritten zum vierten Stil werden entsprechende Darstellungen deutlich häufiger. Diese späteren Darstellungen sind hier nicht berücksichtigt, sie sind im Einzelfall auch nicht sicher dem dritten oder vierten Stil zuzuweisen; vgl. dazu Fröhlich 1991.

163 PPM II (1990) 838-841 s. v. I 12,16 (E. M. Menotti - A. de Vos) 841 Abb. 5; Fröhlich 1991, 260 f. Kat. L28. 


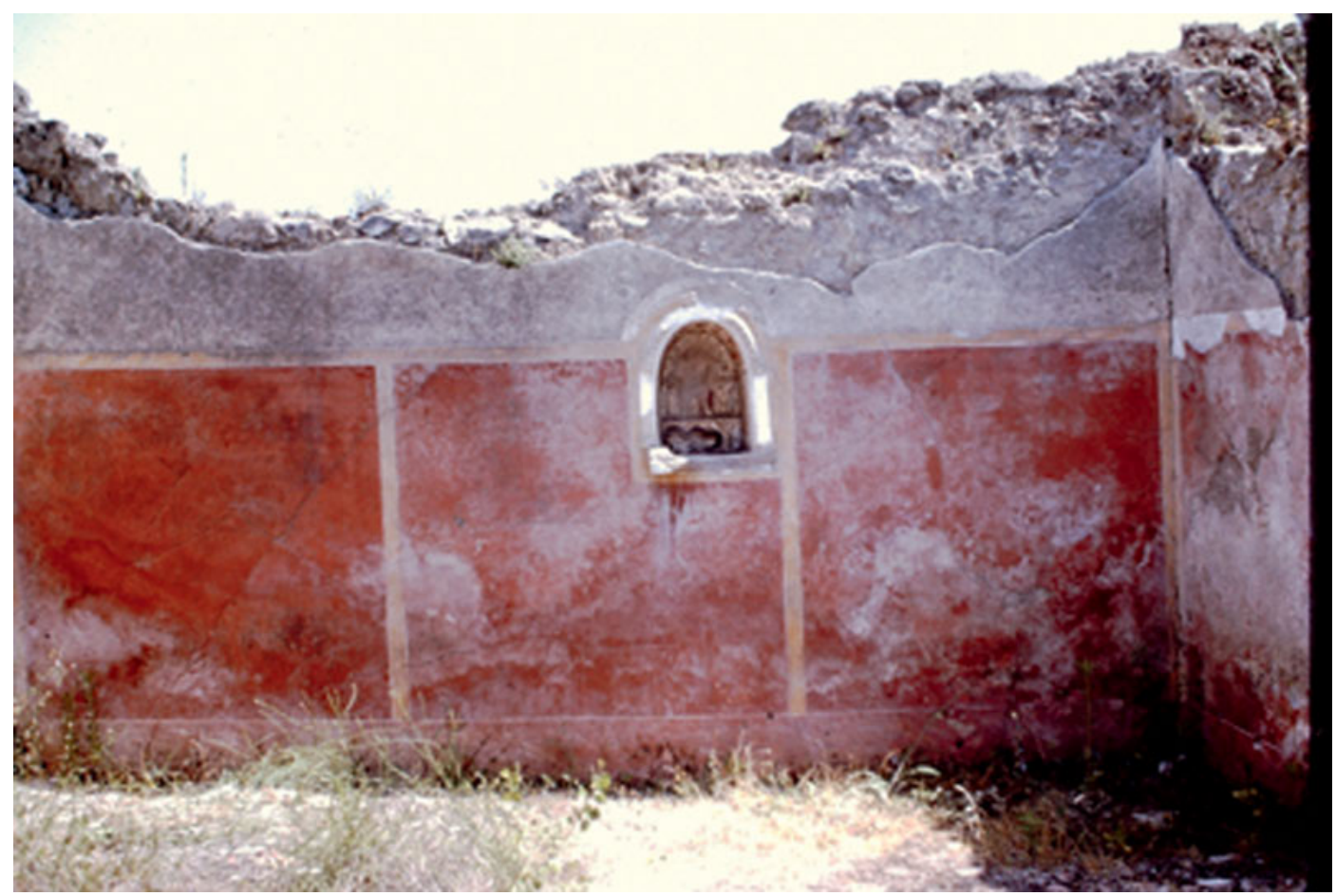

In der Domus IX 1,7 ist die Südwand von Atrium (d) durch eine Rechtecknische, eine Bogennische und eine ,Kultnische" strukturiert. Die Nischen passen sich in die Feldergliederung des dritten Stils ein, auch wenn sie im vierten Stil redecoriert wurden ${ }^{164}$. Im erhaltenen Zustand trägt ein von Stuckpfeilern eingefasstes, marmoriertes Podium eine von vier Halbsäulchen eingefasste Konchennische mit plastischem Giebel. An ihrer Rückwand sind in Stuckrelief Venus und Amor auf einem Ketos (oder Delfin?) dargestellt (Abb. 325). Die Ikonographie lässt eine kultische Nutzung denkbar erscheinen, zwingend ist dies aber nicht, sind doch Venus und Amor fester Bestandteil von Wandmalereien im Haus. Eine Unterscheidung in kultisch genutzte und ,ästhetische‘ Nischen dürfte allerdings kaum einem antiken Verständnis entsprochen haben - konnten doch solche Situationen auch ad hoc ,ritualisiert' werden.

Ein weiterer Befund ist für das Verhältnis von Kultpraxis und ,Bebilderung‘ aufschlussreich. Die Casa del vinaio (IX 9,6) besitzt gleich drei Nischen, die alle keine kultisch signifikante Ausmalung aufweisen ${ }^{165}$. Bei der Nische am Atrium (b) handelt es sich um einen Blumen-Decor ${ }^{166}$, die Nische in der Gartenrückwand (p), für die eine Toga-Statuette und ein Altar eine kultische Nutzung bezeugen, war weiß verputzt. Auch bei dem Sacellum (q), ursprünglich vielleicht eine Küche, in dem verschiedenste Kultobjekte gefunden wurden, fehlt eine spezifische Kultikonographie. Kultisch genutzte Nischen mussten folglich nicht zwingend mit einer Ikonographie versehen werden, die auf das Kultgeschehen Bezug nahm.

164 Damit ist ein Terminus ad oder ante quem für die Anlage der Nischen gegeben; zur Malerei: PPM VIII (1998) 869887 s. v. IX 1,7 (V. Sampaolo) 872-874 Abb. 5-7; Gallo 2001, 20 mit Verweis auf das hohe Alter der Mauerstruktur der Südwand (Opus africanum); zum Decor auch Gallo 2001, 41f.; vgl. auch Boyce 1937, 79 Nr. 381.

165 Boyce 1937, 91 Nr. 457-459.

166 Eine weitere Nische mit Blumen-Decor fand sich in Raum (10) der Domus VI 17 [Ins. Occ.],41; s. PPM VI (1996) 1043 s. v. VI 17 [Ins. Occ.],41 (V. Sampaolo) 24 Abb. 31. 35; De Simone 2006, 45.53. 
Abb. 325: Domus IX 1,7, Südwand von Atrium (d) mit Kult(?)-Nische.

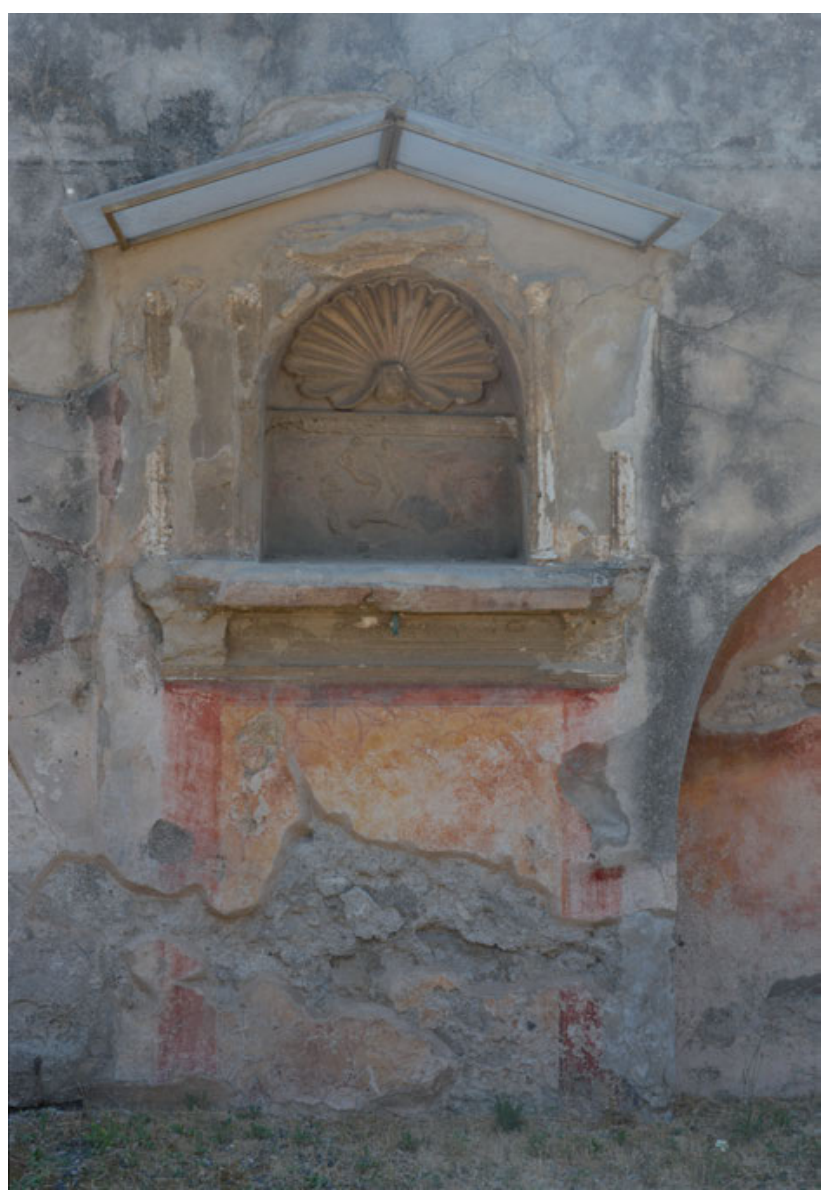

Zwar ist die statistische Basis für die frühen häuslichen Kultikonographien wenig tragfähig. Vielleicht ist es aber kein Zufall, dass sich die frühen Larenbilder ausschließlich in Küchen finden, während die Nischen in Atrien und Peristylen einen anderen Decor erhielten. Möglicherweise rekurrierte die Larenikonographie in ihrem Ursprung auf spezifische Bildbedürfnisse des häuslichen Gesindes, bevor sie im vierten Stil auch als Decor der Atriums-Lararien übernommen wurde. Ob die Küchen-Lararien dem Gesinde vorbehalten waren und der Hausherr und seine Familie ihre Opfer an den Kultorten im Atrium und Peristyl vollzogen, lässt sich nicht entscheiden.

Ausgehend von den verschiedenen architektonischen Innovationen, die so weit möglich auch auf mögliche Handlungskonstellationen hin befragt wurden, soll es im Folgenden konkreter um die Decor-Optionen der beginnenden Kaiserzeit gehen.

\subsection{Das Decor-Konzept für die Wände}

Der dritte Stil bringt eine völlig neue Raumwirkung mit sich, auch wenn er keine homogene Gruppe von Wandmalereien umfasst. Die frühen Wände stehen dem zweiten, die späten dem vierten Stil nahe. Dabei sind, wie das Beispiel der Casa di Marcus Lucretius Fronto gezeigt hat, gleichzeitig erhebliche Variationen möglich. Im Folgenden geht es nicht darum, die ohnehin umstrittene chronologische Entwicklung innerhalb des dritten Stils nachzuzeichnen, sondern einige bedeutsame visuelle Strategien zu konturieren, die sich mit dem Auftreten des dritten Stils ergaben. 


\section{Visuelle Charakteristika des dritten Stils: Architektur als Rahmung}

Der dritte Stil gibt die illusionistische Tiefenwirkung, welche die besonders aufwendigen Malereien zweiten Stils erzielt hatten, weitgehend auf. Die Wand schließt sich, Architekturelemente werden als Rahmung von geschlossenen Flächen (Feldern) eingesetzt ${ }^{167}$. Säulen und Gebälk sind durch eine maximale Verschlankung ihrer architektonischen Funktion, aber auch ihres monumentalen Effekts beraubt ${ }^{168}$ und werden zum ornamentalen, oft in sich ornamentierten Gliederungselement ${ }^{169}$. Erst wenn man die Aufmerksamkeit gezielt auf Kapitelle und Gebälkzonen richtet, wird bisweilen eine gewisse Tiefenräumlichkeit erfahrbar ${ }^{170}$. Indem nicht nur Architekturglieder, sondern auch Gegenstände wie Thyrsoi, Kandelaber und Pflanzenstängel als Trägerelemente eingesetzt und die Raumecken allein durch farbliche Bänder oder Kordeln markiert werden ${ }^{171}$, erhalten die architektonischen Gebilde einen phantastischen und überraschenden Charakter. Ganz entgegen traditioneller Vorstellungen von Tragen und Lasten werden labile Elemente zu Trägern, statische Logik geht verloren ${ }^{172}$. Haben die Wandgestaltungen des ersten und zweiten Stils ein ,Bild‘ von Wand repräsentiert, so ist dieser selbstreferenzielle Bezug nun aufgegeben worden. Erst dadurch wird es möglich, die Wände als Bild-Träger zu konzipieren. Die filigranen Architekturelemente werden zum gliedernden Rahmen-Ornament, das in dieser Logik auch vegetabilisiert werden kann. Mau spricht von einer „ornamentalen Spielerei“: „Dies sind nicht mehr architectonische Darstellungen, sondern Ornamente, welche zufällig die Form von Säulen, Gebälken u. dgl. haben.“173 „[...] Hier ist ein wirklich rein decorativer Stil gefunden: auf der Wandfläche wird nicht mehr irgend etwas dargestellt, sondern sie wird, unter Zugrundelegung eines aus früheren Decorationsweisen überkommenen Schema's, mit Erinnerung an gewisse überlieferte Vorstellungen, getheilt und ornamentirt." ${ }^{\text {(174 }}$

Noch konsequenter als im zweiten Stil treten die Architekturelemente in den Dienst einer horizontalen und vertikalen Dreiteilung der Wand. Die Wandmitte wird meist durch eine filigrane Ädikula-Architektur herausgehoben, die eine übersichtliche und zugleich optisch hierarchisierte Struktur erzeugt. Während der frühe und entwickelte dritte Stil perspektivisch organisierte Architekturen nur in der Oberzone zeigen, können solche Elemente im späteren dritten Stil wie im Tablinum (h) der Casa di Marcus Lucretius Fronto auch als Rahmung der Mittelbilder fungieren (Abb. 288) $)^{175}$. Diese Durchblicke ordnen sich einer axialsymmetrischen Ordnung des Wandsystems unter, sodass die Perspektive in den Dienst einer besonders effektvollen Rahmung von Bildern und Bildobjekten tritt und eine ornamentale Funktion erhält.

\section{Ordnung durch Farbe}

Zur visuellen Organisation der Wand trägt in hohem Maße die Farbigkeit der Paneele bei. Wurde die farbliche Rhythmisierung im ersten und im einfachen zweiten Stil durch farblich unterschiedlich gefasste Quader hergestellt, bezog sich der Farbwechsel nun auf die großformatigen Paneel-

167 Etwa Corlàita Scagliarini 1974, 11; Clarke 1991, 53f. 63. 125f.; Thomas 1995, 34-36.

168 Grüner 2004, 161f. 171.

169 Etwa Bek 1980, 187.

170 Bergmann 2002, bes. 28f. zur Casa di Giasone.

171 Corlàita Scagliarini 1974, 11.

172 Ob man darin tatsächlich, wie Grüner 2004, 185f. meint, Humor und Ironie erkennen darf, möchte ich bezweifeln.

173 Mau 1882, 290.

174 Mau 1882, 448.

175 Bastet - de Vos 1979, 62 bes. 66f.; vgl. Clarke 1991, 152f.; weiterhin Triclinium (t1) der Casa di M. Epidius Sabinus (IX 1,22.29), s. PPM VIII (1998) 956-1044 s. v. IX 1,22.29, Casa di M. Epidius Sabinus (V. Sampaolo) 1028f. Abb. 128f.; Triclinium (e) der Casa di T. Dentatius Panthera (IX 2,16), s. PPM IX (1999) 1-40 s. v. IX 2,16, Casa di T. Dentatius Panthera (V. Sampaolo) 23-27 Abb. 39-45. 
Abb. 326: Casa di Paquius Proculus/ Cuspius Pansa $($ I 7,1), Tablinum (6) mit monochrom weißer Wand.

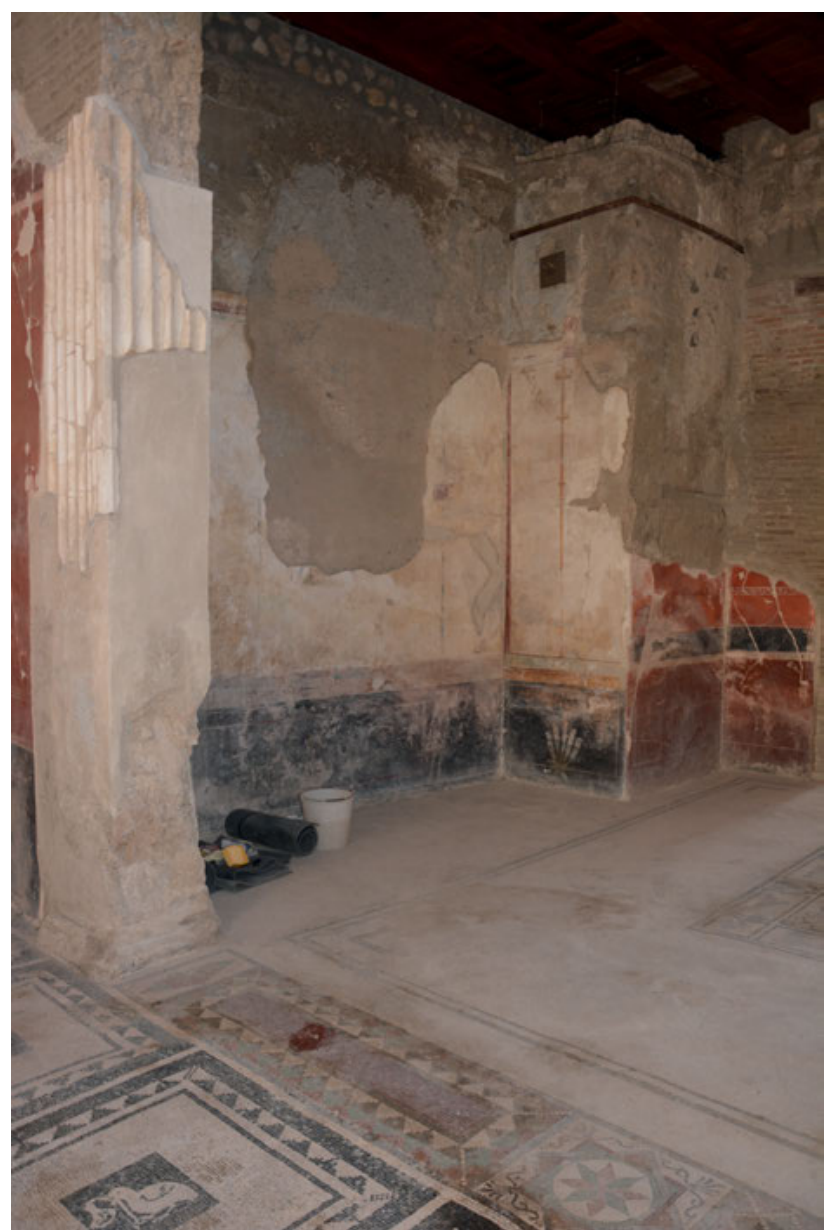

flächen. Der kontrastierenden Platzierung von Farben kam dadurch eine noch wichtigere Rolle zu. Während die Sockel und Oberzonen häufig monochrom ausfallen, sind insbesondere die Mittelzonen durch Farbwechsel rhythmisiert. Diese treten in den Dienst einer Betonung des Wandzentrums ${ }^{176}$. Die Symmetriewirkung konnte verstärkt werden, wenn in der Sockel- oder Oberzone die Farben wie im Tablinum (h) der Casa di Marcus Lucretius Fronto chiastisch angeordnet wurden (Abb. 288).

Nicht alle Räume dritten Stils nutzen jedoch Farbkontraste als Mittel der Wandgliederung. In einigen Fällen hat man monochrome Räume bevorzugt; auch ein solch weitgehender Verzicht auf Polychromie stellt eine Innovation des dritten Stils dar. Vor einfarbigem Hintergrund kommen die filigranen Architekturen besonders gut zur Geltung, die Räume erhalten eine kohärentere Wirkung $^{177}$. Monochrom weiße Räume finden sich allein im Kandelaberstil - Tablinum (6) der Casa di Paquius Proculus/Cuspius Pansa (I 7,1; Plan 6; Abb. 326) wäre ein Beispiel ${ }^{178}$. Monochrom schwarze Räume, die gerade bei Kerzenlicht besonders edel gewirkt haben müssen, sind ebenfalls bereits im Kandelaberstil en vogue ${ }^{179}$, bleiben aber bis in den späten dritten Stil beliebt, wie sich am Atrium der Casa di Marcus Lucretius Fronto zeigt. Um einen gelben Raum handelt es sich bei Cubiculum (r) der Casa di Orfeo, um einen roten Raum mit filigranem Architektur-Decor des späten

176 Clarke 1991, 126.

177 Eine vollständige Aufstellung und Auswertung bei Barbet 2009, 124-126, mit etwas anderen Schlussfolgerungen. 178 Ehrhardt 1998, 45-48. 125.

179 Etwa PPM III (1991) 1069-1098 s. v. V 5,3, Caserma dei gladiatori (F. P. Badoni - F. Narciso) 1094f. Abb. 54-58; Bastet - De Vos 1979, 31f. 


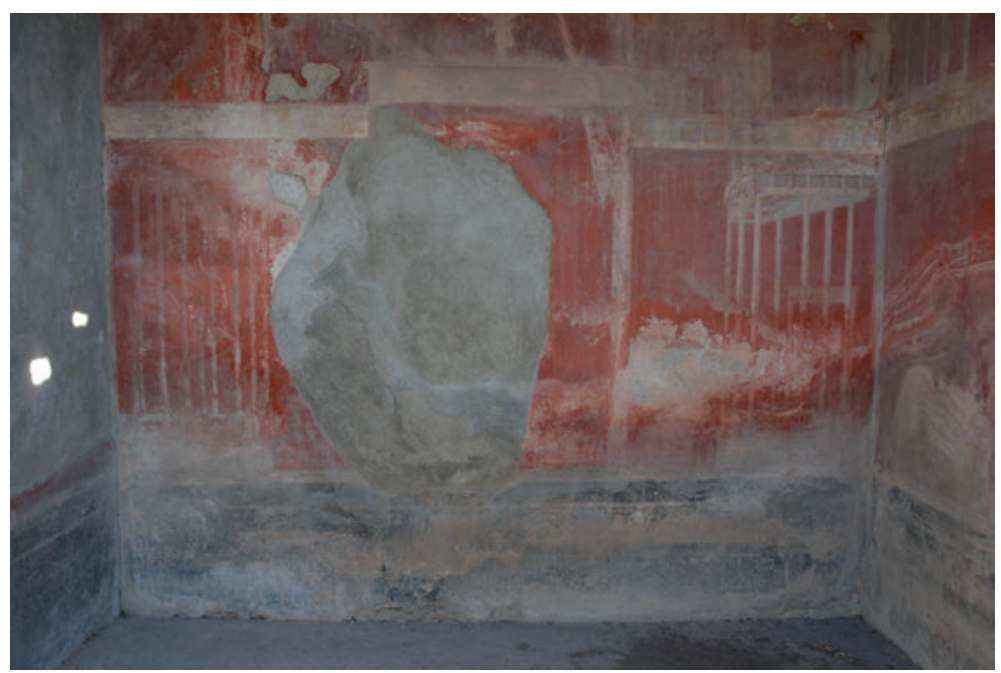

Abb. 327: Casa del Bell'Impluvio (I 9,1), Cubiculum (11), monochrom rot.

dritten Stils bei Cubiculum (11) der Casa del Bell'Impluvio (I 9,1; Abb. 327) ${ }^{180}$. Gerade monochrome Räume wirken durch die Filigranität der Architekturgestänge, sodass in einigen Fällen auf ein prominentes Mittelbild zugunsten von ,leichteren' Vignetten verzichtet wird (Abb. 326. 327). Entscheidet man sich für ein figürliches Mittelbild, so hebt sich dieses jedoch besonders prominent vom monochromen Hintergrund ab (Abb. 372).

\section{Ausdifferenzierung verschiedener Modi von Bildlichkeit}

Für den zweiten Stil konnte gezeigt werden, wie mit der bildhaft-perspektivischen Inszenierung von Architektur ein Interesse an Bildphänomenen einherging. Dieser innere Zusammenhang löste sich mit dem Übergang zur zweiten Hälfte des 1.Jhs.v. Chr. zusehends auf, als die Wand nicht mehr als Bild-Ort, sondern als Bild-Träger begriffen wurde. Das Interesse richtete sich nun verstärkt auf die Darstellung verschiedener Bildmedien, insbesondere von Tafelbildern. Der Repräsentation von Bildrahmungen kam eine ganz neue Bedeutung zu. Sie markieren die Differenz von (fiktiv-gemaltem) Bild und (fiktiv-gemalter) Umgebung, gehören damit aber zugleich beiden (fiktiven) Realitäten an. Als es im dritten Stil zu einer immer weiteren Ausdifferenzierung von Bildmodi kam, ging damit ein Experimentieren mit verschiedenen Rahmenoptionen und Präsentationsformen einher. Die Platzierung von großformatigen, gerahmten Bildern (,Tafelbildern') im Wandzentrum, auf Oberkörperhöhe eines stehenden Betrachters, machte die Räume zu regelrechten Pinakotheken ${ }^{181}$. Andere Bildmodi wie die Darstellung von Pinakes, Vignetten und ungerahmten Einzelmotiven unterliefen die Vorstellung von der Wand als Bild-Träger jedoch wieder. Betrachten wir die einzelnen Bildformen dazu näher.

Großformatige Tafelbilder, die das Wandzentrum besetzen und von Architekturgliedern, meist einer Ädikula, gerahmt werden, sind bereits im ausgehenden zweiten Stil entwickelt worden. Mit dem dritten Stil nehmen sich die verschiedenen ,Rahmungen' des Bildfeldes und deren Verhältnis zur Rahmenarchitektur ausgesprochen vielfältig aus. In Cubiculum (23) der Casa del Citarista

180 PPM I (1990) 919-941 s. v. I 9,1, Casa del Bell’Impluvio (V. Sampaolo) 935 Abb. 27-28.

181 van Buren 1938, 76-81; Schefold 1952, 32-34; 1972, 50-52 (allerdings dort mit der Frage nach griechischen Originalen); Peters 1963, 110-117; Leach 1988, 373f.; Clarke 1991, 64f.; Ling 1991, 112-128; Bergmann 1995 allerdings auch mit dem Hinweis auf einen signifikanten Unterschied: Die Wandmalereien waren gerade nicht mehr beweglich und austauschbar. 
Abb. 328: Casa del Citarista (I 4, 5.6.25.28), Cubiculum (23), Ostwand.

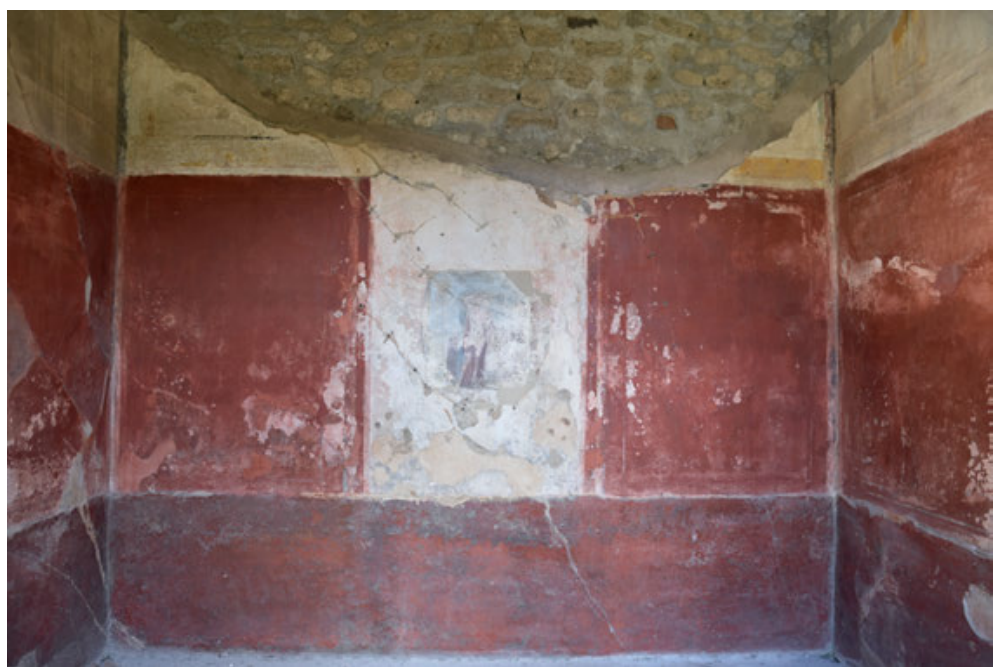

(I 4,5.6.25.28; Plan 5) tritt die Architekturgliederung ganz zurück, sodass die Wirkung der Mittelzone durch den Farbwechsel von zentralem, weißgrundigem Mittelfeld und roten Seitenfeldern bestimmt wird (Abb. 328) ${ }^{182}$. Das Mittelfeld füllt die Scheinarchitektur vollständig aus und bildet den Hintergrund für ein kleinformatiges, annähernd quadratisches Bildfeld, das nochmals eine eigene dünne Rahmenlinie besitzt. Die Ädikula rahmt hier folglich eine opake weiße Fläche, deren materieller Status indefinit bleibt. Sie wird zum Passepartout für das Bildfeld.

In Triclinium (b) der Casa di Sacerdos Amandus (I 7,7; Abb. 350) fasst die Ädikula ein deutlich größeres Bildfeld ein, wodurch zwischen Ädikulasäulen und Bildfeld ein schwarzer und ein roter Streifen als Rahmung verbleiben. Darüber hinaus besitzt es eine ,echte dünne Rahmenlinie. Gerade bei großen Bildern kann das Passepartout folglich auf Rahmenstreifen reduziert werden.

Im Triclinium (11) der Casa del Frutteto (I 9,5; Plan 7) ${ }^{183}$ erzeugt die hohe Ädikula ein besonders gelängtes Innenfeld. Das Bild füllt die Fläche zwar weitgehend in der Breite, nicht aber in der Höhe aus, da sich sonst ein äußerst ungünstiger Bildzuschnitt ergeben hätte. Dies führt dazu, dass das Ädikula-Innenfeld auf allen vier Seiten von einem gleich breiten, hellblauen Streifen gerahmt ist (Abb. 329). Der innere, schwarze ,Passepartout-Rahmen` fällt jedoch im unteren Bereich deutlich breiter aus. Den Übergang zum eigentlichen blaugrundigen Bildfeld markiert eine dünne, weiße Rahmenlinie.

Gerahmte ,Tafelbilder finden sich zwar meist, aber nicht nur im Wandzentrum, sondern von kleinerem Format auch in untergeordneten Wandzonen. So wird im Tablinum (h) der Casa di Marcus Lucretius Fronto ,vor` der Ädikula-Architektur der Oberzone, aber ohne räumlich-logischen Bezug zu dieser, ein von einer breiten, gräulichen Linie gerahmtes Bildfeld mit der Darstellung eines ,Stilllebens‘ platziert (Abb. 298).

Je kleiner die ,Bildtafel` jedoch ausfällt, desto stärker wird der Status als ,Tafelbild‘ infrage gestellt. Gerade in untergeordneten Wandzonen können Rahmungen kleinformatige Einzelmotive oder Motivgruppen aufwerten und ihnen einen bildhaften Charakter verleihen. So ist der zentrale Predellaabschnitt im Tablinum (h) der Casa di Marcus Lucretius Fronto durch geometrische Linien strukturiert, die sich als Rahmengerüst für gelbgrundige Bildfelder auffassen lassen. Die mit einer eigenen, dünnen Rahmenlinie versehenen Bildtafeln zeigen einen Vogel, mithin ein sehr, reduziertes' Sujet (Abb. 291). Schon in Bezug auf ,Tafelbilder` zeigt sich somit, dass die ,Bildhaftigkeit‘ erst durch das Zusammenspiel von Rahmung, Bildgröße, Bildort und Bildgegenstand erzeugt wird. Für andere Bildformen gilt dies nicht weniger.

182 PPM I (1990) 117-177 s. v. I 4,5.25, Casa del Citarista (M. de Vos) 158 Abb. 68.

183 PPM II (1990) 1-137 s. v. I 9,5, Casa dei Cubicoli floreali o del Frutteto (M. de Vos) 52f. Abb. 75. 


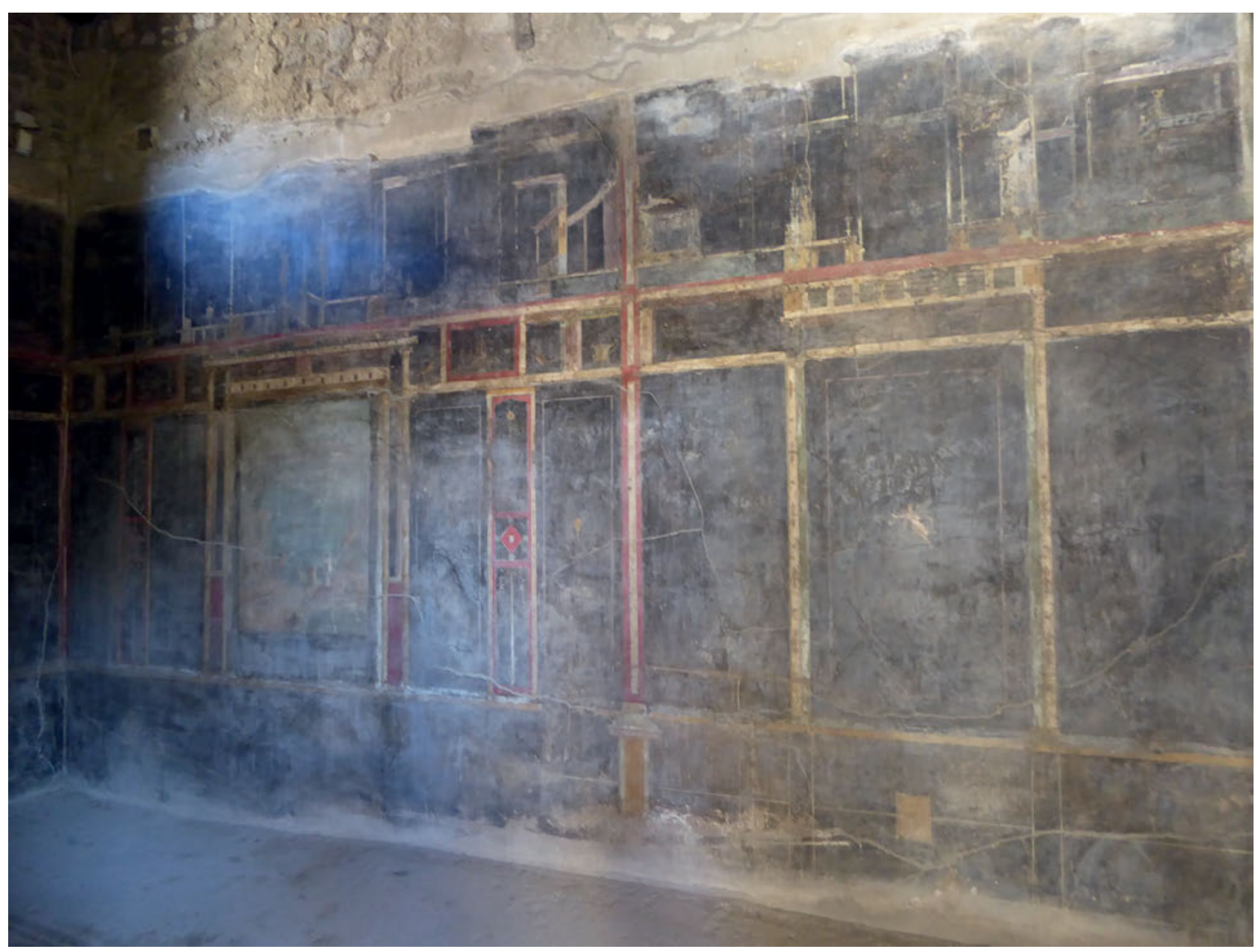

Im Falle der Pinakes handelt es sich um kleine, massiv gerahmte Bildtafeln, deren Präsentationsform ihren Objektcharakter unterstreicht. Im Tablinum der Casa di Marcus Lucretius Fronto werden Kandelaber zum Träger von Pinakes. Ein breiter Streifen simuliert einen Holzrahmen (Abb. 288). In Cubiculum (8) der Casa del Frutteto (I 9,5; Plan 7) werden die Pinakes, die einen äußeren braunen Abb. 329: Casa del Frutteto $(19,5)$, Triclinium (11), Ostwand. und einen inneren weißen Rahmen besitzen, von kleinen weißen Marmorstützen getragen (Abb. 330) ${ }^{184}$. Ihre Materialität fällt dadurch ambivalent aus, sie changieren zwischen marmornem Reliefpinax und Tafelpinax. Die ,Stütze‘ der Pinakes kann wie im Fall von Triclinium (e) der Casa di C. Sulpicius Rufus (IX 9,c) auch labilisiert werden. Hier stehen die Pinakes der Oberzone auf filigranen Ranken bzw. werden von Sirenen getragen ${ }^{185}$. In all diesen Fällen werden die Medialität und damit der Objektcharakter der Pinakes (als pictura) besonders betont, während die Bildkomplexität aufgrund ihrer geringen Größe zurückgenommen ist ${ }^{186}$. 
Abb. 330: Casa del Frutteto $(19,5)$, Cubiculum (8), Detail Pinax.

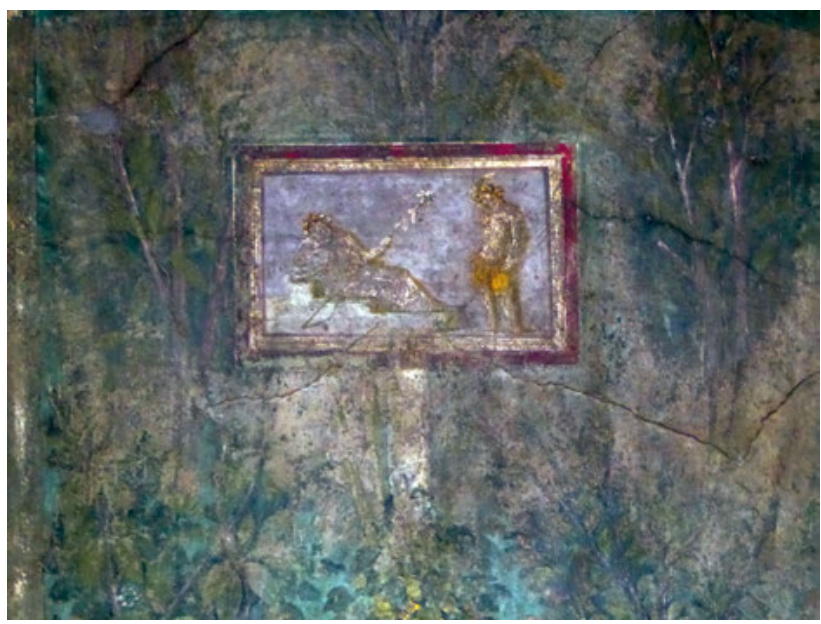

Rahmungen treten nicht nur bei Tafelbildern und Pinakes, sondern bei ganz unterschiedlichen Elementen auf. Dies gilt zunächst für gerahmte Architekturen. Auf der Tablinumswand der Casa di Marcus Lucretius Fronto haben Pilaster und Architekturausblick, welche die Ädikula einfassen, einen eigenen Blüten-Rahmen erhalten. Der Architekturdurchblick ist zusätzlich durch eine dünne weiße Rahmenlinie eingefasst (Abb. 288). Architektur ist einerseits als Rahmung, andererseits als gerahmtes ,Bild' inszeniert, wobei als Rahmung wiederum naturhafte Elemente dienen. Dadurch wird es möglich, die Wand in vielfacher Hinsicht mit Ambiguitäten aufzuladen.

Nicht nur Architektur, sondern auch großformatige Kandelaber, welche die Wand schmücken und gliedern, können mit Rahmen versehen werden. Im Fall von Triclinium (e) der Casa di C. Sulpicius Rufus (IX 9,c) wird der Kandelaber mit seinem Teller von einer T-förmigen Rahmenlinie eingefasst, sodass das ,Bildfeld“ auch zwei Vögel einschließt, die auf dem Kandelaberteller Platz genommen haben ${ }^{187}$. Das Kandelaberfeld hebt sich von der Wand durch seine andersartige Farbe besonders ab. Ähnliches gilt für die von Thyrsoi eingefassten Kandelaber, die auf Ost- und Westwand von Cubiculum (g) der Casa di Marcus Lucretius Fronto die Mittelzone in Felder gliedern, jedoch bis in die Oberzone hineinragen (Abb. 308-309).

Während wir bisher decorative Elemente betrachtet haben, die mit einer Rahmenlinie versehen ,bildhaft' präsentiert werden, wird in anderen Fällen auf solche Rahmenlinien verzichtet. Dies muss ihrer Wahrnehmung als ,Bild‘ jedoch keinen Abbruch tun.

Besonders vielfältige Formen der Inszenierung sind für sog. Vignetten - rahmenlos präsentierte Bildelemente - möglich. Im monochrom weißen Cubiculum (II) der Casa di C. Iulius Polybius (IX 13,1-3) wird das zentrale Feld der Mittelzone durch eine prominente Ädikula-Rahmung eingefasst. Auf dem weißen Ädikula-Innenfeld erscheint eine große Vignette mit der Darstellung einer sitzenden Frau mit Dienerin (Abb. 331) ${ }^{188}$. Die Ädikulainnenfläche wird als geschlossene Wandfläche, aber auch als Bildgrund verständlich. Durch die, grenzenlose‘ Präsentation des Sujets bleibt sein Verhältnis zum umgebenden ,Raum‘ unbestimmt. Im monochrom schwarzen Cubiculum (15) von Boscotrecase erhalten die von äußerst filigranen Architekturgestängen gerahmten, kleinformatigen Landschaftsvignetten einen regelrecht schwebenden Charakter (Abb. 371), obwohl sie auch hier als Mittelbilder in Anspruch genommen werden.

187 PPM X (2003) 1-62 s. v. IX 9,c, Casa di C. Suplicius Rufus (V. Sampaolo) 11f. Abb. 15. 16. 188 PPM X (2003) 183-356 s. v. IX 13,1-3, Casa di Polibio (I. Bragantini) 298f. Abb. 180. 


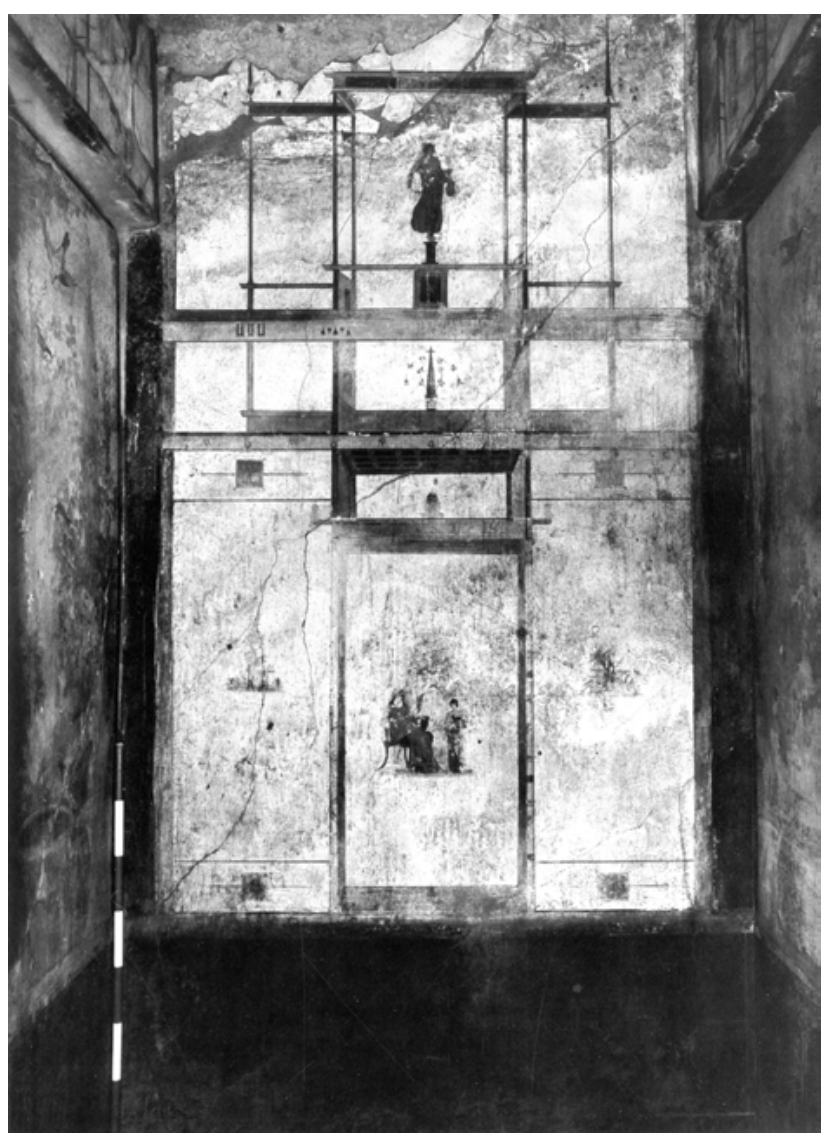

Abb. 331: Casa di C. Iulius Polybius (IX 13,1-3), Cubiculum (II).

Häufiger noch dienen Vignetten als Decor von rahmenden Seitenpaneelen, wo sie die Ambiguität der Wandlogik in besonderer Weise befördern. Vor dem farbigen Hintergrund der Paneele kommen oftmals isolierte, regelrecht ,schwebende‘ Einzelfiguren zur Darstellung. Man denke an die geflügelten Frauenfiguren, die in Triclinium (EE) der Casa di C. Iulius Polybius (IX 13,1-3) 189 $^{180}$ af den Paneelen zu Seiten der Mythenbilder erscheinen, oder an das winzige Cubiculum (c) der Casa del Sacerdos Amandus $(\mathrm{I} 7,7)^{190}$, in dem jeweils auf den Seitenfeldern vor gelbem Grund ein Eros und eine geflügelte Männerfigur dargestellt sind (Abb. 332). Sie stehen in einer logischen Spannung zu ihrem Hintergrund, heben sich von diesem regelrecht ab. Gerade die geflügelten Gestalten verleihen den Wandbildern Leichtigkeit; die Schwerkraft des architektonisch gegliederten Wandsystems wird aufgehoben ${ }^{191}$. Daneben können aber auch ,schwerere‘ Sujets als rahmende Vignetten eingesetzt werden. Im Cubiculum (II) der Casa di C. Iulius Polybius sind es Landschaftsvignetten, die die zentrale, größere Vignette einfassen (Abb. 331). Durch die Auslassung des Rahmens, die geringe Größe und die symmetrisch aufeinander bezogene Präsentation sind diese Vignetten ,ornamentalisiert'.

Rahmenlos präsentierte Einzelmotive können darüber hinaus in allen Wandzonen auftreten, etwa innerhalb von ,Ornamentstreifen' wie der Predella oder am Übergang zwischen Mittel- und Oberzone. Ihre Größe ist dann noch einmal erheblich reduziert, in ihrer ikonographischen Dichte sind sie aber nicht festgelegt. Es kann sich um ein Einzelobjekt, etwa ein Gefäß oder Musikinstru-

189 PPM X (2003) 183-356 s. v. IX 13,1-3, Casa di Polibio (I. Bragantini) 252 Abb. 105.

190 PPM I (1990) 586-618 s. v. I 7,7, Casa del Sacerdos Amandus (V. Sampaolo) 607 Abb. 28; selbiges gilt beispielsweise für das benachbarte Triclinium (b).

191 Zum Aspekt der Schwerelosigkeit schwebender Figuren in der Wandmalerei, s. Augris 2017. 
Abb. 332: Casa del Sacerdos Amandus (I 7,7), Cubiculum (c).

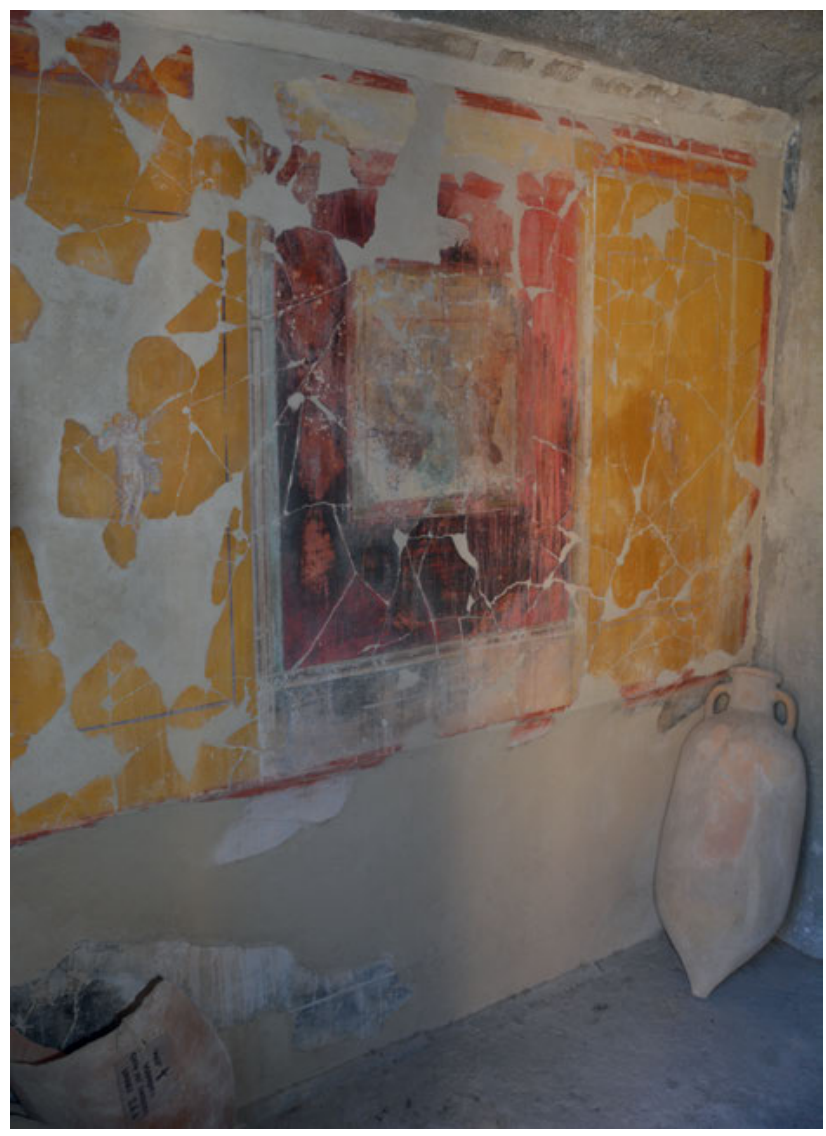

ment handeln, aber auch um komplexere Szenen wie ein Wagenrennen. Einen reichen Fundus an solch rahmenlos präsentierten ,Bild'-Elementen besitzt das Tablinum (h) der Casa di Marcus Lucretius Fronto (Abb. 288). Erst eine intensivere Betrachtung der Wand erfasst auch diese untergeordneten, auf die Rahmenarchitektur bezogenen Elemente. Sie tragen in hohem Maße zum unterhaltenden Charakter der Wände bei. Damit treten sie aber in Konkurrenz zu den prominenten Bildfeldern im Wandzentrum, buhlen mit ihnen um die Aufmerksamkeit des Betrachters.

Nicht zuletzt findet sich eine solch ,rahmenlose' Präsentation von Gegenständlichem auch in Sockelzonen. Vor schwarzem Hintergrund können hier stark stilisierte Pflanzen ,aus dem Boden` herauswachsen ${ }^{192}$. Durch die Auslassung einer Rahmung wird eine tatsächliche Begrünung des Raumes simuliert. Oberhalb des Sockels stellt die Predellazone den Übergang zu einer geschlossenen, nur durch Architektur strukturierten Wand dar - es kommt folglich zu einem logischen Bruch in der Wandauffassung. Besonders beliebt ist ein solcher Pflanzensockel in Peristylen, wo er thematisch auf den Garten Bezug nimmt (Abb. 343) ${ }^{193}$.

192 So etwa die Casa di Epidius Sabinus (IX 1,22.29), s. PPM VIII (1998) 956-1044 s. v. IX 1,22.29, Casa di M. Epidius Sabinus (V. Sampaolo) Abb. 128. 130. 147; vgl. Strocka 1987, 31. Es wären beliebig viele Beispiele zu nennen, etwa Hof (2) im ersten Untergeschoss der Casa di Ma. Castricius (VII 16 [Ins. Occ.], 17), s. PPM VII (1997) 887-946 s. v. VII 16 [Ins. Occ.],17, Casa di Ma. Castricius (I. Bragantini) 891 Abb. 5; weiterhin Triclinium (e) der Casa di T. Dentatius Panthera (IX 2,16), s. PPM IX (1999) 1-40 s. v. IX 2,16, Casa di T. Dentatius Panthera (V. Sampaolo) 20-22 Abb. 34.

193 So in Peristyl (9) der Casa di Paquius Proculus/Cuspius Pansa (I 7,1), s. PPM I (1990) 483-552 s. v. I 7,1, Casa di Paquius Proculus o di Cuspius Pansa (F. P. Badoni - M. de Vos) 526 Abb. 71; weiterhin in Säulenhof (2) der Casa Ma. Castricius (VII 16 [Ins. Occ.],17), s. PPM VII (1997) 887-946 s. v. VII 16 [Ins. Occ.],17, Casa di Ma. Castricius (I. Bragantini) 890-892, bes. Abb. 5 . 


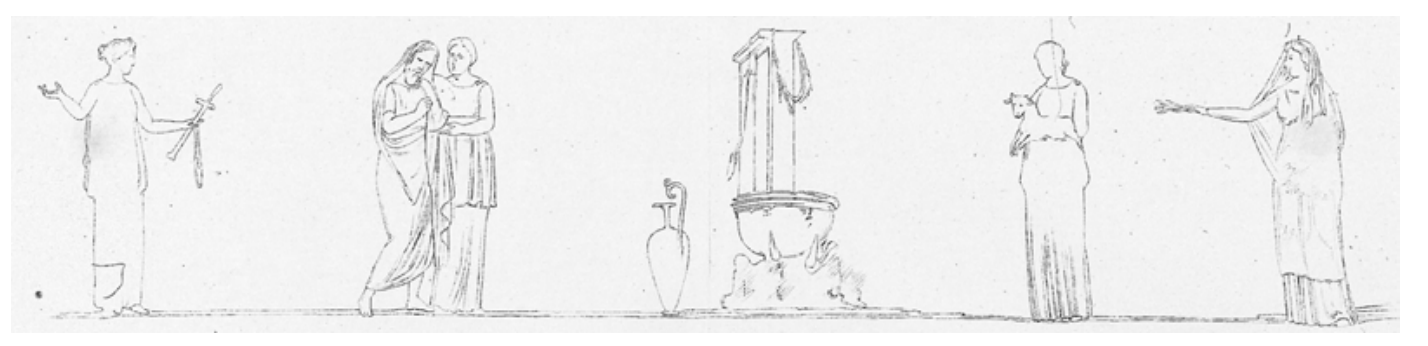

Abb. 333: Casa di T. Dentatius Panthera (IX 2,16), Cubiculum (b), Frieszone der Nordwand, Zeichnung bei Helbig: Medea und die Peliaden.
Nicht zuletzt werden die Wände wie schon im zweiten Stil durch die rahmenlose Präsentation von Objekten bereichert. Dabei kann es sich um Kandelaber, Wasserbecken, Gefäße, Statuen und Hermen, aber auch um Pinakes handeln, die auf Stützen als Bildobjekte präsentiert werden. In den Oberzonen fungieren Bildobjekte noch unmittelbarer als ,Ausstattung der Architektur - dies gilt für Oscilla und Masken, für Statuen, aber auch für Akroterfiguren (Abb. 331). Vögel können als belebendes Element hinzutreten. Dabei sind unterschiedliche Größenskalen möglich. Bildobjekte können wie die Kandelaber im Tablinum der Casa di Marcus Lucretius Fronto regelrecht monumentale Maße annehmen, die Wand dominieren und sich in den Vordergrund drängen, sich aber auch als Ornamentum der Wand ganz der Struktur der Wand unterordnen.

Einen nochmals anderen Bildmodus repräsentieren Bildfriese, die noch immer dort platziert werden, wo an einer realen Architektur eine Frieszone erwartbar wäre. Mit der Entdinglichung von Architektur verliert sich aber auch der architektonische Charakter der Friese, sodass sie häufig wie im Atrium der Casa di Marcus Lucretius Fronto auf einen Ornamentstreifen reduziert sind (Abb. 281). Im besonders bilderreichen Cubiculum (b) der Casa di T. Dentatius Panthera (IX 2,16) ${ }^{194}$ schließt sich an die Mittelzone jedoch ein echter Bildfries mit mythologischen Szenen an. Auf der nördlichen Eingangswand links des Eingangs (im Westen) waren nach Auskunft von Zeichnungen Medea und die Peliaden dargestellt (Abb. 333). Das andersartige Format brachte eine spezifische Erzählweise - die Auflösung eines Themas in ,ornamenthafte‘ Sequenzen - mit sich.

Die Diskussion der verschiedenen Bildmodi vermochte aufzuzeigen, dass Bildlichkeit und Ornamentalität auf den Wänden relational und in Beziehung zueinander entfaltet werden. Die Größe eines dargestellten Elements, sein Ort im Wandsystem, seine Rahmung oder Nicht-Rahmung und die semantische Dichte erzeugen erst im Zusammenspiel eine stärker bildhafte oder ornamenthafte Wirkung.

Besonders signifikant ist daher der Umstand, dass die verschiedenen Präsentationsformen bis zu einem gewissen Grad mit Bildthemen korrelieren. Bei Mythenbildern handelt es sich meist um Tafelbilder, seltener um kleinformatige Tafeln bzw. Pinakes ${ }^{195}$. Sie sind üblicherweise gerahmt und im Wandzentrum platziert. Landschafts- und Genreszenen sowie ,Stillleben' können als Tafelbild, als Pinax ${ }^{196}$, aber auch als Vignette vorgeführt werden. Einzelfiguren - geflügelte Wesen etwa ebenso wie Tiere - treten besonders häufig als Vignette bzw. rahmenloses ,Bild'-Element auf und können als solche - jeweils in unterschiedlichen Größen - in allen Bereichen der Wand erscheinen.

194 PPM IX (1999) 1-40 s. v. IX 2,16, Casa di T. Dentatius Panthera (V. Sampaolo) 8-10 Abb. 10-16.

195 Im Fall von Triclinium (t1) der Casa di M. Epidius Sabinus (IX 1,22.29; Plan 21) finden sich im Vorraum kleine Bildtafeln mit der Darstellung von Ariadne und Bacchus (Abb. 351). ,Mythos“ ist hier freilich auf eine ideale Paarkonstellation reduziert.

196 Croisille 2010, bes. 41 zeichnet eine Geschichte des Landschaftsbildes nach. In der römischen Wandmalerei, die im zweiten Stil zunächst in untergeordneten Decor-Zonen auftritt, im späten zweiten und beginnenden dritten Stil dann als zentrales Bildpaneel (mit und ohne mythologische Elemente) wie auch als Landschaftsvignette. Das Auftreten von Landschaftspinakes setzt er mit der Casa di Marcus Lucretius Fronto in die Zeit um 40 n. Chr.; ,Stillleben“ indes identifiziert Croisille 1965, 9 bereits im zweiten Stil als Sujet von Pinakes, im dritten Stil würden sie selten gerahmt auftreten. Gerade die Casa di Marcus Lucretius Fronto zeugt aber auch von dieser Praxis. 
Allerdings können gerade solche Motive durch eine Rahmung auch als kleine Bildtafeln präsentiert werden.

Umgekehrt lässt sich nach dem Zusammenhang von (imaginierten) Medien und Bildthemen fragen. Tafelbilder werden besonders gerne genutzt für die Darstellung von Mythenbildern, von (mythisch aufgeladenen wie nicht-mythischen) Landschafts- und Architekturbildern ${ }^{197}$, von Gartenbildern und ,Stillleben', von Akteuren, die sich mit einer kulturellen Praxis befassen (Malerei, Musik, Theater) ${ }^{198}$, sowie von (nicht-mythischen) erotischen Szenen ${ }^{199}$. Gerahmte Pinakes zeigen üblicherweise keine komplexen Mythenbilder, sondern ,leichte' Sujets: mythische Einzelfiguren (etwa Satyrn; Bacchus; Amor, der gegen einen Panther kämpft ${ }^{200}$ ), Paarkonstellationen (etwa Ariadne und Bacchus), Landschaften, ,Stillleben', Tiere, Masken, bisweilen auch ägyptisierende Motive. In Vignettenform erscheinen Landschaftssujets, ,Stillleben', Tierbilder und dezidiert ,leichte' Motive wie fliegende Gestalten. In vignettenhaft-ungerahmter Form können schließlich geradezu alle Einzelmotive auftreten.

Die grundsätzliche Beobachtung, dass Bildlichkeit und Ornamentalität durch jeweils spezifische Präsentationsformen zueinander in Beziehung gesetzt werden, gewinnt durch solche Korrelate an zusätzlicher Signifikanz. Insbesondere Mythenbilder werden stärker bildhaft vorgestellt, während Einzelmotive eher als ,Ornament` konzipiert sind. Allerdings zeigt sich auch eine hohe Durchlässigkeit zwischen Themen und ihren Präsentationsformen.

\subsection{Wand-Decor und Raumtypen}

Die schon im ersten und zweiten Stil etablierte Vorstellung, dass spezifische Decor-Formen für bestimmte räumliche Situationen als angemessen gelten, wurde im dritten Stil mit den neuen Möglichkeiten der Zeit weiter ausdifferenziert. Ein kategorialer Unterschied in der Ausstattung bestand auch weiterhin zwischen Räumen der Bewegung (Fauces, Atrien, Peristyle) und Aufenthaltsräumen, da für diese Raumgruppen unterschiedliche Betrachtungsmodi vorauszusetzen sind.

\section{Fauces, Atrien, Peristyle}

Für Durchgangsräume - Fauces, Atrien und Peristyle - bedeutete dies, dass man üblicherweise eine parataktische Gliederung der Wand wählte. Auf die in Innenräumen besonders beliebte Betonung der Wandmitte hat man verzichtet. Mau begründet dies formal: „Für Atrien und Peristylien sind diese um den Mittelbau symmetrisch disponirten Decorationen weniger geeignet. Theils

197 Als Mittelbild etwa in dem ganz auf den Peristylgarten ausgerichteten Oecus (q) der Casa del Gallo (VIII 5,2.5), s. PPM VIII (1998) 547-566 s. v. VIII 5,2.5, Casa del Gallo (V. Sampaolo - I. Bragantini) 558 Abb. 24; Triclinium (t1) Casa di M. Epidius Sabinus (IX 1,22.29), s. PPM VIII (1998) 956-1044 s. v. IX 1,22.29, Casa di M. Epidius Sabinus (V. Sampaolo) 1029 Abb. 129; Leach 1988, 209f. unterscheidet sakralidyllische Landschaftsbilder mit einem zentralen Monument, Architekturlandschaften und Landschaften, die das Setting für eine mythologische Handlung abgeben; zu Landschaftsbildern weiterhin Peters 1990, 249-262; Croisille 2010.

198 Etwa die Darstellung einer Malerin mit zwei Assistentinnen in Cubiculum (3) der Casa dell'Imperatrice di Russia (VI 14,42), s. PPM V (1994) 409-425 s. v. VI 14,42, Casa dell’Imperatrice di Russia (I. Bragantini) 414 Abb. 9. In der Casa dei Ceii (I 6,15) sind gleich zwei Cubicula mit Musikszenen ausgestattet: Cubiculum (c) am Atrium und Gartencubiculum (f), s. PPM I (1990) 407-482 s. v. I 6,15, Casa dei Ceii (M. de Vos) 431 Abb. 36; Michel 1990, 76. 78; eine ganze Serie von Theaterdarstellungen aus dem Atrium der Casa dei Quadretti teatrali (I 6,11), s. PPM I (1990) 361-395 s. v. I 6,11, Casa dei Quadretti teatrali (M. de Vos) 371-373 Abb. 21. 22; 376 Abb. 26; 380 Abb. 33.

199 Dies gilt etwa für ein Symplegma-Mittelbild im Cubiculum (11) der Casa del Bell’Impluvio (I 9,1), s. PPM I (1990) 919-941 s. v. I 9,1, Casa del Bell'Impluvio (V. Sampaolo) 938 Abb. 31.

200 So in Cubiculum (l) der Casa di C. Sulpicius Rufus (IX 9,c), s. PPM X (2003) 1-62 s. v. IX 9,c, Casa di C. Suplicius Rufus (V. Sampaolo) 42f. Abb. 68. 70.57f. Abb. 92f. 


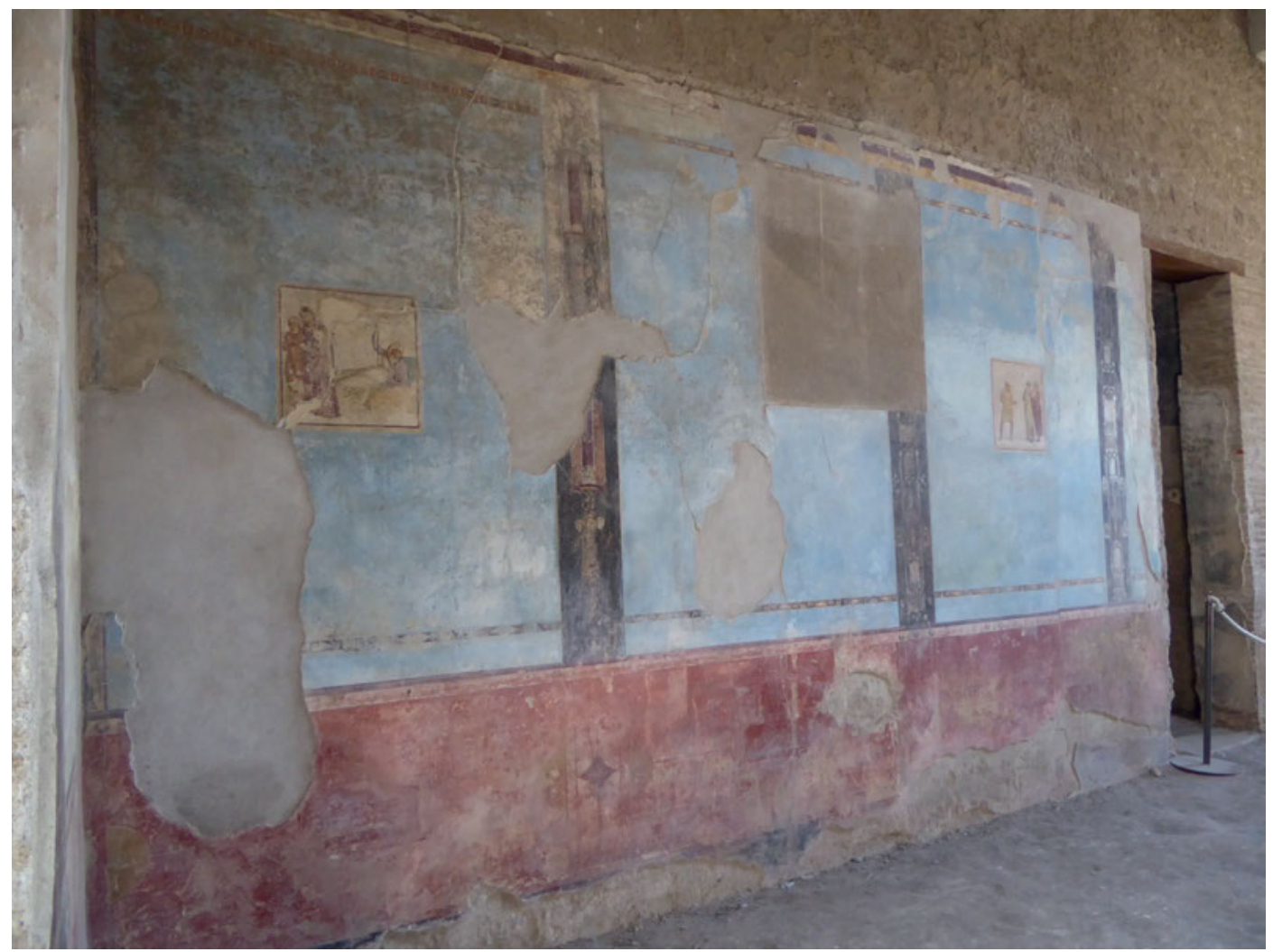

Abb. 334: Casa dei Quadretti teatrali (I 6,11), Atrium (b), Ostwand.

sind hier die Mauern durch die Eingänge der umliegenden Räume allzu sehr zerstückelt, theils sind sie zu lang für die Dreitheilung. Letzteres gilt namentlich für Peristylien, wo eigentlich nur die Querwände den Portiken (Haus der schwarzen Wand) eine für sie geeignete Fläche bieten." ${ }^{201}$ Die stärker repetitive Struktur leistete vor allem eine Rhythmisierung der Raumwahrnehmung ${ }^{202}$. Doch betrachten wir die Hofbereiche dazu etwas näher.

In Atrien wurden auch weiterhin Pilaster eingesetzt, um die ganz auf den Hof geöffneten Räume zu flankieren. Dies konnte wie in der Casa del Frutteto (I 9,5; Plan 7) ${ }^{203}$ oder der Casa del Chirurgo (VI 1,10) durch Stuckpilaster geschehen ${ }^{204}$. In der Casa di Marcus Lucretius Fronto fallen die Stuckpilaster, die das Tablinum rahmen, besonders aufwendig aus (Abb. 279).

Die Rückwände der Atrien wurden zuvorderst durch Türen gegliedert. Besaß ein Atrium geschlossene Wandflächen, so führten gemalte Schmuckstreifen eine vertikale Strukturierung ein. Im monochrom schwarzen Atrium (b) der Casa di Marcus Lucretius Fronto wird die Mittelzone der Nordwand durch gelbe Lisenen in Felder gegliedert (Abb. 281). Im Atrium (b) der Casa dei Quadretti teatrali (I 6,11) sind es schwarze Lisenen mit Binnen-Decor (Kandelaber- bzw. Pilasterdarstellungen), welche die hellblauen Paneele voneinander trennen (Abb. 334).

Die dadurch hergestellte, parataktische Ordnung der Wandfläche hat zur Folge, dass in Atrien und Peristylen in der Mittelzone auf eine Hierarchisierung von Bildelementen verzichtet wurde. Die Auswahl der Bilder reagierte darauf, indem jeweils gleich große und thematisch gleichartige Bilder nebeneinandergestellt wurden. Im Atrium (b) der Casa di Marcus Lucretius Fronto handelt es sich um Tiervignetten (Abb. 281), in der Casa dei Quadretti teatrali (I 6,11) werden in der Mittelzone von

201 Mau 1882, 344.

202 So bereits Corlàita Scargliarini 1974; Clarke 1991, 151; Allison 1992, 235 f.

203 PPM II (1990) 1-137 s. v. I 9,5, Casa dei Cubicoli floreali o del Frutteto (M. de Vos) 4-7 Abb. 4-7.

204 Anderson - Robinson 2018b, $97 \mathrm{f}$. 
Abb. 335: Casa dei Quadretti teatrali ( 6,11), Atrium (b), Ostwand, nördliches Paneel mit tragischer Szene.
Abb. 336: Casa dei Quadretti teatrali (I 6,11), Atrium (b), Ostwand, drittes Paneel von Norden mit Szene aus einer Komödie.
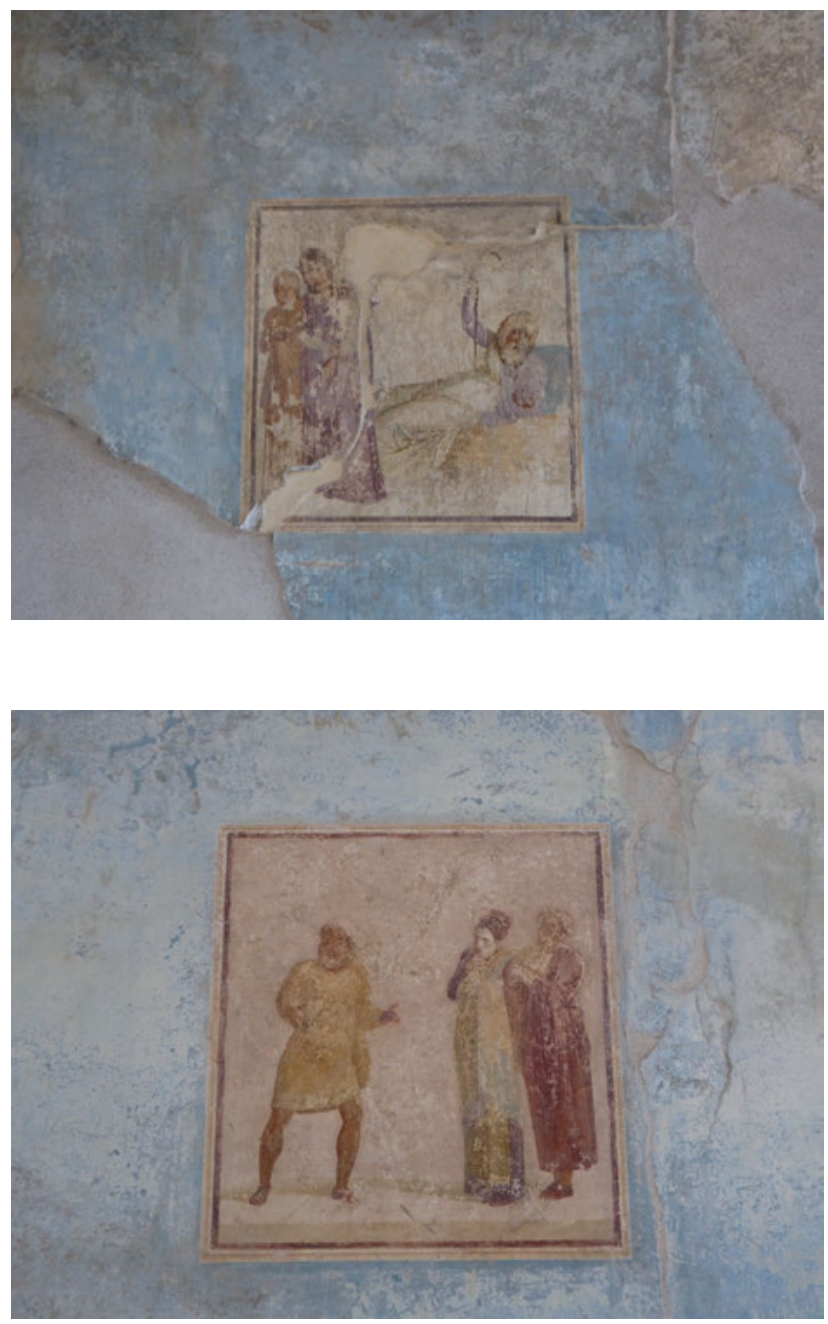

Atrium (b) auf hellblauem Paneelgrund kleine Theaterbilder präsentiert (Abb. 335-336) ${ }^{205}$. Der vorübergehende Betrachter, der ihnen beiläufig Aufmerksamkeit schenkt, wird nur eine parataktische Gliederung des Raumes durch gleich große Bildfelder von ähnlicher Figurenanordnung wahrgenommen haben. Lediglich ein Akteur, der seine Bewegung für eine genauere Betrachtung unterbrach, konnte erkannt haben, dass Szenen aus Tragödie und Komödie alternieren.

Für eine stärkere Hierarchisierung der Wandflächen hat man sich im Atrium (b) der Casa dei Ceii $\left(\right.$ I 6,15) entschieden ${ }^{206}$. Auf der Eingangsseite im Süden sowie auf der gegenüberliegenden Nordwand rhythmisieren jeweils drei Türdurchgänge die Wandfläche, die ,Restflächen` zu Seiten der Türdurchgänge nehmen Paneele mit ,Stillleben`-Vignetten ein (Abb. 337). Für die West- und Ostwand, die nicht von Raumöffnungen unterbrochen waren, wurde indes eine axialsymmetrisch organisierte und dadurch stärker hierarchisierte Felderordnung eingeführt (Abb. 338). Insbesondere die Farbordnung rhythmisiert die Wand - ein schwarzes Mittelfeld wird von roten Paneelen flankiert. Mit den verschiedenen Farben korrespondieren unterschiedliche Sujets. Eine Victoria auf dem schwarzen Mittelfeld wird auf den roten Seitenfeldern von zu ,Stillleben' arrangierten Säulchen und Gefäßen flankiert. Dabei fallen die Viktorien nur wenig größer als die ,Stillleben` aus,

205 PPM I (1990) 361-396 s. v. I 6,11, Casa dei Quadretti teatrali (M. de Vos) 371-381 Abb. 16-35; Zuweisung zum dritten Stil bei Barbet 2009, 112.

206 PPM I (1990) 407-481 s. v. I 6,15, Casa dei Ceii (M. de Vos) 426-428 Abb. 25-30; s. zum Atrium auch Michel 1990, 20-26. 


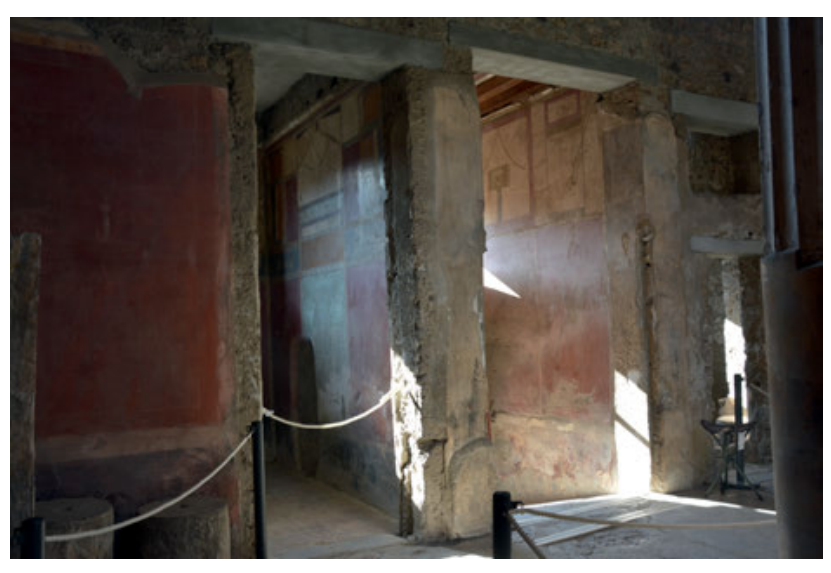

Abb. 337: Casa dei Ceii (I 6,15), Atrium (b) mit Fauces, Paneel mit Gefäßen.

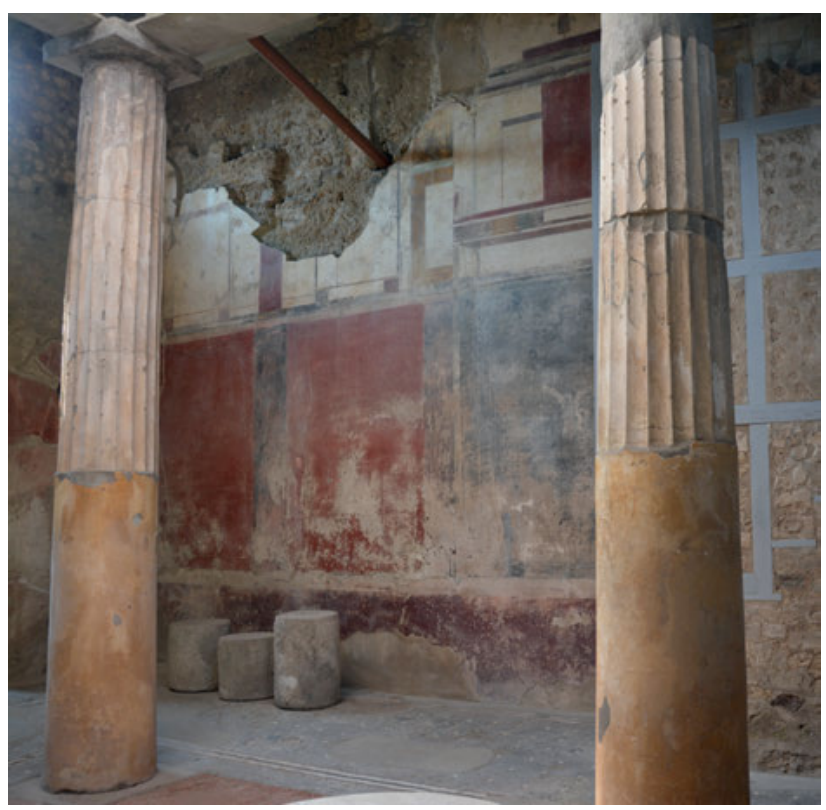

Abb. 338: Casa dei Ceii (I 6,15), Atrium (b), Ostwand.

wodurch eine parataktische Wahrnehmung der inhaltlich verschiedenen ,Bilder möglich wird. Axialität und Parataxe sind in diesem Arrangement miteinander verschränkt.

Einzelne Atrien weichen jedoch gänzlich von einer parataktischen Decor-Konzeption ab. Auf der nicht durch Räume unterbrochenen Südwand von Atrium (a) der Casa di Laocoonte $\left(\right.$ VI 14,28.33) ${ }^{207}$ hat man sich für ein dreiteiliges Wandschema mit zentraler Ädikula entschieden (Abb. 339). Diese umfasste ein großformatiges Mythenbild mit der Darstellung von Laokoon und seinen Söhnen im Kampf mit den Schlangen. Das Mittelbild ist durch seitlich darauf hinführende, perspektivische Architekturen, wie sie im späten dritten Stil beliebt sind, noch einmal besonders akzentuiert. Durch diesen Decor verändert sich der Charakter des Atriums: Es erhält eine Schauseite, wird zum Aufenthaltsraum ${ }^{208}$.

207 Peters 1963, 103; PPM V (1994) 341-362 s. v. VI 14,28.33, Casa di Laocoonte con annessi taberna e panificio (I. Bragantini) 351-353 Abb. 14-16.

208 Ein weiteres Beispiel wären die Mythenbilder in Atrium (B) der Casa degli Amorini dorati (VI 16,7.38; Plan 14), vgl. Lorenz 2008, 416f.; Lorenz 2008, 360 beobachtet zwar ebenfalls, dass Mythenbilder in Atrien kaum eine Rolle spielen und nimmt auf dieser Grundlage an, „dass Statusrepräsentation von Mann und Frau kein derartig zentrales Anliegen“ in diesem Bereich war. Auf die spezifischen Betrachterhaltungen im Atrium geht sie indes nicht ein. 
Abb. 339: Casa di Laocoonte (VI 14,28.33), Südwand von Atrium (a), Rekonstruktion (Fausto Niccolini).

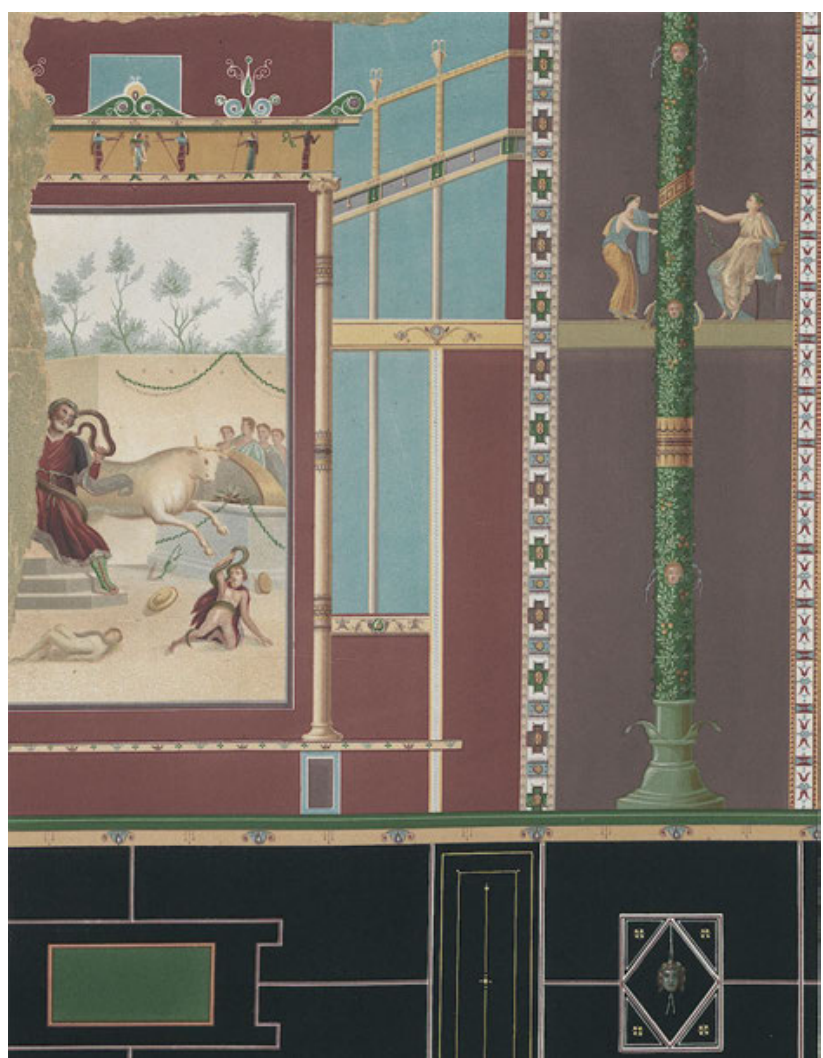

An den Rückwänden der Peristyle wurde die traditionelle Idee der parataktischen Raumordnung mit neuen Mitteln umgesetzt. Die Portikusrückwände wurden in Paneele gegliedert und mit semantisch schwachen Motiven besetzt. Auf den weißgrundigen Paneelen des dreiseitigen Peristyls (CC) der Casa di C. Iulius Polybius (IX 13,1-3) ${ }^{209}$ sind es Vignetten, die Landschaften und Gefäße zeigen (Abb. 340-341). Durch ihre geringe Größe ist ihre Bildwirkung derart stark zurückgenommen, dass sie als ,Ornament' den repetitiven Charakter der Portikusumgänge unterstreichen und eine beiläufige Wahrnehmung erlauben. In der Oberzone korrespondieren damit große querrechteckige und kleine hochrechteckige Felder. In den kleinen hochrechteckigen Feldern enden die Trennlinien der Mittelzone und tragen kleine Bildscheiben. Die querrechteckigen, weißgrundigen Felder sind von großformatigen Vignetten-Bildern mit Genreszenen und ,Stillleben' gefüllt - ein Pfeiler mit Satyr-Maske, Pedum und Bacchus-Maske, ein hockender Vogel zwischen Grashalmen, ein umgefallener Traubenkorb, dem sich ein Vogel im Anflug nähert, sowie Masken von Mänade und Pan (Abb. 342). Es sind somit keine dicht erzählenden Bilder, sondern ,leichte‘ Sujets, die über den Köpfen der Betrachter durch ihre parataktische Reihung eine regelrechte Frieszone bilden ${ }^{210}$. Aufgrund ihrer Größe sind sie aber nicht nur gut wahrnehmbar, sondern nehmen sich auch ,bildhafter' aus als die Vignetten der Mittelzone. 

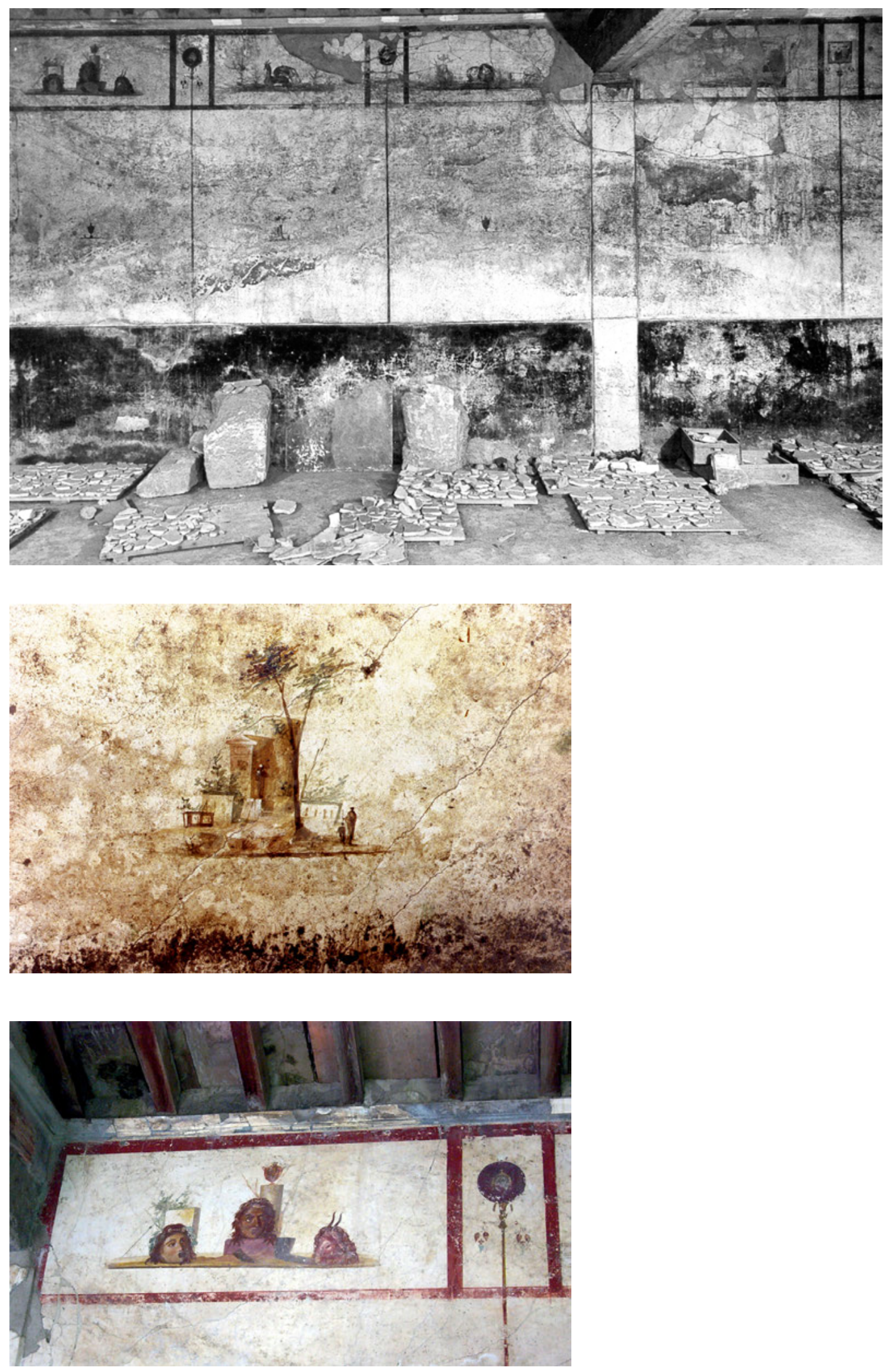

Abb. 340: Casa di C. Iulius Polybius (IX 13,1-3), Peristyl (CC), Ostwand der Ostportikus.
Abb. 341: Casa di C. Iulius Polybius (IX 13,1-3), Peristyl (CC), Ostwand der Ostportikus, Detail mit sakralidyllischer Landschaftsvignette.

Abb. 342: Casa di C. Iulius Polybius (IX 13,1-3), Peristyl (CC), Ostwand der Ostportikus, Detail aus der Oberzone, Stilleben. 


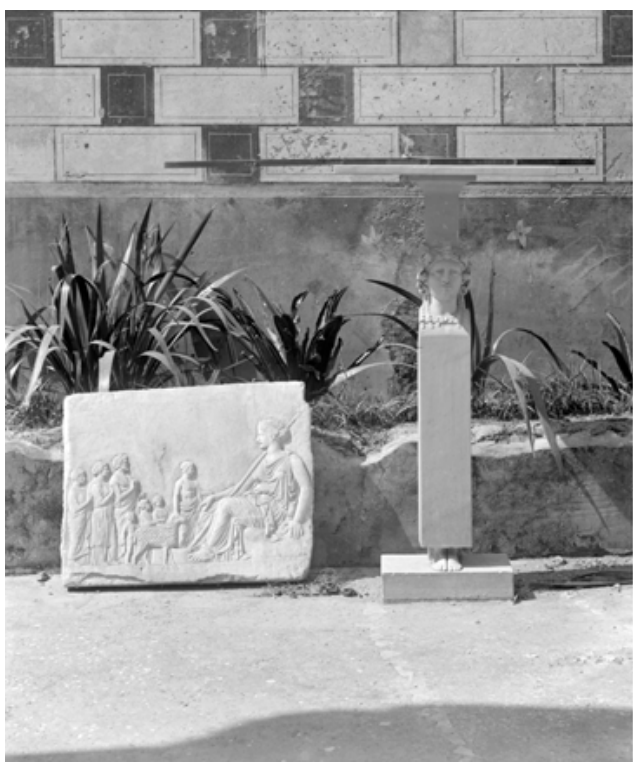

Abb. 343: Domus V 3,10, westliche Rückwand von Garten (l).

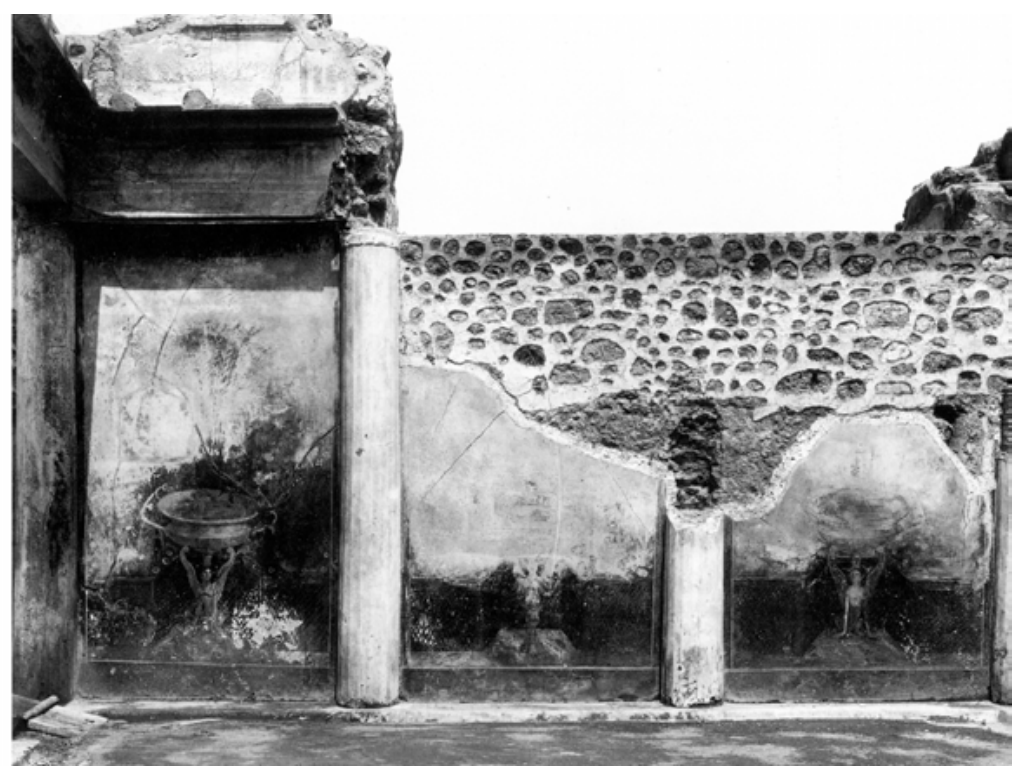

Abb. 344: Domus VII 6,28, Peristyl (4) nördliche Peristylrückwand.

In Rumpfperistylen wurde die geschlossene Rückwand als Schauwand inszeniert und einem axialsymmetrischen Gliederungsprinzip unterworfen. Auf der Gartenrückwand der Domus I 13,1 wird die Symmetriewirkung vor allem durch einen Farbwechsel der Paneele erreicht: Ein zentrales gelbes Paneel wird von seitlichen roten Paneelen eingefasst. Durch einen gleichartigen FelderDecor wird das axialsymmetrische Prinzip jedoch mit einer parataktischen Ordnung verschränkt: In allen drei Feldern werden vor Kandelabern aufgehängte Pinakes gezeigt ${ }^{211}$. In Domus V 3,10 hat man auf eine axialsymmetrische Organisation der Rückwand von Garten (l) ganz verzichtet. Über einem schwarzgrundigen Pflanzensockel schließt sich ein gemaltes polychromes Opus quadratum an (Abb. 343), das der Wand eine farblich differenzierte, horizontale Struktur verleiht ${ }^{212}$.

Besonders häufig wird die geschlossene Peristylrückwand aber genutzt, um die Bepflanzung des Gartens durch eine Gartenmalerei optisch zu erweitern ${ }^{213}$. Der reale Gartenraum und die fiktive Malerei traten in ein reizvolles Wechselspiel. An der axialsymmetrischen Gliederung der Wandflächen hielt man auch in diesem Fall fest. In Peristyl (4) der Domus VII 6,28 wird diese durch plastische Architekturelemente hergestellt ${ }^{214}$. Die beiden gemauerten und verstuckten Halbsäulen simulieren hier eine Fortsetzung der Portikus (Abb. 344) ${ }^{215}$. In ihren Interkolumnien sind große gerahmte Felder mit Gartendarstellungen platziert. Hier ist folglich gerade kein ,hinter einer Portikus sichtbar werdender Garten gemeint. Vielmehr wird durch die Rahmung auf die Bildhaftigkeit des Ausblicks verwiesen. In allen drei Bildfeldern blickt man auf ein vor einem Gartenzaun platziertes Wasserbecken, dahinter entwickelt sich ein Garten. Dabei werden die Motive von Interkolumnium zu Interkolumnium leicht variiert. Die Freiheit des realen Gartens und die visuelle Struktur des gemalten Gartens, verschiedene Pflanzen und Farben, treten in ein aufregendes Wechselspiel.

In der Mehrzahl der Fälle wird die Dreiteilung der Gartenrückwände jedoch malerisch hergestellt. Der auf zwei Seiten von einer Portikus umgebene Garten (h) der Casa annessa alla Casa

211 PPM II (1991) 842-859 s. v. I 13,1 (I. Bragantini) 859 Abb. 29.

212 PPM III (1991) 929-943 s. v. V 3,10 (I. Bragantini) 934f. Abb. 9-11; 936f. Abb. 14.

213 Jashemski 1979, 56; eine statische Auswertung bei De Carolis 1992, bes. 29f.; Zusammenstellung bei Salvadori 2017, $60 \mathrm{f}$.

214 PPM VII (1997) 182-196 s. v. VII 6,28 (V. Sampaolo) 186 Abb. 5; vgl. Salvadori 2017, 43f.

215 Jashemski 1979, 56. 


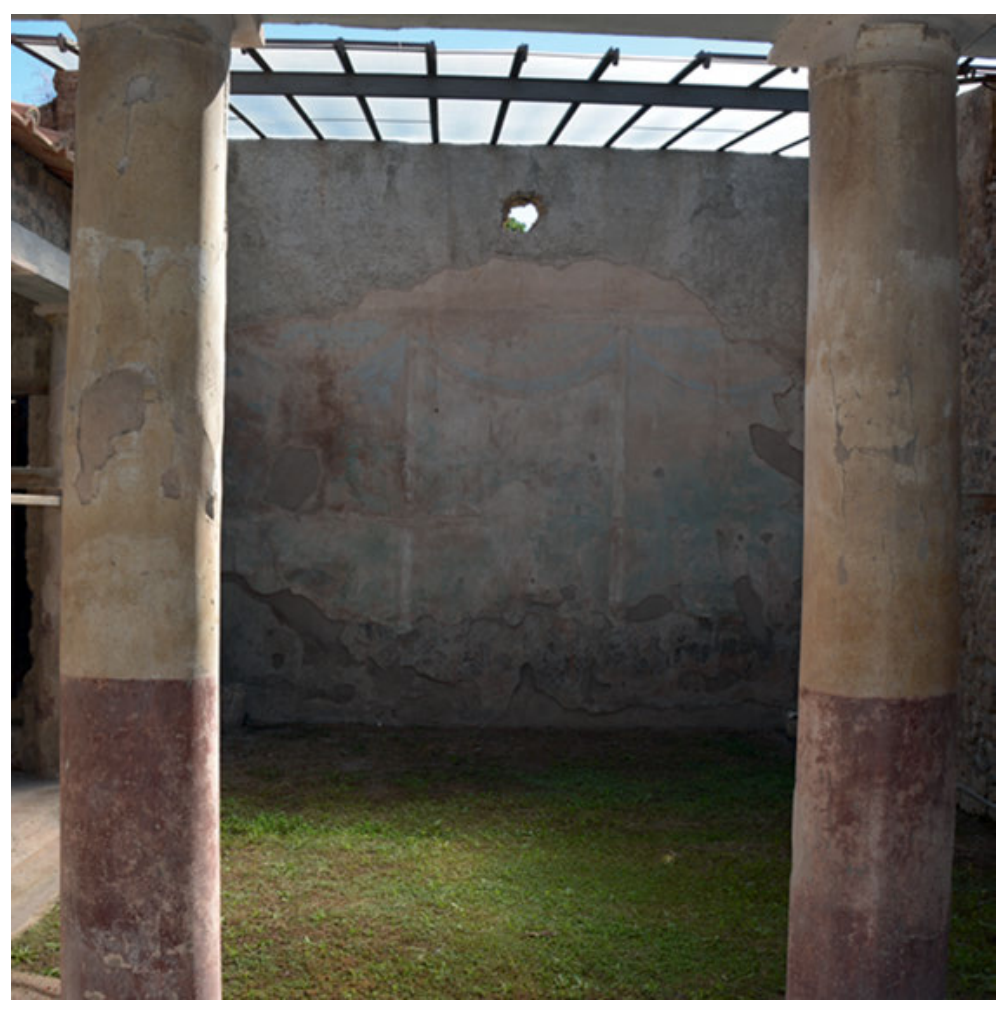

Abb. 345: Casa annessa alla Casa dell'Efebo $(17,19)$, Rückwand von Garten (h).

dell'Efebo (I 7,19) besitzt eine Rückwand, die vollständig von einer Gartendarstellung ausgefüllt wird (Abb. 345). Schlanke, gemalte, weiße Säulchen leisten eine Zergliederung des Gartenbildes in drei bildhaft inszenierte ,Ausblicke'. Im zentralen Interkolumnium ist vor einem niedrigen Gitter ein Kantharos auf einem Sockel aufgestellt, in den seitlichen Interkolumnien sind es Labra. Hinter dem Gitter entwickelt sich ein dicht wachsender Garten ${ }^{216}$. Der Betrachter blickt folglich durch die realen Säulen der Portikus in einen realen Garten, der auf seiner Rückwand durch eine gemalte Säulenstellung und ein gemaltes Gitter abgeschrankt wird. Hinter dieser fiktiven Schranke entwickelt sich in der Tiefe ein gemalter Garten. Der reale Garten fällt in diesem Haus relativ klein aus, sodass die imaginäre Erweiterung nicht nur ein attraktives Spiel mit Medien bereithält, sondern zu einem Substitut des Gartens avanciert ${ }^{217}$. Der kleine Garten wird zu einer regelrechten Oase inmitten des umbauten Areals.

In der Casa di Sallustio (VI 2,4; Abb. 117) stehen die realen Säulen - im unteren Teil mit rotem Verputz, im oberen Teil weiß - vor einem schmalen Gartenstreifen (24), in dem eine Pergola rekonstruiert wird (Abb. 346). Die gemalten Pilaster, welche die Gartenrückwand gliedern, sind demselben Farbschema wie die realen Säulen verpflichtet (Abb. 347) ${ }^{218}$. In ihren Interkolumnien stehen vor einem niedrigen Gitter Becken, die von Vögeln umgeben sind. Hinter dem Gitter wachsen regelhaft geordnete, gleichartige Pflanzen, darüber blickt man in den blauen Himmel. Hinter den Pilastern sind Girlanden aufgehängt, die in die Interkolumnien - vor dem Blau des Himmels herabhängen. Sie werden von Vögeln umflattert, die dem Gartenraum noch einmal Tiefe verleihen. Je nach Aufenthaltsort ergaben sich jeweils unterschiedliche Ausblicke auf dieses Garten-BildEnsemble. Vom Sommertriclinium (25) aus sah man linker Hand auf die gemalte Portikus

216 PPM I (1990) 750-789 s. v. I 7,19, Casa annessa alla Casa dell’Efebo o di P. Cornelius Tages (A. de Vos) 785-787 Abb. 61.

217 Mit Beispielen des vierten Stils Bergmann 2008a.

218 PPM IV (1993) 87-147 s. v. VI 2,4, Casa di Sallustio (V. Sampaolo) 113f. Abb. 44-47; 119f. Abb. 55-57; Eristov 2014, 82. 
Abb. 346: Casa di Sallustio (VI 2,4), Gartenbereich (24) mit Pergola; in der Achse des Gartens, im Norden, Sommertriclinium (25).

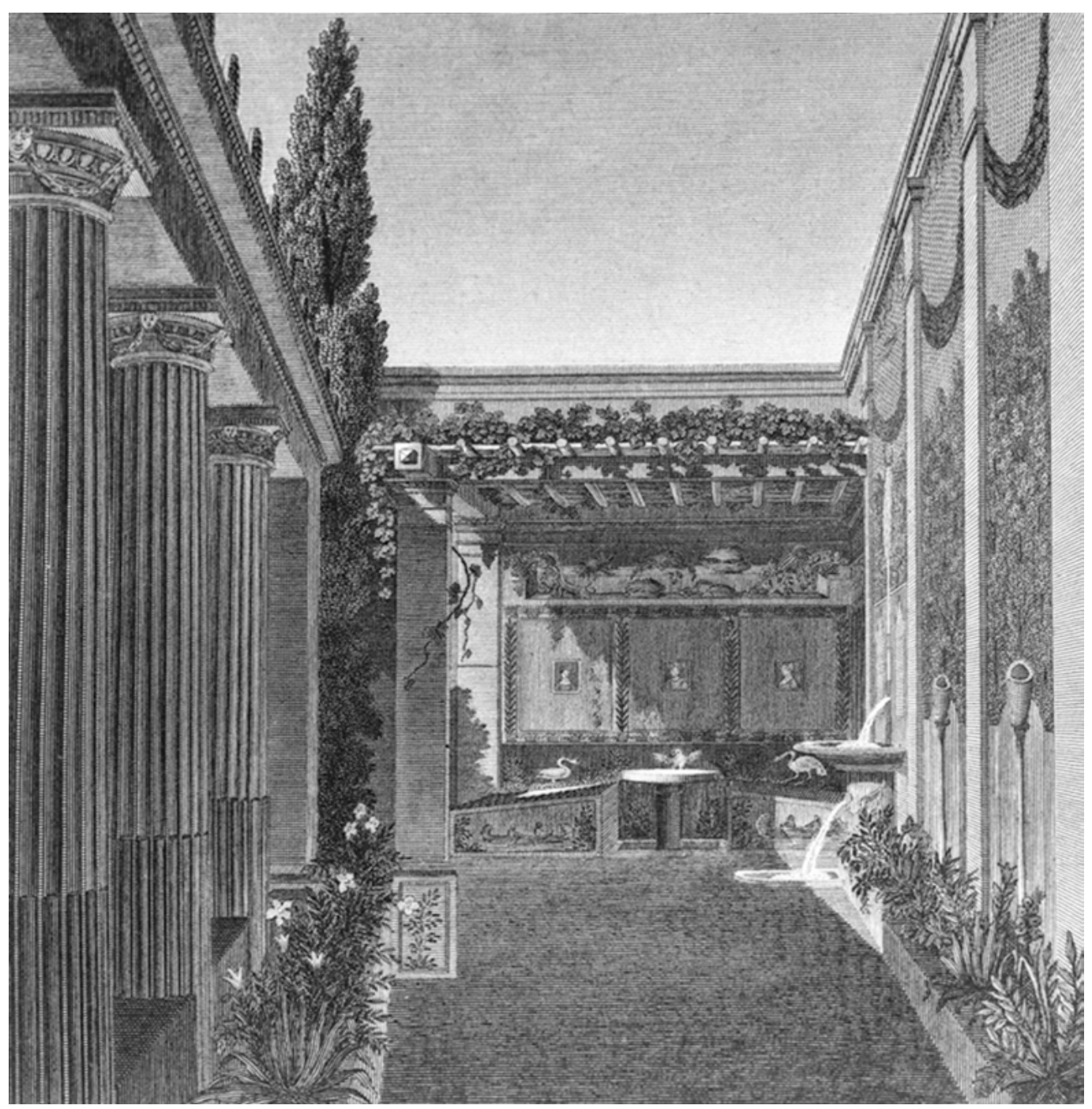

Abb. 347: Casa di Sallustio (VI 2,4), Gartenbereich (24), Rekonstruktion der Westwand (G. Morelli).

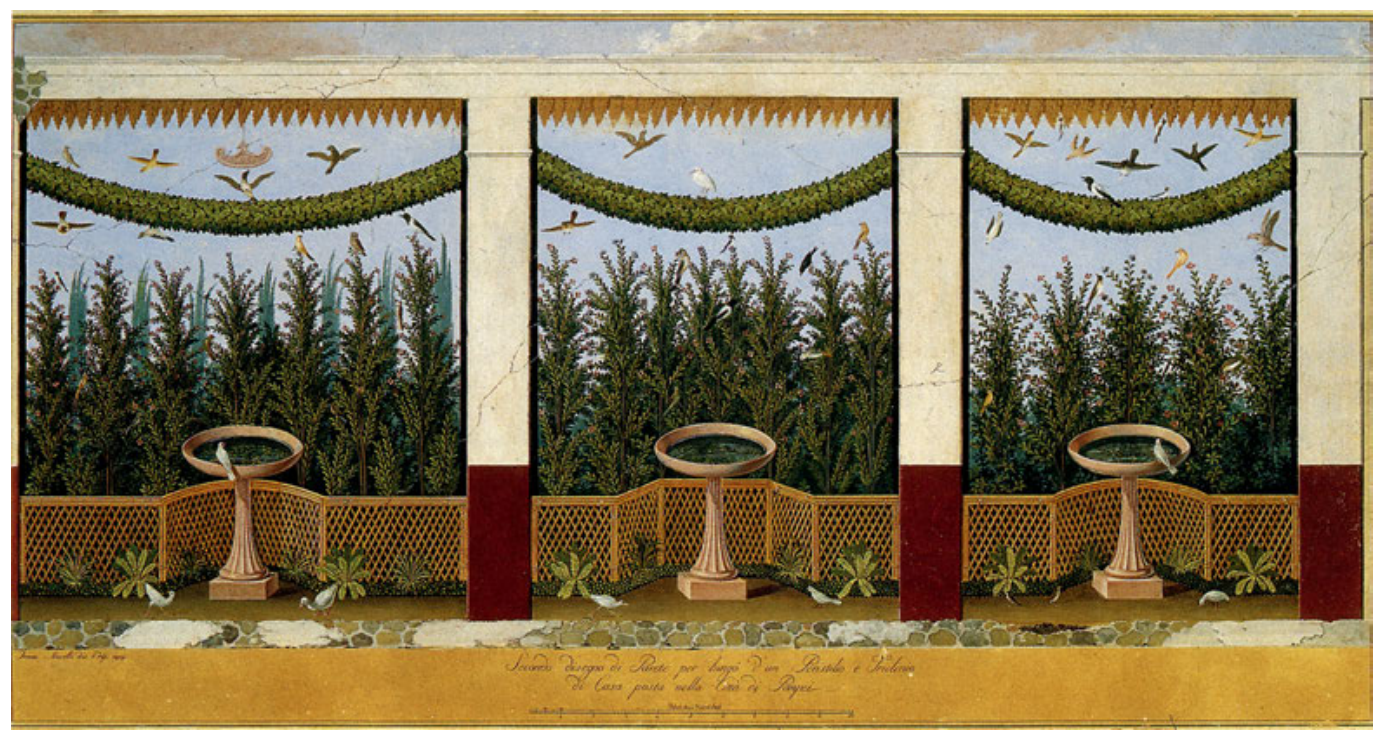




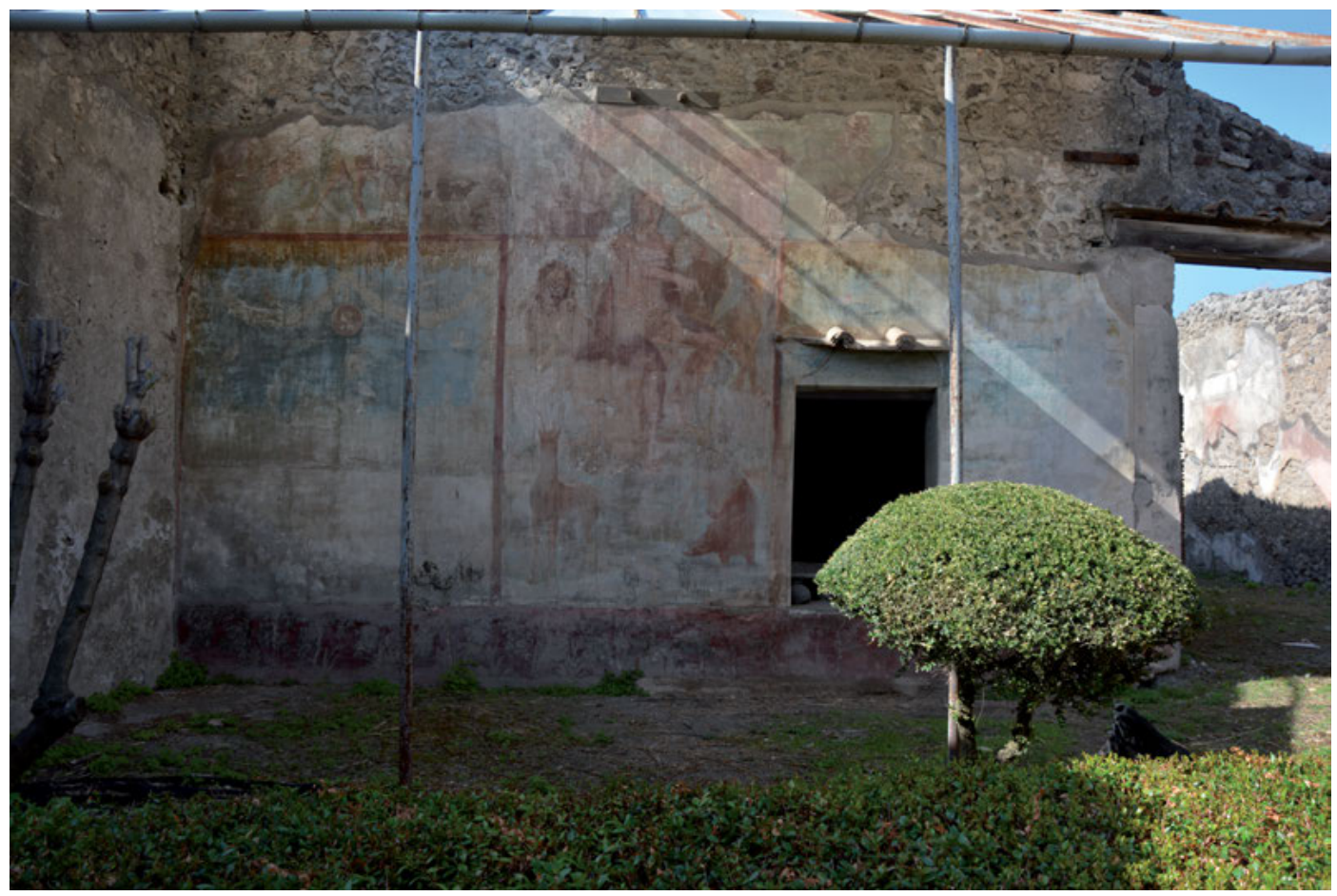

und den ,dahinter liegenden gemalten Garten ${ }^{219}$, in der Achse auf den gewachsenen Garten, rechter Hand auf die reale Portikus. Reale und gemalte Portikus suggerierten eine Rhythmisierung der Raumerfahrung, wie sie sich im Durchschreiten des Gartens ergeben würde. Vom (überdachten) Oecus (22), der sich über eine breite Front auf den Garten öffnete, blickte man durch die reale Portikus und den realen Garten auf die fiktiv-gemalte ,Erweiterung des Gartens ins Unendliche. Der Conviviums-Teilnehmer wurde durch ein Spiel mit Realität und Fiktion verschiedener Gartenelemente unterhalten, das je nachdem, an welchem Ort das Gelage stattfand, unterschiedlich ausfiel. Tatsächlich war die attraktive Gartenrückwand aber bereits vom Eingang aus sichtbar ${ }^{220}$.

In einigen Fällen wurde die Gartenmegalographie durch mythologische Figuren angereichert ${ }^{221}$. Auf der westlichen Rückwand von Rumpfperistyl (o) der Casa di Orfeo (VI 14,20) ${ }^{222}$, die über das Tablinum hinweg, von den zentralen Säulen der Portikus gerahmt, bereits vom Eingang her sichtbar ist, wird über einem niedrigen, durchgehenden Pflanzensockel eine differenzierte Landschaft mit Wasserläufen, Felsen und Bewuchs entfaltet, in deren ungefährem Zentrum der Kithara spielende Orpheus auf einem Felsen sitzt (Abb. 348). Vom Eingang
Abb. 348: Casa d Orfeo (VI 14,20), westliche Rückwand von Rumpfperistyl (o), mit Orpheusdarstellung.

219 Ausführlich thematisiert O’Sullivan 2007 die Portikus als Aufenthaltsort und Abschrankung des Gartens, ausgehend von den Odyssee-Fresken.

220 Eristov 2014, 85f.; mit weiteren Überlegungen zur Sichtbarkeit; sie bezieht sich aber nur auf die Frage, was vom Eingang aus sichtbar war.

221 Eine Zusammenstellung bei Salvadori 2017, 97; mehrheitlich handelt es sich um Malereien des vierten Stils.

222 PPM V (1994) 264-307 s. v. VI 14,20, Casa di Vesonius Primus o di Orfeo (F. Narciso) 284f. Abb. 33a. 33b. 
und Tablinum aus wird er von den beiden Säulen der Portikus gerahmt, das Bild gewissermaßen auf Abstand gehalten ${ }^{223}$.

Er nimmt die gesamte Mittel- und Oberzone ein, dominiert das Bild und mit ihm die dargestellte Natur. Durch seine immense Größe wirkt er auch für denjenigen riesenhaft, der ihn von der Portikus aus in einigem Abstand betrachtet. Indem er aus dem Bild herausblickt, zieht er den Betrachter in das Bild hinein. Seine musikalische ,Performance‘ zeigt bereits Erfolg: Um Orpheus herum lagern Löwe und Panther, aber auch heimische Tiere wie Wildschweine. Sie sind nicht aggressiv, einige von ihnen blicken wie Orpheus aufmerksam aus dem Bild heraus. Über die Figur des Orpheus wird es möglich, ein monumentales Landschaftsbild vorzuführen und mit exotischen Tieren zu bevölkern $^{224}$. In der Mittelzone grenzen nun aber Rahmenlinien zwei ,geordnet-zivilisierte‘ Gartenbereiche aus dieser ,wilden' Landschaft aus. Diese ,Kulturgärten' sind von Vögeln bevölkert und gewähren einen Ausblick in den Himmel. Herabhängende Girlanden und Oscilla schaffen eine festliche Atmosphäre. Damit stehen auf der Rückwand des Gartens zwei konkurrierende Gartenkonzepte nebeneinander: der geordnete, bepflanzte Fest-Garten einerseits, der exotisch bevölkerte Landschaftsraum andererseits. Sie eröffnen ein Bildspiel, das, wie Bergmann zeigte, immer wieder auf die zentrale Figur des Orpheus zurückführt. Von allen möglichen Standpunkten, nicht nur vom Eingang aus, erhält die Bildwand eine Rahmung durch die vorgelagerte Portikus. Die Säulenstellungen sorgen dafür, dass sich immer wieder Teile des Bildes dem Blick entziehen, die architektonische ,Rahmung“ des imaginären Garten-Landschaftsbildes konkret erfahrbar wird ${ }^{225}$.

Die Gartenmalereien fungieren als visuelle Erweiterung und Pendant zur realen Bepflanzung des Gartens. Sie eröffnen ein Spiel mit verschiedenen Medialitäten und Realitäten. Indem die Gartenmalerei auf Höhe des Betrachters ansetzt, bietet sie sich als ambientale Decor-Form im engsten Sinn des Wortes an. Zugleich spielt das Medium mit Immersion und Exklusion. Die Gartenbilder simulieren einen begehbaren Raum, oft ist dieser jedoch durch Gitter abgeschrankt und stellt dadurch eine Welt für sich dar ${ }^{226}$.

\section{Oeci, Triclinia, Cubicula}

Aufenthaltsräume wurden im Unterschied zu den Fauces und Höfen mit einem Decor versehen, der eine intensive Wahrnehmung voraussetzte und mit einem verweilenden Betrachter rechnete. Das Gliederungssystem bediente das Bedürfnis, die vielfältigen Decor-Elemente zueinander und zum umgebenden Raum in Beziehung zu setzen. Dies geschah durch die rahmende Architektur, die im Zentrum meist die Gestalt einer Mittelädikula annahm, durch eine farbliche Rhythmisierung der Felder wie auch durch die Wahl der Sujets. Im Folgenden soll zunächst danach gefragt werden, wie sich das Gliederungssystem der Wände und die Raumformen zueinander verhalten.

Die horizontale und vertikale Dreiteilung der Wandflächen tritt häufig in den Dienst einer Betonung der Wandmitte ${ }^{227}$. Insbesondere kleinere Räume weisen somit eine symmetrische Komposition auf, die alle vier Raumseiten zusammenschließt und auf eine Differenzierung in Vorraum und Klinenbereich verzichtet ${ }^{228}$. In Cubiculum (c) der Casa dei Ceii (I 6,15) entschied man sich auf allen vier Wandseiten für eine Betonung der Mittelachse durch ein herausgehobenes grünes Paneel

223 Eristov 2014, 90.

224 Vergleichbar, wenn auch schlechter erhalten, ist die augusteische Gartenmegalographie an der Rückwand von Garten (13) der Casa di Stallius Eros (I 6,13), s. PPM I (1990) 400-406 s. v. I 6,13, Casa di Stallius Eros (M. de Vos) $405 f$. Abb. 8. 9; Jashemski 1979, 67. Solche Megalographien werden im vierten Stil zu einer neuen Vorliebe für großformatige Venationes führen. Zum ikonographischen Zusammenhang, mit Listung der Belege, s. Jashemski 1979, 68-73; vgl. Leach 2004, 312.

225 Bergmann 2008a, 62f.

226 Im vierten Stil kommen dann Malereien hinzu, die Gartenbilder in einem Fensterausblick zeigen, s. Salvadori 2017, 59.

227 Bereits Mau 1882, 341-344; vgl. etwa Clarke 1991, 58.

228 Anguissola 2010, 99f. 


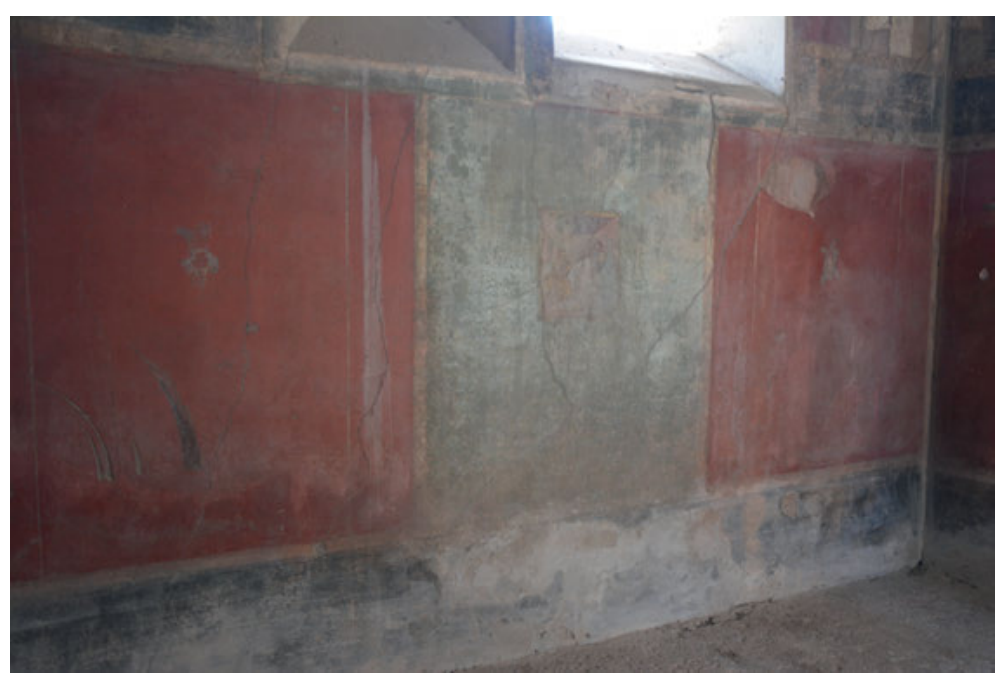

Abb. 349: Casa dei Ceii $(1$ 6,15), Cubiculum (c).

mit Bildfeld, das sich von den flankierenden roten Paneelen mit Vignetten (geflügelt-fliegende Figuren) absetzt (Abb. 349) ${ }^{229}$. Das Zentrum des Raumes besetzt ein quadratischer, geometrischer Mosaikteppich mit breiter Mäanderrahmung, der sich dezentral zum Eingang verhält, jedoch mit allen vier Mittelfeldern korrespondiert.

Je nach Raumzuschnitt und Raumfunktion konnte die Decor-Idee der Axialität auch andere Ausprägungen annehmen. In langrechteckigen Prunkräumen musste das Wandschema auf den langen Seitenwänden in eine Fünfteilung überführt werden, wollte man einen hochrechteckigen Felderzuschnitt beibehalten. So folgen in Triclinium (b) der Casa di Sacerdos Amandus (I 7,7) die Rückwände im Norden und Süden einer Dreiteilung (auch wenn die Seitenfelder durch einen Kandelaber in zwei Felder mit jeweils einer Figur gegliedert sind), während für die Längswände im Osten und Westen eine Fünfteilung mit Mittelbild gewählt wurde (Abb. 350 ${ }^{230}$. Die rotgrundigen Paneele erzeugen mit dem zentralen, blaugrundigen Mythenbild einen auffälligen Kontrast und verstärken so die Symmetriewirkung. Auch für Cubicula, die eine entsprechend langrechteckige Proportion besaßen, hat man auf eine Fünfteilung zurückgegriffen. Im kleinen Cubiculum (i) der Casa della Parete nera (VII 4,59) gilt dies für die dem Eingang gegenüberliegende, lange Querwand $^{231}$.

Daneben blieb für Gelage- und Liegeräume eine visuelle Gliederung in einen Vorraum und einen Klinen- bzw. Alkovenbereich auch weiterhin beliebt. Üblicherweise wird die Unterteilung an der Wand durch gemalte Stützen hergestellt ${ }^{232}$. Im Klinenbereich besitzen häufig alle drei

229 PPM I (1990) 407-481 s. v. I 6,15, Casa dei Ceii (M. de Vos) 429-431 Abb. 32. 34; Michel 1990, 30-34.

230 PPM I (1990) 586-617 s. v. I 7,7, Casa del Sacerdos Amandus (V. Sampaolo) 590-606 Abb. 5-25; weiterhin Triclinium (e) der Casa dei Ceii, s. PPM I (1990) 407-481 s. v. I 6,15, Casa dei Ceii (M. de Vos) 442-444 Abb. 53a-54; Oecus (19) der Casa del Citarista; Tablinum (h) der Domus V 3,10, s. PPM III (1991) 929-943 s. v. V 3,10 (I. Bragantini) 932-935 Abb. 4-8; Triclinium (20) der Casa di Gruppo dei vasi di vetro (VI 13,2), s. PPM V (1994) 142-157 s. v. VI 13,2, Casa del Gruppo dei vasi di vetro (V. Sampaolo) 151-155 Abb. 14-23; Triclinium (7) der Domus VII 14,9, s. PPM VII (1997) 686-697 s. v. VII 14,9 (V. Sampaolo) 689 Abb. 6; Triclinium (e) der Casa di T. Dentatius Panthera (IX 2,16), s. PPM IX (1999) 1-40 s. v. IX 2,16, Casa di T. Dentatius Panthera (V. Sampaolo) 19-27 Abb. 33-45; Triclinium (l) der Domus IX 9,d, s. PPM X (2003) 63-92 s. v. IX 9,d (V. Sampaolo) 84-90 Abb. 28-35.

231 Der Raum hatte bereits im späten zweiten Stil ein Paviment erhalten, das anzeigte, dass hier zwei Klinen jeweils zu Seiten des Eingangs, einander gegenüber, aufgestellt waren. Der Eintretende blickt folglich auf eine relativ breite Rückwand (im Osten), s. PPM VII (1997) 93-139 s. v. VII 4,59, Casa della Partete nera o Casa dei Bronzi (M. StaubGierow) 104f. Abb. 15. 16; Staub Gierow 2000, 30-34.

232 Es lassen sich nur sehr vereinzelte Ausnahmen benennen. Im Triclinium (8) der Casa del Bell'Impluvio (I 9,1) stellen Stuckpilaster eine Gliederung in einen Vorraum und einen Klinenbereich her; s. PPM I (1990) 919-941 s. v. I 9,1, 
Abb. 350: Casa di Sacerdos Amandus ( 7,7), Triclinium (b), Seitenwand mit mythologischem Mittelbild (Icarus).

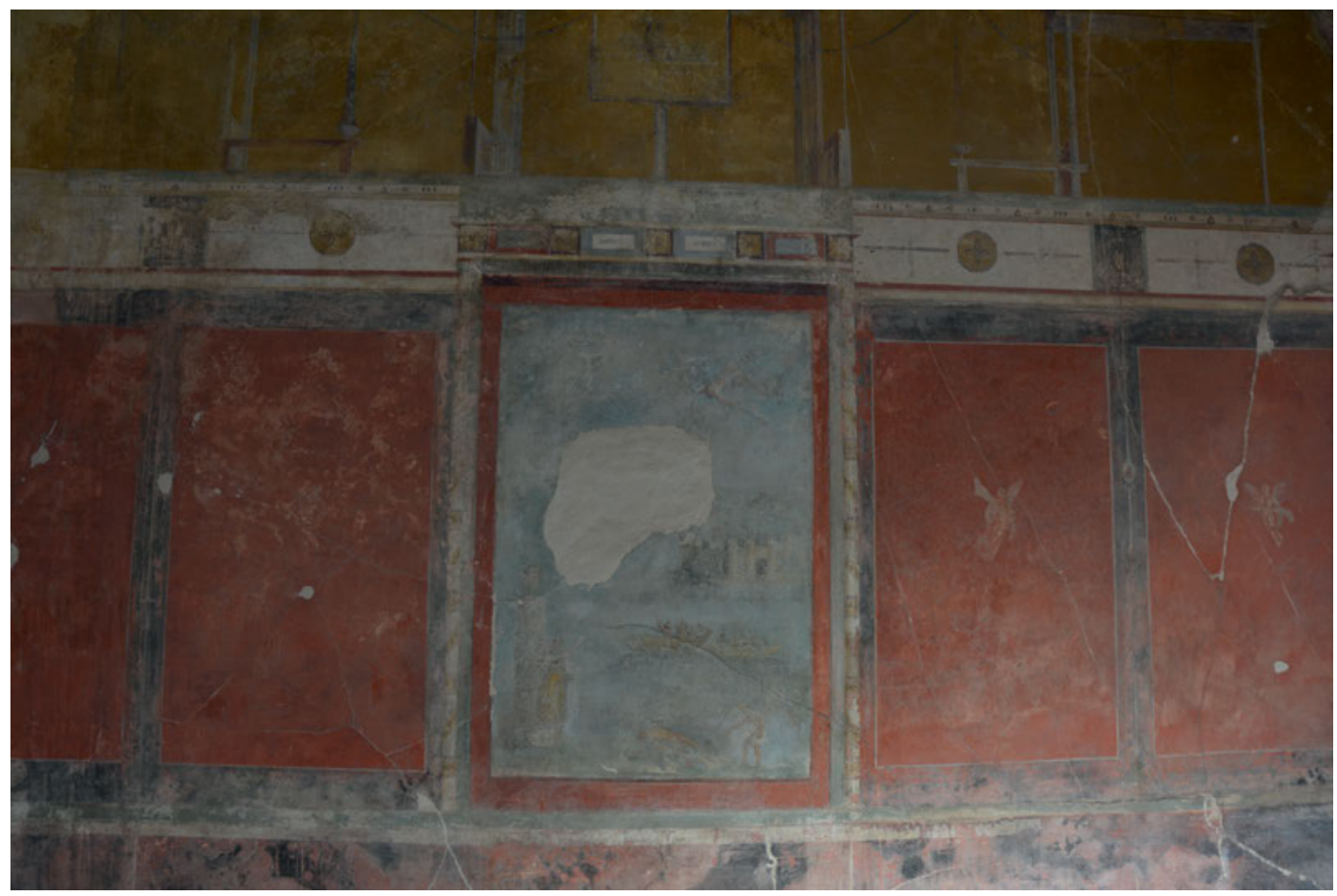

Wandseiten jeweils drei Felder, auf denen das Mittelfeld herausgehoben ist ${ }^{233}$. Ein solches Wandschema mit drei Paneelen im Klinenbereich und zweien im Vorraum findet sich im Triclinium (f) der Casa di Giasone, eine einheitliche Sockelzone stellt Kohärenz her (Abb. 267). Dadurch entsteht im Klinenbereich ein ,Raum im Raum‘.

Die Zahl der im Klinenbereich und im Vorraum platzierten Paneele hängt unmittelbar vom Raumzuschnitt ab. In Triclinium (t1) der Casa di M. Epidius Sabinus (IX 1,22.29; Plan 21) ${ }^{234}$ trennt ein schmaler gemalter Pilaster den dreigeteilten Klinenbereich mit mittigen, mythologischen Landschaftsbildern von dem relativ knappen Vorraum, der hier nur ein einziges, sehr breites Feld aufweist (Abb. 351). Dieses ist durch ein vertikales ,Decor-Band' mit Kandelaber gegliedert, ,vor dem ein kleines quadratisches Bildfeld mit den Büsten von Ariadne und Bacchus platziert ist. Dadurch ergibt sich ein eigener Decor-Rhythmus: Mit kleinen, quadratischen Bildfeldern im Vorraum korrespondieren große Bildpaneele im Klinenbereich ${ }^{235}$. Aus der spezifischen Raumsituation ergibt sich ein individuelles Decor-Schema.

Casa del Bell'Impluvio (V. Sampaolo) 832f. Abb. 21-24. Im Fall von Triclinium (n) der Caserma dei gladiatori (V 5,3) zeigt nicht nur ein kannelierter Stuckpilaster die Raumgliederung an, sie wird vielmehr auch durch ein räumlich gliederndes Mosaikpaviment aufgenommen; s. PPM III (1991) 1069-1098 s. v. V 5,3, Caserma dei gladiatori (F. P. Badoni - F. Narciso) 1079 Abb. 22; 1082f. Abb. 29-31.

233 Über die im Folgenden besprochenen Triclinia hinaus: Domus V 2,10 mit Triclinium (n), s. PPM III (1991) 830-847 s. v. V 2,10 (V. Sampaolo) 836-838 Abb. 13-17; eine Untergliederung durch eine gemalte Lisene in Triclinium (n) der Domus V 3,10, s. PPM III (1994) 929-943 s. v. V 3,10 (I. Bragantini) 939 Abb. 20; Triclinium (8) der Casa di Sirico (VII 1,25.47), s. PPM VI (1996) 228-353 s. v. VII 1,25.47, Casa di Sirico (I. Bragantini) 240f. Abb. 25. 26; weiterhin Triclinium (1) der Casa di M. Spurius Mesor (VII 3,29), s. PPM VI (1996) 902-942 s. v. VII 3,29, Casa di M. Spurius Mesor (V. Sampaolo) 917f. Abb. 32. 33; 922-924 Abb. 39-41; Zuweisung zum späten dritten Stil bei Barbet 2009, 111. Liste bei Barbet 2009, 133 ist deutlich zu erweitern.

234 PPM VIII (1998) 956-1044 s. v. IX 1,22.29, Casa di M. Epidius Sabinus (V. Sampaolo) 1040f. Abb. 147. 148; Barbet 2009, 130f. Abb. 82; Gallo 2015/16, $47 \mathrm{f}$.

235 Dickmann 1999, 338 betont aufgrund einer durchlaufenden Sockelzone und derselben Höhe der Mittelzone die Einheitlichkeit des Raumes, übersieht dabei jedoch den verschiedenartigen Decor-Rhythmus. 


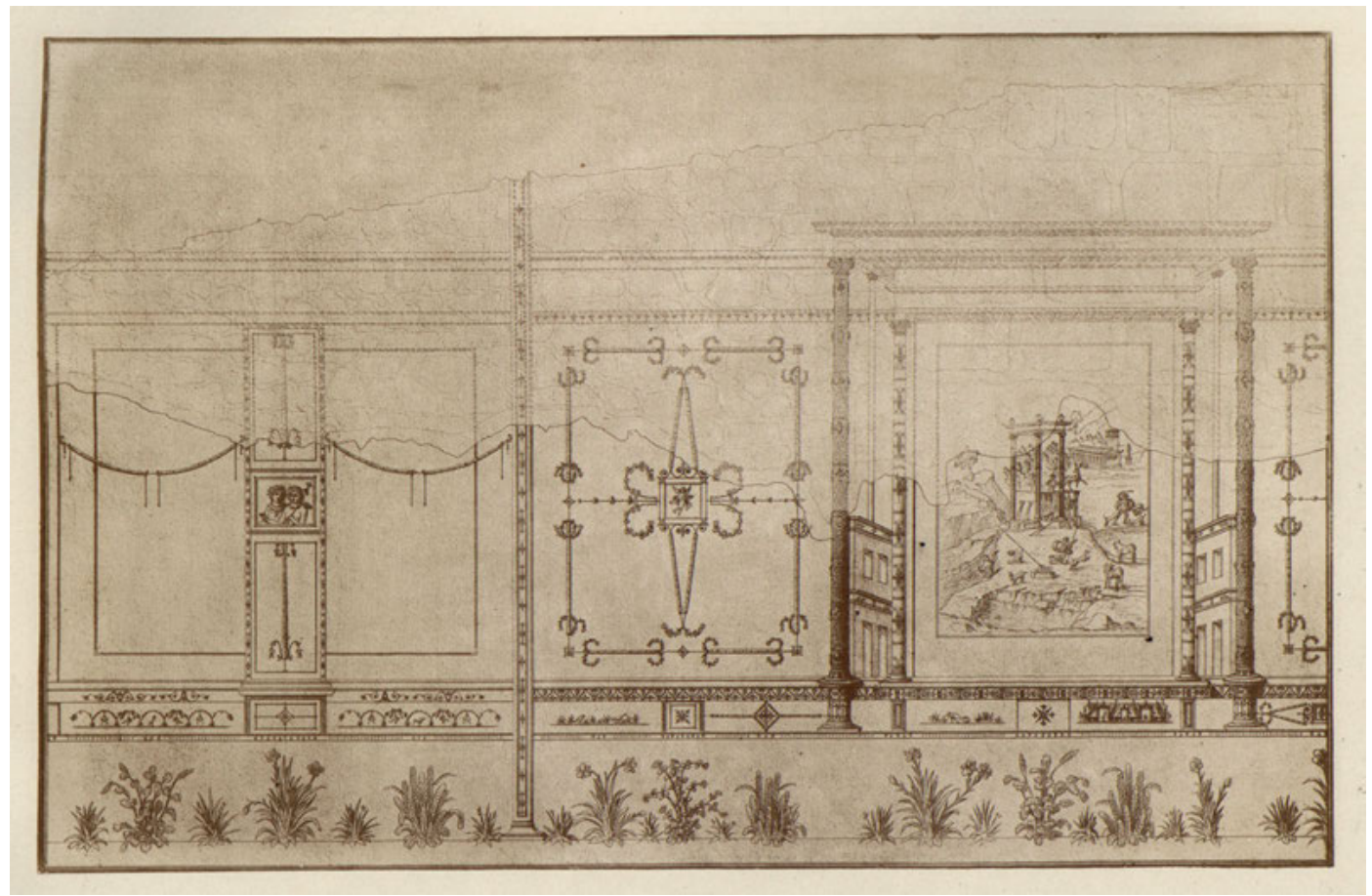

Langrechteckige und besonders tiefe Räume konnten einer Sechsteilung unterworfen werden, sodass sowohl der Klinenbereich als auch der Vorraum eine Dreiteilung aufweisen. Dies trifft auf Triclinium (8) der Casa del Bell'Impluvio (I 9,1) zu, in dem zwei prunkvolle, in pompejanisch Rot gefasste Putzpilaster den Raum in nahezu gleich große Teile gliedern ${ }^{236}$. In Triclinium (11) der Casa del Frutteto (I 9,5; Plan 7; Abb. 329) ${ }^{237}$ erhielten sowohl der Klinenbereich als auch der Vorraum eine Mittelädikula, wodurch beide Raumteile gleichartig organisiert sind. Nur im hinteren Raumteil füllen die Ädikulen jedoch Mythenbilder, im vorderen Raumteil sind es fliegende Figuren, sodass über die Wahl der Sujets eine Hierarchisierung eingeführt wird.

Wenn man sich in kleineren Cubicula für eine Untergliederung in Vorraum und Klinenbereich entschied, mussten Lösungen gefunden werden, um ungünstige Felderproportionen zu vermeiden. In dem monochrom weißen Cubiculum (i) der Casa dei Ceii $($ 6 6,15) trennt ein gemalter Pilaster ein ungegliedertes Paneel im Vorraum von einem ungegliederten Paneel im Klinenbereich (Abb. 352) ${ }^{238}$, allein die Rückwand wurde dreigeteilt. Im Cubiculum (h) der Domus I 11,12 besteht die Orthostatenzone im Vorraum und Klinenbereich aus schwarzen Platten. Im Vorraum fallen sie jedoch etwas schmaler als im Hauptraum aus ${ }^{239}$, wodurch sich eine subtile Differenzierung ergibt.

236 Triclinium (8) der Casa del Bell'Impluvio (I 9,1) mit gliederndem Stuckpilaster, s. PPM I (1990) 919-941 s. v. I 9,1, Casa del Bell'Impluvio (V. Sampaolo) 932f. Abb. 21-24.

237 PPM II (1990) 1-137 s. v. I 9,5, Casa dei Cubicoli floreali o del Frutteto (M. de Vos) 46-49 Abb. 68-70b.

238 PPM I (1990) 407-481 s. v. I 6,15, Casa dei Ceii (M. de Vos) 436f. Abb. 45a. 45b; nachträglich in eine Küche umgebaut, s. Michel 1990, 26-30. Abb. $147 \mathrm{f}$.

239 Cubiculum (h) der Domus I 11,12, s. PPM II (1990) 582-592 s. v. I 11,12 (P. Miniero - M. de Vos) 587-591 Abb. 7-12 b; s. auch Barbet 2009, 128f. Abb. 129; Anguissola 2010, 304 Abb. 159; weiterhin Cubiculum (4) der Casa dell'Imperatrice di Russia (VI 14,42), s. PPM V (1994) 409-425 s. v. VI 14,42, Casa dell'Imperatrice di Russia (I. Bragantini) 414 Abb. 10; Cubicula (d) und (f) der Casa annessa alla Casa dell'Efebo (I 7,19), s. PPM I (1990) 750-789 s. v I 7,19, Casa annessa alla Casa dell'Efebo o di P. Cornelius Tages (M. de Vos) 771f. Abb. 36-39; 778f. Abb. 50a-b; Cubiculum (f) fällt hier so klein aus, dass an den Seitenwänden des Alkovens eine Dreiteilung nur durch einen Rot-Schwarz-RotFarbwechsel simuliert werden kann - für ein großes Bildfeld ist nur auf der Rückwand des Cubiculums Platz; weiterhin Cubiculum (m) der Casa di M. Spurius Mesor (VII 3,29), s. PPM VI (1996) 902-942 s. v. VII 3,29, Casa di M. Spurius Mesor (V. Sampaolo) 927-938 Abb. 46-63; Cubiculum (8) der Domus VII 6,28, s. PPM VII (1997) 182-196 s. v. VII 6,28 (V. 
Abb. 352: Casa dei Ceii $($ 6,15), Cubiculum (i).

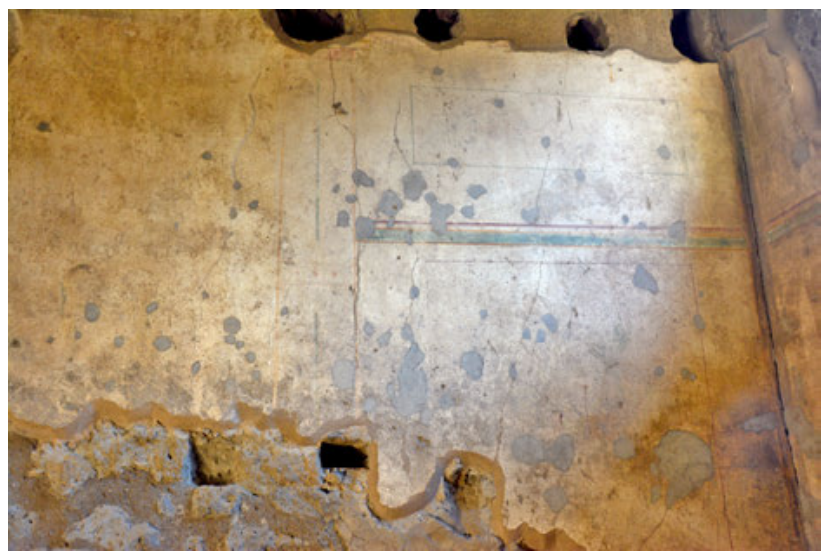

Bisher hat sich gezeigt, dass man insbesondere für größere Aufenthaltsräume eine Gliederung in Vorraum und Klinenbereich wählte. Während für die Längswände vielfältige Optionen zur Verfügung standen, um den Decor an die Raumproportionen anzupassen, folgte die dem Eingang gegenüberliegende Rückwand meist einer Dreiteilung. Wenn der Raum allerdings besonders breit ausfiel, wurden auch hier alternative Lösungen gefunden. Im breit gelagerten, relativ kleinen Oecus (q) der Casa del Gallo (VIII 5,2.5) markiert eine Ädikula mit einem monochrom grünen Landschaftsbild das Zentrum der Mittelzone (Abb. 353). Zu beiden Seiten ist dieses von drei Feldern (Violett - Rot - Violett) eingefasst, wobei das mittlere, rote Feld durch eine vorgelagerte, dünne Säule geteilt wird. Die Mittelzone bietet in ihrem unteren Teil somit eine regelrecht parataktische Feldersequenz ${ }^{240}$. Über den seitlichen Feldern war der Übergang zur Oberzone mit jeweils zwei Pinakes besetzt, die Dreier-Ordnung wurde so in eine Zweier-Ordnung überführt. Durch diese Feldergliederung erhält der auf den Garten geöffnete Raum einen sehr kleinteiligen Decor.

Mit Blick auf eine breite Materialbasis bestätigt sich somit die am Beispiel von Triclinium (f) der Casa di Giasone angestellte Überlegung, dass das Wandsystem des dritten Stils in ausgesprochen flexibler Weise an den jeweiligen Raumzuschnitt angepasst wurde. Entweder schuf man vollständig axialsymmetrisch konzipierte Räume oder aber der Klinenbereich wurde als eigenständiger Raumteil inszeniert. In diesem Sinne entwarf die filigrane Scheinarchitektur einen ,gewichteten Architekturraum.

\footnotetext{
Sampaolo) 191-193 Abb. 12-15; Cubiculum (z1) der Domus VII 7,2 (hier auch eine Bettvertiefung in der Westwand), s. PPM VII (1997) 224-231 s. v. VII 7,2 (I. Bragantini) 230 Abb. 12. 13; Cubiculum (II) der Casa di C. Iulius Polybius (IX 13,13), s. PPM X (2003) 183-356 s. v. IX 13,1-3, Casa di Polibio (I. Bragantini) 298f. Abb. 179. 180; 306f. Abb. 189-193. Liste bei Barbet 2009, 133 ist hier deutlich erweitert.

240 PPM VIII (1998) 547-566 s. v. VIII 5,2.5, Casa del Gallo (V. Sampaolo - I. Bragantini) 558 Abb. 24; Bastet - De Vos 1979, 27 Taf. 3,5.
} 


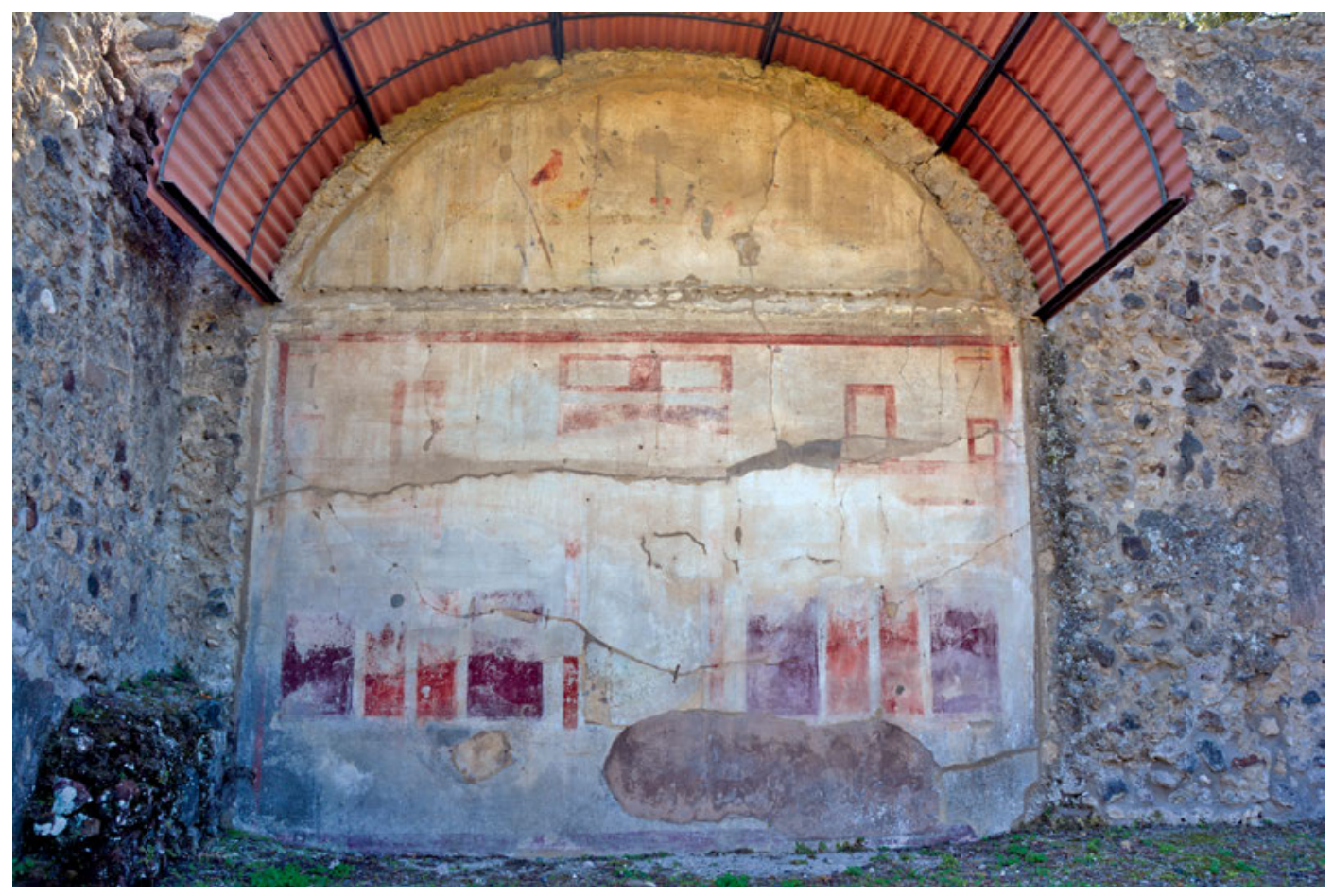

Abb. 353: Casa del Gallo (VIII 5,2.5), Oecus (q).

\subsection{Wand-Decor und die visuelle Organisation des Raums}

Das Decor-System des dritten Stils nimmt, wie sich zeigte, auf den Raumzuschnitt, die Raumachsen, Funktionsbereiche innerhalb eines Raumes und damit auch auf die erwartbaren Betrachterhaltungen Bezug. Dies führt nicht nur zu einer Symmetrisierung des Wandaufbaus, sondern hat auch eine Hierarchisierung der einzelnen ,Stellen' innerhalb der Scheinarchitektur zur Folge. In einem ersten Schritt ist daher danach zu fragen, was dies für die Decor- und Bildordnung bedeutet, in einem zweiten Schritt soll es dann um die Konsequenzen für die Decor-Wahrnehmung gehen.

\section{Aufenthaltsräume und die Hierarchisierung der Decor- und Bildordnung}

Indem der Wandaufbau Prinzipien der Symmetrie und Axialität verpflichtet ist, kommt dem Wandzentrum das größte ,Gewicht‘ zu. Auch Farbrhythmen tragen zur Orientierung und Fokussierung bei. Zugleich führt diese Wichtung zu einer Betonung der Raumrückwand ${ }^{241}$. Durch das strenge, geometrische Gliederungssystem der Räume werden die Bildfelder der Mittelädikulen ebenso wie jene der seitlichen Paneele, der Predella- und Obergeschosszonen in ein klares Bezugssystem eingebunden. Die sich auf den Längsseiten des Raumes einander gegenüberstehenden Bilder sind enger aufeinander bezogen als das Bildfeld bzw. die Bildfelder der Rückwand. Bildformen und Bildinhalte reagieren auf diese Hierarchisierung, zugleich tragen sie ihrerseits zur Wichtung der Wand bei. Großformatige, semantisch komplexe Bilder verleihen der Mittelzone im Wandzentrum zusätzliches ,Gewicht'. Sie treten dem Betrachter auf Augenhöhe entgegen und ziehen so die besondere Aufmerksamkeit auf sich. Dieser Effekt wird dadurch verstärkt, dass man auf den seitlich flankierenden Paneelen semantisch weniger dichte ,Bilder ${ }^{\star}$ bzw. ,Ornamente wählte oder sie ganz leer ließ. 
Abb. 354: Casa del Granduca (VII 4,56), Ostwand von Tablinum (11); Rekonstruktion (Wilhelm Zahn).

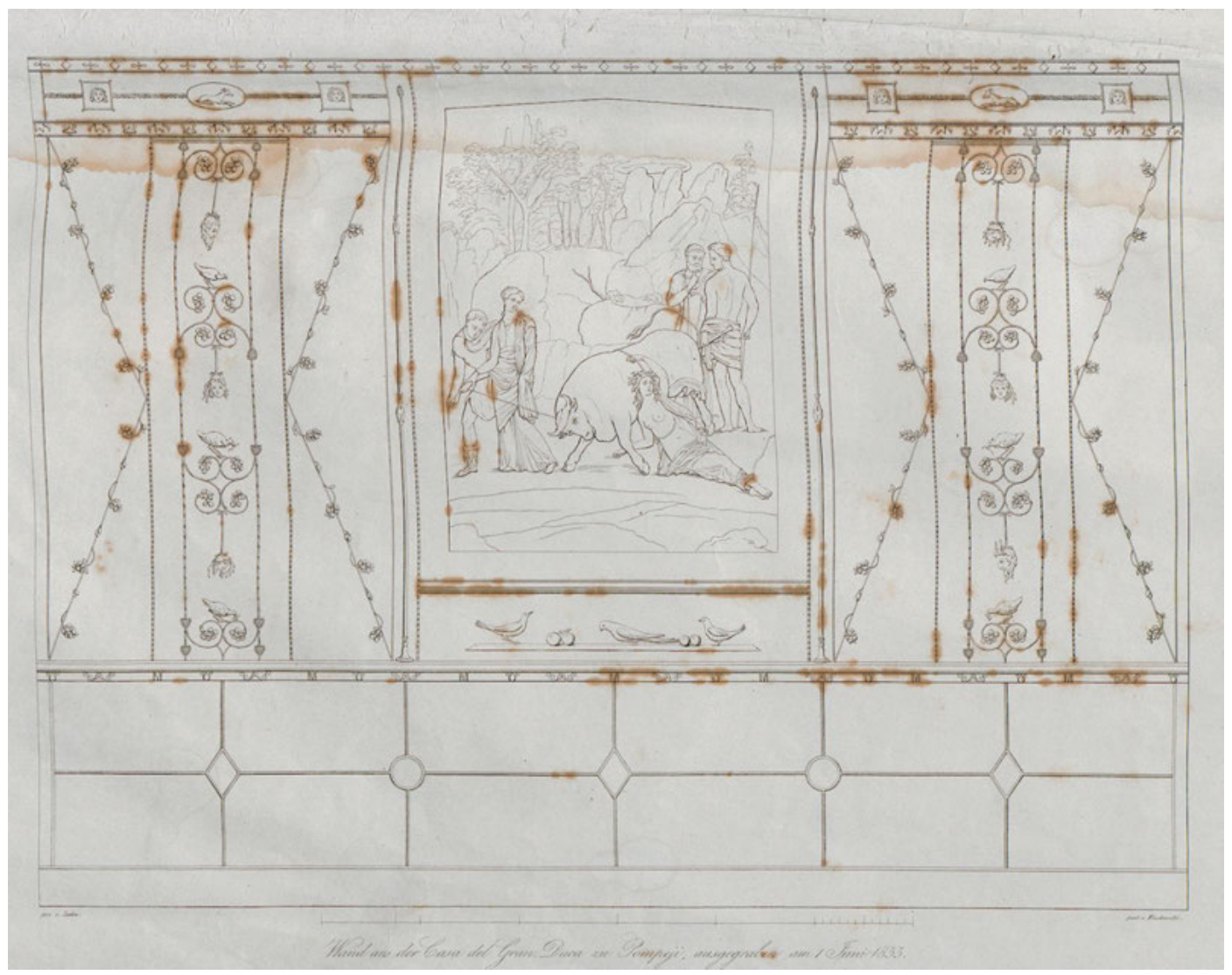

Im Tablinum (h) der Casa di Marcus Lucretius Fronto (Abb. 288) ${ }^{242}$ werden die Mythenbilder im Wandzentrum von nicht-narrativen Landschaftspinakes in den Seitenfeldern flankiert. Im Triclinium (b) der Casa del Sacerdos Amandus (I 7,7) sind mit den zentralen Mythenbildern auf den seitlichen Paneelen schwebende oder stehende Einzelfiguren kombiniert (Abb. 350) 243 $^{42}$ die den Seitenfeldern eine schwebende ,Leichtigkeit' verleihen ${ }^{244}$. Auf der Ostwand von Tablinum (11) der Casa del Granduca (VII 4,56) wird das zentrale mythologische Bildfeld mit der Schleifung der Dirke seitlich von schwarzen Paneelen flankiert, die eine ornamentale Füllung erhalten haben (Abb. 354) $)^{245}$. Sie werden durch einen breiten, in sich noch einmal ornamentierten Streifen halbiert, auf den diagonal gesetzte Stäbe zulaufen, die von Blattgirlanden umwunden werden. Die

242 s. o. S. $375-386$.

243 PPM I (1990) 586-617 s. v. I 7,7, Casa del Sacerdos Amandus (V. Sampaolo) 590f. Abb. 5; 593 Abb. 9.

244 Mit Blick auf Stillleben stellt Squire 2017, 209f. eine solche Hierarchisierung infrage, argumentiert jedoch nicht mit dem visuellen System, sondern mit dem aus den Bildern extrahierten künstlerischen Wert: „If many scholars have consequently judged ,still lifes‘ an ,inferior‘ sort of painterly subject, they have also assumed a hierarchical distinction between the realms of figure and ornament (no less than between peripheral frame and central panel); in doing so, there has been a tendency to undervalue the subtle interplay of different representational elements, thereby overlooking the complex framing of these issues within the larger cultural and representational frameworks of Roman fresco-painting.“ Tatsächlich argumentiert Squire jedoch selbst vom Einzelbild aus, und nicht mit Blick auf das Wandsystem.

245 PPM VII (1997) 44-62 s. v. VII 4,56, Casa del Granduca (M. Staub-Gierow) 52-55 Abb. 17-19; Bastet - De Vos 1979, 55f.; Staub-Gierow 1994, 30-32. 

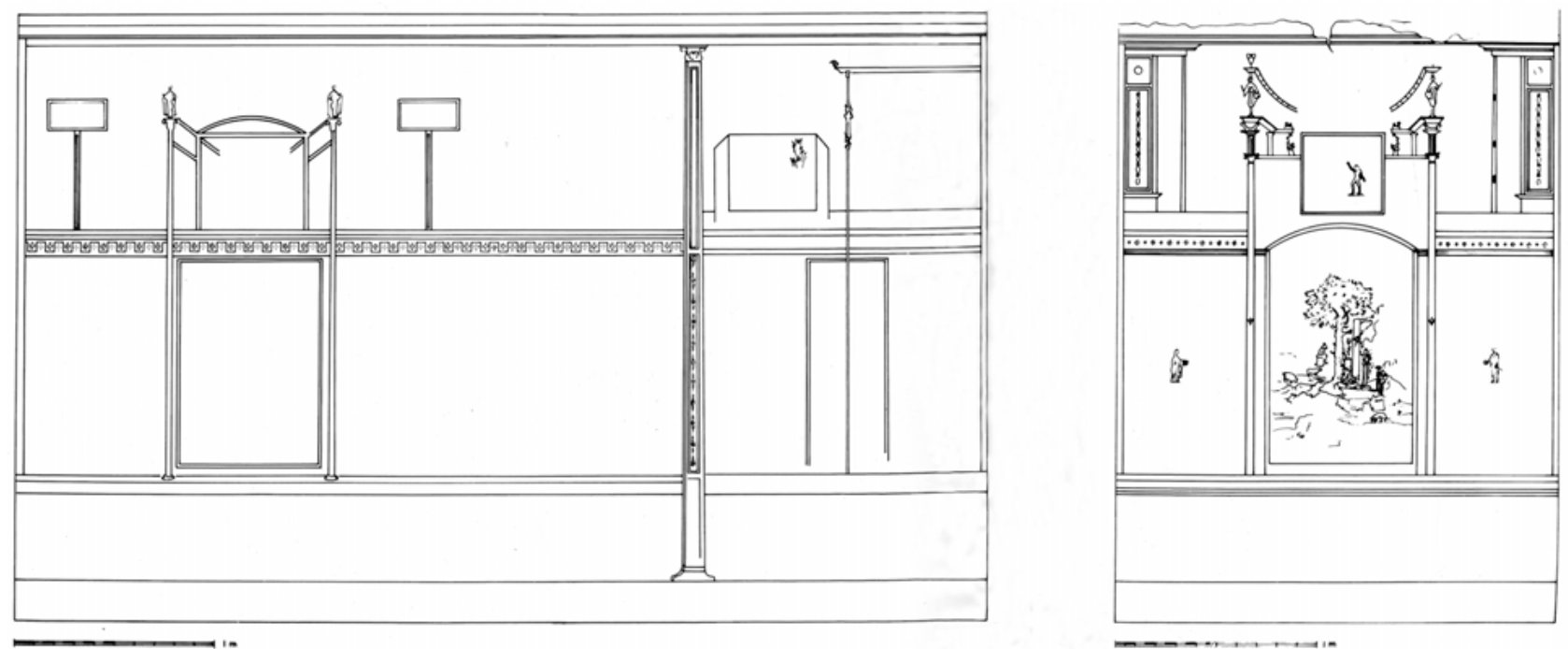

Seitenfelder können aber auch wie im Cubiculum (g) der Casa di Marcus Lucretius Fronto (Abb. 308-309) oder im Cubiculum (d) der Casa annessa alla Casa dell'Efebo (I 7,19) leer bleiben und auf diese Weise den mythologischen Mittelbildern zusätzliches Gewicht verleihen ${ }^{246}$. Im letztgenannten Fall handelt es sich um ausgesprochen kleinformatige quadratische Bildfelder, deren Figuren in reicher Polychromie auf schwarzem Grund angegeben sind. Sie suggerieren damit den Eindruck eines kostbaren Pinax, wobei die schwarzen, leeren Seitenfelder die Hintergrundfarbe des ,Pinax‘ wieder aufnehmen.

Die Mittelbilder müssen nicht notwendigerweise Mythenbilder zeigen, in das Zentrum können auch Landschafts- oder Genrebilder rücken. Auf der Rückwand von Cubiculum (f) der Casa annessa alla Casa dell'Efebo (I 7,19) rahmt eine Ädikula eine Sakrallandschaft, seitlich treten MusenVignetten hinzu (Abb. 355) ${ }^{247}$. In Cubiculum (4) der Casa dei Quadretti teatrali (I 6,11) ist die gerahmte Landschaftsdarstellung im Zentrum auf den seitlichen Feldern mit Siegpreisen für athletische Agone kombiniert ${ }^{248}$. Im Triclinium (H) der Domus VI 16,36.37 hebt eine Ädikula eine Genreszene (Bankett und poetischer Agon) ${ }^{249}$ im Wandzentrum hervor (Abb. 356). Die Kränze auf den Seitenfeldern rahmen das Geschehen und tragen dazu bei, dem Triclinium eine festliche Atmosphäre zu verleihen. In den späten dritten Stil gehört das riesige Tablinum (7) der Casa del Bell'Impluvio (I 9,1), dessen zentrale Ädikula mit Landschaftsdarstellung seitlich von einem perspektivischen Durchblick in Portiken hinein umgeben ist ${ }^{250}$.

In einigen seltenen Fällen wird die Wandmitte durch eine Nische oder ein Fenster besetzt. In der Exedra (47) der Casa delle Vestali (VI 1,7) handelt es sich um eine Konchennische ${ }^{251}$, die mutmaßlich für die Aufstellung von Skulpturen genutzt wurde.

Die Hierarchisierung der Wand erstreckt sich nicht nur auf die Mittelzone, in der das zentrale Feld gegenüber den seitlichen herausgehoben wird. Auch in Bezug auf die Vertikale wird das

246 PPM I (1990) 750-789 s. v. I 7,19, Casa annessa alla Casa dell'Efebo o di P. Cornelius Tages (A. de Vos) 772f. Abb. $37 \mathrm{f}$.

247 PPM I (1990) 750-789 s. v. I 7,19, Casa annessa alla Casa dell'Efebo o di P. Cornelius Tages (A. de Vos) $783 \mathrm{f}$. Abb. 57; Anguissola 2010, 101.

248 PPM I (1990) 361-396 s. v. I 6,11, Casa dei Quadretti teatrali (M. de Vos) 391-393 Abb. 53-58.

249 PPM V (1994) 981-995 s. v. VI 16,36.37 (V. Sampaolo) 987-993 Abb. 11-20.

250 PPM I (1990) 919-941 s. v. I 9,1, Casa del Bell’Impluvio (V. Sampaolo) 929-931 Abb. 16-20; vgl. Fuchs 1956, bes. $17 \mathrm{f}$.

251 PPM IV (1993) 4-49 s. v. VI 1,7, Casa delle Vestali (I. Bragantini) 43 Abb. 74; 44 f. Abb. 78. 
Abb. 356: Domus VI 16,36.37, Triclinium (H), Ostwand.

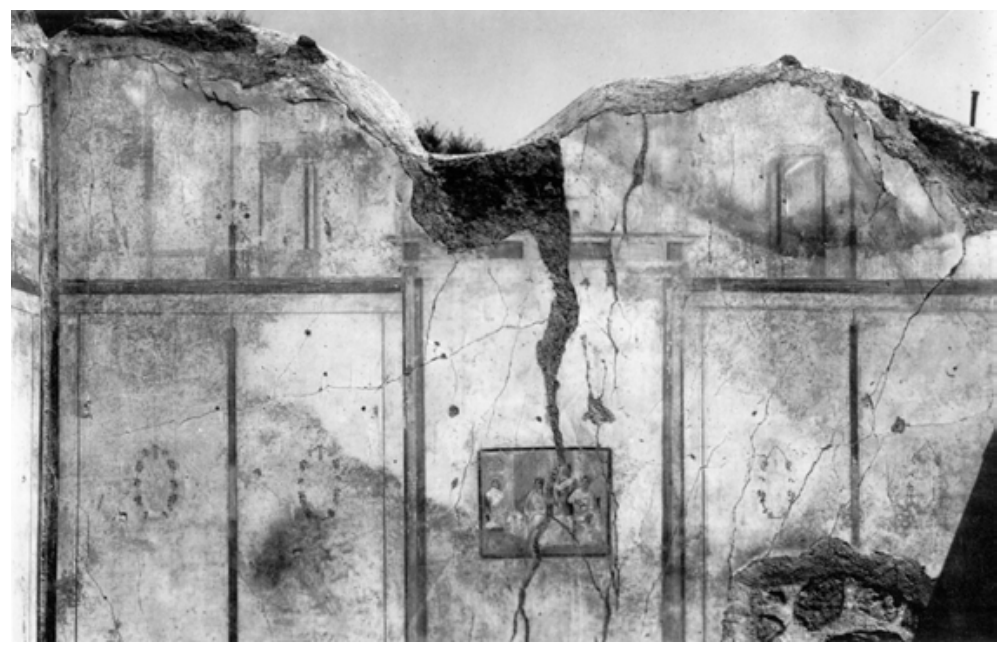

Wandzentrum betont - die Mittelzone hebt sich von der Sockel- und Predellazone sowie der Oberzone ab. Im Tablinum (h) nimmt die Sockelzone ein eingezäunter Garten ein, in der Oberzone wird ein perspektivisch konzipierter Architekturraum entfaltet. Eine vergleichbare thematische Aufladung der ,Randzonen' ist auch sonst zu beobachten. Für den Sockel wurden häufig geometrische Gliederungsmotive oder Pflanzen bzw. Gartendarstellungen gewählt, während sich in der Oberzone - letztlich in der Tradition des zweiten Stils - ein Architekturprospekt öffnet. Während die Sockelzone ,naturhaft' konzipiert ist, erscheint die Mittelzone als eigentliche ,Bildzone‘, die Oberzone als ,Architekturzone‘. Auch diese generelle Ordnung wird jedoch vielfach durchbrochen. Sockel- und Oberzone können ihrerseits für die Präsentation von Bildern genutzt werden. Diese an die Randzonen verlagerten Bildelemente zeichnen sich jedoch meist durch eine schwächere Bilddichte aus.

Diese Hierarchisierungen können in Abhängigkeit von der Zeitstellung des Raumes, vom Ausstattungsaufwand sowie von den intendierten Blicksituationen unterschiedlich ausfallen. Immer jedoch bestätigt sich die Vorstellung, dass Mythenbilder an oberster Stelle der Decor-Hierarchie stehen. Bei allen anderen Darstellungsinhalten - Pinakes, Landschafts- und Gartenbilder, ,Stillleben' und Einzelfiguren bzw. -motive - entscheidet die Präsentationsform (Rahmung/NichtRahmung; Größe; Farbigkeit, Platzierung, Repetition) über den ,Stellen-Wert‘.

Die axiale Decor-Ordnung, mit der eine hierarchisierte Bildordnung einherging, ist in einzelnen Fällen gezielt unterlaufen worden, um andersartige Effekte herzustellen. So hat man in manchen Aufenthaltsräumen einen stärker parataktisch organisierten Decor bevorzugt, wie er in Höfen beliebt war. Beispielhaft zeigt sich dies an Raum \{26\} im Obergeschoss der Casa del Moralista (III 4,2; Abb. 357). Auf der Südwand werden alle drei Felder von gerahmten Bildern besetzt. Auch wenn das zentrale Bild größer ausfällt und dadurch hervorgehoben ist, wirkt der Raum durch die parataktische Präsentation von gerahmten Bildern. Die Bildinhalte reagieren auf diese Präsentationsform. Im Wandzentrum ist ein dionysischer Thiasos dargestellt, zu dem auf der Seite die Darstellung eines Satyrs hinzutritt, der eine schlafende Mänade aufdeckt; das zweite seitliche Bild ist nicht erhalten ${ }^{252}$. Man darf wohl eine ,Sequenz' dionysischer Themen voraussetzen. 


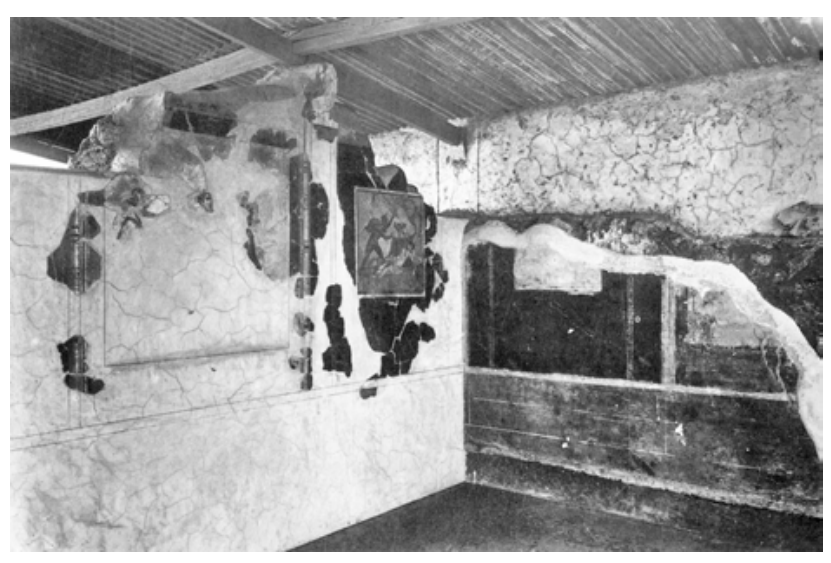

Abb. 357: Casa del Moralista (III 4,2), Raum $\{26\}$ im Obergeschoss, Süd- und Westwand.

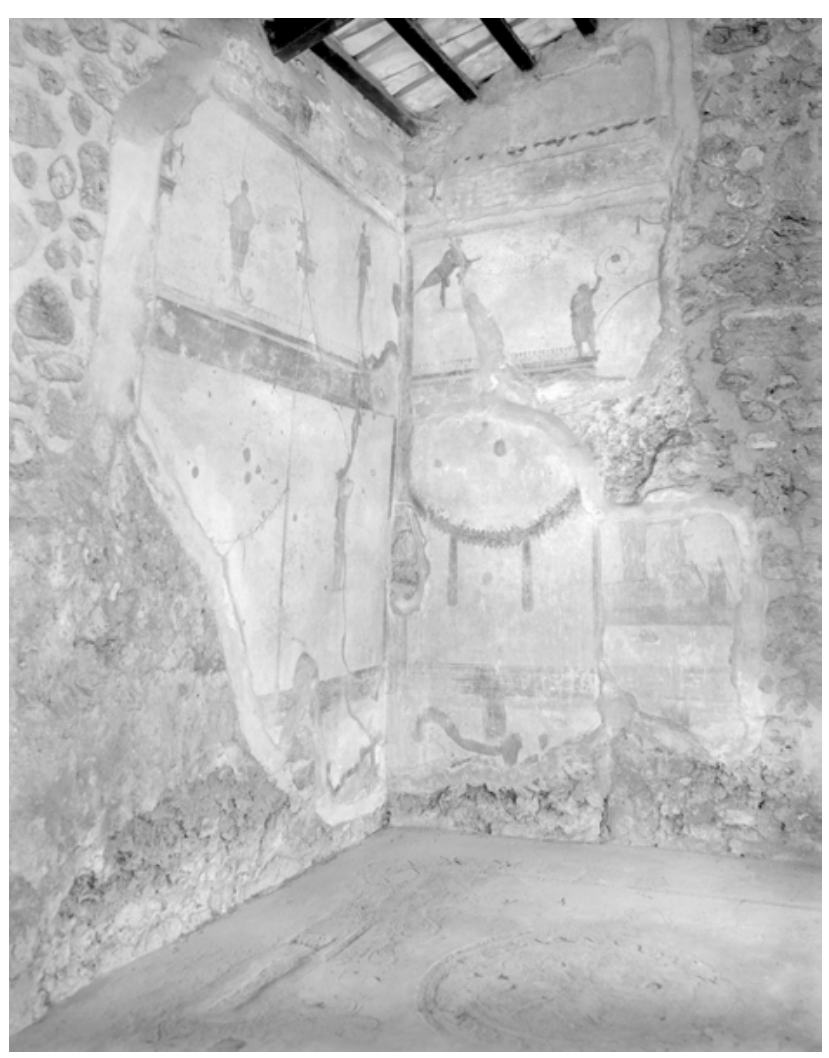

Abb. 358: Caserma dei gladiatori (V 5,3), Triclinium (n).

Eine eigenwillige Bildordnung wurde für den Klinenbereich des im Kandelaberstil ausgemalten Tricliniums (n) der Caserma dei gladiatori (V 5,3) gewählt (Abb. 358) ${ }^{253}$. Allein auf der Rückwand ist das zentrale Paneel durch ein Bildfeld mit Landschaftsdarstellung betont, während die seitlichen Felder von herabhängenden Girlanden gefüllt sind. Auf den Längsseiten des Raumes ist das Schema umgekehrt. Vor dem mittigen Paneel hängt eine Girlande, während in den Seitenfeldern stehende Figuren dargestellt sind. Durch diese Inversion ergibt sich im Klinenbereich ein eigener Rhythmus. Auf das Landschaftsbild im Zentrum folgen seitlich Girlanden, dann - über Eck -

253 PPM III (1991) 1069-1098 s. v. V 5,3, Caserma dei gladiatori (F. P. Badoni - F. Narciso) 1086 Abb. 39; 1092 f. Abb. 50. 
Abb. 359: Casa detta di Trebius Valens (III 2,1), Triclinium (d), Südwand.

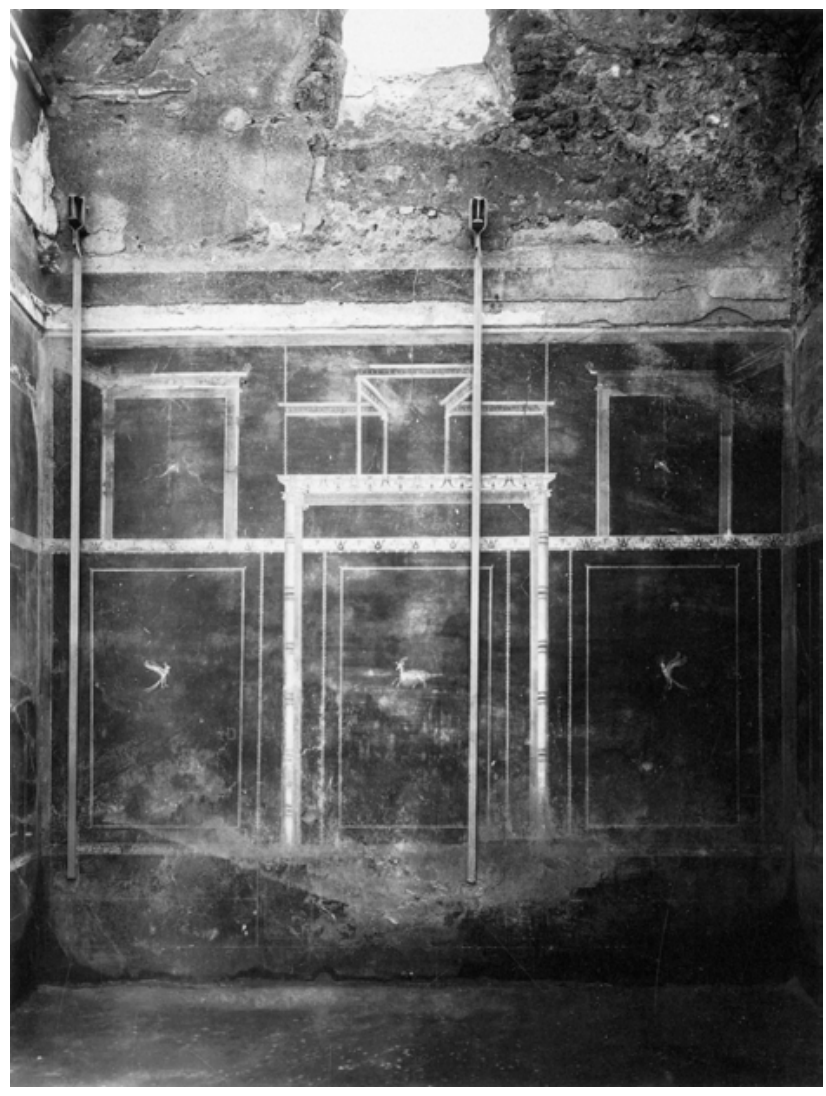

Bildfiguren, dann wieder eine Girlande und wieder eine Bildfigur. Es entsteht folglich ein ganz auf das Bild der Rückwand ausgerichteter Rhythmus, der auch die Seitenwände einschließt.

Wenn Bildlichkeit massiv zurückgenommen wird, stellt sich ein nochmals andersartiger Effekt ein. Dies konnte bereits für die Bebilderung von Atrien und Peristylumgängen beobachtet werden, bisweilen findet sich diese Decor-Form aber auch in Aufenthaltsräumen. Triclinium (d) der Casa detta di Trebius Valens (III 2,1) weist einen monochrom schwarzen Decor auf (Abb. 359) ${ }^{254}$. Auf einen Sockel folgt eine dreigeteilte Mittelzone mit Tiervignetten. Mit dem Verzicht auf komplexe Bilder kommt der weißen Ädikula-Architektur mit ihrer feinen Ornamentierung eine gesteigerte Aufmerksamkeit zu, während über die Vignetten-,Ornamente' eine parataktische Wahrnehmung der Wand befördert wird.

Einer eigenen Ausstattungslogik folgen Räume, die nicht als Pinakotheken, sondern als Gartenräume entworfen wurden ${ }^{255}$. In diesen Fällen suggerierten Gartenmalereien auf allen Wandseiten, dass sich die Raumnutzer im Freien befänden ${ }^{256}$. Mit den Cubicula (12) (Abb. 360) und (8) (Abb. 361) besitzt die Casa del Frutteto (I 9,5; Plan 7) gleich zwei solche Räume - einer davon am Atrium, der andere am Peristyl. In beiden Räumen sind die Wände durch filigrane Architekturen in Felder gegliedert ${ }^{257}$, durch die Interkolumnien blickt man auf einen regelhaft bepflanzten Garten, der zusätzlich durch (Bild-)Objekte ,kultiviert` ist. Das Wandzentrum wird durch die Bildobjekte nur subtil hervorgehoben.

254 PPM III (1991) 341-391 s. v. 2,1, Casa detta di Trebius Valens (I. Bragantini) 350f. Abb. 12.

255 De Carolis 1992, 30 zählt in Pompeji im Ganzen acht Fälle, während für 43 Peristyle/Viridaria eine entsprechende Ausmalung bezeugt ist.

256 Bei Varro rust. die Gegenüberstellung von oporothecae und pinacothecae.

257 Salvadori 2017, 44. 


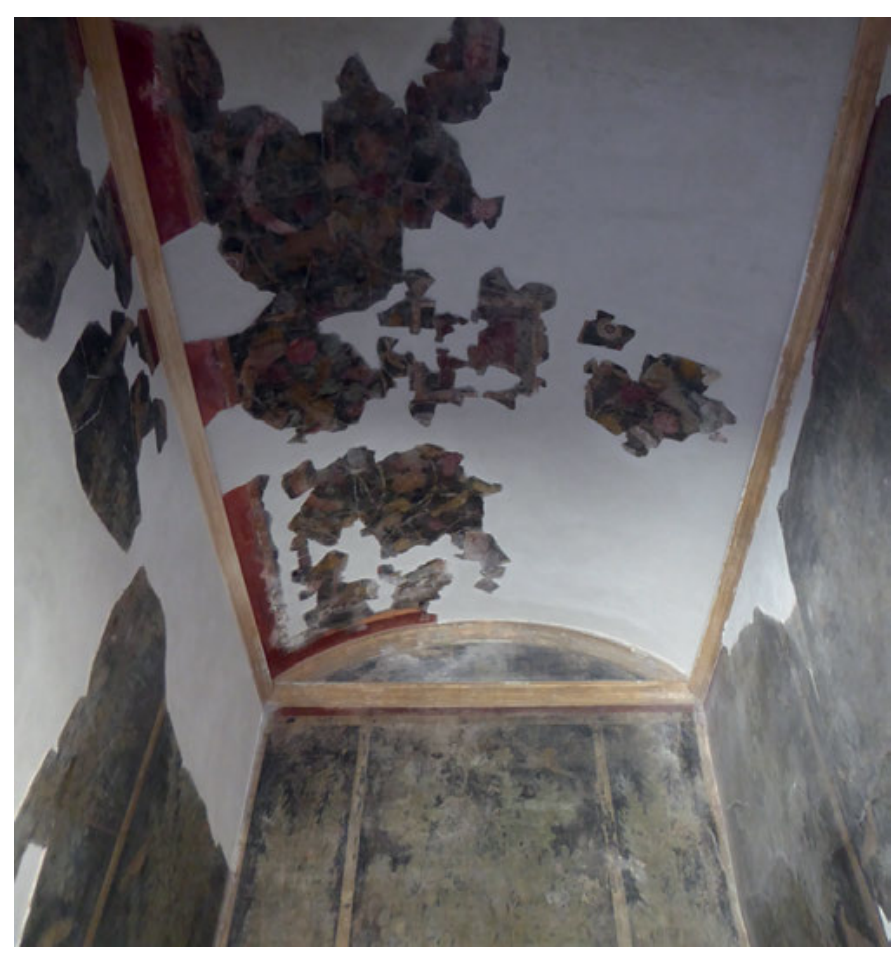

Abb. 360: Casa del Frutteto $(19,5)$, Cubiculum (12), Decke.

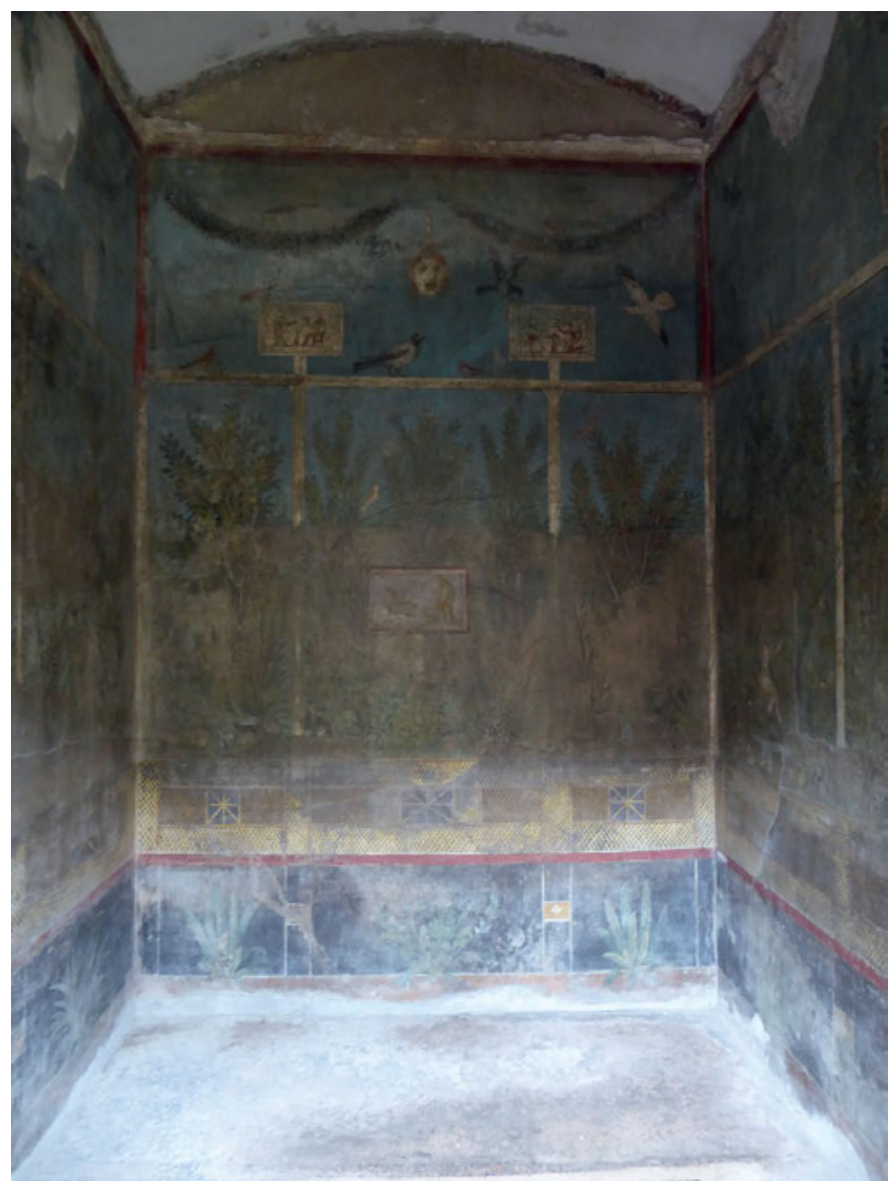

Abb. 361: Casa del Frutteto $(19,5)$, Cubiculum (8), Rückwand. 
In Cubiculum (8) folgt auf eine durch geometrische Linien dreigeteilte schwarzgrundige Sockelzone mit Pflanzen eine dreigeteilte Predella, die einen Gartenzaun vorstellt und dadurch Distanz schafft (Abb. 361) $)^{258}$. Der Garten ist nicht betretbar, der Betrachter wird auf Abstand gehalten. ,Dahinter entwickelt sich in der Mittelzone ein durch Säulchen in Felder gegliederter Garten, der durch Bildobjekte ,hierarchisiert' wird. Auf der Nordwand sind in jedem Feld großformatige Bildobjekte platziert - im Raumzentrum ist es ein Pinax auf einem Marmorständer mit der Darstellung von Bacchus und Ariadne, in den Seitenfeldern statuenhafte, ägyptisierende, stehende und sitzende Figuren ${ }^{259}$. Die Bildobjekte werden von einem dicht sprießenden, symmetrisch organisierten Pflanzenwuchs hinterfangen, hinter dem man in den blauen Himmel blickt. Der Detailreichtum, mit dem die Pflanzen angegeben werden, erlaubt es dem Betrachter, sie botanisch zu bestimmen ${ }^{260}$. In der Oberzone der Rückwand tragen die gliedernden Säulen Pinakes mit ägyptisierenden Opferszenen. Es treten weitere Motive hinzu, die in unterschiedliche materiell-kulturelle und naturhafte Kontexte verweisen: Masken und Gefäße, Oscilla, aber auch Vögel. Während Bacchus und Ariadne auf dem ,zentralen ' Pinax erscheinen, sind die ägyptischen Themen ,marginalisiert' - in Gestalt von Statuen auf den Seitenfeldern, auf Pinakes versetzt in die Oberzone. In Cubiculum (8) wird folglich ein kohärenter und homogen wirkender Gartenraum entworfen, der durch seine Architektur und die darauf bezogenen Bildobjekte eine gewichtete Struktur erhält. Kultur und Natur ${ }^{261}$, fremd und eigen, werden in ein ,System' gebracht.

Am Beispiel von Cubiculum (12) wird deutlich, wie die Decke eine solche Bild-Raum-Erfahrung weiter verdichten kann: Vor schwarzem Hintergrund wird ein richtiggehendes Blütenmeer entfaltet (Abb. 360). Durch den Decor werden die Innenräume zum Außenraum, die Heterotopie ${ }^{262}$ des Gartens wird in den Raum eingeholt. Das Gartenbild wird zur ,Umgebung', ohne jedoch betretbar zu sein.

\section{Raum, Wandsystem, Bilder und wahrnehmender Betrachter}

Die Diskussion der Wandlösungen hat offengelegt, dass das Raumvolumen, das Gliederungssystem der Wand, die Formen der Bildpräsentation und die Bildinhalte in Abhängigkeit voneinander gewählt wurden. Der auf verschiedenen Skalen entfaltete Zusammenhang von Architektur und Decor legt nahe, dass die Decor-Strategien bestimmte Wahrnehmungsformen stimulieren sollten.

Indem die Bilder nicht mehr am Boden, sondern an der Wand erscheinen, von filigranen Rahmen umgeben, entsteht der Eindruck einer Pinakothek oder aber eines virtuellen Gartenraumes. Nicht alle Bilder einer Wand stehen jedoch gleichermaßen ,im Fokus', da sich die Bilder in ihrer Anbringungshöhe unterscheiden. Einige befinden sich auf Kniehöhe, andere hoch über den Köpfen der Betrachter. Privilegiert sind naheliegender Weise jene auf Oberkörperhöhe, in der Mittelzone der Wand. An diesem herausgehobenen Ort sind die großen zentralen, meist mythologischen Bildfelder platziert. Sie werden zum Gegenüber ihrer Betrachter, der ihnen ,auf Augenhöhe‘ entgegentritt. Die anderen, tiefer oder höher angebrachten Bilder nimmt er entweder nur oberflächlich wahr oder aber er muss seine Haltung der Bildplatzierung anpassen, etwa in die Hocke gehen, um die Bilder gut sehen zu können.

Die axialsymmetrische Platzierung der Mittelbilder lädt zu einer vergleichenden Betrachtung ein. Dabei ist die soziale Aneignung eines Aufenthaltsraums in Rechnung zu stellen, aus der

258 PPM II (1990) 1-137 s. v. I 9,5, Casa dei Cubicoli floreali o del Frutetto (M. de Vos) 16-31 Abb. 25-43.

259 Jashemski 1979, 74 schließt aus den repräsentierten Bildwerken methodisch unzulässig auf die religiöse Haltung des Hausbesitzers; zur ,Gartenausstattung‘ Salvadori 2017, $54 \mathrm{f}$.

260 Leach 2004, 125 als „catalogue of species or a conversation piece“.

$261 \mathrm{Zu}$ den Objekten schreibt Bergmann 2018a, 291, dass sie „showcased a state-of-the-art cultivation in the early Empire, when Egyptianizing motifs and Nilotic landscapes became standard features in garden displays.”

262 So Anguissola 2010, 107. 
sich Asymmetrien ergeben. Bei Cubicula mit rückwärtig aufgestellter Kline blickt allein der Eintretende auf das ,zentrale‘ Mythenbild, während die Liegenden diesem den Rücken zukehren. In einem Triclinium ist für die Klinennutzer jeweils das hinter ihnen platzierte Bild unsichtbar. Insbesondere in Cubicula und Triclinia mit visuell abgesetztem Klinenbereich stehen die Klinen unmittelbar vor den Bildpaneelen, sodass die Lagernden immer einen Teil des Bildes verdeckt haben müssen. Detaillierte komparative Analysen der Mittelbilder setzen einen unmöblierten, unbevölkerten Raum und einen am Eingang stehenden Betrachter voraus ${ }^{263}$. Geht man aber von einer aktiven Nutzung des Raumes aus, so können die Mythenbilder nicht immer in vollem Umfang sichtbar gewesen sein, ihre Ikonographie damit auch nicht im Detail verständlich. Dennoch muss eine intensive Analyse von Bild-Ensembles nicht an der Realität vorbeigehen: Bildinhalte können selbst, wenn sie nicht für alle einsehbar waren, durch die Kommunikation der Anwesenden geteilt worden sein. Die Bilder können die Klinennutzer auch dazu eingeladen haben, ihren Platz zu verlassen, auf die Darstellungen ,zuzugehen', sich im Raum zu bewegen, um die Ensembles einer vergleichenden Analyse zu unterziehen.

Neben der Platzierung stellt die Größe der Bildelemente einen entscheidenden Faktor für die Wahrnehmung dar. Der Ort der Präsentation innerhalb des Wandsystems sagt per se noch nichts über die Bildgröße aus. Im prunkvollen Triclinium (f) der Casa di Giasone oder auch im Oecus (19) der Casa del Citarista (I 4,5.6.25.28; Plan 5) nehmen die Mittelbilder riesige Maße an und sind hoch über den Köpfen der Betrachter platziert, sodass sie von allen Raumteilen aus bis in ihre Details erkennbar sind ${ }^{264}$. In kleinen Cubicula hingegen können Mittelbilder die Größe von Pinakes annehmen, die eine besondere Nahsicht einfordern. Eines von beliebig vielen Beispielen wäre Cubiculum (c) der Casa di Marcus Lucretius Fronto (Abb. 303-305). Folglich sind auch Raumgrößen und die Größen der Mittelbilder aufeinander bezogen. In großen Räumen sind Mittelbilder auf eine relative Fernsicht kalkuliert, während sie in kleinen Räumen die Größe von Kabinettstücken annehmen. Eine verbindliche Regel stellt dies jedoch nicht dar. In dem mittelgroßen TricliniumCubiculum (20) der Casa del Citarista (I 4,5.6.25.28; Plan 5) besitzen die Bilder im Verhältnis zum Raum ausgesprochen große Maße (Abb. 366) ${ }^{265}$.

Darüber hinaus ist für die ,Präsenz‘ des Bildes die Figurengröße entscheidend. Während sie auf Landschaftsbildern zur Staffage der Szenerie werden und auf Pinakes schon durch das Bildformat klein ausfallen, können sie auf Mythenbildern ganz in den Vordergrund rücken ${ }^{266}$. In diesem Fall ist der Betrachter mit ,großen` Akteuren konfrontiert, die sich geradezu in den Raum drängen, eine hohe Präsenz entfalten und mit dem Betrachterkörper konkurrieren. Die verschiedenen Bilder eines Raumes können folglich auch mit verschiedenen Figurengrößen operieren. Im Tablinum (h) der Casa di Marcus Lucretius Fronto beherrschen die mythischen Protagonisten die Mittelbilder, während die rahmenden Landschaftspinakes von geradezu ,verschwindend“ kleinen Figuren bevölkert werden. In Triclinium (b) der Casa del Sacerdos Amandus (I 7,7) ${ }^{267}$ treten neben

263 Strocka 2007, 302 geht indes recht pauschal von weitgehend ,leeren', d.h. spärlich möblierten Räumen aus, in denen ein freier Blick auf die Wände möglich gewesen sei. Gerade für die Aufenthaltsräume lässt sich diese zu pauschale Ausgangsthese jedoch spezifizieren.

264 PPM IX (1999) 670-719 s. v. IX 5,18, Casa di Giasone (V. Sampaolo) 693-697 Abb. 35-38; PPM I (1990) 117-177 s. v. I 4,5.25, Casa del Citarista (M. de Vos) 146f. Abb. 51. Eine Rekonstruktion bei Bergmann 2014, 79 Abb. 9. Allerdings werden die Dimensionen darin gerade nicht erfahrbar, weil das Betrachterauge knapp über dem Boden platziert ist.

265 PPM I (1990) 117-177 s. v. I 4,5.25, Casa del Citarista (M. de Vos) 149-153 Abb. 54-61; vgl. Rekonstruktion bei Bergmann 2014a, Abb. 10.

266 Ausführlich zu den Gestaltungsoptionen von Mythenbildern, s. u. S. 447-454.

267 Bei dem vierten Bild, Hercules bei den Hesperiden, nehmen die Figuren eine prominente Rolle ein. Es handelt sich um die besonders betonte, dem Eingang gegenüberliegende Nordwand des Raumes. Entweder wird die Figurengröße als Mittel der Wandakzentuierung eingesetzt, oder aber - so vermutet bei Valeria Sampaolo (PPM I (1990) 586-617 s. v. I 1,7, Casa del Sacerdos Amandus (V. Sampaolo) 587) - es handelt sich um eine Erneuerung im vierten Stil. Da sich die Figurenzeichnung deutlich von den anderen Bildfeldern unterscheidet, ist Sampaolos Annahme zuzustimmen. Der visuelle Effekt der Betonung der Nordwand ergab sich erst mit Erneuerung des Hercules-Bildes. 
die mythologischen Landschaftsbilder mit ihren kleinen Akteuren in den seitlichen Paneelen Vignetten mit isolierten Einzelfiguren. Während die Protagonisten auf den Mythenbildern jedoch in einen Handlungsrahmen eingebunden sind, erhalten sie auf den Seitenpaneelen eine geradezu ornamenthafte Wirkung ${ }^{268}$. Die Figurengröße hat damit wie auch die Kontextualisierung der Akteure einen nachhaltigen Einfluss auf die Betrachtungsintensität und die Aufmerksamkeit des Betrachters.

Nicht zuletzt erzeugen die Bildinhalte selbst spezifische Wahrnehmungshaltungen. Mythenbilder fordern aufgrund ihrer narrativen Dichte eine höhere Betrachtungsintensität ein als beiläufig wahrnehmbare Architektur- und Landschaftsbilder oder Vignetten von geflügelten Gestalten. Insbesondere Mythendarstellungen bieten sich für ein Eintauchen in das Bild an. Der Betrachter vermag das Verhältnis zum erzählten Mythos auszuloten, sich auf die Erzählstrategien einzulassen oder über die Verbindung zwischen den Mythenbildern eines Raumes nachzudenken (s. u.).

Kleinformatige Landschaftsbilder wie die Pinakes im Tablinum der Casa di Marcus Lucretius Fronto sowie Landschaftsvignetten führen die Landschaft aus einer Vogelperspektive vor ${ }^{269}$. Dieser (unwirkliche) Standpunkt erlaubt einen ,Überblick', der Betrachter kann sich dem Ausblick aus der Distanz hingeben. Dies befördert eine beiläufige, überblicksartige Wahrnehmung. Häufig sind diese Bilder mit Architekturen, darunter villenartige Anlagen oder Heiligtümer, mit Kultmalen sowie wie mit winzigen Menschenfiguren angereichert, die es erlauben, sich länger im Bild zu verlieren. Landschaftselemente - Bäume und Sträucher - entwickeln sich ,freier‘ als in den eingezäunten Gärten. Bilder spielen so mit Nähe und Distanz, flüchtiger und intensiver Wahrnehmung.

Vollständig als Gartenräume ${ }^{270}$ ausgemalte Cubicula wie jene der Casa del Frutteto (I 9,5), die den Betrachter allseitig auf Höhe des Oberkörpers und über Kopfhöhe umgeben, bieten ihm eine Immersion in das Naturambiente an. Er nimmt den Garten auf Augenhöhe und über dem Kopf wie einen realen Naturraum wahr. Pflanzen sind in hoher Detailtreue wiedergegeben, die in den Garten integrierten Bildobjekte sind als ,reale‘ Gartenausstattungen denkbar. Der Garten ist aber architektonisch gefasst, durch Säulen gegliedert, und der Betrachter wird durch Zäune ,auf Abstand“ gehalten. Durch die parataktische Ordnung der ,Ausblicke‘ gewinnt der Garten eine bildhafte Dimension. Die Garten-Fiktionen eröffnen so ein Spiel mit Nähe und Ferne, mit Zugänglichkeit und Abgeschlossenheit, mit Bild und Realität.

Wird ein Garten als geometrisch eingezäunte, menschenleere Grünfläche in Vogelperspektive gezeigt, ist die Distanz weiter gesteigert, die Gartenidee zugleich einer Abstraktion zugeführt. Häufig werden solche Garten-Axonometrien wie im Tablinum der Casa di Marcus Lucretius Fronto in der Sockelzone vor schwarzem Grund gezeigt, sodass der Betrachter tatsächlich von oben auf sie hinunterblickt. Sie können aber auch in der Oberzone angebracht sein, sodass der Betrachterblick und die Bildperspektive einander zuwiderlaufen ${ }^{271}$.

Wieder anders fällt das Betrachterangebot von ,Stillleben` aus, die ihre (unbelebten wie auch belebten) Gegenstände in Aufsicht zeigen. Allerdings werden die Objekte in Realgröße oder, je nach Anbringungsort, in erheblich gesteigerter Größe repräsentiert. Sie sind für den Betrachter zum Greifen nah und laden so zu einer ästhetisch aufgeladenen Detailbetrachtung ein. Die zahllosen figürlichen Bild-Ornamente, mit denen Wände dritten Stils aufgeladen sind, erlauben schließlich gleichermaßen eine oberflächliche Wahrnehmung wie ein Verlieren im Detail.

Raumgröße, Bildgröße, Präsentationsform, Figurengröße, Bildinhalt und Betrachterhaltung bedingen sich folglich gegenseitig. Vor allem aber ist für die Form der Wahrnehmung die Dichte an Decor-Elementen in Rechnung zu stellen. Besitzt ein Raum nur wenige gegenständliche Darstellungselemente wie etwa das Atrium der Casa di Marcus Lucretius Fronto, so fallen diese

268 Zum Aspekt der Schwerelosigkeit schwebender Figuren in der Wandmalerei, s. Augris 2017.

269 Bergmann 2018a, 282f.

270 Bergmann 2018a, 287-293.

271 Bergmann 2018a, 279. 
stärker ins Auge. Im geradezu überladenen Tablinum (h) desselben Hauses konkurrieren jedoch zahlreiche Bildelemente miteinander.

Zusammenfassend zeigt sich, dass die Decor-Räume durch die jeweiligen Gestaltungsstrategien bestimmte Wahrnehmungsformen stimulieren. Mythenbilder werden gezielt ,in den Fokus‘ gerückt, drängen sich für eine vergleichende Wahrnehmung auf. Allerdings kann der Betrachter auf die vielfältigen Wahrnehmungsoptionen und -angebote in ganz unterschiedlicher Weise einsteigen. Überblickt er einen Raum wie das Tablinum der Casa di Marcus Lucretius Fronto als Ganzes, werden die zahlreichen Bildelemente zu Ornamenten. Lässt er sich auf eine intensive Wahrnehmung einzelner ,Darstellungen“ ein, vermag er ihnen den Status von Bildern zu verleihen. ,Bild' und ,Ornament' sind folglich zwar durch die Gestaltungsform vorstrukturiert, aber durch die Wahrnehmungshaltung modellierbar.

\subsection{Mythenbilder: Erzählstrategien und Wahrnehmungsoptionen}

Mit den Mythenbildern soll im Folgenden ein Darstellungselement näher betrachtet werden, das sich aufgrund seiner erzählerischen Komplexität für eine besonders intensive Betrachtung anbot. Das Verhältnis von Bild und Text konnte sich sehr unterschiedlich ausnehmen ${ }^{272}$. Dabei wird das narrative Potential durch die Bildkomposition vorstrukturiert: Mythologische Landschaftsbilder platzieren das Geschehen in einer Landschaft, sodass die mythischen Protagonisten wie die Figuren in ,reinen' Landschaftsbildern ausgesprochen klein ausfallen, während ,Figurenbilder' die mythischen Protagonisten in den Vordergrund rücken.

Mythologische Landschaftsbilder nutzen den Landschaftsraum, um verschiedene Episoden der Mythenerzählung in einem Bild zu ,montieren ${ }^{6273}$. Im Triclinium (EE) der Casa di C. Iulius Polybius (IX 13,1-3) $)^{274}$ hat das große Mythenbild (2,44×1,54 m) in der Mittelädikula der Ostwand die Bestrafung der Dirke zum Thema (Abb. 362). Der ausführlich geschilderte Landschaftsraum gliedert verschiedene Episoden ein und derselben Erzählung. Das Zentrum des Bildes wird von einem ländlichen Bacchus-Heiligtum mit archaistischer Bacchus-Statue dominiert. Dieses ruhige Bildmotiv schafft einen ambientalen, sakralidyllischen Rahmen für das dramatische Geschehen, steht aber nicht unmittelbar damit in Beziehung. Am linken Bildrand, vor dem Bacchus-Heiligtum, führt Dirke eine Gruppe von Bacchantinnen an, während sie von Zethus und Amphion ergriffen wird. Am rechten Bildrand vollzieht sich die Bestrafung; Dirke ist bereits an einen wild springenden Stier gebunden, von dem sie zu Tode geschleift werden wird. Es bleibt dem Betrachter überlassen, die Verbindung zwischen den beiden ,herausgegriffenen' Szenen herzustellen - der wenig prägnanten Kultszene und der Schlüsselszene der Schleifung. Im Bildhintergrund wird der Betrachter in eine sakralidyllische Welt mit Hirten und Hunden entführt. Die Landschaftsdarstellung, die für den erzählten Mythos weitgehend irrelevant ist, tritt in den Dienst einer visuell-räumlichen Gliederung des mythischen Geschehens.

272 Die anhand griechischer Bildwerke entwickelte Terminologie synoptisch/monoszenisch/kontinuierend führt hier nur bedingt weiter; s. Robert 1881; Wickhoff 1912, 9-17; Weitzmann 1947; Snodgrass 1982; ein Überblick zur Forschungsgeschichte bei Schörner 2014, 356-359; zu visuellen Narrationen im römischen Kontext, s. Brilliant 1984, dessen Interesse jedoch weniger der narrativen Ausgestaltung des Einzelbildes, sondern den Bildkombinationen gilt. 273 Allgemein Dawson 1965; konkret Bergmann 1999, 89.

274 PPM X (2003) 183-356 s. v. IX 13,1-3, Casa di Polibio (I. Bragantini) 256 Abb. 115; das Bild ist ausführlich diskutiert bei Leach 1986. 
Abb. 362: Casa di C. Iulius Polybius (IX 13,1-3), Mythenbild der Ostwand von Triclinium (EE): Bestrafung der Dirke.

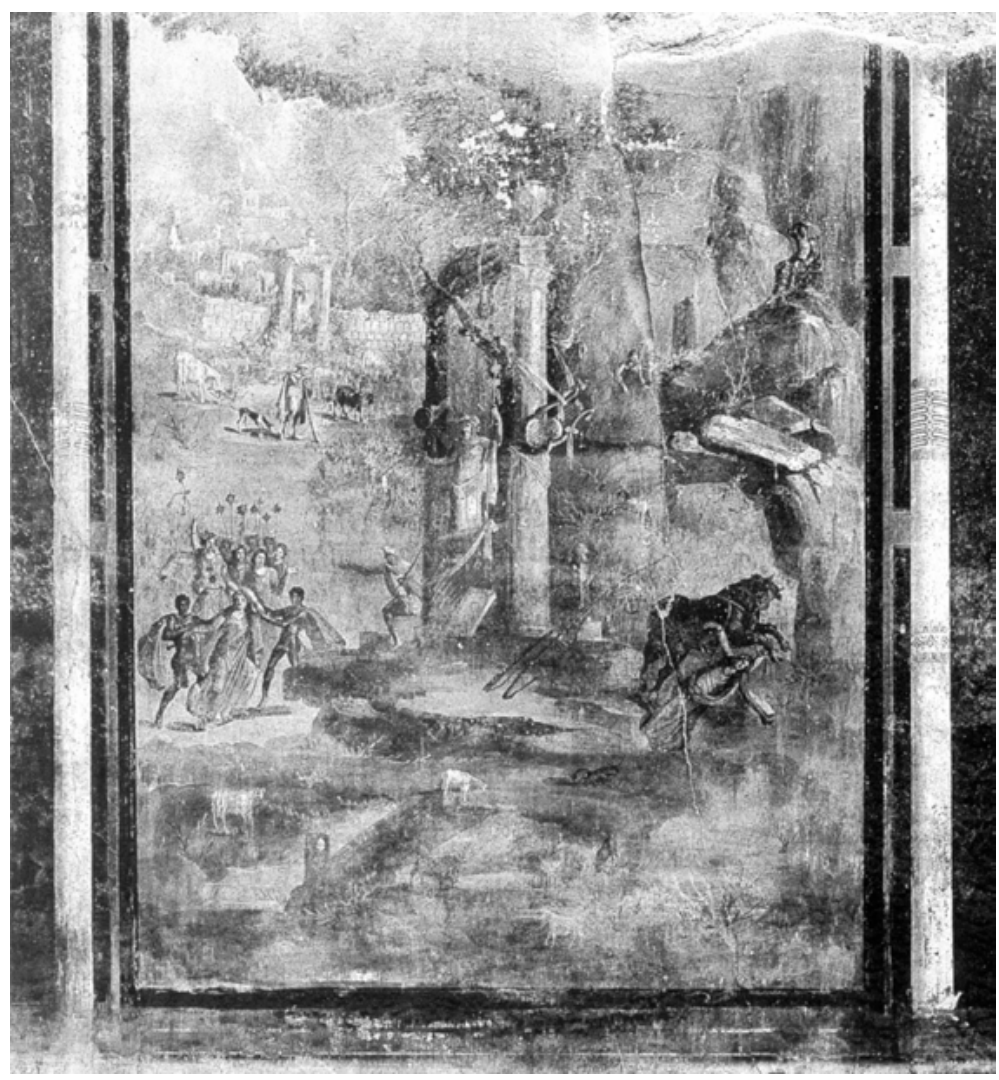

Der durch Landschaftselemente strukturierte Erzählraum kann auch dazu eingesetzt werden, unterschiedliche inhaltliche Ausdeutungen eines Mythos zueinander in Beziehung zu setzen. Ein besonders prägnantes Beispiel ist die Darstellung von Mars und Rhea Silvia im Triclinium (R) der Casa delle Origini di Roma (V 4,13; Abb. 363) $)^{275}$. Mars steigt im Stil eines Liebhabers zur schlafenden Rhea Silvia herab - das Bild wird als Thematisierung einer Paarbeziehung verständlich. Im Vordergrund verweisen eine Ortspersonifikation, Mercur und eine weibliche Figur auf einen politischen Deutungsrahmen: Das Geschehen wird zur Gründung der Stadt Rom führen. Eine sinnlicherotische und eine politisch-historische Auffassung des Mythos werden über zwei ,konkurrierende، Episoden aufeinander bezogen.

Landschaftselemente können jedoch auch ein regelrechtes Eigenleben entwickeln. Im Fall des Icarus-Bildes in Triclinium (b) der Casa del Sacerdos Amandus (I 7,7 ${ }^{276}$ sind im Vordergrund zwei voll besetzte, kleine Boote dargestellt, deren Ruderer gestikulierend zum Himmel schauen, wo sich das dramatische Geschehen abspielt (Abb. 350). Im Bildmittelgrund, am rechten Bildrand, zieht eine in Vogelperspektive, höchst detailreich wiedergegebene, bewehrte Stadt die Aufmerksamkeit des Betrachters auf sich. Sie steht vermutlich für Kreta, führt jedoch von der mythischen Narration weg und bringt ein attraktives Landschaftselement in das Bild ein. Das Bild divertiert, indem es ein verweilendes Betrachten einfordert und zugleich ein Schweifen des Blicks provoziert. Unterhaltung wird nicht über die narrative Komplexität, sondern über die vielfältigen visuellen Details erreicht.

275 PPM III (1991) 1062-1068 s. v. V 4,13, Casa delle Origini di Roma o di M. Fabius Secundus (I. Bragantini) 1064 Abb. 4; Dawson 1965, 103f.; Peters 1963, 88f.

276 Dawson 1965, 98f.; Peters 1963, 91-95; PPM I (1990) 586-617 s. v. I 7,7, Casa del Sacerdos Amandus (V. Sampaolo) 590 Abb. 5; 595 Abb. 11; 599 Abb. 15; 603 Abb. 20. 


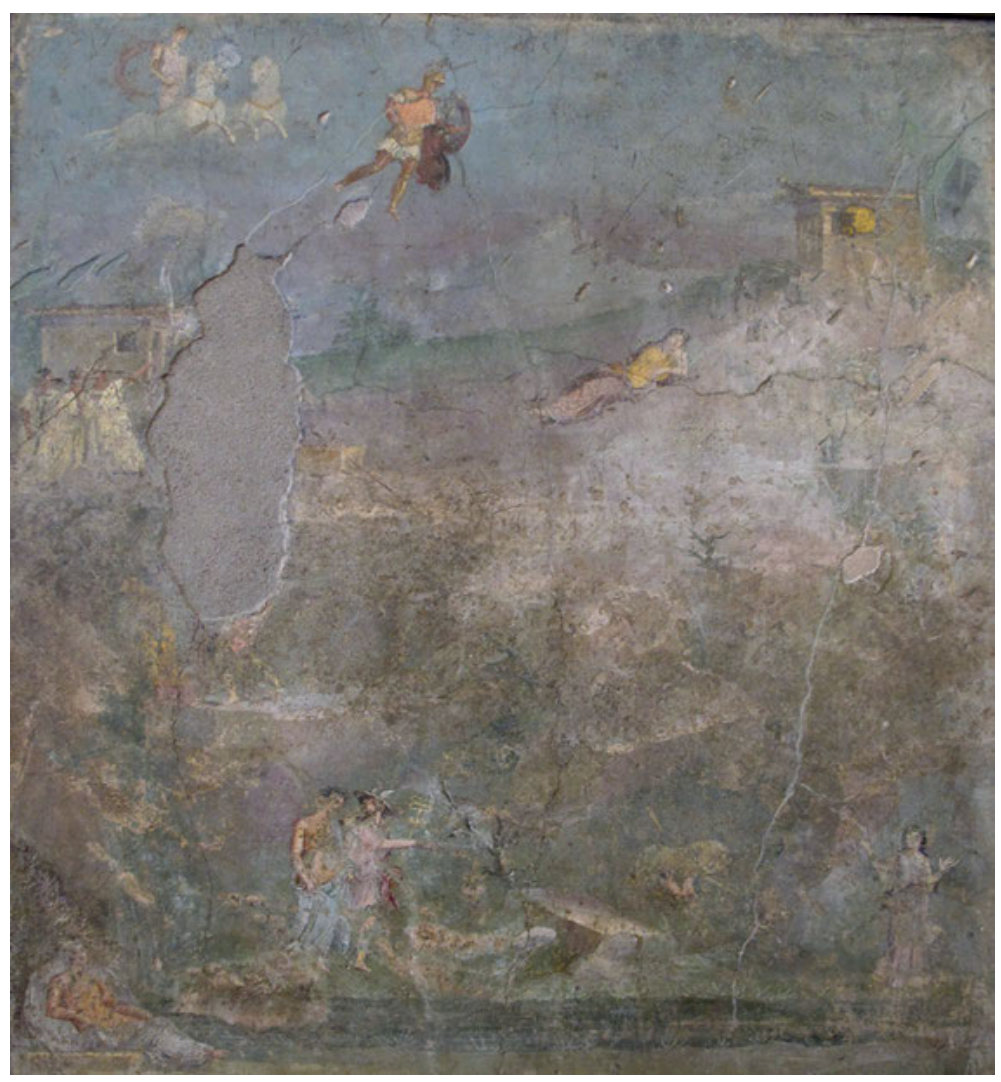

Abb. 363: Casa delle Origini di Roma (V 4,13), Mythenbild der Nordwand von Triclinium (R): Mars und Rhea Silvia (Neapel, NM o. N.).

Das Interesse an der Landschaft kann so weit gehen, dass die Narration ganz in den Hintergrund tritt. Auf der Ostwand von Triclinium (b) der Domus IX 7,16 ${ }^{277}$ begleitet Athena inmitten eines sakral aufgeladenen Landschaftsambientes Bellerophon zu dem im Bildvordergrund an einer Wasserquelle trinkenden Pegasos (Abb. 364). Hier geht es nicht um die Vorführung einer mythologischen Narration, vielmehr werden mythologische Protagonisten zu Statisten in einer sakralidyllischen Szenerie.

Mit der Fokussierung auf wenige, klar benennbare Protagonisten geht der Verzicht auf eine Darstellung verschiedener Episoden einher. Solche ,übersichtlichen' Bilder werden sich im vierten Stil immer mehr durchsetzen. Auf der Rückwand von Triclinium (f) der Casa di Giasone wird dieser Darstellungsmodus gewählt, um das Bild auf einen ganz konkreten Moment der Narration das Zusammentreffen von Iason und Pelias - zuzuspitzen (Abb. 268) ${ }^{278}$. Im Zentrum des Bildes steht eine hexastyle Tempel- oder Palastarchitektur, zu der vier Stufen hinaufführen ${ }^{279}$. Auf den oberen Treppenstufen steht ein bärtiger und bekränzter Mann, der durch ein Zepter in seiner linken Armbeuge als König charakterisiert ist. Er reicht seine rechte Hand der links unterhalb von ihm stehenden Frau, während sich eine zweite Frau rechts hinter ihm befindet. Rechts unterhalb der Treppe wendet sich ein jugendlich-bartloser Mann im Reisegewand (Chlamys) und mit Stab ausgestattet zur Bildmitte hin. Auffällig ist ein ikonographisches Detail: Er trägt nur einen Schuh. Hinter ihm befindet sich ein Tisch, auf und vor dem Gefäße stehen. Auf der anderen Seite des Tisches steht ein bekränzter bartloser Diener, der sich ihm zuwendet und im Begriff ist, auf dem

277 PPM IX (1999) 782-814 s. v. IX 7,16 (V. Sampaolo) 794f. Abb. 21.; Dawson 1965, 83; zur Singularität Hodske 2007, 229.

278 Beschreibung bei Mau 1880, 79-81; Peters 1963; Bergmann 2002, 26f.; Lorenz 2008, 426.

279 Peters 1963, 99; anders Lorenz 2008, 426, die für Raum (f) pauschal von „Palastkulisse“ spricht - ohne dabei den hexastylen Bau explizit zu nennen - und auch ohne Rekurs auf den Opferstier, der m. E. die Deutung der Architektur als Tempel zusätzlich sichert. 
Abb. 364: Domus IX 7,16, Aquarell des ,Mythenbildes' der Ostwand von Triclinium (b): Athena und Bellerophon.

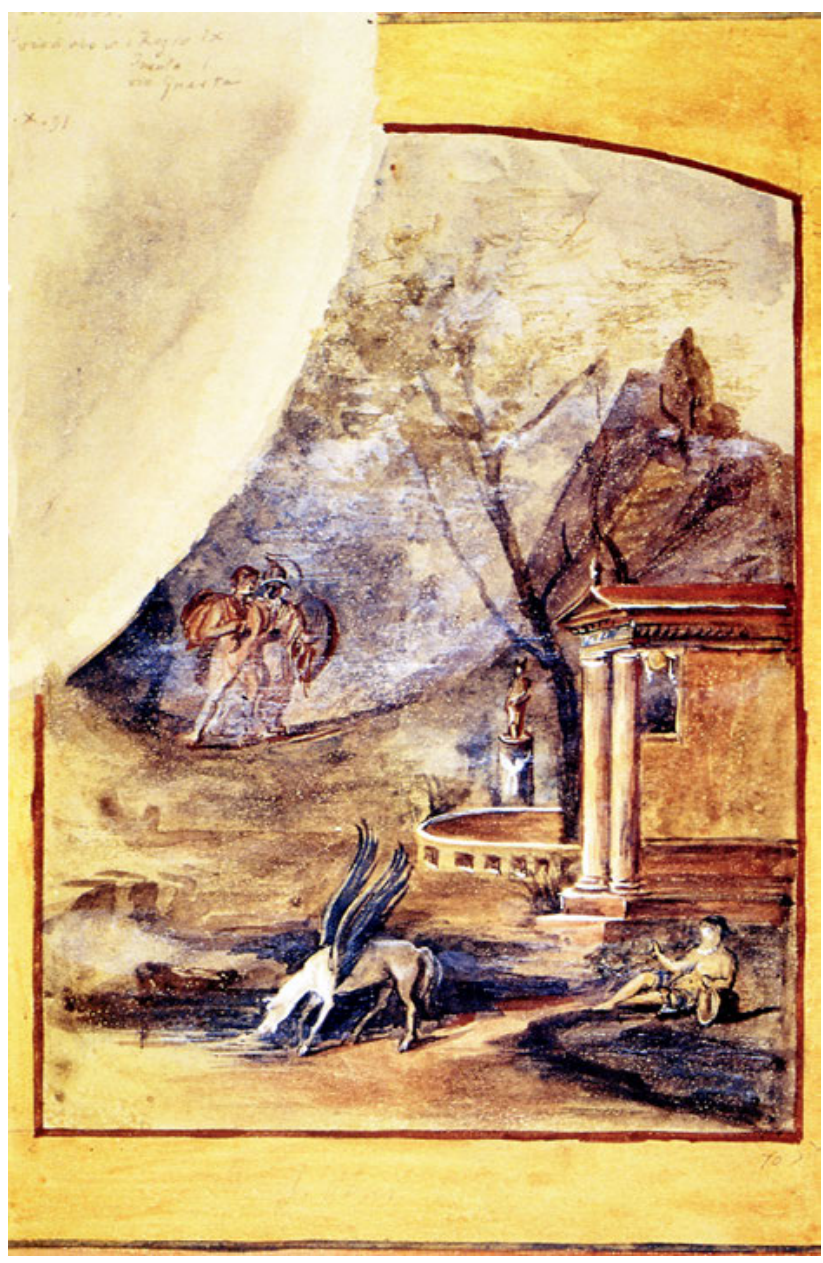

Tisch eine Patera abzustellen ${ }^{280}$. Links vor der Treppe ist ein jugendlicher Mann mit Tunica und Mantel dabei, einen (Opfer-)Stier zu bekränzen. Auch er wendet sich, wie der Stier, zur Bildmitte hin. Der fehlende Schuh wird zum Schlüssel für das Verständnis der gesamten Szene. Pelias erkennt den Ankömmling, da ihm vom Orakel angekündigt worden war, dass Iason, der sein Erbe fordern wird, nur einen Schuh tragen würde. Pelias, als König von Iolkos charakterisiert, wohnt im Beisein seiner Töchter einer Opferzeremonie bei, als Iason, der einseitig Beschuhte, auftaucht ${ }^{281}$. Es ist hier der szenische Zusammenhang, der in Verbindung mit dem ikonographischen Detail die Benennung zuverlässig sichert. Das Bild zeigt den schicksalhaften Moment des Aufeinandertreffens des bisherigen und künftigen Herrschers von Iolkos. So übersichtlich die Bildkomposition ausfällt: Der Sinn der Szene erschließt sich - eine gute Mythenkenntnis vorausgesetzt - erst auf den zweiten Blick. Dann aber wird es möglich, das Bild auf einen besonders dramatischen Moment einer Narration zu beziehen.

Auf anderen Mythenbildern wie auf der Nordwand von Tablinum (26) der Casa del Centauro (VI 9,3.5; Plan 17; Abb. 365) ${ }^{282}$ sind die Figuren durch Attribute eindeutig charakterisiert, ohne dass jedoch der Mythos selbst für den Bildsinn eine tragende Rolle spielen würde. Der nackte Meleager, dessen Oberschenkel ein Manteltuch umspielt, wendet sich, entspannt sitzend, mit entblößtem

280 Bei Ghirardini 1879, 154 fälschlich als Frau und dementsprechend als weitere Tochter des Pelias aufgefasst. 281 Sogliano 1878, 264; sehr ausführlich zu Mythos und Bild bereits Ghirardini 1879; Zevi 1964, 34.

282 Heute Neapel, NM 8980; Peters 1963, 102; PPM IV (1993) 819-859 s. v. VI 9,3.5, Casa del Centauro (I. Bragantini) 852f. Abb. 66; vgl. Lorenz 2008, 67-70. 


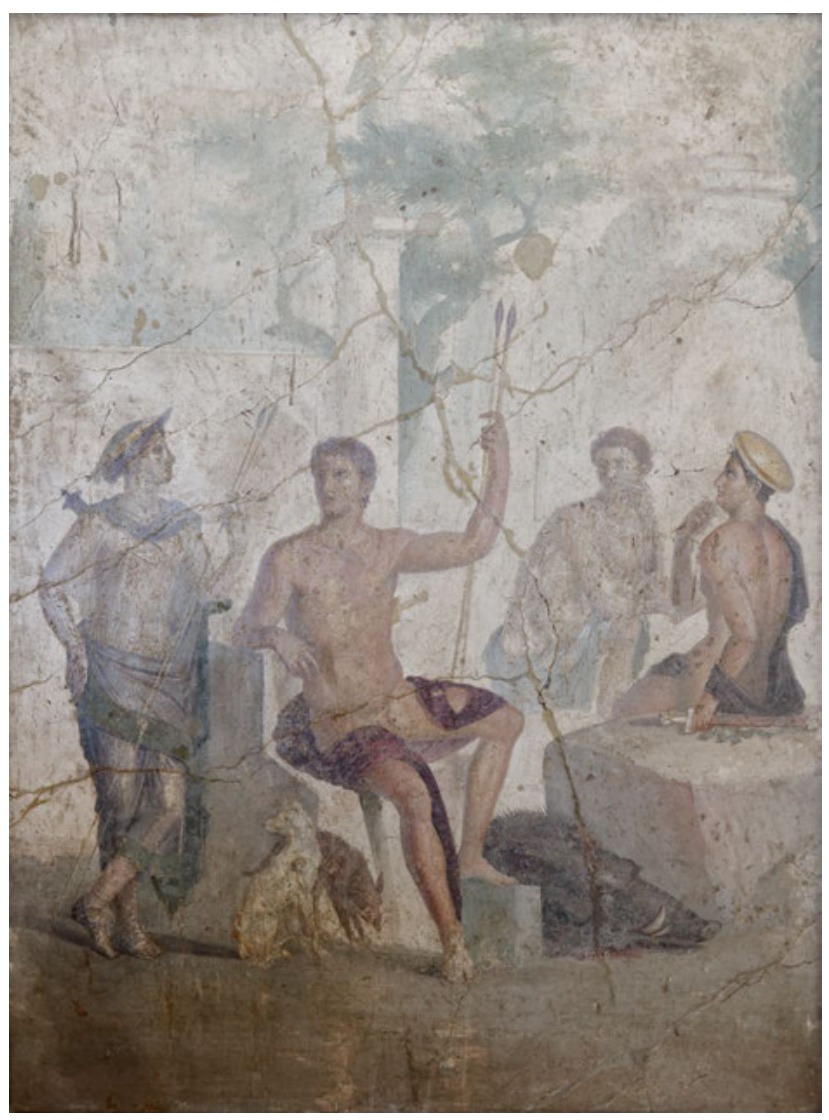

Abb. 365: Casa del Centauro (VI 9,3.5), Mythenbild der Nordwand von Tablinum (26): Meleager und Atalante (Neapel, NM 8980).

Oberkörper der neben ihm stehenden Atalante im Jagdgewand zu, zwischen ihnen Jagdhunde. Während er sie anblickt, geht ihr Blick an ihm vorbei und durchstreift den Bildraum. Die Protagonisten sind durch ihre Attribute eindeutig benennbar; Haltungsschema, Kleidung und Blicke werden eingesetzt, um sie auch in ihrem Verhältnis zueinander zu charakterisieren. Die Szene ist von Architektur hinterfangen, über eine halbhohe Mauer blickt man auf eine Landschaft, sodass das Geschehen zwischen kulturell gestaltetem und naturhaftem Raum angesiedelt ist. Die beiden männlichen Zuschauer am rechten Bildrand, einer davon mit Schwert gerüstet, darf man als Vertreter der männlichen Peergroup ansprechen, in deren Handlungsraum Atalante eingedrungen ist $^{283}$. Sie zeigen durch ihren Blick und ihre Gesten an, dass sie dem Geschehen ihre Aufmerksamkeit schenken. Handlung ist zugunsten einer Gegenüberstellung der Protagonisten und der Präsentation ihres Körpers ganz zurückgenommen. Indem Meleager und Atalante als Paar ins Zentrum rücken, wählt das Bild eine Akzentuierung, die in der Narration nicht angelegt ist. Der Mythos wird zur Folie, um eine Paarkonstellation zu entfalten ${ }^{284}$. Dennoch ,informiert‘ der Mythos, auch wenn er implizit bleibt, den Betrachter über die dargestellten Protagonisten.

Die Herauslösung aus einem narrativen Zusammenhang kann dazu führen, dass sich die Benennung der Protagonisten nicht aus der Handlung oder Figurencharakterisierung ergibt. Im Fall des Meleager-Atalante-Bildes sind nur die Hauptprotagonisten, nicht aber die Zuschauer, durch Attribute eindeutig charakterisiert. In manchen Fällen werden die Bildprotagonisten allerdings gezielt vieldeutig charakterisiert. Ein signifikantes Beispiel stellt das Mittelbild der Nordwand 
Abb. 366: Casa del Citarista (1 4, 5.6.25.28), Mythenbild der Nordwand von Cubiculum (20): Paarbild (Neapel, NM 112282).

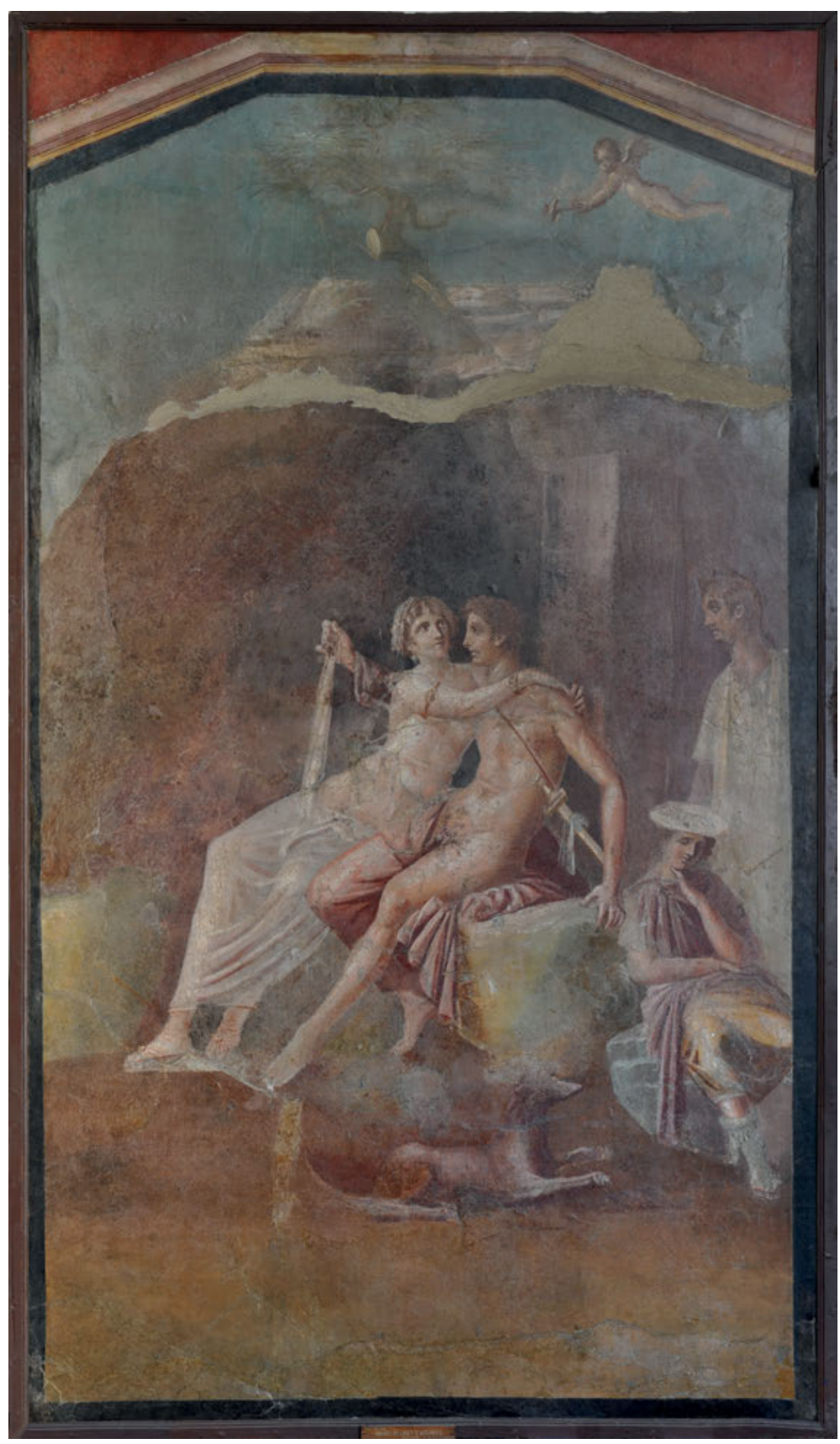

von Cubiculum (20) der Casa del Citarista (I 4,5.6.25.28; Plan 5; Abb. 366) dar ${ }^{285}$. Das Bildzentrum nimmt ein sich umarmendes, sitzendes Paar ein. Der jugendlich-bartlose, mit einem Schwert gegürtete Mann ist weitgehend nackt, ein purpurnes Manteltuch, auf dem er sitzt, verhüllt sein rechtes Bein. Er führt den Arm um den Oberkörper seiner Partnerin und hält in der erhobenen Hand eine weiße Binde ${ }^{286}$. Mit der anderen stützt er sich auf dem Felsensitz ab. Seine Gefährtin führt beide Arme um seinen Oberkörper und richtet ihren Blick auf ihn. Ihr Oberkörper ist in ein

285 Neapel, NM 112282, s. PPM I (1990) 117-177 s. v. I 4,5.25, Casa del Citarista (M. de Vos) 151-153 Abb. 61; mit falscher Lokalisierung der Mythenbilder Schefold 1957, 15; Peters 1963, 59f.; Diskussion der Ikonographie bei Lorenz 2008, 173f.; 2018, 151-156; Bergmann 2014a, 78f.

286 Anders Lorenz 2008, 173, die hier das Lüpfen des Gewandes erkennt. 
durchscheinendes, geradezu unsichtbares Gewand gehüllt, ein dünnes Mäntelchen umspielt ihre Beine. Ohrringe, Arm- und Schulterreifen charakterisieren sie als attraktive Frau. Ein über den Bergen schwebender Amor mit Fackel thematisiert das Offensichtliche: Gemeint ist ein sich zugewandtes Liebespaar. Zunächst wäre an Mars und Venus zu denken. Der männliche Partner ist jedoch nicht, wie dies für Mars üblich ist, mit Helm und Rüstung ausgestattet, außerdem bleibt er passiv. Auch die weiteren Bildelemente tragen nicht zur Klärung des Bildinhalts bei. Im Bildvordergrund lagert ein Jagdhund, wie er zu Mars nicht passen mag. Rechts neben dem Liebespaar sitzt, an den Felsen gelehnt, eine schlafende Figur. Sie trägt Stiefel, einen Chiton, darüber einen roten Mantel und eine petasosartige Kopfbedeckung, sodass es sich wohl um einen Jüngling handelt. Hinter ihm, vom rechten Bildrand teils abgeschnitten, steht ein ,Zuschauer' in weißem Chiton, der seinen Blick auf das Liebespaar richtet. Diese männlichen Beifiguren machen im Beisein von Mars keinen Sinn ${ }^{287}$. Insbesondere der Jagdhund würde eine Deutung des Liebhabers als Jäger nahelegen - etwa als Adonis. Die schlafende Nebenfigur ließe sich so als Jagdgefährte auffassen. In gängigen Adonis-Bildern wendet sich Venus ihrem Geliebten, der dann zumeist verwundet gezeigt wird, eher besorgt denn erotisch interessiert zu, auch wenn zahlreiche Eroten das Geschehen umflattern $^{288}$. Zudem wird die Rolle des Adonis als Jäger üblicherweise nicht durch ein Schwert, sondern durch Jagdspeere angezeigt. All diese Indizien für eine Adonis-Ikonographie fehlen jedoch. Diese Schwierigkeiten haben dazu geführt, dass man weitere Interpretationen erprobt hat. So ließe der Hund an eine Deutung des männlichen Parts als Hirte denken - mit Blick auf die Liebschaften der Venus käme der Hirte Anchises infrage. Problematisch ist dann jedoch nicht nur der Umstand, dass sich Anchises-Bilder in der antiken Kunst kaum finden ${ }^{289}$, sondern auch das Schwert, das einer Hirten-Deutung zuwiderliefe. Schließlich wurde beobachtet, dass die Fußhaltung der Akteure jener auf einem Bild der Domus IX 6,d-e entspricht, wo die (dort allerdings verlorenen) Protagonisten durch eine Beischrift als Dido und Aeneas ausgewiesen werden ${ }^{290}$. Auch diese Deutung lässt sich nicht ohne Probleme auf das Citarista-Bild übertragen ${ }^{291}$, fehlt doch etwa der Jagdhund in der Version der Domus IX 6,d- $\mathrm{e}^{292}$. Die ikonographischen Unklarheiten resultieren nicht aus dem Erhaltungszustand, vielmehr ist die Komposition in sich ambivalent. Gerade der freie Umgang mit Bildschemata und Attributen hat folglich zur Erzeugung von Polysemie beigetragen ${ }^{293}$. Für die Rezeption der Bilder dürfte dies durchaus reizvoll gewesen sein, kann eine Bildkomposition doch auf diese Weise die Rezipienten zur Diskussion verschiedener Deutungen herausfordern.

Zusammenfassend zeigt sich, dass mythologische Landschafts- und ,Figurenbilder jeweils Unterschiedliches leisten. Landschaftsbilder ermöglichen es, verschiedene Episoden der Erzählung einzuführen, während Figurenbilder eine ausdifferenzierte, auch psychologische Charakterisierung der Protagonisten erlauben, damit verbunden auch die Zuspitzung auf einen ,fruchtbaren Augenblick ${ }^{294}$. Beide Darstellungsmodi sind aber auch dazu angetan, vom mythologischen Geschehen wegzuführen. So kann in den Landschaftsbildern das Setting Aufmerksamkeit beanspruchen, sogar in den Vordergrund treten, während bei Figurenbildern das Interesse an Figurenkonstellatio-

287 Deutung als Mars und Venus bereits bei Overbeck - Mau 1884, 362, in der Folge vielfach wiederholt - etwa Wirth 1927, 38; mit der Deutung als Hirte Anchises Simon 1974, 37f.; kritische Diskussion der Deutung als Adonis, Anchises und Mars bei PPM I (1990) 117-177 s. v. I 4,5.25, Casa del Citarista (M. de Vos) 151. 153 Abb. 61; ebenso kritisch Hoffmann 2014, 136; letzterer führt über das oben genannte Gegenargument zwei weitere, jedoch schwächere Argumente an: Mars und Venus werden üblicherweise (aber nicht zwingend) in einem Interieur dargestellt, und Mars trägt keine weiteren Waffen.

288 Mit Deutung als Venus und Adonis Hodske 2007, 148; kritisch zur Adonisdeutung Lorenz 2008, 176-178; ihr folgend Hoffmann 2014, 136.

289 LIMC I (1981) 761-764 s. v. Anchises (F. Canciani).

290 PPM IX (1999) 722-732 s. v. IX 6,d-e (I. Bragantini) 730f. Abb. 15.

291 PPM I (1990) 117-177 s. v. I 4,5.25, Casa del Citarista (M. de Vos) 151-154 Abb. 61.

292 Lorenz 2008, $175 f$.

293 In Bezug auf Narcissus etwa auch Pearson 2015, $160 \mathrm{f}$.

294 s. o. S. 363. 
nen zu einer Ambiguisierung ihrer mythischen Identität führen kann. In all diesen Fällen gilt, dass Mythenbilder sich für eine intensive Auseinandersetzung anbieten. Der unterhaltende Charakter stellt sich jedoch über ganz unterschiedliche visuelle Strategien ein.

\subsection{Bild-Ensembles: formale und inhaltliche Bezüge}

Die visuelle Komplexität wird im dritten Stil dadurch gesteigert, dass verschiedene, bereits für sich anspruchsvolle Bilder in einem Raum zueinander in Beziehung treten. Solche Bild-Spiele sind in der Forschung insbesondere für die Mythenbilder beobachtet worden, die das Wandzentrum besetzen und visuell aufeinander bezogen sind. Die Diskussion soll noch einmal aufgegriffen werden, um sie in einem zweiten Schritt auf ein noch komplexeres Phänomen hinzuführen: Die Mythenbilder selbst sind zwar ein wichtiger, aber keinesfalls der einzige Bildbestandteil eines Raums. Visuelle Komplexität kann nur unter Berücksichtigung aller Bildelemente adäquat beschrieben werden.

\section{Mythenbilder als Gegenstücke: Positionen der Forschung}

Die Diskussion, in welchem Verhältnis die Mythenbilder eines Raumes zueinander stehen, hat in der Erforschung der pompejanischen Wandmalerei eine lange Tradition. Im 19.Jh. wurden die Mittelbilder zunächst im Hinblick auf ihre formalen Bezüge analysiert. Adolf Trendelenburg begriff das Wandbild als „Glied des decorativen Ganzen, welches uns im Zimmerschmuck entgegentritt““295. Er benannte die Größe, die Anzahl und die Gruppierung der Figuren und die „Scenerie des Hintergrundes“ als Gestaltungskategorien, die den Zusammenschluss von Bildern zu „Gegenstücken“ herstellen. Auch Mau sah nur selten inhaltliche Gründe für die Zusammenstellung von Bildern am Werk ${ }^{296}$. Stattdessen sei, wie schon Trendelenburg erkannt hatte, die „Ähnlichkeit der Figuren und der Scenerie“ ausschlaggebend ${ }^{297}$. Auch in der zweiten Hälfte des 20. Jhs. sind formale Aspekte der Bildzusammenstellung betont worden ${ }^{298}$, jüngst wurde diese Position emphatisch von Emanuel Mayer vertreten ${ }^{299}$. Schon die Antike selbst hat formale Parallelen zwischen Bildern erkannt. Im Roman Kleitophon und Leukippe des Autors Achilles Tatius werden zwei Bilder im Tempel des Zeus Kasius vor allem im Hinblick auf motivische und formale Aspekte verglichen ${ }^{300}$.

\footnotetext{
295 Trendelenburg 1876, 2.

296 Mau 1908, $470 f$.

297 Mau 1908, 472.

298 So stimmt auch Schefold der Beobachtung zu, dass „Gegenstücke [...] im dritten und vierten Stil in Größe und Figurenzahl ungefähr überein[stimmen] [...]. Häufig entsprechen sich liegende und stehende, nackte und bekleidete Gestalten. Die Mittelbilder werden zuweilen durch Größe und Zahl der Figuren herausgehoben [...]. Bilder desselben Themas sind bald auf eine einzelne Figur beschränkt, bald von reicher Staffage mit Nebenfiguren umgeben, je nachdem es das Gegenstück erforderte." Schefold 1962, 74f. leitet seine Überlegungen mit einer ausführlichen Kritik an Mau (und Trendelenburg, S. 75) ein, die jedoch, wie mir scheint, an Maus Aussageabsicht vorbeigeht: Für Trendenlenburgs und Maus Beobachtung formaler Äquivalenzen ist nicht wirklich entscheidend, ob es sich bei den pompejanischen Wandbildern um genaue Kopien griechischer Vorlagen handelt oder nicht. In dieser Tradition steht Fausto Zevis Analyse der Casa di Giasone (IX 5,18), für die er einen Zusammenschluss von Bildelementen durch formale Bezugnahmen beobachtet (Zevi 1964). Bergmann 1994, 231 beobachtet für die Casa del Poeta Tragico, dass die Räume im Bereich des Atriums mit einem roten Sockel und gelben Wänden versehen sind, am Peristyl mit schwarzem Sockel und roten Wänden. Darüber hinaus weist sie für die Bilder am Atrium darauf hin, dass Farben, Körperhaltungen und Gewänder die Szenen miteinander verbinden (s. 241). Diese Beobachtung verbindet sie dann in einem zweiten Schritt mit Überlegungen zu einem semantischen Zusammenhang (s. u.).

299 Er erteilt der Existenz von Bildprogrammen als „Gesamtkunstwerken“ eine Absage - Mayer 2012, 190.

300 Ach. Tat. 3,6; Lorenz 2008, 262.
} 
In der zweiten Hälfte des 20.Jhs. hat die Mehrzahl der Forscher danach gefragt, ob Bilder darüber hinaus durch „ideelle Zusammenhänge“, wie Karl Schefold dies nannte ${ }^{301}$, verbunden seien. Und auch für ein solches Bildverständnis lässt sich mit Lukian ein antiker Gewährsmann beibringen $^{302}$. In de domo erschließt sich dem Betrachter der Sinn der Bilder erst in ihrer vergleichenden Betrachtung, bei einem Spaziergang ${ }^{303}$. $\mathrm{Zu}$ Recht hat die Forschung sich daher um eine Systematisierung solcher Bildbezüge bemüht. Schefold führte dazu die Termini Zyklus und Pendant ein. „Unter Zyklen verstehen wir inhaltlich zusammengehörige Decorationsmotive, die über die Wände verteilt sind, unter Pendants Bilder, die ihres Sinns wegen zusammengestellt sind“304. Mit dem Terminus Zyklus bezeichnet er zuvorderst Bilderfolgen, die auf eine übergreifende Narration rekurrieren. Aus Triclinium (6) der Casa dei cinque scheletri (VI 10,2) stammen drei Mythenbilder, die Paarkonstellationen des trojanischen Sagenkreises zeigen: Paris und Helena, die Prophetie der Kassandra sowie Odysseus und Penelope ${ }^{305}$. Zugleich kommen mit dem Parisurteil, der Kassandravision und der Heimkehr des Odysseus jeweils Schlüsselmomente des Epos zur Darstellung. In diesem eng gefassten Sinn sind Bildzyklen auf den Wänden des dritten und vierten Stils jedoch ein Sonderfall. Darüber hinaus versteht Schefold unter einem Zyklus aber auch Bilderfolgen, die demselben thematischen Rahmen verpflichtet sind - etwa ,Zyklen“ von Landschaftsbildern oder ,Stillleben‘.

Der Begriff des Pendants - die ,sinnhafte‘ Zusammenstellung von Bildern - ist noch weiter gefasst, weil er den Modus der Sinn-Erzeugung offenlässt. Gut greifbar sind Pendants dann, wenn die Bilder auf ein gemeinsames Thema rekurrieren - wenn etwa verschiedene mythische Liebespaare kombiniert werden ${ }^{306}$. Schefold bringt aber auch sehr viel breitere Kategorien ins Spiel, indem er insbesondere in der Religion den Schlüssel für das Zusammenspiel von Bildelementen sieht $^{307}$. Gegen ein einseitig religiöses oder gar moralisierendes Bildverständnis haben sich bereits frühzeitig Mary Lee Thompson, später auch Zanker ausgesprochen, erweisen sich solche Bezüge für die Bildinterpretation doch häufig als gesucht ${ }^{308}$. Bacchus, der die schlafende Ariadne aufsucht, kann im Haus nicht als Bild der Erlösung aufgefasst werden ${ }^{309}$. Gleichzeitig versteht Schefold das Haus als Ort der Muse(n), sodass er die Ausstattungselemente auf die Bildung des Hausherrn bezieht ${ }^{310}$. Auf diese Weise ließe sich letztlich jedes Ausstattungselement als Referenz auf Bildung begreifen. Noch stärker von den konkreten Darstellungen abstrahiert ist sein Postulat, die Bilder würden sich auf Vorstellungswelten beziehen - etwa auf die „Wege zur Unsterblichkeit“. Aber selbst unter solch allgemeinen Kategorien lassen sich nicht immer alle Bilder eines Raumes (geschweige denn eines Hauses) subsumieren, weshalb Schefold gezwungen ist anzunehmen, dass

301 Schefold 1962, 75; Schefold 1948, 936-945; rezipiert etwa bei Pappalardo 1990, 226.

302 Eine ausführliche Diskussion von antiken Schriftquellen, die sich mit Bilderzyklen befassen, bei Thompson 1960, 10-45, zum römischen Haus bes. 34-45; vgl. Lorenz 2005, 206-209.

303 Lukian. de domo 22; s. Newby 2002; Thompson 1960, 36f.; Lorenz 2005, 207 f.; 2008, 263.

304 Schefold 1962, 186; aufgegriffen bei Brilliant 1984, 65f.; allgemein zu Pendants unter Rekurs auf Schriftquellen auch Schefold 1972, $46 \mathrm{f}$.

305 PPM IV (1993) 1029-1043 s. v. VI 10,2, Casa dei cinque scheletri (V. Sampaolo) 1039-1041 Abb. 17-19; Rossi 2006, 60-62. Kassandra-Prophetie: Neapel, NM 8999; Paris und Helena: Neapel, NM 9002; Penelope und Odysseus: Neapel, NM 9107.

306 Schefold 1962, 192-196.

307 Schefold 1952, 34-44, bes. 34: „[...] Die Kunst [...gibt] dem Leben eine religiöse Weihe [...].“; vgl. Schefold 1972, 52-68. Ausgehend von Schefolds Konzept untersucht Mary Lee Thompson insbesondere religiöse Zyklen, für die sie jedoch einen engeren thematischen Rahmen voraussetzte, als Schefold dies tat. Sie untersuchte Zyklen des trojanischen Krieges, Bacchus-Zyklen, Zyklen, in deren Zentrum Venus steht; s. Thompson 1960. Sie selbst stellt allerdings keine methodenkritische Diskussion zum programmatischen Verhältnis der Bilder zueinander an, sondern setzt eine thematische Zusammengehörigkeit voraus.

308 Zanker 1999, 43f.

309 Mit dieser Kritik etwa Thompson 1960, bes. 59f.

310 Schefold 1952, 44-51; Schefold 1962, 77-98; Schefold 1972, 69-78. 
Bilder auch auf verschiedene Werte verweisen könnten ${ }^{311}$. So wundert es nicht, dass er zu dem Schluss kommt, dass alle pompejanischen Bilder zu Ensembles gehörten. Gelingt es einmal nicht, diese zu entschlüsseln, so liege dies an unserer mangelnden Kenntnis ${ }^{312}$. Strocka und Lorenz kritisieren am Vorgehen Schefolds, dass Bildinhalte abstrahiert würden und die Bezüge daher nicht von den Bildern ausgingen, sondern auf einer Metaebene lägen - etwa der Ebene des Religiösen oder der Bildung ${ }^{313}$. Zu Recht fordert Lorenz daher, dass die inhaltlichen Akzentuierungen, welche die Bilder vornehmen, zunächst aus diesen selbst zu gewinnen seien.

Bergmann hat bei ihrer Analyse des Atriums der Casa del Poeta Tragico (VI 8,3.5) die Bezugsmodi, die zwischen den Mythenbildern entfaltet werden, aus Denk- und Argumentationsschemata der antiken Rhetorik hergeleitet: „The visitor [...] could have perceived myriad combinations in walking through this space - pairs, triplets, and diagonal cross-references from wall to wall depending upon the chosen route. [...]. But despite their apparent looseness, the formal and thematic arrangements of panels, and even of whole walls, corresponded to the well-known rhetorical principles of similitudo, vicinitas, and contrarium [...]." ${ }^{314}$ Stephanie Pearson schlägt als weitere, vierte Kategorie die Verdopplung, conduplicatio, vor ${ }^{315}$. Damit sind zwei Aspekte hinzugewonnen: die Auflösung binärer Strukturen zugunsten einer (antik fassbaren) Vielfalt an Beziehungsformen und die Bedeutung des Betrachterhandelns für die Bildrezeption.

Lorenz entwickelt aus einer exemplarischen Analyse der Bildkombinationen von Mars und Venus etwas anders gelagerte Kategorien, die es erlauben, den semantischen Zusammenhang, der sich zwischen Mythenbildern entfaltet, zu charakterisieren. Sie unterscheidet „affirmative, komplementäre, kontrastierende und konsekutive Verknüpfungen““316. Um visuell verfasste Konzepte jedoch auf diese sprachlichen Kategorien beziehen zu können, sind sie in sprachlich verfasste und damit auch abstraktere Konzepte zu überführen. Hermes und Demeter werden so etwa zu Repräsentationen von ,Wohlleben ${ }^{317}$. Auf dieser Ebene ergeben sich dann wiederum Bezüge zu anderen Bildern. Werfen wir vor diesem Hintergrund einen Blick auf die Bildkombinationen selbst.

\section{Formale Bildbezüge}

Dass sich mythologische Mittelbilder eines Raumes in formaler Hinsicht zusammenschließen, lässt sich an messbaren Größen ablesen - sie besitzen üblicherweise dasselbe Format. Am Beispiel der beiden Cubicula (e) und (g) der Casa di Giasone hat sich darüber hinausgehend gezeigt, dass die formalen Parallelen bis in die Bildanlage hineinreichen, d.h. Figurengröße, Gestaltung des Bildhintergrundes, Bildkomposition und die Wahl der Erzählform betreffen ${ }^{318}$.

311 Schefold 1962, 80.196.

312 Schefold 1962, 78.

313 Strocka 1997, 129; Lorenz 2008, 10f.; ähnlich Muth 1998, 106-110 für das Verständnis von Mythenbildern auf Mosaiken; Eristov 1987, 117 weiterhin mit der Kritik, dass die von Schefold benannten Bezugskategorien nirgendwo in der Literatur thematisiert würden.

314 Bergmann 1994, 246; erneut, dann in Bezug auf Landschaftsbilder dritten Stils: Bergmann 1999, 101; mit Verweis auf bei Varro explizierten rhetorischen Kategorien von similitudo, vicinitas, contrarium bereits Brilliant 1984, 71.

315 Pearson 2015, 157 als rhetorisches und ästhetisches Prinzip; ähnlich zuvor bereits Bartman 1988, bes. 219 für Skulpturen-Pendants.

316 Lorenz 2008, bes. 272. Mayer 2012, 194 unterstellt Lorenz, dass sie bei der Zusammenstellung von Bildern allein formale Kriterien am Werk sieht, andere Verbindungen seien vom Betrachter hergestellt, aber nicht a priori intendiert gewesen. Dies entspricht weder dem Vorgehen von Lorenz allgemein noch ihrer Interpretation von Tatius' Roman, worauf sich Mayer zu beziehen scheint (Lorenz 2008, 262).

317 Lorenz 2008, $274 \mathrm{f}$.

318 s. o. S. 361-367. 

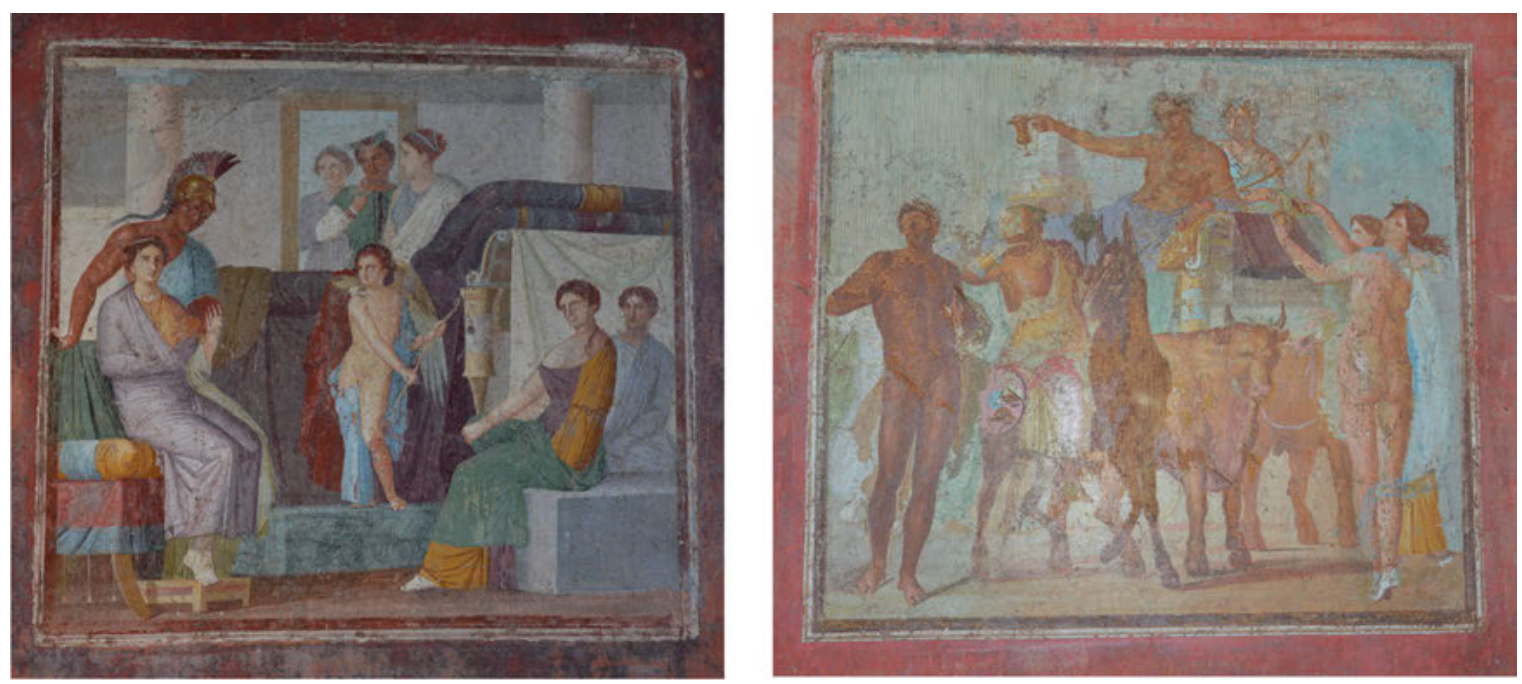

Abb. a

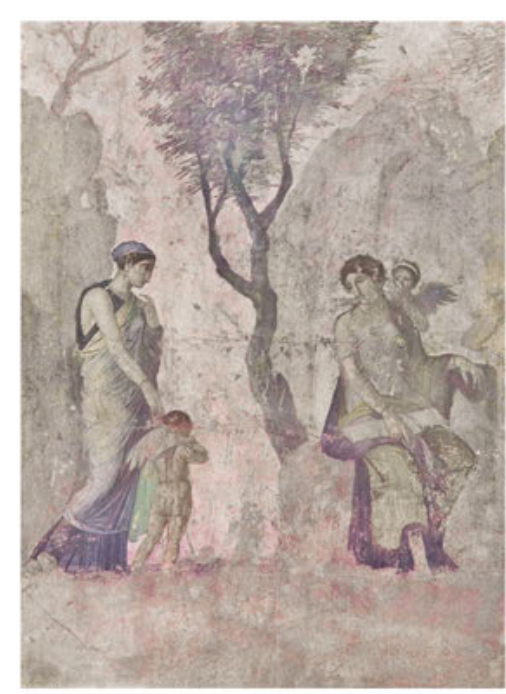

Abb. b

Abb.c

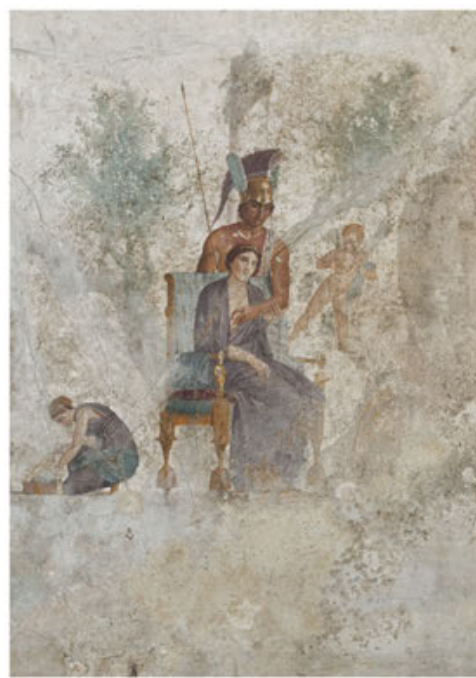

Abb. d
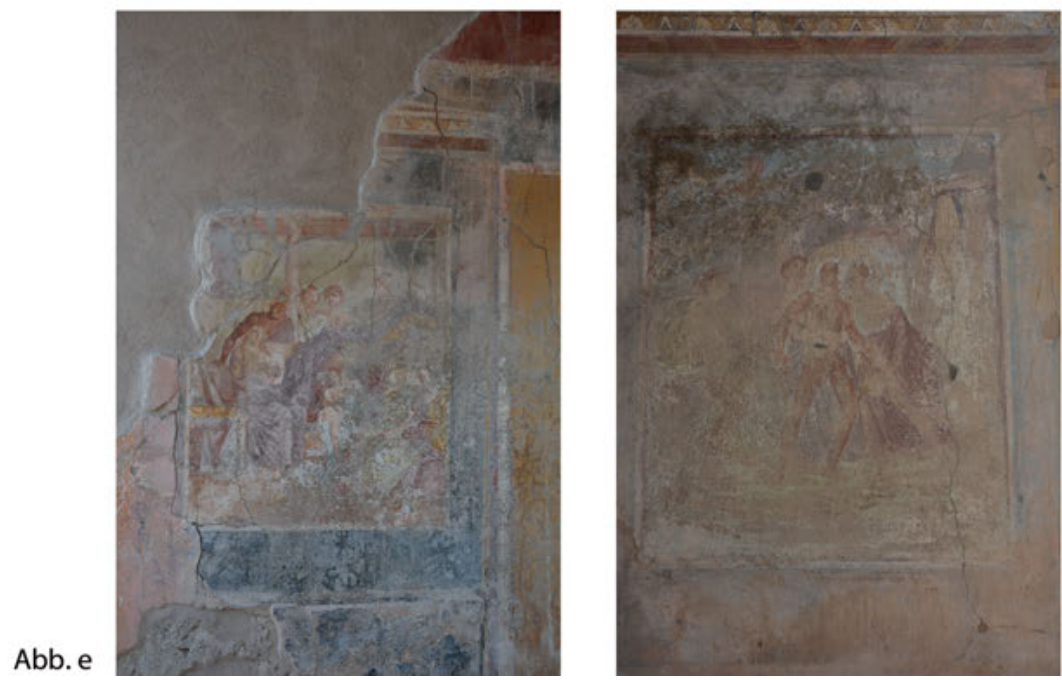

Abb.f

Abb. 367: a) Casa di Marcus Lucretius Fronto, Tablinum, Mars und Venus. b) Casa di Marcus Lucretius Fronto, Tablinum, Bacchus und Ariadne. c) Casa dell'Amore punito (VII 2,23), Tablinum, Mars und Venus (Neapel, NM 9249). d) Casa dell'Amore punito (VII 2,23), Tablinum, Bestrafung Amors (Neapel, NM 9257). e) Casa annessa alla Casa dell'Efebo (I 7,19), Tablinum, Mars und Venus. f) Casa annessa alla Casa dell'Efebo (I 7,19), Tablinum, Hylas. 
Dies bedeutet notwendigerweise, dass die Maler nicht ,fertige“ Bildschemata auf die Wände brachten, sondern die Bildkomposition in Bezug auf die anderen Mythenbilder eines Raumes anpassten bzw. modellierten ${ }^{319}$. Besonders gut ist diese formale Anpassungsleistung für Bildschemata zu greifen, die in mehreren Exemplaren vorliegen und deren Vergesellschaftung mit anderen Mythenbildern in einem Raum nachvollziehbar ist. Dies trifft auf das bereits von Lorenz ausführlich diskutierte Mars-Venus-Schema $\mathrm{zu}^{320}$, das sich im Tablinum (h) der Casa di Marcus Lucretius Fronto (Abb. 367a), im Tablinum der Casa dell'Amore punito (VII 2,23) ${ }^{321}$ (Abb. 367c) sowie im Tablinum (c) der Casa annessa alla Casa dell’Efebo (I 7,19; Abb. 367e) findet ${ }^{322}$. Die Ergebnisse sollen mit Blick auf die Frage der Anpassungsleistungen kurz referiert werden.

Mars tritt in allen drei Fällen von hinten an die thronende, aus dem Bild blickende Venus heran und fasst ihr an die Brust, während sie mit ihrer linken Hand an seinen Unterarm greift. Die erotische Begierde des Mannes trifft in dieser Bildformel das Einverständnis der Frau ${ }^{323}$. Darüber hinaus unterscheiden sich die Bilder aber in zahlreichen Details - und diese Differenzen erklären sich aus der Kombination mit den jeweils unterschiedlichen Gegenbildern. In der Casa di Marcus Lucretius Fronto ist Venus vollständig bekleidet, die Szenerie spielt in einem Innenraum. Das ,züchtige' Bild der Liebenden ist hier auf die repräsentative Pompe von Bacchus und Ariadne bezogen (Abb. 367b). Die beiden, repräsentativen' Paarbilder legen eine Assoziation mit Dominus und Domina nahe. Im Tablinum der Casa annessa alla Casa dell'Efebo wird mit dem Bild des ,übergriffigen' Mars, der Venus an die Brust fasst, das Bild von ,übergriffigen` Nymphen kontrastiert, die nach dem nackten Hylas greifen (Abb. 367f) ${ }^{324}$. Hier sind zwei Bilder erotischen Begehrens einander gegenübergestellt ${ }^{325}$ : Das Mars-Venus-Bild ist erotisiert, um als Pendant für das HylasBild zu fungieren. In der Casa dell'Amore punito schiebt Mars das Gewand der Venus zur Seite, während auf der Gegenseite die auf einem Felsen sitzende Venus traurig-nachdenklich auf den kleinen, an den Beinen gefesselten Amor blickt, den eine Frauengestalt, mutmaßlich Peitho, im Begriff ist wegzuführen (Abb. 367d) ${ }^{326}$. Diese Bildkombination eröffnet die Möglichkeit, verschiedene Verständnisoptionen zu erproben. Begreift man das Paarbild in konventioneller Weise als Mars und Venus, dann wäre die Bestrafung des Amor auf der Gegenseite die Konsequenz für den Ehebruch. Das Bestrafungsbild mag den Betrachter aber auch dazu stimulieren, die Frau gerade nicht als Venus aufzufassen, sodass sich aus dem Liebesbild die Bestrafungsszene ergibt ${ }^{327}$. Mit Blick auf das Mars-Venus-Schema lässt sich zeigen, dass die Zahl der Beifiguren, der Hintergrund und auch ikonographische Details wie die Bekleidung modifiziert werden können, um ein Bild

319 Ein solch flexibler Umgang mit Vorlagen, der gegen ein wörtliches Kopieren von Meisterwerken spricht, ist jüngst erneut negiert worden, s. Salvo 2017.

320 Zu den drei 'Repliken', s. Hodske 2007, 145f.; dort auch eine Zusammenstellung weiterer Bildschemata für Mars und Venus, wie sie dann im vierten Stil beliebt sind; Lorenz 2005, 210-214; 2008, 151-158, die die Parallelen und Unterschiede der drei genannten Bilder bespricht; Strocka 1997, $130 \mathrm{f}$.

321 PPM VI (1996) 665-679 s. v. VII 2,23, Casa dell'Amore punito (V. Sampaolo) 674f. Abb. 16; Lorenz 2008, $264-267$.

322 Peters 1963, 197; PPM I (1990) 750-789 s. v. I 7,19, Casa annessa alla Casa dell’Efebo o di P. Cornelius Tages (A. de Vos) 766f. Abb. 28.

323 Lorenz 2008, 155-158. 264-268.

324 Lorenz 2008, 210-212. $267 \mathrm{f}$.

325 Anders Strocka 1997, 131, der bei Hylas an dessen tragisches Schicksal denkt, dabei jedoch nicht von dem Bild selbst, sondern von der Erzählung ausgeht.

326 Neapel, NM 9257; PPM VI (1996) 665-679 s. v. VII 2,23, Casa dell’Amore punito (V. Sampaolo) 672f. Abb. 14; Lorenz 2008, $266 \mathrm{f}$. Die Bestrafung des Eros findet eine Parallele in Domus IX 2,19-21, Ala (d); hier sind die Seitenbilder jedoch zerstört, sodass sich hier die Frage nach der Bildkombination in Abhängigkeit von Bildartikulation nicht weiterspinnen lässt; s. PPM IX (1999) 82-96 s. v. IX 2,19-21 (I. Bragantini) 86f. Abb. 7-10; Lorenz 2008, 266 f.

327 Peters 1963, 100f.; PPM VI (1996) 665-679 s. v. VII 2,23, Casa dell'Amore punito (V. Sampaolo) 672f.

Abb. 14. 
konkreter auf sein ,Gegenstück' im Raum zu beziehen. Formale Bildangleichungen treten in den Dienst inhaltlich-visuellen Argumentierens ${ }^{328}$.

Besonders deutlich kommt das Streben nach einer formalen Angleichung der Mittelbilder darin zum Ausdruck, dass man für die Ausstattung eines Raumes entweder mythologische Landschaftsbilder oder mythologische ,Figurenbilder' wählte. So wird der Mythos von Perseus und Andromeda, für den beide Darstellungsformen zur Verfügung stehen ${ }^{329}$, als mythologisches Landschaftsbild ${ }^{330}$ ausschließlich mit anderen mythologischen Landschaftsbildern kombiniert, als „Befreiungsbild“331 ausschließlich mit Bildern, die ebenfalls Protagonisten ins Zentrum stellen. In augusteischer Zeit bevorzugte man Darstellungen spektakulärer Landschaftsräume und wählte dementsprechend die ,Landschaftsversion' von Perseus und Andromeda. Im vierten Stil stieg das Interesse an Figurencharakterisierungen, sodass man sich für das ,Befreiungsbild‘ entschied. In der sich ändernden Auffassung dieses einen Mythos kommt damit ein grundsätzlicher Geschmackswandel zum Ausdruck. In augusteischer Zeit begünstigte die Vorliebe für spektakuläre Landschaftsräume die Auswahl von Mythen, die sich für eine solche Landschaftsinszenierung eigneten: Daedalus und Icarus, Diana und Aktaion, Europa auf dem Stier sowie Polyphem und Galatea ${ }^{332}$. In Einzelfällen trat der Mythos sogar wie im Fall von Athena und Bellerophon auf der Ostwand von Triclinium (b) der Domus IX 7,16 (Abb. 364) hinter der Landschaftsinszenierung zurück. Im genannten Fall war das ,mythische‘ Landschaftsbild mit weiteren mythologischen Landschaftsbildern kombiniert - Daedalus und Icarus auf der Südwand sowie, stark zerstört, Diana und Aktaion oder Selene und Endymion auf der Westwand ${ }^{333}$. Im vierten Stil verloren einige zuvor beliebte, Landschafts-Mythen` an Bedeutung - und zwar insbesondere jene, die sich wie Daedalus und Icarus ${ }^{334}$ nicht auf eine Paarkonstellation zuschneiden ließen ${ }^{335}$. Dies hatte schon im fortgeschrittenen dritten Stil zur Folge, dass sich Mythenbilder gegenüberstanden, die den Fokus ganz auf die Protagonisten legten.

Zusammenfassend zeigt sich, dass in der formalen Angleichung von Mythenbildern eines Raumes immer schon inhaltliche Akzentsetzungen und potentielle Parallelisierungen angelegt sind.

328 Siehe dazu Bergmann 1995, bes. 95f.; 1996; Clarke 2008; Lorenz 2008; Pearson 2015; Swetnam-Burland 2018, bes. $171 \mathrm{f}$.

329 Eine Listung aller Bildkombinationen, die mit Perseus und Andromeda existieren, bei Brilliant 1984, 81f.; eine Listung der ,Landschaftsbilder' und ,Befreiungsbilder‘ sowohl bei Hodske 2007 als auch bei Lorenz 2008, 124-142.

330 So in Triclinium (b) der Casa del Sacerdos Amandus (I 7,7); Oecus (m) der Casa della Parete nera (VII 4,59); Exedra (z') der Casa del Marinaio (VII 15,2); Cubiculum (a) der Domus IX 7,16.

331 So in Cubiculum (12) der Casa dei cinque scheletri (VI 10,2); Casa di Sextus Pompeius Axiochus (VI 13,12.19); Oecus (6) des Scavo del Principe di Montenegro (VII 16 [Ins. Occ.],10); Triclinium (l) der Domus IX 9,d; Casa del Cenacolo II (IX 12,1-2).

332 Zum begrenzten Themenrepertoire bereits Dawson 1965, 116-135; erneut Bergmann 1999, 82; vgl. Bragantini 2010, 288.

333 Mau 1883, 131 Bezug nehmend auf eine ihm zugängliche Zeichnung als Selene und Endymion; ihm folgend Esposito 2017, 69; Peters 1963, 80 als Diana und Aktaion, ihm folgend die Mehrheit der Forschung. Eine Zusammenführung der zwei Bilder als Exempla für Hybris (so Lorenz 2008, 312) wäre allerdings nicht nur dann fraglich, wenn das Bild im Westen als Endymion und Selene rekonstruiert wird. Auch die Bellerophon-Darstellung rekurriert nicht auf den Moment des Frevels, sondern führt eine heitere Landschaftsszenerie vor. Bergmann 1999, 98 geht zwar ebenfalls von einer Deutung als Aktaion aus, führt die Bilder aber in einer etwas anderen Deutung zusammen: „Thus the theme of the cross-over resonates in the room: a man trying to fly like a bird, a hunter transformed into a stag, and a hybrid combining the speed of horse and bird. Through their particular powers, each borrowed from another realm, the three will find death: Icarus through artificial wings, Actaeon through his trained hunting dogs, and Bellerophon by his captured, winged horse.“ Tatsächlich ist der Tod des Bellerophon ebenfalls nicht im Bild.

334 Im dritten Stil in drei Häusern belegt, im vierten Stil nur noch einmal, ohne Kontext; s. Hodske 2007, $206 \mathrm{f}$.

335 Zu den Bildbeispielen, s. Hodske 2007, 193-195; Perseus und Andromeda: Hodske 2007, 180-184. 


\section{Inhaltliche Bezüge: Meta-Narrationen}

Für die inhaltlichen Verbindungen, die zwischen Mythenbildern entstehen, soll auf die vorausgegangenen Überlegungen zum Verhältnis von Mythos und Narration zurückgegriffen werden. Damit soll es weniger um die gut erforschte Frage nach dem formalen und inhaltlichen Bezug der Bilder untereinander gehen, sondern nach der Rolle, die die mythologische Narration für die Etablierung von Metadiskursen spielt. Wie gesehen können sich sowohl mythologische Landschafts- als auch Figurenbilder eng auf eine Narration beziehen, sich aber auch davon entfernen, sodass diese Trennung im Folgenden nicht weiter verfolgt wird.

In einigen Räumen spielt die Narration bei der Erzeugung von Metadiskursen eine relevante Rolle. Cubiculum (e) der Casa di Giasone ist als Beispiel für einen Raum vorgeführt worden, in dem alle drei Mythenbilder durch die Thematisierung tragisch-problematischer Liebesgeschichten zusammengeschlossen werden ${ }^{336}$. Es ist hier jeweils ein zugespitzter Moment der Entscheidung, der zur Darstellung kommt.

Im Cubiculum (g) desselben Hauses fällt der Bezug der Bilder zum erzählten Mythos schwächer aus. Dies zeigt sich schon darin, dass mit zwei Mythenbildern im engeren Sinn - Europa auf dem Stier sowie Hercules und Nessos - ein drittes, nur mythisch inspiriertes Bild, Pan und Nymphe, kombiniert wird. Verknüpfungen lassen sich auf verschiedenen Ebenen suchen. Es handelt sich um ,naturhafte‘ Akteure, wobei der jeweils männliche Part unterschiedliche Qualitäten einsetzt, um eine Frau für sich zu gewinnen. Ein solcher Metadiskurs ist aber letztlich auch mit einer nur rudimentären Kenntnis der Narrationen verständlich.

Innerhalb eines Raumes können sich Mythenbilder aber auch in unterschiedlich konkreter Weise auf eine Vorlage beziehen. Eine solch komplexe ,Verschränkung' verschiedener Erzählweisen ist im Cubiculum (q) der Domus V 2,10 (Abb. 368) mit ihren vier mythologischen Landschaftsbildern anzutreffen. Auf der Rückwand im Norden waren Daedalus und Icarus dargestellt, im Süden (als einziges Bild erhalten) Marsyas, Athena und die Musen ${ }^{337}$. Es handelt sich in beiden Fällen um aktionsreiche mythologische Landschaftsbilder, die jedoch keine motivischen Parallelen aufweisen. Vielmehr werden die beiden Bilder durch ein vergleichbares Narrativ zusammengeschlossen - beide Bilder thematisieren die Bestrafung eines Frevels. Davon setzen sich die Bilder der Eingangswand im Westen und der gegenüberliegenden Ostwand ab, die eine Sakrallandschaft zum Gegenstand haben; das Geschehen ist deutlich beruhigt. Auf der Westwand handelt es sich um Hercules, der sich - hinterfangen und inszeniert von einer geschlossenen Gebäudewand - den drei Hesperiden am Altar zuwendet ${ }^{338}$. Auf der Gegenseite im Osten nähern sich mehrere Jäger einem Kultbild der Diana/Isis, welches das Bildzentrum einnimmt. Einer von ihnen könnte Hippolytos sein, doch zwingend ist eine solche Identifikation nicht ${ }^{339}$. Damit stehen sich auf Nord- und Südwand zwei aktionsreiche Bilder des Frevels gegenüber, während es sich auf West- und Ostseite um mythisch aufgeladene, sakralidyllische und nicht im engeren Sinn narrativ verfasste Landschaftsbilder handelt ${ }^{340}$. Indem die Mythenbilder $\mathrm{zu}$ antithetischen Paaren gruppiert sind, wird zugleich eine Kontrastierung von Erzählweisen und Aussagen möglich ${ }^{341}$.

336 PPM IX (1999) 670-719 s. v. IX 5,18, Casa di Giasone (V. Sampaolo) 681-688 Abb. 16-23; s. o. S. 361-367.

337 Neapel, NM 120626; PPM III (1991) 830-847 s. v. V 2,10 (V. Sampaolo) 839 Abb. 19; 842 Abb. 22.

338 PPM III (1991) 830-847 s. v. V 2,10 (V. Sampaolo) 844 Abb. 21. 24.

339 Als Hippolytos etwa Leach 1988, 388; Bergmann 1999, 95.

340 Bergmann 1999, 95 bindet bei ihrer Deutung des Bildes sehr viel stärker den mythologischen Hintergrund ein, entfernt sich dadurch aber von den Akzentsetzungen der beiden sakralen Bilder. Klein 1919, 293-295 und erneut Leach 1988, 388f. mit Fokus auf die Unterschiede in der formalen Komposition.

341 Siehe auch Lorenz 2008, 299-302 mit dem Hinweis, dass nicht alle Bilder eines Raumes denselben Verknüpfungszusammenhängen verpflichtet sein müssen. 


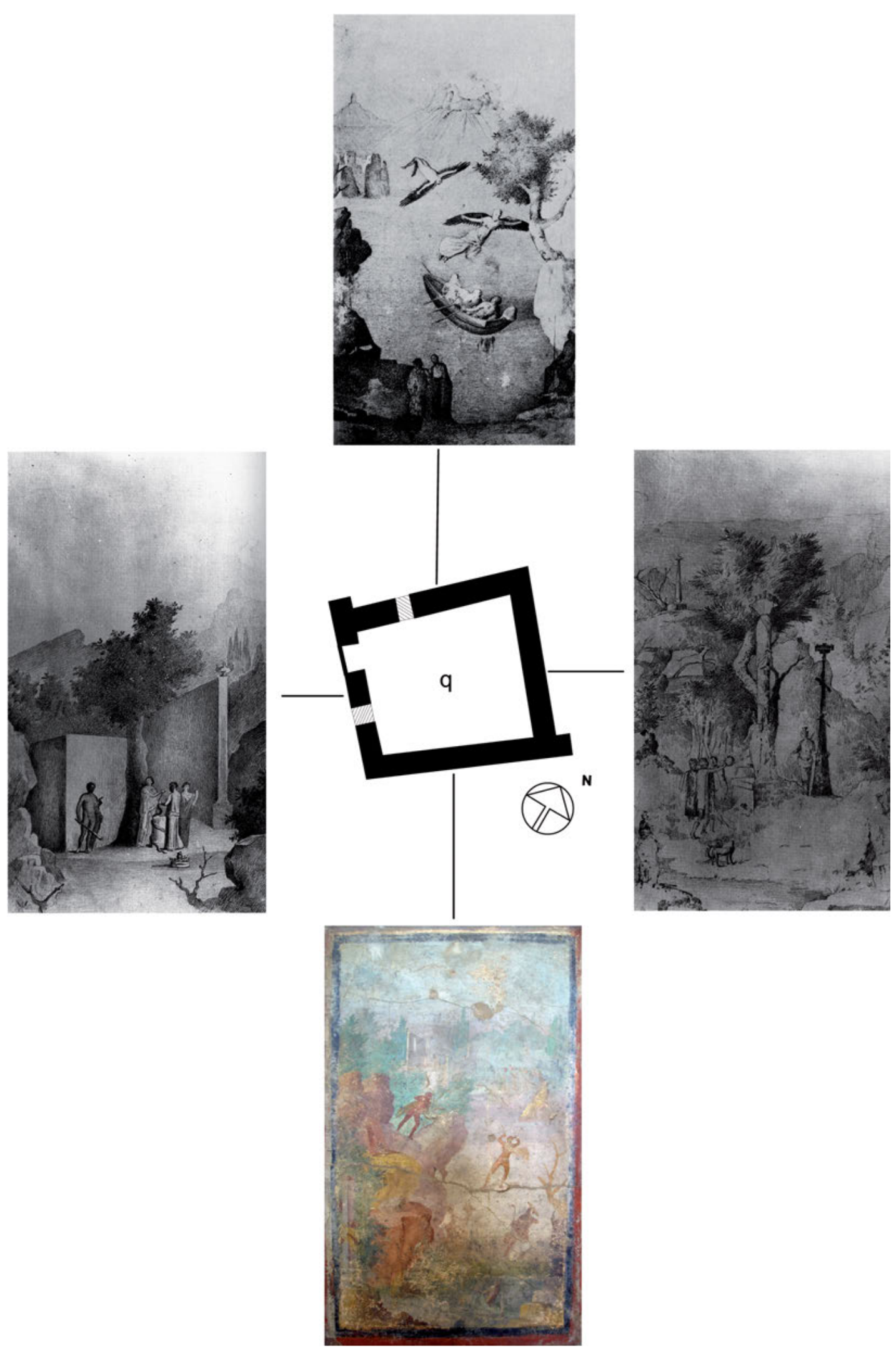

Abb. 368: Domus V 2,10, Cubiculum q, Mittelbilder der vier Wände; Nordwand: Daedalus und Icarus; Zeichnung (G. Mariani); Südwand: Marsyas, Athena und die Musen (Neapel, NM 120626); Westwand: Heracles bei den Hesperiden, Zeichnung (G. Discanno); Ostwand: Kultbild von Diana/Isis, Zeichnung (G. Mariani). 
Mythenbilder können sich auf ein gemeinsames ,Thema' beziehen, ohne dass die mythologische Erzählung eine prominente Rolle spielt. Die Verbindung zwischen den Bildern wird in diesem Fall zuvorderst mit ikonographischen Mitteln erzeugt. Dies gilt insbesondere für Mythenbilder, die einen Mythos auf wenige benennbare Einzelfiguren reduzieren und damit den Fokus auf die Inszenierung von Rollenbildern legen. Wie gesehen wird ein solcher Erzählmodus im späteren dritten Stil immer beliebter ${ }^{342}$. Häufig sind es Liebespaare, für die verschiedene Konstellationen durchgespielt werden. So lassen sich Mars und Venus sowie Bacchus und Ariadne im Tablinum (h) der Casa di Marcus Lucretius Fronto im Hinblick auf ihre genderspezifischen Rollenbilder diskutieren. Die Mythenerzählung spielt jedoch weder für das Einzelbild noch für den Zusammenhang zwischen den Bildern eine zentrale Rolle. Einer vergleichbaren Logik folgen Bild-Ensembles, deren Protagonisten derselben Handlungssphäre angehören. Im Tablinum (n) der Casa detta di Trebius Valens (III 2,1) ist auf der Westwand das mittige Bild, das Bacchus mit Panther zeigte, auf der Gegenwand mit der Darstellung eines trunkenen Silen kombiniert ${ }^{343}$. Der Gott und sein Gefolge bilden so eine Gruppe, die durch die schwebenden Psychen auf den Seitenpaneelen eingerahmt ist. Ein großes Fenster, durch das man auf das Gartentriclinium blickte, dürfte zusammen mit den Darstellungen von Weingirlanden über dem Fenster die leichte Atmosphäre verstärkt haben. Narrativität ist in dieser Bildkombination ganz zurückgenommen. Für Bergmann wären entsprechende Ensembles mit dem Terminus der similitudo zu beschreiben, mit Lorenz könnte man von einer affirmativen Verdichtung der Bildaussagen sprechen.

Die Reduktion des narrativen Gehalts der Einzelbilder kann aber auch dazu genutzt werden, mythologische Bilder zu kombinieren, deren thematisch-ikonographischer Zusammenhang auf verschiedenen Ebenen gesucht werden kann. So verbindet sich im Tablinum (26) der Casa del Centauro (VI 9,3.5; Plan 17) die Darstellung von Meleager und Atalante (Abb. 365) mit Hercules und Deianeira (Abb. 369) 344 $^{34}$ Beide Bilder entfalten eine Paarbeziehung, in beiden wird aber auch die Störung einer sozialen Konstellation thematisiert. Atalante dringt in einen männlichen Handlungskontext ein, während sich Nessos in die eheliche Gemeinschaft hineindrängt. Liebe und das Moment des Störens werden chiastisch verflochten.

Wenn bereits die mythologischen Einzelbilder vieldeutig ausfallen, potenziert sich die Polyvalenz. Im Cubiculum (20) der Casa del Citarista (I 4,5.6.25.28; Plan 5) tritt zu dem polyvalenten Paarbild der Nordseite (Mars/Venus oder Adonis/Venus, s. o.) auf der gegenüberliegenden Südseite die Darstellung einer Frau im Heiligtumskontext hinzu - Leda oder Nemesis. Das Bild der Ostseite zeigt einen orientalischen Herrscher vor einer Reihe von Zelten; es mag sich um Laomedon handeln. Für Lorenz ergeben sich aus dem Bildvergleich gewisse Vereindeutigungen ${ }^{345}$. Das Herrscherbild verbindet sie mit officium und virtus, das Leda-Bild mit pietas, das Paarbild als Hinweis auf matrimonium und concordia. Allerdings lassen sich die schon in sich polyvalenten Bilder nicht zwingend auf solche Wertvorstellungen zuschneiden - es ergeben sich letztlich unendlich zahlreiche, denkbare Verbindungen ${ }^{346}$. Bergmann führt einige davon aus ${ }^{347}$ : „Falls die Szenen auf der Nord- und der Ostwand Leda, die Königin von Sparta, oder Laomedon, den König von Troja, zeigen, konnte der Betrachter die Krieg führenden Griechen und Trojaner Seite an Seite sehen. Falls es sich bei dem Liebespaar auf der Südwand um Dido und Aeneas handelt, sind auf dem dritten Wandge-

342 Lorenz 2008, 313-316.

343 PPM III (1991) 341-391 s. v. 2,1, Casa detta di Trebius Valens (I. Bragantini) 367 Abb. 40; 374 Abb. 47.

344 Peters 1963, 102f.; s. Lorenz 2008, 282f. mit leicht anderer Ausdeutung; zum Boden, der hier in der Phase des dritten Stils erneuert wurde, s. Zapheiropoulou 2006, 152.

345 Lorenz 2018, 158-164; sie allerdings geht bei dem Leda- und Laomedon-Bild von einer ,eindeutigen` Ikonographie aus.

346 Auf eine ausführliche ikonographische Detaildiskussion der Einzelbilder wird hier verzichtet; s. Hoffmann 2014, 136-141.

347 Bergmann 2014a, 79. 


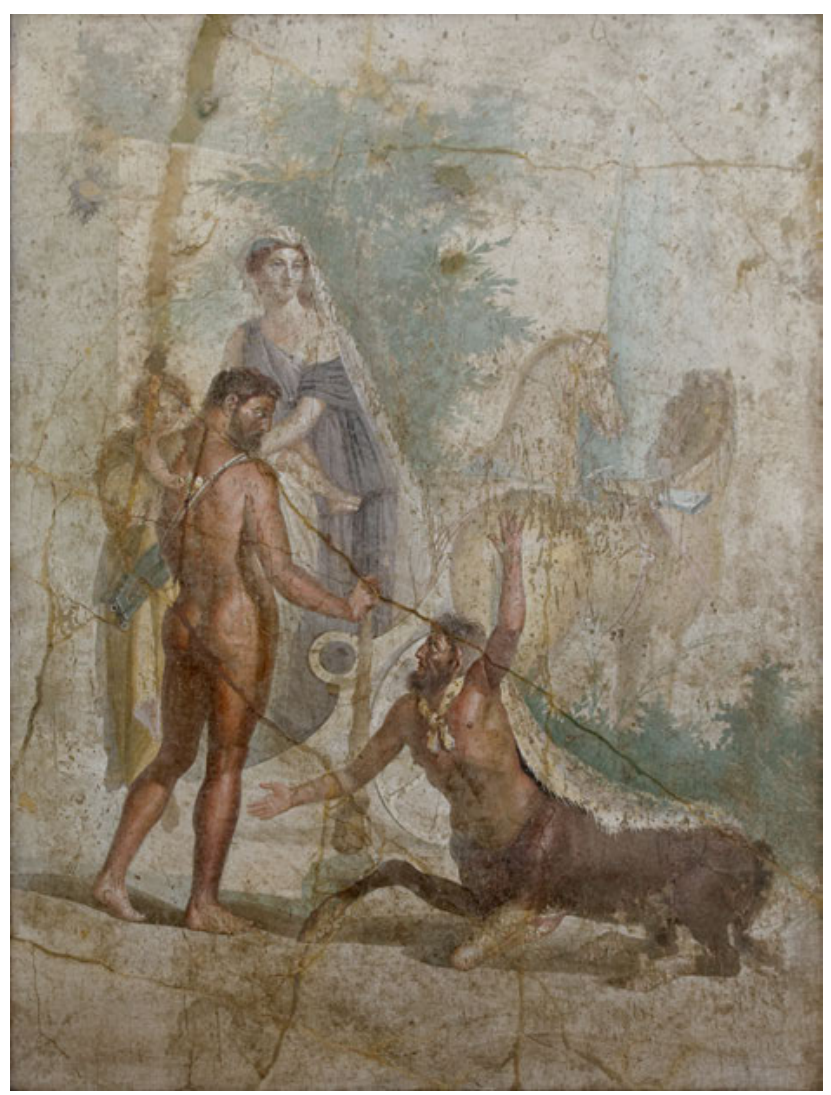

Abb. 369: Casa del Centauro (VI 9,3.5), Mythenbild der Südwand von Tablinum (26): Hercules und Deianeira (Neapel, NM 9001).

mälde wiederum zwei rivalisierende Mächte dargestellt: Karthago und Rom.“ Wieder andere Beziehungen ergeben sich freilich bei anderen Einzeldeutungen.

Die Zusammenstellung von Mythenbildern kann auch deren Erzählzusammenhang zuwiderlaufen, sodass die Verbindung allein auf einer ikonographisch-motivischen Ebene liegt. Dies trifft auf das Bild-Ensemble in Cubiculum (g) der Casa di Marcus Lucretius Fronto zu. Das Bild von Theseus und Ariadne steht der Darstellung von Venus im Frauengemach gegenüber. Mit der Präsentation des nackten Theseus-Körpers hier (Abb. 310), der nackten Venus dort (Abb. 311) liegt der Fokus auf der Thematisierung von Schönheit, Attraktivität und Liebe.

Die Komplexität der thematisch-motivischen Verbindungen kann schließlich durch die Einbeziehung anderer Medien weiter gesteigert werden. Ein solcher Fall intermedialer Referenzen wurde bereits für das Spiel mit Realität und Fiktion in den Peristylen mit ihrem realen Garten und ihren Gartenmalereien thematisiert. Ein besonders raffiniertes Beispiel, bei dem auch Mythenbilder zum Tragen kommen, stellt Oecus (e) der Casa e panificio di Papirius Sabinus (IX 3,19-20) dar (Abb. 370). Auf der dem Eingang gegenüberliegenden Westwand sind Demeter, Proserpina und Triptolemos zu sehen - letzterer den Schlangenwagen führend. Auf der Eingangswand handelt es sich um die schlafende Ariadne. Auf den seitlichen Wänden im Norden und Süden nimmt jeweils ein Fenster den Ort des Mittelbildes ein. Durch das nördliche Fenster blickt man in den Hof (a), in dem die Mühlen der Bäckerei stehen, im Süden in ein weiteres Triclinium (c) ${ }^{348}$. Die Mythenbilder korrespondieren so mit den realen Ausblicken: Demeter schafft die Voraussetzungen für die erfolgreiche Bäckerei-Produktion, während das stärker erotische Ariadne-Bild einen Assoziationsrahmen für den Durchblick in das benachbarte Triclinium darstellt. Hier sind mythologische Bilder und gerahmte Fensterdurchblicke als Pendants aufgefasst. Damit handelt es sich um ein besonders 

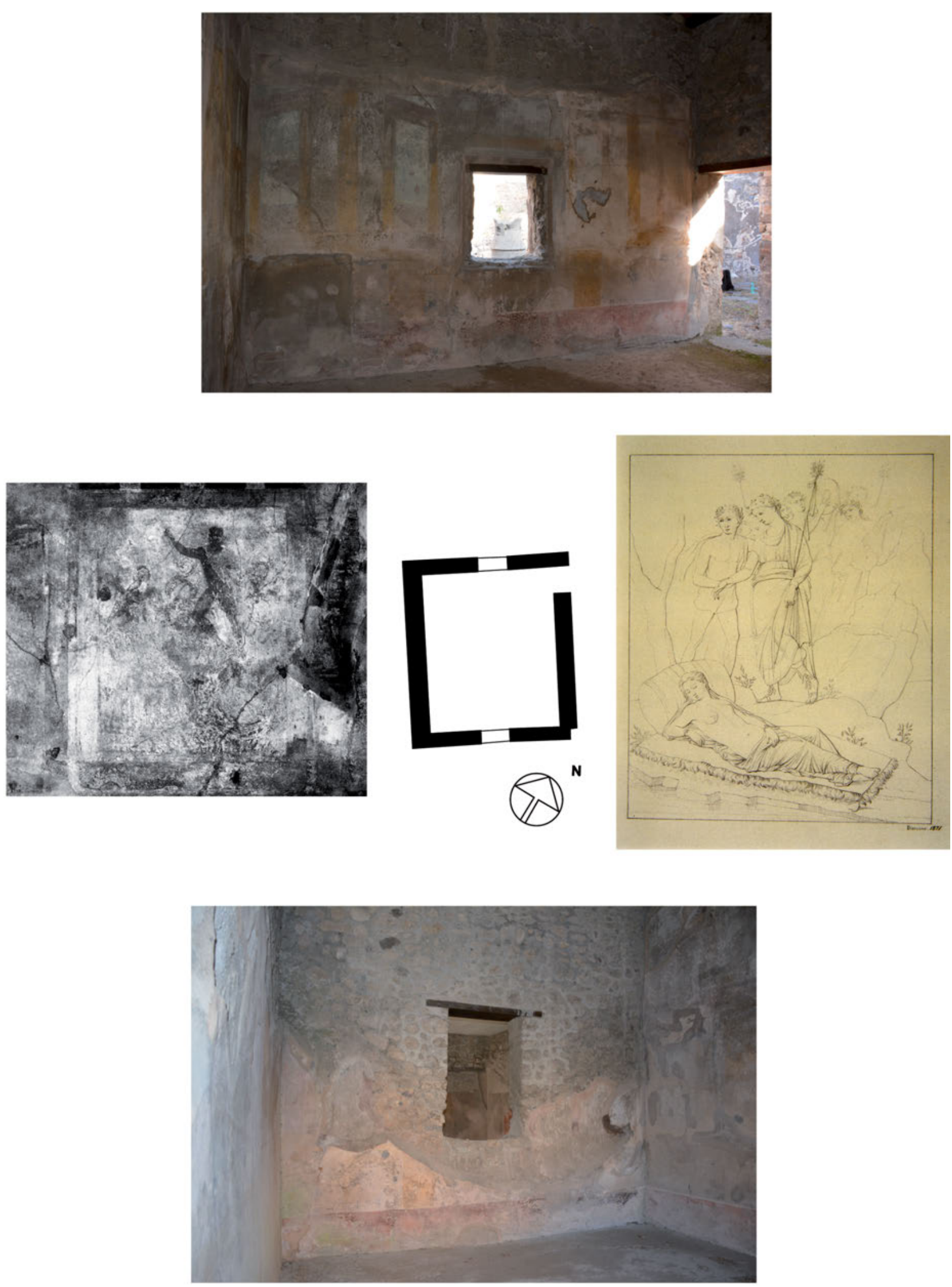

Abb. 370: Casa e panificio di Papirius Sabinus (IX 3,19-20), Oecus (e): Westwand: Demeter, Proserpina und Triptolemos; Ostwand: Ariadne schlafend; Nordwand mit Fenster: Blick in Hof (a); Südwand mit Fenster: Blick in Triclinium (c). 
ungewöhnliches Beispiel der Pendantbildung, das zugleich Auskunft über das Aktualisierungspotenzial von Mythenbildern gibt.

Zusammenfassend zeigt sich, dass das narrative Potenzial, das Mythenbilder mitbringen, nicht nur bei der Gestaltung des Einzelbildes, sondern auch bei der Aktivierung von Metadiskursen in unterschiedlicher Weise eingesetzt werden kann. Quer dazu können die thematischen Verflechtungen liegen, die sich zwischen den Mythenbildern ergeben.

\section{Plurale Bilder: Die Komplexität der Decor-Ensembles an den Wänden}

Schon auf der Ebene der mythologischen Mittelbilder entstehen ausgesprochen komplexe Beziehungsgeflechte. Doch sind durch das Decor-Schema nicht nur diese aufeinander bezogen, sondern alle Gestaltungselemente eines Raumes. Dabei ergeben sich zwei mögliche Bezugsebenen. Einerseits stehen die Decor-Elemente in Korrespondenz mit ihren visuellen ,Pendants' auf den anderen Wandseiten. Andererseits treten sie in Konkurrenz zu den Gestaltungselementen auf ein und derselben Wand. Die möglichen Bezugs- und Assoziationsgeflechte nehmen sich dadurch letztlich endlos aus.

Um dennoch einen Eindruck davon zu vermitteln, dass auch diese Meta-Bilder ganz unterschiedlich ausfallen können, sollen an dieser Stelle zwei verschiedenartige Raum-Ensembles kontrastiert werden: die in augusteischer Zeit ausgestatteten Cubicula (15), (16) und (19) der Villa di Agrippa Postumus in Boscotrecase ${ }^{349}$ (die hier ausnahmsweise als extraurbaner Kontext eingeführt wird, weil es nicht um die soziale Aneignung des Raumes geht) und die bereits bekannten Räume am Atrium der Casa di Marcus Lucretius Fronto. In den Raum-Ensembles unterscheiden sich sowohl die ästhetischen wie auch die semantischen Effekte, die im Folgenden in Abhängigkeit voneinander betrachtet werden sollen.

Die Cubicula (15), (16) und (19) der Villa des Agrippa Postumus bilden eine Raumflucht und sind durch ästhetische Variationen aufeinander bezogen. In Cubiculum (15) kontrastiert mit einem roten Sockel ein monochrom schwarzer Wandaufbau (Abb. 371a-b), in Cubiculum (16) mit einem schwarzen Sockel ein monochrom roter Wandaufbau (Abb. 372). Während die Cubicula (15) und (16) ästhetisch folglich maßgeblich durch die Monochromie der Wände geprägt waren, flankieren in Cubiculum (19) rote Seitenfelder das schwarzgrundige Mittelfeld (Abb. 373-374). Auch die gliedernde Architektur unterscheidet sich und trägt zur Variation des Raumeindrucks bei. In Cubiculum (15) handelt es sich um ein filigranes Gestänge, das regelrecht ornamenthafte Landschaftsvignetten einfasst, während sich das Rahmensystem im roten Cubiculum (16) dinghafter ausnimmt und großformatige Landschaftsbilder auf weißem Grund rahmt. Noch einmal massiver wirken die Ädikulen in Cubiculum (19), die als Rahmung für mythologische Landschaftsbilder dienen. Die Räume unterscheiden sich folglich hinsichtlich ihrer Farbigkeit, der Mächtigkeit des Architekturgestänges und hinsichtlich der Größe und semantischen Dichte ihrer Mittelbilder. Ein weiterer Unterschied ergibt sich in Bezug auf die Kombination mit anderen Bildelementen.

349 Von Blanckenhagen - Alexander 1962; Dawson 1965, 100f. 114. 119. 145f.; von Blanckenhagen - Alexander 1990. Die Wandmalereien des schwarzen Cubiculums (15) sowie Teile von Cubiculum (19) befinden sich heute im Metropolitan Museum of Art in New York, die Malereien des roten Cubiculums (16) im Museo Archeologico Nazionale di Napoli. Der Kontext wurde auch ausführlich im Rahmen eines Seminars besprochen, einige Anregungen verdanke ich der Referentin für das Thema, Irene Ebke. 


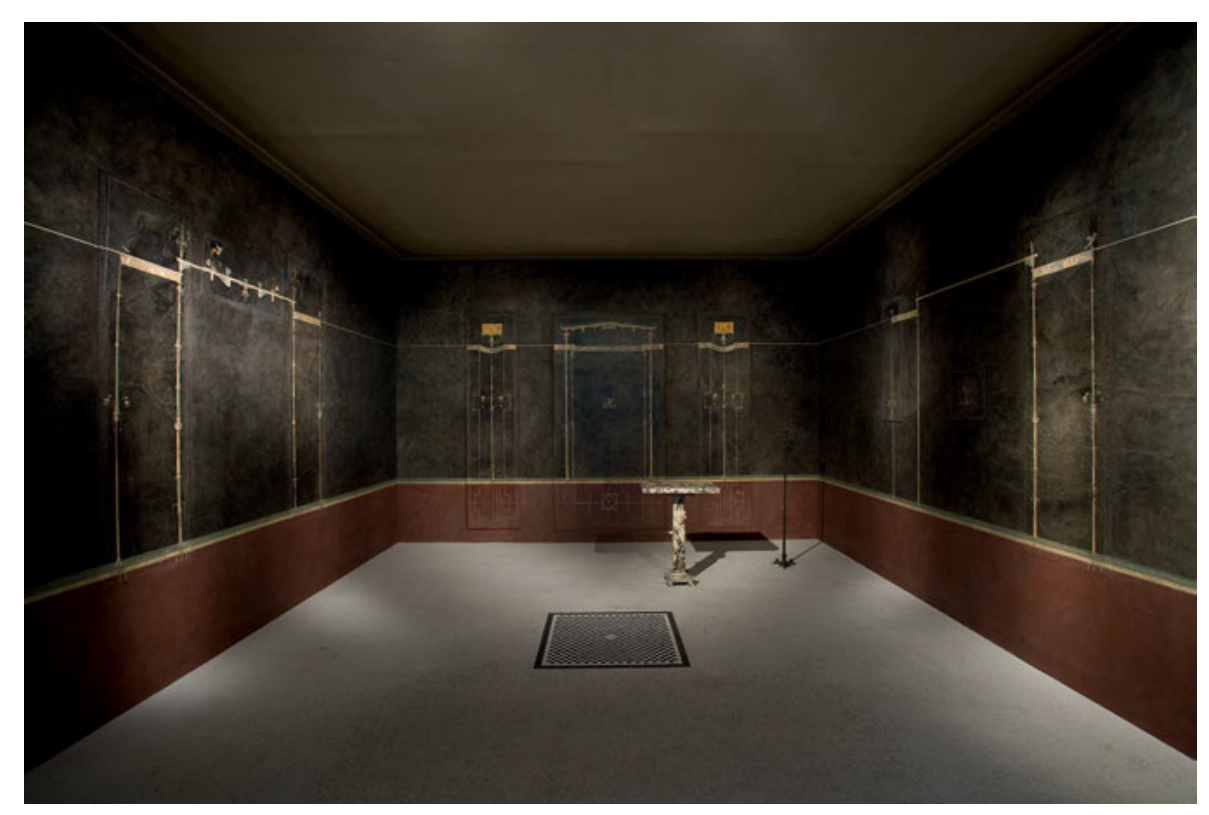

Abb. 371a: Boscotrecase, Villa des Agrippa Postumus, schwarzes Cubiculum (15), Rekonstruktion des Cubiculums, New York, MMA

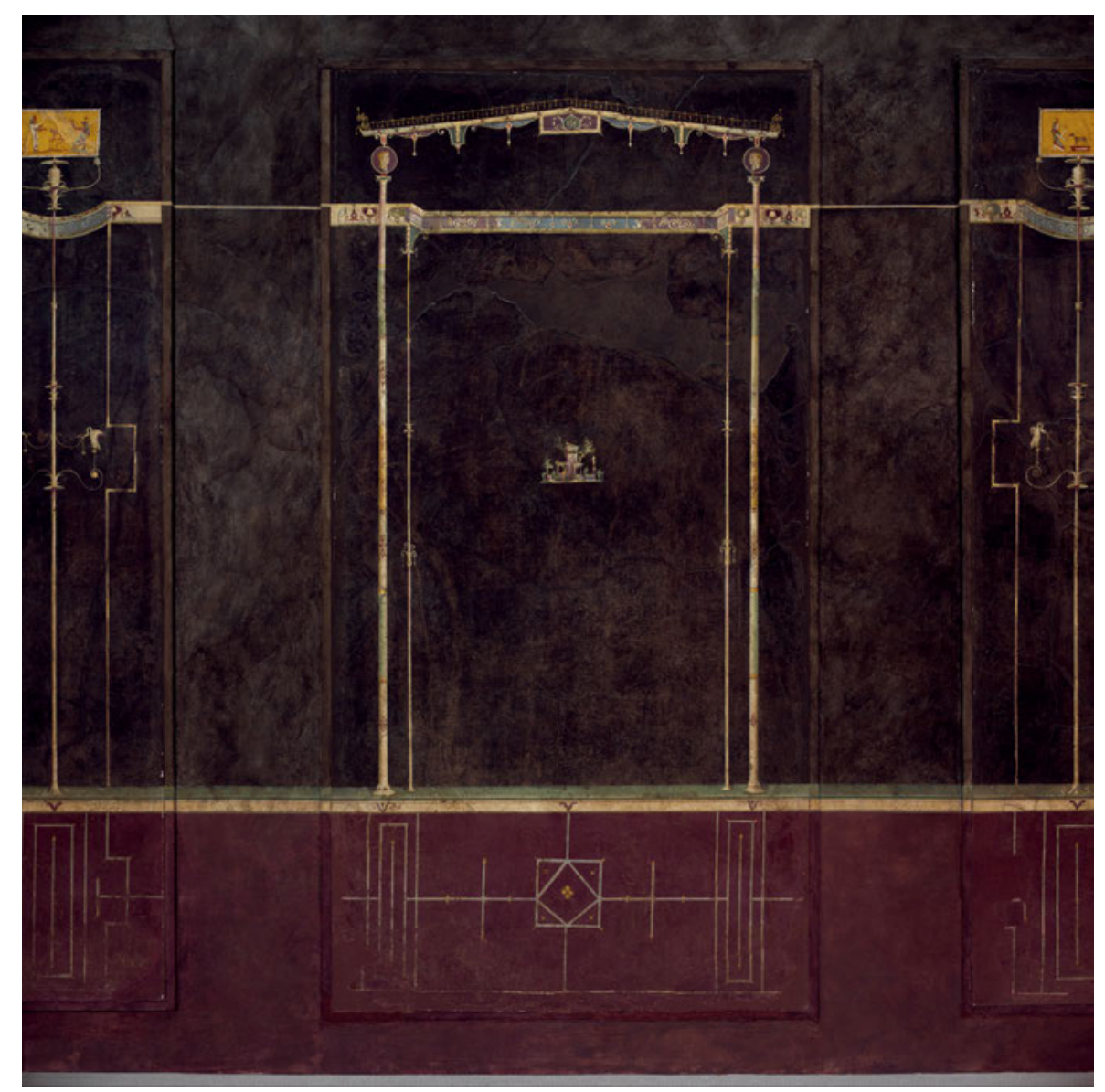

Abb. 371b: Boscotrecase, Villa des Agrippa Postumus, schwarzes Cubiculum (15), New York, MMA, Detail. 


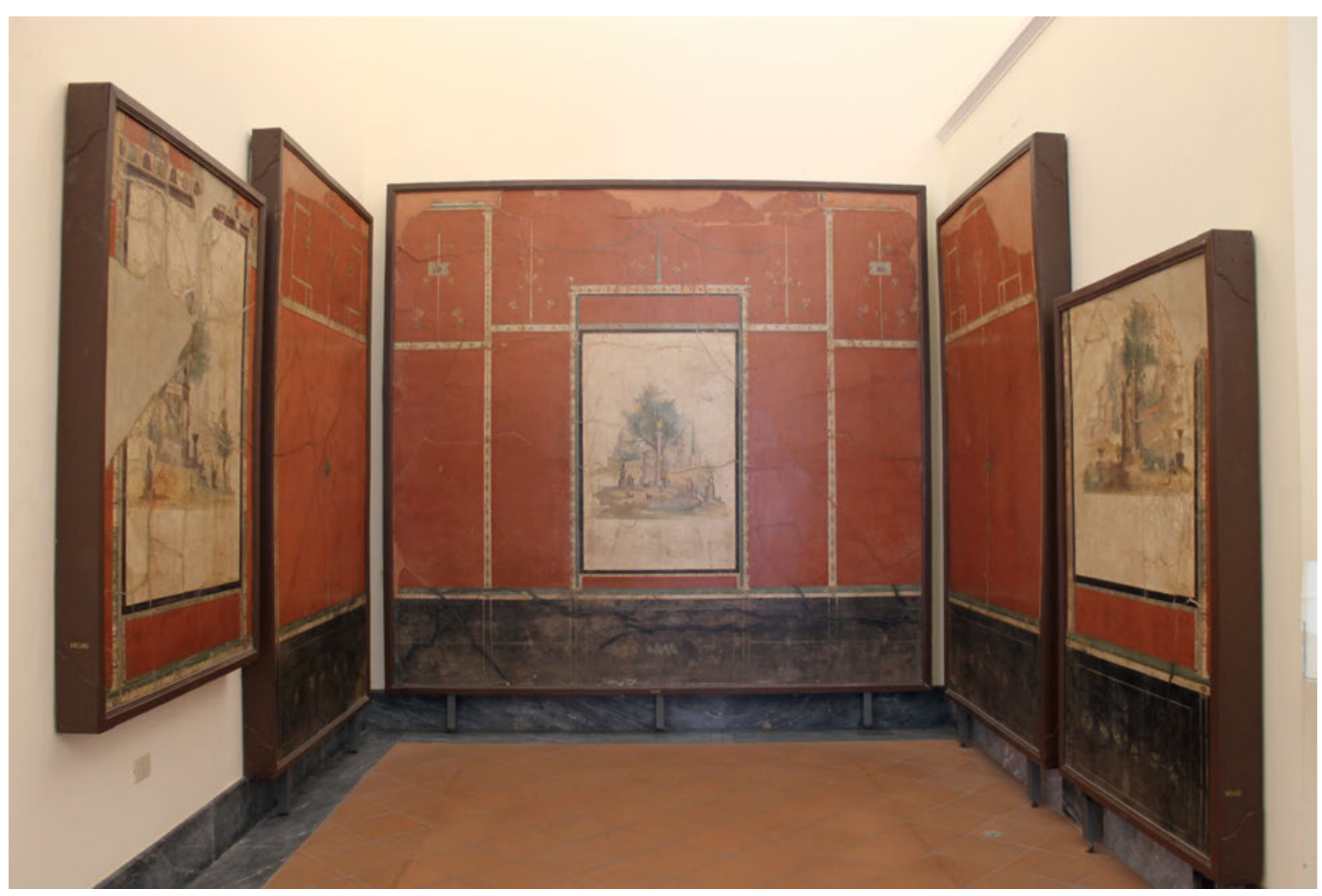

Abb. 372: Boscotrecase, Villa des Agrippa Postumus, rotes Cubiculum (16), Rekonstruktion in Neapel, NM 147501.

Im schwarzen Cubiculum (15) vermag ein intensiverer Blick auf die Landschaftsbilder Ähnlichkeiten und Unterschiede offenzulegen. Auf der Nordwand ist es eine Turmarchitektur mit Anbauten; Altar und Statuensäule verleihen dem Arrangement ein sakrales Flair. Auf der Ostwand ist die Architektur auf eine grazile Säulenstellung reduziert. Alle Architekturen werden von Bäumen umrankt und sind von Menschen bevölkert, die teilweise mit Sakralhandlungen beschäftigt sind oder Vieh vor sich hertreiben. Auf den zweiten Blick bemerkt man dann vielleicht auch an der Rückwand des Raumes die kleinen Pinakes in der Oberzone, die jedoch durch ihren gelben Hintergrund besonders auffällig leuchten. Ägyptisierende Figuren rahmen jeweils eine tiergestaltige, gesockelte Götterstatue. Auch die Pinakes machen damit ein Spiel mit Ähnlichkeit und Varianz auf. Die Bildlichkeit der Rückwand wird weiter verdichtet, indem zwischen den Säulenkapitellen und dem Giebel der zentralen Ädikula Medaillons mit im Profil angegebenen Porträtköpfen eingefügt $\operatorname{sind}^{350}$. Sie labilisieren die Architektur, indem sie die statische Logik infrage stellen, und brechen zugleich aus der generischen Darstellungsweise des Wandbildes aus: Sie beziehen sich auf die Jetztzeit und schaffen einen eigenen ,Bildraum', indem sie sich anblicken. Hinzu kommen Details, welche die ,Rahmungen“ ästhetisch aufwerten. Das filigrane Gliederungsnetz besteht aus Kandelabern und aus Thyrsoi gebildeten Dreifüßen. Auf der Nordwand wachsen Ranken aus den Kandelabern, auf denen sich antithetisch platziert Schwäne niedergelassen haben, die ein Schmuckband im Schnabel halten. An den Seitenwänden ist das Ädikuladach von Vögeln und Greifen bevölkert, in die Ranken sind Masken eingesetzt.

350 Anderson 1987 mit der (m. E. hypothetischen) Identifikation als Livia und Iulia - Frau und Tochter des Augustus. 

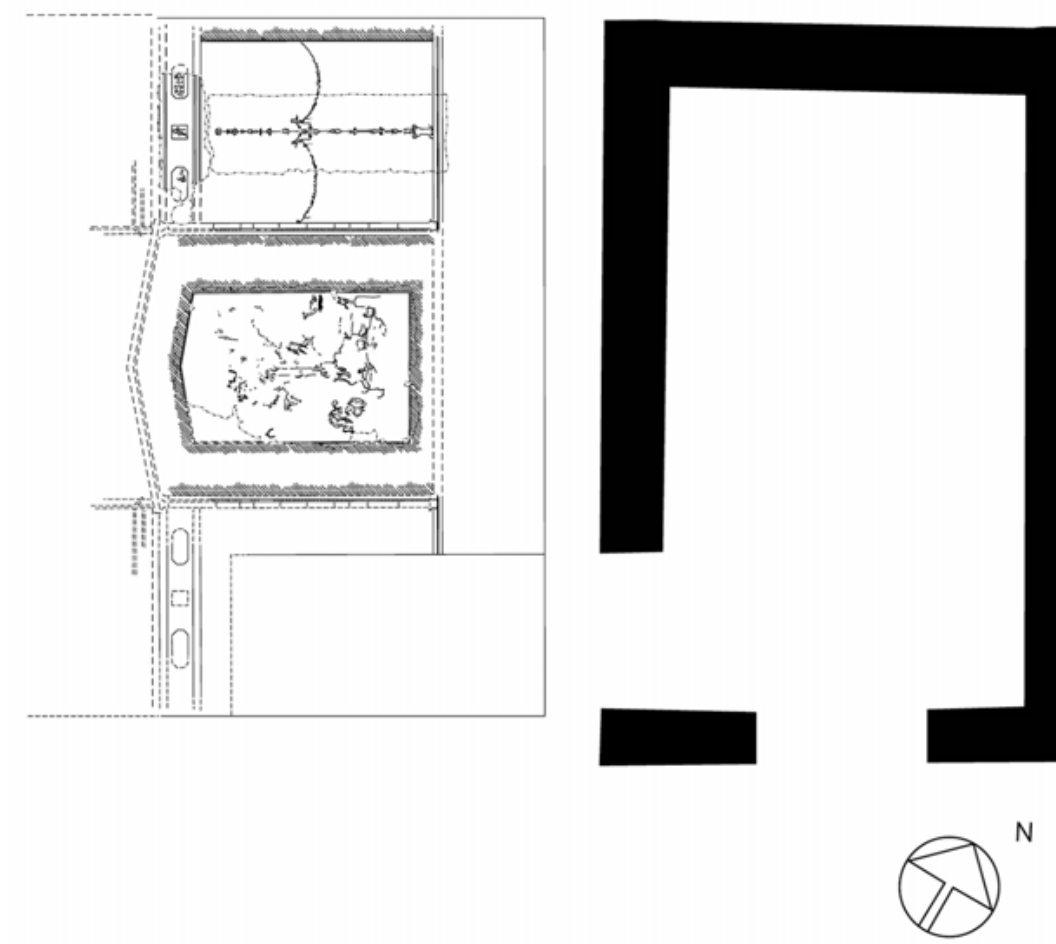

Abb. 373: Boscotrecase, Villa des Agrippa Postumus, Cubiculum (19), Rekonstruktion (Peter H. von Blanckenhagen).
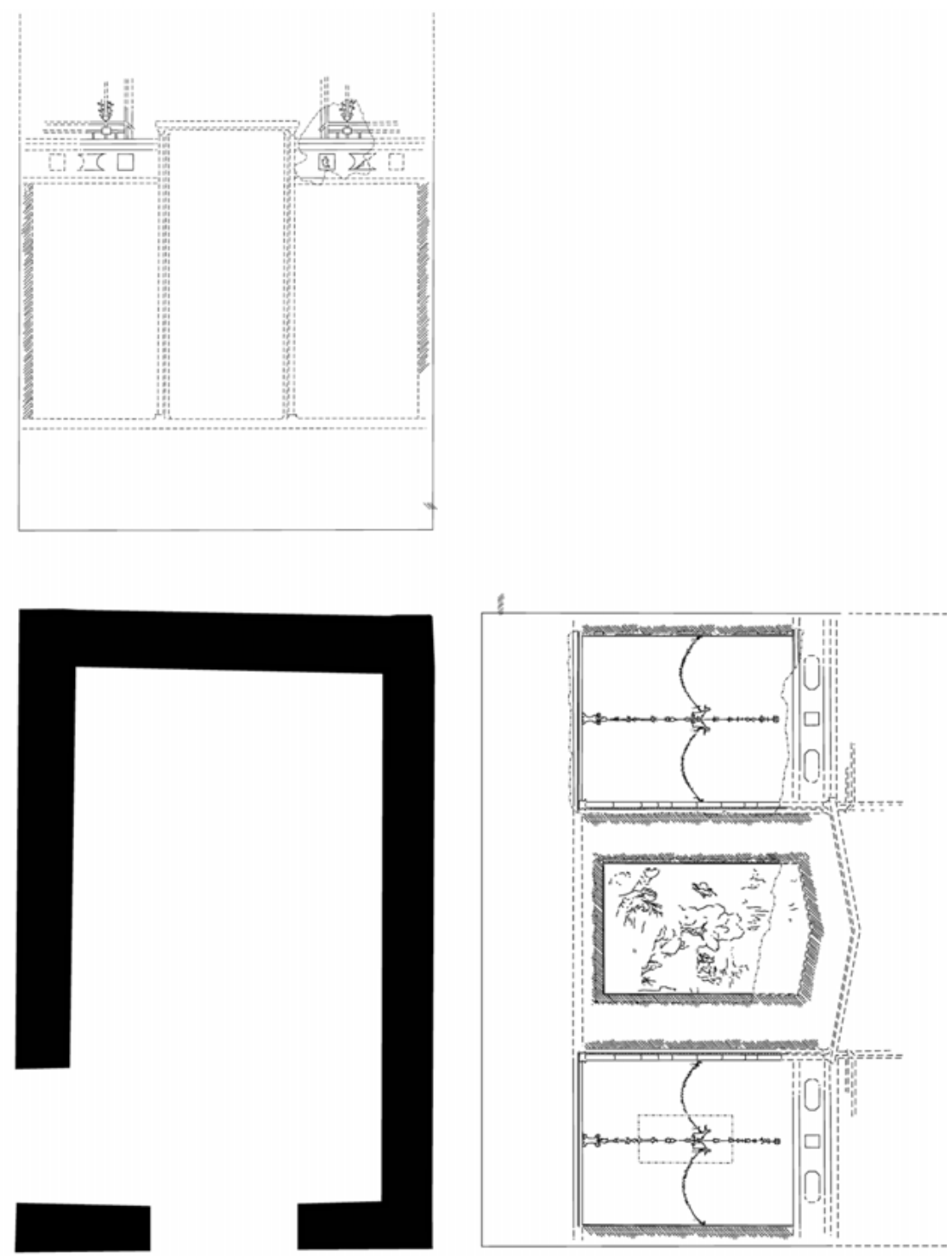
Im roten Cubiculum (16) gewinnen die deutlich größeren Landschaftsvignetten auf weißem Grund eine bildhafte Qualität. Auf der Nordwand treten in der Oberzone - hier jedoch deutlich weniger auffällig - Pinakes mit Maskendarstellungen hinzu, die von stabartigen, von Blüten umrankten Trägern präsentiert werden. Auf den Seitenwänden ist vor den hohen Thyrsoi jeweils ein Medaillon mit dionysischer Maske platziert, in die Architekturen der Oberzone sind kleine Pinakes mit Tieren und Fabelwesen integriert. Vögel und Gefäße ohne Rahmung fungieren als Akrotere. Mit den Masken und Thyrsoi sind es im roten Cubiculum somit zuvorderst dionysische Motive, die zu den Landschaftsbildern hinzutreten. Diese zusätzlichen Bedeutungsschichten erschließen sich erst auf den zweiten Blick, bei einer intensiveren Betrachtung des Raumes.

In beiden Cubicula $(15 ; 16)$ ist damit jedoch nur die erste Ebene der Aufmerksamkeitslenkung angesprochen. Die Architektur selbst ist durch kleinteilige Ornamente differenziert: geometrisch (Cubiculum 15) bzw. floral (Cubiculum 16) gestaltete Sockelzonen, ornamental gemusterte Säulchen bzw. Pilasterchen, vegetabilisierte, mit Ranken und Tellern versehene Kandelaberstängel, eine reich ornamentierte Attika- und Giebelzone. Diese Binnenornamente verdichten den Eindruck von Filigranität und Kostbarkeit, stören jedoch nicht die übersichtliche und großflächige Strukturierung der Räume.

Cubiculum (19), dessen Wandaufbau sich weniger gut rekonstruieren lässt, ist insofern aufschlussreich, weil gerade im Kontrast der Räume deutlich wird, dass mit den mythologischen Mittelbildern ein deutlich stärkerer Fokus auf das Wandzentrum einhergeht (Abb. 373-374). Die roten Seitenfelder mit ihren filigranen Kandelabern treten hinter den Mythenbildern zurück. Aus ihrem mittleren Teller sprießt eine Ranke, auf der Sirenen hocken. An ihnen sind Girlanden festgemacht. Damit konkurrieren die schwarzgrundigen, ägyptisierenden Bilder in der Frieszone.

An allen drei Räumen zeigt sich, dass zu den zentralen Mittelbildern - seien es Landschaftsdarstellungen oder mythologische Landschaftsbilder - zahlreiche weitere figürliche Elemente hinzutreten. Dies gilt in den Oberzonen insbesondere für kleinformatige Pinakes, aber auch für Medaillons. Vor allem aber tragen eine Vielzahl von kleinteiligen ,Ornamenten` zur visuellen Komplexität der Räume bei. Eine homogene Lektüre der Räume ist dadurch nicht möglich. Konkret aufeinander bezogen sind jeweils nur die Elemente, die sich formal entsprechen: mittige Mythenbilder, Pinakes, Akroterbilder. Dennoch wirken die Räume nicht überladen: Die klare architektonische Gliederung und die Reduktion der zahlreichen figürlichen Details auf eine ornamenthafte Größe tragen zur Übersichtlichkeit der Räume bei.

In der im späten dritten Stil ausgestatteten Casa di Marcus Lucretius Fronto fallen die Gestaltungskontraste zwischen den Räumen größer aus. Das monochrom schwarze Atrium zeichnet sich durch eine relative Übersichtlichkeit aus, auch hier erschließen sich beim längeren Verweilen jedoch zahlreiche decorative Details. Darin ist der Raum letztlich Decor-Prinzipien augusteischer Zeit verpflichtet. Damit kontrastieren die bunte Farbigkeit sowie die Bild- und Ornamentfülle des Tablinums (h). Sockel-, Mittel- und Oberzone sind mit verschiedensten Bildformen (Tafelbilder, Pinakes, Einzelmotive) und -inhalten (Mythenbilder, Landschaftsbilder, ,Stillleben', Tierbilder, Objekte) besetzt. Zwar behält der Raum durch seine Symmetriebeziehungen eine gewisse Übersichtlichkeit. Indem jedoch verschiedene große und ikonographisch dichte ,Bild‘-Elemente in den Wandaufbau Eingang finden, ist die ästhetische wie auch semantische Heterogenität massiv gesteigert. An den Cubicula (g) und (c) wird deutlich, dass diese Form der Überforderung des Auges nicht für alle Räume gleichermaßen gewählt wurde. Während das polychrome Cubiculum (g) den Farbrhythmus und die Fokussierung auf mythologische Mittelbilder aufgreift, aber die Bilddichte erheblich reduziert, wird im monochrom weißen Cubiculum (c) auf eine Strukturierung durch Farbe verzichtet. Indem hier alle drei Felder der Mittelzone kleine Bildfelder tragen - im Zentrum ein quadratisches Bildfeld, seitlich langrechteckige - ist zwar ein Rhythmus vorgegeben. Das Auge nimmt jedoch stärker eine parataktische, ornamentale Reihung der Bilder wahr. 

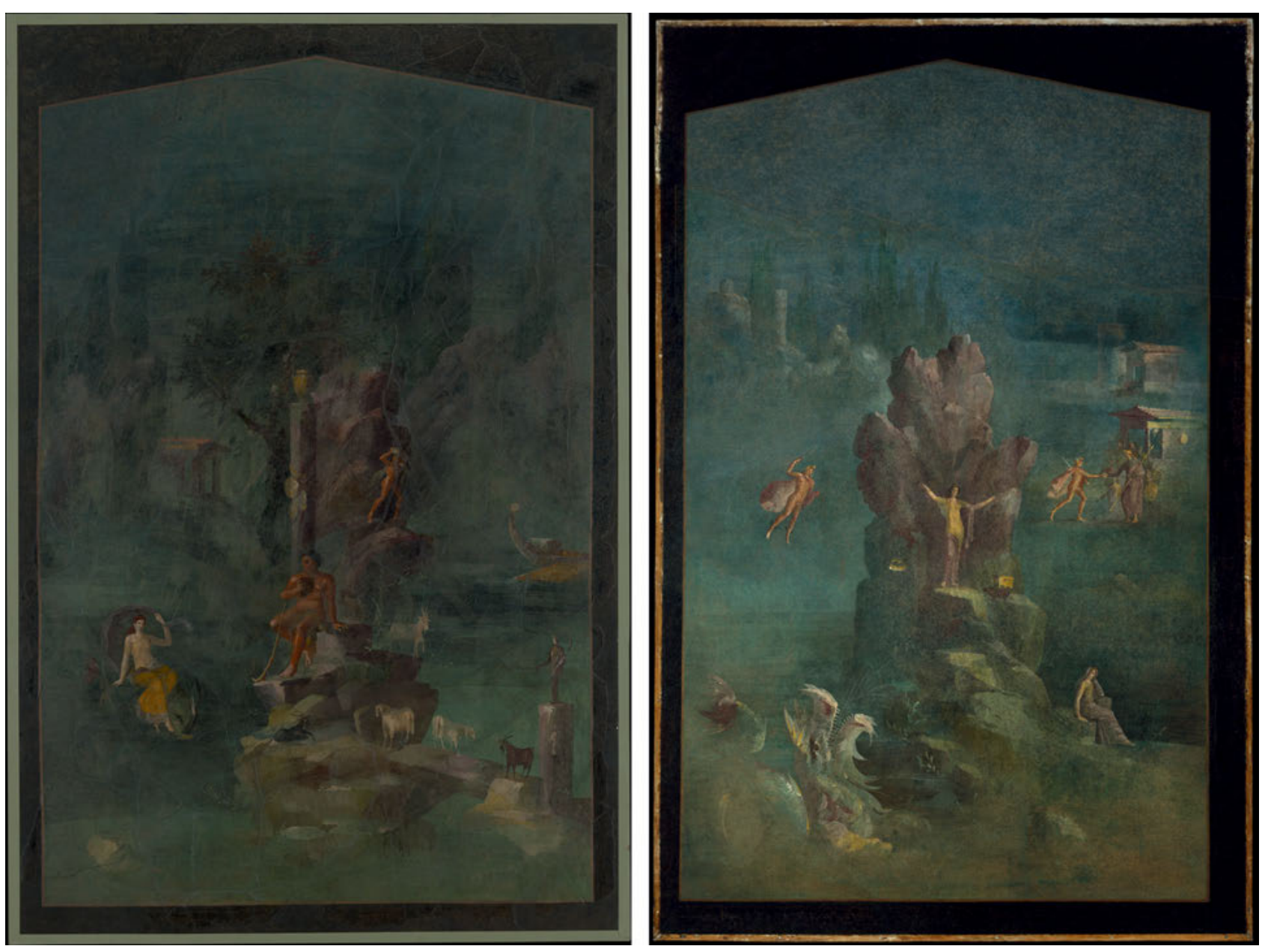

Abb. 374a-b: Boscotrecase, Villa des Agrippa Postumus, Cubiculum (19), Mythenbilder; a: Westwand (links): Polyphem und Galatea (New York, MMA 20.192.17); b: Ostwand (rechts): Perseus und Andromeda (New York, MMA 20.192.16).

Im Vergleich einer frühen und einer späten Raumgruppe zeichnen sich zunächst einige Parallelen ab. Raumfolgen werden im dritten Stil noch stärker als zuvor als Ensemble begriffen. In der Villa di Agrippa Postumus wurde dies am schwarzen und roten Cubiculum deutlich, in der Casa di Marcus Lucretius Fronto an Tablinum (h) und Cubiculum (g). Weiterhin ist deutlich geworden, dass ähnliche Strategien der Wandgliederung, der Kontrastierung von Wandflächen, aber auch der Hierarchisierung von Bildelementen zum Einsatz kamen.

Ein Unterschied ergibt sich jedoch im Vergleich der Prunkräume. In augusteischer Zeit bleiben auch Räume mit Mythenbildern ,übersichtlich‘. Die zentralen Bildfelder sind besonders hervorgehoben, die anderen Bildelemente treten, Ornamenten gleich, deutlich dahinter zurück. In einem späten Prunkraum wie Tablinum (h) der Casa di Marcus Lucretius Fronto hingegen treten verschiedene Bildformen und Farben stärker in Konkurrenz zueinander, die Bilddichte ist erheblich gesteigert. Die Tendenz ging offensichtlich gerade für solche Prunkräume hin zu immer heterogeneren, komplexeren Formen der Wandorganisation ${ }^{352}$.

352 Eine solche Tendenz angedeutet bei Ling 1991, 52-70. 


\subsection{Das Decor-Konzept für die Böden}

Mit dem Übergang zum dritten Stil vollzieht sich am Boden kein grundlegender Wandel. SchwarzWeiß-Mosaiken dominieren das Erscheinungsbild der Böden, daneben werden Räume weiterhin mit Opera signina ausgestattet. Auch die Darstellungsstrategien zeichnen sich durch ein hohes Maß an Kontinuität aus, werden nun jedoch noch konsequenter als zuvor umgesetzt.

\section{Die visuelle Ordnung des Raumes: Schwarz-Weiß-Mosaiken}

Schwarz-Weiß-Mosaiken werden weiterhin dazu eingesetzt, räumliche Zusammenhänge durch den Wechsel von schwarzem und weißem Grundton herzustellen. Im Fall der Casa di L. Caecilius Iucundus (V 1,23.26; Plan 14) $)^{353}$ sind die Fauces weiß (Abb. 375), der Atriumsraum schwarz (Abb. 376), die Alae und das Tablinum (Abb. 377) wieder weiß pavimentiert. Dadurch ergibt sich ein Schwarz-Weiß-Kontrast zwischen dem zentralen, dunklen Hof und den angrenzenden, hellweißen Aufenthaltsräumen.

An der Casa di L. Caecilius Iucundus zeigt sich weiterhin, dass die Raumordnung wie zuvor durch auffällige Schwellornamente, Randstreifen - im Atrium fallen sie doppelt aus (Abb. 376) und Mittelemblemata akzentuiert wird. Im Tablinum besetzt das Mittelemblema zwar die zentrale Raumachse, ist aber aus der Querachse etwas versetzt, sodass es nicht exakt auf die mythologischen Mittelbilder an der Wand fluchtet (Abb. 377). Grundsätzlich geht die Tendenz jedoch hin zu einer immer systematischeren Raumgliederung.

Dies zeigt sich insbesondere in dem gesteigerten Aufwand, der für die Impluviumsrahmungen getrieben wird. Sie markieren im Hausinneren den Übergang zwischen Drinnen und Draußen, vor allem aber fokussieren sie die Aufmerksamkeit auf jenen Bereich, der im dritten Stil regelrecht als Brunnenspektakel inszeniert wird (s. u.). In der Casa di L. Caecilius Iucundus (V 1,23.26) hebt sich das weiße, kostbare Marmorbecken mit seiner weißgrundigen Mosaikrahmung ${ }^{354}$ auffällig vom schwarzen Atriumsboden ab (Abb. 376). Auch andernorts treten marmorne Becken an die Stelle der Tuff- und Cocciopesto-Becken ${ }^{355}$. In einer Zeit, in der Marmor zunächst noch sparsam verwendet wurde, dürften Marmorimpluvien mit besonderer Wertschätzung belegt worden sein. Auch

353 PPM III (1991) 574-620 s. v. V 1,26, Casa di L. Caecilius Iucundus e casa annessa V 1,23 (A. de Vos) 586-587 Abb. 18-21; Pernice 1938, 96 mit Zuweisung zum dritten Stil; Dexter 1979, 37. 112 hingegen als später zweiter Stil, allerdings mit Hinweis darauf, dass es sich um eine Übergangsphase handelt (S. 114). Eine scharfe Abgrenzung scheint mir an dieser Stelle nicht entscheidend, es geht um das Phänomen als solches.

354 Dexter 1979, 13f.; PPM III (1991) 574-620 s. v. V 1,26, Casa di L. Caecilius Iucundus e casa annessa V 1,23 (A. de Vos) 580-582 Abb. 7.

355 Etwa Domus VI 2,16, s. PPM IV (1993) 198-220 s. v. VI 2,16 (V. Sampaolo) 206 Abb. 16; Casa di Meleagro (VI 9,2.13), s. PPM IV (1993) 660-818 s. v. VI 9,2.13, Casa di Meleagro (I. Bragantini) 671 Abb. 28; Casa dei cinque scheletri (VI 10,2), s. PPM IV (1993) 1029-1043 s. v. VI 10,2, Casa dei cinque scheletri (V. Sampaolo) 1034 Abb. 8; Rossi 2006, 40; Casa del Naviglio (VI 10,11) Marmoreinfassung mit Tessellat-Becken, s. Cassetta - Costantino 2006, 262; Pesando 2011, 429; Casa di Orfeo (VI 14,20), s. PPM V (1994) 264-307 s. v. VI 14,20, Casa di Vesonius Primus o di Orfeo (F. Narciso) 265 Abb. 1; Fullonica di Vesonius Primus (VI 14,21.22), s. PPM V (1994) 308-332 s. v. VI 14,21.22, Fullonica di Vesonius Primus (I. Bragantini) 311 Abb. 5; Casa di Sirico (VII 1,25.47), s. PPM VI (1996) 228-353 s. v. VII 1,25.47, Casa di Sirico (I. Bragantini) 234 Abb. 11; Casa di M. Gavius Rufus (VII 2,16-17), s. PPM VI (1996) 530-585 s. v. VII 2,16-17, Casa di M. Gavius Rufus (V. Sampaolo) 535 Abb. 6; Casa di C. Vibius Italus (VII 2,18), s. PPM VI (1996) 586-614 s. v. VII 2,18, Casa di C. Vibius Italus (V. Sampaolo) 588; Domus VII 12,17.21, s. PPM VII (1997) 502-519 s. v. VII 12,17.21 (I. Bragantini) 506 Abb. 7; Atrium (2) der Casa di M. Fabius Rufus (VII 16 [Ins. Occ.],22), s. PPM VII (1997) 947-1125 s. v. VII 16 [Ins. Occ.],22, Casa di M. Fabius Rufus (I. Bragantini) 950 Abb. 2; Casa del Cinghiale (VIII 2,26-27), s. PPM VIII (1998) 191-225 s. v. VIII 2,26-27, Casa del Cinghiale (V. Sampaolo) 198 Abb. 9; Casa di Cornelius Rufus (VIII 4,15.30), s. PPM VIII (1998) 518-525 s. v. VIII 4,15.30, Casa di Cornelius Rufus (I. Bragantini) 519-521 Abb. 1; Casa del Medico (VIII 5,24), s. PPM VIII (1998) 604-610 s. v. VIII 5,24, Casa del Medico (I. Bragantini) 605 Abb. 1; Domus IX 5,11.13, s. PPM IX (1999) 528-599 s. v. IX 5,11.13 (I. Bragantini) 529-531 Abb. 2. 
Abb. 375: Casa di L. Caecilius lucundus (V 1,23.26), Fauces mit Hundemosaik.
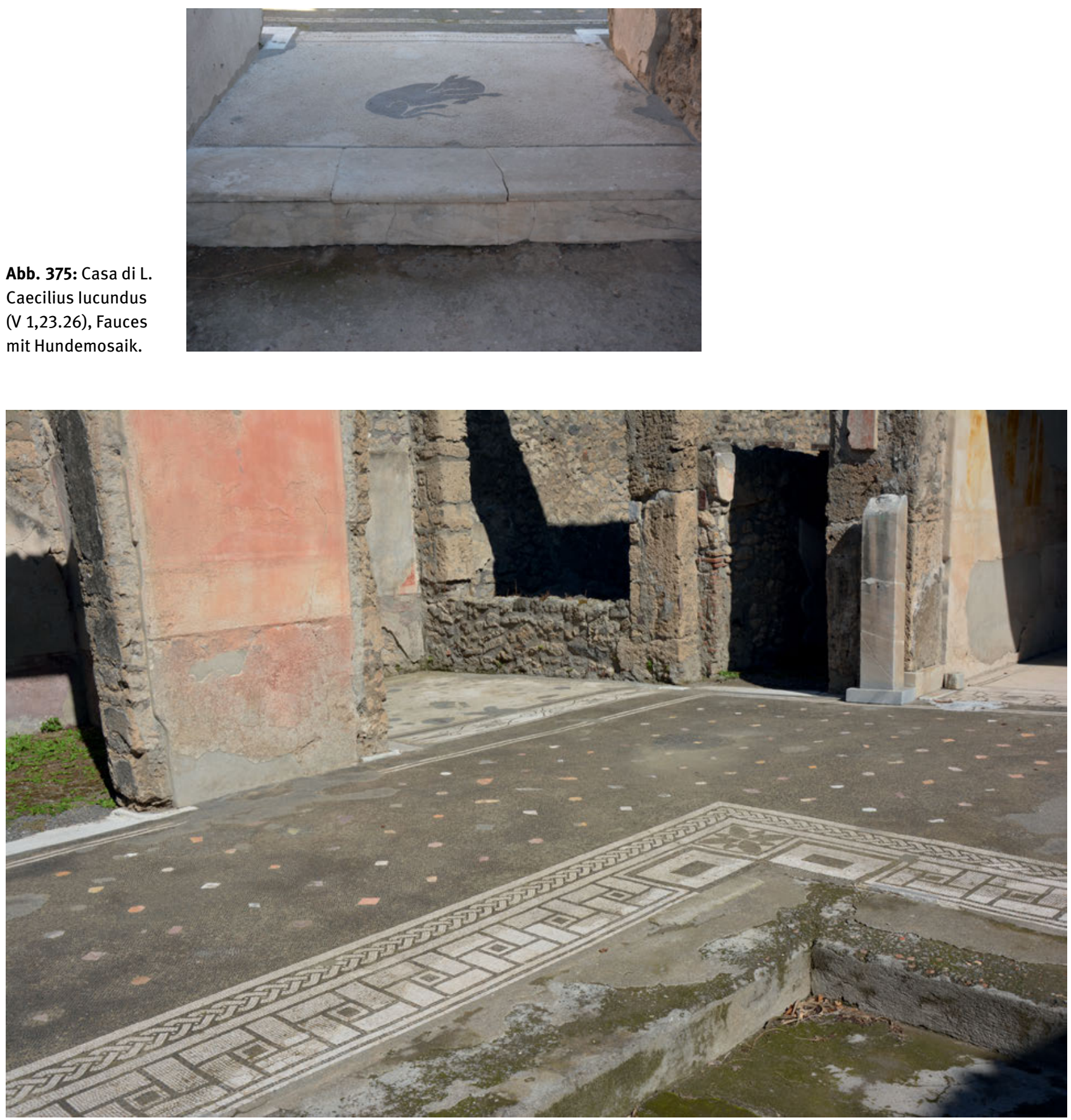

Abb. 376: Casa di L. Caecilius lucundus (V 1,23.26), Blick über das Impluvium und das schwarze Mosaik des Atriums, in das Marmorplättchen eingesetzt sind, hinweg, in Richtung Nordala. 

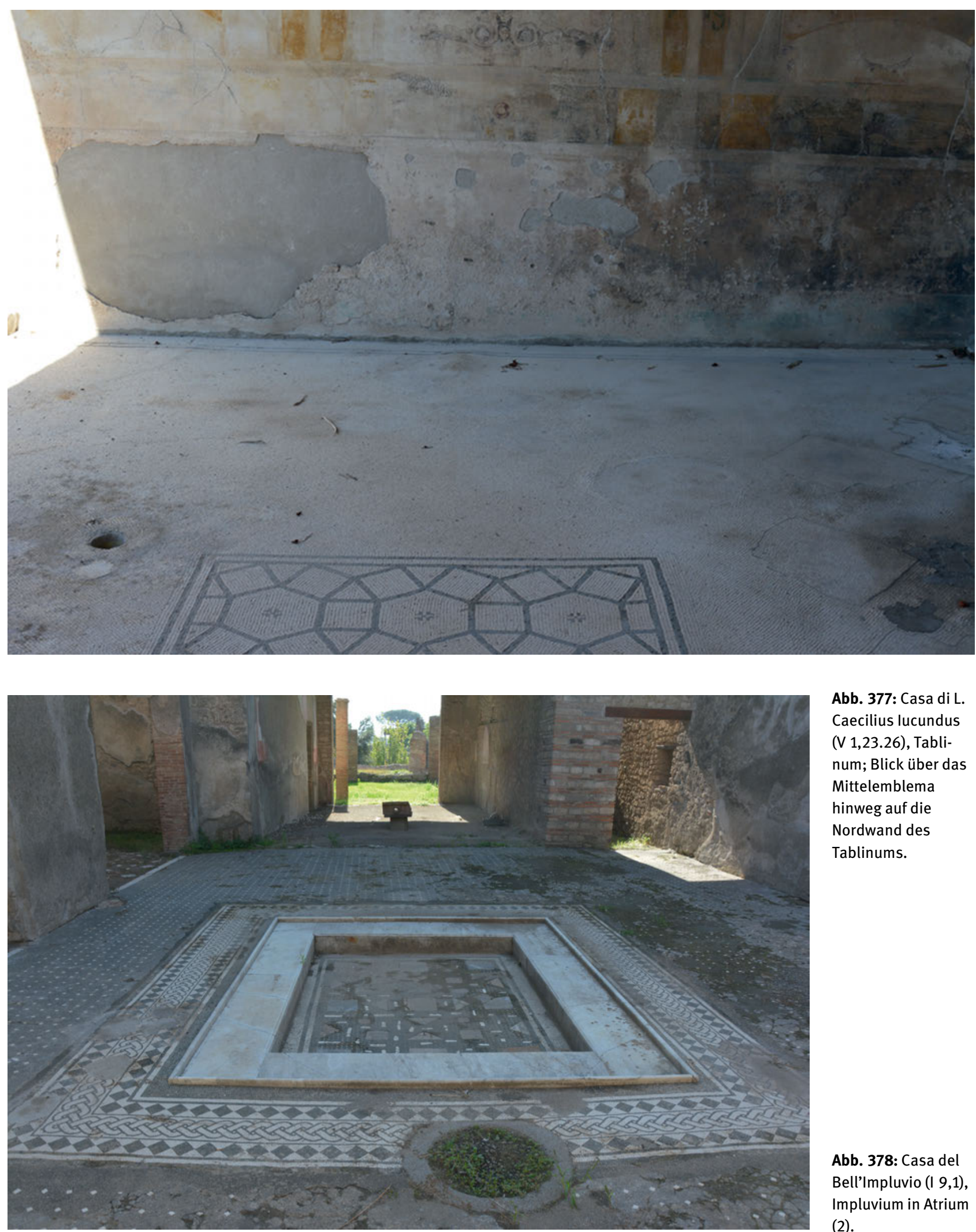

Abb. 377: Casa di L. Caecilius lucundus (V 1,23.26), Tablinum; Blick über das Mittelemblema hinweg auf die Nordwand des Tablinums.

Abb. 378: Casa del Bell'Impluvio (I 9,1), Impluvium in Atrium (2). 
in Häusern, deren Atriumspaviment aus Opus signinum bestand, hat man für die Impluviumsrahmung auf die neue, effektvollere Mosaiktechnik gesetzt. In der Casa del Bell'Impluvio (I 9,1; Abb. 378 $)^{356}$ ist das schwarz mosaizierte Impluviumsbecken von einer weißen Marmoreinfassung umgeben, die ihrerseits durch eine Mosaikrahmung mit schwarzen, geometrischen Ornamentbändern auf weißem Grund hervorgehoben und dadurch vom (älteren) Lavapesta-Boden mit TesseraReihen abgesetzt wird.

Dass Pavimente nun sogar auf die Raumausstattung Bezug nehmen, zeigt sich an der Impluviumsgestaltung der Casa di Cornelius Rufus (VIII 4,15.30; Abb. 379) ${ }^{357}$. Das marmorne Impluviumsbecken wird von einem schwarz-weißen Mosaikrahmen eingefasst, der ,hinter dem Impluvium, zum Tablinum hin, umbiegt, um einen (älteren) Tisch mit geflügelten Widderlöwen zu berücksichtigen. Im Südosten, auf der Ecke des Impluviums, umfasst die Mosaikrahmung eine Zisternenmündung. Sie akzentuiert somit nicht nur das Impluvium, sondern auch semimobile Ausstattungselemente.

Figürliche Mosaiken bleiben die Ausnahme, und auch weiterhin sind sie darauf angelegt, auf Betrachterhaltungen Bezug zu nehmen. In den Fauces wählte man wie in der Casa di L. Caecilius Iucundus (V 1,23.26; Abb. 375) gerne Hunde, die auf den Eintretenden ausgerichtet waren. Sie nötigten den Eintretenden zum Innehalten ${ }^{358}$ und markierten mit ikonographischen Mitteln eine letzte ,Hürde‘, die es vor dem Betreten des Hauses zu überwinden galt (Abb. 375). In den Thermalbereichen sind Verweise auf die Praxis des Badens oder auf Fische wie in der Casa del Centenario (IX 8,3.7; Abb. 381) üblich. Insbesondere in Thermen nehmen damit die (seltenen) figürlichen Schwarz-Weiß-Mosaiken nicht nur in ihrer Orientierung auf Betrachterhaltungen Bezug, sondern auch thematisch auf die in einem Raum vorauszusetzenden Handlungen.

In den Höfen und Aufenthaltsräumen blieb Figürlichkeit auf kleinformatige ,Ornamente‘ beschränkt, die zumeist in Schwellmosaiken auftraten. In Tablinum (E) der Casa degli Amorini dorati (VI 16,7.38; Plan 18) besteht die Mosaikschwelle zwischen Atrium und Tablinum (Abb. 380) aus einer Sequenz von Quadraten, in die verschiedene florale und figürliche Motive eingesetzt sind. Während die Blütenornamente und Delfine beide Ansichtsseiten bedienen, sind Greifenprotome, auffliegender Schwan und Capricorn auf den im Tablinum Befindlichen hin orientiert und stehen für den vom Atrium her Eintretenden auf dem Kopf ${ }^{359}$. Indem das Prinzip von möglichst allansichtigen Bildern partiell durchbrochen wird, kommt eine gewisse Hierarchisierung von Betrachterperspektiven zum Ausdruck. Privilegiert wird die Perspektive aus dem Tablinum, das als ein auf das Peristyl ausgerichteter Gelageraum inszeniert wird.

\footnotetext{
356 PPM I (1990) 919-941 s. v. I 9,1, Casa del Bell'Impluvio (V. Sampaolo) 923 Abb. 4. Auf das chronologische Verhältnis zwischen Lavapesta-Boden und Mosaik geht die Forschung üblicherweise nicht ein. Allerdings ist vor Ort sichtbar, dass das Mosaik nachträglich eingesetzt ist. Für ein höheres Alter des Lavapesta-Bodens sprechen neben dem Decor-Muster auch Tesseragröße und Tesserazuschnitt.

357 PPM VIII (1998) 518-525 s. v. VIII 4,15.30, Casa di Cornelius Rufus (I. Bragantini) 519-521 Abb. 1. 2; Dickmann $1999,114$.

358 Dexter 1979, 7-9, mit Verweis auf real angekettete Hunde - ein entsprechender Hundekadaver stammt aus der Casa di Orfeo (VI 14,20). So bestätigt Clarke 1979, 9 denn auch, dass die Mehrzahl der figürlichen Schwarz-WeißMosaiken in Pompeji aus Fauces stammen, ohne dies jedoch plausibel erklären zu können.

359 PPM V (1994) 714-846 s. v. VI 16,7.38, Casa degli Amorini dorati (F. Seiler) 738-740 Abb. 43-46; Seiler $1992,30$. Abb. 154-157.
} 

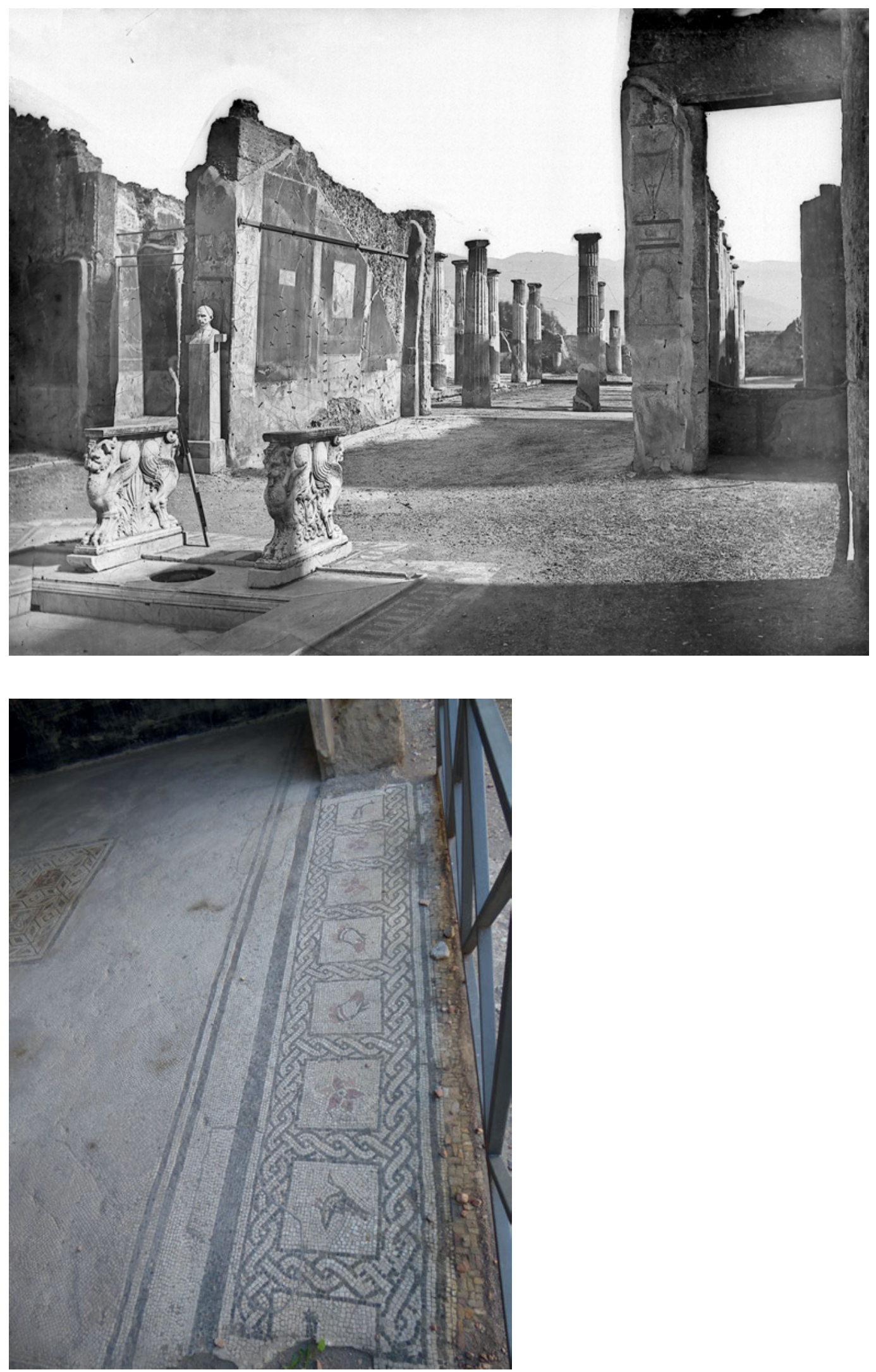

Abb. 379: Casa di Cornelius Rufus (VIII 4,15.30), Atrium mit Impluvium.
Abb. 380: Casa degli Amorini dorati (VI 16,7.38), Schwelle von Tablinum (E). 


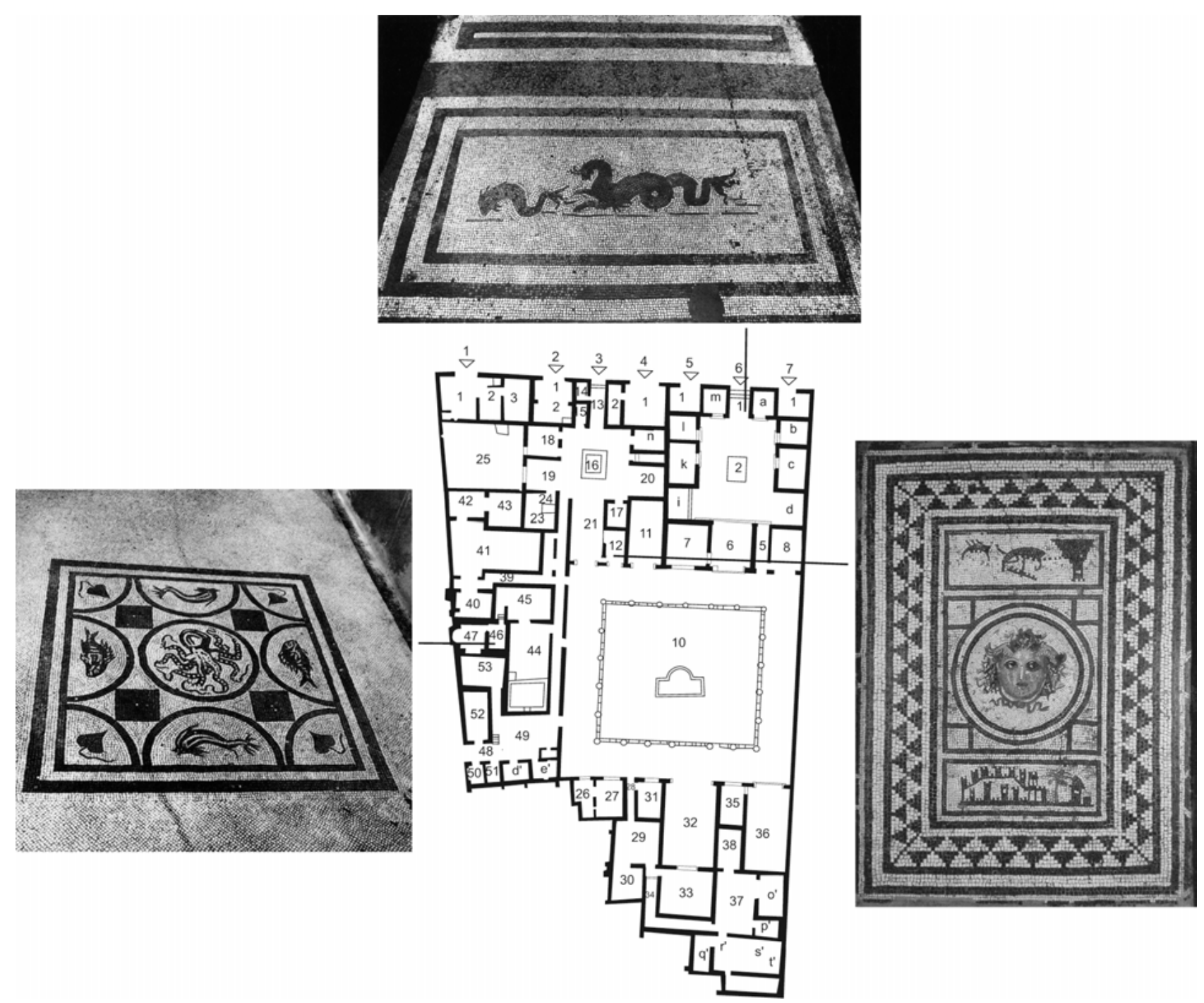

Abb. 381: Casa del Centenario (IX 8,3.7), Grundriss mit Pavimenten.

In verschließbaren Wohnräumen sind figürliche Mosaiken selten. Eine Ausnahme stellt Cubiculum (12) der Casa del Centenario (IX 8,3.7; Abb. 381) ${ }^{360}$ dar. Das inmitten eines Rautenteppichs platzierte Mosaikfeld zeigt im Zentrum ein polychromes Gorgoneion, das auf den Raumeingang ausgerichtet ist. Es wird auf den Schmalseiten von bichromen Architekturbildern flankiert. Die Stadtansicht ist wie das Gorgoneion vom Eingang her lesbar, die Hafenansicht für die im Raum befindlichen Akteure. Hier bestätigt sich noch einmal das Interesse, auch Bildmosaiken mehransichtig zu gestalten.

Eine Aufwertung der Mosaiken konnte sich im dritten Stil aber nicht nur durch den Gebrauch von Bildern, sondern auch durch ihre Materialität ergeben. Wie schon zuvor konnten in die Mosaiken kleine, polychrome Marmorplättchen von dreieckigem, rautenförmigem, hexagonalem oder auch unregelmäßigem Zuschnitt eingesetzt werden und den Boden auf diese Weise aufwerten

$360 \mathrm{Zu}$ den Bildmosaiken im Kontext, s. Coralini 2001; die Raumnummerierung bezieht sich auf die von ihr publizierten Raumnummern; zur Datierung Coralini 2001, 52. Sie spricht sich für eine Rückbindung der tatsächlich häufig singulären Bildthemen an die Interessen des Hausherrn aus (S. 53f.) - ein Vorschlag, dem ich hier nicht folge. 


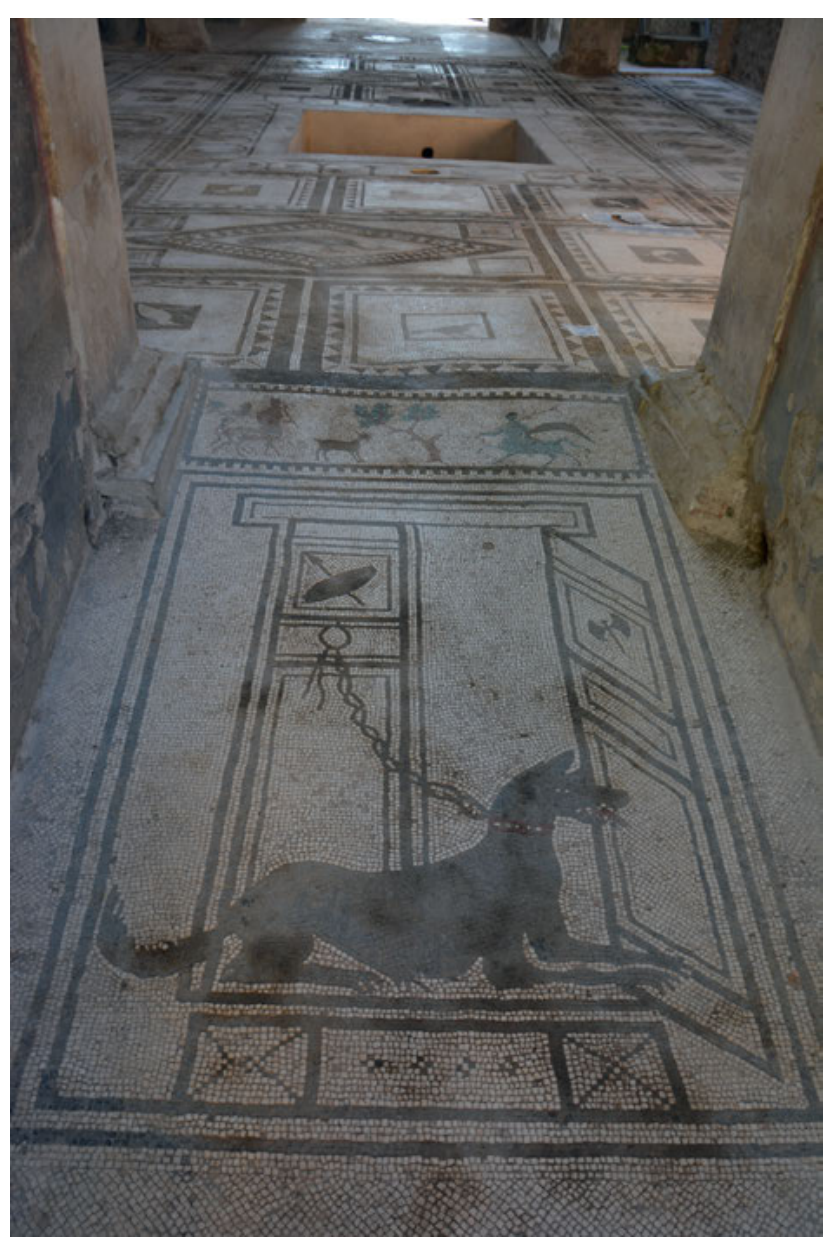

Abb. 382: Casa di Paquius Proculus/ Cuspius Pansa (I 7,1), Fauces.

(Abb. 376). Die gänzlich auf Regelmäßigkeit und Symmetrie angelegte Mosaiktechnik ,integriert‘ dadurch ein asymmetrisches und dadurch den Boden, belebendes` Element.

\section{Ein Bild-Ensemble am Boden: der Sonderfall der Casa di Paquius Proculus/Cuspius Pansa}

Einen völlig singulären Umgang mit Bildern, der zugleich für die ästhetischen Strategien, die in Häusern wirksam werden, erhellend ist, trifft man in der Casa di Paquius Proculus/Cuspius Pansa $(\text { I 7,1; Plan 6) })^{361}$ an.

Der ins Haus Eintretende wurde im Vestibulum von einem schwarz-weißen Hundemosaik empfangen. An der Schwelle zum Atrium fiel sein Blick auf ein kleinteiligeres, friesartig präsentiertes, polychromes Bild mit der Darstellung von zwei Kentauren, die Baum und Ziege flankieren (Abb. 382). Dieses Schwellmosaik bereitet auf einen regelrechten Bilderteppich vor, der den rechteckigen Atriumsraum (3) ausfüllt. Er besteht aus schwarz gerahmten, weißgrundigen Quadraten

361 Spinazzola 1953, 297-307; PPM I (1990) 483-552 s. v. I 7,1, Casa di Paquius Proculus o di Cuspius Pansa (F. P. Badoni - M. de Vos); Ehrhardt 1998, bes. 125 mit einer Einordnung der Pavimente in Fauces, Atrium und Tablinum in den zweiten Stil, ebenso auch zur Wandmalerei; allerdings erachtet er den Kandelaberstil in der Nische des Tablinums als zeitgleich. Bei Ehrhardt 1998 eine Detailvorstellung der Befunde. 


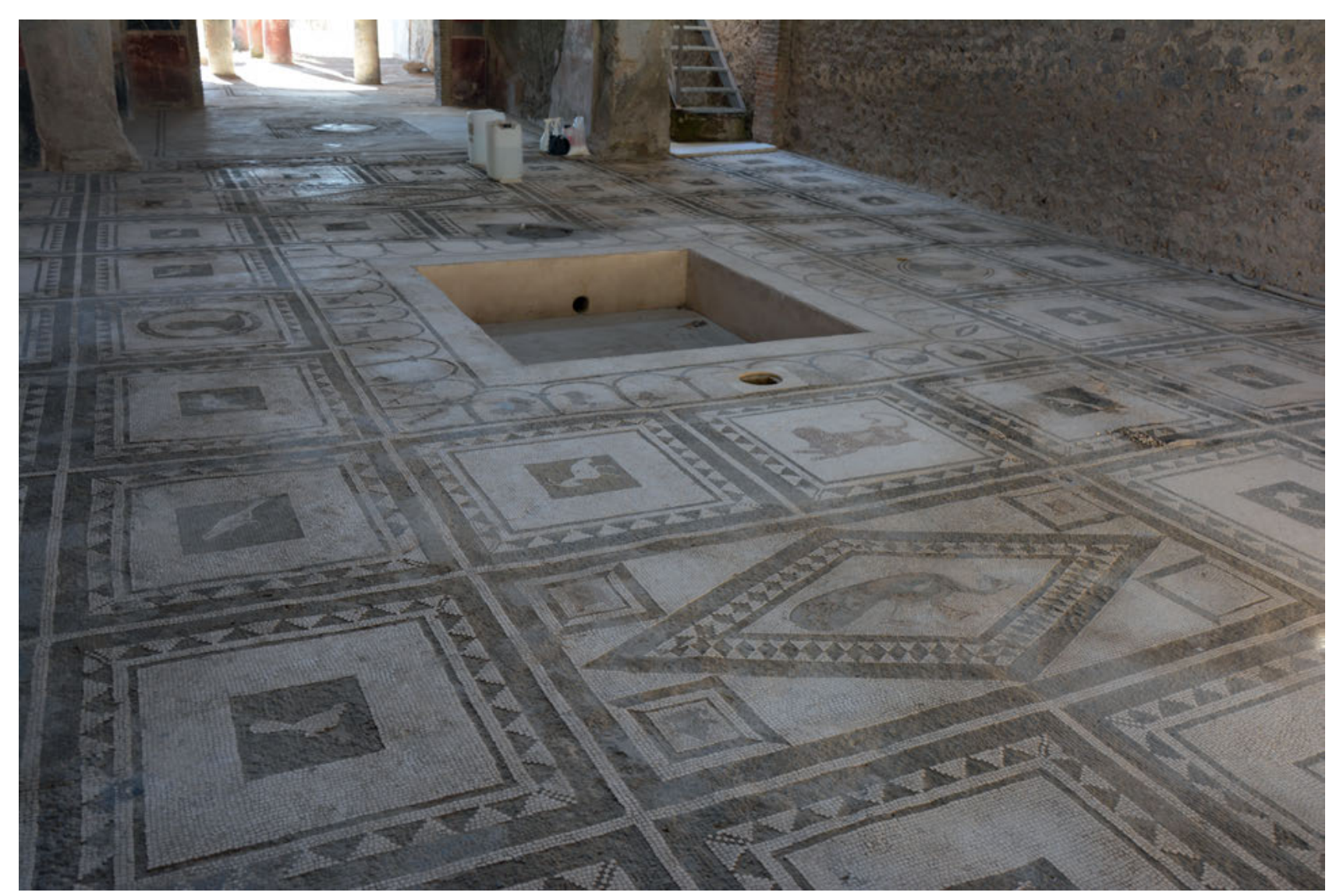

Abb. 383: Casa di Paquius Proculus/ Cuspius Pansa (I 7,1), Atrium. und nimmt in dieser Struktur auf Kassettierungen an Decken Bezug (Abb. 383). Im Zentrum eines jeden Bodenquadrats findet sich ein kleines schwarzgrundiges Bildfeld mit einem in weißen Tesserae wiedergegebenen Vogel. Die Vögel besitzen verschiedene Orientierungen, sind in unterschiedlichen Haltungen und Aktionen erfasst und rechnen folglich mit unterschiedlichen Betrachteransichten. Nur einzelne Felder weichen von dieser Teppich-Logik ab. Vom Eingang aus trifft der Betrachter zunächst auf ein Quadrat, bei dem die Farbordnung invertiert ist - ein polychrom angegebener Vogel auf weißem Grund. Auf der Nord- wie auf der Südseite des Impluviums folgt ein großes, aus zwei Quadraten zusammengeführtes Rechteck mit der Darstellung eines Pfaus in polychromem Opus vermiculatum. Aus dem Felderteppich herausgehoben ist zudem das in der Achse befindliche, auf den Eingang ausgerichtete Feld auf der Südseite des Impluviums mit einem Löwen in Opus vermiculatum ${ }^{362}$. Auf diese Weise ist die Eingangsachse privilegiert, eine gewisse Betonung erhält aber auch die Querachse. Die beiden mittigen Mosaikquadrate auf den Längsseiten des Impluviums zeigen Büsten, die nach innen, zum Impluvium hin, orientiert sind. Das Impluvium selbst besitzt eine eigene Einfassung, die aus einer nach außen, zum Atrium hin geöffneten Arkadenreihe besteht. Die Arkadenbögen dienen als Rahmung für weitere, kleinteilige Bildmotive, die teilweise verloren und durch weiße Tesserae ersetzt sind. Bildfeldorientierung, Bildfeldgrößen und Fertigungstechnik werden folglich eingesetzt, um innerhalb des Raumes ein komplexes Beziehungssystem herzustellen, das auf den Betrachter und seine potenziellen Bewegungsformen ausgerichtet ist.

362 Eine übersichtliche Visualisierung der Opera vermiculata bei Wohlgemuth 2008, 74 Abb. 2,2; vgl. weiterhin die Katalogeinträge bei Wohlgemuth 2008, 102-105. 


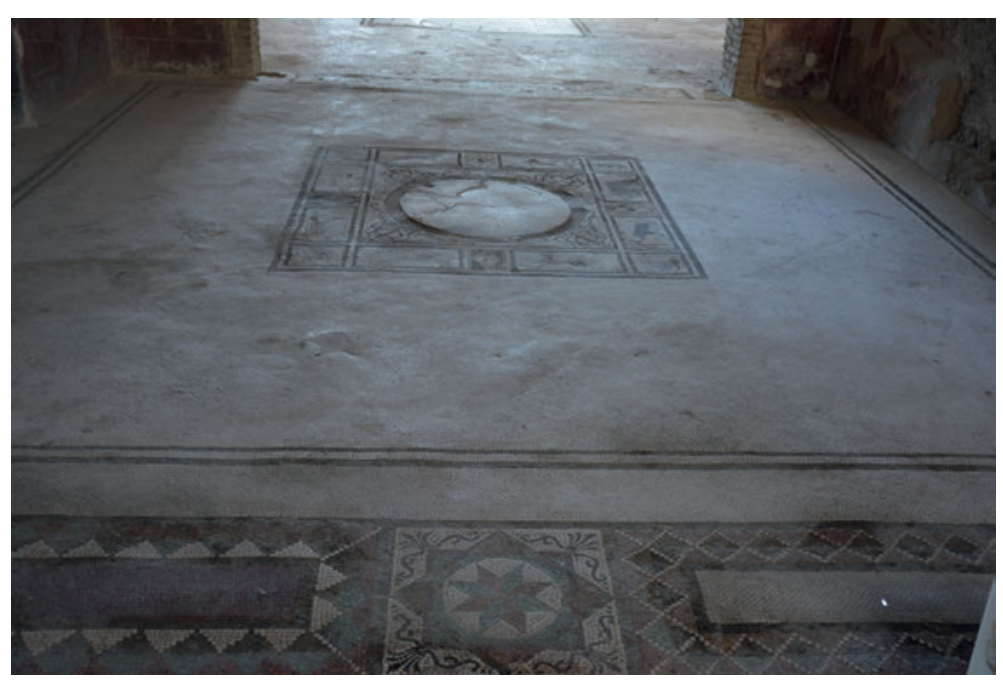

Abb. 384: Casa di Paquius Proculus/ Cuspius Pansa (I 7,1), Tablinum.

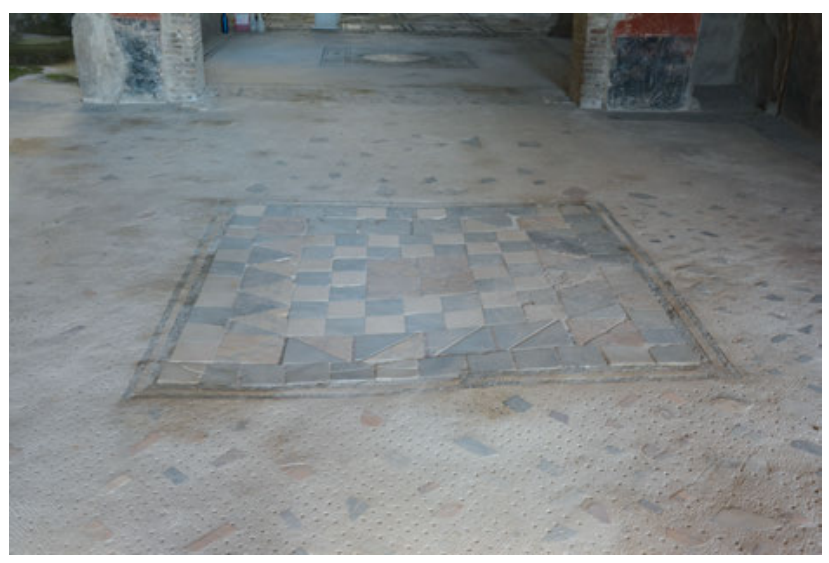

Abb. 385: Casa di Paquius Proculus/ Cuspius Pansa (I 7,1), Oecus (8) mit Opus sectile.

Tablinum (6) wird vom Atrium sowie von Oecus (8), dem Durchgangsraum zum Peristyl, durch aufwendige polychrome Schwellpavimente abgesetzt (Abb. 384). Sein Zentrum nimmt ein runder Alabastertondo ein, der von einem doppelten Quadratrahmen eingefasst ist, zwischen den kleine rechteckige und quadratische Bildfelder mit Tierdarstellungen eingesetzt sind. Die Tiere in der Raumachse sind zum Atriumseingang gerichtet, die der Quadratseiten jeweils nach außen. Die Perspektive vom Atrium aus wird dadurch privilegiert, die beiden Raumteile aufeinander bezogen: Beide Bild-Ensembles evozieren eine reiche Flora und Fauna ${ }^{363}$.

In dieselbe Ausstattungsphase gehören Oecus (8) sowie die auf das Peristyl geöffneten Räume (16) und (18). In diesen drei Aufenthaltsräumen lässt sich ein jeweils unterschiedlicher Umgang mit Pavimentbildern greifen. In Oecus (8), der als Durchgangsraum zwischen Tablinum und Peristyl fungierte, wählte man ein weißes Tessellat mit zentralem Opus sectile aus quadratischen und dreieckigen, polychromen Marmorplatten (Abb. 385) ${ }^{364}$. Das unfigürlich-geometrische Paviment des Durchgangsraums rechnet folglich mit verschiedenen Betrachterperspektiven.

Figürliche Opera vermiculata finden sich hingegen in den beiden ,echten' Aufenthaltsräumen Triclinium (16) und Oecus (18). Im etwa quadratischen Oecus (18), den man mittig im Süden betritt, ist das aufwendig gerahmte Emblema in vier Quadrate geteilt, in die Masken eingesetzt sind

363 Corlàita Scagliarini 1974, 22 möchte hier ein regelrechtes Programm realisiert sehen, doch die Motive bleiben inhaltlich derart schwach, dass sich kein enger Nexus aufdrängt.

364 Zum Folgenden PPM I (1990) 483-552 s. v. I 7,1, Casa di Paquius Proculus od di Cuspius Pansa (F. P. Badoni - M. de Vos). 
Abb. 386: Casa di Paquius Proculus/ Cuspius Pansa (I 7,1), Oecus (18) mit viergeteiltem Emblema.

Abb. 387: Casa di Paquius Proculus/ Cuspius Pansa $(\mathbf{1} 7)$, Triclinium (16) mit nilotischem Emblema.
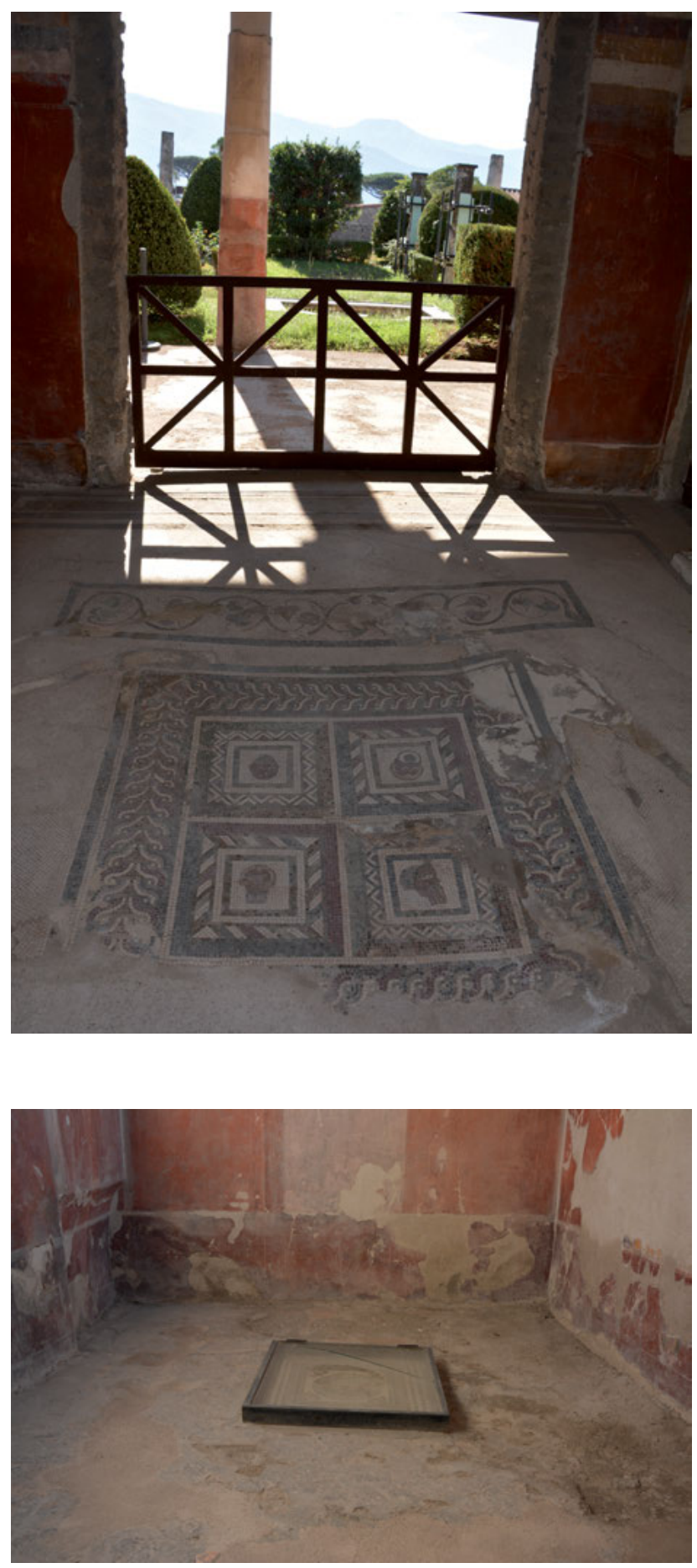

(Abb. 386). Diese sind jeweils nach außen orientiert, sodass sie zwei Ansichtsseiten bedienen: Die vorderen sind zum Eingang ausgerichtet, die beiden hinteren zum Klinenbereich. Die Eingangsseite wird zusätzlich durch ein breites, gerahmtes Rankenband betont, das ,vor dem Emblema platziert ist. Nicht nur der Pavimenttypus und die Ornamentplatzierung nehmen auf die Raumqualität Bezug, sondern auch die Bildkomposition.

Das benachbarte Triclinium (16) betritt man dezentral über eine Tür in der Westhälfte des Raumes. Im hinteren Teil ist in der Raumachse ein nilotisches Emblema nachträglich in das Paviment eingesetzt. Es suggeriert eine Klinenaufstellung, ist aber auf den Eingang ausgerichtet, 
sodass die Gelageteilnehmer das Bild auf dem Kopf sahen (Abb. 387). Es stellt somit eine hochwertige, jedoch zugleich traditionelle Form der Ausstattung dar ${ }^{365}$.

Der ungewöhnliche Bilderreichtum am Boden korrespondiert in diesem Haus mit einer zurückgenommenen Wandgestaltung: In die Phase der Pavimentgestaltung gehört die im Kandelaberstil ausgestattete Nische in Tablinum (6), die ganz auf Eleganz und Schlichtheit setzt (Abb. 326) ${ }^{366}$. Auf dem schwarzen Sockel werden Frauenfiguren zwischen Girlanden von Telamonen gerahmt, welche die weißgrundige Mittelzone,stützen'. Die Vignette des Mittelsegments ist verloren, die Seitenfelder zeigen Kandelaber mit einem Miniatur-Pinax.

An der Casa di Paquius Proculus/Cuspius Pansa $(I$ 7,1) mit ihren zahlreichen Pavimentbildern bestätigt sich somit, dass Pavimentbilder des dritten Stils auf bestimmte Betrachterhaltungen ausgerichtet sind. Zudem wird deutlich, dass mit einem aufwendig bebilderten Boden eine einfachere Wandgestaltung zusammengeht. Man darf folglich von einer intendierten Gesamtwirkung von Wand und Boden ausgehen.

\section{Die visuelle Ordnung des Raumes: Opera Signina}

Im Fall der Opera signina nimmt sich die Binnenstruktur weniger systematisch aus als bei den Mosaiken. Insbesondere ohne Tessera-Decor, schwimmt' das Paviment im Raum. Tritt ein TesseraDecor hinzu, so werden Schwellornamente und Decor-Motive im Raumzentrum zur räumlichen Gliederung eingesetzt.

In der Casa del Bell'Impluvio (I 9,1), die über ein Set an Böden in Opus signinum aus der Zeit des späten dritten Stils verfügt (Abb. 388), fasst im Vestibulum (1) ein Tessera-Rahmen einen dynamischen ,Decor-Teppich` ein, der aus größeren, unregelmäßigen Marmorplättchen und unregelmäßig platzierten Tesserae besteht. Symmetrie und Asymmetrie treten in ein Spannungsverhältnis zueinander. Indem der Decor-Teppich mittig im Gang platziert ist, entsteht ein undecorierter Randstreifen, der zur Wand vermittelt. Ein zweiter Tessera-Rahmen, der einen Rautenteppich einfasst, besetzt den Schwellbereich zwischen Vestibulum (1) und Atrium (4). Das Vestibulum nimmt somit ein Decor-Prinzip vorweg, das in variierter Form auch zur Gestaltung der Ala und des Tablinums genutzt wurde. Das Tablinum (7) wird durch ein Schwellornament vom Atrium abgesetzt $^{367}$, im Raumzentrum sind größere Marmorplatten in ein komplexes Tessera-Netzmuster integriert $^{368}$. In der Ala (10) hat man auf einen lockeren visuellen Effekt gesetzt. Frei im Opus signinum (Cocciopesto) verteilt sind kleine Marmorplättchen von unregelmäßigem Zuschnitt, allein das Raumzentrum besetzt ein quadratisches Emblema aus regelhaft versetzten Buntmarmorplatten ${ }^{369}$. An den ganz auf das Atrium geöffneten Räumen wird somit das Spiel mit Regelmäßigkeit und Unregelmäßigkeit besonders deutlich. In dieser Logik wird auch das mittige Impluvium durch eine nachträgliche, aufwendige Mosaikrahmung hervorgehoben (Abb. 378), das sich dadurch von dem (älteren) Atriumsmosaik mit seinen Tessera-Reihen absetzt.

365 Ehrhardt 1998, 125 betont, dass es in den Estrich eingesetzt ist - prinzipiell könnte es daher auch einer älteren Ausstattungsphase angehören und hier zweitverwendet sein. Die stilistische Uneinheitlichkeit der Pavimente ist auch diskutiert bei Ehrhardt 1998, $140 \mathrm{f}$.

366 PPM I (1990) 483-552 s. v. I 7,1, Casa di Paquius Proculus o di Cuspius Pansa (F. P. Badoni - M. de Vos) $514 \mathrm{f}$. Abb. 48-51; Ehrhardt 1998, 47 f. 146.

367 Zum Folgenden PPM I (1990) 919-941 s. v. I 9,1, Casa del Bell’Impluvio (V. Sampaolo).

368 Ähnlich auch Triclinium (6) der Casa del Cinghiale, s. PPM VIII (1998) 191-225 s. v. VIII 2,26-27, Casa del Cinghiale (V. Sampaolo) 217 Abb. 51.

369 Für Ala (10) wird nur eine allgemeine Datierung in das 1.Jh.n. Chr. vorgeschlagen, s. PPM I (1990) 919-941 s. v. I 9,1, Casa del Bell'Impluvio (V. Sampaolo) 934. Da das Paviment durch einen Marmorsteg vom Atriumspaviment getrennt ist, letzteres aber möglicherweise ohnehin noch deutlich älter ist, lässt sich hier nur festhalten, dass es später als das Atriumspaviment selbst ist. 


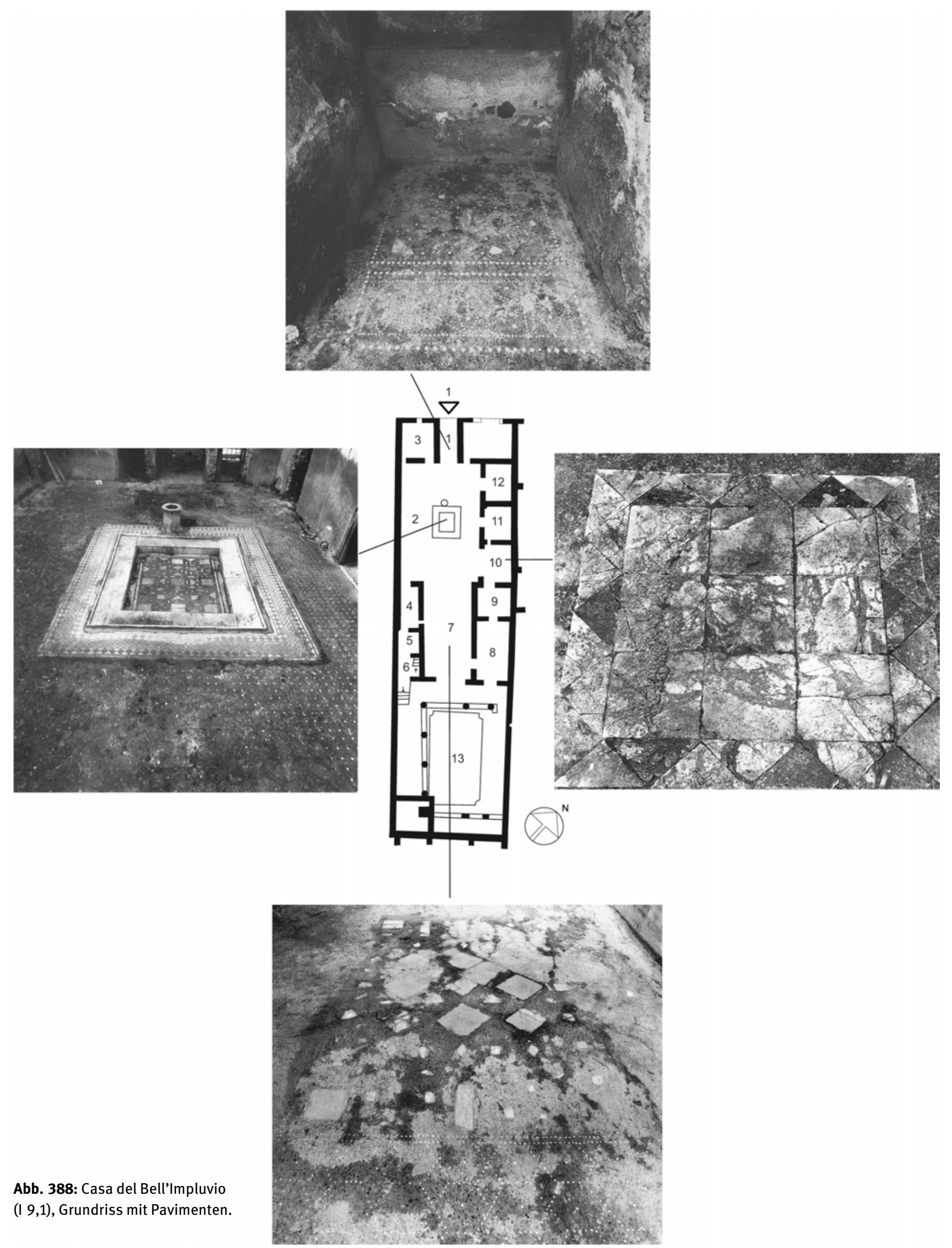




\section{Zusammenfassung: Mosaiken und Opera signina im Vergleich}

Schwarz-Weiß-Mosaiken und Opera signina treten hinter der Polychromie und Bilddichte der Wände zurück. In ihrer bichromen Gestaltung und reduzierten Ornamentalität bieten sie einen ruhigen und soliden ,Grund', vor dem die Wirkung der Wände entfaltet wird. Unabhängig davon, welche Technik zum Einsatz kommt, fügt sich der Paviment-Decor zu einem regelrechten ,Teppich', der das gesamte Haus ,bedeckt'. Bodenornamente - Schwellmosaiken und Emblemata - werden zum festen Bestandteil dieser Raumordnung.

Beide Pavimenttechniken können durch das Einfügen von Marmorplättchen aufgewertet werden. Technisch gesehen ist eine Integration von unregelmäßigen Elementen in ein Estrich-Bett einfacher als die Einpassung in ein Mosaik. Ästhetisch variiert der Effekt: Im Fall der Estrichböden ,schwimmen' die Marmorplättchen in dem ohnehin unstrukturierten Paviment, während sich bei den Mosaiken ein auffälliger Kontrast zwischen Struktur und Asymmetrie ergibt. In beiden Fällen tragen die eingestreuten Marmorplättchen jedoch dazu bei, den Boden aufzulockern, zu dynamisieren und mit Farbakzenten zu versehen. Ein solcher Materialluxus wird häufig im Atrium entfaltet, wie sich an der Casa di L. Caecilius Iucundus (V 1,23.26; Plan 14) (Mosaik), aber auch an der Casa di Marcus Lucretius Fronto (Signinum) gezeigt hat.

Bilder, die geradezu ausschließlich in Mosaiktechnik realisiert werden, stellen einen weiteren Modus der Aufmerksamkeitserzeugung dar. Sie werden jedoch einer adäquaten, allansichtigen Raumwahrnehmung fast vollständig untergeordnet, treten also nicht in den Dienst einer visuellen Hierarchisierung von Räumen.

\subsection{Weitere Ausstattungselemente im Kontext: eine kurze Hinführung}

Die Wirkung eines Raumes ergibt sich nicht allein durch seine Decken-, Wand- und Bodengestaltung, sondern auch durch seine (semi-)mobilen Ausstattungselemente. Ihre kontextuelle Analyse steht allerdings vor verschiedenen methodischen Schwierigkeiten, die eingangs kurz skizziert werden sollen.

Der Fundkontext von Ausstattungsobjekten wurde häufig nicht präzise dokumentiert. Selbst wenn der Fundort bekannt ist, sagt dies aber noch nichts über den ursprünglichen Aufstellungszusammenhang aus, da sich dieser im Laufe der Zeit ändern konnte ${ }^{370}$. Schwierigkeiten bereitet nicht nur die räumliche Verortung, sondern auch die zeitliche Einordnung. Auf stilistischer Basis ist meist lediglich eine pauschale Datierung in ,hellenistische' Zeit oder das ,1.Jh.n. Chr.' möglich, eine Korrelation mit Ausstattungsphasen ist daher schwierig. Im Folgenden sind insbesondere jene Ausstattungsensembles und Einzelstücke berücksichtigt, für die sich eine Datierung in die frühe Kaiserzeit möglichst plausibel machen lässt. Schließlich ist eine systematische Trennung zwischen semimobilen und kleinformatig-mobilen Ausstattungselementen nicht möglich. Da hier jedoch nicht alle (zumeist unpublizierten) Statuetten und Kleinbronzen Berücksichtigung finden können, liegt der Fokus auf Objekten, die über $50 \mathrm{~cm}$ groß $\operatorname{sind}^{371}$.

Im Folgenden kommen mit dem Atrium und dem Peristyl zwei für exquisite, semimobile Objekte zentrale Ausstattungskontexte in den Blick. Der Fokus soll auf frühen Kontexten der beginnenden Kaiserzeit liegen - die großen Skulpturen-Ensembles, die aus den letzten Jahren Pompejis überliefert sind, bleiben außen vor ${ }^{372}$. Während die Höfe sich als Showrooms für wertvolle Ausstellungsstücke erweisen, dürften nach Auskunft der Kontexte in Herculaneum hölzerne

370 Etwa Bartman 1991, 72; Hartswick 2018, $344 \mathrm{f}$.

371 Dies bedeutet, dass insbesondere die Ausstattung der Lararien/Kultorte mit ihren kleinen Bronzefiguren hier ausgeschlossen wird; vgl. dazu Simelius 2018, 52.

372 In der Skulpturforschung gilt ihnen üblicherweise das Interesse, vgl. exemplarisch Farrar 1998, 99 zur Casa degli Amorini dorati (VI 16,7.38) sowie zur Casa di Marcus Lucretius IX 3,5.24. 
Möbel vor allem in kleineren Aufenthaltsräumen aufgestellt gewesen sein ${ }^{373}$. In Pompeji haben sie sich nicht erhalten, sodass die Ausstattung von Aufenthaltsräumen nicht eigens zur Sprache kommen wird.

\subsection{Das Atrium und die Inszenierung des Impluviums: Wasserspeier, Labrum, Tisch}

Das optische Zentrum des Atriums markierte seit jeher das Impluvium. Ab augusteischer Zeit wurde dieses nicht nur durch die Verwendung kostbarer Materialien und durch aufwendige Rahmungen aufgewertet, sondern in zahlreichen Häusern zu einem Brunnen umgestaltet ${ }^{374}$. Dazu stellte man am hinteren Impluviumsrand einen Sockel für eine Brunnenfigur auf, die das Wasser in das Impluviumsbecken oder in ein eigens dafür aufgestelltes Labrum spie ${ }^{375}$. Das neuartige Wasserspiel wurde zu einem attraktiven Blickfang im Atriumsraum. Dazu gesellte sich in einigen Häusern ein Marmortisch, der üblicherweise zwischen Impluvium und Tablinum in der Achse des Hauses aufgestellt wurde ${ }^{376}$. Dadurch verschieben die Objekte den visuellen Fokus hin zum Tablinum. Ausnahmsweise konnte ein Tisch aus der Achse versetzt werden und durch eine solche Asymmetrie einen besonderen Akzent setzen. Das Atriumspaviment der Casa di Cornelius Rufus (VIII 4,15.30; Abb. 379) spricht für eine solch dezentrale Aufstellung eines Tisches an einer der Impluviumsecken $^{377}$. Entsprechende Tische konnten in verschiedene Inszenierungs- und Handlungszusammenhänge eingebunden werden. Im Rahmen von bestimmten Riten und Festen dürften sie als Schautische fungiert haben ${ }^{378}$, auf ihnen mochte das kostbare Geschirr des Hauses, aber auch kleine Statuen zur Schau gestellt worden $\operatorname{sein}^{379}$.

Im Folgenden sollen verschiedene Kontexte zur Sprache kommen, die jeweils schlaglichtartig einen Einblick in die Ausstattung und Wirkung der Atrien geben. Ein Ausstattungsset, das sich wenigstens in einigen Teilen augusteisch datieren lässt, ist für die Casa di Sirico (VII 1,25.47) bezeugt. Das Impluvium des tuskanischen Atriums (24) wurde nun mit einem marmornen Brunnenbecken ausgestattet (Abb. 389) (380 $^{38}$. Auf einer marmorverkleideten Basis wird man sich auf dem östlichen Impluviumsrand eine Brunnenfigur vorstellen dürfen. Im Impluviumsbecken war ein Labrum aufgestellt, dessen Fuß mit vegetabilem Decor von Robert Cohon in die Zeit zwischen 10 und 1 v.Chr. datiert wird ${ }^{381}$. Vermutlich in denselben Zeithorizont gehört ein zweibeiniger Tisch mit geflügelten Löwen-Greifenstützen und Pflanzen- bzw. Cornucopiadarstellungen ${ }^{382}$. Darauf befand

373 Mols 1994, $129 \mathrm{f}$.

374 Zur Transformation der Impluvien in Brunnen, s. bereits Maiuri 1958a, 201. 470; vgl. Stefani 1992, 53f.; Morvillez 2018, 27.

375 Eine typologische Zusammenstellung hellenistischer und römischer Brunnenfiguren (darunter auch verschiedene Stücke aus Pompeji) bei Kapossy 1969, er verzichtet jedoch auf eine Datierung.

376 Döhl - Zanker 1979, 202; Dickmann 1999, 115f. nimmt die Formierung dieses Sets für augusteische Zeit an. Exemplarisch verweist er auf die Domus VI 14, 39. Das Atrium erhielt in spätrepublikanischer Zeit ein neues Paviment, das Impluvium einen neuen Rand, weshalb Dickmann auch den hier aufgestellten Tisch mit diesen Maßnahmen in Verbindung bringt; vgl. Sinn 2015, 304-306.

377 s. o. S. 474.

378 Moss 1988, 277-281.

379 Siehe dazu den nachfolgend besprochenen Kontext. Im Einzelfall sind Tische nach Auskunft von Ehreninschriften, die an den Tischplatten angebracht waren, als Träger von Standbildern in die Atrien gestiftet worden. In diesen Fällen dürften die Tische, Statuenbasen vergleichbar, mit ihrer Schmalseite zum Eingang ausgerichtet gewesen sein, wo auch die Inschrift angebracht war (Eck - von Hesberg 2004, 146f.). Für Pompeji sind solche Inschriften und Aufstellungsformen von Tischen nicht positiv belegt, aber gerade angesichts der auch hier für das Haus bezeugten Porträthermen (s. u.) auch nicht auszuschließen.

380 PPM VI (1996) 228-353 s. v. VII 1,25.47, Casa di Sirico (I. Bragantini) 317-319 Abb. 166-171.

381 Cohon 1984, 464; PPM VI (1996) 228-353 s. v. VII 1,25.47, Casa di Sirico (I. Bragantini) 318 Abb. 169.

382 Cohon 1984, 464; PPM VI (1996) 228-353 s. v. VII 1,25.47, Casa di Sirico (I. Bragantini) 319 Abb. 170. 171. 


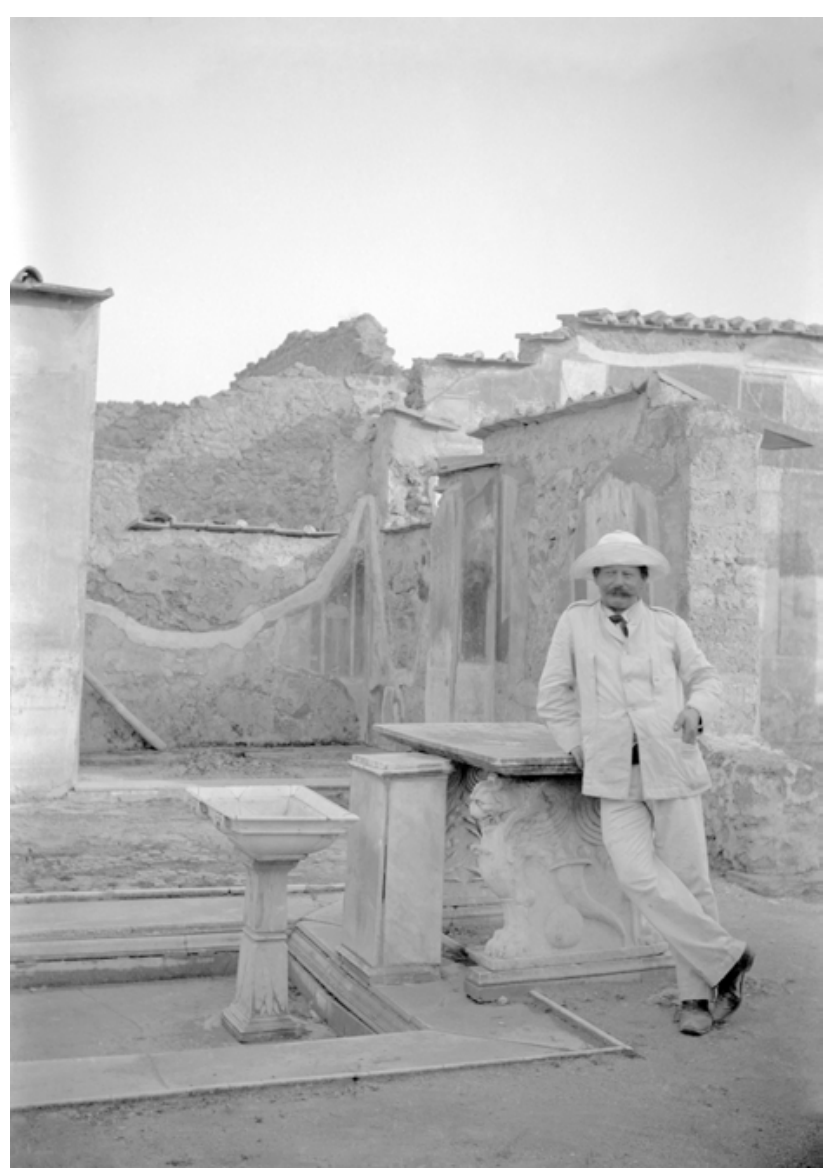

Abb. 389: Casa di Sirico (VII 1,25.47), Atrium (24) mit Ausstattung des Impluviums.

sich im Moment der Ausgrabung eine kleine Bronzegruppe, die Hercules und einen knienden Perser zeigte. Es handelt sich damit um einen der wenigen Fundkontexte, die Aufschluss darüber geben, dass die Tische für die Inszenierung kleinformatiger Skulpturen genutzt wurden ${ }^{383}$. Da die Atriumsrückwand im vierten Stil neu gestaltet wurde ${ }^{384}$, lässt sich über die ursprüngliche ,Rahmung der Bildobjekte nichts mehr sagen. Durch die Ausstattungselemente drangen jedoch Flora und Fauna in Gestalt von Löwen-Greifen und Pflanzen in den Atriumsraum ein, die kleinformatigen Bronzefiguren haben dieses Setting u. a. mythologisch verdichtet.

In einigen Häusern gehen solche Ausstattungsensembles mit einer systematischen Erneuerung des Atriumhofes zusammen. Besonders schlagend ist das Beispiel der Casa di Cornelius Rufus (VIII 4,15.30; Abb. 379). Die Impluviumsrahmung nimmt hier auf Tisch und Zisternenabdeckung Rücksicht. Der Tisch, dessen Stützen mit sphingenartigen Wesen sich erhalten haben ${ }^{385}$, ist folglich als Teil des Decor-Ensembles konzipiert worden.

In der Casa di Obellius Firmus (IX 14,4) hat das tetrastyle Atrium (B) ein neues Ausstattungsset erhalten, ohne dass man das alte Tuff-Impluvium verändert hätte (Abb. 390-391). Nach dem Erdbeben sind die Wände für eine Neuverputzung vorgesehen worden, sodass zum ursprünglichen Framing der Skulpturen keine Aussagen möglich sind. Durch die hoch aufragenden, massiven Säulen und das altertümliche Impluvium ergibt sich jedoch ein eigener Effekt. Die modernen Elemente nehmen sich kleinteilig aus, heben sich aber durch ihre weiße Marmorfarbe von der Umgebung ab. Ein erster Wasserspeier befand sich im Zentrum des Impluviums. Auf der Impluvi-

383 Moss 1988, 279f.; s. Eck - von Hesberg 2004, 162.

384 PPM VI (1996) 228-353 s. v. VII 1,25.47, Casa di Sirico (I. Bragantini) 315-317 Abb. 163-167.

385 Neapel, NM 43371; PPM VIII (1998) 518-525 s. v. VIII 4,15.30, Casa di Cornelius Rufus (I. Bragantini) 519-521 Abb. 1. 2; Mostra Domus 1992, Kat. 31. 
Abb. 390: Casa di Obellius Firmus (IX 14,4), tetrastyles Atrium (B).

Abb. 391: Casa di Obellius Firmus (IX 14,4), tetrastyles Atrium (B), Detail.
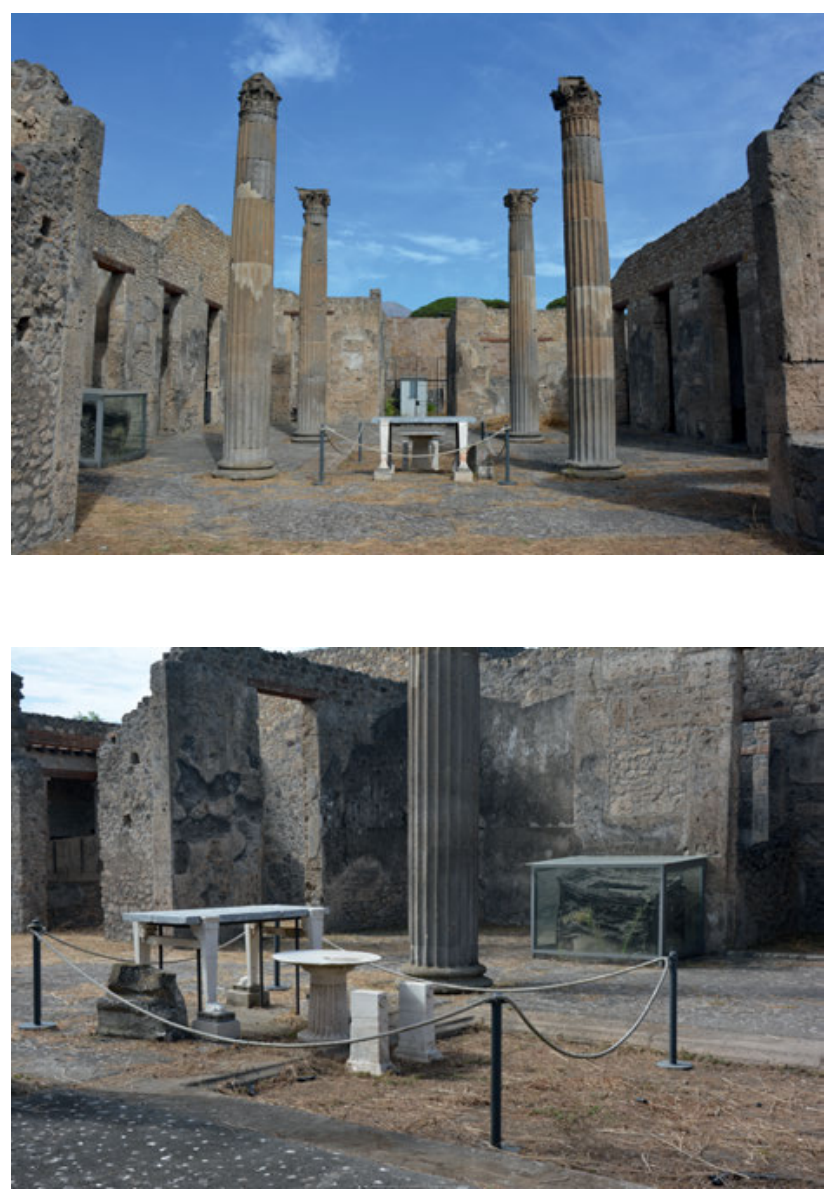

umsrückseite wurde auf einem älteren Puteal eine marmorne Satyr-Statue aufgestellt, die aus einem Weinschlauch ihr als Wein imaginiertes Wasser in ein Labrum im Impluvium ergoss ${ }^{386}$. Dahinter befand sich ein Marmortisch mit vier kannelierten Tischbeinen, die in Löwentatzen enden. Erhalten hat sich im Atrium außerdem, aufgestellt vor der Südwand, die mit Nägeln beschlagene Arca-Truhe. Neues und Altes hat hier nebeneinander gestanden.

Besonders altertümlich muss in augusteischer Zeit das Atrium der Casa di Sallustio (VI 2,4) gewirkt haben, dessen Boden und Wände dem ersten Stil angehören. Mit diesem traditionellen Rahmen kontrastierte eine Basis, auf der die bronzenen Brunnenfiguren von Hercules und der Hirschkuh aufgestellt waren; weiterhin ein muschelförmiges, im Impluvium platziertes Becken sowie hinter dem Impluvium in der Hausachse ein Marmortisch ${ }^{387}$.

Mit Blick auf die Wasserinszenierung besonders aufschlussreich ist das Atrium der Casa del Toro (V 1,7; Plan 13 $)^{388}$. Bleiröhren führten Wasser zu einer am Impluvium auf einem Marmorsockel

386 PPM X (2003) 361-499 s. v. IX 14,4, Casa di Obellius Firmus (V. Sampaolo) 366f. Abb. 6. 7; Spinazzola 1953, Abb. 384.386 (Satyr); zum Ensemble auch Dickmann 1999, 306f.; Morvillez 2018, 53.

387 PPM IV (1993) 87-147 s. v. VI 2,4, Casa di Sallustio (V. Sampaolo) 87f.; zur Lokalisierung Laidlaw 2014, 27-29, bes. Abb. 1.8 und 1.9a.

388 Jashemski 1993, 107f.; Andersson 1990; Staub 2008, 109. 


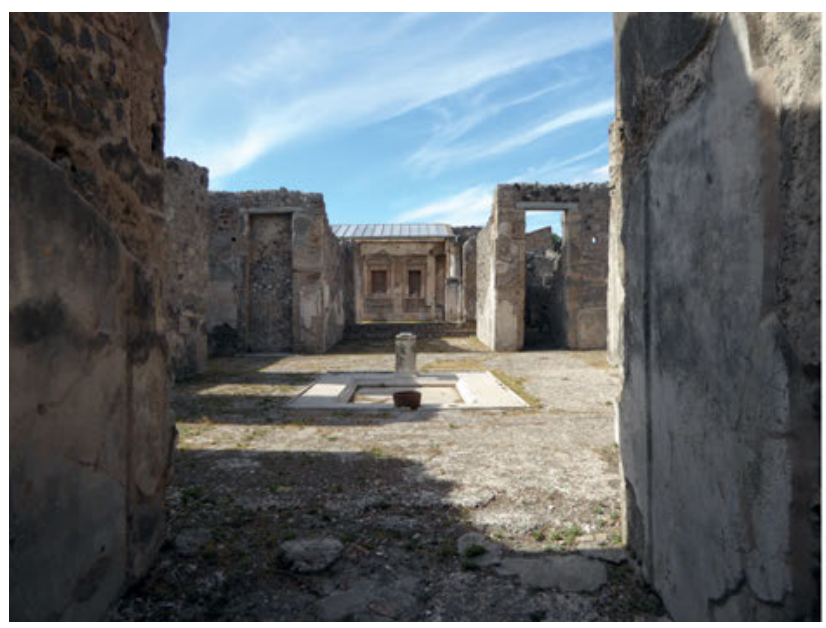

Abb. 392: Casa del Toro (V 1,7), Atrium.

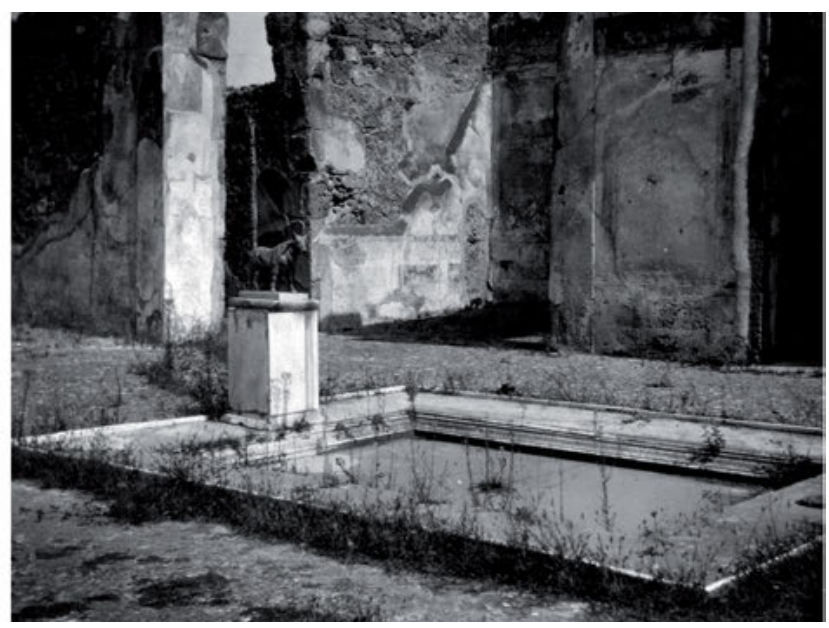

Abb. 393: Casa del Toro (V 1,7), bronzener Stier, der als Brunnenfigur diente (Neapel, NM 4890).

aufgestellten, kleinen, bronzenen Brunnenstatue in Stiergestalt (H $38 \mathrm{~cm}$; L $43 \mathrm{~cm}$ ) (Abb. 392393) ${ }^{389}$. Der Stier spie das Wasser in ein marmornes Labrum mit Tierreliefs und war so durch den Wasserstrahl regelrecht verlebendigt. Im Rand des marmornen Impluviums unterhalb des Statuensockels war eine Öffnung eingesetzt, aus der ein viergeteilter Wasserstrahl ausgeleitet werden konnte. Ein drittes Wasserspeier-System befand sich im Zentrum des Impluviums. In der Casa del Toro gewann die Inszenierung von Wasser am Atrium folglich eine neue Qualität. Das ,moderne‘ Arrangement setzte das alte Puteal außer Funktion - der Sockel der Stierstatuette wurde über der Zisternenöffnung platziert ${ }^{390}$.

Die Beispiele zeigen, dass im Atrium seit augusteischer Zeit ein regelrechter Brunnenluxus inszeniert wurde, der durch ein Set an Ausstattungselementen Gestalt gewann. In Atrien, die ihr älteres Erscheinungsbild ganz oder teilweise bewahrt hatten, muss die moderne Marmorausstattung in einen deutlichen Kontrast mit der Altehrwürdigkeit der Wandausstattung getreten sein. Andernorts entstanden ,moderne' Atrien, die als Gesamtensembles entworfen wurden und auf die Ausstattungselemente gezielt Bezug nahmen.

Mit der Brunnenfigur wurde ein optisch ansprechendes (Bild-)Element in das Atrium eingeführt, das die Aufmerksamkeit auf sich gezogen hat ${ }^{391}$. Sie war auf den Eingang ausgerichtet und vom Tablinum und den Alae aus in Rück- bzw. Seitenansicht zu sehen. Indem sie am hinteren Rand des Impluviums aufgestellt war, verschob sie den visuellen Akzent aus der vertikalen Raumachse hin zum Tablinum. Üblicherweise fielen die Brunnenfiguren kleinformatig aus. Dies wird man jedoch kaum als Indikator für die soziale Zugehörigkeit der Käufer zur Mittelschicht werten können ${ }^{392}$. Vielmehr fordert das kleine Format spezifische Betrachterhaltungen ein. Selbst gesockelt treten die Skulpturen nicht mit dem Betrachterkörper in Konkurrenz, sind leicht zu ,überblicken' und erlauben eine intime Kunsterfahrung ${ }^{393}$. Durch ihre Aufstellung im Zentrum des Atriums kann der Betrachter sie umschreiten und als allansichtige Objekte ,begreifen'. All diese Phänomene hatten sich bereits für die bronzene Satyr-Figur der Casa del Fauno beobachten lassen. Anders als diese Satyr-Statue waren die späteren Brunnenfiguren durch den Wasserstrahl, den sie

389 Stier: Neapel, NM 4890. Die Zugehörigkeit des Labrums ist nicht gesichert; vgl. Stefani 1992, 53.

390 Dickmann 1999, $303 \mathrm{f}$.

391 Zu dieser Neudefinition Andersson 1990, $213 \mathrm{f}$.

392 So Döhl - Zanker 1979, 208.

393 So auch Bartman 1992, 43. 
in das Labrum oder das Impluvium spien, jedoch regelrecht verlebendigt. Diese Form der Aktivierung dürfte sie besonders in den Fokus der Aufmerksamkeit gerückt haben.

In Bezug auf die ästhetische Inszenierung von Wasser ist auch ein Blick auf die traditionelle Markierung der Wasserstellen zu werfen: die Puteale. Sie besitzen in Pompeji eine lange Tradition, weshalb umso mehr auffällt, dass man bei den spätrepublikanisch-kaiserzeitlichen Exemplaren auf einen figürlichen Reliefschmuck verzichtete, obwohl solche Decor-Formen andernorts bekannt waren $^{394}$. Tatsächlich zeigten Puteale den ,altertümlichen' Gebrauch einer Zisterne an. Kaiserzeitliche Puteale wurden nur in solchen Atrien aufgestellt, die nicht an die neue Druckwasserleitung angeschlossen waren ${ }^{395}$. Bei ihrem Decor blieb man vielleicht deshalb bei einer verhaltenen, schlichten Form.

\subsection{Die Bildobjekte am Atrium und ihre Sujets}

Mit der Inszenierung des Impluviums als Brunnen fanden neuartige (Bild-)Objekte in das Atrium Eingang. Der Bild- und Objektluxus war jedoch nicht auf dieses Ensemble aus Brunnenfigur, Labrum und Tisch beschränkt, vielmehr avancierte das Atrium generell zu einem Showroom für die Präsentation dreidimensionaler Ausstattungsobjekte. Im Folgenden kommen diese neuen Bildmedien und -themen noch einmal systematischer in Bezug auf ihren jeweiligen Präsentationskontext in den Blick.

\section{Figürliche Wasserspeier}

Besonders im Fokus standen die in der Hausachse platzierten Brunnenfiguren. $\mathrm{Zu}$ den bereits erwähnten Wasserspeiern zählen die bronzene Satyr-Statue der Casa di Obellius Firmus, die Bronzestatue des Hercules mit der Hirschkuh in der Casa di Sallustio sowie die Bronzestatue eines wasserspeienden Stiers in der Casa del Toro (V 1,7; Plan 13). Es handelt sich um Figuren, die durch ihre Verbindung mit Wasser verlebendigt wurden und durch ihren Glanz zusätzlich Aufmerksamkeit auf sich gezogen haben.

\section{Marmorskulpturen am Impluvium}

Nicht für alle Statuen, die in der Hausachse hinter dem Impluvium aufgestellt waren, lässt sich eine Nutzung als Wasserspeier greifen. Dieselbe Position konnte für die Präsentation kleinformatiger Marmorskulpturen auf niedrigen Statuensockeln in Anspruch genommen werden. In gleich mehreren Fällen handelt es sich um nackte Venus-Statuen, die sich als Badende zeigen.

In der Casa di P. F. L. (IX 6,3) war die leicht unterlebensgroße Statue einer Venus marina $(\mathrm{H} 118 \mathrm{~cm} \text { ) in der zentralen Hausachse aufgestellt (Abb. 394) })^{396}$. Ihr relativ massiger Körper und ihre aufrechte Haltung dürften im Atrium eine gewisse Präsenz entfaltet haben, zumal, wenn man auch für sie eine Sockelung annimmt. Sie wurde von einem hohen Türdurchgang hinterfangen, der von seitlichen Durchgängen flankiert wurde. Die Statue wird so vor dem Hintergrund einer regelrechten Bühnenarchitektur inszeniert. Damit aber nicht genug. Durch den mittleren Durchgang

394 s. Katalog bei Golda 1997.

395 Pernice 1932, 22-24; Dickmann 1999, $302 \mathrm{f}$.

396 Neapel, NM 111387; Marmora Pompeiana 2008, 173; Jashemski 1993, 238 spekuliert, dass auch sie zur Gartenausstattung gehört haben könnte; zum Kontext, s. PPM IX (1999) 736-746 s. v. IX 6,3, Casa di P. F. L. (V. Sampaolo). 


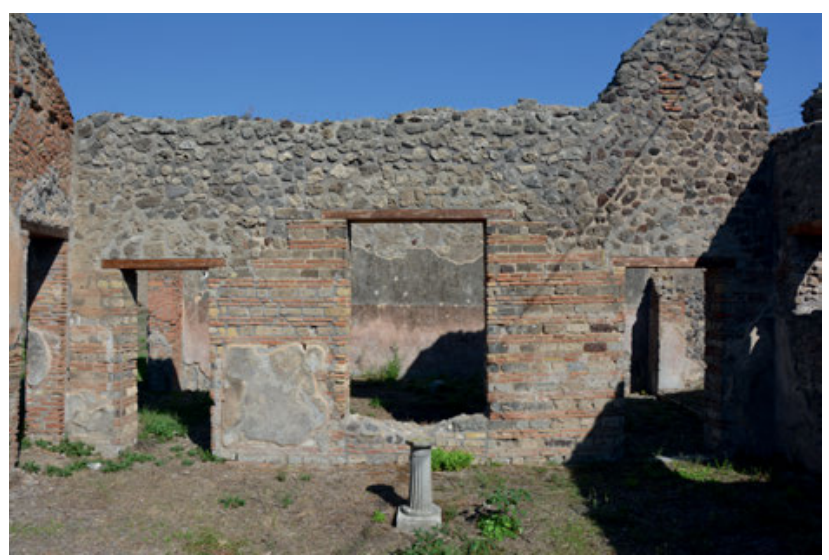

Abb. 394: Casa di P. F. L. (IX 6,3), Atrium, Blick in Richtung Peristyl.

blickt man in einen kleinen Peristylgarten, an dessen Rückwand - in der Achse der Venus - auf einem Podium ein kleiner Amor aufgestellt war ${ }^{397}$.

Venus war in augusteischer Zeit generell ein beliebtes Sujet im Atrium, die Darstellungsformen unterschieden sich jedoch erheblich. In der Casa della Venere in Bikini (I 11,6-7) $)^{398}$ handelt es sich um die namensgebende Venus im Bikini ( $\mathrm{H} 62 \mathrm{~cm}$ ), auf deren marmorweißem, nacktem Körper ein Bikini-Dress in Gold angegeben ist ${ }^{399}$. Die in der Casa del Triclinio (V 2,4) aufgestellte kauernde Venus $(\mathrm{H} 32 \mathrm{~cm})^{400}$ ist in dem Moment eingefangen, in dem sie nach dem Bade mit erhobenen Armen ihre Haare auswringt und so den Blick auf ihren nackten Körper freigibt. In der Casa di Memmius Auctus (VI 14,27) ${ }^{401}$ handelt es sich um eine kaiserzeitliche Marmorstatuette der Venus Anadyomene $(\mathrm{H} 36 \mathrm{~cm})$. Mit der badenden Venus wird ein Thema in verschiedenen Variationen aufgegriffen, das in besonderer Weise dazu angetan ist, ein heiteres Wasserambiente zu suggerie$\operatorname{ren}^{402}$. Zusammen mit dem realen Regen- bzw. Brunnenwasser vermag ein semantisch wie ästhetisch verdichtetes, multisensoriell erfahrbares Setting zu entstehen.

Für die Impluviums-Statuetten konnten aber auch andere Themen gewählt werden. In der Casa di Diomede (I 2,17) ${ }^{403}$ entschied man sich für den massigen, in einen Kurzmantel gehüllten Hercules $(\mathrm{H} 72 \mathrm{~cm})^{404}$, der sich als Identifikationsfigur des (männlichen) Hausbesitzers anbot. Die in Domus V 2,10 aufgestellte, männliche Hüftmantelstatue $(\mathrm{H} 50 \mathrm{~cm})$, vielleicht Iuppiter oder Asclepius $^{405}$, mag als Schützer des Hauses begriffen worden sein ${ }^{406}$.

Alle Statuen verbindet, dass sie die Aufmerksamkeit auf den Impluviumsbereich lenkten. Wenn sie als Brunnenfiguren dienten, fiel der Bezug zur Wasserinszenierung in funktionaler Hinsicht konkret aus. Sie konnten aber auch semantisch auf das Wasserthema Bezug nehmen, indem sie eine Situation des Badens darstellten. Dadurch wurde es zugleich möglich, das Impluvium mit einer besonders sinnlichen, sogar erotischen Atmosphäre zu belegen. Die Präsentation der

397 Neapel, NM 111388; s. S. 511.

398 PPM II (1990) 526-569 s. v. I 11,6-7, Casa della Venere in Bikini (L. Fergola) 531 Abb. 6.

399 Neapel, NM 152798; Wohlmayr 1991, 113 Nr. 32; Marmora Pompeiana 2008, 53f. Jashemski 1979, 125 macht auf ein Spiel mit verschiedenen Medien aufmerksam - auf der Rückwand von Garten (8) habe man eine entsprechende gemalte Venus-Statue erblickt. Allerdings gehört diese einer deutlich späteren Ausstattungsphase (vierter Stil) an, vor allem ist aber schwer zu entscheiden, ob es sich bei der nackten Statue mit eng geschlossenen Beinen wirklich um Venus handelt.

400 Neapel, NM 114536; Marmora Pompeiana 2008, $75 \mathrm{f}$.

401 Neapel, NM 110602; Marmora Pompeiana 2008, $92 \mathrm{f}$.

402 So Kapossy 1969, 70 f. allgemein zu Brunnenfiguren.

403 PPM I (1990) 37-44 s. v. I 2,17 (A. De Vos).

404 Neapel, NM 109677; Marmora Pompeiana 2008, $23 \mathrm{f}$.

405 Neapel, NM 120512; Marmora Pompeiana 2008, $76 \mathrm{f}$.

$406 \mathrm{Zu}$ Hercules ausführlich, mit Literatur, Marmora Pompeiana 2008, $22 \mathrm{f}$. 
nackten Körper und das ,intime 'Baden fanden im Zentrum des Hauses statt und waren auf den Eintretenden hin inszeniert. Auch darin waren Öffentlichkeit und Privatheit ineinander verschränkt.

\section{Dionysische Hermen}

Die mythische Atmosphäre am Atrium konnte durch Hermen verdichtet werden, die Bacchus und sein Gefolge zeigen ${ }^{407}$. In manchen Atrien stellte man ganze Sets dionysischer Hermen auf. So kaufte man für Atrium (e) der Domus VII 3,11.12 nach und nach mehrere dionysische Hermen an. Die stilistisch älteste Herme, ein archaistischer Bacchus, lässt sich in die frühe Kaiserzeit weisen ${ }^{408}$. Aus einem nicht sicher identifizierbaren Atrium, vielleicht jenem der Domus IX 1,25.27, stammen eine Satyr ${ }^{-409}$ und eine Bacchus-Herme ${ }^{410}$. Durch die Präsenz gleich mehrerer dionysischer Hermen konnte das Personal des Bacchus ,in personam' in die Atrien eingeführt werden. Anders als die Statuetten besaßen die Hermen einen relativ großen, freilich abstrahierten Körper, mit dem sie sich unter die Nutzer des Atriums mischen konnten. Sicher waren sie vor einer Wand aufgestellt, möglicherweise wie die Porträthermen (s. u.) vor den Anten des Tablinums.

\section{Repräsentation am Atrium: Porträthermen, Büsten und Ehrenstatuen}

Eine ganz andere Tonlage als die bisher besprochenen Impluviums-Statuetten und dionysischen Hermen schlägt eine Gruppe von Medien an, die im Dienst der direkten oder indirekten Repräsentation des Hausherrn stehen.

Dies gilt zuvorderst für die in augusteischer Zeit neu auftretenden Porträthermen ${ }^{411}$. Aus Pompeji sind sieben Exemplare bekannt ${ }^{412}$, die - soweit sich der Aufstellungskontext rekonstruieren lässt - vor den Anten des Atriums aufgestellt waren ${ }^{413}$. Mehrheitlich sind sie augusteisch ${ }^{414}$. Das für sich genommen traditionelle Medium der Herme war in pompejanischen Häusern offensichtlich inhaltlich nicht festgelegt. Indem an die Stelle eines Statuenkörpers ein Steinblock trat, wurde der Dargestellte entkörperlicht. Als alleiniges Körpermerkmal erhalten blieb der Phallos, der ihn vermutlich mit Kraft versehen bzw. Übel abwehren sollte. Eine solche Darstellungsweise empfand man für mythische Figuren wie für ,reale' Personen als angemessen. Betrachten wir einzelne Kontexte mit Blick auf die soziale Funktion der Hermen und ihre Präsentationsform näher.

407 Andere mythologische Figuren bleiben die Ausnahme. Im Fall der Casa della Fortuna (IX 7,20; Plan 22) wird eine weibliche Herme mit seitlichen Hörnern als Nymphe Io gedeutet; Neapel, NM 119584; Marmora Pompeiana 2008, 188; Palmentieri 2017, 219f. Abb. 145; zum Interesse an bärtigen Hermen in späthellenistischer Zeit, s. Krämer 2001, bes. 165f.; zur besonderen Beliebtheit von dionysischen Hermen im späten Hellenismus, s. Wrede 1985, 21.

408 Neapel, NM 123183; Marmora Pompeiana 2008, 119; s. PPM VI (1996) 860-865 s. v. VII 3,11-12 (V. Sampaolo) 863 Abb. 4.

409 Neapel, NM 109612; Marmora Pompeiana 2008, 198f.

410 Neapel, NM 120452; Marmora Pompeiana 2008, $200 \mathrm{f}$.

411 Ein Zusammenhang mit den nur literarisch überlieferten Imagines maiorum ist nicht greifbar; so allerdings suggeriert bei Fejfer 2008, 90 f.; auch eine Verbindung zum griechischen Kultpfeiler ist unplausibel, vgl. Wrede 1985, 76.

412 Dickmann 1999, 118-120 Anm. 382.

413 Über die im Folgenden ausführlich besprochenen Fälle hinaus ist dies für die Porträtherme der Casa di Orfeo (VI 14,20) bezeugt. Hermenschaft: Neapel, NM 407/4; der zugehörige Kopf (in Pompeji, Antiquarium) wurde im Peristyl gefunden; De Franciscis 1951, 30; vgl. Foto Warsher collection Nr. 1847, s. PPM V (1994) 264-307 s. v. VI 14,20, Casa di Vesonius Primus o di Orfeo (F. Narciso) 264; s. auch Bonifacio 1997, 90-92 Nr. 35. Für die anderen Porträthermen Pompejis ist der Aufstellungskontext nicht rekonstruierbar.

414 Döhl - Zanker 1979, 195; De Franciscis 1951. 


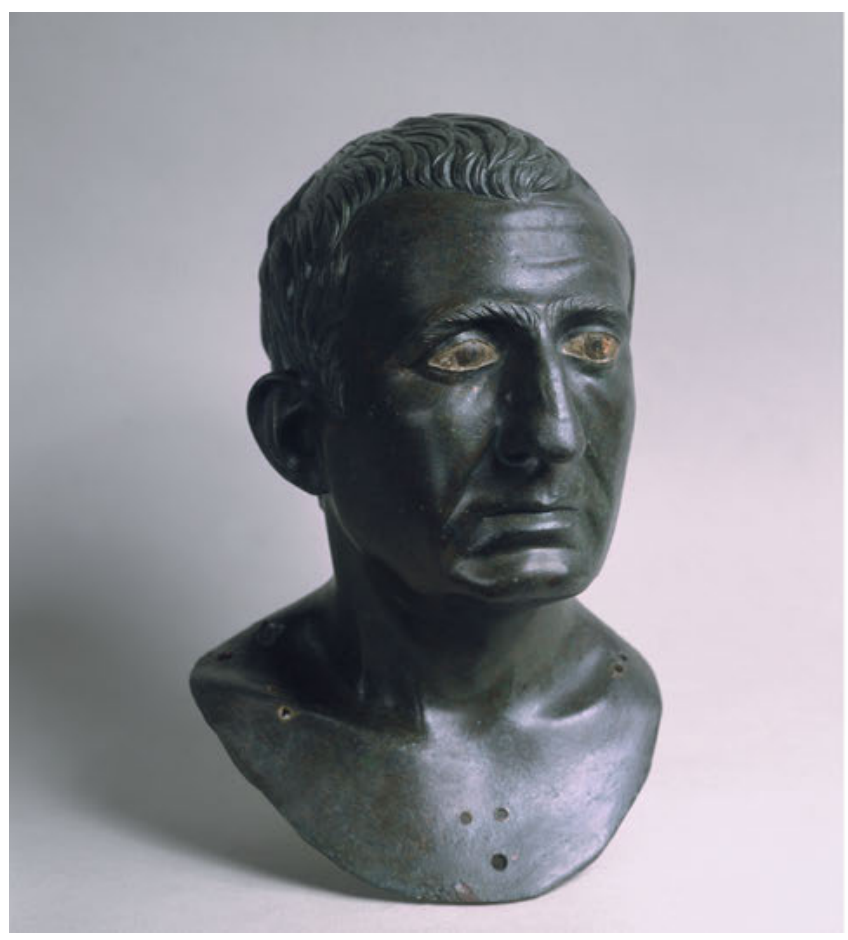

Abb. 395: Männliches Bronzeporträt aus Atrium (6) der Casa del Citarista (Neapel, NM 4989).

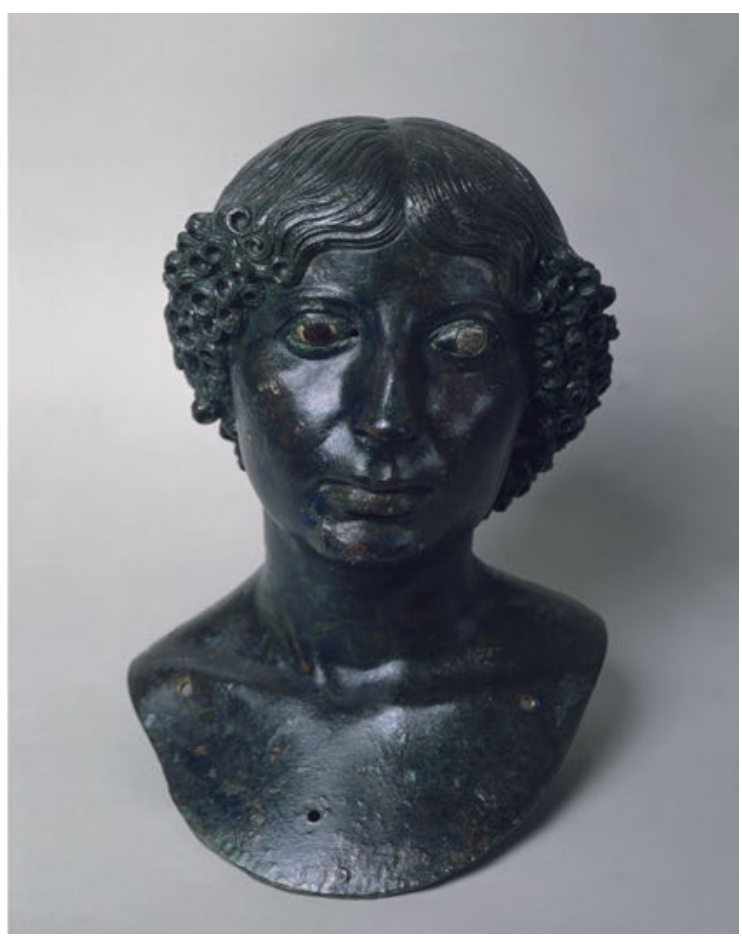

Abb. 396: Weibliches Bronzeporträt aus Atrium (6) der Casa del Citarista (Neapel, NM 4990).

Im Atrium (6) der Casa del Citarista (I 4,5.6.25.28; Plan 5; Abb. 314. 395-396) wurde am Übergang von der Republik zur Kaiserzeit eine Herme mit Bronzeporträt aufgestellt - der zugehörige Schaft ist verloren. Der Fundort in der südlichen Ala (12) an der südlichen Ante des Tablinums dürfte dem Aufstellungsort entsprochen haben. In claudischer Zeit erhielt das Porträt ein weibliches Pendant, gefunden in der nördlichen Ala (13). Es war damit vielleicht vor der Nordante des Tablinums aufgestellt ${ }^{415}$. In beiden Fällen handelt es sich um bronzene Porträts von hoher Qualität mit Einsatzaugen aus Glaspaste. Das architektonisch einfache Atrium dürfte durch die Hermen in besonderer Weise aufgewertet worden sein. Ein vergleichbarer Aufstellungszusammenhang ergibt sich für die Porträthermen der Casa di L. Caecilius Iucundus (V 1,23.26; Plan 14). Die beiden erhaltenen Hermenschäfte, die jeweils eine Inschrift tragen, sind vor den Tablinumsanten platziert $\left(\right.$ Abb. 376) ${ }^{416}$. Nur bei einem der Hermenschäfte hat sich das eingesetzte Bronzeporträt erhalten ${ }^{417}$. Die auf den Basen der beiden Hermenschäfte gleichlautenden Inschriften (CIL X 860) geben Auskunft über den sozialen Sinn der Objekte: Genio L(ucii) nostri / Felix L(ibertus). Die Inschriften nennen einen Libertus Felix als Stifter der Hermen ${ }^{418}$ und geben darin zu erkennen, dass die Hermenporträts als Form der Ehrung im privaten Kontext des Atriums fungierten. Im genannten Fall handelt es sich um eine Ehrung durch einen Freigelassenen. Das Marmorporträt des Vesonius Primus ist in eine Marmorherme eingesetzt, welche die Inschrift Primo N. / Anteros arcar trägt

415 Mann: Neapel, NM 4989; Frau: Neapel, NM 4990; Hoffmann 2014, 103f. Kat. 3-4; Döhl - Zanker 1979, 195 mit sehr pauschalen Überlegungen; Bonifacio 1997, Nr. 44; Lahusen - Formigli 2007, 96f. B1. 120 f. B9.

416 PPM III (1991) 574-620 s. v. V 1,26, Casa di L. Caecilius Iucundus e casa annessa V 1,23 (A. de Vos) 583f. Abb. 13. 14; Dexter 1979, bes. 178-187.

417 Porträt: Neapel, NM 110663; Phallus: Neapel, NM 110664; Marmorherme: Neapel, NM 110666; De Franciscis 1953, 31f.; Dexter 1979, 178; Bonifacio 1997, Nr. 36.

418 Zur Diskussion, s. S. 31 Anm. 182. 
Abb. 397: Hermenporträt des Vesonius Primus aus der Casa di Orfeo (VI 14,20).

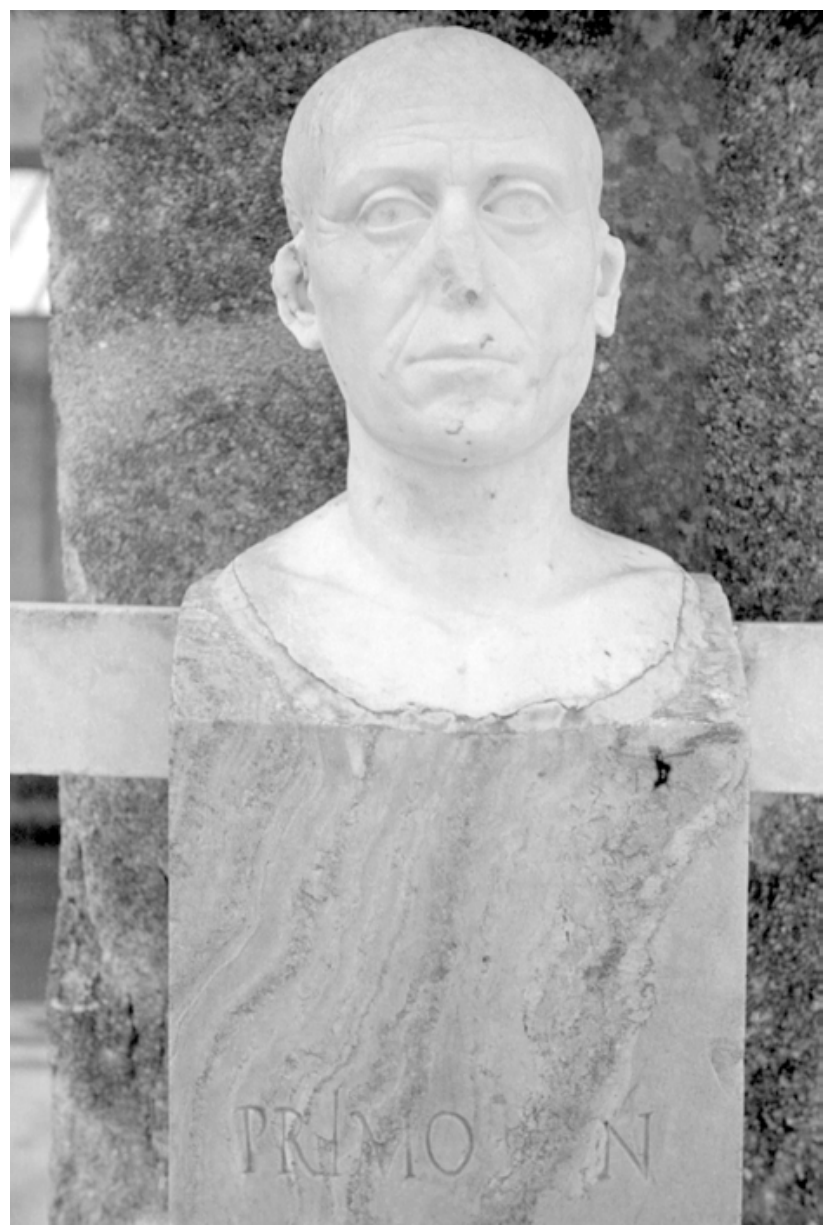

(Abb. 397). Sie bezeugt, dass die Herme für (Vesconius) Primus von einem Sklaven mit dem Namen N. Anteros arcarius aufgestellt wurde ${ }^{419}$. Schließlich ist auch für die Herme mit dem Marmorporträt des Cornelius Rufus in der Casa di Cornelius Rufus (VIII 4,15.30) ${ }^{420}$ eine Aufstellung vor einer Tablinumsante belegt (Abb. 379). Hier gibt die Inschrift auf dem Hermenschaft nur den Namen des Empfängers, Cornelius Rufus, $\mathrm{an}^{421}$.

Die Inschriften, welche die Porträthermen begleiten, nennen damit ganz ähnlich wie Ehrungen im öffentlichen Raum Stifter und Adressat, lassen aber jede offizielle Titulatur des Geehrten fort. Die Nähe zu öffentlichen Ehrungen kommt darüber hinaus in der Wahl des Mediums zum Ausdruck. Im Haus waren Hermen jedoch in andersartige Formen der Kommunikation und sozialen Interaktion als im öffentlichen Raum eingebunden ${ }^{422}$.

Die spezifische Materialität und Medialität der Porträthermen hat Konsequenzen für ihre Präsentation. Sie waren unbeweglich und damit auf einen konkreten Ort festgelegt, ,fest' mit dem Haus verbunden. Konventionellerweise wählte man als Aufstellungsort die Anten des Tablinums. Dadurch verdoppeln und akzentuieren die Hermen die Einfassung des Tablinums und sind unmittelbar auf diesen Hauptraum am Atrium bezogen. Umgekehrt tragen die Anten zur Wirkung der

\footnotetext{
419 Giornali degli Scavi 1875, 100; CIL X 865.

420 Aufstellung durch altes Foto gesichert, s. PPM VIII (1998) 518-525 s. v. VIII 4,15.30, Casa di Cornelius Rufus (I. Bragantini) 519-521 Abb. 1. 2; De Franciscis 1951, 39f.; Bonifacio 1997, 86f. Nr. 32.

421 CIL X 864 (C. Cornelio Rufo); Mau 1908, 260f. 464f.; Bonifacio 1997, Nr. 32; Franciscis 1951, 30f. 39f. Abb. 16-20. 27.

422 Dickmann 2010, 102.
} 
Hermen bei. Für die Wahrnehmung der Porträthermen ist darüber hinaus entscheidend, dass sie im Unterschied zu Wand- und Bodenbildern ,Raum' einnehmen. Indem sich das Porträt annähernd auf Kopfhöhe der Betrachter befand, wurde es zu seinem visuellen Gegenüber ${ }^{423}$.

Neben den in Hermen eingesetzten Bronzeporträts stammen aus den Atrien auch Marmorbüsten. So war in der Casa di Oppius Gratus e Quartilla (IX 6,4-7) in der Nische links des Eingangs eine Marmorbüste aufgestellt, die sich in claudische Zeit weisen lässt ${ }^{424}$. Die tiberische Marmorbüste eines Jugendlichen stammt aus dem Atrium (2) der Casa di P. F. L. (IX 6,3) ${ }^{425}$. Ebenfalls um eine Privatperson mag es sich bei dem in seiner Identifizierung umstrittenen, tiberischen Porträt aus dem Prothyron-Bereich der Domus VIII 4,23 handeln ${ }^{426}$. Das ,moderne‘ Format der Büste erlaubte eine Abbreviatur der Porträtstatue, wodurch sich neuartige Präsentationsformen in Nischen, möglicherweise auch auf Sockeln oder Tischen ergaben.

In Einzelfällen wurde dieses Format genutzt, um Personen der großen Politik in Rom im Haus die Ehre zu erweisen. In der Casa del Citarista (I 4,5.6.25.28; Plan 5) fanden sich zwei Marmorköpfe auf Höhe des Zwischengeschosses, oberhalb von Raum (27), die wohl erst nach dem Erdbeben dort deponiert wurden. Einer der Köpfe gehörte zu einer augusteischen Porträtbüste, die vielleicht Agrippa darstellte ${ }^{427}$. Mit der Aufstellung von Porträts öffentlicher Personen war es dem Hausbesitzer möglich, seine - vielleicht auch nur gedankliche - Nähe zu den am Hof einflussreichen Akteuren visuell in Szene zu setzen. Eine gesellschaftliche Wirkung können solche Porträts nur entfaltet haben, wenn sie für die Gäste des Hauses sichtbar waren. Man möchte sich für den ,Agrippa' der Casa del Citarista daher am ehesten eine Aufstellung in einem der repräsentativen Hofbereiche vorstellen ${ }^{428}$.

Bei dem zweiten marmornen Porträtkopf aus dem Zwischengeschoss der Casa del Citarista handelt es sich um den frühaugusteischen Einsatzkopf des Marcus Claudius Marcellus, der für eine Togastatue vorgesehen war $^{429}$. Solche Statuen blieben im häuslichen Kontext die absolute Ausnahme, dürften aber in besonderer Weise an öffentliche Ehrenstatuen erinnert haben. Auch für den Marcellus der Casa del Citarista wird man daher eine Aufstellung an einem gut sichtbaren Ort im Haus voraussetzen dürfen.

\section{Das Mobiliar als Bildträger: Tische und Altäre}

Zwar handelt es sich bei den bisher betrachteten Statuetten, Hermen und Büsten um wirkmächtige Bildobjekte, doch auch Funktionsobjekte können am Atrium zu Bildträgern werden und so die Handlungen, die an ihnen vollzogen werden, semantisch ,rahmen'.

Dies gilt, wie schon gesehen, zunächst für die prominent in der Hausachse platzierten Tische. Mit Beginn der Kaiserzeit schätzte man vor allem Marmortische mit zwei schweren, reliefierten Stützen ${ }^{430}$, daneben finden sich Tische mit einer Stütze (Monopodia/Cartibula), dreibeinige Tische (Mensae Delphicae) und vierbeinige Tische. Mit ihren vertikalen und horizontalen Achsen - d.h. den Tischbeinen und der Tischplatte - folgen sie einem architektonischen Strukturprinzip. Die verschiedenen Typologien und Gestaltungsformen der Tische trugen unterschiedlichen Ansichtigkeiten Rechnung.

423 Elsner 2014, 2.

424 Neapel, NM 111385; s. Bonifacio 1997, Nr. 41.

425 Neapel, NM 111386; Marmora Pompeiana 2008, 172.

426 Neapel, NM 109516; eine ausführliche Diskussion zur Benennung, mit älterer Literatur, in Marmora Pompeiana 2008, $147 \mathrm{f}$.

427 Neapel, NM 6028; Hoffmann 2014, 152-155 Kat. 50-51; Döhl - Zanker 1979, 195; De Franciscis 1951.

428 So auch Zanker 1987, 264. 352.

429 Neapel, NM 6025; Bonifacio 1997, 94-96 Nr. 37 Taf. 30.

430 Cohon 1984, 68-76. 59-105; Dickmann 1999, 115f.; Sinn 2015, 302. 
Abb. 398: AttisStütze eines Tisches (NM 120403), aus dem Atrium der Domus VII 12,22-23.

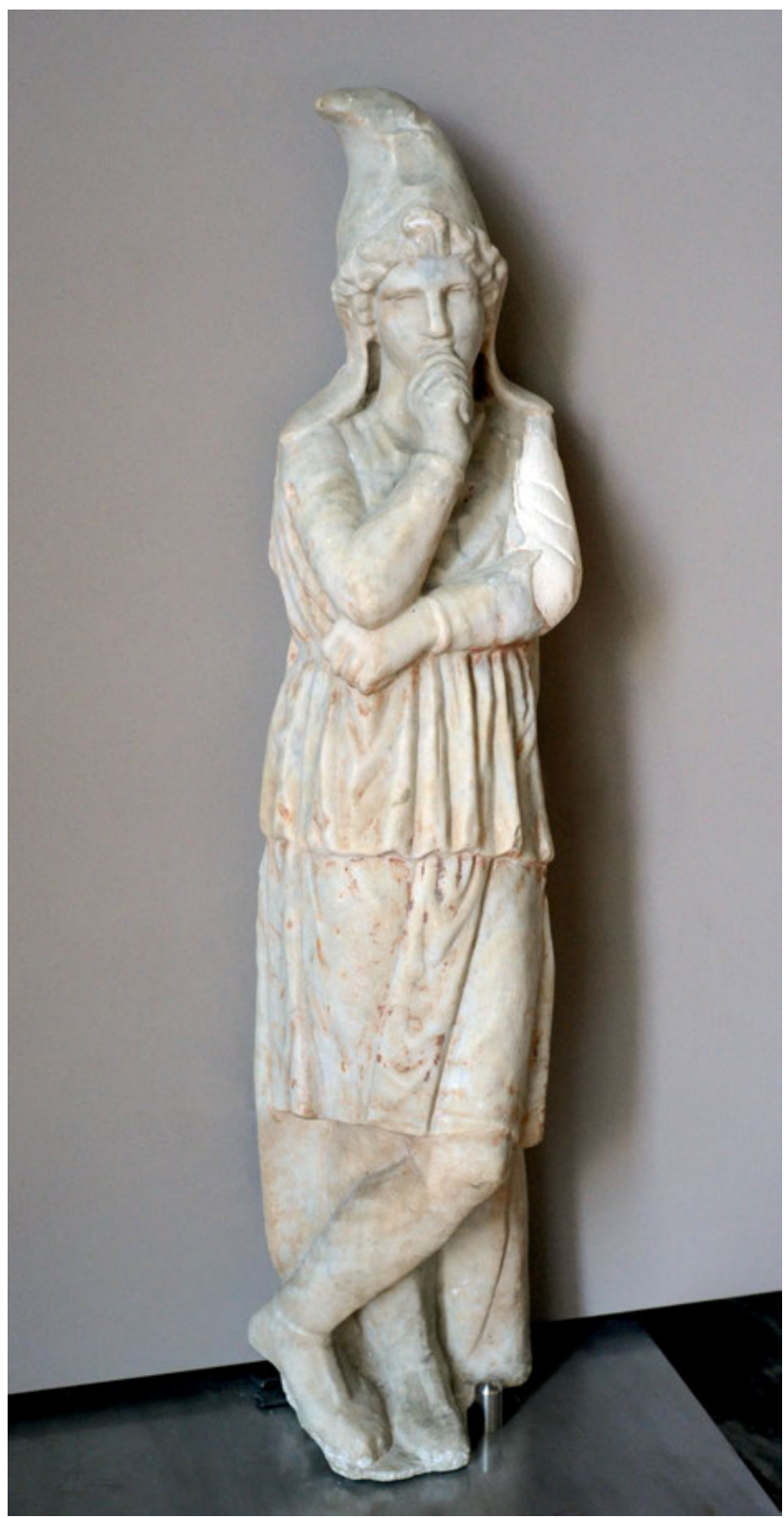

Die Stützen von Monopodia nehmen häufig figürliche Gestalt an. Vor den Tischfuß kann eine AttisFigur gestellt sein (Abb. 398) ${ }^{431}$, der Tischfuß kann aber auch als hockender, nach vorn blickender Panther ${ }^{432}$, als Panther-Protome ${ }^{433}$ oder als Herme ${ }^{434}$ gestaltet sein. Figürliche Monopodia besitzen

431 Atrium von Domus VI 14,37, Tisch Neapel, NM 120425 (Cohon 1984, Kat. A 26; Marmora Pompeiana 2008, 96f.); Atrium der Casa di L. Caecilius Iucundus (V 1,23.26), Tisch Neapel, NM Mag. (Cohon 1984, Kat. A 27); Atrium der Domus VII 12,22-23, Tisch Neapel, NM 120403 (Cohon 1984, Kat. A 29); aus dem Atrium der Domus VI 2,16, Tisch Neapel, NM 120402 (Cohon 1984, Kat. A 33).

432 Domus V 4,c mit Tisch Pompeji, Antiquarium 2588 (Cohon 1984, Kat. A 84, dort als Domus V 4,b; PPM III (1991) 1033-1046 s. v. V 4,c (I. Bragantini) 1035f. Abb. 3).

433 Casa del panattiere (VII 3,30) mit Tisch Pompeji, Mag. 404-4 [20528] (Cohon 1984, Kat. 143).

434 Nur ausnahmsweise ist die Aufstellung im Atrium positiv belegt: Domus I 10,16 - Tisch mit bartlos-jugendlicher Bacchus-Herme, Pompeji, Antiquarium SN 1595 [20398] (Cohon 1984, Kat. 246); weiterhin denkbar für Domus V 4,3, mit einem Tisch vor der Ostwand des Atriums, der Kopf beim Impluvium gefunden, Pompeji, vermisst (Cohon 1984, 


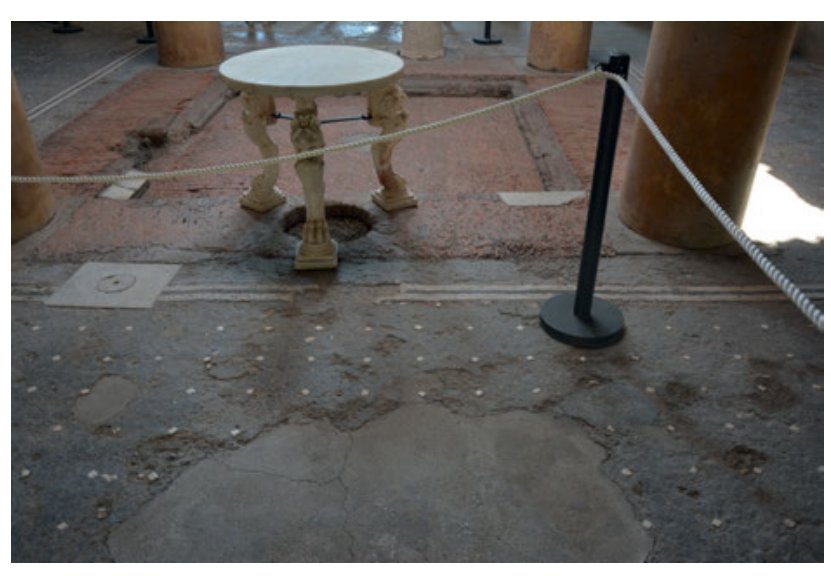

Abb. 399: Casa dei Ceii (I 6,15), dreibeiniger Tisch, Blick vom Tablinum in Richtung Eingang.

eine Ansichtsseite und dürften wie die kleinformatigen Skulpturen auf den Eintretenden ausgerichtet gewesen sein; ihre Präsentationsform unterscheidet sich jedoch grundlegend. Während die figürlichen Tischstützen als Träger einer Tischplatte ,dienen` und dadurch letztlich als Ornamentum eines Tisches konzipiert sind, werden die kleinformatigen Skulpturen ihrerseits von einer Basis getragen und so vom Gehniveau des Betrachters ,heraus'-gehoben.

Während die Monopodia regelrecht skulptural aufgefasst werden konnten, fällt die Bildlichkeit bei den anderen Tischformen üblicherweise schwächer aus. Bei drei- und vierbeinigen Tischen nahmen die Tischfüße üblicherweise die Gestalt von Tiertatzen an. Im Fall des dreibeinigen Tischs aus der Casa dei Ceii (I 6,15) verbinden sich mit den Löwentatzen Löwen-Greifen-Protomen (Abb. 399) ${ }^{435}$. Bei dem vierbeinigen Tisch aus der Casa di Inaco e Io (VI 7,19) sind die Tischbeine säulenhaft-architektonisch aufgefasst, kanneliert und schließen mit einem vegetabilen Kapitell ab (Abb. 400) $)^{436}$. Beide Tischtypen sind allansichtig. Insbesondere dreibeinige Tische führen in den Atriumsraum eine Form ein, die sich nicht an der orthogonalen Organisation des Atriums orientiert und dadurch Variatio schafft.

Kat. A 253); im Atrium der Casa della Grata metallica (I 2,28) besteht die Stütze aus einer Hercules-Herme (Neapel, NM 120509; Marmora Pompeiana 2008, 29).

435 Vom hinteren Impluviumsrand der Casa dei Ceii (I 6,15), Tisch Pompeji, Antiquarium 2029-4 [20530] (Cohon 1984, Kat. C 65).

436 Domus IX 5,11.13, in situ (Cohon 1984, Kat. D 47); Domus I 4,9 mit Tisch Pompeji, Mag. [Granaio del Foro] (Cohon 1984, Kat. D 49); Casa di Marcus Lucretius Fronto (V 4,a), in situ (Cohon 1984, Kat. D 50); Casa del fabbro (I 10,7), in situ (Cohon 1984, Kat. D 51); Casa di Obellius Firmus (IX 14,4), in situ (Cohon 1984, Kat. D 52); Casa dell'Efebo (I 7,11), Tisch Pompeji, Mag. (Cohon 1984, D 53); Casa di Inaco e Io (VI 7,19), in situ (Kat. D 56). 
Abb. 400: Casa di Inaco e lo (VI 7,19), Tisch mit vier Stützen, Blick von den Fauces. Die Beine sind hier aus Pavonazzetto, die Tischplatte aus Brekzie.
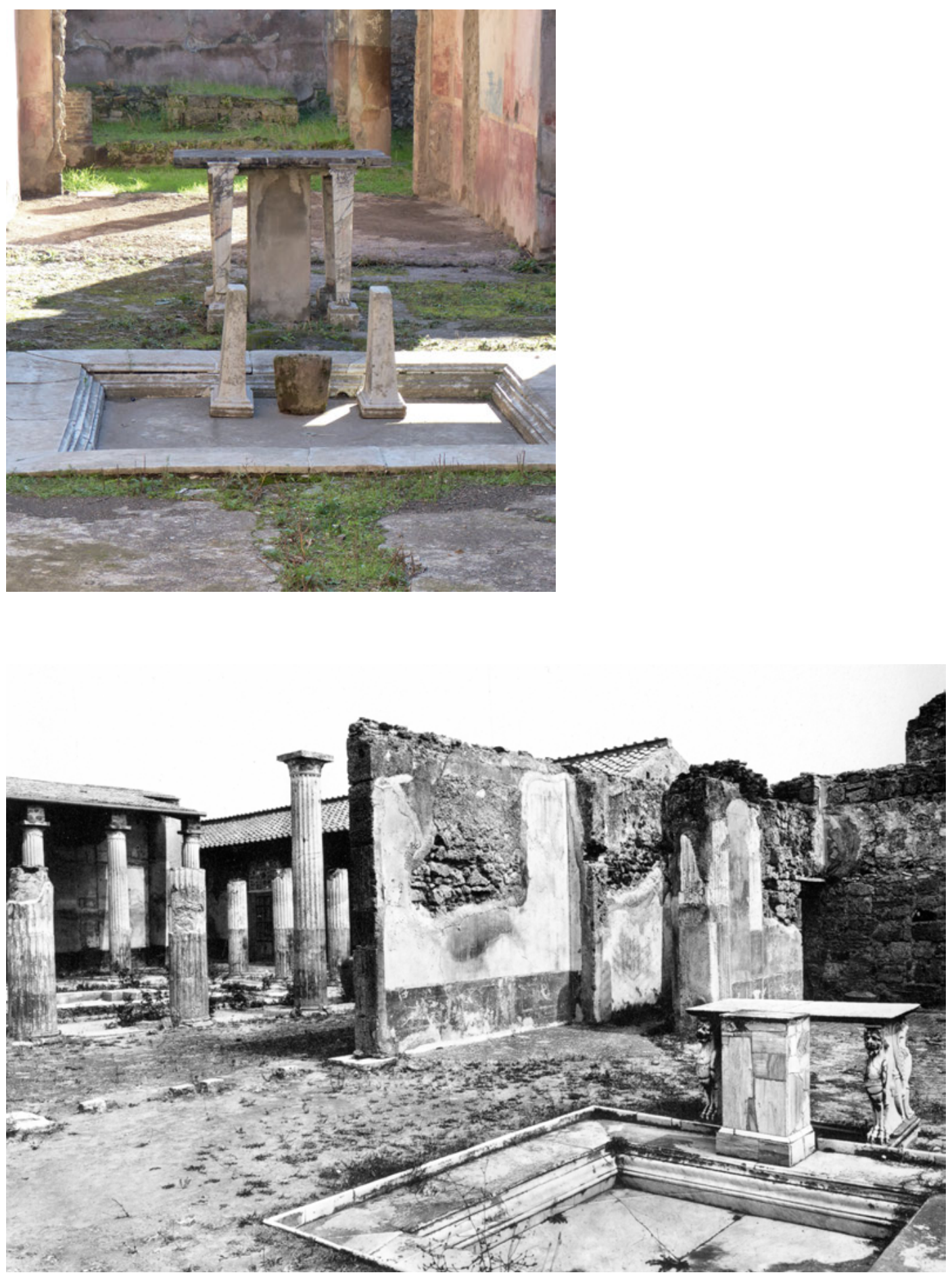

Zweibeinige Tische mit ihren massiven Tischwangen weisen den Vorzug auf, eine attraktive Seitenansicht zu bieten, die von den Alae aus wahrgenommen werden konnte. Im Fall des Tisches im Atrium der Casa di Meleagro (VI 9,2.13) tragen vier Greifen, deren Flügel auf die Tischwangen ausgreifen, die Tischplatte (Abb. 401) ${ }^{437}$; eine Cornucopia füllt den Zwischenraum zwischen den Flügeln. 


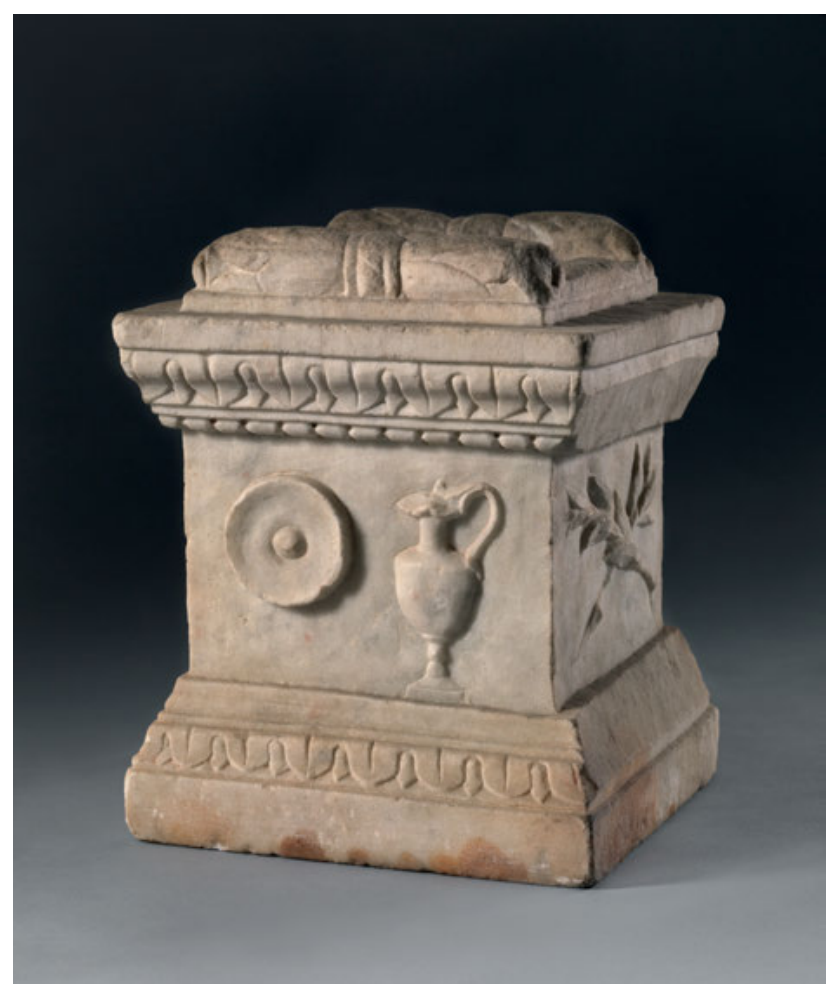

Abb. 402: MiniaturAltar aus Atrium (6) der Casa del Citarista (Neapel, NM 110022).

$\mathrm{Zu}$ den Bildträgern am Atrium zählen nicht zuletzt kleine Altäre. Ein besonders prunkvolles Exemplar stammt aus der Casa del Citarista (I 4,5.6.25.28; Plan 5; Abb. 402) ${ }^{438}$. Sakrale Handlungen, die man für das Atrium voraussetzen darf, wurden durch den Decor auf seinen vier Seiten kontextualisiert: Patera und Urceus, schnäbelnde Sperlinge, geflügelte Eroten und sich kreuzende Palmzweige schaffen ein sakralidyllisches Ambiente. Der Assoziationsrahmen changiert in Abhängigkeit davon, welche Altarseite im Blick war. Erst beim Umschreiten des Altars ergibt sich ein umfängliches Verständnis des Decors. Der genaue Aufstellungsort des Altars ist unbekannt, seine Motive dürften jedoch zu einer sakralen Aufladung des Atriums beigetragen haben.

Gerade die bebilderten Funktionsobjekte sind in besonders unmittelbarer Weise auf die Handlungen bezogen, in welche die Objekte involviert waren. Die Gegenüberstellung von Tischen und Altären ist in dieser Hinsicht aufschlussreich. Während der Decor des Altars mit Patera und Urceus auf Opferhandlungen Bezug nimmt, folgt der Decor der Tische einem allgemeinen Decor-Repertoire, das für die Ausgestaltung von Objekten verfügbar war: Kannelierte Stützen, die den ,festen ‘ Charakter der Tische unterstreichen, gehören ebenso dazu wie deren (konterkarierende) Verlebendigung durch Tiertatzen ${ }^{439}$. Die im engeren Sinn figürlichen Stützen der Monopodia ,entführen` mit Attis oder den Panthern, die an Bacchus erinnern, in andere, fremde Welten.

\section{Bildobjekte am Atrium}

Die Ausstattungsobjekte machen vielfältige ästhetische und semantische Angebote. Mit der Neuausstattung der Impluvia wird Wasser als solches zum Decor. Das Atrium wird in ein heiteres

438 Neapel, NM 110022; zum Altar und seinem Kontext: Overbeck - Mau 1884, 361; anders bei Hoffmann 2014, 162f. Kat. 53, der den Altar in Bezug auf jüngere Literatur im Peristyl (32) lokalisiert; ein weiteres Exemplar eines kleinen Marmoraltars augusteischer Zeit (Neapel, NM 3217) stammt aus der Casa di Paquius Proculus/Cuspius Pansa (I 7,1), vgl. Mostra Domus 1992, Kat. 22.

439 Demnächst ausführlich Adrian Hielscher. 
Brunnenambiente überführt. Die neue, sinnliche Erfahrungsdimension des Hofes wird durch Statuen von Venus und Amor noch einmal intensiviert. Mit den dionysischen Hermen, aber auch mit Tischstützen, die in die Welt des Bacchus verweisen, werden neue Medien gefunden, die dieses schon seit dem 2.Jh.v.Chr. am Atrium formulierte Thema in neuer Form vergegenwärtigen. Das Dionysische ist in den abbreviierten Darstellungsformeln (dionysische Hermen, Tischstützen mit Panthern) offen für verschiedenste Assoziationen, die vom Convivium, dem Haus als Ort des Festes bis zu Lebensgenuss und Kultur im Allgemeinen reichen. Gerade bei den Tischen ergibt sich eine assoziative Nähe zwischen den hier vollzogenen Handlungen und dem Bild-Decor. In Porträthermen und Marmorbüsten erhält eine andere, traditionelle Funktion des Atriums eine neue visuelle Gestalt: das Atrium als Ort der Repräsentation des Dominus und der Familie. Mit Porträthermen und -büsten stehen dafür nun dauerhafte Medien zur Verfügung. Sie sind Ausdruck einer in neuartiger Weise konventionalisierten und ritualisierten Interaktion zwischen dem Dominus und den von ihm abhängigen Klienten und Sklaven.

\subsection{Das Peristyl als Decor-Raum: die Casa del Citarista und die Casa della Fortuna}

In den besonderen Fokus der Gestaltung rücken in augusteischer Zeit die Peristylgärten. Dies manifestiert sich in der Ausrichtung der Aufenthaltsräume auf den Garten, in neuen Bepflanzungskonzepten, in der aufwendigen Gestaltung der Peristylrückwände, nicht zuletzt aber auch in der Aufstellung von dreidimensionalen Objekten. Die neue Vorliebe für Skulpturen im Gartenbereich soll im Folgenden über drei analytische Schritte greifbar werden. Anhand der frühkaiserzeitlichen Ausstattungsensembles der Casa del Citarista und der Casa della Fortuna lässt sich die Aufwertung der Peristylgärten durch Bildobjekte zunächst exemplarisch beschreiben. In einem zweiten Schritt soll das prominenteste neue Ausstattungselement der Peristyle näher betrachtet werden: ihre Brunnen und Nymphäen. Abschließend soll auch für die Peristyle ein vergleichender Blick auf ihre Objekt- und Bildausstattung geworfen werden.

\section{Die Ausstattung von Peristyl (17) der Casa del Citarista}

Peristyl (17) der Casa del Citarista (I 4,5.6.25.28; Plan 5) ist für die neuartige atmosphärische Aufladung der Gartenbereiche besonders aussagekräftig ${ }^{440}$. In augusteischer Zeit wurde der bereits vorhandene Euripus umgestaltet, an seine westliche Schmalseite setzte man ein halbkreisförmiges, mit Marmor verkleidetes Brunnenbecken an (Abb. 403). Euripus und Becken wurden mit wasserfestem Mörtel verputzt und blieben zeitgleich in Funktion ${ }^{441}$. Am Beckenrand stellte man die bronzenen Statuen von einem Eber, der von zwei Hunden angegriffen wurde, von einem springenden Löwen, einer Hirschkuh und einer sich aufrichtenden Schlange auf. Löwe, Eber und Schlange fungierten als Wasserspeier ${ }^{442}$. Der Wasserstrahl hat die Tiere verlebendigt, ihnen eine Sprache

440 Die Skulpturenausstattung des Hauses besprochen bei Mattusch 2014.

441 Anders Maiuri 1931, 575f., der m. E. zu Unrecht von einer Verfüllung des älteren Euripus ausgeht; er bringt die Eingriffe in Zusammenhang mit der Erweiterung des Hauses nach Norden - auch deren Datierung ist aber, wie schon gesehen, umstritten; Morvillez 2018, 50 schlägt vor, dass das Haus bis in die Spätphase der Stadt einen großen Pool besessen habe, der erst im Zuge der Wasserknappheit durch das apsidiale Becken ersetzt worden sei. Zur Datierung der Brunnenfiguren äußert er sich nicht. Da der wasserfeste Mörtel vom alten Becken über das neue Becken zieht, sind m. E. beide Becken gleichzeitig in Funktion. Die Erweiterung des Pools um ein Präsentationsbecken für die Skulpturen könnte in augusteische Zeit gehören.

442 Eber: Neapel, NM 4900; zwei Hunde: Neapel, NM 4899; 4901; Hirschkuh: Neapel, NM 4902; Löwe: Neapel, NM 4897; Schlange: Neapel, NM 4898; s. Hoffmann 2014, 109-111; Kellum 2018 schlägt vor, das Ensemble über Tierfabeln zu verstehen. 


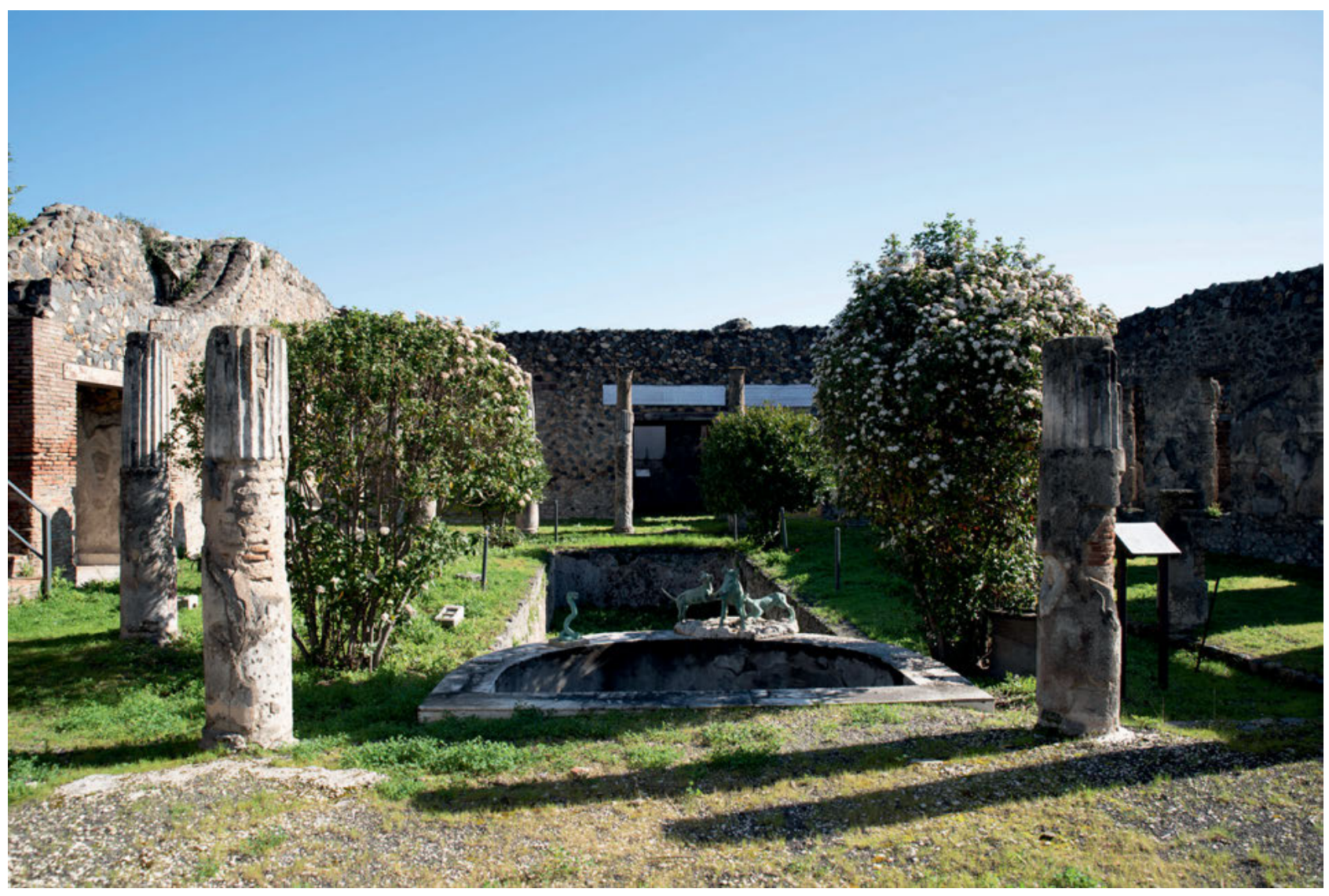

Abb. 403: Casa del Citarista (I 4, 5.6.25.28), Peristyl (17) mit Brunnen, Brunnenfiguren (Repliken) und Kanopus.
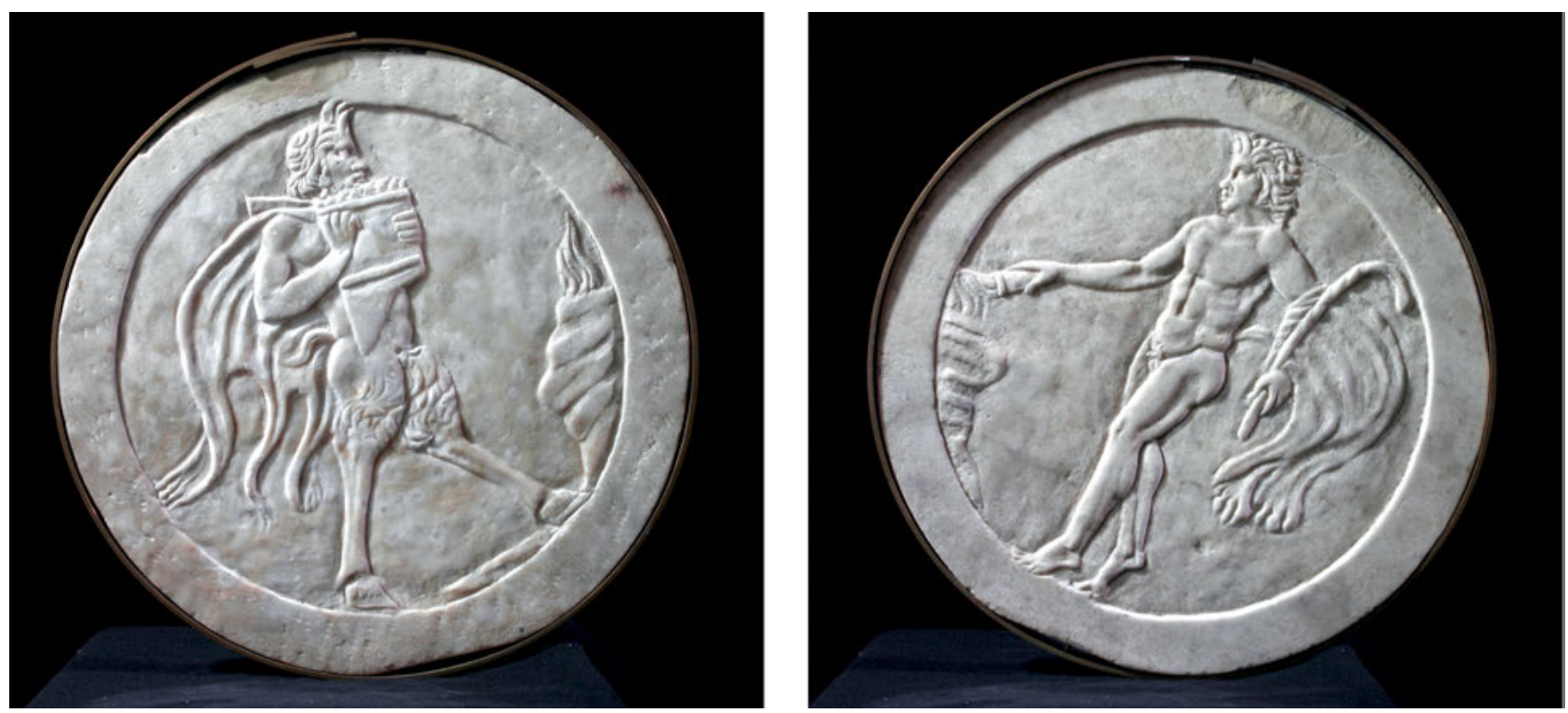

Abb. 404a-b: Rundes Oscillum aus Peristyl (17) der Casa del Citarista (I 4, 5.6.25.28), Vorder- und Rückseite (Neapel, NM 6646). 

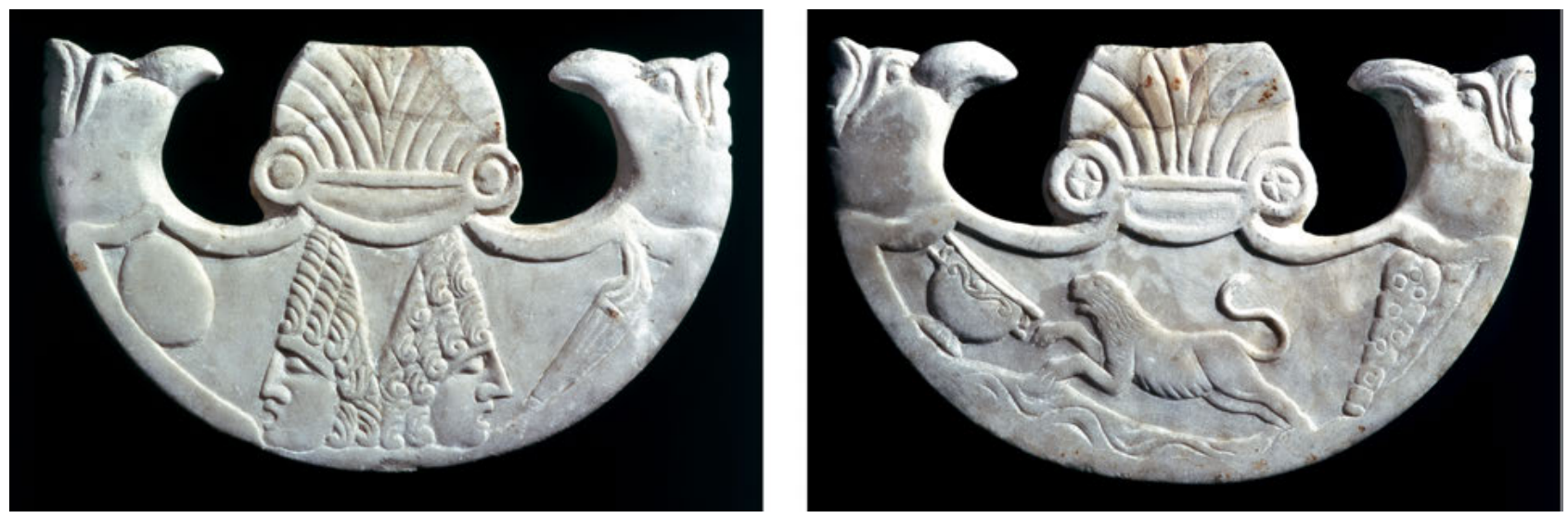

Abb. 405a-b: Peltaförmiges Oscillum aus Peristyl (17) der Casa del Citarista (I 4, 5.6.25.28), Vorder- und Rückseite (Neapel, NM 6665). verliehen. War der Brunnen nicht aktiv, dürften sich die Skulpturen auf der ruhigen Wasseroberfläche des Brunnenbeckens gespiegelt haben. Dabei sind Skulpturengröße, -platzierung und -anordnung auf einen statischen Betrachter hin konzipiert, der sich in Exedra (18) aufhält. Die zentrale Blickachse besetzt das Brunnenbecken mit seinen Skulpturen sowie der Euripus, der die Achse in die Tiefe verlängert. Gerahmt wird dieses Spiel mit Wasser und Bild durch den umgebenden Garten und die Portikusarchitektur. Die Skulpturen nehmen zwar einen zentralen Ort am Ausgangspunkt der Blickachse ein, fallen aber proportional klein aus und ordnen sich dadurch der Wahrnehmung des Gesamtensembles unter. Die Rückansicht der Brunnengruppe ist nur wenig attraktiv.

Zur ambientalen Ausstattung des Peristyls gehören weiterhin fünf runde und vier peltenförmige, vermutlich kaiserzeitliche Oscilla, aus weißem Marmor (Abb. 404-405). Sie waren sehr wahrscheinlich in den Interkolumnien aufgehängt ${ }^{443}$. Die runden Oscilla mit z.T. unterschiedlicher Relieftiefe zeigen sakralidyllisch aufgeladene, dionysische Sujets: (1) einen jungen Satyr, der eine Cista mystica öffnet, sowie einen Tibia blasenden Satyr vor einer Priapus-Herme; (2) einen Panflöte spielenden Pan vor einem brennenden Altar und einen jungen Satyr, der einen Altar mit einer Fackel entzündet (Abb. 404); (3) einen Satyr vor einem Altar und einen Pan vor einem Altar; (5) eine Mänade mit Fackel vor einem Altar und einen Satyr mit Doppelflöte vor einem Altar; (5) einen Silen vor einem Altar und einen Satyr vor einem Altar $^{444}$. Die peltenförmigen Oscilla führen neben dionysischen Sujets auch Naturelemente vor: (1) Satyrkopf mit Hirtenstab und Lotusblüte mit Efeuranken; (2) Ente und Korb mit Früchten; (3) zwei tragische Masken und Löwe mit Kantharos (Abb. 405); (4) Silens-Maske mit Thyrsos, Tympana und zwei Delfine über Wasser ${ }^{445}$. Das Gartenareal ist durch die im ,Durchblick ' aufgehängten Bildscheiben mit einer dionysischen und naturhaften Atmosphäre aufgeladen worden. Dabei dürften sich die Zierscheiben als ,Mobile` im Wind hin und her bewegt haben. Die Bilder sind dadurch dynamisiert worden, bei Drehbewegungen entzog sich dem Betrachter die eine Seite immer wieder zugunsten der anderen. Die Oscilla führen in das Peristyl ein ,leichtes', vom Wind bewegtes Bildrepertoire ein, das den Garten mit dionysischem Personal, aber auch mit Tieren bevölkert. Durch ihre Aufhängung in den Interkolumnien waren sie unmittelbar auf die Architektur bezogen und auf eine parataktische Präsentation festgelegt. Dadurch wurden sie zum Ornamentum des Ambiente.

443 Fundort Peristyl (17): Neapel, NM 6651; Neapel, NM 6642; Neapel, NM 6652; Neapel, NM 6660; Neapel, NM 6664; Neapel, NM 6665; Neapel, NM 6661; einzige Ausnahme: Neapel, NM 6646 aus Cubiculum (9) oder (10) - vermutlich nachträglich verlagert. Zu den Kontexten Hoffmann 2014, 113-117.

444 (1) Neapel, NM 6551; (2) Neapel, NM 6646; (3) Neapel, NM 6651; (4) Neapel, NM 6642; (5) Neapel, NM 6652; vgl. Hoffmann 2014, 113-115, Kat. 12-16.

445 (1) Neapel, NM 6660; (2) Neapel, NM 6664; (3) Neapel, NM 6665; (4) Neapel, NM 6661; vgl. Hoffmann 2014, 116f. Kat. 17-20. 


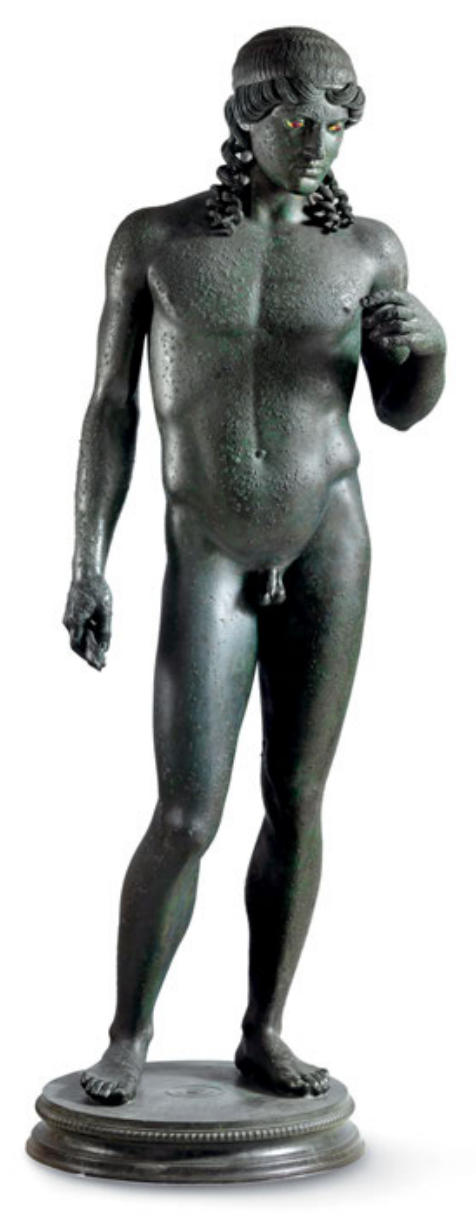

Abb. 406: Bronzestatue des Apollo Citarista aus einem der Peristyle der Casa del Citarista ( 4 , 5.6.25.28)

(Neapel, NM 5630).

Im Peristyl sind darüber hinaus mehrere kleine Terrakotta-Statuetten gefunden worden, die sich in einen sakralen Assoziationsrahmen fügen. Dies gilt für die Statuette eines Priapus wie auch für die Schulterbüste einer weiblichen Gottheit ${ }^{446}$. Ob diese Figuren auf einen Kultbereich bezogen waren, lässt sich mangels konkreterer Fundortangaben nicht mehr sagen. Priapus als Sohn des Bacchus verdichtet mit seinem übergroßen Phallus erotische Konnotationen, verweist aber auch auf Fruchtbarkeit und Wohlergehen im Allgemeinen, während die Göttin im kurzärmeligen Chiton nur allgemein Sakralität konnotiert.

Eine andere Konnotation besitzt die claudische Marmorbüste einer Frau, die auf einen Pfeiler gesetzt gewesen sein muss ${ }^{447}$. Vielleicht zeigte sie dieselbe Person wie das Frauenporträt im Atrium $^{448}$. Sie wurde im Ostflügel des Peristyls gefunden und war vermutlich am Ostende der Südportikus, in der Blickachse des Tablinums, aufgestellt ${ }^{449}$. Nicht allein das Atrium, sondern auch das Peristyl wurde als Ort der Repräsentation genutzt ${ }^{450}$.

446 Priapus: Neapel, NM 20248; Gottheit: Neapel, NM 20574.

447 Neapel, NM 6192; Hoffmann 2014, 119 Kat. 21; Bonifacio 1997, 107f. Nr. 43 zitiert für den Fundort das Giornale: „Nel muro di fronte del peristilio della succennata prima casa, uscendo dal tablino e propriamente accosto al pilastro sinistro dell'arco che quivi trovasi si è rinvenuto: marmo. Una testa muliebre con capellatura inanellata che si rannoda al di dietro. La grandezza è al natural e I capelli sono dipinti in rosso.”

448 Vermutet bei Mattusch 2014, 89.

449 So Mattusch 2014, 89.

450 Besonders zahlreich sind Hermenporträts in der Villa von Oplontis, vgl. Fejfer 2008, $96 \mathrm{f}$. 
Ein besonders prominentes Objekt, die bronzene Statue des Apollo, ist vermutlich in dem südlich anschließenden Peristyl (32) gefunden worden (Abb. 406) ${ }^{451}$. Mit ihren $158 \mathrm{~cm}$ ist sie leicht unterlebensgroß, fällt damit aber deutlich größer aus als fast alle anderen, in den Peristylen Pompejis aufgestellten Statuen ${ }^{452}$. Aufgrund ihrer materiellen Präsenz tritt sie mit dem Betrachterkörper unmittelbar in Konkurrenz. Der Gott ist gänzlich nackt, seine lockigen Haare fallen in den Nacken ${ }^{453}$. Es handelt sich um die älteste bekannte Replik einer eklektischen, klassizistischen Neuschöpfung, die im ausgehenden 1.Jh.v.Chr. entstanden sein dürfte ${ }^{454}$. Damit steht zur Diskussion, ob die Statue bereits ursprünglich im südlichen Peristyl (32) aufgestellt war oder ggf. erst nach dem Erdbeben dorthin verbracht wurde ${ }^{455}$. Belastbare Argumente für die eine oder andere Option sind nicht beizubringen. Deshalb sollen die Konsequenzen für beide Lokalisierungen kurz umrissen werden. Nähme man eine ursprüngliche Aufstellung in Peristyl (17) an, so wäre es dieses zentrale Peristyl, das in augusteischer Zeit als Luxusambiente mit einer Vielzahl von Skulpturen inszeniert worden wäre. Sehr unterschiedliche Stilformen - heitere Brunnenskulpturen, hellenistisch-dionysische Oscilla, Porträts und eine klassizistische Statue - wären miteinander in visuelle Konkurrenz getreten. Wäre die Statue ursprünglich im Südperistyl (32) aufgestellt gewesen, so hätte die Statue wohl stärker ,für sich` gewirkt und hätte dem Hof eine ,strenge‘ Atmosphäre verliehen.

Einige weitere Ausstattungsobjekte des Gartens haben sich nicht erhalten, sind damit nicht datierbar, aber für die Komplexität des Ensembles interessant: ein reliefierter Marmorkrater, zwei kleine, marmorne Bacchus-Doppelhermen, eine bronzene Bes-Figurine sowie eine große weibliche Terrakotta-Statuette ${ }^{456}$.

In der Casa del Citarista begegnet somit ein Hauskontext, dessen Peristyl schon relativ frühzeitig, ab augusteischer Zeit, mit zahlreichen Skulpturen ausgestattet wurde. Als ein prominenter Präsentationsort für dreidimensionale Bildobjekte dient das neu angelegte Brunnenbecken, an dem sich gleich mehrere bronzene Tierfiguren ,niedergelassen" haben. Thematisch weisen die Bildobjekte in verschiedene Richtungen: Sie akzentuieren die Naturhaftigkeit des Ambiente (Brunnenfiguren, Oscilla), verweisen auf Dionysisches (Oscilla, Hermen) und auf Exotisches (Bes), besitzen auch religiös-kultische Assoziationen (Terrakotten, Apollo). Mit den Porträts kamen repräsentative Bilder hinzu. Darin wird deutlich, dass die Bilder am Peristyl verschiedenste Rezeptionsangebote machten.

\section{Die Ausstattung von Peristyls (g) der Casa della Fortuna}

Stellen wir der Casa del Citarista mit Peristyl (g) der Casa della Fortuna (IX 7,20; Plan 22) einen weiteren frühen Ausstattungskomplex gegenüber, der von Angela Palmentieri in augusteische Zeit datiert wird ${ }^{457}$. Auch hier tritt uns eine große Vielfalt an Bildmedien und -themen entgegen. Zur Ausstattung gehören zwei Brunnenfiguren - ein bronzener Amor, der einen wasserspeienden Delfin schultert $(\mathrm{H} 56 \mathrm{~cm})^{458}$, sowie ein Silen, der auf einem Weinschlauch hockt, aus dem das

451 Overbeck - Mau 1884, 361 mit Lokalisierung in Peristyl (17). Mit Lokalisierung des Fundortes im Südperistyl, auf Fiorelli 1862, 586f. 361. 671-673 Bezug nehmend, Dwyer 1982, 79f.; Minervini 1853, 65 lokalisiert den Fund unspezifisch: „rinvenuta presso una colonna angolare del peristilio“; ohne Fundortangabe Minervini 1859, 129f.; kritisch zur Rekonstruktion als Kitharaspieler, s. Mattusch 2014, $91 \mathrm{f}$.

452 So bereits Monaco 1907, 78; Döhl - Zanker 1979, 205, die zugleich darauf hinweisen, dass es sich nur bei diesem Stück um die Kopie eines bekannten Kunstwerks handle. Ähnlich groß fällt der Ephebe (Neapel, NM 143753) aus der Casa dell'Efebo (I 7,11) mit 165 cm Größe aus; dazu jüngst ausführlich Melillo 2017, 48-51.

453 Neapel, NM 5630; s. Wohlmayr 1991, 33-36. 110 Nr. 13 Abb. 17a-b.

454 Hoffmann 2014, $160 f$.

455 Eine Umsetzung vermutet bei Nappo 2007, 357.

456 Zusammengestellt mit Referenzen bei Mattusch 2014, 90.

457 Palmentieri 2017, 216f.; mit flavischer Datierung Marmora Pompeiana 2008, 189. 193. 194; PPM IX (1999) 824-864 s. v. IX 7,20, Casa della Fortuna (I. Bragantini) 835 Abb. 22. 23; Giglio 2017a, 102.

458 Neapel, NM 111701; Jashemski 1993, 240f.; Pesando - Giglio 2017, 265 Abb. 171 (Foto Wilhelm von Gloeden). 
Wasser herausfloss $(\mathrm{H} 39 \mathrm{~cm})^{459}$. Für die kleine Marmorstatuette eines Amor, der sich auf einem Fels niedergelassen und auf seinem linken Bein eine Pans-Maske platziert hat $(\mathrm{H} 42 \mathrm{~cm})^{460}$, ist der Aufstellungskontext plausibel zu rekonstruieren: Die Skulptur war auf einer eigens dafür gemauerten, mit Marmor verkleideten Basis aufgestellt.

Zur Gartenausstattung gehört des Weiteren ein Set an Oscilla. Motivisch zeigen sie verschiedene Natursujets - pickende Vögel (Neapel, NM 120324), einen Schwan, Ähren pickende Hähne, Hund oder Wolf, aber auch Theatermasken und einen geflügelten Amor. Spektakulär ist das bemalte Marmoroscillum in Form einer Syrinx, das eine multisensorielle Wahrnehmung stimulierte ${ }^{461}$. Auch in der Casa della Fortuna werden für die Oscilla somit mehrheitlich dionysische Themen und Natursujets gewählt, wobei die Bilder diese Ideen in ganz unterschiedlichen Formen umsetzen konnten.

Der Besitzer der Casa della Fortuna hat sich darüber hinaus ein Set von vier Reliefpinakes geleistet, die vermutlich im Übergangsbereich zwischen Atrium und Peristyl präsentiert wurden. Zwei der Objekte zeigen mythologische Themen - den bärtigen Dädalus bei der Anfertigung der Flügel für Icarus (Neapel, NM 120325) sowie den jugendlich-bartlosen Icarus, der die zu fertigenden Flügel anreicht (Neapel, NM 120333). Thema des dritten Pinax ist ein Hirte mit drei Ziegen (Neapel, NM 120334). Auf allen drei Pinakes treten auf der Gegenseite dionysisch konnotierte Masken hinzu.

An den beiden exemplarisch besprochenen Peristylen wird deutlich, dass für ihre Ausstattung gerade nicht thematisch, stilistisch oder medial homogene Ensembles gewählt wurden. Vielmehr schaffen verschiedene Bildträger, Bildthemen, Stile, Inszenierungs- und Präsentationsformen vielschichtige Wahrnehmungsangebote ${ }^{462}$. Die Vielfalt erklärt sich, wenn man das Peristyl wie das Atrium als Raum für vielfältige Handlungen begreift, die jeweils unterschiedliche Wahrnehmungshaltungen befördern. Die verschiedenen Ausstattungselemente werden je nachdem, ob der Betrachter Teilnehmer einer Kulthandlung oder eines Gelages, eines festlichen Empfangs oder einer gelehrten Unterhaltung war, unterschiedlich wahrgenommen worden sein. Beide Beispiele belegen darüber hinaus, dass Statuen und Statuetten besonders häufig im Kontext von Brunnen aufgestellt wurden. Im Folgenden sollen daher verschiedene Brunnen- und Nymphäums-Ensembles der beginnenden Kaiserzeit zur Sprache kommen.

\subsection{Das Peristyl und die Inszenierung von Wasserluxus: Brunnen und Nymphäen}

In den Peristylen der beginnenden Kaiserzeit lag ein besonderer Fokus auf der Einrichtung von Brunnen und Nymphäen. Die Inszenierung von Wasser konnte ganz unterschiedliche Gestalt annehmen.

In einigen Peristylen entschied man sich wie in der Casa di Giasone und der Casa del Citarista für die Anlage eines zentralen Wasserbeckens ${ }^{463}$. Ein entsprechend ästhetisch inszeniertes Ensemble entstand in augusteischer Zeit in der Casa del Centenario (IX 8,3.7). Im Zuge der Neugestaltung von Vollperistyl (9) wurde im Zentrum von Garten (10) ein mit Marmor eingefasstes Wasserbecken angelegt. Nach Auskunft von Pflanzlöchern war es von einer Weinpergola umrankt. Als Wasserspeier diente eine hellenistische Bronzestatuette (1.Jh.v.Chr.) eines trunkenen Satyrn mit Weinschlauch (H $51 \mathrm{~cm}$ ); ausgespienes Wasser wird in der Vorstellung zu Wein ${ }^{464}$. Das Ensemble war zur großen Exedra (32) hin ausgerichtet und dürfte seinen besonderen Reiz im

459 Neapel, NM 120332; möglicherweise gehörte diese Brunnenfigur zum zentralen Brunnenbecken des Peristyls; vermutlich zum benachbarten Haus gehörig die Silens-Statuette Neapel, NM 114594; s. Jashemski 1993, 241 f.

460 Neapel, NM 114595.

461 Palmentieri 2017, 219 Abb. $143 \mathrm{f}$.

462 Zur Vielfalt der Assoziationsangebote in Bezug auf die Villa dei Papiri auch Zanker 2015, 20.

463 Zur Typologie solcher Pools, s. Morvillez 2018, 47-51 mit zahlreichen Beispielen.

464 Neapel, NM 111495; Jashemski 1993, 244; Coralini 2017, 286-290. 
Abb. 407: Casa del Granduca (VII 4,56), Nymphäum der Peristylrückwand.

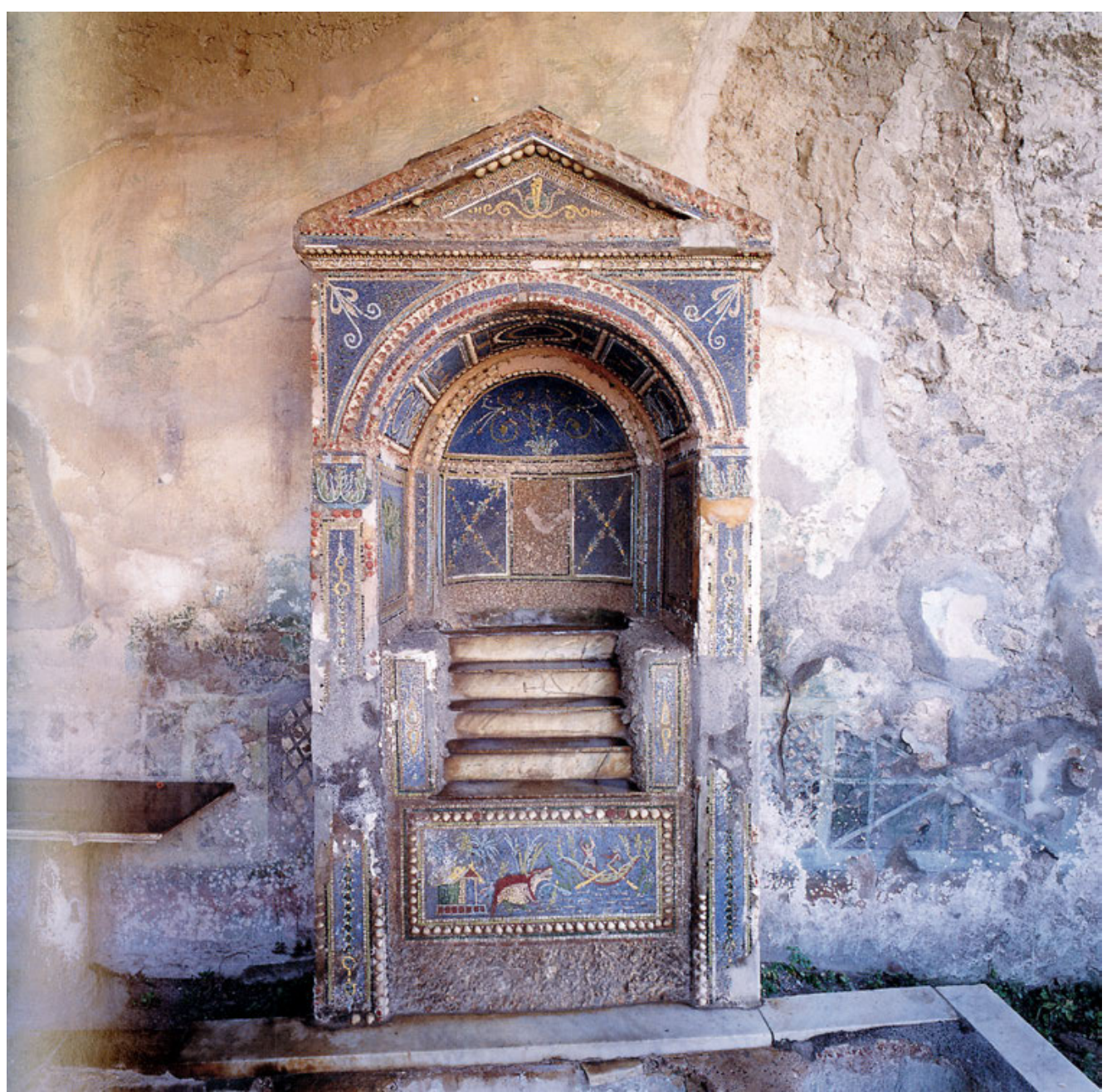

Rahmen eines Conviviums entfaltet haben. Garten, Wasser und Bildwerke werden als ästhetisches Gesamtensemble inszeniert ${ }^{465}$.

Eine ganz neue, multimediale Form der Wasserinszenierung stellen seit augusteischer Zeit mosaizierte Nymphäen dar, die meist in eine geschlossene Gartenrückwand hineingebaut wurden. Ein frühes, noch dem dritten Stil zuzurechnendes Gartennymphäum besitzt die Casa del Granduca (VII 4,56; Abb. 407) ${ }^{466}$. Es wurde nicht im Zentrum der südlichen Peristylrückwand (15) installiert, sondern leicht nach Westen versetzt, wodurch es in die Blickachse des Tablinums rückte ${ }^{467}$. Eine Ädikula mit Dreiecksgiebel fasst eine zentrale Nische mit vierstufiger Wassertreppe ein, von der aus das Wasser in ein vor das Nymphäum gesetztes, dreiteiliges, mit Marmor eingefasstes Wasserbecken floss. Im mittleren Becken ragte ursprünglich eine marmorne Lotusblüte aus dem Wasser.

Die Ädikulafront, die Nische und die Nischenwölbung sind mit Mosaiken besetzt. An den Stirnseiten ,tragen` zwei mosaizierte, in sich ornamentierte Pilaster mit Muscheleinfassung und

465 Weitere Befunde für Wasserbecken in Peristylen zusammengestellt bei Jashemski 1993, 33f., die jedoch auf eine chronologisch differenzierte Analyse verzichtet.

466 PPM VII (1997) 44-62 s. v. VII 4,56, Casa del Granduca (M. Staub-Gierow) 53-60 Abb. 21-26; Jashemski 1993, 180f.; Staub-Gierow 1994, 32-37.

467 Besonders explizit fällt die Ausrichtung eines Brunnens auf die Blickachsen in der Casa del Centenario (IX 8,3.7) aus. In dem (nacherdbebenzeitlich umgestalteten Viridarium) ist das Becken schräg vor die Rückwand gesetzt, um einen attraktiven Blick von den Fauces und insbesondere vom Tablinum her zu erzeugen; s. Baronio 2017, bes. $302 \mathrm{f}$. 


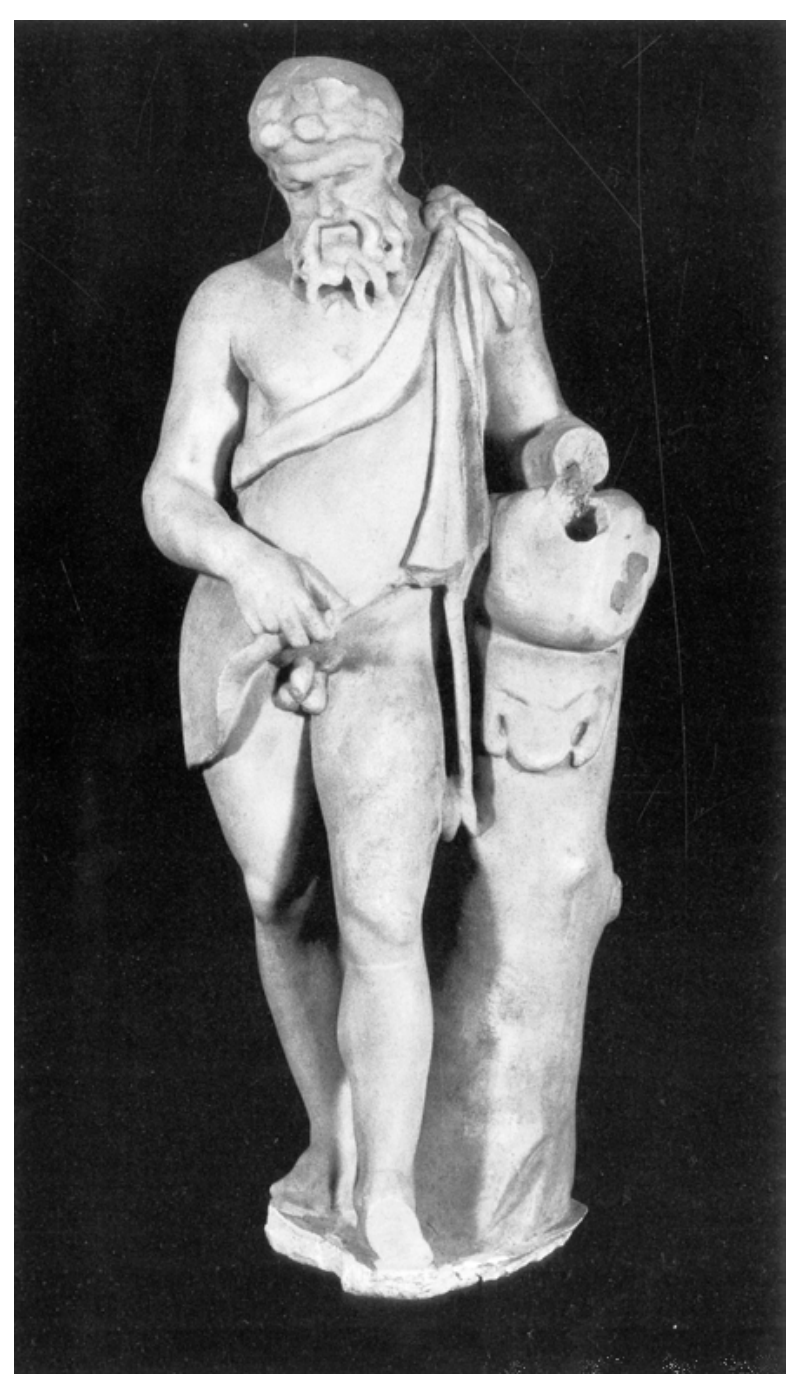

Abb. 408: Silensstatuette (Neapel, NM 6341) aus dem Nymphäum der Casa del Granduca (VII 4,56).

vegetabilem Phantasiekapitell die Nischenwölbung. Die Nischenrückwand ist in Paneele gegliedert - ein zentrales mit Kalksteinbröckchen-Muschel-Besatz und zwei seitliche mosaizierte, blaugrundige Paneele, die von sich diagonal kreuzenden Ranken gegliedert werden. Auch in der Apsiskalotte entwickelt sich ein Rankengeflecht ${ }^{468}$. Die Ädikulatonne weist eine Feldergliederung auf, die auf eine Kassettendecke verweist. Hergestellt wird auch diese durch Muschelsetzungen. In diese Felder sind zwei Pinakes eingesetzt, die Vögel in Verbindung mit Gefäßen zeigen. Auf den Seitenwangen der Nische wächst, von einem Rahmen eingefasst, jeweils ein grün-gelber Baum auf blauem Grund. Indem die Feldergliederungen durch Muschelmaterial hergestellt und die gesamte Architektur mit einem blauen Grund versehen ist, wird das ,Tektonische' geradezu ironisiert. Diese Ambiguisierung wird durch das Bildfeld in der Predellazone noch weitergeführt. Hier machen zwei Figuren von einem Boot aus Jagd auf ein Nilpferd; die Szene ist von typischen Nilpflanzen und einer kleinen Hütte umgeben. Das Nilbild wird hier durch das herabfließende Wasser gewissermaßen ,geflutet ${ }^{\star 469}$. In diesem pseudonaturhaft, zugleich hoch artifiziell gestalteten Nymphäum waren in der Nische eine Silensstatuette (H $64 \mathrm{~cm}$ ) (Abb. 408) ${ }^{470}$, auf den Flügeln der Wasser-

468 Bastet - de Vos 1979, 55 f. mit Verweis auf einen vergleichbaren Wand-Decor im Tablinum desselben Hauses. 469 So Barrett 2019, 124.

470 Neapel, NM 6341; Jashemski 1993, 180 f.; Marmora Pompeiana 2008, 122; PPM VII (1997) 44-62 s. v. VII 4,56, Casa del Granduca (M. Staub-Gierow) 53. 57 Abb. 22; 61 Abb. 27. 
Abb. 409: Casa del Toro (V 1,7), Nymphäumsperistyl.

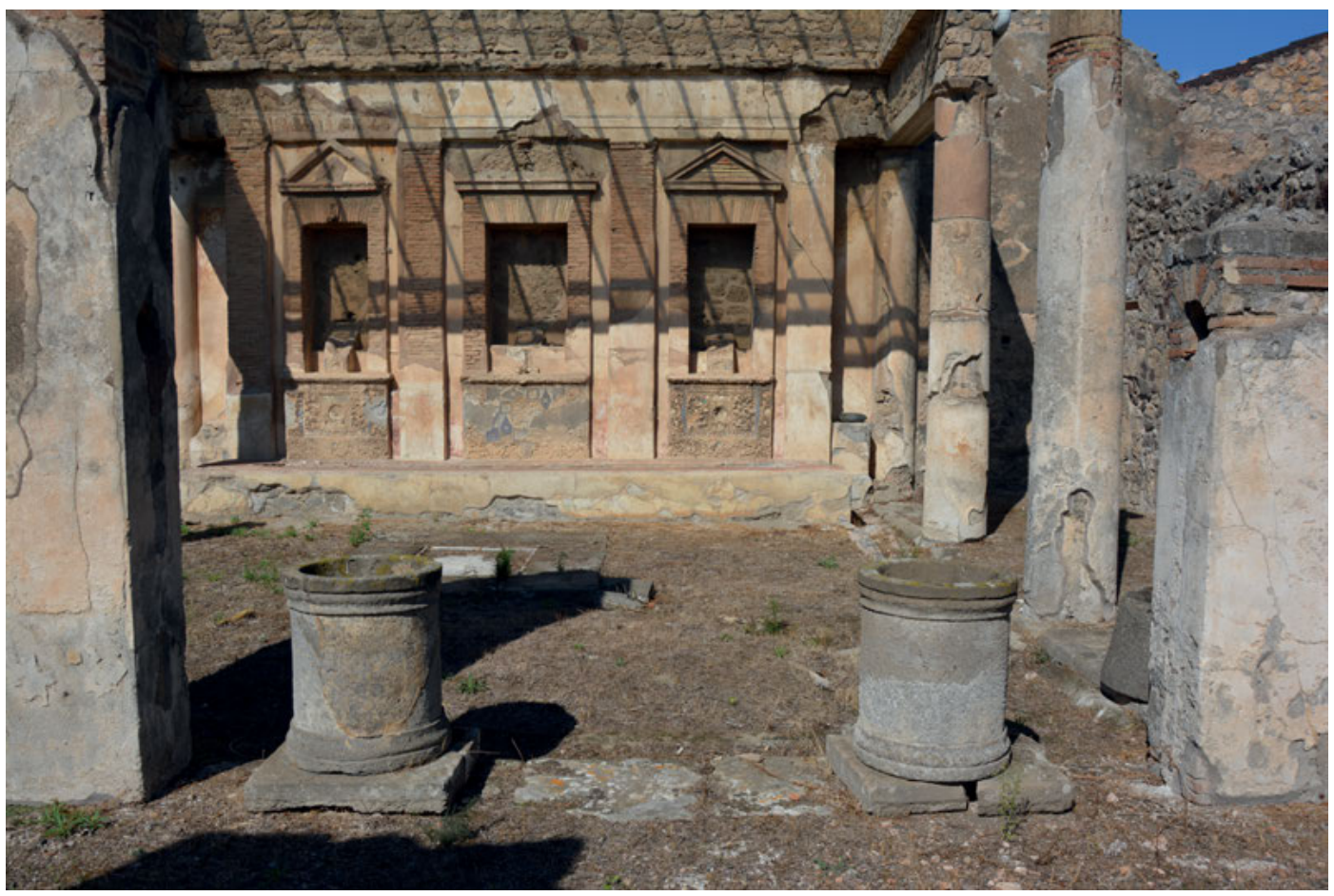

treppe ein Paar Hasen sowie ein Paar Widder aufgestellt ${ }^{471}$. Am Beckenrand ist ein zu einer Herme gehöriger Satyrkopf aufgefunden worden, an der Rückwand links neben dem Nymphäum befand sich ein Monopodium ${ }^{472}$. Durch die Kombination von ,authentischen' Wasserelementen (Muscheln, grobes Steinmaterial) und hochartifiziellem Mosaik, das durch die blaue Farbe und die Bildthemen auf die Wasserthematik verweist, suggeriert das Nymphäum einen naturhaften Raum, der zugleich kulturell ,konstruiert' ist. Es wird zu einem multisensoriellen Wirkensemble, welches das Erlebnis von fließendem Wasser durch Bilder von Wasserpflanzen und naturhaften Materialien visuell kontextualisiert. Dabei weisen die Bilderwelten in unterschiedliche Kontexte: Das Mosaik lässt an einen exotischen, fremdartigen Nilkontext denken, die Muscheln zeugen von der Nähe zum heimischen Meer, während die dreidimensionalen Bildobjekte einerseits ,fremde‘ dionysische Wesen, andererseits auch ,heimische‘ Tiere einführen. Nicht nur Natur und Kultur, sondern auch fremd und eigen werden in diesem Konzept verschränkt ${ }^{473}$.

Eine besondere Prominenz gewinnt das Wasserthema in der Casa del Toro (V 1,7; Plan 13). Hier dominierte das Nymphäum mit seinem Mosaik- und Malerei-Decor die Wahrnehmung des Peristyls, ja sogar des gesamten Hauses (Abb. 409) ${ }^{474}$. Die Anlage des Nymphäums geht wohl bereits auf augusteisch-tiberische Zeit zurück ${ }^{475}$. In jedem Fall taugt das Beispiel zum Verständnis, in welche Richtung sich der Wasserluxus im Verlauf des 1.Jhs.n.Chr. entwickeln wird: Wasser wird zum DecorElement per se. Die gesamte Rückwand des dreiseitigen Peristyls (b) nimmt ein Latericium-Nymphäum mit drei durch Pilaster gegliederte und rhythmisierte Ädikulen ein ${ }^{476}$. Die Mittelädikula mit Segmentgiebel fasste ein Wasserspiel ein, die seitlich flankierenden Ädikulen mit Ädikulagiebel

471 PPM VII (1997) 44-62 s. v. VII 4,56, Casa del Granduca (M. Staub-Gierow) 53.57 Abb. 22; 61 Abb. 27.

472 Zur Platzierung PPM VII (1997) 44-62 s. v. VII 4,56, Casa del Granduca (M. Staub-Gierow) 56 Abb. 21; 60 Abb. 26.

473 Ähnliche Überlegungen von Barrett 2019, bes. 180 f. zur Casa dell’Efebo (I 7,10-12).

474 Zum Folgenden Andersson 1990; Staub 2008; Staub 2013, 37-48. 89-92; eine Rekonstruktion bei Andersson 1990, 227 Abb. 15.

475 Die Wasserinstallationen weisen zwei Phasen auf, s. Andersson 1990, 230-232; Staub 2013, 45-48.

476 PPM III (1991) 481-532 s. v. V 1,7, Casa del Toro (V. Sampaolo) 513-515 Abb. 68-71; 517-525 Abb. 77-86. 
Wassertreppen, die das Wasser in ein quer vor die Rückwand gesetztes Brunnenbecken führten ${ }^{477}$. Darin waren weitere Leitungen für Fontänen angebracht, es mag zugleich als Fischbecken gedient haben. Die Nymphäumsarchitektur war verstuckt, auf die Pilaster waren Pflanzen und Nymphen gemalt. Besonders aufwendig gestaltet waren die drei Ädikulen und deren Podien. An den Podien folgt auf eine aus Sarnokalk gestaltete Sockelzone, die einen Grotteneindruck erzeugt, ein DecorBereich mit geometrischen Mustern, die aus unregelmäßigen Mosaiksteinchen, vulkanischem Glas und Muscheln hergestellt waren. Damit aber nicht genug. Auch in die Peristyl-Pfeiler wurden Wasserzuleitungen integriert, die Wasser in die Puteale spritzten, die im Interkolumnium aufgestellt waren $^{478}$. Dementsprechend wurde die Blickachse vom Tablinum in das Peristyl durch ein solches Wasserspiel eingefasst. Auch der Blick von Oecus (g) in Richtung Hof wurde durch ein Wasserspiel gerahmt ${ }^{479}$. Schließlich besaß der innere Peristylhof ein Marmorbecken $(120 \times 86 \mathrm{~cm})$ mit einer weiteren Fontäne ${ }^{480}$, das einen zusätzlichen Blickfang dargestellt haben muss.

In den Peristylen standen mit Beginn der Kaiserzeit verschiedene, nicht selten nebeneinander genutzte Optionen zur ästhetischen Inszenierung von Wasser zur Verfügung. Sie reichten von Brunnenbecken mit ansprechenden Brunnenfiguren, wie wir es in der Casa del Citarista kennengelernt hatten, bis zu aufwendigen Prunk-Nymphäen, an denen sich vielfältige Materialitäten und Medien zu multimedialen, multisensorisch erlebbaren Settings verbinden.

\subsection{Das Peristyl und die Vielfalt von Ausstattungsformen}

Mit den Ausstattungssets der Casa del Citarista und der Casa della Fortuna sowie den exemplarisch besprochenen Prunk-Nymphäen der Casa del Granduca und der Casa del Toro sind entscheidende Neuerungen greifbar geworden: die Aufwertung der Gartenareale durch Wasserspiele einerseits, durch vielfältige neuartige Bildobjekte andererseits. Die Vielfalt der Bildthemen, Stilformen und Medien soll im Folgenden noch einmal unter Berücksichtigung weiterer Kontexte konturiert wer$\operatorname{den}^{481}$.

\section{Skulpturen und Plastiken}

Skulpturen und Plastiken, die nicht als Wasserspeier oder Brunnenschmuck fungierten ${ }^{482}$, konnten auf eigenen Sockeln in den Interkolumnien, im Gartenbereich, aber auch in Nischen aufgestellt $\operatorname{sein}^{483}$. Bisweilen binden sie in kultische Arrangements ein. Wie im Atrium zeichnen sie sich durch ein kleines Format aus und werden so zum Ornamentum des Gartenambiente. Die konkreten Bedeutungszuweisungen können je nach Präsentationsform variieren, sodass im Folgenden für besonders beliebte Themen auch mögliche Aufstellungskontexte zur Sprache kommen ${ }^{484}$.

477 Andersson 1990, 222; Staub 2008.

478 Andersson 1990, 232.

479 PPM III (1991) 481-532 s. v. V 1,7, Casa del Toro (V. Sampaolo) 513-515 Abb. 68-70.

480 Andersson 1990, 227 vermutete, dass um diesen zentralen Brunnen drei Klinen aufgestellt waren, das Areal folglich als Sommertriclinium genutzt wurde; kritisch Staub 2013, 37-48. 90.

481 Ein statistisch abgesicherter Überblick über die Bildthemen und -medien in Gartenbereichen bei Farrar 1998, 106129, allerdings ohne chronologische Differenzierung.

482 Nach Simelius 2018, 94 f. wurden von 21 Brunnenfiguren nur 12 als Wasserspeier genutzt.

$483 \mathrm{Zu}$ Nischenarchitekturen, die Peristylrückwände gliedern, Hornbostel-Hüttner 1979, 135f. Sie nennt als Beispiel die Casa di Sextus Pompeius Axiochus (VI 13,19), die Domus VI 13,5, die Casa del Menandro (I 10,4) und die Villa di Giulia Felice (II 4,3; Plan 6). In allen Fällen weist sie z. T. fälschlich die Nischenarchitektur in vespasianische Zeit; Bartman 1992, 40.

484 Die Zusammenstellung bleibt selektiv; mit statistischem Zugriff (allerdings nicht allein für Pompeji) Farrar 1998. 
Abb. 410: Archaistische Diana-Statuette (Neapel, NM 6008), aus Peristyl (18) der Domus di M. Spurius Saturninus e di D. Volcius Modestus (VII 6,3).

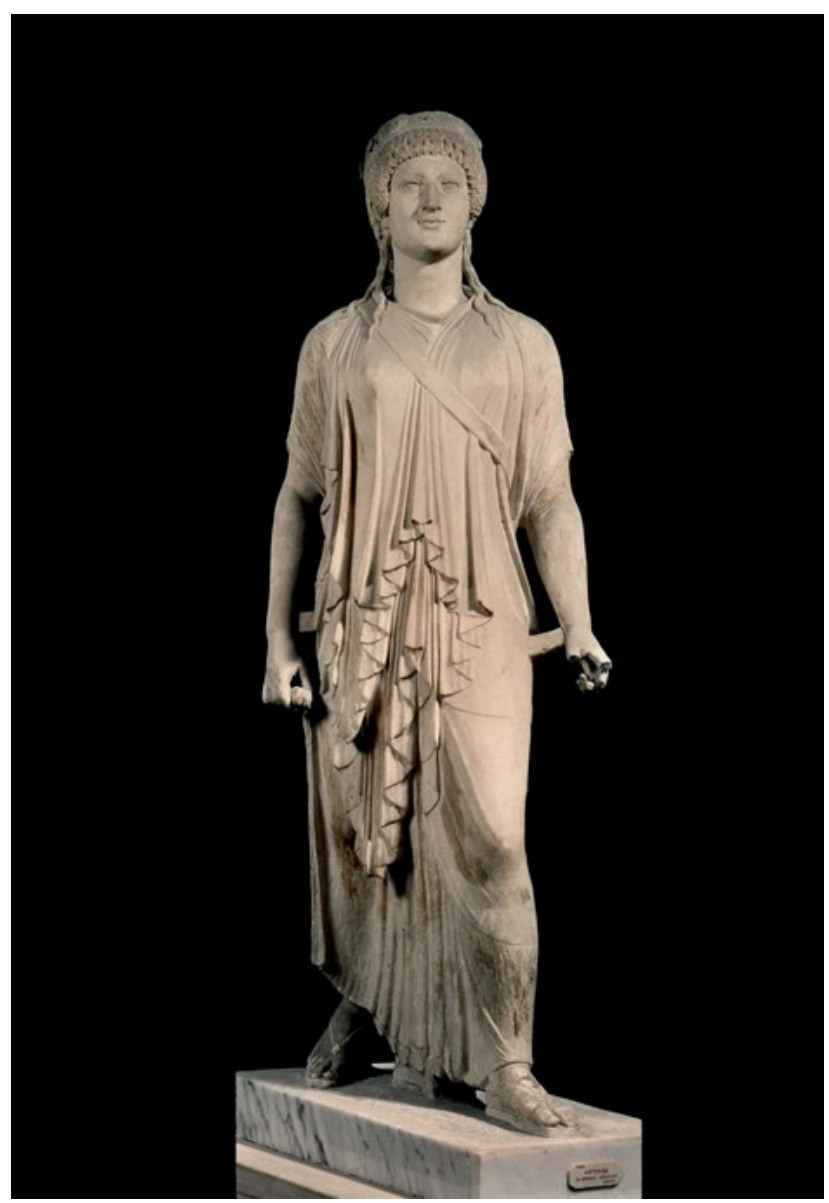

In den Peristylen augusteischer Zeit schätzte man Apollo- und Dianastatuen, die auf archaistische oder klassizistische Formen zurückgreifen. Dies gilt für eine kleine, archaistische Diana-Statuette $(\mathrm{H} 16 \mathrm{~cm})$ mit einem langen, am Körper herabfließenden Gewand, die im Peristyl (18) der Domus di M. Spurius Saturninus e di D. Volcius Modestus (VII 6,3) aufgestellt war - wohl in der Ädikula eines kleinen ,Gartenheiligtums ‘ (Abb. 410) ${ }^{485}$. Der Kontext und die Stilform ${ }^{486}$ dürften die religiöse Aura des Gartens befördert haben und umgekehrt wurde der private Garten als sakralidyllischer ,Hintergrund' für die Statuette wahrnehmbar. Gleich mehrere Apollo- und auch Dianastatuen aus den Gärten Pompejis belegen die Beliebtheit des Themas insbesondere in augusteischer Zeit ${ }^{487}$. Dass man das Sujet mit der Religionspolitik des Augustus in Verbindung brachte ${ }^{488}$, ist zwar möglich, in den privaten Gärten aber nicht unbedingt wahrscheinlich. Diana und Apollo fügen sich in ihrer Rolle als Jäger auch thematisch in den Gartenkontext.

485 Neapel, NM 6008; Döhl - Zanker 1979, 205; Jashemski 1979, 133; Wohlmayr 1991, 114 Nr. 39; Marmora Pompeiana 2008, 127 f.; zum Kontext, s. PPM VII (1997) 173-175 s. v. VII 6,3, Casa di M. Spurius Saturninus e di D. Volcius Modestus (V.Sampaolo).

486 Hölscher 1987.

487 Weiterhin eine archaistische Marmorstatuette des Apollo im Kouros-Schema (Neapel, NM 146103; H $105 \mathrm{~cm}$ ) aus dem Nordumgang des Peristyls (55) der Casa del Menandro (I 10,4), s. Marmora Pompeiana 2008, 50-52; PPM II (1990) 240-397 s. v. I 10,4, Casa del Menandro (R. J. Ling - F. P. Badoni) 262-263 Abb. 33-34; in Bronze gefertigter sog. Kanachos-Apoll (Neapel, ohne Inv.) aus Domus I 6,8, s. Wohlmayr 1991, 110 Nr. 11 Abb. 42, weiterhin der schon erwähnte klassizistische Bronze-Apollo aus dem Peristyl der Casa del Citarista.

488 Wohlmayr 1991, 35. Für die Casa del Citarista sieht er sogar in der Wandmalerei ein apollinisches Programm am Werk. 


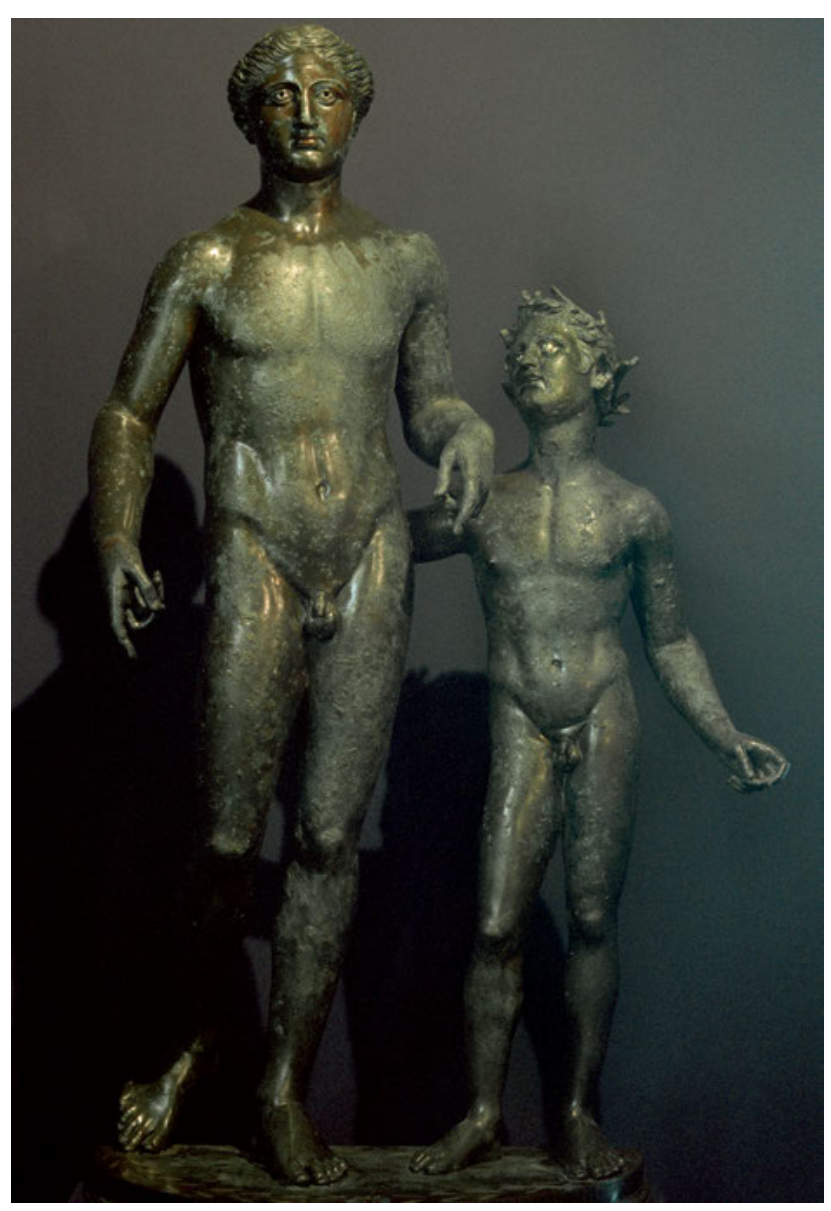

Abb. 411: Bronzegruppe, die Bacchus und einen Satyrknaben darstellt (Neapel, NM 4995), aus dem Peristyl der Casa di Pansa (VI 6,1).

Damit kontrastieren dionysische Themen, für die mehrheitlich hellenistische Stilformen gewählt wurden ${ }^{489}$. Sie lassen sich mit dem Faun der Casa del Fauno bis in das 2.Jh.v. Chr. zurückverfolgen und avancieren in der Folge neben aphrodisischen Sujets zum beliebtesten Thema im Garten ${ }^{490}$. Aus dem mittleren 1.Jh.n.Chr. stammt die vermutlich im Peristyl (9) der Casa di Pansa (VI 6,1) aufgestellte Bronzegruppe, die Bacchus und einen Satyrknaben darstellt $(\mathrm{H} 83 \mathrm{~cm})$ (Abb. 411). Der halbrunde Sockel lässt an eine Aufstellung vor der Wand oder in einer Nische denken ${ }^{491}$. Solche sinnlich präsentierten Figuren des dionysischen Gefolges - der Gott selbst ist nur ausnahmsweise dargestellt - bleiben im gesamten 1.Jh.n. Chr. beliebt. Entsprechende Darstellungen reichern den Garten mit der Vorstellung von Fest, Convivium und Gelage, Erotik, aber auch Bildung und Hedonismus $\mathrm{an}^{492}$, jeweils abhängig von der jeweiligen Ikonographie und Stilform.

Mit dem 1.Jh.n.Chr. werden Skulpturen, die auf Venus und ihr Gefolge Bezug nehmen, äußerst beliebt ${ }^{493}$. Die Statuetten konnten in verschiedenartige Inszenierungszusammenhänge eingebunden werden. In der Casa del Camillo (VII 12,22-23-24) war die Rückwand von Peristyl (q)

489 Zanker 1998, 103-105.

490 Jashemski 1979, 123f.; Simelius 2018, 50 f.

491 Neapel, NM 4995; Wohlmayr 1991, 42f. 112 Nr. 22. Abb. 27; Jashemski 1993, 127. Etwas früher oder gleichzeitig ist die hellenistische Satyr-Statuette aus der Casa del Poeta Tragico (VI 8,3.5). Solche sinnlich präsentierten Figuren des dionysischen Gefolges bleiben auch im gesamten 1. Jh.n. Chr. beliebt, s. Wohlmayr 1991, 65.

492 Neudecker 1988, 47-51.

493 Zur Beliebtheit von Venus und Bacchus als Thema für Gartenausstattungen, s. Farrar 1998, 198f.; von Stackelberg 2009, 27. In mehreren Fällen wird man die Skulpturen erst in der Zeit des vierten Stils erworben und aufgestellt haben. Die Vorliebe wird jedoch kaum mit dem Wechsel der Wandmalereistile zusammenfallen. 
Abb. 412: Casa del Camillo (VII 12,2223-24), Rückwand von Peristyl (q).

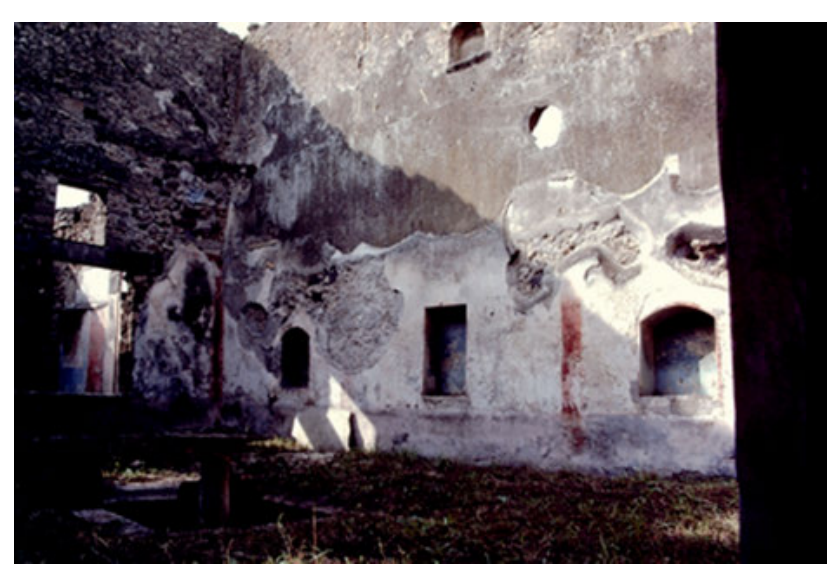

Abb. 413: Venus Anadyomene aus einer der seitlichen $\mathrm{Ni}$ schen der Rückwand von Peristyl (q) der Casa del Camillo (Neapel, NM 6292).

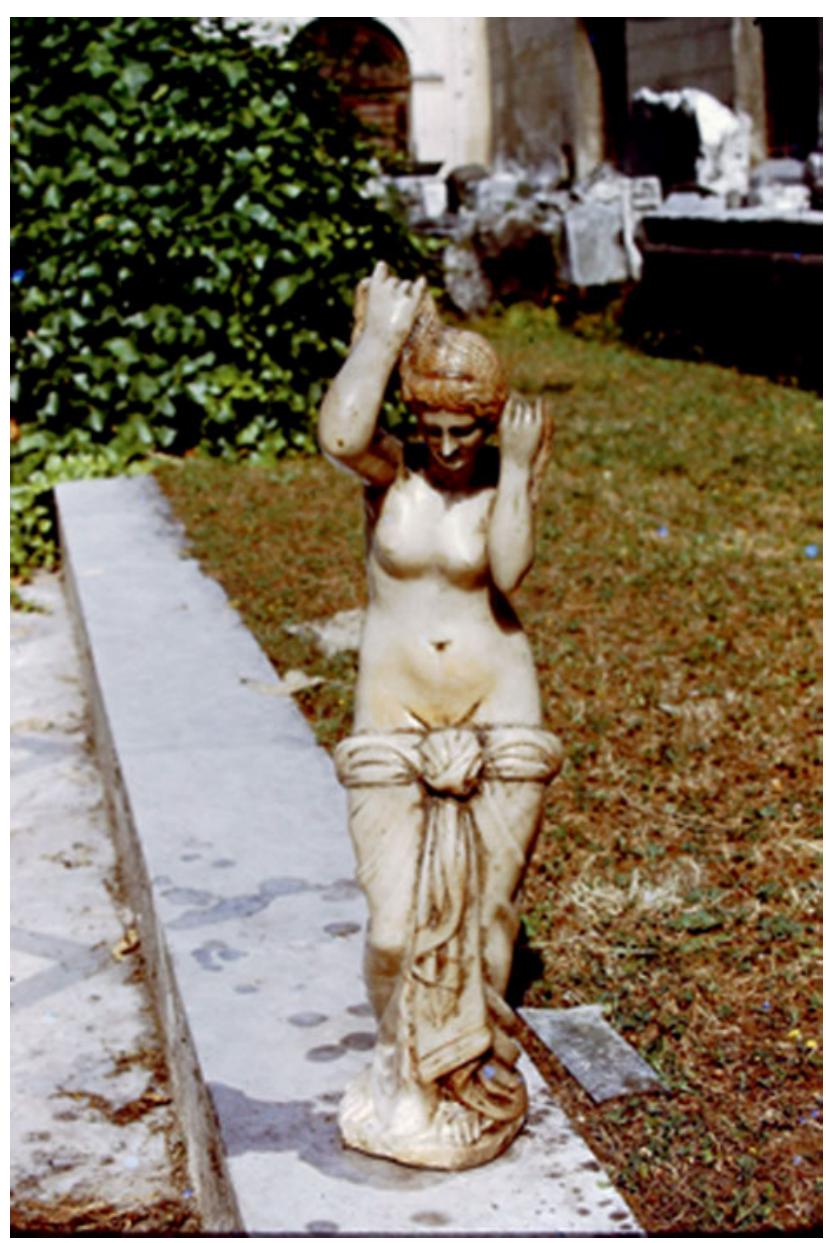

durch verschiedene blau gefasste Nischen strukturiert - eine zentrale Rechtecknische und seitliche Rundbogennischen (Abb. 412) ${ }^{494}$. In der westlichen Rundbogennische war eine Venus Anadyomene (H $63 \mathrm{~cm}$ ) aus lunensischem Marmor aufgestellt (Abb. 413), in der zentralen Nische eine nackte männliche Jünglingsstatue (H $75 \mathrm{~cm}$ ), in der östlichen Rundbogennische eine Kinderstatue mit

494 Die Skulpturenausstattung des Hauses ist diskutiert bei Dwyer 1982, 57-67. 
Hase $(\mathrm{H} 40 \mathrm{~cm})^{495}$. Die Statuen waren in einen optischen Rhythmus eingebunden und hoben sich vor dem blauen Hintergrund der Nischen besonders ab. Sie schlossen sich nicht zu einem übergreifenden Thema zusammen, eröffneten aber - ganz ähnlich wie die Wandmalereien - ein Spiel mit assoziativen Bezügen. Das Statuen-Ensemble wurde durch weitere Ausstattungsobjekte ergänzt. Neben der zentralen Nische war auf einer Seite ein Tisch mit Stütze in Form einer Attis-Figur aufgestellt ${ }^{496}$, auf der anderen Seite eine dionysische Herme, die vielleicht ebenfalls zu einem Monopodium gehörte 497 . Im Zentrum des Gartens befand sich ein Brunnen mit einer Brunnenfigur in Schlangengestalt ${ }^{498}$. Die Venus-Statuette wurde folglich neben anderen Figuren, bei denen es sich gerade nicht um Götterbilder handelt, als Bild-Element an der theatral inszenierten Rückwand des Hofes gezeigt.

Die Domus I 11,12 steht für ein kleines Haus mit Skulpturenausstattung. Sie besaß einen Weingarten (j), in dessen Südwand eine Venus-Statuette $(\mathrm{H} 50 \mathrm{~cm})$ in einer Ädikula-Nische aufgestellt war. Zu beiden Seiten waren jeweils Vertiefungen in die Wand eingelassen, in denen kleine Hermen präsentiert wurden ${ }^{499}$.

In der Casa di P. F. L. (IX 6,3) waren, wie schon gesehen, die Skulpturenausstattung von Atrium und Peristyl aufeinander bezogen. Mit einer Venus im Atrium korrespondierte an der Gartenrückwand, auf einem Podium aufgestellt, ein stehender, kindlicher Marmor-Amor mit gesenktem Kopf $(\mathrm{H} 49 \mathrm{~cm})^{500}$.

An den drei Kontexten wird die Vielfalt möglicher Statueninszenierungen deutlich. In allen drei Fällen handelt es sich um nicht-sakrale Settings, die sich aber durch entsprechende Handlungen sakralisieren ließen. Varianz entstand nicht nur durch die Inszenierung, sondern auch durch die verschiedenen Stilformen und Bildtypen, die für die Realisierung der Statuen gewählt wurden. Während die Venus Anadyomene und die Venus Lovatelli auf einen Typus des 4.Jhs. zurückgehen, rekurrieren Amor- bzw. Knabenstatuetten auf hellenistische Vorlagen.

Zur Gartenausstattung konnten naturhafte und exotische Sujets gehören, die sich ohne Sockel unter die Pflanzen ,mischten', sodass man sich gut vorstellen mag, dass sie für den Betrachter einen Überraschungseffekt boten. Der Garten der Domus VIII 5,39 war zum Betreten gedacht, auf seiner Nordseite befand sich ein (spätes) Sommertriclinium mit Tisch und Wasserspiel. Zur Gartenausstattung gehörten ein Frosch (H $14 \mathrm{~cm}$ ) (Abb. 414) sowie eine Schildkröte (H $9 \mathrm{~cm}$; B $12 \mathrm{~cm}$ ), beide auf einer knappen Basis hockend ${ }^{501}$. Beide besitzen eine Ausgussöffnung, sodass sie inmitten des Gartens als Wasserspeier fungiert haben werden. Sie führen in die bepflanzten Gärten ein reizvolles Spiel von Natur und Kultur ein, real und medial gespiegelt. Andere Statuetten tragen zur Exotisierung des Gartenerlebnisses bei. Dies gilt für zwei Bes-Figurinen aus Fayence und Pseudo-Fayence ${ }^{502}$, eine pygmäenähnliche Fayence-Figurine mit erigiertem Phal$\operatorname{lus}^{503}$ sowie drei Zwergen-Figurinen aus Pseudo-Fayence. Diese Objekte erinnern in ihrer Materialität wie auch thematisch an das ferne Ägypten ${ }^{504}$. Schließlich gehören zur Gartenausstattung fünf

495 Venus: Neapel, NM 6292; Jüngling: Neapel, NM ohne Inv.; Kind mit Hase: Neapel, NM 6533; Dwyer 1982, 61-64; Wohlmayr 1991, 113 Nr. 29.3; Jashemsky 1993, 194; Marmora Pompeiana 2008, 134 f.

496 Neapel, NM 120404; Dwyer 1982, 64f.; Cohon 1984, Kat. A 29.

497 Neapel, NM 120443; Dwyer 1982, 65.

498 Neapel, NM 69789; Kapossy 1969, 53; Dwyer 1982, 65; weiterhin nicht präzise lokalisierbare und datierbare Skulpturen, vgl. Dwyer 1982, $65 \mathrm{f}$.

499 Venus: Pompeji, Inv. 12164; Hermen: Pompeji, Inv. 12165 -12167; Jashemski 1979, 52.

500 Neapel, NM 111388; Jashemski 1993, 238; Marmora Pompeiana 2008, 174; zum Kontext: PPM IX (1999) $736-746$ s. v. IX 6,3, Casa di P. F. L. (V. Sampaolo).

501 Frosch: Neapel, NM 120042; Schildkröte: Neapel, NM 120043; Marmora Pompeiana 2008, 150 f.

502 Neapel, NM 116665; Neapel, NM 117178.

503 Neapel, NM 116666; Barrett 2019, $258 \mathrm{f}$.

$504 \mathrm{Zu}$ den Ägyptiaca des Hauses Barrett 2019, 252-258. 263-277. 
Abb. 414: Frosch aus dem Garten der Domus VIII 5,39 (Neapel, Inv. 120042).

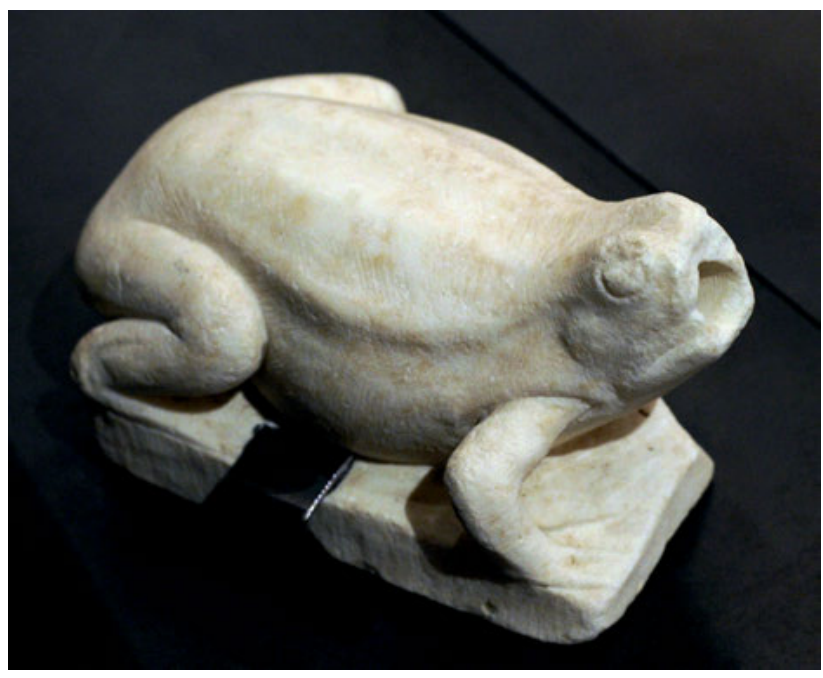

dionysische Hermen, die teilweise ebenfalls ,ägyptisierende‘ Züge tragen ${ }^{505}$. Die Objekte gehören in das 1.Jh.n.Chr., vielleicht bereits in die letzten Jahre der Stadt. Sie vermögen aber anzuzeigen, in welche Richtung sich die Gartenausstattungen entwickelten: Skulpturen konnten nicht nur in Sichtachsen platziert werden, sondern auch überraschend im Grün auftauchen. Bild und Natur verbinden sich auf diese Weise aufs Unmittelbarste, bestimmen sich gegenseitig. Die Bildobjekte werden naturhaft inszeniert, und umgekehrt reichern sie die Atmosphäre des Gartens an - in diesem Fall mit exotischen Konnotationen.

Eine andersartige Gegenwelt wird über ein wohl frei zusammengestelltes Skulpturen-Ensemble entworfen, das nachträglich an dem (späten) Nymphäum der Casa della Fontana piccola (VI 8,23.24) aufgestellt wurde ${ }^{506}$. Zu diesem gehörten mit dem sitzenden Fischer (H 53,5 cm) und einem Eros mit Gans $(\mathrm{H} 55,5 \mathrm{~cm})^{507}$ zwei Bronzefiguren des beginnenden 1.Jhs. n. Chr., weiterhin ein schlafender Fischerknabe aus Marmor (L $31 \mathrm{~cm}$ ), wohl des 1.Jhs.n.Chr., sowie eine vorkaiserzeitliche archaistische Marmorkore $(\mathrm{H} 32,3 \mathrm{~cm})^{508}$. Besonders sinnliche Bildobjekte kontrastierten mit Genrebildern, aber auch mit stilistisch ganz anders konzipierten Skulpturen.

Von den besonders beliebten Bildthemen ausgehend ist deutlich geworden, dass man in den Gärten heterogene Sujets und Stile schätzte. Ob der visuelle Kontrast gezielt gesucht wurde oder ob sich die Heterogenität durch die Erwerbungssituation ergab, ist oft nicht verlässlich zu entscheiden. Immer dann, wenn Skulptur in Bezug auf einen kleinräumigen Kontext als thematisch kohärentes oder sogar funktionales Ensemble präsentiert wird - etwa im Fall der Brunnenfiguren der Casa del Citarista - darf man von einer intentionalen Zusammenstellung ausgehen.

\section{Oscilla und Silens-Masken}

Zur Ausstattung der Gärten gehörten Reliefs, die in den Interkolumnien oder auch vor der Wand präsentiert wurden und je nachdem eine einseitige oder beidseitige Betrachtung implizierten. In jedem Fall war ihre Wahrnehmung auf einen konkreten Ort im Peristyl bezogen.

In den Interkolumnien aufgehängte, bewegliche und beidseitig gestaltete Oscilla haben wir bereits in der Casa del Citarista (I 4,5.6.25.28; Plan 5) und der Casa della Fortuna (IX 7,20; Plan 22) angetroffen. Weitere, vermutlich spätere Ensembles stammen aus der Casa di L. Caecilius Iucundus

505 Neapel, NM 120036-120040; Barrett 2019, 270 f.

506 Zur Heterogenität der zweitverwendeten Skulpturen, s. Fröhlich 1996, 98-102.

507 Fischer: Neapel, NM 4994; Eros mit Gans: Neapel, NM 5000; Fröhlich 1996, 98-100.

508 Fischerknabe: Neapel, NM 6509; Stützfigur: Neapel, NM o. Inv.; Fröhlich 1996, 100 f. 
(V 1,23.26; Plan 14) $)^{509}$ und der Casa della Parete nera (VII 4,59) . $^{510}$. Ihr Reiz lag in ihrer semimobilen Präsentation, welche die Bilder zu animieren schien. Häufig zeigten sie dionysische Sujets und verdichteten somit die Präsenz des Bacchus im Garten ${ }^{511}$.

Mit ihnen verwandt sind marmorne Silens-Masken, die man sich vor der Wand aufgehängt oder frei herabhängend vorstellen darf. So stammt aus dem Peristyl der Fullonica di Vesonius Primus (VI 14,21.22) neben verschiedenen anderen Skulpturen auch eine Satyr-Maske ${ }^{512}$, wie sie im Garten der Casa di M. Pupius Rufus (VI 15,5) ${ }^{513}$ gefunden wurde. Auch solche Masken gehören im Verlauf des 1.Jhs.n.Chr. zur Ausstattung von Peristylen und dürften ähnlich wie die Oscilla die dionysische Aufladung des Gartens verdichtet haben.

\section{Dionysische Hermen}

Dionysische Hermen finden sich nicht nur am Atrium, sondern häufig auch in Peristylen. Dies gilt für die iulisch-claudische Hermenbüste eines Knaben mit Efeukranz, die auf einem Podium des Garten (f) der Casa di P. F. L. (IX 6,3) aufgefunden wurde ${ }^{514}$. Zwei Bacchus-Hermen im Typus des Hermes Propylaios des Alkamenes waren wohl im Peristyl (l) der Casa di L. Caecilius Iucundus (V 1,23.26; Plan 14) aufgestellt ${ }^{515}$. Aus dem rückwärtigen Hof (i) der Casa di Memmius Auctus (VI 14,27) stammen eine Bacchus-Herme, die den Gott mit langen Haaren, jung und unbärtig wiedergibt ${ }^{516}$, und eine weibliche Herme, die Korymben im Haar trägt und daher ebenfalls mit dem Gefolge des Bacchus in Verbindung gebracht wird ${ }^{517}$.

\section{Peristyle als Ort der Selbstdarstellung}

Während die bisher besprochenen Bildobjekte den Garten mit dionysischen, aphrodisischen, naturhaften wie exotischen Semantisierungen und Ästhetisierungen versahen, weisen andere Skulpturen in eine ,offiziöse' Richtung. Unbestimmte Privatporträts wie eine tiberische Porträtbüste aus dem Peristyl der Casa degli Amorini dorati (VI 16,7.38; Plan 18) ${ }^{518}$ bestätigen, dass auch der Gartenbereich als Ort für die Selbstdarstellung des Hausherrn in Anspruch genommen wurde. Porträts in Peristylen konnten aber auch Mitglieder des Kaiserhauses ${ }^{519}$ oder Dichter und Denker

509 Dexter 1979, 173f.; PPM III (1991) 574-620 s. v. V 1,26, Casa di L. Caecilius Iucundus e casa annessa V 1,23 (A. de Vos) $576 f$.

510 Tondi: Neapel, NM 6641; 6643; 6647; 6552; Pelta: Neapel, NM 6662; Staub Gierow 2000, 51-53; Marmora Pompeiana 2008, 122-126.

511 Ausführlich Corswandt 1982 (mit optimistisch präzisen, eher frühen Datierungen); Bacchetta 2006 (mit einer späten Datierung, zumeist in flavische Zeit). Tatsächlich sind für Datierungen die gattungsspezifischen Eigenheiten des (meist einfachen) Reliefstils in Rechnung zu stellen. Aus den genannten Gründen wird daher auf eine eingehende Diskussion der Exemplare verzichtet, da der Großteil von ihnen wohl in das spätere 1.Jh.n. Chr. gehört.

512 Neapel, NM 110659; Jashemski 1993, 150; Marmora Pompeiana 2008, 91.

513 Neapel, NM 124906; Neapel, NM 124917; Kapossy 1969, 59; Jashemski 1993, 156; Marmora Pompeiana 2008, 101.

514 Neapel, NM 120532; Marmora Pompeiana 2008, 174f.; bei Jashemski 1993 als Neapel, NM 120532.

515 Neapel, NM 120487 im Peristyl gefunden; Neapel, NM 120427 aus dem Triclinium des benachbarten Hauses; zu den Objekten und ihrer Lokalisierung, s. Marmora Pompeiana 2008, 71f.; Jashemski 1993, 109.

516 Neapel, NM 110874; Marmora Pompeiana 2008, $94 \mathrm{f}$.

517 Neapel, NM 110875; Marmora Pompeiana 2008, 95.

518 Neapel, NM 3015; PPM V (1994) 714-846 s. v. VI 16,7.38, Casa degli Amorini dorati (F. Seiler) 716; Bonifacio 1997, Nr. 39; Seiler 1992, 126 Kat. Nr. 29. Abb. 590-593.

519 So stammt aus der Casa di Diomede (I 2,17) eine männliche Porträtbüste, die kurioser Weise in einen Keramikbecher eingesetzt war und als Agrippa angesprochen wurde; s. Bonifacio 1997, 89f. Nr. 34; Jashemski 1993, 24; Marmora Pompeiana 2008, 27. Im Fall einer nackten, bronzenen Sitzstatuette mit Herrscherbinde (H $71 \mathrm{~cm})$ aus Domus VII 12,22 handelt es sich um Demetrios II. Nikator (Neapel, NM 4892), s. Wohlmayr 1991, 45f. 111 Nr. 19. Abb. 30. Sie vermag zu 
repräsentieren. So stammen aus dem rückwärtigen Hof (i) der Casa di Memmius Auctus (VI 14,27) vier kleine, kaiserzeitliche Philosophenbüsten, darunter ein Porträt Epikurs ${ }^{520}$, sowie das Porträt des sog. Pseudo-Seneca ${ }^{521}$, die möglicherweise für Hermen vorgesehen waren ${ }^{522}$. Im Garten der Domus IX 7,12 oder $14.15^{523}$ tritt zu einer dionysischen Doppelherme ${ }^{524}$ und einer Hercules-Herme $\mathrm{e}^{525}$ auch eine Miniatur-Herme des Metrodor $(\mathrm{H} 14 \mathrm{~cm})^{526}$ hinzu.

Während im Falle der Porträts des Hausbesitzers und seiner Familie die Repräsentation über die Darstellung der Bewohner selbst funktioniert, wird im Falle der Angehörigen des Kaiserhauses und der griechischen Dichter und Philosophen eine indirekte Form der Repräsentation gewählt: eine Aufwertung der eigenen politischen, sozialen und kulturellen Bedeutung über die Repräsentation von ,Stellvertretern', die für die eigene ,Haltung' in Anspruch genommen werden. Für die unterschiedlichen Repräsentanten werden dementsprechend auch sehr unterschiedliche Stilformen gewählt. Die männlichen Angehörigen des Kaiserhauses und seines Umfeldes zeigen sich im für das beginnende 1.Jh.n.Chr. charakteristischen Habitus, bartlos, mit geordneter Kurzhaarfrisur, während für die Intellektuellen auf traditionelle Typen zurückgegriffen wird, die diese üblicherweise mit langen, bisweilen zotteligen Haaren und Bart zeigen. Damit sind nicht nur verschiedene Inhalte, sondern auch verschiedene Habitus-Konzepte nebeneinander präsent.

\section{Funktionsobjekte und ihr Decor}

Zur Ausstattung von Peristylen gehörten auch pragmatisch nutzbare Objekte, die zu Decor-Trägern werden konnten. Dies gilt, wie das Beispiel der Casa di Giasone zeigte, zuvorderst für Tische. Neben schlichten Monopodia mit Säulen- oder Pfeilerstütze finden sich figürliche Exemplare mit Attis-Stützen ${ }^{527}$, Stützen in Gestalt einer sitzenden Sphinx ${ }^{528}$, Adler-Greifen-Protome und SilensProtome ${ }^{529}$, aber auch Hermen-Tische ${ }^{530}$. Dabei konnten die Tische an der Hofrückwand aufgestellt sein. In der Casa del Camillo (VII 12,22-23-24) gilt dies für das Monopodium mit Attis-Stütze, während sich das Monopodium der Casa del Granduca (VII 4,56) an der Hofrückwand neben dem Nymphäum befand ${ }^{531}$. Besonders attraktiv waren für Peristyle allansichtige Dreifußtische mit Tierprotomen (mensae delphicae) ${ }^{532}$. Dass nun Tische überhaupt in größerer Zahl aus den Peristyl-

bezeugen, dass nicht nur Personen des aktuellen Zeitgeschehens, sondern auch hellenistische Könige in den Gärten Pompejis in rundplastischen Medien präsentiert wurden. Im vorliegenden Fall wurde die Plastik jedoch ,mythologisiert', erhielt Flügelschuhe und wurde dadurch als Hermes aufgefasst PPM VII (1997) 540-564 s. v. VII 12,22-23-24, Casa del Camillo (I. Bragantini).

520 Neapel, NM 110872, Marmora Pompeiana 2008, 93.

521 Neapel, NM 110873, Marmora Pompeiana 2008, 94.

522 Jashemski 1993, 150.

523 Zum Gesamtkontext, s. Jashemski 1993, 239; PPM IX (1999) 779-781 s. v. IX 7,12 (V. Sampaolo).

524 Neapel, NM 120465.

525 Neapel, NM 120488; Marmora Pompeiana 2008, $183 \mathrm{f}$.

526 Neapel, NM 119585; Marmora Pompeiana 2008, $180 \mathrm{f}$.

527 Domus VII 12,22-23, Tisch Neapel, NM 120403 (Cohon 1984, Kat. A 29); Caserma dei Gladiatori (V 5,3), Tisch Neapel, NM 126151 (Cohon 1984, Kat. A 32).

528 Neapel, NM 6869 (Cohon 1984, Kat. A 76; Marmora Pompeiana 2008, 87).

529 Adler-Greifen-Protome: Domus VII 6,3, Tisch Neapel, Mag. (Cohon 1984, Kat. A 108); Silens-Protome mit Kind: Casa del Principe di Napoli (VI 15,7.8), Tisch Pompeji, Mag. 406-4 [1109] (Cohon 1984, Kat. A 139; Strocka 1984, 31f. Abb. 130. 131; PPM V (1994) 647-679 s. v. VI 15,7.8, Casa del Principe di Napoli (V. M. Strocka) 679 Abb. 45. 46).

530 Domus VI 13,2, Tisch mit Stütze in Gestalt einer bärtigen Satyr-Herme: Neapel, NM 120466 (Cohon 1984, Kat. A 215); Domus V 3,10, Tisch mit Stütze in Gestalt einer jugendlichen Bacchus-Herme: Neapel, NM 126175 (Cohon 1984, Kat. A 222); Domus VI 16,19.26, Tisch mit Stütze in Gestalt einer bärtigen Herme: Pompeji, Antiquarium 3604 (Cohon 1984, A 235).

531 s. o.S. 506.

532 De Carolis 2017, 254. Ein Exemplar stammt aus Domus I 6,6-8, Pseudoperistyl, Tisch mit Löwen-Protome, derzeit in der Casa dei Quadretti teatrali (I 6,11) (Cohon 1984, Kat. C 66); Casa dei Vettii (VI 15,1), Ostflügel des Peristyls, Tisch 
bereichen stammen, belegt einmal mehr, dass die Wandelgänge und Gärten als Wohnbereiche in Anspruch genommen wurden.

Weiterhin darf man für die Peristyle die Aufstellung kleinformatiger Altäre annehmen ${ }^{533}$. Bekannt ist der Fundort eines kleinformatigen, augusteischen Marmoraltärchens (H $10 \mathrm{~cm}$ ), das an der Rückwand des Peristyl-Gartens (b) der Domus I 2,16, ,nel larario', aufgestellt war ${ }^{534}$. Aufgrund seiner Größe konnten hier allein symbolische Handlungen vollzogen werden.

Aus insgesamt acht Peristylgärten sind Sonnenuhren bekannt ${ }^{535}$. Die Objekte bereicherten die Peristyle nicht nur ästhetisch, sondern verwiesen auf die Kompetenz wissenschaftlicher Zeitmessung, boten Anlässe für gelehrte Gespräche ${ }^{536}$ und lieferten wenigstens bei guten Wetter eine Zeitangabe, die den Tagesablauf zu strukturieren vermochte ${ }^{537}$.

Die Funktionsobjekte entfalteten ihre Wirkung folglich durch ihren Gebrauch - oder durch die Assoziation spezifischer Gebrauchsformen. Decor konnte solche Assoziationen verstärken, aber auch in andere Richtungen weisen.

\subsection{Bildobjekte am Atrium und Peristyl}

Mit Blick auf die verschiedenen Bildobjekte, die in Atrium und Peristyl Eingang finden, soll im Folgenden noch einmal grundsätzlich nach den Gründen für ihre Auswahl gefragt werden. Während sich die Wahl von Funktionsobjekten wie Tischen und Altären aus ihrem Gebrauch ergibt und die Brunnen-Ensembles dem Wunsch nach einer Ästhetisierung der Höfe durch Wasserelemente Rechnung trugen, stellt sich die Frage in besonderer Weise für die kleinformatigen Statuetten.

In der Forschung hat man häufig versucht, die dreidimensionalen Ausstattungsobjekte pauschal zu charakterisieren - etwa als Kunstwerke $e^{538}$, als wenig qualitätvolle Massenware ${ }^{539}$ oder als religiöse Objekte ${ }^{540}$. Nicht selten schloss man aus dem Darstellungsgegenstand auf die Rezeptionsform, sodass man Götterstatuetten als Gegenstand kultischer Praxis aufgefasst hat ${ }^{541}$. Die unterschiedlichen Objektgrößen, Materialien, Inszenierungszusammenhänge und Themen, aber auch die unterschiedliche Datierung der Stücke sprechen jedoch entschieden dagegen, die Ausstattungsstücke auf einen homogenen Rezeptionshorizont oder gar ein homogenisierendes Programm zu beziehen. Vielmehr bieten sie in den polyfunktionalen Höfen Anknüpfungspunkte für verschiedene Rezeptionshaltungen und -situationen.

mit Löwen-Protome, in situ (Cohon 1984, Kat. C 67); Domus VI 13,13, Tisch mit Panther-Protome, aufgestellt im Zentrum des Peristyls, derzeit Pompeji, Mag. [VII 3.25] (Cohon 1984, Kat. C 71).

533 Der Fundort der in größerer Zahl erhaltenen Objekte wurde meist nicht dokumentiert, vgl. D’Ambrosio - Borriello 2001, 27-36. Aus einem geschlossenen Raum (5) stammt der kleine Tonaltar der Domus I 9,9 mit Girlanden-Decor (H: 16,2 cm) (Neapel, NM 9666; D’Ambrosio - Borriello 2001, 29 Kat. B3a), aus dem 1.Jh.n. Chr.

534 Neapel, NM 119578; Marmora Pompeiana 2008, $20 \mathrm{f}$.

535 Simelius 2018, 31: Casa del Menandro (I 10,4), Casa del Triclinio (V 2,4), Caserma dei gladiatori (V 5,3), Casa degli Amorini dorati (VI 16,7.38), Peristyl Nordseite (Winter 2013, Kat. Pompeji 22), Casa dei Capitelli figurati (VII 4,57), Peristyl (t) (Winter 2013, Kat. Pompeji 10), Domus di M. Spurius Saturninus e di D. Volcius Modestus (VII 6,3), Casa del Centenario (IX 8,3.7), Casa di Obellius Firmus (IX 14,4), Garten (Winter 2013, Kat. Pompeji 12). Winter 2013 listet darüber hinaus aber zahlreiche weitere Objekte, deren Aufstellungsort sie als unbekannt angibt.

536 Winter 2013, 219f.

537 Winter 2013, 220.

538 Wohlmayr 1991.

539 Farrar 1998, 103.

540 Für die beiden letztgenannten Deutungen, s. Döhl - Zanker 1979, 177. 205.

541 Jashemski 1979, 124-126 schließt aus der großen Zahl an Venus-Statuetten auf die Rolle von Venus als Beschützerin des Gartens. Dies hatte laut Plinius nat. 19,19 bereits Plautus beschrieben, während Plinius selbst diese Funktion als kaum bekannt auffasst. Eine Diskussion von Quellen, die einen Zusammenhang von Venus und Gärten herstellen, bei Nohrnberg 1976, 510. 
Die Statuetten am Atrium und Peristyl nehmen vielfach eine ,zentrale‘ Position ein, können sogar auf bestimmte, besonders attraktive Blickpunkte hin inszeniert werden. Dennoch wird ihre Bildlichkeit zurückgenommen - zuvorderst durch ihr kleines Format. $\mathrm{Zu}$ einer Reduzierung der Aufmerksamkeit konnten aber auch die große Fülle von miteinander konkurrierenden Bildobjekten sowie eine repetitive Inszenierung beitragen.

Indem man insbesondere für die ,Idealplastik‘ auf (modifizierbare) Bildschemata zurückgriff, kommt bei der Skulptur eine der Wandmalerei vergleichbare Decor-Strategie zum Tragen. Man operiert mit Versatzstücken, die sich erst als Ensemble zu einer schillernden Aussage verdichten. Während allerdings in der Wandmalerei ,Sets‘ aufgrund des Herstellungsprozesses (die Ausmalung eines Raumes in einem Stil) plausibilisierbar sind, lassen sich intentional zusammengestellte Skulpturengruppen nur im Ausnahmefall greifen ${ }^{542}$.

Von der Option, die Idealplastik zu individualisieren - d.h. mit Porträtköpfen zu versehen hat man in Pompeji bis in claudische Zeit kaum Gebrauch gemacht. Eine Ausnahme macht die Jünglingsstatuette im Doryphoros-Schema (H $70 \mathrm{~cm}$ ) aus der Casa degli Scienziati (VI 14,43) ${ }^{543}$. Der Sonderfall bestätigt umgekehrt, dass die zahlreichen Statuetten der dionysischen und aphrodisischen Welt nicht für eine explizite ,Selbstdarstellung‘ der Hausbesitzer genutzt wurden. Vielmehr reichern die Körperbilder das Ambiente atmosphärisch an, führen Schönheit, Luxus und Lebensgenuss, aber auch Bildung in die Hofbereiche ein. Sie bieten sich damit - ähnlich wie die Wandmalereien - für ein exemplarisch-paradigmatisches Verständnis an, ohne dass man diese Leitbildfunktion durch Porträtzüge konkretisiert hätte. Solche Konkretisierungen scheinen jedoch mit neronischer Zeit häufiger zu werden. In Wandbildern wie in der Skulptur können mythische Figuren mit Zeitfrisuren ausgestattet werden - oder das Bildarrangement stellt entsprechende Bezüge her ${ }^{544}$.

Besonders auffällig ist der Umstand, dass in den Häusern Pompejis kaum griechische Originale vorkommen. Die Mehrzahl der Skulpturen wurde in hellenistischer Zeit neu gefertigt und zeichnet sich durch eine eher durchschnittliche Qualität aus. Auch besonders kostbare Objektgattungen der Zeit wie Marmorkandelaber ${ }^{545}$, prunkvolle Marmorkratere ${ }^{546}$ und figürliche Reliefs wurden kaum rezipiert. Bei allem Ausstattungsluxus zeichnet sich folglich ein Abstand zu den in Rom, Baiae oder Puteoli gepflegten Formen der Ausstattung ab. Manche Auswahlkriterien für (Kunst-)Objekte, die für die Kunstsammler in Rom bedeutsam waren, ${ }^{547}$ wie das Alter der Statuen und ihr Künstler, kamen in den Häusern Pompejis daher nicht zum Tragen.

\subsection{Architektur- und Decor-Elemente im Zusammenspiel: Raumatmosphären}

An dieser Stelle soll noch einmal die Frage nach dem Zusammenwirken verschiedener Ausstattungsformen in ihrem Wirkungskontext gestellt werden.

542 In jenen Kontexten, die sich durch eklektische Objekt-Assemblagen auszeichnen, lässt sich letztlich nicht klären, ob sich diese durch den Erwerbungsmodus (etwa Kauf oder Schenkung) ergeben haben, oder Ergebnis einer gezielten Strategie waren; vgl. knapp Farrar 1998, 104f.; s. zu Skulpturensammlungen etwa Tronchin 2011 zur Casa di Octavius Quartio (II 2,2).

543 Neapel, NM 126249; Bonifacio 1997, 83f. mit Deutung als Porträtstatue; s. o. S. 200.

544 Bergmann 2018, 157 verweist auf eine lagernde Venus mit Zeitfrisur aus der Casa della Venere in Conchiglia (II 3,3), sowie darüber hinaus auf verschiedene Räume (meist aus dem vierten Stil), die ,Porträt‘-Medaillons zu Seiten eines Mythenbildes platzieren.

545 s. Katalog bei Cain 1985.

546 Vermutlich für die Casa del Citarista vorauszusetzen, s. o. S. 502.

547 Eine Diskussion der literarischen Quellen und der daraus erschließbaren Auswahlkriterien für Skulpturen bei Bartman 1991; Beard 2009, 74 mit dem Hinweis, dass griechische Originale aus Pompeji und Herculaneum fast vollständig fehlen. 
In den Atrien und Peristylen sind Wand- und Boden-Decor zurückgenommen, auf komplexe bildliche Darstellungen wird weitgehend verzichtet. Der Decor nimmt auf einen sich bewegenden Betrachter Bezug. Dabei wird die Architektur zur ,Rahmung von dreidimensionalen Objekten, die Raum einnehmen und dem Betrachter entgegentreten. Vor dem Hintergrund relativ ,neutraler Rückwände wird eine hohe Objekt- und Bilddichte entfaltet. Die dreidimensionalen Objekte werden auf die neuen Wasserarrangements (Brunnen, Nymphäen), in den Peristylen sicher aber auch auf die Gartenbepflanzung bezogen. Dreidimensionale (Bild-)Objekte eignen sich folglich in besonderer Weise für eine ambientale Inszenierung. Besonders bemerkenswert ist daher der Umstand, dass sie vielfältige ästhetische und semantische Dimensionen aufmachen. Die Höfe werden nicht als eindimensionale Decor-Räume erfahrbar, sondern als Settings, in denen verschiedene, auch heterogene Rezeptionsangebote verfügbar sind. Für die dreidimensionalen (Bild-)Objekte in den Höfen darf daher die Frage gestellt werden, welche Betrachterhaltungen sie voraussetzen.

In den Atrien waren Brunnenskulpturen auf den Eintretenden ausgerichtet, mithin auf einen sich bewegenden Betrachter hin kalkuliert. Vom Tablinum oder von den Alae aus waren sie in Rück- bzw. Seitenansicht sichtbar. Gerade im Atrium kamen daher häufig allansichtige Skulpturen zum Einsatz. Dies gilt auch für die Tische. Allein die Hermen waren, soweit rekonstruierbar, vor einer Wand, konkreter noch: vor den Antenpilastern des Tablinums, aufgestellt. Durch den klaren Bezug der Skulpturen auf die Symmetrien des Atriums erlaubten sie eine ambiental-beiläufige Betrachtungsweise. Insbesondere die Porträthermen forderten mit ihren individualisierten Zügen den Betrachter zum Innehalten auf.

In den Peristylen waren Skulpturen-Ensembles bisweilen auf einen Prunkraum ausgerichtet, wie sich am Brunnenensemble der Casa del Citarista (I 4,5.6.25.28; Plan 5) zeigte. Sie gewannen eine spezifische Ansichtigkeit, rechneten mit einer statisch-intensiven Betrachtung. Dies gilt auch für Nymphäen an der Rückwand von Peristylen, die als Schau-Ensembles nicht selten auf einen Prunkraum ausgerichtet waren. Besonders klar wird die Orientierung von Skulpturen dann, wenn sie in einer Nische aufgestellt waren. Oscilla und frei aufgehängte, bewegliche Masken rechneten hingegen mit einem vorübergehenden Betrachter.

Während Atrien und Peristyle zu Orten der dreidimensionalen Bild- und Objekterfahrung wurden, hatten verschließbare Innenräume nicht oder nur in begrenztem Umfang am Ausstattungsboom teil, der die Höfe erfasste. Decken und Pavimente blieben mehrheitlich unfigürlich bzw. waren mit semantisch schwachen Elementen versehen, strukturierten und rhythmisierten die Räume. Stattdessen wurde die Gesamtwirkung der Innenräume maßgeblich durch die Wände geprägt. Im Wandzentrum war der Betrachter auf Augenhöhe mit mythologischen Mittelbildern konfrontiert, der Innenraum wurde zur Pinakothek. Die Mittelbilder wurden jedoch von einer Vielzahl weiterer, mehr oder weniger dichter Bilder begleitet, die der Betrachter erst durch eine intensive Betrachtung, auch ein Schweifen des Blicks, erschließen konnte. Die Bildervielfalt wurde durch ein filigranes Gliederungssystem strukturiert, das aus stilisierten Säulchen, Kandelabern und Pflanzenstängeln bestehen konnte. Es trennte die zentrale Bildzone vom Sockel, aber auch von der Oberzone, in der ,luftige ' Architekturen entfaltet wurden. Die einzelnen Flächen - geschlossenopaker Boden, die Wand mit ihrer komplexen Verschränkung von Offenheit und Geschlossenheit, und die Decke - treten so in einen auffälligen Kontrast.

\subsection{Die soziale Bedeutung von Decor}

Mit der Omnipräsenz von Bildern auf den Wänden dritten Stils ist der ,Konsum“ von Bildern ab augusteischer Zeit kein Phänomen der Eliten mehr. Bilder sind zu einem Allgemeingut geworden, sie finden sich in großen Stadthäusern ebenso wie in kleinen.

Verschiedene Bildformen sind mit unterschiedlichen ästhetischen, damit aber auch sozial aufgeladenen Wertigkeiten versehen worden. Mythenbilder stehen am oberen Ende der Ausstattungshierarchie. Gerahmte Landschafts- und Genrebilder werden als nachgeordnete Elemente 
eingesetzt, ebenso auch Vignetten. In dieser Logik sieht Wallace-Hadrill in der Entwicklung der vier Stile eine Tendenz, immer stärker sozialhierarchische Informationen in die Wandgliederung einzuschreiben $^{548}$. Tybout formuliert für den dritten Stil die These, dass Differenzierungen über Farbe, Ornamentik sowie die Einbindung bzw. den Ausschluss figürlicher Zentralpaneele hergestellt würden ${ }^{549}$. Wallace-Hadrill nennt das Tablinum (h) der Casa di Marcus Lucretius Fronto beispielsweise „evidently the climatic part of its surrounding decorative scheme”550. Raum (c) bezeichnet Moormann als "meno rappresentativa, ma sempre fine" 551.

Mit der ästhetischen Hierarchisierung, wie sie an der Wertigkeit einzelner Decor-Elemente ablesbar wird, konkurriert jedoch das Prinzip der Anpassung des Decors an bestimmte räumliche Situationen. Guidobaldi und andere formulieren dies für die Casa di Marcus Lucretius Fronto relativ indefinit: „Man hat [die Wandmalereien dritten Stils] einer einzigen Werkstatt zugeschrieben, der es gelungen ist, die Ausschmückung auf Größe und Funktion der einzelnen Räume abzustimmen. In repräsentativen Räumen wie Atrium (3) und Tablinum (7) sieht man gut, wie die Decoration, die im Atrium schnell zu erfassende, serielle und repetitive Motive präsentiert, im Tablinum sehr viel feinere Züge annimmt und diesen Raum, der sich dazu anbietet, eingehend betrachtet zu werden, in eine Art Pinakothek verwandelt [...].“552 Hier ist zwar der kontextuellen Verortung Rechnung getragen, die unterschiedliche Verwendung von Decor wird jedoch zum Argument für die unterschiedliche Wertigkeit der Räume.

Tatsächlich zeigt Decor nicht nur Raumwertigkeiten an, sondern reagiert auf spezifische visuell-ästhetische Bedürfnisse, die sich je nach architektonischem Rahmen und den damit verknüpften Handlungsoptionen unterscheiden. So nehmen die Mittelbilder des Oecus (l) der Casa di Orfeo (VI 14,20) mit ihren Landschaftsdarstellungen auf den Ausblick in den Garten Bezug. In der Sockelzone treten Landschaftsbilder und Reiher zwischen Pflanzen hinzu, die Architektur der Oberzone ist u.a. mit ägyptisierenden Statuen bereichert ${ }^{553}$. Es würde sich, gemessen an strengen Ausstattungshierarchien, um einen ,einfach' gestalteten Raum handeln. Allerdings blickt man von der privilegierten Kline in der nordöstlichen Raumecke auf die spektakuläre Gartenrückwand mit Orpheus-Megalographie ${ }^{554}$. Der nicht-mythologische Decor des Raumes mit seinen naturhaften Motiven und Bildern bereitet ,passender 'Weise auf den Ausblick vor.

Auch der Wand-Decor des dritten Stils wird offenkundig in Abhängigkeit vom architektonischen und decorativen Setting gewählt. Mit einem besonders aufwendigen Boden kann, wie sich an der Casa di Paquius Proculus/Cuspius Pansa (I 7,1) gezeigt hat, eine zurückgenommene Wandgestaltung korrespondieren. Dies stellt nicht infrage, dass über den Wand-Decor nicht auch soziale Raumqualitäten angezeigt und kommuniziert werden konnten. Korridor (10) der Domus VI 17 [Ins. Occ.],41 besitzt etwa einen Sockel in Rohputz, während die weiße Mittelzone durch rote Linien in Felder untergliedert ist. Kleinteilige ,Ornamente füllen die Decor-Bänder ${ }^{555}$. Hier ist folglich ein ,Ort des Übergangs‘ mit einem besonders einfachen Gestaltungselement versehen worden. Dem Decor dritten Stils ist damit schon innerhalb eines Hauses keine strenge sozialhierarchische Wertung eingeschrieben. Vielmehr besitzt er das Potenzial, räumlich-atmosphärische Adäquatheit mit viel differenzierteren Mitteln als zuvor herzustellen.

Das große Spektrum an Ausstattungsoptionen, die der dritte Stil bereithielt, stand nun aber nicht allein großen Häusern zur Verfügung. Insbesondere mittelgroße und auch kleinere Häuser

548 Wallace-Hadrill 1988, 75-77.

549 Tybout 2001, 44-48. Als Wertelemente begreift er mythologische Bilder, Marmorwandverkleidungen (v.a. im vierten Stil greifbar), Farbe und die Komplexität des Architektursystems.

550 Wallace-Hadrill 1988, 74f. Anm. 101; aufgegriffen bei Moormann 1993a, 403.

551 Moormann 1993, 403.

552 Guidobaldi u.a. 2002, 271.

553 PPM V (1994) 264-307 s. v. VI 14,20, Casa di Vesonius Primus o di Orfeo (F. Narciso) 276f. Abb. 20a. 20b.

554 PPM V (1994) 264-307 s. v. VI 14,20, Casa di Vesonius Primus o di Orfeo (F. Narciso) 284f. Abb. 33a. 33b.

555 PPM VI (1996) 10-43 s. v. VI 17 [Ins. Occ.],41 (V. Sampaolo) 24 Abb. 33. 
machten davon Gebrauch. In der relativ kleinen Casa del Sacerdos Amandus (I 7,7) wurden sowohl Triclinium (b) als auch Cubiculum (c) mit mythologischen Bildern ausgestattet ${ }^{556}$. Mit dem dritten Stil waren aufwendige Wandmalereiausstattungen offenkundig für breitere Schichten der Bevölkerung erschwinglich. Umgekehrt kommen auch ausgesprochen einfache Formen der Wandgestaltung in großen Häusern vor. Im Hanghaus VIII 2,36-37 ist in den rückwärtigen, jedoch recht großen Räumen $(\delta)$ und $(\varepsilon)$ die Wand durch rote Linien auf weißem Grund in Felder gegliedert ${ }^{557}$. In der Casa di T. Dentatius Panthera (IX 2,16) ist ein relativ einfacher Decor mit nur kleinen, nichtmythologischen Bildfeldern für Oecus (f) der sonst durchaus bilderreichen Domus gewählt worden $^{558}$. Wieder bestätigt sich, dass Ausstattungselemente einzelner Räume keineswegs mit Grundstücksgröße und sozialem Status des Hausbesitzers korrelieren müssen.

Es werden folglich drei miteinander verwobene Phänomene greifbar. Zum einen lassen sich Wandmalereien nur in ihren Extremen als einfach und aufwendig beschreiben. Dabei existieren zahlreiche alternative Optionen nebeneinander, um einen Raum ,prächtig' auszustatten. Zum zweiten war die Wahl bestimmter Ausstattungsoptionen durch den räumlichen Zusammenhang bedingt - Gartenmalereien galten etwa für Peristyle und Gartencubicula als besonders angemessen. Drittens korrelieren ,aufwendige‘ Ausstattungsformen nur bedingt mit Hausgrößen. Auch Besitzer kleinerer Häuser leisteten sich wenigstens in einzelnen Räumen einen aufwendigen Decor, und umgekehrt konnten in großen Stadtvillen einzelne Räume ,einfacher‘ ausgestattet sein.

Ganz ähnliche Überlegungen lassen sich für die Skulpturenausstattungen anstellen. In einer Initialphase, zu Beginn der Kaiserzeit, mögen es vor allem die Besitzer prunkvoller Häuser wie der Casa del Citarista (I 4,5.6.25.28) gewesen sein, die sich mit den neuen Ausstattungselementen umgaben. Schon im Verlauf des 1.Jhs.v. Chr. wurden Skulpturen aber zu einem Allgemeingut der pompejanischen Stadtbevölkerung (eine konkretere zeitliche Einordnung ist nicht möglich, da sich die Stilformen nicht präzise datieren lassen). Besonders offensichtlich trifft dies auf die kleine Domus VIII 5,39 zu. Der Ausstattungsaufwand konzentrierte sich in Ermangelung eines Atriums ganz auf den Gartenbereich. Dieser jedoch zeichnete sich durch eine hohe Dichte ungewöhnlicher, auch exotischer Bildobjekte aus ${ }^{559}$. Der Umgang mit dreidimensionalen Bildobjekten bestätigt somit die vorausgegangenen Überlegungen: Der Gebrauch von Bildern war mit dem dritten Stil immer stärker zu einem Allgemeingut geworden. Auch zunächst innovative, luxuriöse Gattungen sind schnell in breiten gesellschaftlichen Schichten rezipiert worden.

556 Peters 1963, 91-95; PPM I (1990) 586-617 s. v. I 7,7, Casa del Sacerdos Amandus (V. Sampaolo) 592-603 Abb. 720; 607 Abb. 27. 28.

557 PPM VIII (1998) 291-307 s. v. VIII 2,36-37 (V. Sampaolo) 297 Abb. 9; 299 f. Abb. 13.14.

558 PPM IX (1999) 1-40 s. v. IX 2,16, Casa di T. Dentatius Panthera (V. Sampaolo) 30f. Abb. 50-52.

559 Barrett 2019, 277-280. 
